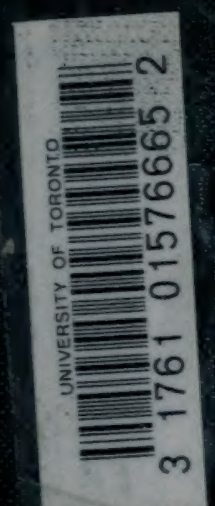

EXTREME Hande CARE

This volume is damaged or brittle and CANWOT be repaired!

- photocopy only if necessary

- return to staff

do not put in bookdrop

Gerstein Science Information Centre 
Digitized by the Internet Archive in 2007 with funding from Microsoft Corporation 
<smiles>CC(C)(C)C1CCC1</smiles> 


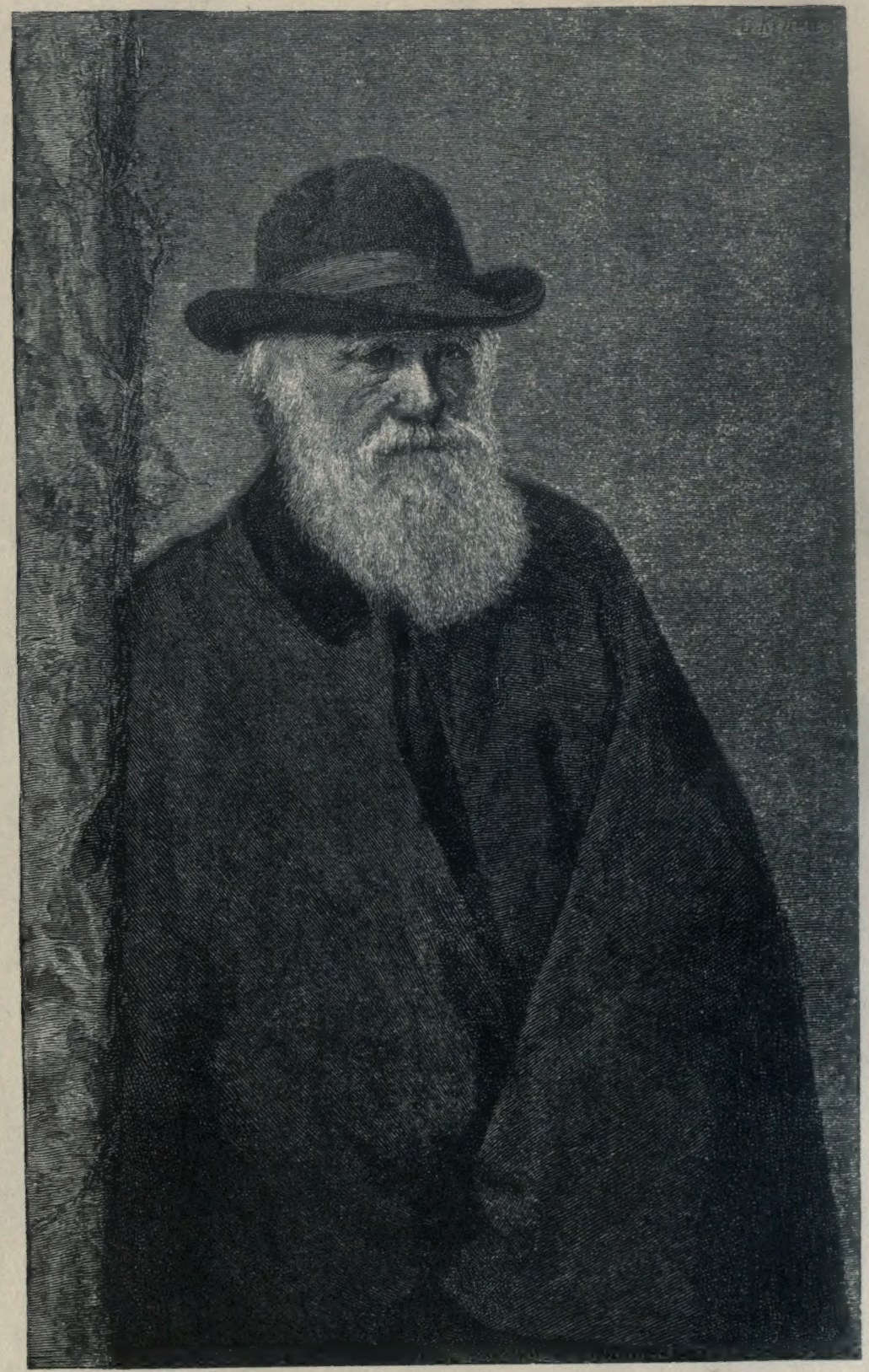

CHARLES DAR W IN

(From a photograph, 1881, by Messrs. Elliott and Fry) 


\title{
THE
}

\section{ANATOMY OF THE FROG}

BY

\author{
DR. ALEXANDER ECKER \\ PROFESSOR OF HUMAN AND COMPARATIVE ANATOMY
}

IN THE UNTYRRSITY OF FREIBURG

Eransfated, with numerous Annotations and Zlositions

\author{
BY \\ GEORGE HASLAM, M.D.
}

\begin{abstract}
SCIESTIFIC ASSISTANT IX THE MRDICAL DEPARTMENT IN THE UNIVERSTTY OF zÜRICH; PORMERLY ASSISTANT LECTURKR IX PHYSIOLOEY IS THE

OWRAS COLLFGR, VICTORIA UXIVERSITY, MAXCHISTER
\end{abstract}

ILLUSTRATED WITH MANY WOOD ENGRAVINGS

AND TWO COLOURED PLATES EXECUTED EY HOFMANN, WÜRTZEURG, BAVARIA

\section{Oxford}

AT THE CLARENDON PRESS

\begin{tabular}{l|c}
1889 & SEEN BY \\
\cline { 2 - 3 } & PRll rights reserved] \\
PESERVATION \\
SERVICES
\end{tabular}





\section{TRANSLATOR'S PREFACE.}

I UNDERTOOK the publication of a translation of Ecker's 'Anatomie des Frosches' at the suggestion of Professor A. Gamgee while I was working under his superintendence in the physiological laboratory of the Owens College. The work was subsequently accepted by the Delegates of the Clarendon Press; as one of the series of 'Foreign Biological Memoirs,' published by them. Early in the progress of the work it became evident that a mere translation would be unsatisfactory, and that it would be desirable to recast and modify several portions of the book. It was deemed advisable to give greater completeness to the work by descriptions of the minute structure of the several organs. For these purposes the appearance of the work has been unavoidably delayed.

I have done my best to bring the book up to date by including the results of recent researches, to which I have added many facts derived from my own personal investigations. All such additions are enclosed within square brackets [ ]. More than a hundred new figures, of which one-third are original, have been added; and copious, though it is feared still incomplete, lists of references to frog-literature have been drawn up. By these additions the size of the book has been considerably increased.

In the several sections into which the book is divided the following points may be more particularly noticed :-

Sect. I. The Bones and Joints. The nomenclature of Parker and Bettany has been adopted throughout.

Sect. II. The Muscles. This section remains in its original form.

Sect. III. The Nervous System. The chapters on the central 
nervous system and the sympathetic system have been rewritten. The description of the arteries of the brain is entirely new, while the chapters on cranial and spinal nerves have received many smaller additions, and have been rearranged to facilitate reference.

Sect. IV. The Vascular System. The chapter on the heart is practically new, and many additions and alterations have been made in the descriptions of the blood-vessels and lymphaties.

Sect. V. The Alimentary Canal, with its appendages, the Spleen and the Peritoneum. In this section much new material has been added : the descriptions of the blood-vessels of the liver, the ducts of the liver and pancreas, ete., being the results of original investigation.

Sect. VI. The Respiratory Organs, the Thymus and Thyroid Glands. These organs have been carefully studied and numerous new details are noted. The lymphatic glands of the hyoid region have, after some hesitation, been designated tonsils.

Sect. VII. The Urino-Genital Organs. A very large number of preparations have been made to investigate the vessels and uriniferous tubes of the kidneys; and the descriptions of the remaining organs of this section have received large additions from recent publications.

Sect. VIII. The Skin and the Sense-Organs. This section has, with the exception of very small portions, been re-written and very much enlarged.

Before concluding this preface, I must thank my friend Professor A. Milnes Marshall, of the Owens College, for all the help and kindness he has extended to me before and during the time this work has been in hand; to him I am indebted not alone for the loan of books, pamphlets, ete., and for much useful information, but also for the care and patience with which he has read and corrected the whole of the proof-sheets.

To Professor G. Lunge, of Zürich, I am indebted for the use of the library of the Gesellschaft der Naturforscher of Zürich; and 
to my friend Mr. C. Herbert Hurst, of the Owens College, for the drawings for figures $132,133,134$, and 136 ; also to Dr. Max Köppen, of Strasburg, for the proof-sheets of his valuable paper, 'Zur Anatomie des Froschgehirns': to these gentlemen I beg to express herewith my heartiest thanks. Lastly, I must express my sense of indebtedness to the Delegates of the Clarendon Press, who have kindly allowed me to alter the original plan of the book, and to make extensive additions far beyond the limits originally intended.

A second edition of the original German work is in course of publication. The first part, on the bones and muscles, has already appeared.

GEO. HASLAM.

Zürнен, 1888. 


\section{PREFACE TO THE FIRST PART.}

THE idea of this manual on the anatomy of the frog, of which I now offer the first part to physiologists and to those who would become such, occurred to me during the preparation of the plates for my 'Icones Physiologicae.' I was then convinced of the necessity of such a book. I regret that many direct and indirect causes have hindered its earlier completion; fortunately, however, its appearance is still opportune, as the need for the book has not diminished. I am conscious that the book requires a recommendation to the indulgent judgment of my fellow-workers, since almost every one has studied the frog for one purpose or another, and each will closely criticize in that department with which he is most familiar. Although I shall not be able to satisfy all, still I hope that my work may serve as a useful basis for further investigations, and I would apply to it the words with which Sömmering prefaced his anatomy: 'Ich wünschte ein Handbuch zu liefern und seine Einrichtung so zu treffen, dass man künftig an ihm als einer Basis nach Erforderniss leicht ändern, wegnehmen und zusetzen könnte ${ }^{1}$ ?

Lest more be anticipated from the book than it is intended to supply, I would observe that I have throughout had in mind only a descriptive anatomy of the indigenous (German) frog; a comparative anatomy of Batrachians was as foreign to my intention as were developmental or histological questions : hence morphological details must not be expected. Any hope of formulating a systematic nomenclature of the muscles has been abandoned; as neither one based upon their mode of action, of which we know so little, nor one based upon their origins and insertions, as demonstrated by the unpronounceable names of Chaussier and Dugès, is really practicable. I have therefore preferred to avail myself, as far as possible, of the received names, which have been chosen partly

1. 'I wished to furnish a manual so arranged that it might serve as a basis easily altered, pruned, or enlarged as the future might need.' 
according to mode of action, partly according to origin and insertion, and partly according to position and form; while in the chnice of new names I have given preference to the simplest.

The figures are, with few exceptions, original, and drawn by myself. Their careful execution in woolcut has added a very necessary neatness to that correctness, which alone I claim as mine.

ALEXANDER ECKER.

Freiburg,

February, 1864 .

\section{PREFARE TO THE SECOND PART.}

Sixtwex years have elapsed since the first portion of this anatomy of the frog appeared; this second portion, therefore, requires a somewhat apologetic introduction.

The nerrous and vascular systems have, in substance, been known for some years; still, certain pnints required a thorongh revision : this seemed especially necessary with regard to the cranial nerves. In consequence of $\mathrm{my}$ anthropological investigations, and particularly through undertaking the editorship of the 'Archiv für Anthropologie,' my attention was drawn into another channel, and I found it impossible to work out this chapter: consequently the whole was deferred, and would have been still longer delayed had I not received assistance.

At my request Professor W"iedersheim undertonk to investigate afresh the cranial nerves, the brain, the spinal cord, and the sympathetic system ; and the descriptions of these parts are the result of his work alone. I regard it as most advantageous to this seennd part that so experienced an investigator in the anatomy of Amphibia should have given me his help.

The remaining portions appear almost unaltered as written several years ago; and the majority of the illustrations date from 
the same period. I had neither the time nor the zeal necessary to re-examine the whole; besides, it is doubtful whether eyes some twenty years older would improve matters.

This somewhat neglected book is therefore commended to the indulgence of my fellow-workers, with the hope that it may at least form a basis upon which further work may easily be done; to proffer more than this, as I stated, with a quotation from Sömmering, in the preface to the first part, I have never even hoped.

The final part of the work, on the viscera and sense-organs, has been undertaken by Professor Wiedersheim, and will appear in the Spring of 1882 .

- Freiburg,

ALEXANDER ECKER. August. 188r. 


\section{CONTENTS.}

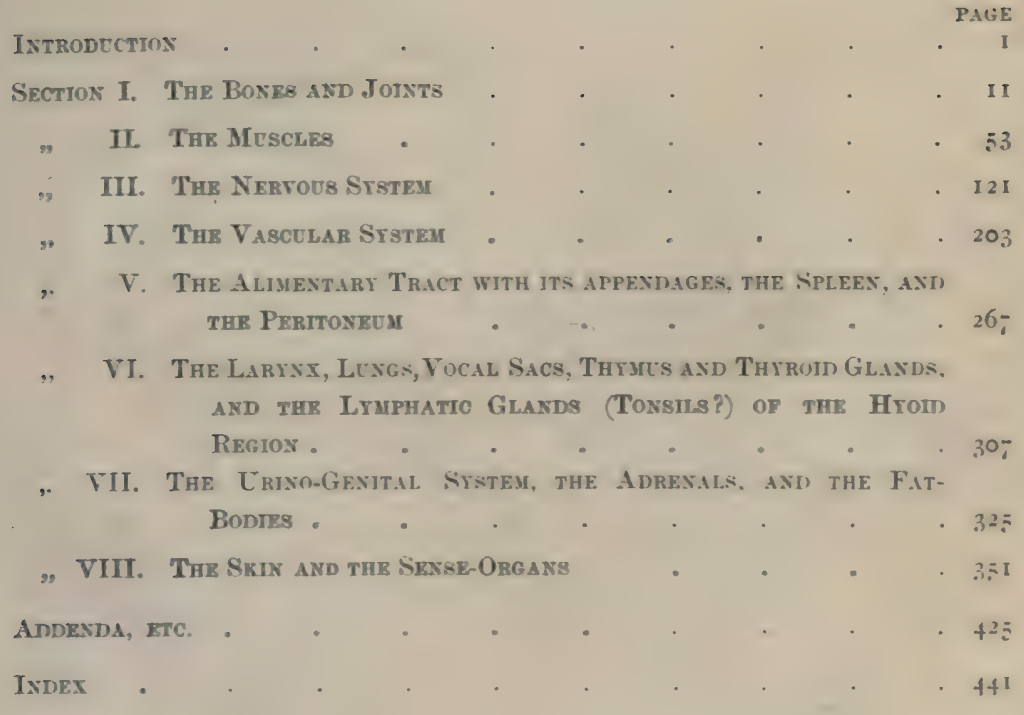





\section{ILLUSTRATIONS.}

FIGURE PAGE

1. The Green water-frog, Rana esculenta, $\mathbf{L}$.

2. The Brown grass-frog, Rana temporaria, $L_{\text {. }}$. . . . 8

3. Femur of Rama evententa: : 16

4. Vertebrae of do. . . . I7

5. Vertebral column of do. . . 18

6,7 . Section through a vertebra of Rama esculenta. . . 20

8, 9. Urostyle of Rawa esculenta. 21 10-14. Skull of da $\quad-22,23,25,28$

15. Nasal Cartilages of frog - . 29

16,17 . Skull of Rana esculenta 29, 30

18. Origin of suspensory cartilage from the skull : . $3^{2}$

19, 20. Skull of Rana esculenta 32, 33

21. Mandible of Rana esculenta - 34

22. Hyoid of Rana esculenta - 35

23. Omorternum of Rasa esculenta 36

24. Shoulder-gindle and sternum of do.

25. Shoulder-gindle of the frog :

26,27 . Supraseapula of Rana esculewte

28. Left scapula of Rana esculenta

29. Scapuls seen from behind . 38

30. Ieft coracoid . • • 39

31. Clsvicle of the left side : $\quad 39$

32. Right shoulder-girdle of Rana esculenta

33. Hinder border of the scapula and corracoid

34. Clavieular cartilage of Rana eseulenva : .

35. Humerus of Rave esculenia (femalo) . . . . 4r

36. Do. (male) . . . $4 \mathrm{I}$

37. Do. (female) - : . $4 I$

35. Radio-ulnar of Rana esculenta 43

39,40 . Bones of the forearm and hand of Rana esculentis 44, 46

41, 42. Pelris of Rana esculenta . 48

43. Horizontal section through the iliac bones, ete. - . 49

44. Femur of Rana esculenta : 49

45. Tibio-fibula of do. - : $\quad 50$

46. Section of the tibio-fibula : 50

47. Right foot of Rana cecuslenta - 5I

48-50. Eye-muscles of do. $\quad 55,56$

51. Skull and orbital envities of Rana esculenta.
TIGURT

PAGE

52. M. levator bulbi of Rawa coculenta - . . $\quad 57$

53. Eye-muscles of Rana esculenta

54. Facial museles of do. - . 59

55. Muscles of the back and shoulder

56, 57. Muscles of the lower jsw of Rana esculenta.

$6 x, 62$

58. Muscles of the throsit, chest, and abdomen of do. .

59. Muscles of the hyoid bone and the tongue of do.

60. Do. (from below)

61. Do. (from right side) : . 66

62. Muscles of the throst, eheat, and belly of Rama esculenta

63. Muscles of trunk of Rama eseulenta (from the right aide)

64. Second layer of abdominal muscles of Rana csculenta, from right side and below.

65. M. obliquas internus : : $7^{x}$

66. Muscles of the back and shnulder blade

67. Museles of the back and pelvic girdle of Rana esculenta.

68. Muscles of the shoulder, from below.

69. Muscles of the right shoulder and upper arm . .

70. Right shoulder, from below .

71. Muscles of the back and shoulder

72. Muscles of the chest, thront, and belly of Rana enculenta

73. Muscle of right shoulder and upper arm.

74. Muscles of the right arm of Rama esculenta. .

75. Do. (deep layer) : . 85

76. Mascles of forearm of Rana esculentas

77. Muscles of hand of Rana culenta, volar surface.

78. Second layer of mascles on volar surface of hand of Rana esculewta

79. Muscles of hand of Rana osculenta $\cdot \quad \cdot 9^{2}$

80. Muscles of left thigh of do. 95 81,82 . Do. (ventral surface). $\quad 98,99$ 
FIGURE

83. Deep muscles of left thigh of Rana esculenta.

PAGE

84. Do. (Dorsal view)

85. Left half of pelvis of Rana es. culenta IOI

86. Muscles of the right leg and
foot of Rana esculenta (Dor-

86. Muscles of the right leg and
foot of Rana esculenta (Dorsal view)

IOI . . 103

87. Do. (seen from below) . . 105

88. Do. (Dorsal view) . . . I06

89-91. Muscles of the plantar surface of foot of Rana escu lenta. . . $\mathrm{x} 07, \mathrm{III}, \mathrm{II}_{2}$

92-94. Dorsal view of muscles of foot of Rana esculenta

I I 5, I I7, I 18

95. Pectoral region of Rana esculenta

96. Hind portion of back and thigh of Rana esculenta 120

97. The nervous system of Rana esculenta, from the ventral surface

98. Dorsal view of brain of Rana esculenta . . . .

99. Transverse section through hinder end of Medulla oblongata

- 44

100. Do. at the point of origin of the abducens nerve - . 145

101. Do. of the auditory nerve . 146

102. Ventral view of brain of Rana esculenta . . . . I49

103. Lateral do.

. 150

104. Transverse section through the anterior portion of the optic lobes opposite the origin of the motor-oculi nerve.

105. Horizontal section through the brain to show the ventricles

106. Section through the lower division of the pituitary body

107. Transverse section through the hinder portion of the cerebral hemispheres

ansverse section near the middle of the cerebral hemispheres

109. From a transverse section through one of the cerebral hemispheres

110. Diagram to show the Vena spinalis posterior, etc. . . $x_{4}$

111. Dorsal view of the orbit, ete. (deep dissection) (coloured)

Plate I.

112. Do. (superficial do.) (coloured) Plate I.

113. View of roof of mouth; mucous membrane,etc. (coloured)

Plate I.

114. Lateral dissection of head, etc.

(coloured) Plate I.
PIGURR

PAC R

115. Dissection of the floor of the mouth (coloured) Plate I.

116. Right half of skull of Rana esculenta

- 174

117. The nervous system of Rana esculenta, from the ventral surface

118. Ventral view of the brain and spinal cord, to show the points of exit of the spinal nerves . . . . 178

119. Ventral view of the spinal ganglia . . I . I79

120. Schema of spinal ganglion $\quad$ I79

121. Dorsal branches of the spinal nerves

122. The brachial plexus: : 184

123, 124. Nerves of the ventral surface of the arm . . 185,186

125. The N. radialis : . 186

126. Ventral view of the brain and spinal cord . . . . I88

127. The sciatic plexus , . . I90

128. Distribution of the sciatic nerve $x 93$

129. Nerves of the leg and sole of the foot

130. Distribution of the $\dot{N}$. peroneus 196

131. Sympathetic cord .

132. The heart and blood-vessels, seen from the ventral surface . . . . 213

133. The heart, seen from above . $2 \mathrm{I}_{4}$

134. The frog's heart, seen from the ventral surface. . .

135. Dissection of a case in which the auricular septum is placed more to the left than is normal . . . . 215

136. Dissection of the heart from the left side . . . . 216

137 I. Transverse section through the junction of the hinder and middle thirds of the ventricle of $\boldsymbol{R}$. temporaria . 217

137 II. Tranverse, section through junction of the middle and anterior thirds of the same heart .

rtion of a transverse section through the middle of the ventricle of $R$. temporaria . 218

139. Course of the cardiac nerves in the auricular septum .

140. Group of nerve-cells on the eardisc nerve, from the auricular septum . .

141a. Small group of nerve-cells from the auricular septum . . 221

141b. Isolated nerve-cells from frog's heart .

142. Arteries and veins of the Truncus arteriosus of $B u j o$ vulgaris . . . 22 
RTGURE

143. Scheme of the arterial system of Rava esculenta

144. Right carotid gland

145. Arterial system of Rans esculenta.

146. Transverse section at level of the laryns.

147. Dissection to show the occipitovertebral and the cutaneous arteries

148. Branches of the occipito-vertebral and cutaneous arteries in the head

149. Dirsection to show the occipitovertebral and the cutaneons arteries

150. Subclavion artery of the left side.....23I

151. Arteries of the palmar surface of the hand

152. Arteries of the dorral surface of the hand

153. Arterial system of Rowa escwlenta. . . 234

154. The urinogenital arteries 235

155. Bifurcation of the aorta and the iliac arterios

1b6. Arterien of the hinder ex- tremity

157. Arteries of the doncil surface of the foot

158. A rteries of the gole of the foot 239

159. Schems of the veins of Rana esculenta . . . 242

160. Distribution of the internal jugular vein and the anterior portion of the eutaneuns vein.

161. The anterior caval vein and ita branches

162. Course of the entaneous vein as seen from the side .

103. Veins in the region of the kidney

164. Veins of the liver

165. Veins of the hinder extremity. 250

166. Transverse section of a septum with the attached skin . 252

167. The sinus abdominalis lateralis 352

168. Sinus thoracicns transversus . 253

169. The lymph-sacs of Rana eseulewta (seen from the dorsal surface)

254

170. Do. (eeen from the ventral do.) 256

171. Do. (seen from the side). $\quad 257$

172. Transverse section through the trunk in the region of the iliac lymph-sac . . . 258

173. Dissection to show the iliac lymph-sac . . . 259

174. Plan of sttachments of the inferior femoral etc septa 259

175. Transverse section of the thigh 260
PIGUBE

PAG:

176. The anterior Iymph-hearts - 26r

177. The posterior lymph-hearts . $26 \mathrm{I}$

178. The roof of the mouth - . 276

179. The floor of the mouth . .277

180. The capillaries of the submucous layer (coloured) Plate II.

181 I. Transverse section of the premaxillary bone, to show at. tachment of the teeth. . 279

181 II. Dontine and enamel . . 279

181 III. Enamel . . . . 279

182,183 . Muscles of the tongue 281,232

184. The alimentary canal . . $29_{3}$

185. The abdominal viscers of Rama ceculenta. . . 284

186. Iongitudinal folds of stomach of Rana temporaria . $\quad .285$

187. The cells at the mouth of the gland of the fondus of the stomach - (coloured) Plate II.

188. The mucons membrane of the pyloric end of the stomach of Rana esculenta.

286

189. Mucons membrane of the pyloric end of stomach and duodenum .

190. Isolated fold of mucous membrane of small intestine of Rava temporaria

191. Fold of mucous membrane of Rana temporaria . : 291

192. The large intestine of Rana temporaria

- 292

193. Large intestine of Rava enevlenta. . . . . 293

194. The liver . . . . . 395

195. The pancreas and bile-cansls . 296

196 I. The hepatic veing

196 II. (coloured) Plste II.

196 III. $\left\{\begin{array}{r}\text { The hepatic arteries } \\ \text { (coloured) Plate II. }\end{array}\right.$

197. Liver-cells . . . . 299

198. The bile-capillaries . . . 299

199. The pancreas and bile-canals . 300

201. The peritonemu of Rana esculesta . . . . 305

202. The position and relations of the larynx . . . 3II

203. The cartilaginous skeleton of the larynx.

204. The larynx and surrounding parts - . . $3^{\mathrm{I}} 3$

205. The muscles of the larynx . 314

206. Three sections through the laryax of Rana esculenta . 316

207. The Rima glottidis : - 317

208. The lnng of Rana temporaria

(colonned) Plate II.

209. The vocal ane of the right side. . . . . 330

210. The thymus gland. .321

211. The thymus gland of $\boldsymbol{R}$ ana esculenta 
212. The thyroid gland of Rana esculenta : * . $\quad 323$

213. The lymphatic gland of Rana - esculenta. . . .

214. The male urino-genital organs . 33I

215. The right kidney . • . 332

216. The blood vessels and lymphatics of the kidney . 333

217. Vertical sections through the kidney - (coloured) Plate II.

218. The uriniferous tubes

219. A gold preparation of the kidney of Rana esculenta

(coloured) Plate II.

220. Transverse section of the kidney 338

221. The bladder . . . 339

222. The male reproductive organs . 34I

223. Various preparations from the testis .

224. The female reproductive organs 344

225. Preparations from ovary and oviduct . . . 346

226. The male urino-genital organs $34^{8}$

227. The fat-body of Rana esculenta 349

228. The epidermis from the head of Rana esculenta . . . 367

229. Vertical section through the skin of the bsck . . . 368

280. Surface view of epidermis of Rana temporaria . $\quad 368$

231. Nerve terminations of the branched pigment-cells of the cutis $\quad . \quad \cdot \quad 368$

232. The temporary papillae in Rana temporaria. . . $37 x$

233. The epidermis of the supplemental toe of Rana esculenta.

234 I. Fore-foot of a male frog $\quad .375$

234 II. The swelling on the supplemental toe of a male frog .375

235. The blood-vessels and lym. phaties of the skin : . 376

236. Lateral sense-organ of tadpole of frog

237. Various parts from the fungiform papillae $\cdot \quad \cdot 3^{81}$

238, 239. Frontal sections through the nose of two tadpoles $\cdot 384$

240 I A. Bowman's glands in situ from Rana temporaria $\quad 386$

240 I B. Section of Bowman's gland $3^{86}$

240 II. Veasels of nasal mucous membrane of Rana esculenta 386

241. Separations from the olfactory mucous membrane of Rana temporaria.

242. The tympanic membrane of Rana esculenta . . $\quad 389$

243. The columella $\quad: \quad 39$ I

244. Antero-posterior section through the capsule of the right labyrinth of Rama esculenta $39^{2}$

245. The membranous labyrinth of Rana esculenta.

246. Part of the outer wall of the perilymphatic space $\quad$ - 395

247,248 . The right membranous labyrinth of Rana esculenta 397

249, 250. The membranous labyrinth of Rana esculenta ? 399, 401

251. Preparations from the ear of Rana esculenta." .' .

252. The nerve-terminations in the membranous labyrinth of Rana esculenta . . . 404

253. Endothelium from the inner surface of the sclerotic cost . 406

254, 255. Preparation from cornea of Rana esculenta . 407,408

256. The ressels of the choroid and iris 410

257. Fibres from the lens of the frog 414

258. Vertical section through retina of frog . . .

259. Various preparations from the eye of the frog . . $4^{I} 7$

260. The vessels of the vitreous body 42 I

261. Preparations from the nictitating membrane of Rana esculenta. . . 42 


\section{INTRODUCTION.}

THERE is no oceasion, now-a-days, to offer a lengthened apology for devoting a treatise solely to the anatomy of the frog, which enjoys the doubtful honour of being, $\kappa a \tau^{\prime} \dot{\xi} \xi o x \eta \dot{v}$, the physiological domestic animal. It is kept in every phrsiological laboratory, and is daily sacrificed in numbers upon the altar of science. The physiologist has recourse to it, not only to obtain answers to new questions, but for the sake of demonstrating easily and quickly the most important known facts of the science. These unlucky batrachians are to be had in any number, and are specially adapted for experimental investigation: they have consequently fallen under a harsher trrant than the stork in the fable, and their prophetic outcry in the frog-chorus of Aristophanes, $\delta \epsilon \iota \nu a ̀ ~ \pi \epsilon \iota \sigma o ́ \mu \epsilon \tilde{\theta} \theta a$, has been literally fulfilled.

As the history of the most important physiological discoveries is elosely related with the employment of the frog in physiological researeh, it will not be without interest to review briefly the history of its use in scientific, especially in physiological, inrestigations, and to record the services which it has already rendered to seience. Swammerdam (1637-1685), as du Bois-Reymond justly remarks, was the first to make known the frog as an important means of research; he says concerning it:-'An den Thieren, die das heisseste Blut haben, ist die Bewregung der Muskeln nicht so merklich oder hält vielmehr nicht so lange an, als an Thieren die mit kälterem Blute begabt sind. Dergleichen sind die Fische und viele andere Wasserthiere, wie auch solche, die so wohl im Wasser als auf dem trocknen Lande leben können. Deswegen habe ich insonderheit mit dem Frosch meine Versuche angestellt. Denn an diesem Thiere sind die Sehnen sehr sichtbar und lassen sich leicht entdecken 
und entblössen"' Swammerdam made the earliest experiments on the contraction of muscle by means of chemical and mechanical stimulation of its nerves; thus laying the basis of our present nerve and muscle physiology, which has been built up within rather less than two hundred years; though during the first half of this period but little advance was made.

From the famous September evening of the year I786, on which Galvani first observed the twitchings of a frog's leg suspended by a metallic hook to an iron balcony, the frog has, down to the present time, afforded almost the only material for the investigation of the excitability of nerve and its associated electromotive changes, and also no inconsiderable part of the remaining nerve and muscle physiology. It was not until Müller devised the method of operating on the frog that Bell's law became capable of easy proof; and much of our knowledge of the functions of the spinal cord is derived from experiment upon it. Again, the muscles of frogs served, from the time of Swammerdam to that of Eduard Weber and his followers, for the investigation of the phenomena and the conditions of contraction; and in almost all other branches of physiology there are important doctrines which were first definitely established by experiment upon the frog. But for the web of the foot of this animal (and the gills and tail of its tadpole, in which Leeuwenhoek ${ }^{2}$ describes the phenomena most clearly) we should not, perhaps for a long time, have arrived at a satisfactory knowledge of the existence and the conditions of the capillary circulation. As is well known, an accurate aequaintance with the constituents of the blood directly concerned in nutrition has been obtained by observation on the frog, as well as important facts in the physiology of the blood and lymph, such as the intimate knowledge of the corpuscles of both fluids, and the coagulability of the plasma; while in no less degree have experiments on these animals served to establish the laws of the heart's action. Moreover, physiology is not the only science indebted to the frog: in histology many important results have been obtained from observations on it, and for histological instruction it is now indispensable. To it we owe much of our

1 ' In animals with warm blood the action of the muscles is neither so apparent nor so long continued as in those animals which have cold blood, such as fishes and many other aquatic animals, and those also which live both in water and on dry land. On this account $I$ have made my investigations chiefly on frogs, for in them the nerves are very distinct, and are easily found and exposed.' Buch der Natur, Leipzig, $175^{2}$, p. 330 .

${ }^{2}$ Leeuwenhoek, Arcana Naturæ III, epist. 65 ad Reg. Soc. Lond., p. $15^{8}$. 
knowledge of the structure of nerve fibres, their origin and termination, especially in muscle, their relations within the ganglia, and even the structure of muscular fibre itself. For the study of reproduction and development the frog has, next to the chick, afforded the most important material: one need but refer to the investigations on impregnation from the time of Spallanzani to that of Newport ${ }^{1}$, the phenomena of cleavage, and many others.

Thus with progress of time the field in which the frog has been submitted to observation and experiment, whether for the demonstration of established facts to students or for the solving of new problems, has vastly increased, and this batrachian has indeed become, as we have stated, the physiologist's domestic animal.

That, for these manifold uses, a more exact anatomical knowledge of the frog is very necessary is self-evident. The majority of students commeneing the study of physiology have little more than a superficial knowledge of the sciatic nerve and the leg-muscles; at most, of the spinal cord and its nerve-roots; and only acquire any further knowledge in a disconnected manner. For this they can searcely be reproached, the literature of the anatomy of the frog being so widely seattered in monographs and journals that reference to it involves the expenditure of much time. This attempt, therefore, to produce a complete anatomy of the frog, based throughout upon my own observations, cannot be considered superfluous; it is rather to be feared it may be thought insufficient.

The European frogs ${ }^{2}$ alone are treated of in the following description, i.e. the two species, Rana esculenta, L., and R. temporaria, L., the former being more particularly deseribed, though such differences in structure as occur are noted. This is not the place to discuss the exact systematic eharacters of the two species, yet they cannot be ignored entirely. The species were, from their habitats, long ago distinguished by C. Gessner ${ }^{3}$, and named Rana rubeta, 8. giblosa, the garden or grass-frog, and Rana aquatica, 8. innoxia, the water-frog; at least, from his figure, the former ean be no other than $R$. temporaria, though Gessner,

1 It may be well to remind the reader that this introduction was written in 1864

2 For purposes of comparison other than European frogs were examined, especially American species of Rana, for which I am indebted to the kindness of my much esteemed friend Agassiz. These were Rana Catexbyana, Shaw ( $R$. mugiens, Catesby-$\boldsymbol{R}$. pipiens, Harlan); $\boldsymbol{R}$. sylvatica, Leconte; $\boldsymbol{R}$. clamitans, Daudin; $R$. palustrib, Leconte; R.halecina, Leconte. To these, however, no further reference will be made in the text.

3 C. Gessner, Thierbuch. Zürich. Fol, p. I57. 
probably expecting to find in it the rubeta of older writers, adds that it 'ist für giftig zu halten.'

Leeuwenhoek ${ }^{1}$ also, correetly distinguished between them, but it is to Rösel ${ }^{2}$ that we are chiefly indebted for a careful discrimination and an arcurate knowledge of the life-histories of the two species.

Fig. 1 .

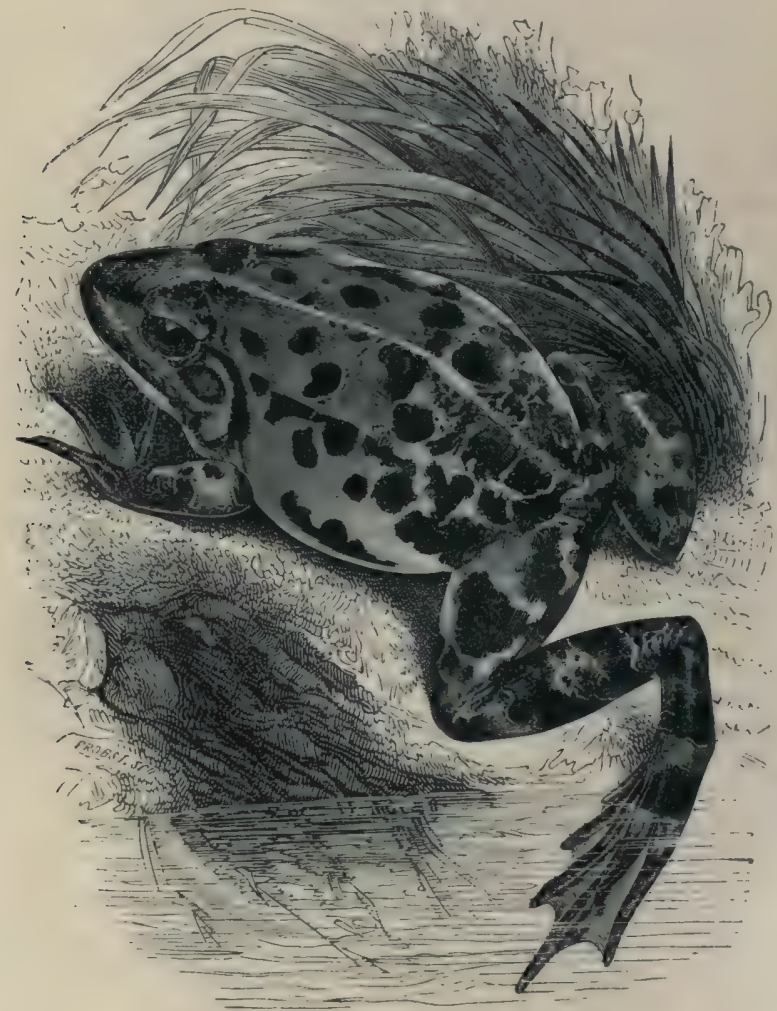

The green water-frog, Rana esculenta, $\mathbf{L}$.

Rana esculenta, L. The green water-frog, Fig. I, usually attains a larger size ${ }^{3}$ and is more active than the other species, and for this

${ }^{1}$ Leeuwenhoek, Arcana Naturæ, Vol. III of Ecker's edition. Leyden, I 722 . Epist. 65 ad Reg. Soc. Lond., p. 154 .

${ }^{2}$ Rösel, Naturgeschichte der Frösche Deutschlands, ed. Schreber. Nürnberg, I8I 5. p. 36 .

${ }^{3}$ The extreme sizes are much more pronounced in this species. I have never found R. temporaria of the size attained by large specimens of the water-frog. 
reason is better adapted to the purposes of the physiologist; hence I have chosen it for description.

The head is flat, as broad as it is long, and triangular with an obtuse snout in front. The upper surface of the head, i.e. the space between the eyes, is slightly coneave, grooved, and narrower than in $R$. temporaria. The tympanic membrane is circular, and relatively to the eve is larger. The upper eyelids have several transverse folds in their hinder part. The pupil is oval, with the long axis horizontal. The romerine teeth are arranged in two clusters, which are relatively larger than in $R$. temporaria and lie exactly between the posterior nares, without however touching them. 'The openings of the Eustachian tubes do not exceed in size the posterior nares to so great an extent as they do in $R$. temporaria. The male possesses a vocal sac on either side, which reaches the surface beneath the tympanic membrane through a cleft placed behind the angle of the mouth, and is, in well-developed specimens, about the size of a cherry. The hind limbs are relatively longer. The toes are long, and taper towards their tips: the webs between the toes are cut out semicircularly, and that of the longest or fourth toe is continued to the tip of the last phalanx. The supplemental toe is an oval prominence of cartilaginous hardness. The skin of the back has wart-like tubercles arranged longitudinally in raised lines; one of these lines runs on each side from the posterior canthus as far as the thigh, and is very constant: in the male a second line surrounds the posterior margin of the vocal sac; a corresponding line exists in the female.

The skin of the belly is quite smooth, the colour presenting many variations which appear to depend upon very diverse circumstances. It varies with changes in the physiological condition of the animal. Von Wittich ${ }^{1}$ has shown that a bright green specimen changes to a dark leafy green colour on exclusion of light; also, that dark specimens become almost a lemon-yellow colour on exposure to bright sunlight; and he has pointed out that this brightening of the skin is an active condition dependent upon contraction of the stellate pigment-cells. It is therefore not surprising, as the same inquirer observes, that one should sometimes find specimens of $R$. esculenta in which the ground colour is almost a greenish yellow (as in Rösel's figure, Pl. XIII), whilst in others it can only be distinguished from the dorsal black patches by a faint greenish

1 Vou Wittich, Müller's Archiv, 1854, p. 41 . 
shade. There is no doubt that difference of habitat influences the colour; but this may again be modified by light ${ }^{1}$, as has been established in the case of fish by direct observation ${ }^{2}$. Apparent varieties may thus occur.

In frog-tanks such diversities of colour may not unfrequently be observed in the same individual, as for example when the lower part of the body immersed in muddy water is dark, while the part above the water is bright. That the process of casting the skin exercises an influence on the brightness of the colouring is certain, yet there are, as von Wittich has correctly remarked, other alterations of colour which are in no way connected with this process, and are evidently more of a pathological nature; such as when the frog assumes a dirty green spotted appearance, the green fading more and more, until all the patches which are usually green appear of a dirty greyish-brown with a faint bronze shimmer. According to this author these changes are most readily brought about by starvation. The dark colour which frogs exhibit after hibernation is perhaps to be ascribed to the co-operation of several of the causes mentioned above.

The usual colouring of healthy animals is as follows: the back is bright green with three golden yellow longitudinal stripes, one median and two lateral, and a number of irregular brown or black stripes of approximately uniform width: on the head are a pair of black stripes which pass from the angles of the eyes across the nares to the tip of the nose; now and then the tympanic membrane and surrounding parts have also a black patch, as in $R$. temporaria: another black stripe is found on the anterior surface of the arm, in the region of the shoulder: and on the thighs are black, yellow, and white mottlings. The whole of the under-surface is white or yellowish. At times the yellow stripes of the back are wanting or are indistinct. It has already been mentioned that many varieties may occur; and these have in all probability given rise to the deseriptions of reputed new species, such as $R$. maritima, Risso, found in South Europe; $R$. alpina, Risso, found in the high-lying Alpine lakes; $R$. hispanica of Fitzinger and Bonaparte, and $R$. calcarata of Michahelles, the last three of which certainly cannot be retained. It

1 Lister, On the Cutaneous Pigmentary System of the Frog. Phil. Trans., 1857, p. 627 .

${ }^{2}$ Agassiz et Vogt, Histoire naturelle des poissons d'eau donce (Neuchatel, 1839), Pl. IV, mention that the colour of trout is very variable and that in shaded and deep-lying brooks and rivers a variety is found which is black. 
is not improbable that the water-frog, which Spallanzani ${ }^{1}$ used in his experiments on impregnation, was the $R$. maritima of Risso. $\mathrm{He}$ says, one must not confound his frog with that which Rösel calls the green water-frog; the former being much smaller, without the three dorsal golden-yellow stripes, and the spawning season (in Lombardy) occurring during April and May. Rusconi ${ }^{2}$ also describes two varieties in Northern Italy.

Rana temporaria, L., the brown or grass-frog, is so named from the large black patch in the temporal region, i.e. between the eye and the shoulder. While the separation of the preceding species into several varieties does not seem to be well founded, it appears that two distinct species have been included under the name of R. temporaria. Millet of Angers ${ }^{3}$ first described, in his Fauna du département de Maine-et-Loire, as 'grenouille rousse,' a species differing from $R$.temporaria, and gave the species previously known as $R$. temporaria the name of $R$. flaviventris, 'grenouille à ventre jaune.' No further notice, however, was taken of this observation, not even by Duméril and Bibron in their ' Erpétologie.' Quite independently Steenstrup $\$$, in the year 1846 , pointed out that two frogs, differing in structure and habits, had been confounded under the name $R$. temporaria; these he distinguished as $R$. platyrhinus and R. oxyrhinus. Von Siebold ${ }^{5}$, and also Schiff ${ }^{6}$ in part, have confirmed these statements. My own observations lead me to a like conclusion; I shall therefore distinguish two species, viz.:-(I) Rana temporaria, L., Rana platyrhinus, Steenstrup; (2) Rana oxyrhinus, Steenstrup.

Rana temporaria, L.; Rana platyrlinus, Steenstrup. The brown grass-frog, Fig. 2, does not attain the dimensions of $R$. esculenta, L., but is, however, always larger than $R$. oxyrhinus. The head is somewhat broader than long, and the upper surface of the skull is not grooved, as in $R$. esculenta, but is flat. The space between the eyes is wider (according to Duméril, equal to the width of the upper eyelid, whereas in $R$. esculenta it is just two-thirds this

1 Spallanzani, Versuche über Erzeugung der Thiere und Pflanzen. Leipzig, 1786 , p. 5 .

Rnsconi, Développ. de la Grenouille. Milan, 1826, p. 6.

3 A nnales des Seiences naturelles. Zoologie, IV Série, Vol. IV, I855, p. 368.

- Amtl. Bericht über die 24. Versammlung deutscher Naturforscher in Kiel, 1846, p. I4I ; Wiegmann's Archiv, 1847, Vol. II, p. 34I ; Steenstrup, Oversigt K. Danske Selsk. Forhandlgr., 1846, p. 92.

5 Wiegmann's Archiv, 1852, Vol. I, p. 14.

6 Annales des Sciences naturelles. Zoologie, IV Série, Vol. IV, 1885, p. 368. 
width): the fronto-parietal bones are wide and flat. The tympanic membrane, in comparison with the eye, is smaller than in $R$. esculenta, and is usually less distinguishable from the surrounding parts as regards colour and transparency. The apertures of the Eustachian tubes are, relatively to the posterior nares, larger than in the waterfrog. The vomerine teeth are comparatively small and lie in two groups placed obliquely to each other, their anterior ends diverging from each other and being prolonged as ridges to the anterior margins of the posterior nares. The two groups do not lie between

Fig. 2.

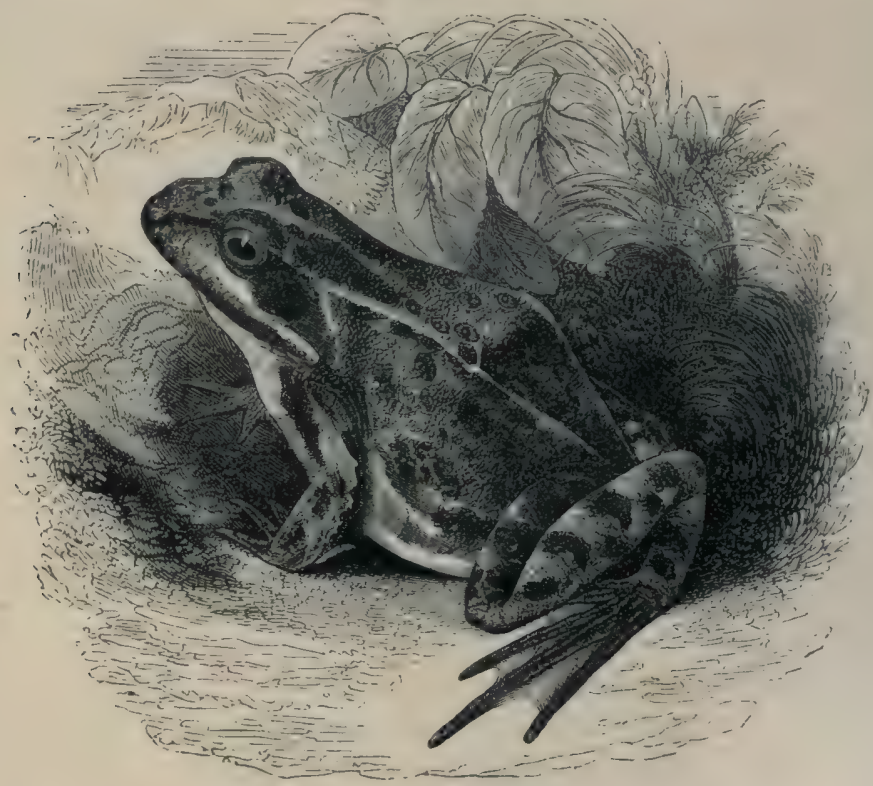

The brown grass-frog, Rana temporaria, L.

the nasal apertures, but behind a line drawn transversely through their posterior margins. Vocal saes are absent in both sexes. The hind legs are relatively shorter: the toes are not so evenly tapered off, indeed they are slightly swollen: the fourth toe, as compared with the third and fifth, is somewhat longer than in $R$. esculenta; the web of this toe does not extend to the tip of the toe, but terminates in both sexes at the last phalanx but one; the web on the third toe is less developed on the thumb side than on the other: on the remaining toes also the margins of the web 
are less developed than in $R$. esculenta, so that the free borders appear more crescentic. The supplemental toe forms only a soft and inconspicuous prominence. The back is mostly smooth; the raised glandular ridge, which extends along each side from the eye to the thigh, is present, but is much narrower and less prominent than in $R$. esculenta; another ridge passes from the angle of the mouth to the shoulder. The colouring in general, and especially the ground colour of the dorsal surface, varies from the brightest tints to the darkest brown-black; the conditions causing these variations being, no doubt, the same as those described above in $R$. esculenta. A dark-brown specimen taken from a dark frogtank is usually yellowish red on the following day. The black patch between the angle of the mouth and the shoulder has given this species the name of $R$. temporaria, and is constant. A black stripe passes from the eye across the nostril to the tip of the snout, and a similar one is found upon the anterior surface of the upper arm. On the hind legs the bands are chiefly transverse. The ventral surface is yellowish, and sometimes spotted. The thighs have a granular appearance, and these as well as the belly and the neighbourhood of the anus have frequently a reddish coloration presenting the appearance of an irritated surface.

Rana oxyrhinus, Steenstrup. This species is always smaller and more elegant in shape than the preceding one. The head is conical, with the pointed snout projecting beyond the lower jaw ; a feature which is especially evident on looking from below. The space between the eyes is narrower than in $R$. temporaria, and is not grooved, but convex; the fronto-parietal bones are narrow and arehed. With respect to the arrangement of the vomerine teeth and the sizes of the apertures of the Eustachian tubes, this species holds an intermediate position between the other two. Next to the pointed snout, the greatest difference between this species and $R$. temporaria is the presence of a much larger supplemental toe, which is of cartilaginous hardness, compressed from side to side, and contains a larger bone ${ }^{1}$. The vocal saes are absent. In the males the web of the longest toe reaches to the last phalanx but one; in the females, on the contrary, the last three phalanges project freely beyond the web. The extremities of the toes are more pointed than in $R$. temporaria, in which respect, as also in several

1 According to Steenstrup, l.c., the size of the supplemental toe is in $R$. temporaria one-half and in $\boldsymbol{R}$. oxyrhiwus two-thirds of that of the next toe. 
others, it approaches $R$. esculenta. In colouring, $R$. oxyrhinus resembles $R$. temporaria; the throat, however, is usually pure white, at least in the males, the breast dusky white and spotted, while in $R$. temporaria the throat and breast are more uniformly coloured and yellowish. V. Siebold has remarked that, during the pairingseason, the males are covered with a bluish bloom ${ }^{1}$; and, the whole ground colour being bright at this period, very beautiful tints result. V. Siebold ${ }^{2}$ moreover states that the note which the males produce during the pairing-season is different in the two species. On the whole, $R$. oxyrhinus appears to stand midway between $R$. esculenta and $R$. temporaria.

Thomas $^{3}$, in addition, distinguishes another species, $R$. agitis, which however may be the 'grenouille rousse' of Millet. Schlotthauber ${ }^{4}$ has described a frog which, in marking and colouring, might hold a middle place between $R$. esculenta and $R$. temporaria; in my opinion this is probably a cross between the two. That attempts at copulation are made, despite the difference of the pairing-season, is well known; Pontallié ${ }^{5}$ mentions this, and I have myself often found males of $R$. temporaria in conjunction with females of $R$. esculenta.

I use the following terminology. I suppose the animal to be in its natural position, the belly towards the ground, the back upwards; a horizontal plane passing from the snout to the anus divides the body into a superior or dorsal half and an inferior or ventral half. The terms superior and inferior, dorsal and ventral, indicate positions with relation to this plane. I call that part anterior which looks towards the head, and that posterior which looks towards the anus. A vertical plane at right angles to the middle of the longitudinal axis of the body, divides it into an anterior or cephalic and a posterior or caudal half. All sections and planes which lie parallel to this, as well as this itself, are frontal. Lastly, by a perpendicular section along the middle line of the body the animal is divided into right and left halves; this plane is the median plane; and the position relative to this plane is expressed by the terms median or lateral. Planes parallel to the median plane are termed sagittal.

1 I do not find, however, that this disappears when the animals are on land; in fact $I$ have animals before me in a glass in which it is plainly seen.

${ }^{2}$ l, c., p. 15 .

3 Annales des Sciences naturelles. Zoologie, IV Série, Vol. IV, 1855.

4 Wiegmann's Archiv, Vol. I, 1844, p. 255.

5 Annales des Sciences naturelles. Zoologie, III Série, Vol. XVIII, I852, p. 243. 


\section{SECTION I.}

\section{THE BONES AND JOINTS.}





\section{THE BONES AND JOINTS.}

\section{IITHRATURE.}

van Altena, Commentatio ad quast. zoologicam in academia Lugduno-Batav. a. MDcc XXVIII propositam, qua desideratur ut systematice enmmerentur species indigenæ reptilium ex ordine bstrachiorum addits unius saltem speciei anatomia et prasertim osteographia accurata. Lugd. Bat. 1829. $4^{\circ}$. With 4 Plates.

Ange, Martin St., Recherches sur les organes transitoires des batraciens. Annales des Sciences naturelles. $x^{\text {ro }}$ Série. Vol, XXIV. 1831.

Bell, Article Amphibia, in Todd's Cyclopaedia of Anatomy and Physiology. Vol. I, p. $90.1835^{-1836}$.

Born, Dr. Gustav, Ue.d. Nasenholen u.d.Thränennasengang der Amphibien. Leipzig, 1877 .

Bruch, G., Beiträge zur Naturgeschichte und Klassification der nackten Amphibien. Würzburger Naturzeitsehrift, 1862.

Bruch, G., Neue Beobachtungen zur Naturgeachichte der einheimischen Batrachier. Würzburger Naturzeitzchrift, 1863.

Cuvier, Recherches sur les ossements fossiles. Vol. V. Pt. II. Paris, 1825.

Cuvier, Leçons d'anatomie comparée. Paris, 1835. Vol. I.

Cuvier, Ueber die Rückenwirbel der Reptilien und Amphibien, Froriep's Notizen. Vol. XIII, p. 74. 1826.

Daudin, Histoire naturelle des Rainettes, Grenouilles et des Crapauds. Paris, 1802.

Ducrotay de Blainville, Ostéographie ou description iconographique comparée du squelette et du système dentaire des cinq classes d'animaux vertebrés. Paris, $184 \mathrm{I}$.

Dugès, Recherches gur l'ostéolngie et la myologie des batraciens à leurs différents àges. Paris, 1834, $4^{\circ}$. With 20 Plates.

Duméril et Bibron, Erpétologie générale ou Histoire complète des Reptiles. 1836.

Gegenbaur: I. Ceber Bau und Entwicklung der Wirbelsäule bei Amphibien überhaupt und beim Frosehe insbesondere. Abhandlungen der naturforschenden Gesellschaft zu Halle, Vol. VI. Halle, 186r.

2. Cntersuchungen zur vergl. Anatomie der Wirbelsäule bei Reptilien und Amphibien. Pt. I. Leiprig, I 862. (Carpus and Tarsus.) With 4 Plates. $4^{\circ}$.

Gegenbaur, Untersuchungen zur vergl. Anatomie der Wirbelthiere. Pt. II. Schultergürtel. 1865 .

Günther, Ueber geschlechtliche Differenzen in Knochen von lebenden und fossilen Fröschen und Fischen. Annals of Natural History. 1859. Vol. III.

Hallmann, Die vergleichende Osteologie des Schläfenbeins, etc. Hannover, 1837. $4^{\circ}$. With 3 Plates.

Hoffmann, C. K., Beiträge zur Erkenntniss des Beckens der Amphibien und Reptilien. Leyden, 1876 .

Hoffmann, C. K., Bronn's Klassen und Ordnungen des Thierreichs, Vol. VI. Amphibien. Leipzig, $1873-8$.

Huxley, On the Theory of the Vertebrate Skull; Croonian Lecture, Proc. Royal Society, p. 381 . 1858 .

Hurley, Article Amphibia, Encyclopredia Britannica, IXth Edition. 1875.

Huxley, Lectures on the Elements of Comparative Anatomy.

Huxley, Handbuch der Anatomie der Wirbelthiere. Deutsche Ausg. von T. Ratzel. 1873 .

Kehrer, G., Beiträge zur Kenntniss d. Carpus und Tarsus d. Amphibien, Reptilien, und Säiger. Berichte d. naturf. Gesell. z. Freiburg. 1886. 
v. Klein, Beiträge zur Anatomie der ungeschwänzten Batrachier. Jahres-Heft. Würtemberg, 1850 .

Köstlin, Der Bau des knöchernen Kopfs. Stuttgart, 1844. $8^{\circ}$.

Leukart, Zwischenkiefer. Valentins Repertoire. 184I, p. I 55.

Marshall, A. M., The Frog. Manchester anḍ London. 2nd Edit., r885, pp. 45-59.

Mayer, A. F., Beiträge zu einer anatomischen Monographie der Rana pipa. Acad. Caes. Leop. Nov. Acta. I825. Vol. XII, p. 527 ; and Isis v. L. Oken. I825. col. 317 .

Meckel, System der vergleichenden Anatomie. II. Thl. I. Abthlg. Halle, 1824. $8^{\circ}$.

Meckel, Ueber das Zungenbein der Amphibien. Meckel's Arch. f. Physik. I818. Vol. IV, p. 60 .

Mertens, Anatomiæ batrachiorum prodromus sistens observationes nonnullas in osteologiam batrachiorum nostratium. Halre, 1820. $8^{\circ}$.

Mivart, On the Classification of the Anurous Batrachians. Proc. Zool. Soc. 1869.

Morren, Observations ostéologiques sur l'appareil costal des batraciens. Bulletins de l'Acad. de Bruxelles, I835, II.-Mémoires de l'Académie, 1837. Tome X.

Müller, Beitrag zur Anat. d. Amph. Zeitschrift f. wissenschaftliche Zoologie. Vol. IX. I858, p. I78.

Parker, W. K., Structure and Development of the skull of the common frog. Phil. Trans. 187 r, p. 137 .

Parker, W. K., Skull of Batrachia. Phil. Trans. I 876, p. 601 .

Parker, W. K., and Bettany, G. T., Morphology of the Skull. London, 1877.

Pouchet, Note sur les différences que le sexe imprime au squelette des grenouilles. Comptes rendus. Vol. XXV, p. 76r. 1847.

Reichert, K. B., Vergleichende Entwicklungsgeschichte des Kopfs der nackten Amphibien nebst den Bildungsgesetzen des Wirbelthierkopfs im Allgemeinen und seinen hauptsächlichen Variationen durch die einzelne Wirbelthier-Classe. Königsberg, 1838 .

Remak, Untersuchungen über die Entwicklung der Wirbelthiere. Berlin, 1855.

Rösel, von Rosenhof, Historia naturalis ranarum nostratium. Nörnberg, I $\mathbf{j} 5$.

Rudolphi and Breyer, Observationes anatomicae circa fabricam Ranae pipae. Berolini, 1811.

Rusconi, Développement de la grenouille commune. Milan, 1826 .

Rusconi, Sulle metamorfosi delle osse della testa della rana. Annali di Bologna. I $^{\text {ro }}$ Série, Vol. II, p. 357 .

Schneider, Historia amphibiorum. Jenae, I799.

Shaw, General Zoology. London. Vol. II, Pt. I, p. 167.

Stannius, Zootomie der Amphibien (Handb. der Zootomie der Wirbelthiere, 2. Buch). 2nd Edit. Berlin, 1856. 8 。

Stricker, Untersuchungen über die Entwicklung des Kopfes der Batrachier. Arch. f. Anat. u. Physiol. 1864, pp. 52-76.

Stricker, Beiträge zur Biologie der Batrachier. Verhandl. der Wiener Akademie. 1866. Vol. XVI, pp. $451-456$.

Townson, R., Facts and Observations in Natural History. London, 1799.

Troya, Mémoire sur la structure singulière du tibia et du cubitus des grenouilles et des crapands. Mémoires de mathématique et de physique présentées à l'acad. de Paris. Vol. IX. 1780.

Wagner, Icones Zootomicae. Leipzig, 184I.

Wagner, Lehrbuch der vergleichenden Anatomie. Leipzig, 1834-1835.

Wiedersheim, R., Lehrbuch d. vergleichenden Anatomie der Wirbelthiere auf Grundlage d. Entwickelungsgeschichte. Jena, 1886. 2nd Edit.

Wiedersheim, R., Elements of Comparative Anatomy of Vertebrates, translated by W. Newton Parker. London, 18จ6. 


\section{THE BONES AND JOINTS.}

THE consideration of the differences in form, number, and histological structure, which the parts of the skeleton present during the various stages of development does not fall within the scope of this book: we have here but to deal with the adult frog.

The skeleton is made up of histologically different materials; these are:-(I) bone, (2) hyaline cartilage, and (3) so-called calcified cartilage. Concerning the last it is necessary to make some observations. I have chosen for it the name calcified cartilage in place of the more usual names 'cartilaginous bone' or 'primordial ossification,' as by this term its nature appears to be expressed without any ambiguity ${ }^{1}$ : it is hyaline cartilage in which ealcareous particles have been deposited to a greater or less extent : in the fresh state it has the appearance of moderately firm cartilage; when dry it becomes opaque and white, like the ealeareous erusts on the eartilages of the Plagiostomata. The ealcareous material is deposited in the cartilage in finer or coarser granules; after removal of the lime by means of acids, the cartilaginous structure becomes apparent although not so perfectly as in unchanged cartilage.

This calcified cartilage is widely distributed in the frog's skeleton : very many parts, which in higher animals consist only temporarily of this substance during the transition from cartilage to bone, are in the frog formed of it throughout life. It is especially well-marked in the epiphyses of the long bones in the hand and foot, in the bones of the shoulder-girdle, ete. To avoid repetition later on I will briefly describe it as found in the first-mentioned situation. Dugès ${ }^{2}$ has described its external appearance, while Bruch $^{3}$ has made us

1 Compare Müller, Zeit. f. wissen. Zoolog., Vol. IX.

: Dugès, Recherches sur l'ostéologie et la myulogie des batraciens à leurs différents âges, p. II6.

${ }^{3}$ Bruch, Beiträge zur Entwicklungsgeschichte des Knochensystems. Schweiz. Denkschriften, p. 1 I8. 
acquainted with its histological peculiarities. If a long bone of the frog be dried, the femur for example, the middle part is found to

Fig. 3.

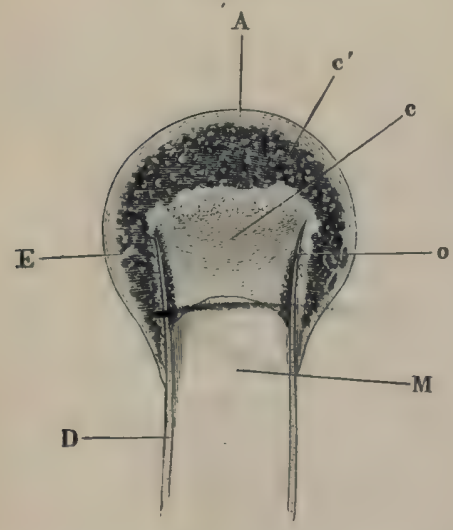

Longitudinal section through the upper extremity of the femur of Rana erculenta, magnified.

A Hyaline cartilage (articular cartilage).

c Hyaline cartilage closing end of bony cylinder.

$c^{\prime}$ Calcified cartilage of epiphysis.

D Bony cylinder of diaphysis.

E Epiphysis.

M Marrow cavity.

- Fnd of diaphysis.

differ considerably from the epiphyses in colour and in other particulars. The shaft alone has the appearance of bone, the epiphysis consisting of a white, opaque, firm substance, resembling plaster of Paris or lime, but which in the fresh moist state is exactly like cartilage. The epiphyses, which are fitted to the ends of the diaphysis like the cap of a stickhandle, have sharply defined margins (Fig. 3), as is well seen in Figs. $36,39,45$, and 46 . If a section be made through the epiphysis and part of the diaphysis, the long tube of true bone is seen to cease abruptly above 0 , Fig. 3 , and over the end of it the epiphysis $E$ is fixed. This epiphysis consists almost entirely of calcified cartilage $c^{\prime}$, and has merely a superficial layer of hyaline cartilage $A$. The bony cylinder of the diaphysis 0 , which contains the marrow $M$ in its interior, is shut off from the epiphysis by hyaline cartilage, the cells of which are arranged in transverse layers, $o$.

\section{THE VERTEBRAL COLUMN.}

The vertebral column of the frog consists of ten bones, riz. nine true vertebrae, and the rod-shaped urostyle, which alone is almost as long as all the remaining vertebrae.

\section{General Description of the nine Vertebrae.}

a. The bodies of the vertebrae are compressed from above downwards; the posterior surface of each body, with the exception of 
the eighth, presents an articular head covered with cartilage; the anterior surfaces, with the exception of the ninth, present corresponding articular depressions, covered with cartilage.

b. The arches, which have somewhat sharp margins both before and behind, bear the following processes :-

1. The articular processes (Figs. 4 and 500 ) are similarly placed to. those of the dorsal vertebrae of man: they project horizontally, the cartilaginous articular surfaces on the posterior processes being directed downwards, those on the anterior upwards.

\section{The transverse processes} (Figs. 4 and $5 t^{\prime}$ ) are strong, flat, and of very varying size and direction. The transverse processes of the fourth vertebra are the longest, those of the third only a little shorter; the shortest are those of the seventh and eighth. The atlas has no transverse processes. Those of the second and third vertebrae project directly outwards and slightly downwards; those of the fourth, fifth, and sixth upwards and backwards. The seventh and eighth project more directly out wards and at the same time backwards; the ninth upwards and markedly backwards. All the transverse processes have cartilaginous epiphyses; the largest are those of the second, third, fourth, and ninth vertebrae.

3. The spinous processes are generally small, but individually of varying size, appearance, and direc-

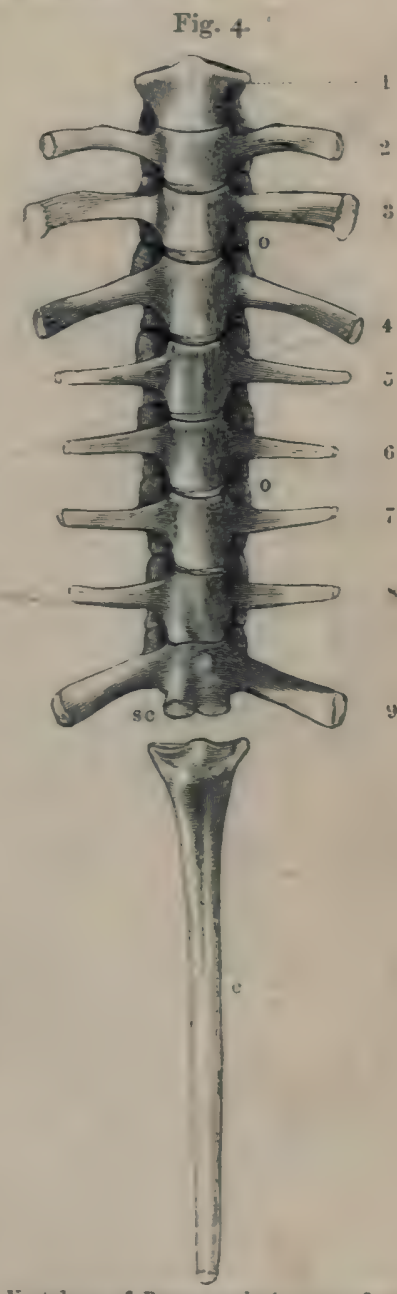

Vertebrae of Rana escukenta, seen from below, twice the natural gize.

$x$ to $g$ First to ninth vertebre.

c Uroatyle.

- 0 Articular proceses.

\&c The two facets for articulation with the urostrle.

- tion. The longest are those of the third, fourth, and fifth vertebrae; these are, in transverse section, of a three-sided prismatic form, as 
in the dorsal vertebrae of man; they are directed backwards and provided with cartilaginous epiphyses. The spinous processes of the sixth and seventh are shorter, compressed from side to side, project

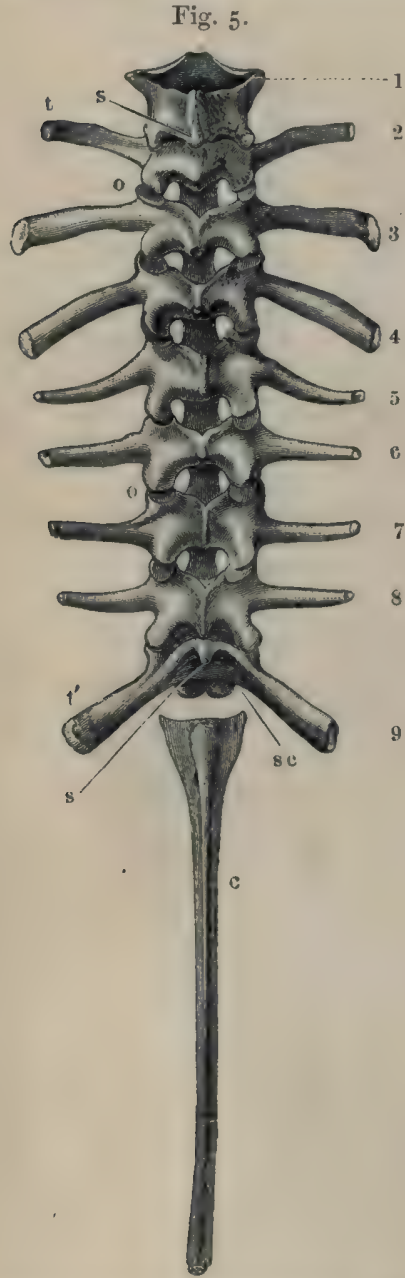

Vertebral column of Rana esculenta, from above, twice nat. size.

I to 9 First to ninth vertebrse.

c Urostyle.

00 Articular processes.

$s e$ Facets for articulation with the urostyle.

$t t^{\prime}$ Transverse processes. directly upwards, and are visually without cartilaginous epiphyses; that of the eighth is still shorter: As regards the spinous processes, those of the third, fourth, and fifth vertebrae resemble those of the dorsal vertebrae in man; those of the sixth, seventh, and eighth, lumbar vertebrae. The ninth has either no spinous process or only a rudimentary one. The first and second vertebrae may be looked upon as cervical vertebrae : the second has a short spinous process with a cartilaginous epiphysis. In the first, the cartilage which unites the two halves of the arch represents the rudiment of a spinous process.

\section{Description of Particular VERTEBRAE.}

1. The atlas or first vertebra has a thin body, compressed from above downwards, and an arch. The body has posteriorly a slightly raised, cartilaginous, articular head, which is broader transversely: in front it has two oval articular facets, which are separated from each other by a median projection. Each facet is concave, and directed forwards, outwards, and slightly upwards. The arch is completed above by cartilage, which projects slightly to form the rudiment of a spinous process. The hinder margin of the arch bears two articular processes. Transverse processes are wanting.

2. The second vertebra presents all the general characters of an 
ordinary vertebra, except that the transverse processes are directed somewhat downwards.

3. The transverse processes of the third vertebra are longer than those of the second: each is directed downwards, is broader at its extremity than at its base, and bears a hammer-shaped cartilaginous epiphysis larger than those of the remaining transverse processes.

4. The transverse processes of the fourth vertebra are the longest: each is broader at its free end than at its base, is directed upwards and backwards, and provided with a cartilaginous epiphysis.

5, 6, 7. The transverse processes of the fifth, sixth, and seventh vertebrae are smaller, contracted towards their free extremities, and directed upwards.

8. The eighth vertebra is distinguished from the rest by its body possessing no articular head. It presents, at each end, a concave articular depression. The transverse processes resemble those of the seventh.

9. The ninth vertebra unites the vertebral column with the hipbones, and is hence to be regarded as a sacrum. The body bears on its anterior surface an articular head for articulation with the eighth vertebra: on its posterior surface are two small rounded and closely approximated processes (Figs. 4 and 58 ) for articulation with the urostyle. The transverse processes are strong, broader at the free ends than at their origin, directed upwards and backwards, and provided with eartilaginous epiphyses.

\section{Articulations of the Vertebrae.}

The articular heads and depressions of the vertebral bodies, together with the joint surfaces of the articular processes, are covered with hyaline cartilage. The periosteum of the bodies, as also that of the articular processes, forms true capsular joint ligaments. The articulations of the vertebrae are still further strengthened by longitudinal fibres, which extend along the anterior and posterior surfaces of the vertebrae, and correspond to the ligamentum vertebrale commune anticum et posticum of man. Between the vertebral arches are membranes which represent the ligamenta intercruralia. Between the spinous processes are bands of connective tissue which form ligamenta interspinalia. (For the articulation of the atlas with the occiput, see page 24.) 


\section{Structure of the Vertebrae ${ }^{1}$ (Figs. 6 and 7).}

Each vertebral body consists of a cylinder of compact bone, which is directly continued into the bony substance of the arch. In the interior of the cylinder is found an isolated persistent vestige of the chorda dorsalis $(C h)$ : this is surrounded by cancellous bone $(c)$, which extends backwards towards the articular head and forwards directly into the articular cartilage, compact bone being absent in these

Fig. 6.

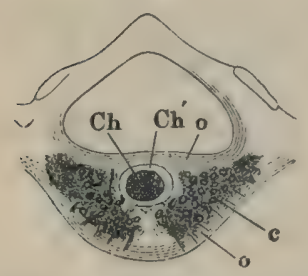

Transverse section through a vertebra of Rana esculenta, magnified.

c Cancellous bone.

Ch Chorda dorsalis.

$C h^{\prime}$ Sheath of chorda dorsalis.

- Compact bone on the upper and lower surfaces of the budy.

Eig. 7 .

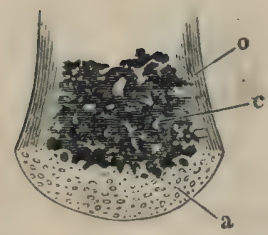

Longitudinal section through the posterior half of the body of a vertebra of Rana esculenta.

a Cartilage of the head.

c Cancellous bone.

- Shell of compact bone. parts. In a transverse section of a vertebral body the following parts are seen (Fig. 6):-a. An outer layer of compact bone (o) (the transverse section of the above-mentioned cylinder), which is formed of parallel lamellae of varying thickness. These, according to Gegenbaur, and as I can confirm, are arranged in well-defined groups, each of five to eight lamellae. The number of the secondary lamellae increases with the age of the animal. b. In the interior, in the form of a cylinder, is the remnant of the chorda dorsalis. It consists of a double sheath $\left(C h^{\prime}\right)$ and contents $(C h)$ composed of chorda-cells. c. Immediately around the persistent portion of the chorda lies the central part of the vertebral body, formed by transformation of the vertebral cartilage and of the bases of the original cartilaginous arches. At each side of the chorda are large marrowspaces $(c)$, filled with cells, from which proceed narrower canals, winding in various directions, and anastomosing freely with one another both before and behind. Their walls are constituted partly of true bone, partly of cartilage.

1 Cf. Gegenbaur, (I) Über Bau u. Entwicklung der Wirbelsäule hei Amphibien iiberhaupt u. beim Frosch insbesondere. Abhand. d. Naturforsch. Gesell, zu Halle, vol. vi, 1861 ; (2) Untersuch. zur vergleich. Anat. d. Wirbelsäule bei Amphibien u. Rept., Leipzig, 1862. As regards the adult animal I can bear ont Gegenbaur's observations. The scope and limits of this book forbid me to go further into the developmental history. 


\section{The Urostrue (Figs. 8 and 9).}

The urostyle is a long, median, rod-like bone, which projects backwards, midway between the two hip-bones, and terminates over the anus. The anterior end (Fig. $8 a$ ) is the thicker and broader part of the bone, and has two articular depressions (Fig. 9) for articulation with the two facets of the ninth rertebra. The hinder end is pointed and cylindrical, and terminates in a cartilage, which is fixed in the tubular end of the bone. The middle portion is almost cylindrical, and has a groove along the ventral surface which gradually becomes less marked behind. The dorsal surface bears a ridge (Figs. 8 and $9 s$ ), which is high and thick in front, becomes sharper and less prominent as it proceeds backwards, and gradually disappears towards the hinder third of the bone, so that in transverse section the an-

Fig. 9 .

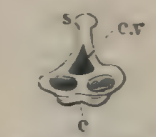

Urostyle of Rum esculenta. seen from the side? twice nat. size.

c Ventral bonder.

c.e. Canal. vertebralis.

s Donsal ridge (pr. spinoc). terior two-thirds of the bone appear triangular. with a ventral and two lateral surfaces: while the hinder third is eylindrical. The anterior portion of the bone contains a canal, canalis rertebralis (Fig. 9 c.x.), which is a continuation of the rertebral canal, along which the hindermost spinal nerves pass. On each side of the anterior portion of the urostyle are small apertures (Fig. 8 c.c.), which lead into canals (canales cocengei), which open into the vertebral canal, and through which the coceygeal nerves pass. In front of these openings and partly overhanging them are small triangular projections (Fig. 8) (jrocessus transversarii): these, howerer, are unt constant, and are more often found in $R$. esculenta than in $R$. temporaria, in which latter species the openings are smaller.

Fig. \&.

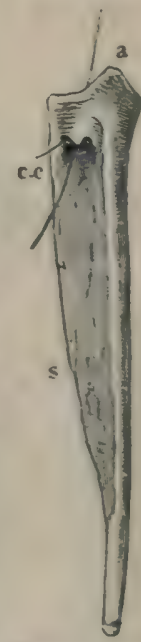

Urastyle of Ruma esculenta, seen from the side, twice nat. size. A bristle is passed through the canal. rert. and out through the camul. coccyo. of the right side.

a Anterior extremity.

c.c. Canal coceyg. - Durzal ridge (pr. spinos).

\section{THE SKULL.}

The flat form of the frog's head, as in batrachians generally, depends upon the wide separation of the jaw-bones of the two sides, and on the large size of the orbital eavities and the horizontal 
direction of their floors. The outer circumference of the head forms a parabolic frame (Figs. IO and II), composed of the maxillary $(m)$, premaxillary $(i)$, and quadratojugal bones $(j)$. In the middle of this curved framework lies the elongated prismatic cranium. Anteriorly, this is attached to the fore-part of the frame by means of the cartilaginous skeleton of the organs of smell (Fig. II $e^{\prime}$ ); posteriorly, it widens out into two transverse arms $(p)$, which contain the organs of hearing. From this base, on either side, a bony strut, composed of the posterior arms of the squamosal $\left(t^{\prime}\right)$ and of the pterygoid bones, passes backwards to the hinder end

Fig. 10.

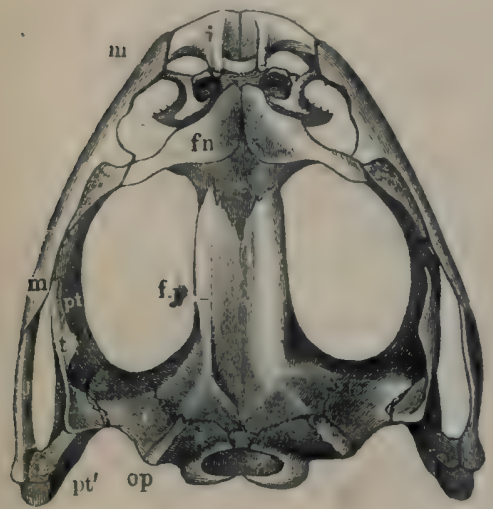

Skull of Ranc esculenta, seen from above, twice natural size.

e Sphenethmoid.

Ir Nasal. $x$

f.p. Fronto-parietal $\times$

i Premaxillary.

-j Quadrato-jugal.

sim Maxillary. $x$

- Exoccipital $\lambda$

op Opisthotic,

\& $p$ Prootic. $x$

Lpt Pterygoid.

- $p t^{\prime}$ Posterior limb of pterygoid.

ti Squamosal.

- $t^{\prime}$ Posterior arm of the same.
Fig. II.

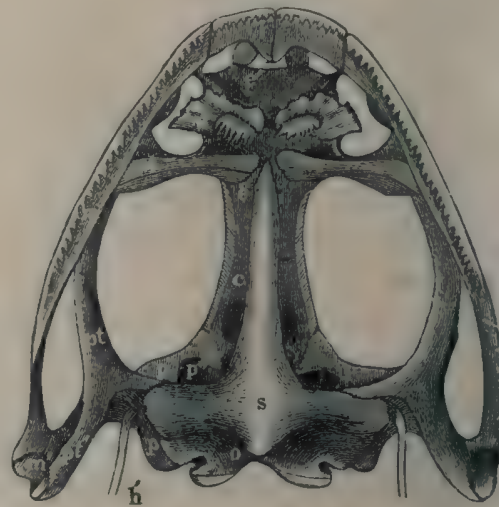

Skull of Rana esculenta, seen from bolow, twice natural size.

c Cartilaginous wall of skull.

e Sphonethmoid. - -

$\varepsilon^{\prime}$ Cartilaginous skoleton of nose. :-

$h^{\prime}$ Stylo-hyoid.

i Premaxillary. - i

a) Maxillary.

. Quadrato traot.

- Exoccipital.

p Prootic.

$p^{\prime}$ Anterior arm of prootic (ala magna anth).

$p^{\prime \prime}$ Trigeminal foramen.

- $p l$ Palatine.

- pt Pterygoid.

pt Posterim arma of pterygoid.

- Parasyenoid.

- v Vomer.

of the frame. The anterior arm of the squamosal bone $(t)$ does not quite reach the framework, but is attached to it by ligament alone. Between the last-named arm posteriorly, the cranium on the inner side, and the maxillary frame-work laterally, is a large space representing the orbital and temporal fossae of human anatomy. 


\section{A. The Cranium.}

The cranium of the frog is a prismatic tube, wide behind, narrow in front, and formed in great part of cartilage (Figs. $5_{5}$ and 17 ). Our indigenous species are characteristically distinguished from cne another by peculiarities in the form of the cranium. In $R$. esculenta it is long and narrow, in $R$. temporaria short and wide. The superior surface in the former is markedly concave, while in the latter it is flat, and in $R$. oxyrhinus arched. These differences are readily recognised in the living animal.

\section{The Bones of the Cranium.}

1. The exoccipital bones, ossa occipitalic, lateralia, Cuvier (Figs. 10, 11, 12, I4, 160 ).

Cuvier, l.c., p. $3^{5}$;, Pl. XXIV, bb.-Dugès, l.c., n. 1 4.-Parker and Bet-

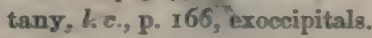

These paired bones form the hinder part of the rranium; they bound the foramen magnum, and articulate with the rertebral column. They are imbedded in the cartilaginous matrix of the skull, and are separated above by an unossified part of this matrix (occipitale superius, Dugès), which represents the tabular portion of human anatomy: below they are separated by a similar part (occipitale basilure, Dugès) which represents the body of the occipital bone. They therefore properly represent only the condylar portions ( parles conalyloideae) of the human occipital

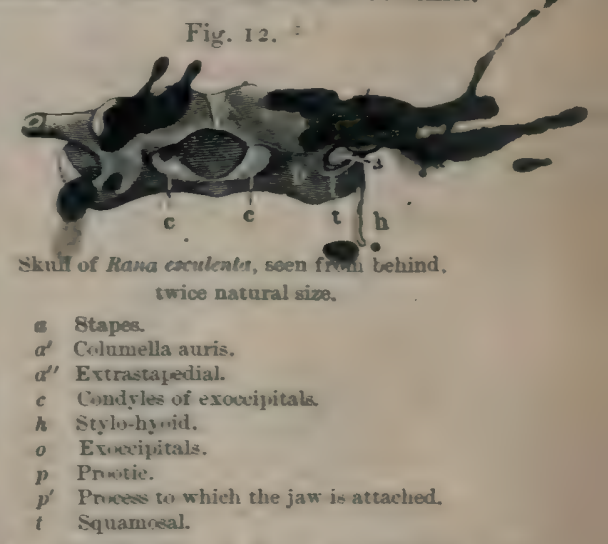
bone. Each possesses a cartilaginous articular head, for articulation with the first vertebra: these converge below, and suriound the Iower half of the circumference of the foramen magnum. This latter has, in $R$. esculenta, a transversely oval outline; in $R$. tempioraria, a somewhat heart-shaped outline, with the apex directed upwards: in accordance with this the whole bone is wider than high in the first species; and in the latter it is higher than it is wide. From the upper and outer border of the foramen magnum on each side 
a ridge runs obliquely outwards and downwards, in which lies the suture between this bone and the prootic bones. This bony ridge (processus mastoideus, autt.) is usually cartilaginous in $R$. esculenta, even in old animals; in R. temporaria, even in young specimens, it is bony. In the latter species the bones unite very early, while in the former they remain separated by the primitive cartilage. Between this crest and the processus condyloideus there is a depression (fossa condyloidea), with a hole (foramen condyloideum) through which the vagus nerve leaves the cranium. The exoccipital take part in the formation of the labyrinth of the ear, as will be noticed later on.

Articulation of the Exoccipital Bones with the Atlas. From the middle of the anterior surface of the body of the atlas a ligament arises, representing to a certain extent the lig. suspensorium clentis, and attached to the basal portions of the exoccipital bones.

2. The prootic bones, ossa petrosa, Cuvier (Figs. IO, II, and $12 p)$.

Cuvier, rocher, l.c., p. 388, Pl. XXIV, ee.-Dugès, n. I2, rupéo-ptéréal. -Stannius, ala temporalis.-Meckel, Schädelstück des Schläfenbeins,-Parker and Bettany, l.c., prootic.

These parred bones lie at the sides and in front of the exoccipital bones. As already explained, they remain in $R$. esculenta separated from these by cartilage, while in $R$. temporaria they early enter into bony union with them; this is due to the complete ossification of the processus mastoideus in the latter species, as stated above. The prootics form the lateral expansions of the posterior part of the skull in which the organs of hearing are placed. The large cavity which contains the ear labyrinth is completed by the exoccipital: internally it opens freely into the skull, and externally on the posterior wall of the skull through the foramen ovale, which is formed by both these bones. The postero-lateral part of the prootic usually remains cartilaginous: at the side and in front of the foramen ovale this cartilage is pierced by a small opening, through which passes the nervus faciatis or ramus tympanicus n. vagi (Volkmann). At the side there is a process to which the suspensorium of the lower jaw is attached (Fig. I $2 p$ ): behind this is a hollow in which the auditory ossicles lie, and which may be designated fossa tympanica (Fig. 12 t). The anterior border of the bone forms the 
hinder and inner walls of the orbit. Here also is the trigeminal foramen (Fig. II $p^{\prime \prime}$ ) through which the N.trigeminus and the several nerves for the muscles of the eye pass; it represents the foramen ovale, for. rotundum, and the fissura orbitalis superior (sphenoidal fissure) of the human sphenoid bone. The foramen is sometimes, especially in young animals, only a noteh, which is completed by cartilage. On account of the relation of this part (Fig. II $p^{\prime}$ ) of the bone to the nerves which pierce it, the whole bone has been named by Stannius the ala magna or temporalis of the sphenoid; it has been also looked upon as a bone which contains these elements, as by Dugès, who on this account calls it rupéo-ptéréal.

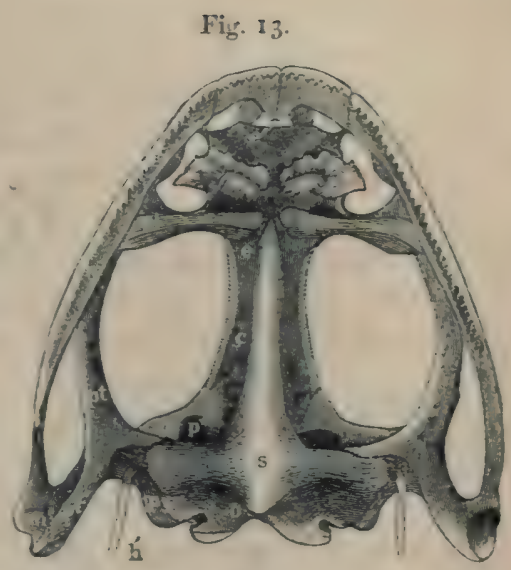

Skull of hana eaculenta, eeen from below, twice natural size.

\section{Appendages of the Prootic Bones.}

I. The styloid cartilage. From the cartilaginous portion of the prootic the styloid cartilage runs downwards, backwards, and inwards, and is continued directly into the anterior cornu of the hyoid bone (Figs. II $h^{\prime}$ and I $_{2} h$ ).

\section{The auditory ossicles.}

a. A thick eartilaginous dise, the operculum. (Fig. 12 a), closes the foramen ovale.

b. To the opereulum is attached a bony, club-shaped piece, the columella auris (Fig. I $2 a^{\prime}$ ), which has at its inner, thicker end a cartilaginous epiphysis, the interstapedial; it lies transversely with the apex directed outwards, and this longer portion is the mediostapedial.

$\therefore$ To the apex of the medinstapedial is attached, at an 
obtuse angle, the third cartilaginous piece, the extrastapedial (Fig. I $2 a^{\prime \prime}$ ). It is attached to the tympanic membrane, and by its upper portion is fastened to the cartilaginous tympanic ring by a smaller piece, the suprastapedial.

3. The tympanic ring (annulus tympanicus) is an annular cartilaginous frame; or more exactly, has the shape of a short, truncated cone, as it narrows towards the middle line: it is attached to the squamosal bone. (See Organ of hearing.)

3. The parasphenoid, os sphenoideum, Cuvier (Figs. I I and I6s).

Cuvier, l.c., p. 388, Pl. XXIV, d.-Dugès, n. 8.-Meckel, Theil des Grundbeins.-Parker and Bettany, l.c., parasphenoid.

A large portion of the base of the cranium is taken up by this cruciform bone. Of the two longitudinal median processes, the posterior is by far the shorter, and lies in front of and partly below the cartilaginous os accipitale basilare. The anterior longer longitudinal arm closes in the greater part of the cranium from below, and articulates by its outer edges with that part of the prootic bones often described as the alae magnae, and also with the cartilage lying in front, which forms the greater part of the lateral walls of the cranium. The anterior extremity of the bone articulates with the palatine bones. The transverse arms lie on the under surface of the exoccipitals and of the prooties.

The greater width of the cranium in $R$. temporaria is associated with the greater relative width of the anterior arm of this bone.

4. The fronto-parietal bones, ossa fronto-parietalia, Cuvier (Figs. Io and I4 fp).

Cuvier, l.c., p. 387 , Pl. XXIV, c.c.-Dugès, n. I.-Parker and Bettany, l.c., fronto-parietal.

These are a pair of somewhat long, flat bones, which form the principal part of the upper wall or roof of the cranium, and cover in superiorly the cartilaginous cranium, which is here, in great part, persistent. They are united in the middle line by the sagittal suture; posteriorly they articulate with the exoccipital and prootic bones; anteriorly with the sphenethmoid, which they overlap like tiles. The outer margin of each bone is bent somewhat downwards (Fig. $16 f p$ ), and between it and the parasphenoid there is a space in the wall of the cranium which is closed in by cartilage and connective tissue only. 
These bones are narrower in $R$. exculenta, and along the sagittal suture are depressed into a groove: where the superior surface bends down to become lateral the edges are much more prominent. In $R$. temporaria the bones are broader and flat or eren somewhat arched. The latter condition is still more marked in R. oxyrhinus.

5. The sphenethmoid, os ethwoideun (Figs. IO, II, I4, and I6e).

Cuvier, os en ceinture, l.c., p. $3^{8}$ 7, Pl. XXIV, a.-Dugès, n. I 5.--Rathke, anterior or sphenoidal wing (Vortr. z. vergl. A nat. d. Wirbelthiere, Leipzig, I862, p. 42).-Meckel, Riechbein, l.c., p. 502.-Parker and Bettany, l.c., ethmoid.

The long tubular cranium is completed anteriorly by a single bone, which forms at once the roof, floor, and lateral walls. It is consequently more or less ring-shaped, on which account it has been named ' os en ceinture' by Curier. Only the posterior portion is annular, however : the anterior portion forms a double canal, with a median partition, for the passage of the nerves of smell, and as these eanals are widened out anteriorly, this part of the bone helps to complete the nasal carities, which, however, are bounded for the most part by cartilage, as described below. In some species of frogs (as for example $R$. occellata, Rathke) this cartilage is partly ossified.

The sphenethmoid has on each side a small bony canal, running forwards and inwards, through which the ramus nasalis of the first division of the trigeminal nerve passes.

The cartilaginous skeleton of the nose (Figs. I 4 and $16 n, n^{\prime \prime}, n^{\prime \prime \prime}$, $\left.n^{\prime \prime \prime \prime \prime}\right)$. The anterior borders of the funnel-shaped cavities of the sphenethmoid pass into cartilage, which forms two capsules, separated from each other by a median cartilaginous septum, and opening laterally. We can distingruish, (a) a cartilaginous septum, forming a continuation of the bony one; (b) the floor of the nasal cavity, narrower behind, wider in front; $(c)$ a roof somewhat narrower than the floor. The floor and roof are united in front by an arched surface. From this cartilaginous capsule various processes project, which unite it to other portions of the facial skeleton : firstly, from the most posterior portion of the capsule there passes transversely outwards a bar of cartilage ( $(s n)$, which, widening, becomes continuous with the cartilage $\left(s \mu^{\prime \prime}\right)$ forming the basis of the anterior arm of the ptergoid bone. From the anterior angle a cartilaginous process passes outwards (Figs. I4, $16 n^{\prime \prime}$ ), which is attached to a projection on the 
anterior end of the maxillary bone; from the same spot a hornshaped cartilaginous process $\left(n^{\prime \prime}, n^{\prime \prime \prime}\right)$ curves round backwards and towards the middle line. This projection bounds the nasal cavity externally, sending off

Fig. 14.

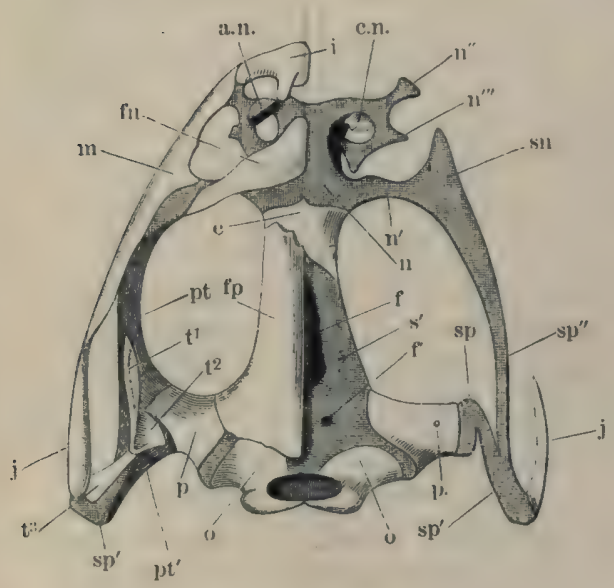

Cartilaginous basis of the skull of Rana esculenta, from above, twice natural size. Cartilage shown by stippling.

a. $\boldsymbol{n}$ : Wings of nasal cartilage. c.n. Coneha narium.

e Sphenethmoid.

$f f^{\prime}$ Foramina of cranium.

fn Nasal.

fp Fronto-parietal.

$i$ Premaxillary.

$j$ Quadrato-jugal.

$m$ Maxillary.

$n, s n$ Cartilaginous nasal skeleton.

$n^{\prime}, x^{\prime \prime}, x^{\prime \prime \prime}$ Processes of the cartilage.

- Exoccipital bonea. a free process $\left(n^{\prime \prime \prime}\right)$ on the way, and ends with a double point on the roof of the eartilaginous nasal cavity $\left(n^{\prime \prime \prime \prime}\right)$. On the floor of the nasal capsule, on either side, is a knobshaped cartilaginous eminence, running from behind, forwards and outwards; this may. be regarded as an indication of a turbinated bone. From the anterior wall there passes into each nasal cavity an almost horizontal, partly ossified plate (c.n.), ending posteriorly in a free pointed border. These are the cornets of Dugès $(l . c$., p. 12, Pl. I, Figs. I, 5), who correctly regarded them as turbinated bones. Cuvier described them as rudimentary nasal bones ${ }^{1}$.

The alar cartilages of the nose have still to be described. They are $(a . n$.) shell-shaped cartilages, hollowed out on the inner sides and

${ }^{1}$ Cuvier (Ossem. fossil., V, 2. 388 ) says that these little bones are fixed outside the nasal cavity, so that we may suppose that he confounded them with the nasal cartilages found in this situation. Dugès correctly indicates their position to be inside of the nasal capsule. Meckel (Vergl. Anat. II, 504) also regards them as nasal bones. Bruch (Würzb. naturwiss. Zeitschrift, vol. II, r86 I, p. 213) could not find them in any frog-skull, doubtless berause he did uot look inside the nasal capsules. 
decreasing in width from before backwards. They are movably attached br their anterior broader ends to the tips of the projecting portions of the premaxillary bones, and are so arranged as to bound the lateral margins of the nasal apertures, which they orerlap.

\section{The cartilaginous basis of the} skull, Primordial cranium (Figs. I t, 16).

a. If the fronto-parietals be removed, (Figs. 1 4,16 ), a cartilage $\left(s^{\prime}\right)$ is found which partially closes the cranial carity, and which is usually perforated on either side by a foramen $\left(f^{\prime}\right)$.

More anteriorly in the median line is found a space (f) which extends to the sphenethmoid bone, and is only closed by connective tissue: posteriorly the cartilage extends between the exoccipitals as far as the foramen magnum, representing theosoccipilale superius.

b. The base of the cranium is (Fig. I6)also partly cartilaginous. If the parasphenoid ( $(8)$ be removed we find above it a cartilage ( $\left.s^{\prime}\right)$ which passes backwards between the exoccipitals, and extends as far back as the foramen wagnum: it corresponds to the os occipitale basilare.

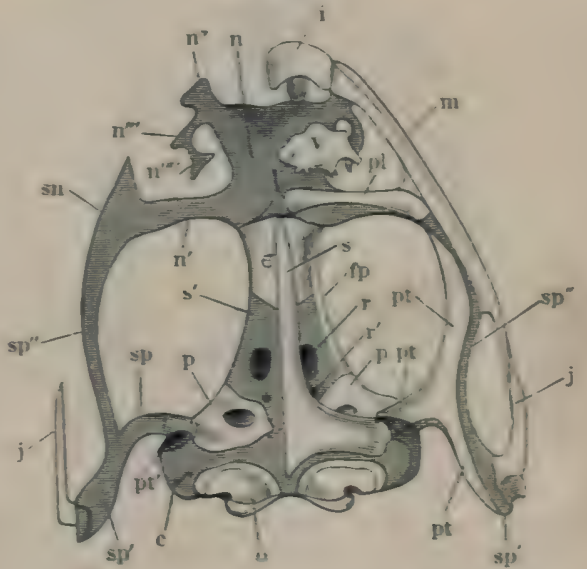

Cartilaginuus skall of Rana cectlenta, fmm heluw, twice natural size. Cartilage shum bs stipyling.

c Cartilage of prootic.

e splienethmeid.

of Fnontu-jarietal.

i Premaxillary.

$f$ Quatratio-jugal.

on Maxillars.

$n, s n$ Cartilaginoas nasal skeleton.

$n^{\prime}, n^{\prime \prime}, n^{\prime \prime}, n^{m \prime}$ Procusces of nasal cartilige.

- Exincipital.

P. Prootic.

14 Palatine.

$$
\begin{aligned}
& \text { pe Pterygoid. } \\
& \mu t^{\prime} \text { Articuiar surface for } \\
& \text { ptervarid. } \\
& \text { - Civio formen. } \\
& \text { } \text { Foramea fir } \mathbf{X} \text {. abdaceno } \\
& \text { - Pamastienvil. } \\
& \text { * Cartilaynntas cranium. } \\
& \text { sp Cartilage of anspensorium. } \\
& \text { sp' Cartilage nnder squa- } \\
& \text { minal. } \\
& \text { sy" Cartiligge nuder pters. } \\
& r \text { Vinmer. }
\end{aligned}
$$

Fig. 15.

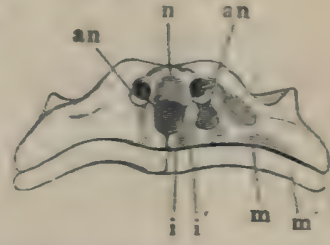

Sasal cartilages of frug, frunt view.

an Concha narinm.

i Premaxillars bunes.

p. Asending juncess of ame.

tomer jaw.

a' Lawer jaw.

n Olfactury cajernle.

Fig. J6

c. The sides of the cranium are formed almost entirely of car- 
tilage. This cartilage fills the space bounded by the nasals above, the parasphenoid below, the so-called ala magna of the prootic bone behind, and the sphenethmoid in front; and has in its posterior part an aperture $(r)$ through which passes the nervus opticus, and below this a smaller one $\left(r^{\prime}\right)$ for the nervus abducens. The extent of the cartilage in the antero-posterior direction is greater in $R$. esculenta than in $R$. temporaria, or in other words the sphenethmoid stretches further back in the latter than in the former.

\section{B. The Bones of the Face.}

Firs. 17 .

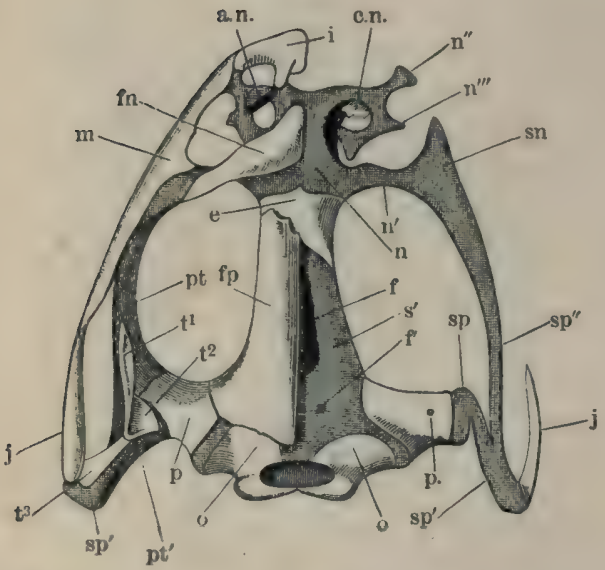

Cartilaginous basis of the skull of Rana esculenta, from above, twice natural size. Cartilage shown by stippling.

a.n. Wings of nasal cartilage.

c.n. Concha narium.

$e$ Sphenethmoid.

$f f^{\prime}$ Foramina of cranium.

fin Nasal.

$j p$ Fronto-parietal.

i. Premaxillary.

j Quadrato-jugal.

$m$ Maxillary.

$n, s n$ Cartilaginous nasal skeleton.

$n^{\prime}, n^{\prime \prime}, n^{\prime \prime}$ Processes of the cartilage. o Exoccipital bones.

p. Prootic.

$p t$ Anterior arm of pterygoid.

$p t^{\prime}$ Pusteriur amm of pterygoid.

$s^{\prime}$ Cartilaginous cranium.

sp Cartilage of suspensorium.

$s p^{\prime}$ Cartilage under the squamosal.

$s p$ " Cartilage under the ptery. goid.

$t$ Anterior, arm of the

$\begin{array}{ll}t^{2} & \text { Middle } \\ t^{3} & \text { Posterior }\end{array}$

\section{The Suspensorium.}

7. The squamosal bones, 088a tympanica, Cuvier (Figs. I0, $14 t$ ).

Cuvier, os8. foss., V, 2. 39o, Pl. XXIV, Figs. I, 2 n.-Dugès, temporomastoidien, n. тo. Meckel, Articular part of temporal. - Hallmann and others, quadrate-bone. - Parker and Bottany, l.c., squamosal.

The suspensorium, which forms the articulation between the cranium and the lower jaw, is $T$ shaped, and consists of cartilage covered by bone. Of the three arms of the $T$ the anterior has a free pointed cxtremity (Fig. I4 $t^{1}$ ) at the postero-lateral margin of the temporo-orbital fossa : it forms a true

processus zygomaticus, and is bound to the upper jaw by ligaments. In $R$. temporavia it is comparatively much shorter than in $R$. esculenta. The posterior upper arm $\left(l^{2}\right)$ articulates with the prootic 
bone: the third or lower arm $\left(l^{3}\right)$, supported by a cartilage ${ }^{1}$, runs backwards and downwards to unite with the side of the broad hinder extremity of the quadrato-jugal bone.

The eartilaginous basis ${ }^{1}$ of the suspensorium (Fig. $78,8 p^{\prime}$ ) is a direct continuation of the cartilaginous basis of the cranium, and proceeds from it to the outer extremity of the prootic; from this point the cartilage runs backwards and divides into two branches; of these, one $\left(s p^{\prime}\right)$ retains the original course backwards and outwards towards the articulation of the lower jaw, and in conjunction with the quadrato-jugal $(j)$ forms this joint. The other $\left(8 p^{\prime \prime}\right)$ is directed forwards along the anterior arm of the pterygoid bone; it widens in front $(8 n)$, and becomes directly continuous with the cartilaginous strut described above as projecting from the hinder part of the cartilaginous olfactory capsule.

8. The quadrato-jugal bones, ossa jugalia, Cuvier (Figs. IO, I 7, 19j).

Dugès, tympano-mallial, n. It.-Cuvier, l. c., p. 399, Pl. XXIV, Figs. I, 2 o.-Hallmann, quadrato-jugal bone, l.c., p. 39.-Parker and Bettany, $l$, c., quadrato-jugal.

This is a small process of bone, likened by Dugès to a comma, which rests by its posterior broader extremity on the cartilage of the mandibular arch ${ }^{1}$, and forms with it a portion of the articular head for the lower jaw. The anterior extremity is pointed, directed forwards, and attached by ligament to the maxillary bone.

9. The pterygoid bones, assa pterygoilea (Figs. I0, I I , I 7, I 9 pt). Cuvier, l.c., p. 399, Pl. XXIV, Figs, I, 2 m m.-Dugès, n. 9--Parker and Bettany, l.c., pterggoid bnnes.

These bones, shaped like the Greek letter $\lambda$, possess each three arms : of these the middle one is attached to the under surface of the prootic bone by a cartilaginous process (Fig. $18 \%$ ); the hinder grooved arm lies upon the under surface of the cartilaginous suspensorial arch (Fig. $\left.18 s j^{\prime}\right)$; and the anterior arm ( $\left.j t\right)$ runs forwards along the inner border of the anterior ramus of the suspensorium $\left(s p^{\prime \prime}\right)$, in contact with the maxillary, palatine, and nasal bones.

The cartilage just mentioned, by means of which the middle arm of the pterygoid is connected with the cranium (compare Fig. 18), proceeds from the cranial origin of the cartilaginous arch $(8 \%)$, turns downwards and then forms a sort of articular head $(c p t)$, which is articulated to an oval flat elevation of the prootic cartilage

1 This cartilage is the quadrate cartilage of Parker; others regard it as the upper end of the cartilaginous mandibular arch, of which Meckel's cartilage is the lower distal part. 
Fig. 18.

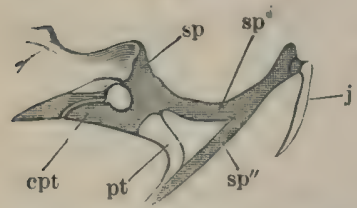

Origin of the suspensory cartilage $(s p)$ from the skull, with attachment of the pterygoid ; front view. Cartilage shown by stippling.

cpt Cartilaginous epiphyses of the pterygoid bone, from the cartilaginous suspensorium.

3 Quadrato-jugal bone.

pt Pterygoid bone.

$s p$ Origin of suspensorial cartilage from the skull.

$s p^{\prime}$ Hinder arm of same.

$s p^{\prime \prime}$ Anterior arm of same.

Fig. 19.

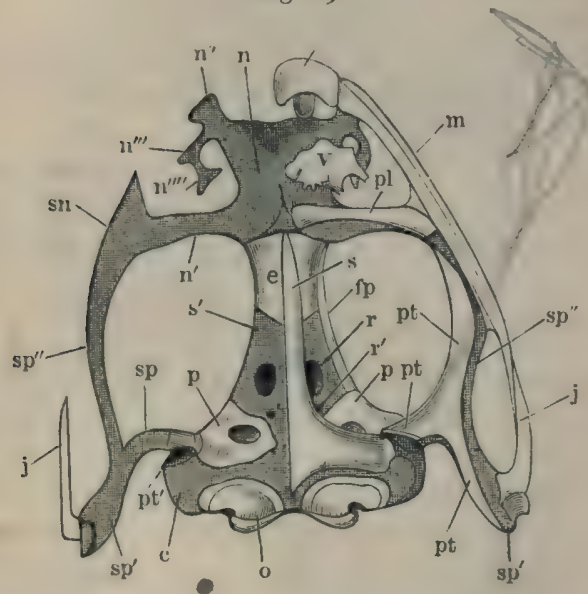

Cartilaginous skull of Rana esculenta, from below, twice natural size. Cartilage shown by stippling.

c Cartilage of prootic.

e Sphenethmoid.

fp Fronto-parietal.

$i$ Premaxillary.

Quadrato-jugal.

m Maxillary.

$n, s n$ Cartilaginous nasal skeloton.

$n^{\prime}, n^{\prime \prime}, n^{\prime \prime \prime}, n^{\prime \prime \prime \prime}$ Processes of nasal cartilage.

- Exoccipital.

p Prootic.

pl Palatine.

by a movable joint. Externally the articular head curves somewhat abruptly into the bony substance (Fig. $18 p t$ ) of the pterygoid bone.

10. The maxillary bones, os8a maxillaria superiora, Cuvier (Figs. Io, II, I7, $19 \mathrm{~m}$ ).

Cuvier, l.c., p. 389, Pl. XXIV, Figs. I, 2 k k. -Dugès, n. 4, maxillo-jugal. - Parker and Bettany, l.c., maxillary bones.

These are elongated, curved bones, narrower behind, broader in front, and forming with the quadrato-jugals the bony support of the face. The superior surface is convex and directed outwards, the inferior surface is grooved and bears teeth along the outer edge of this groove. From the upper and inner border of the anterior half of this bone a process (processus. frontalis) passes upvards, which artieulates with the nasal bone. The anterior extremity of the bone articulates with the premaxillary bone, the posterior with the quadrato-jugal.

The maxillary bone articulates at its anterior end (Fig. I9 $n^{\prime \prime}$ ) with a process of the cartilaginous capsule of the nose. The broad plate of cartilage (Fig. I9 $u$ ), under 
cover of the jrocessus frontalis, connects the hindermost transverse portion of the nasal cartilage with the eartilage which runs forwards from the suspensorium upon the anterior arm of the pterygoid.

11. The nasal bones, os:a fronto-nasalia, Dugès (Figs. 10, I $7 f n$ ).

Cuvier, froutule anterius, l. c., h.-Dugès, n. 2.-Meckel, nasal bone.- Parker and Bettany, l.c., nasal bones.

These flat, triangular bones, which rest upon the nasal cartilages (i), assist to bound the orbital cavities in front, and are connected by their external angles with the maxillary bone on either side ${ }^{1}$.

12. The premaxillary bones, o.sia intermaxillaria (Figs. IO, II, 17,19 i).

Cuvier, l.c. p. $3^{88}, \mathrm{Pl}$. XXIV, Figs. I, 2 f f.-Dugès, n. 3.-Parker and Bettany, l.c., premaxillary bones.

These two bones are united in the middle line : each consists of a tooth-supporting portion, which completes the maxillary arch, and an ascending process, to the apex of which the - nasal cartilage is articulated by a movable joint $(a n)$. As muscles are attached to this process, it becomes a lever, by which movements are effected.

13. The palatine bones, (1s:a jalatina (Figs. I9, $20 \mu l$ ).

Cuvier, l.c., p. $3^{89}$, Pl. XXIV, Figg, 1, 2 i i.-Dugès, n. 7.-

Parker and Bettany, l.c., palatine bones.

Are two transverse bony bars, situated nnder the anterior portion of the sphenethmoid bone on either side: each extends outwards from the apex

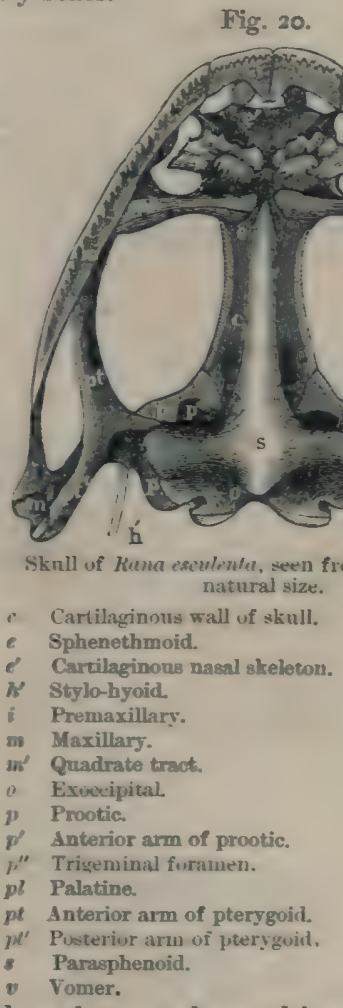
of the parasphenoid to the maxillary bone, where this gives off its ascending process to the nasal bone.

1 For os nasale, Curier (1.c., g), cornet (concha), Dugès, see cartilaginous nasal capsule, p. 27 . 
14. The vomers, vomer (Figs. I9, $20 v$ ).

Cuvier, l.c., p. 389 , Pl. XXIV, Figs. I, 21 1.-Dugès, n. 6.-Parker and Bettany, l.c., vomer.

A pair of flat bones, placed horizontally on the under surface of the cartilaginous nasal capsule in the triangular space between the palatine bone and the anterior portion of the arch of the jaw. They limit the outer border of the floor of this capsule, which lies in a groove on the dorsal surface of the bone. The outer border of each bone has three processes, and between them two notches; the hinder of these notches bounding the posterior nares. The inner borders of the two bones touch, and the under surface of each bears a transverse row of small, pointed teeth.

0 15. The mandible, maxilla inferior (Fig. 2I).

Cuvier, 1.c., p. 398, Pl. XXIV, Figs. 1, 2 rst.-Duges, n. 16, I7, I8, 19.Parker and Bettany, $l . c$, mandibular arch.

The mandible consists of two bony arches united by ligament in the middle line, and each formed of four pieces. These are, (I) the

F'g. 2 .
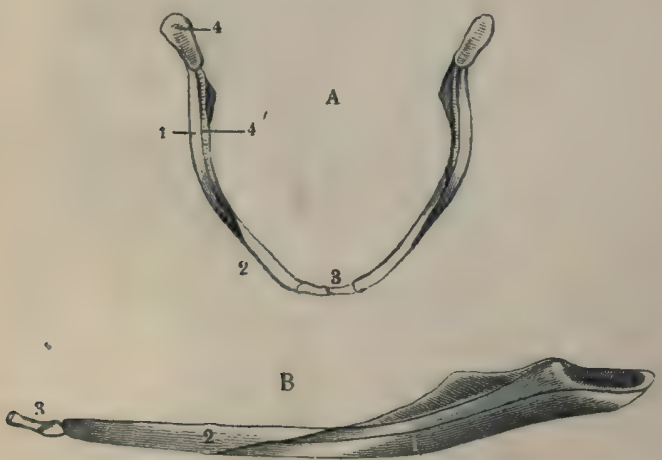

b External view of left side, twice nat. size.

x. Anguloeplenial.

2. Dentary.

3. Mentemeckelian.

4, 4' Meckel's cartilage,

a. Rudimentary processus coronoideus.

b. Groove for Meckel's cartilage. angulosplenial, a strong, bony piece (Fig. 21 I,$B$ 1, $A$ I), which forms the inferior and internal part of the lower jaw; below, it extends posteriorly, as far as the articulation; in front, it is attached to the dentary. In the greater part of its length it has a groovedirected upwards and outwards $(C, b)$, and above has a process which represents the processus coronoideus : (2) the dentary ( $\begin{array}{lll}A & 2, B\end{array}$ 2), a bony lamella which rests on the 
outer surface of the anterior half of the angulosplenial, and articulates in front with Meckel's cartilage; it is a thin, flat lamella of bone; (3) in the groove of the angulosplenial is found a cartilage occupying its entire length $\left(A_{4}, B 4\right)$, Meckel's cartilage; it is broader behind, and here forms the articular fossa of the lower jaw ; anteriorly it is corered by the dentary, and articulates with the (4) mentomeckelian $\left(A_{3}, B_{3}\right)$ at its anterior end, which is bound to its fellow of the opposite side by ligaments, and unites the two halves of the lower jaw.

The upper part of Meckel's cartilage, which forms the joint with the suspensorium, must be regarded as the articulare; to this also belongs the anterior, ossified portion of the mentomeckelian ${ }^{1}$; the dentary, which covers Meckel's cartilage, must represent the os dentale ${ }^{2}$; the first and largest bone, the angulosplenial, which lies on the inner side of the cartilage, must be considered as the os oper $\%$ cnlo-angulare, Dugìs, for it contains the elements of these bones.

\section{The hyoid bone, os hyoideum (Fig. 22).}

Parker and Bettany, l.c., hyoid.

This consists of a broad, thin, cartilaginous plate, with processes passing from it as represented in the figure. We distinguish in it:(a) the body $(H)$, somewhat oblong, and wider in front than behind. From the anterior angles there projects on either side a blunt rounded process $(h)$; from either posterior angle a more pointed process $\left(h^{\prime}\right)$. (b) The anterior cornua $\left(H^{\prime}\right)$ (согииa styloidea) project from the anterior border of the body, first in a forward direction, then in a curve backwards and upwards (compare Fig. I2), to unite with the cartilage of the prootic bone. Where the direction of these cornua is changed each sends off a short blunt process. (c) The posterior cornua (cornua thyroidea) $\left(H^{\prime \prime}\right)$ are bony rods which

Fig. 22.

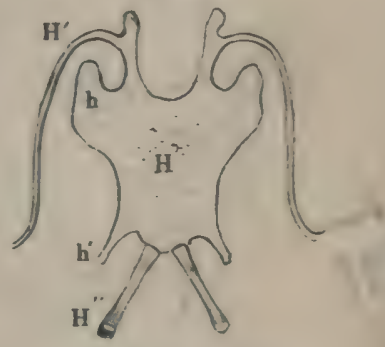

Hyoil of Rumas isculcula. twice nat, size.

$H$ Budy; $h \dot{h}^{\prime}$ provesivex.

$H^{\prime}$ Anterior lworn.

$H^{\prime \prime}$ Pusterior horn. run from the hinder margin of the bodr, diverge posteriorly, and enclose the larynx. 


\section{* III. THE STERNUM (Fig. 24 es, hs).}

Cuvier, l.c., p. for, Pl. XXIV, Fig. 3 I ef.-Dugès, n. 27, 28,--Parker and Bettany, $l_{.} c_{n}$, sternum.

The bones of the sternum are in very close relationship with the shoulder-girdle, and some difference of opinion exists as to the relations of the several parts.

Fig. 23.

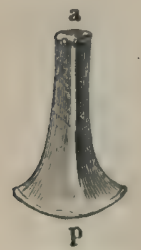

The following parts must be regarded as undoubtedly belonging to the sternum :-

1. An anterior part, consisting of a bony and a cartilaginous portion.

a. The omosternum (Figs. 23,24 e.8.) is a bony rod, wider behind, narrower in front, and supports

b. The episternum (Fig. $24 e^{\prime}$ ), a semicircular

Omosternum of Rana escu-

lenta, twice

nat. sizo.

a Anterior,

$p$ Posterior

extremity. plate of calcified cartilage, with a thin free border of unchanged hyaline cartilage.

2. A posterior part, which also consists of a bony and a cartilaginous portion.

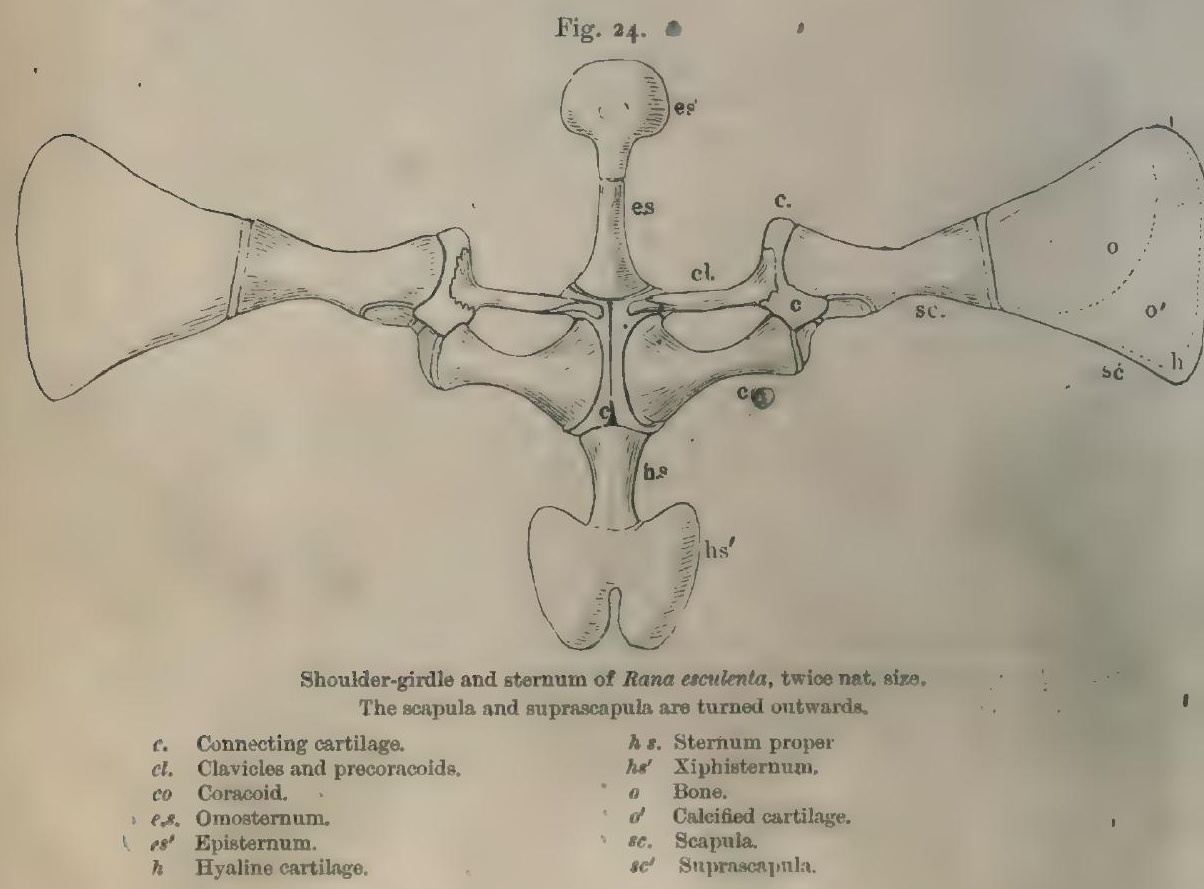


a. The sternum proper (Fig. $24 /$. 8 .), a rod of cartilage ensheathed in bone, broader in front and narrower behind. To its posterior extremity is attached

८. The cartilaginous xiphisternum (Fig. $24 / 18^{\prime}$ ), a plate, the shape of which is best understood by referring to Fig. 24 , and the structure of which is similar to that of the episternum.

3. The epicoracoids ${ }^{1}$ lie between the episternum and the sternum proper: they are a pair of narrow cartilages, closely applied to each other and placed between the ventral ends of the precoracoids and coracoids, see p. 40.

\section{THE BONES OF THE ANTERIOR EXTREMITY.}

\section{A. Bones of the Shoulder-girdle.}

The shoulder-girdle of the frog (Fig. 25) consists of four bones, two in the upper or scapular portion, and two in the lower or coracoid portion.

1. The scapular portion. a. The suprascapula, pars suprascapularis scapulae, scapula superior 8. omolita (Figs. 25 \&, 26, 27). This forms the upper, thinner portion. It is trapezoid in shape, its narrowest, thickest, and lowest border articulating with the seapula. The remaining three borders are free; the posterior and superior borders are very considerably" thinned out, the inferior surface is curved towards the ventral surface." Only the thin upper and hinder borders ( $h / h$ ) are of hyaline cartilage; the middle portion (co) consists of calcified cartilage ; the

Fig. 25.

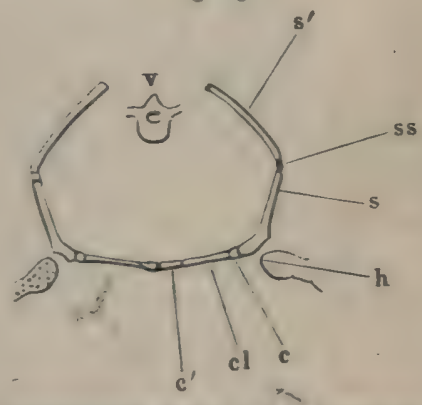

shoulder-yinlle of the fong in tranoverse section, diagrammatic.

c Connecting cartilage.

c' Epicoracoids.

il Clavides.

h Humerns.

8 cicaunda.

$s^{\prime}$ Sinrazispula.

s8 Artienlation of these two.

v Vertebra. lateral part $(o)$ and the anterior border $\left(o^{\prime}\right)$ of true bone.

The bony part forms a thin plate striated both radially and

1 Dugès, l.c., p. 6I, regards the cartilaginous laminae as os episternale and proc. riphoideus, and the two boufere.s. and h.s. (Fig. 24) as sternum. 
concentrically with the margin. The anterior border $\left(o^{\prime}\right)$ is bent on itself so as to form a groove (Fig. 27). The dorsal surface of this bony plate is quite smooth, and covered only by periosteum ; the ventral surface, on the contrary, is for the most part covered

Fig. 26.

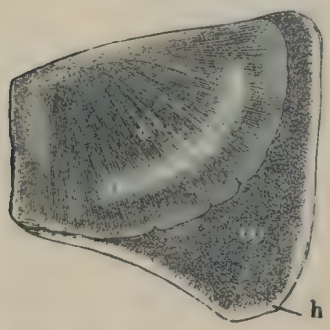

Suprascapula of Rana esculenta, from above, twice nat. size.

co Calcified cartilage.

h Hyaline cartilage.

o Bony portion.

ó Anterior curved border.
Fig. 2\%.

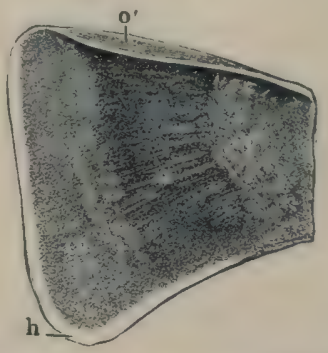

Suprascapula of Rana esculenta, from below, twice nat. size.

co Calcified cartilage.

$\mathrm{co}^{\prime}$ Layer of calcified cartilage on the under surface of the bone.

h Hyaline cartilage.

- Bony portion.

$\sigma^{\prime}$ Anterior curved border.

by an even layer of calcified eartilage (Fig. $27 \mathrm{co}^{\prime}$ ). This passes directly into the second portion of calcified cartilage ( $c 0)$; so that if the whole be dried, the thin hard lamina of bone can easily be split away from the underlying parchment-like cartilage. The layer of calcified cartilage is, however, not so complete that the suprascapula can be said to consist of calcified cartilage.

b. The scapula (Figs. $258,28,29$ ) is a long, flat, four-cornered plate of compact bone, contracted in the middle, and wider at either end. From above (Fig. 281) it descends to the shoulder-joint with a

Fig. 28 .

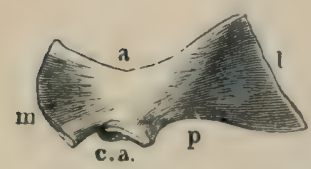

Left scapula of Rana esculenta, from below, twiee nat. size.

a Anterior border. c.a. Cavitas articularis.

$l$ Outer border.

im Inner border.

l) Posterior border.
Fig. 29.

c. a

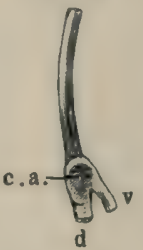

Scapula moen from behind, twice nat, gize. c.a. Cav articularis. d Dorsal process. v Ventral jurocess. slight curvature, with the convexity directed outwards. The inferior or ventral border (Fig. $28 \mathrm{~m}$ ), which assists in the formation of the shoulder-joint, is cleft into two processes, a ventral and a dorsal. This may be best seen by looking at the border of the bone from behind or before (as in Fig. 29). The lower ventral process (Fig. $29 v$ ) may be regarded as the acromion, or at 
least as a rudiment of the acromion, i.e., spina scapulae. The upper dorsal process evidently represents a rudimentary processus coracoideus. The anterior border (Fig. $28 a$ ) is free, somewhat sharp, and slightly concave; the posterior (Fig. $28 \mathrm{p}$ ), also concave, is free externally; while internally, where the division of the ventral border commences, it takes part in the formation of the articular cavity of the shoulder (Figs. 28 and 29 c.a.).

Irticulation with the suprascapula. The scapula consists of a shell of compact bony tissue and an inner portion of cancellous tissue; this latter passes, at the boundary between this bone and the suprascapula, through an internediate layer of calcified cartilage, which is directly continuous with the eartilage of the suprascapula. The compact superficial layer ceases where the calcified cartilage begins, and the periosteum of the scapula passes directly into the perichondrium of the suprascapula.

2. The ventral portion of the shoulder-girdle consists of three parts, which lie one behind the other.

a. The larger and posterior bone, the coracoid (Figs. 24 co, 30), is contracted in the middle, and expander at either end, especially at the sternal end. The inner half is flattened from above downwards; externally it becomes more cylindrical. The anterior and posterior borders are markedly concave; the outer border (Fig. 30 l) articulates by means of a cartilage with the proc. coracoilleus of the seapula; the inner border $(m)$ is separated from its fellow of the opposite side by the epicoracoids. This inner border is so broad, that it almost touches the inner end of the clavicle (Fig. $2+c \%$ ). A coracoid foramen is thus formed between the two bones, similar to the foramen orale of the
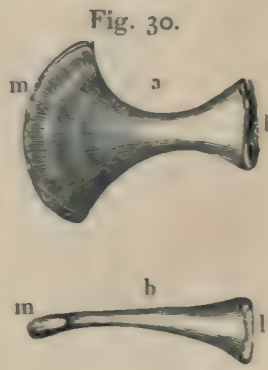

Left coracoid twice nat. size.

a Froun below.

b. Frum behind.

$l$ Cuter extrenity.

m Inner extrenuits pelvis.

b. The small anterior bones of the rentral portion of the shouldergirdle (Figs. $24 \mathrm{cl}, 31$ ), I, like Cuvier and others, regard as clavicles. Dugis (n. 33) names them 'acromial.' Each bone is narrower than the coracoid, smaller internally $(m)$, broader externally ( $I)$, and articulates by this broader end with the cartilage uniting the

Fig. 31.

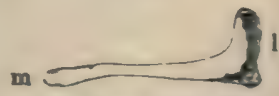

Clarivle of the left side, twite nat. size.

$l$ Onter extremity.

w Inner extremity. 


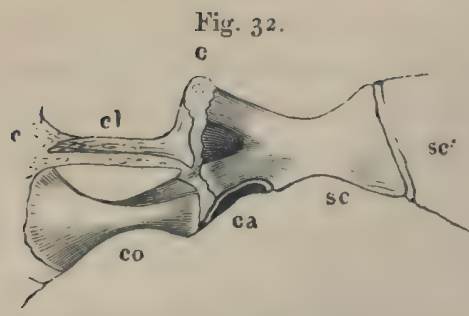

Right shoulder-girdle of Rana esculenta, from above.

ca Cav, articularis, co Coracoid.

c. Cartilage. sc Scapula.

cl Clavicle. sct Suprascapula. dorsal and ventral portions; the inner extremity rests upon the epicoracoid. The clavicle is grooved on its superior and posterior surfaces in almost its whole length; the groove widens externally $(l)$, and contains

c. The precoracoid (Fig. $\left.34 \mathrm{cl}^{\prime}\right)$, a slender bar of cartilage, connecting the anterior edge of the scapula with the sternum.

Cartilages of the shoulder-girdle (Figs. 24, 32, 34). A cartilage $(c)$, described by Dugès as the 'paraglénal,' connects the scapula with the coracoid, and converts the notch between the two processes $(s$ and $v$ ) on the inner border of the scapula into an aperture opening posteriorly into the glenoid cavity, and which is filled up by the lining cartilage. This cartilage connects the two processes with the coracoid; being thicker between this and the proc. coracoideus, it takes an important share in the formation of

Fig. 33

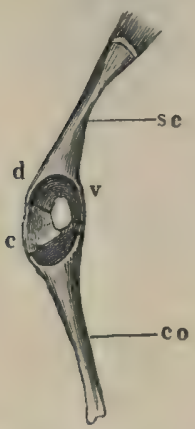

Hinder border of the serpula and coracoid, with the connecting cartilage and shoulder-joint, iwice nat. size.

c Connecting cartilage.

d Dorsal process.

su Coracoid.

$8 c$ Scapula

v Ventral process.
Fig. 34 .

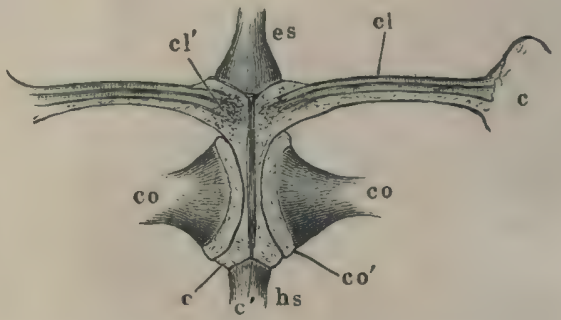

Clavicular sartilage of a young specimen of Rana esculentu. enlarged to the adult size.
c Connecting cartilage.
e Epicoracoids.
$c^{\prime}$ Ligament between the two vartilages.
el Clavicle.
$\mathrm{cl}^{\prime}$ Clavicle and procoracoid.
co Coracoid.
$c u^{\prime}$ Cartilage of same.
es Omosternum.
he Sternum proper.

the floor of the glenoid cavity. At the outer extremity of the clavicle the cartilage projects and is then continued in the groove 
on this bone towards the middle line (Figs. 32, 34), where it widens out, and is united by its external margin with the sternum, thus forming the precoracoid as already described, see p. $f \circ$. These connections are best seen in young animals, as is shown in Fig. 34.

The clavicle $(c t)$ is of ossifying cartilage; the cartilage $(c)$, the epicoracoid, is very large, and hyaline, and at of runs directly into the epicoracoids, which are here united mesially by ligament. In the fully developed animal the whole of the epicoracoid changes to calcified cartilage, as also does the precoracoid lying in the groove of the clavicle.

\section{B. Bones of the Fore LiMB.*}

1. The arm has but one bone.

The humerus, os humeri (Figs. 35, 36, 37). The shaft of the humerus is, on the whole, cylindrical, the middle part being the

Fig. 35.

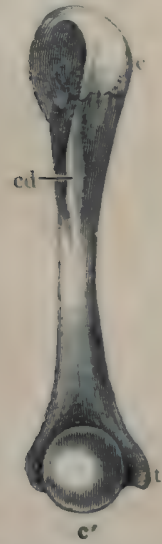

Humerus of Ruma esculcuta, female, seen from below.
Fig. 36 .

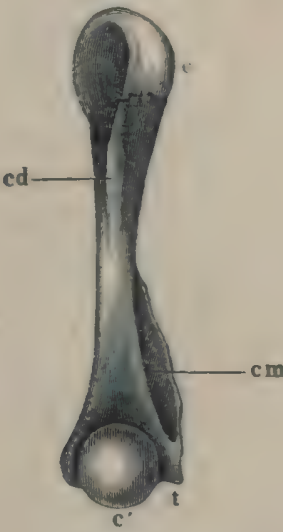

Humerts of Rana cacelenta, mals, soan from below.
Fig. 37.

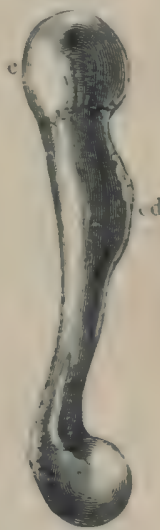

Humerns of Rund esculcuta, female. onter side.

Higures twice natural gize.

c Anterior extremity. C' Posterior extromity. cd Crista deltwidea. cm Crista medialis it trochlea.

narrowest; its dorsal surface is slightly concave, the ventral surface convex. In the upper half the cylindrical form is indistinct, from the presence of a well-marked crest (crista deltoilea) upon the under ur ventral surface. The hinder half of the bone has very different 
shapes in the two sexes: in the female it remains cylindrical as far as the elbow-joint; in the male, on the posterior surface, where the crista deltoidea ceases, a marked ridge (crista merlialis) arises, which gradually winds inwards and terminates at the inner condyle. This sexual difference is found in all the three species described in the Introduction, and it would seem that this ridge increases in height during the pairing season. The muscle which arises from this process is the flexor carpi radialis (Fig. $74 F c$ ), and it attains, in the males, a very large size at the same period; indeed, it is at its origin twice as broad as in the female. Dugès ${ }^{1}$ has incorrectly stated that this crista is a peculiarity of Rana temporaria, and is wanting in Rana esculenta. Pouchet ${ }^{2}$ first observed that it was a sexual distinction.

The anterior articular extremity presents a rounded head, which is somewhat flattened externally. The inferior ventral border is sharp, and developed into the above-mentioned bony crest (crista deltoidea); the free border is arched and curved outwards. Above, on the outer surface of the head, is found an eminence which may be a rudimentary tuberc. maius. The inner half of the head is articular.

The posterior articular extremity consists of a rounded head $\left(c^{\prime}\right)$, attached to the posterior extremity of the shaft ; internal to this is a small trochlea (t), placed upon the inner condyle. The external condyle is but small. The head is embraced by these condyles. Upon the under surface, above the head, is the fossa cultitalis anterior. The structure of the two articular extremities of the humerus differs; the upper, as in long bones generally (see page I6), consists of hyaline cartilage surrounded by calcified cartilage, which again is covered by hyaline articular cartilage ; the lower extremity is composed of spongy bone, with roundish marrow spaces, and for the most part covered by a layer of calcified cartilage.

The shoulder-joint. The socket is formed by the posterior border of the scapula, by both the processes of that bone, the outer portion of the coracoid, and besides these by cartilage, which forms the articular surface already described (Fig. 33). In the macerated bone the floor of the socket opens dorsally into a fossa between the processes of the scapula (Fig. 32). This opening, in the natural condition, is closed by synovial membrane only; the cartilage covering the rest of the space being absent (the sac may 
easily be inflated, either from the joint itself or through the opening). The margin of the socket consists of a labrum, partly fibrous and partly cartilaginous, which is easily removed entire. The eapsule, which is attached beneath the caput humeri, arises from this. From the articular cartilage of the ventral margin of the socket, and from the adjacent part of the scapula, proceeds a strong band, which is inserted into the flattened outer surface of the head.

2. The forearm.

The radio-ulnar, os antilrachii (Fig. $3^{8}$ ). The two bolly elements of the forearm are fused into one, which, however, shows traces of its compound character. Of these two bones, that which forms the inferior (in man anterior) border is the radius, the other the ulna. The relative positions of the bony elements are such that they appear to be in a state of semi-pronation; by this the thumb-border of the arm is directed downwards (in man forwards). The two bones so united form a flattened, tube-like bone, the grooved surfaces of which are directed inwards and outwards respectively; the borders being dorsal and ventral. The shaft of the bone is narrower above, becoming gradually wider below. In the upper half, the groove showing the line of junction of the two bony elements is searcely visible, and it appears as though this part consisted of ulna alone, the radius not reaching so far; below the groove is more marked. The upper articular extremity appears to consist of an olecranon (Fig. $3^{8} u^{\prime}$ ) and a processus coronoideus $\left(r^{\prime}\right)$, between

Fig. 38 .

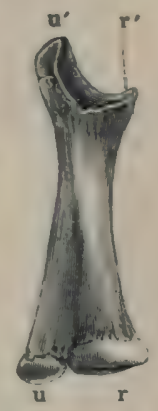

Radis)-nlnar of the right side of Rana eseulenta, twieenat. size.

$r$ Radits.

$r$ Capituium radii.

u Lina.

$u^{\prime}$ Olecranun. which is the greater sigmoid cavity (caritas sigmoinlea major) for the processus culitalis humeri. A more careful examination shows this to be incorrect: the portion of the concave articular surface, which lies in the immediate neighbourhood of the ventral border, undoubtedly represents the articular surface of the capitulum radii, and the upper portion of the articular surface (at $u^{\prime}$ ) belongs to the ulna and articulates with the trochlea (Figs. $35,36 t$ ) of the humerus. The inner border of the upper extremity of the bone articulates with the groove $t$ of the humerus. The inferior extremity forms one of the usual cartilaginous epiphyses, enclosing the two bones. That part of the extremity corresponding with the radius is triangular and convex, it is prolonged upon the inner or under surface of the bone by means of a process; the 
ulnar portion of the bone forms a cajitulum. The structure of the inferior extremity is that of epiphyses in general, except that there are two medullary cavities in a common sheath of calcified cartilage; the anterior head consists of cancellous tissue, with a covering of calcified cartilage.

Fig. 39.

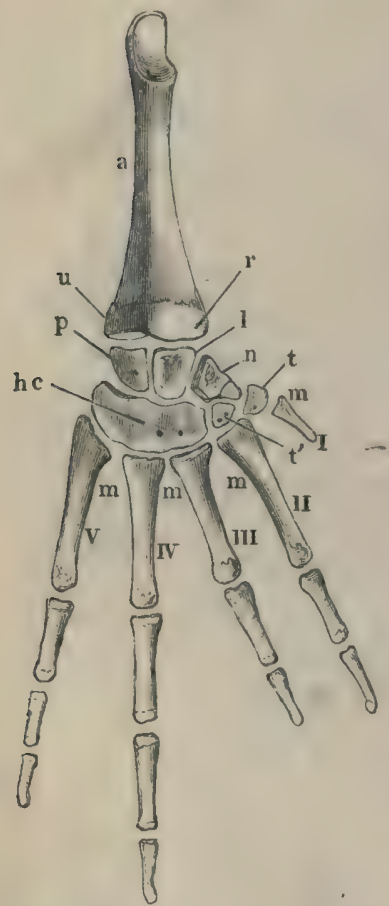

Bones of the forearm and hand of Runc isculentu, right side, dorsum, twice nat. size.

a Os antibrachii.

hc Us eapitato-hamatum.

$l$ Os lunatum.

m Ossa metacarpi.

$n$ Os navienlare.

p Os pyramidale.

$r$ Radial purtion of the radio-nluar.

$t$ Os multangulum majus or trapezium.

$t^{\prime} \mathrm{Os}$ multitngulum minus or trap̧eztrides.

$u$ Cinar portion of the radio-ulnar.

$I-V$ First to fifth fingers, the ffrth only of os metacarlin, the second and third of two, fourth and fifth of three phalanges.
3. Bones of the hand (Fig. 39).

Dugès, Pl. VIII, Figs. $37,38,39,40,4$, $42,43,52$.

a. Bones of the wrist, ossa carpi. These are arranged in two rows, proximal and distal. The proximal or anterior row has three bones, viz. :-

I. Os lunatum, the middle bone (Fig. 39 l), Dugès, n. $3^{8}$, articulates with the radial part of the articular surface of the radio-ulnar by a concave surface; with the large bone of the second row (hc) it articulates by means of a rounded head; and with the two other bones of this row, os naviculare $(n)$ and pyramidale $(p)$, with the former by a saddleshaped surface, with the latter chiefly by ligament. The bone is irregularly cuboid; the dorsal and palmar surfaces are non-articular. With Dugès I regard this bone as os lunatum; Mertens ${ }^{1}$ regards it as 08 naviculare.

2. Os pyramidale (Fig. 39 p), Dugès, n. 37 , articulates with the ulnar part of the posterior articular extremity of the radio-ulnar. Anteriorly the bone has a facet which receives the capitulum uluae, and alongside this a small flat surface which articulates with the radius. Posteriorly, opposite to the second row, it presents a long raised articular surface, extending from the dorsum to the palmar surface; and on 
the palmar aspect of the bone is a ridge running from before backwards. Mertens names this bone os lunatum.

3. Os naiculare (Fig. 39 u), Dugès, n. 39. The third bone of the first row does not articulate with the bones of the forearm. It is connected with the os lunatum by a saddle-shaped surface, posteriorly with the os cajitatum by means of a concave surface. On the inner surface is a small concave articular facet for the os multangulum minus or trapezoidles (Fig. $39 t^{\prime}$ ). The convex palmar surface of the bone articulates with the os multangulum majus $(t)$; the radial side is non-articular, and with the os lunutum forms a ridge directed forwards. Mertens names this bone os triquetrum. It is evident, however, that if the arrangement in man obtains as a standard, the nomenclature of Dugès, which I have here used, is correct; but the os naviculare is no longer in contact with the articular surface of the os antibrachii.

The second or distal row also eonsists of three bones:-

4. Os capitato-hamatum (Fig. 39 lec), Dugès, n. 4c, 41, 42, corresponds with the 0 s capilatum and hamatum ${ }^{1}$, which are here fused together. It is the largest bone, and articulates with all three bones of the first row; it is crescentic, with the concavity directed posteriorly, and on the convex surface has three facets for the three outer ossa melacarpi.

5. Os multangulum minus, s. trapezoirles (Fig. 39t'), Dugès, n. 43 , is a small bone lying next to the foregoing; it articulates with the o.s melacarpi $I I$, and anteriorly with the nos nariculare. Dugis considers it to be the os trapezium.

6. Os multangulmm majus. s. trapesium (Fig. 39t), is a small bone, which is placed on the convex palmar auricular side of the no naciculare. Dugès regards this bone as os metacarpi pollicis (Dugès, n. 44), Mertens as multangulum minus. It appears to me that the interpretation here given is justified, because it articulates with the rudiment of the thumb, and as it possesses no resemblance ti a long bone it cannot be regarded as an os metacarjii.

Structure of the carpal bones. All the carpal bones consist of calcified cartilage, though variations due to age occur in the amount of the deposit.

Wrist joint. As stated above, the os lunatum and os yyramilale are articulated with the forearm. In addition to the capsules uniting the parts, there are strengthening ligaments, two of which require special mention. One of these arises from the palmar surface of

2. Dugès thinks that os trapezoides is also inclnded. 
the posterior extremity of the ulna, and passes to the sharp palmar ridge of the os pyramidale, where it is attached, and is inserted into the os capitato-hamatum; the second ligament passes in a similar manner on the palmar surface from the radius to the os naviculare. Between the two ligaments there is on the volar surface a deep excavation.

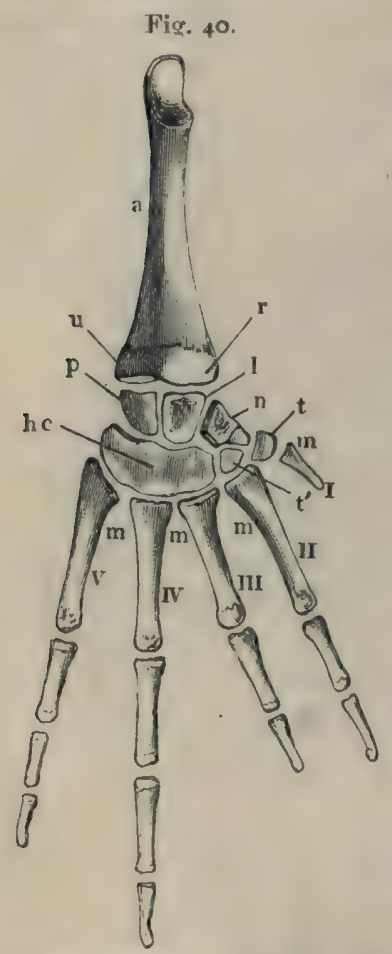

Bones of the forearm and hand of Rana esculenta, right side, dorsum, twice nat. size.

a Radio-ulnar.

he Os capitato-hamatum.

$\ell$ Os lunatum.

$m$ Ossa metacarpi.

$n$ Os naviculare.

p Os pyramidale.

$r$ Radial portion of the radio-ulnar.

$t$ Osmultangulum mains or trapezium.

t' Os multangulum minus or trapezoides,

$u$ Ulnar portion of the radio-ulnar.

$\boldsymbol{I}-\boldsymbol{V}$ First to fifth fingers, the first only of a metacarpal, the second and third of two, fourth and fifth of three phalanges.

first phalanx.
Movements of the hand. The two bones of the forearm being firmly united, pronation and supination, as in man, are impossible. The normal position, as already remarked (see radioulnar), is that of semi-pronation (compare Figs. 2 and 74). If the animal be in its natural posture, with the arm bent at the elbow (Fig. I), it can touch the ground with the ulnar border only; but when the whole surface of the hand rests upon the ground, the action is brought about as follows: the plane of the carpus is in extension parallel with that of the forearm; in flexion, almost at right-angles with that plane (Fig. 74). The os lunatum glides on the prolongation of the articular surface on. the inner palmar surface of the radius, while the os pyramidale is held firmly by the ligament just described. The hand follows the movement of the os lunatum, and at the same time the three outer ossa metacarpi gliding with it inwaids, the fingers of the hand turn inwards.

b. The Bones of the metacarpus, ossa metacarpi (Fig. $40 \mathrm{~m}$ ). Of these there are five: the second to the fffth are of about equal length; the first, forming the rudiment of the thumb, hidden beneath the skin, is much shorter. This metacarpal bone of the thumb is regarded by Dugès and others as the for describing it as a metacarpal has 
already been given. This bone also presents differences in the two sexes. Meckel's ${ }^{1}$ observation that it exists only in the male is incorrect; it is a large, broad and sickle-shaped mass of caleified cartilage or even true bone, while in the female it is simply a small cartilaginous rod; as this almost entirely disappears in dried specimens, Meckel's statement is explained. The second finger has in the frog assumed the functions of the thumb, and, in the males, in the breeding season swells and undergoes an essential alteration of structure. The metacarpal of this finger also displays differences in the sexes, being in the male stronger, broader, and on the inner side provided with a spine-like prolongation, for the tendon of the abrluctor digiti II (pollicis) longus, which attains an unusual development during the breeding season. The remaining metacarpal bones, the third, fourth, and fifth, are of similar form, the last being provided with a tubercle. The anterior articular extremities are rather broad and concave, and the posterior have rounded heads.

c. The phalanges, jillalanges digitorum. The hand has four fingers and the rudiment of a fifth, which latter is completely hidden under the skin, and as already explained, consists of a metacarpal only. Of the four fingers, the fourth is the longest, the third the shortest, the second and fifth of intermediate and about equal length; the fourth and fifth fingers have each three phalanges, the second and third have each two. Their shape is not unlike that of the human phalanges.

\section{THE BONES OF THE HINDER EXTREMITY.}

\section{A. Bones of the Peltic Girdle (Fig. 4I).}

The pelvis has a characteristic $V$-shape, the pubic and ischiatic bones of the two sides together forming a vertical plate $(a p)$, which divides anteriorly into the two iliac bones (il). The pubic and ischiatic bones being united by their median surfaces, one can only speak of the pelvic cavity as the space between the two ilia.

1. The ilia, ossa ilii (Fig. $42 \mathrm{il}$ ). In these a broader part or

$$
\text { I. } l . c ., \mathrm{II}, 464 \text {. }
$$


body can be distinguished, which takes part in the formation of the acetabulum $(a)$. The hinder and broadest part of the bone is joined to the corresponding portion of its fellow by ligament; anteriorly the two diverge, bounding a cone-shaped cavity, the pelvis. The suture, by which the body of the iliac bone is united with the ischiatic and pubic bones, runs from above downwards through the middle of

Fig. 42 .

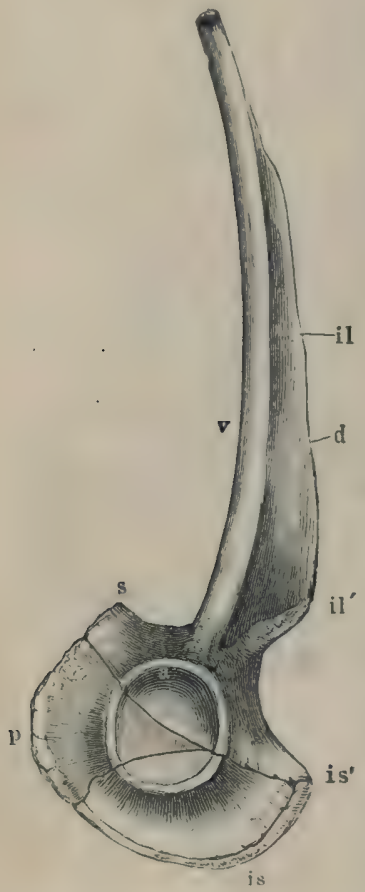

Pelvis of Rana esculenta, left side, twice nat. size.

a Acotabulum.

d Upper sharp border.

il Iliac bone.

il' Superior process.

- is Ischium.

¿'s' Tuber ischii.

$p$ Os pubis.

$s$ Inferior process of the ilium.

v Lower border of same, the acetabulum (Fig. 42, from $p$ through the ace-

Fig. $4 \mathrm{r}$.

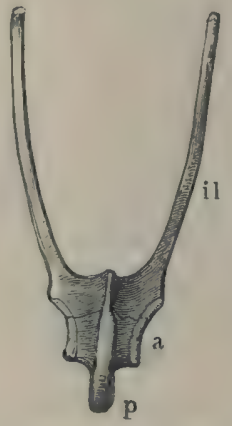

Pelvis of Rana esculenta, from below, nat. size.

a Acetabulum.

il Tiac bone.

p Pubic bone. tabulum to is). Inferiorly and in front the united ilia form a prominence (s), which represents the sympliysis oss. pub. of man. The expanded portions of the ilium rest directly over the articular eavity by means of a somewhat constricted part or root. The ala is a sabre-like bone, with the sharper, more convex border directed upwards ; the more concave, thicker border downwards. The two surfaces, of which the inner is grooved, are directed respectively inwards and outwards. The broader part of the blade springs directly from the neck or root (at $\left.i l^{\prime}\right)$, and at this end of the sharp convex border is a process, process. sup., from which the tendon of the m. vastus externus arises. The anterior end of the blade is a hollow cylinder, containing cartilage, movably articulated to the transverse process of the last vertebra or sacrum.

2. The ischia, ossa ischii $(i s)$, are irregular, four-cornered plates of bone, united together by the whole extent of their inner surfaces. The vertical plate formed by the union of the two bones takes only a very small share in the formation of the articular cavity. Above, it has a somewhat sharp border, continued with the ilium into a process. 
(is') corresponding with the united tubera ischii; the hinder border, which is united below with the pubic cartilage, is curved.

3. The pubes, os pulbis (Figs. 4I, 42, 431 ). Ossified pubie bones do not exist; even in old animals they are composed of calcified eartilage. Each is a triangular eartilage, wedged between the ilium and ischium, but also taking part in the formation of the acetabulum. The pubes of opposite sides are, as shown in section in Fig. 43, united by ligaments in the median plane.

Fis. 43 .

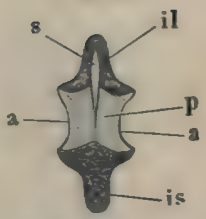

Horizontal Bection through the liliac, pubic, and ischistic bones.

a Acetabulum.

il Iliutu.

is Ischium.

p Pubic cartilage.

s. Iigaments which tunite the bones of opposite sides.

\section{B. Bones of the HrNd-Limb.}

\section{The thigh.}

The femur, os femoris (Fig. 44). The shaft is cylindrical, with a slight double or S-shaped curve. In the anterior portion the convexity is directed upwards, in the two hinder thirds downwards. Towards the hinder extremity it is flattened from above downwards. The anterior extremity is a rounded articular head placed directly on the shaft like that of the humerus. This head is somewhat flattened from side to side; and in structure resembles that of the humerus. The inferior extremity is rounded below, but flattened above (towards the hollow of the knee) and behind.

Hip-joint. The articular cavity is deepened by a fibrous ring, labrum cartilaginem, which fits closely upon the caput femoris; from this 7abrum the joint-capsule arises, to be inserted behind the head; close to the lower border of the cavity a ligamentum teres arises, which is inserted into the caput femoris.

\section{The leg.}

Tibio-fibula, of cruris (Fig. 45). This consists of a single bone, the os cruris; it is often called the tibia, but presents, however, distinct indications of being formed of two bones, the tilia and filula. The shaft is not quite straight; it is thinner in the middle and flattened
Fig. 44.

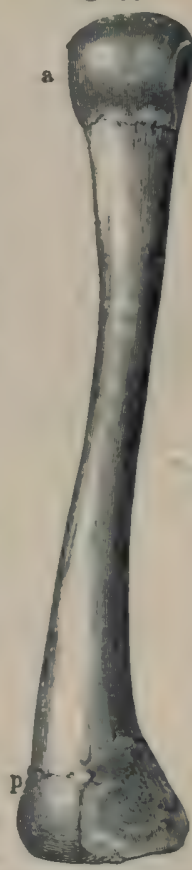

Femur of Rana escuInta, right side, twice nat. gize.

a Anterior extremity. p Posterior extremity. 
Fig. 45. from above downwards. On the upper as also

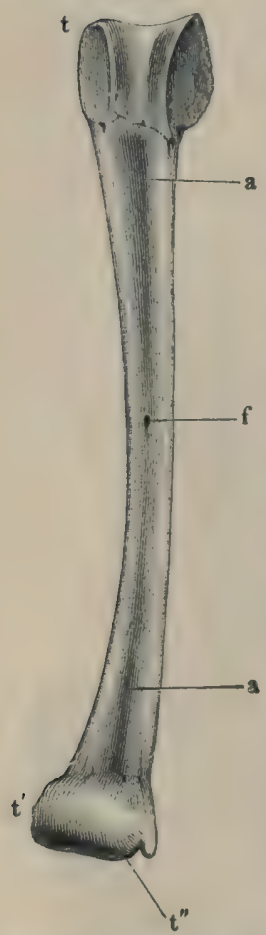

Tibio-fibula of Rana escu. lenta, twice nat. size, seen from below.

a a Girooves.

$f$ Furamen nutritium.

$t$ Anterior articular extremity.

$t^{\prime}$ Posterior articular ex. tremity.

$t^{\prime \prime}$ Grovve on malleolus internus for tendon of m. tibialis posticus. on the lower surface of the bone is a groove, passing from the middle towards each extremity; this deepens as it proceeds, and is an indication of the compound nature of the bone. In the middle of each surface of the bone is the opening of a canal, through which a bristle may be passed: the canal has bony walls. The medullary cavity is, for the most part, double, being single only in the middle. The anterior extremity is articular, and presents a median groove, which is prolonged on to the under surface. The posterior extremity forms a transverse condyle, which has at its inner part a notch for the tendon of the $m$. tibialis posticus.

The kneo-joint consists of a capsule strengthened by theinsertions of numerous tendons.

Fig. $4^{6 .}$

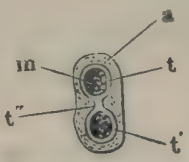

Section of the tibiofibula through the under extremity.

a Cartilaginous epiphysis.

$m$ Marrow cavities.

$t^{\prime \prime}$ Connecting mass.

$t t^{\prime}$ The two cylinders of bone. Within this the articular surfaces of the femur and tibio-fibula are connected by means of fibro-elastic bands, which spring from the latter bone and cross each other, thus representing the lig. cruciata. The articular surfaces are moreover deepened by loose semilunar cartilages, corresponding with the inter-articular cartilages of the knee-joint of man. In addition, on either side of the joint, are found auxiliary ligaments.

\section{The foot (Fig. 47).}

a. The ankle, osia tarsi. The tarsus consists of two rows of bones.

a. The proximal row consists of two long tubular bones (Fig. $47 \mathrm{ac}$ ), which are parallel to each other, and undoubtedly correspond with the astragalus (talus) and calcanoum. The bones are separated in the middle, but approach each other at either end. The outer of these bones $(c)$ I have named calcaneum, following Cuvier and Dugès; the inner, astragalus $(a)$. The two bones are 
surrounded and enclosed at their anterior and posterior extremities in a common epiphysis of calcified cartilage, which has the usual structure found elsewhere. The ligamentum calcanei, which will be described below (see Muscles of Foot, Fig. $88 \mathrm{lc}$ ), may be regarded as an unattached process of the heel ${ }^{1}$.

$\beta$. The distal row of the tarsals are all composed of calcified cartilage. They are :-

I. Os cuboideum (Fig. 47 cb), a flat plate of cartilage, concave in front, convex behind, placed between the common epiphysis of the astragalus and calcaneum (ac) and the ossa metatarsi II and III. This corresponds, as Dugès suggests, with the separated os cuboideum and cuneiforme III of other batrachians, e.g. Bufo.

2. On the inner side of the above, between the astragalus and metatarsus $I$ lies a small body, concave in front, convex behind, which we may regard, with Dugès, as the analogue of the 08 naxiculare (Fig. $47 n$ ).

3. This latter supports a cartilage which forms a projection on the inner border, covered with skin. This consists of closely-mited pieces, a small round, basal
Fig. 4\%.

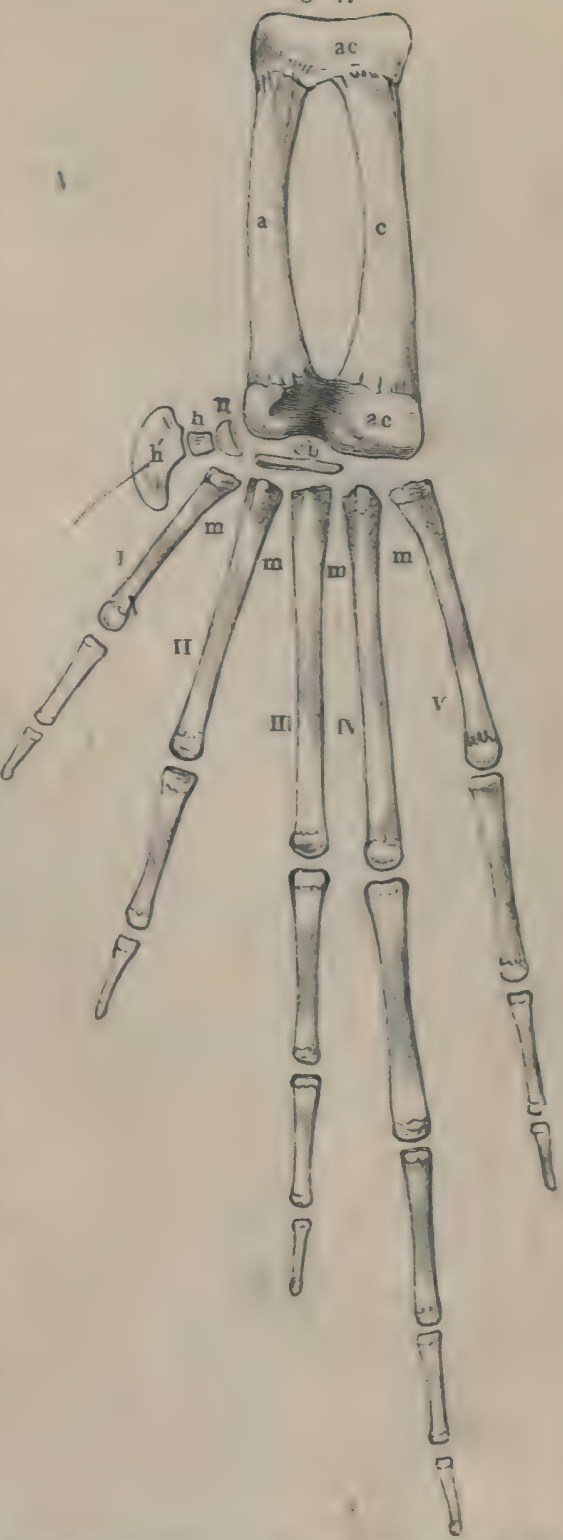

Right foot of Rana esculentn. palmar surface, twice nat. size. a Astragalus. ac Common epiphysia. c Calcaneum. cb Os cuboideum.

\footnotetext{
$h$ First, $h^{\prime}$ sevond vartilage of supplemental tue. m Osisa wetainaryi. - Os naviculare. $I$ tor $I$ First to firth toe.
}

${ }^{1}$ Meckel, l.c., II, p. 488, regards the cartilage in the tendo Achillis as such. 
piece $(h)$, and a flattened beak-like piece $\left(h^{\prime}\right)$. Dugès considers these pieces as the first and second ossa cuneiformia; I rather incline to Meckel's opinion that they represent a rudimentary hallux, the first being the os metatarsi, the second a phalanx. Both are composed of calcified cartilage; in R. temporaria the lime-deposit seems to be less than in $R$. oxyrhinus and $R$. esculenta, and the projection consequently softer ${ }^{1}$.

b. The metatarsal bones, ossa metatarsi (Fig. 47, $m I-V$ ). The five ossa metatarsi are long, thin tubular bones, the anterior articular extremities of which are broader above and narrow below, hence are wedge-shaped, and anteriorly present flat surfaces for articulation with the tarsus. The shafts are long and thin; the posterior extremities have rounded heads. The comparative length of these is as follows: the fourth is the longest, then come the third, fifth, second, and first in order. In structure they resemble other tubular bones.

c. The phalanges, phatanges digitorum (Fig. 47). The total lengths of the separate toes correspond with that of the ossa metatarsi, but the distinctive differences are increased, partly by the difference in number and partly by the varying lengths of the phalanges. The first and second toes have each only two phalanges, the third and fifth have each three, the fourth, which is the longest, has four. The terminal phalanges are somewhat hooked towards the plantar surface.

1 In the text these two cartilages are termed the 'supplemental toe.' 
SECTION II.

\section{THE MUSCLES.}




\section{THE MUSCLES.}

\section{ITTERATURE.}

v. Altena, see p. 13 .

Anonymous, Ueber das Schultergerüst der Schildkröten mit den daran sitzenden Muskeln. Isis, 1827. (Contains remarks on the shoulder-muscles of the frog.)

Carus, C. G. (I) Lehrbuch der vergleichenden Zootomie. 2nd Edit. Leipzig, 1834.

(2) Erläuterungstafeln zur vergleichenden Anatomie. 1 Part. 1826. (Muscles of the Leg.)

Chappuis, Morphologisehe Stellung der kleinen hintern Kopfmuskeln. Zeit. f. Anat. u. Entwickl. 1876. Vol. II, pages 287-297.

Cuvier, Leçons d'anatomie comparée. Paris, I835. Vols. I, II.

Dugès, Recherches anatomiques et physiologiques sur la déglutition dans les Reptiles. Ext. des Annales des Sciences naturelles. Paris, I827.

Dugès, Leçons d'anatomie comparée. Paris, 1835 .

Duméril and Bibron, Erpétologie générale ou Histoire complète des Reptiles. 1836.

Führbringer, Zur vergleichenden Anatomie d. Schultermuskeln. Jenaische Zeitschr. I873. Vol. VII.

Klein, Beiträge zur Anatomie der ungeschwänzten Batrachier (Rana temporaria, L.): in Jahrshefte des Vereins für vaterländische Naturkunde in Würtemburg. 6 Jahrgang. 1850. Page 1.

Kuhl, Beiträge zur Zoologie der Rana esculenta : in Beitr. z. Zool. Frankfurt, a. M. 1820. Page II5.

de Mann, Vergelykende myologische en neurologische studien over Amphibien en Vogels. Acad. Proefschrift. 1873.

de Mann, Myologie comparée de l'extrémité post. chez les amphibiens. Niederl. arch. f. Zool. I874. Vol. II.

Marshall, The Frog. London and Manchester. 2nd Edit. 1885. Pages 60-71.

Martin St. Ange, Annales des sciences naturelles. Vol. XXIV. 1831. Page 393.

Meckel, System der vergleichenden Anatomie. Halle, 1828. Vols. III and IV.

Pfeiffer, Zur Anatomie des Schultergürtels und der Schultermuskeln bei Säugethieren, Vögeln und Amphibien. Giessen, 1854.

Rymer Jones, Article 'Reptiles' in Todd's Cyclop. of Anatomy and Physiology. 1847-1852. Vol. IV. Page 263.

Stannius, Handbuch der Anatomie der Wirbelthiere. Vol. II. Zootomie der Amlphibien. Berlin, 1856 .

Wagner, Icones Zootomicae. Leiprig, I84I.

Wagner, Lehrbuch der vergleichenden Anatomie. Leipzig, 1834-35.

Zenker, Batrachomyologia. Disø. Jena, 1825. 


\section{THE IIUSCLES.}

\section{MUSCLES OF THE HEAD.}

I. Muscles of THE Ere.

1. M. rectus inferior (Fig. $48 \mathrm{ri}^{\prime}$ ).

Dugès, post-orbito-sous-oculaire, n. I 2,-Zenker, depreszor oculi.

This muscle arises by a very thin, almost thread-like tendon from the parasphenoid, near the foramen opticum, and becomes rapidly broader; it lies beneath the tendon of the memlrana nictitans and a part of the m. retractor bulbi: then runs forwards and outwards to be attached into the lower part of the circumference of the eyeball.

2. M. rectus externus (Fig. 48 re). Dugès, post-orbito-ex-oculaire, n. I4.

Arises by a thin, thread-like tendon from the parasphenoid near the foramen opticum, internal to and a little behind the $m$. rectus inferior : it then passes obliquely outwards over the m. retractor bulbi and the tendon of the membrana nictitans, to be inserted into the outer and hinder part of the circumference of the eyeball.

3. M. rectus internus (Fig. 48 ri). Dugès, post-orbito-in-oculaire, n. I3.

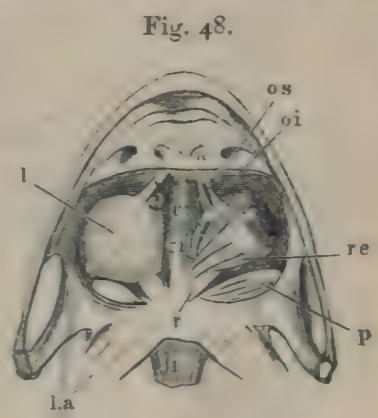

Eye muscles of Rama esculenta, from below.

On the right side (i. $e$, in the left eye) the lev. bulbi $(l)$ is taken away; on the left side it is atill present.
l. M. levator bulbi.
la M, lev. anguli gcapulae
oi M. obliquas inferior.
os $\mathbf{Y}$. obliquns superior.
p M. pterygoidens
M. netractor bulbi.
re M. rectus externus.
1 First cervical vertebra.

A long, thin muscle, which arises by a thread-like tendon from the parasphenoid at the inner and 
hinder angle of the orbit, passes along its inner wall, and is inserted into the antero-internal part of the circumference of the eyeball.

4. $M$. rectus superior (Fig. 49 rs.).

Dugès, post-orbito-sous-oculaire.

Arises by a slender tendon from the fronto-parietal bone, widens

Fig. 49 .

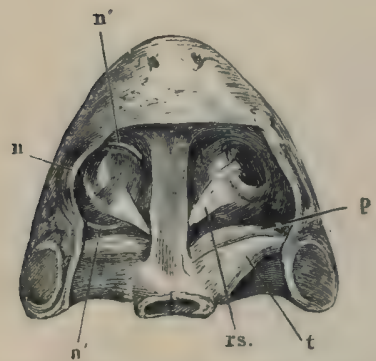

Eye-muscles of Ranc esculenta, from above.

n Membrana nictitans.

$n^{\prime}$ Tendon of membrana nictitans.

$p$ M. pterygoideus.

rs. M. rectus superior.

t I. temporalis. rapidly, and runs forwards and outwards to be inserted into the upper part of the circumference of the bulbus.

\section{M. obtiquus inferior (Fig. 48 oi).} Dugès, pré-sous-orbito-oculaire.

This muscle arises near the floor of the orbital cavity, at the inner and anterior angle, from the palatine bone by a thin and long tendon, runs under Harder's gland outwards and backwards, and is inserted, almost at a right angle with the axis of the eye, into the anterior part of the circumference of the eyeball.

\section{M. obliqun superior (Fig. 48 os).}

Dugès, pré-sus-orbito-oculaire, n. 7 .

The tendon of this small muscle arises from the inner end of the

Fig. 50 .

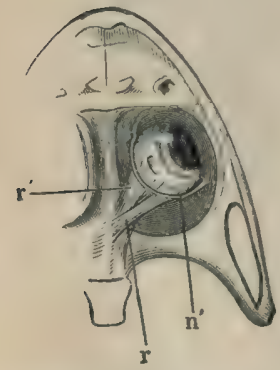

Eye-muscles of Rana esculenta, from below, the $\mathrm{m}$. recti and obliqui have been removed.

$n^{\prime}$ Tendon of membrana nictitans.

r M. retractur bulbi, lower part.

$r^{\prime}$ Second part of same. palatine bone, near the origin of the $m$. obliquus inferior, runs upwards, backwards, and outwards, and passes into a flat muscle, whick. rapidly becomes broader, and is inserted into the upper surface of the eyeball.

7. M. retractor bulbi (Figs. $48 r, 50 r, r^{\prime}$ ).

Dugès, orbito-post-oculaire or choanide, n. 10.Zenker, $m$. opticus.

This muscle surrounds the optic nerve, and is situated within the cone formed by the four recti muscles; it consists of three portions, which take their broad and fleshy (the recti and olliqui arise by thin tendons) origins from the under surface of the parasphenoid. The first portion (Fig. $50 \mathrm{r}$ ) arises from the under surface of the parasphenoid, nearly as far as the 
middle line, is broad and fleshy, and covers, from below, the tendon of the rectus externus, then runs forwards and outwards. The second portion $\left(r^{\prime}\right)$, which lies over this and the tendon of the $m$. rectus externus, has also a broad and fleshy origin, but runs more directly forwards, slightly crossing the preceding. The third portion arises above the two others by a strong thin tendon from the parasphenoid : it runs almost in the direction of the $m$. rectus internus, but more directly forwards. The first two portions pass more to the upper surface of the eyeball, the third more to the under surface; consequently the whole muscle forms a sheath surrounding the eyeball. The fibres to the upper surface of the eyeball are inserted somewhat in front of the equator of the eyeball, those to the under surface somewhat behind it.

\section{M. levator bulbi, Dugès (Figs. $48 l, 51 l, 52 l$ ).}

Dugès, fronto-pterygoidien, n. 9.-Klein, sustentator bulbi.

There is no bony floor to the orbital eavity, and the oral and orbital cavities are only separated by soft tissues; these are:-the mucous membrane of the mouth, a thin fascia, and above this the muscle under consideration. The fibres of this musele run from before and from the inner side obliquely backwards and outwards, below all the remaining muscles of the eye, with the exception of the origin of the m. retractor bulbi, and the tendons of the $m$. obliques inferior, and the $m$. pterygoideus; they arise on the inner side from the upper and outer border of the frontoparietal bone (Fig. 5I),

Fig. 52.

Fig. 51 .

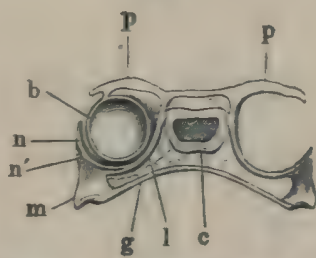

Transvorso section throngh the skull and orbital cavities of Rana esculenta.

b Bulb of eye.

c skull cavity.

- Mncons membrana.

6 M. levator bulbi.

$m$ Upuer jaw.

n Membrana nictitans.

$n^{\prime}$ Continuation of same to the lower eyelid.

p Cpper eyelid.

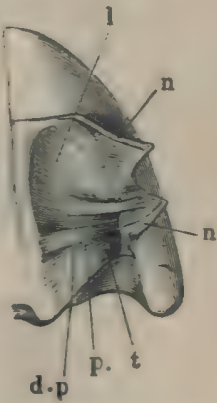

M. levator bulbi of Ranas crcuknta, seen from above; the eyeball which rests on it has been remored.

d. $p$ M. depressor palpebrae inferioris

l. M. levat or balbi.

n Membrana nictitans.

p. M. piterygoideus.

i. temporalia also from the transverse portion of the parasphenoid and pterygoid bones, anteriorly from the sphenethmoid and palatine bones; they run first downwards, then, in the direction indicated; under- 
neath the eye; and are inserted externally by means of tendinous fibres into the superior border of the upper jaw.

9. From the foregoing nuscle certain fibres pass to the lower eyelid, which may be regarded as a depressor palpebrae inferioris (Fig. 52 d.p).

Manz ${ }^{1}$ has described a muscle as depressor palpelurae inferioris which arises in the neighbourhood of the external angle of the eye, somewhat behind and below the lower border of the orbit, thence passes obliquely upwards to be inserted into the lower eyelid. This description is right as regards the insertion, but needs correction as regards the origin. The muscle is attached to the orbital border in so far that the tendinous expansion, into which the levator bulti passes at its external border, is attached into the upper jaw; this bundle splits off from the upper surface of the levator lulbi at its middle, and runs outwards on the under surface of the eyeball to the hinder part of the lower eyelid.

10. Tendon of the membrana nictilans ${ }^{2}$ (Fig. $53 x^{\prime}$ ). The pigmented free border of the nictitating membrane passes, at the

Fig. 53.

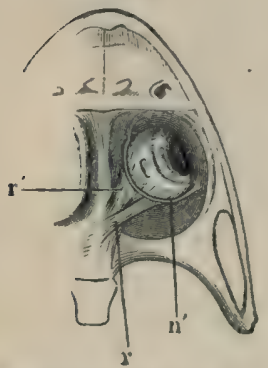

Eye-muscles of Rana esculenta, from below, the $\mathrm{m}$. recti and obliqui have been removed.

$\boldsymbol{n}^{\prime}$ Tendon of membrana nictitans.

$r$ M. retractor bulbi, lower part.

$r^{\prime}$ Second part of same. inner and outer angles of the eye, into a tendon which passes for some distance through fibrous tissue, then descends to the under surface of the eyeball and joins that of the opposite side, so that the free border of the eyelid, together with this tendon, form a complete ring. The tendinous part of the ring, which is thin and thread-like, is found on the under surface of the eyeball, and lies under the $m$. retractor bulbi, and is bound to this muscle by connective tissue. Manz is right in saying that the two muscles deseribed by Dugès as levatores palpebrae inferiores (orbito-palpebral anterieur and posterieur, n. 5 and 6) do not exist; as is also the suggestion that he has confounded the tendon of the nictitating membrane with these; this is clearly shown in the figure in Plate VI of Dugès. With regard to the actions of these eye-muscles, it is plain that the four straight

1 Manz, Berichte der naturf. Gesellschaft zu Freiburg, 2 Band, 4 Heft, I862, p. 39 I.

${ }^{3}$ Compare Manz, l.c. 
and two oblique muscles rotate the eveball about three axes, one the axis of the eve, one vertical, and the third passing from behind forwards and inwards. The $m$. retractor pulls the eyeball into the orbital cavity backwards and downwards, while the levator raises it.

There is less agreement abont the movements of the eyelids, or rather of the lower evelid, for the upper has no independent movements. Dugès (I.c.) says that the two muscles, which he considers to be levatores palpetsae inferiores, and which, according to him, are connected with the m. retractor bulbi, draw up the lid as it is being drawn backwards and downwards by the latter muscle. The depression of the lid on the relaxation of the retractor and projection of the eyeball is due simply to elasticity. Manz ${ }^{1}$, on the contrary, has shown that the sinking of the eyeball by the contraction of the retractor must necessarily cause a rising of the nictitating membrane, as its tendons are attached to that muscle and so must follow its movements.

The depression of the lower lid occurs simultaneously with the raising of the eyeball by means of the $m$. levator bulli, through the contraction of the $m$. depressor palpelrae inferioris, which proceeds from that muscle; this is easily understood, as they are but parts of the same muscle.

\section{Muscles or the Face.}

11. 11. intermaxillaris s. dilatator narium (Fig. $54 \mathrm{im}$ ).

Dugès, intermaxillaire, n. 1.-Zenker, intermaxillaris medius.

This small muscle lies in the space between the rertical processes of the two premaxillary bones, and consists of obliquely-crossing fibres arising from the one bone and inserted into the opposite one. It brings together the processes of the intermaxillary bones, so that their upper extremities approach each other. At the same time, the cartilaginous nasal coverings or wings (an) diverge and the nares expand; hence we may regard this muscle as corresponding to a dilatator narium.

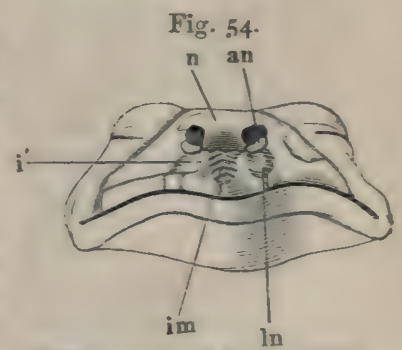

Facial museles of Rana esculenta.

un Carrilaginous nasal alae.

$i^{\prime}$ Vertical process of premaxillary bone.

im 31. intermaxillaris.

in $\mathbf{M}$, lateralis narium.

n Cartilaginons nuse cajeule. 
12. M. Zateralis narium (Ecker), (Fig. $54 l u$ ).

Zenker, $m$. intermaxillaris lateralis.-Klein, $m$. nasalis inferior.Dugès, sus-maxillo-pré-nasal, n. 2.

This small muscle occupies the space between the anterior portion of the maxillary bone and the ascending process of the premaxillary bone. It arises from the maxillary, and ascends obliquely forwards to be inserted into the outer border of the ascending process of the premaxillary bone. It is antagonistic to the foregoing.

A third muscle is described by Dugès as sus-maxillo-post-nasul, n. 3 (nasalis externus, Klein); according to him it passes from the proc. nasalis of the maxillary bone to the outer border of the nasal opening, which it widens. According to Klein (l.c., p. 9), this muscle in $R$. temporaria runs to the upper border of the maxillary bone beneath the lower eyelid, and is long and narrow. I have, however, never been able to find muscular fibre in this situation.

\section{Muscles of the Lower Jaw.}

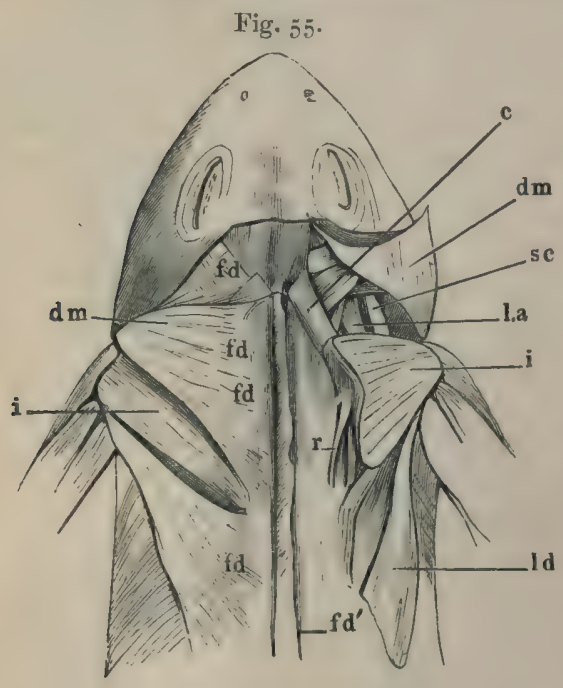

Muscles of the back and shoulder.

c M. cucullarig.

$d m, d m$ M. depressor maxillae, arising from the fascia dorsalis. On the right side it is cut through and reflected.

fd Fasoia dorsalis.

$f d^{\prime} \quad$ Same cut near the spinous processes,

i M. infraspinatus.

l.a M. levator anguli seapulae.

b.d M. latissimus dorsi.

$r \quad M$. retrahens nerupulae.

sc M. sternocleidomastoideus.

13. M. depressor maxillae inferioris, Carus, Zenker (Figs. 55, 56, 63 d.m.).

Cuvier, l.c., II, I4I, digastricus.-Dugès, sus-occipitodorso-angulaire, 32 .

This is a strong, triangular muscle, wide above, pointed below. It is placed between the head and the shoulder-blade. It arises in two portions; the greater, from the fascia dorsalis $(f d)$, covers the scapula, and passes iniwards and backwards over the muscles of the back ; anteriorly it passes over the $m$. temporalis and is attached to the frontoparietal and squamosal, being continued to the fascia of the upwer eyelid. The second part is smaller, and arises by fleshy fibres from the postero-superior 
arm of the squamosal, and from the posterior and inferior border of the cartilasinous tympanic ring. The two parts unite and are inserted into the hinder angle of the lower jaw. Cuvier correctly considers that only the anterior portion corresponds to the digastricus, the posterior answering to the $m$.cervico-maxillaris of snakes. It draws the lower jaw down and opens the mouth.

\section{M. temporalis (Figs. 49, 52, 56, 57 ).}

Cuvier, m. temporulis, I, l.c., p. I38.-Dugès, sous-rupéo-temporo-coronoidien.

This muscle, together with the $m$. pterygoideus, occupies the space between the prootic and the eyeball; it arises by the greater part of its fibres from the upper surface of the prootic ; it passes, narrowing, beneath the anterior arm of the squamosal, then over the pterygoid bone, between this and the maxillary and quadrato-jugal, receiving on the way other fibres which arise from the anterior border of the inferior arm of the squamosal and from the anterior circumference of the tympanic ring. The collected fibres end in a broad, flat tendon, which is inserted into the inner surface of the socalled proe. coronoidens.

Fig. 56.

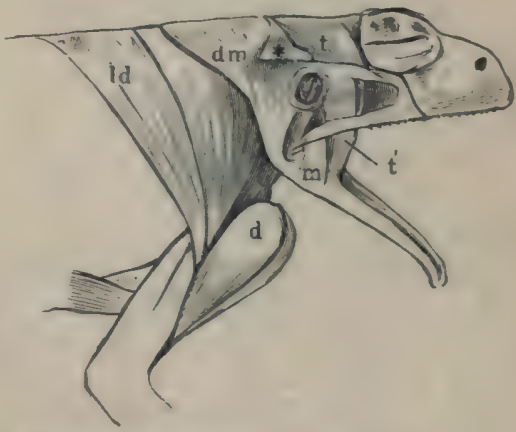

Muscles of the lower jaw of Rama excullemta.

d Y. deltridens.

dm M. lepressor maxillae, its origin where cuvering the $\mathrm{m}$. tempwralis refleeted at *.

ld M. latissimusdursi.

it $\mathbf{~ I . ~ m a s e e t e r . ~}$

t M. temporalis, origin.

t Lower portion of same.

\section{H. pterygoideus (Figs. $49 p, 52,57 p t$ ).}

Cuvier, m. temporalis, II, l.c.-Zenker, m. massetericus, l.c., p. $25 .-$ Dugès, pré-rupéo-pterygo-maxillaire, 31 .

This is partly covered by the foregoing, and lies between it and the eveball. It arises at the inner wall of the orbit from the frontoparietal, and from that portion of the prootic which may be regarded as the ala magna, above the $m$. retractor bulli. The muscle is broad, and compressed from before backwards : it runs downwards covered by the $m$. temporalis, and soon passes into a long. thin tendion (Fig. $57 \mathrm{pt}$ ). which is inserted, behind the m. temporalis and immediately in front of the joint, into the inner surface of the lower jaw. 
16. $M$. masseter (Figs. $56,57 \mathrm{~m}$ ).

Dugès, zygomato-maxillaire, n. 29.

Arises as a somewhat broad muscle from the horizontal process of

Fig. 57.

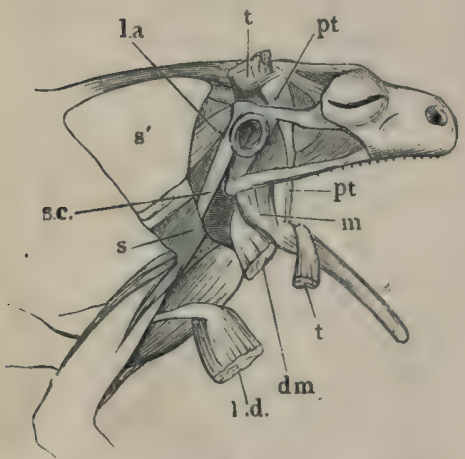

Muscles of the lower jaw of Rana esculenta.

$d m$ M. depressor maxillae cut through and reflected.

l. a M. levator anguli scapulae.

l.d. M. latiss, dorsi, cut through and reflected.

m. M. masseter.

pt M. pterygoidens.

- Scapula.

* Suprascapula.

s.c. M. sternocleidomastoidens,

tt M. temporalis cut through and refected. the quadrato-jugal and is inserted into the outer side of the lower jaw, opposite the insertion of the m. temporalis.

\section{Y 17. M.submaxillaris (Figs. 58,} 59, 6 I $s m, s m^{\prime}$ ).

Cuvier, m. mylo-hyoidens, l.c., II, 536. - Zenker, myln-sternoideus, p. 25. - Dugès, sous-maxillaire, $\mathbf{n}$. I 5 .

This muscle forms the floor of the mouth as does the mylohyoideus in man; it is, however, not inserted into the hyoid bone.

It arises-I. From the whole of the inner surface of the upper border of the lower jaw ${ }^{1}$, except near the angle (Fig. $58 \mathrm{sm}$ );

2. By a small portion (Figs. 58 , 59, 6I $8 m^{\prime}$ ) near the skull, from the cartilaginous anterior cornu of the hyoid-bone which projects from the cartilaginous part of the prootic bone. This portion descends along the cornu to unite with the other portion. The two together form a membranous layer, the fibres of which run transversely and meet in a band of connective tissue along the middle line, forming a kind of linea alba. The sheath runs forwards to the most projecting part of the lower jaw superficially to the $m$. sulmentalis. Slightly in front of its posterior border the muscle is attached in its whole breadth to the skin of the throat by a fine lamella of connective tissue, which is not always complete. The posterior border of the muscle is attached to a fascia, which passes between the deeper muscles and is attached to these. It is known that this muscle plays an important part in the movements of respiration and swallowing; but its precise action has not yet been worked out.

1 A second origin from the lower border of the mandible, described by Klein, is not to be found. The appearance is due to the exit of vessels and nerves from the groove between the mandible and the muacle. 
X 18. M. submentalis (Fig. $59 \mathrm{smt}$ ).

Cuvier, transrersus, l.c., p. 588. - Dugès, 4, souz-mentonnier. - Zenker, $m$. lingualis (incorreetly brought into connection with $m$. hyoglossus).

This small muscle lies in the anterior angle of the lower jaw between the dentary bones. It consists of transverse fibres which

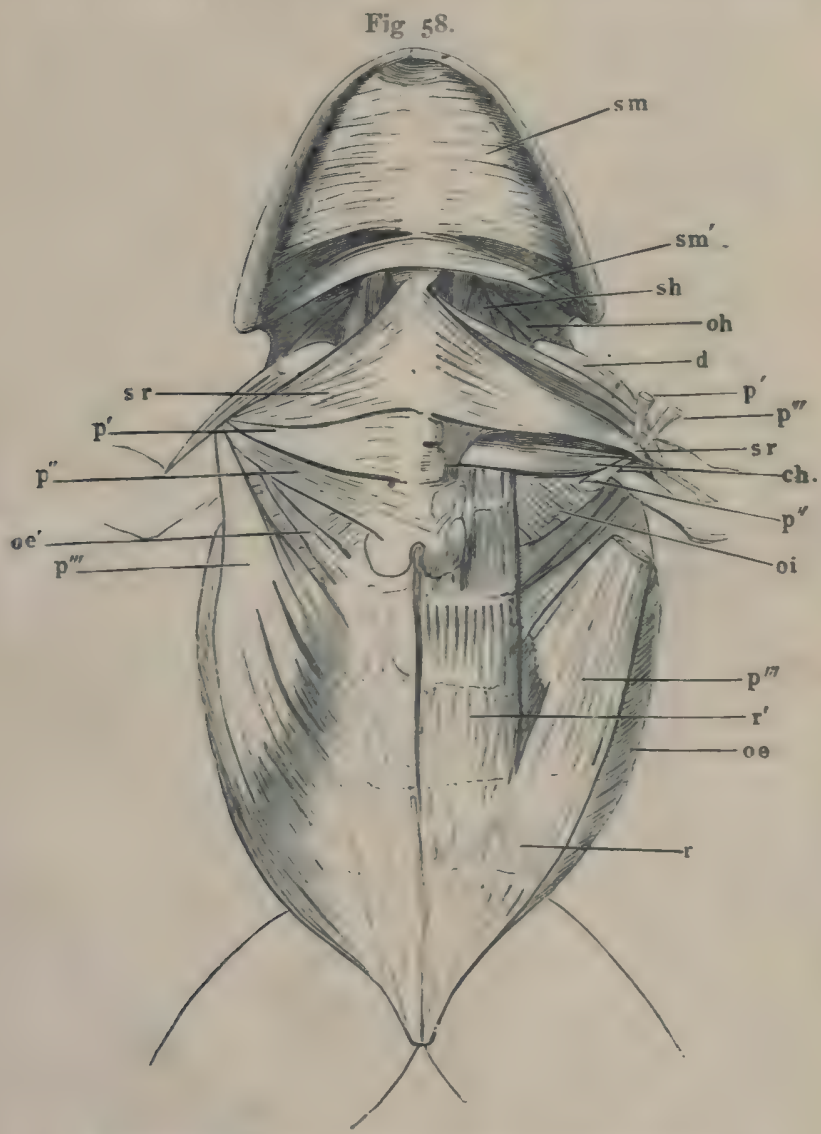

Muscles of the throst, chest, and abdomen of Rana esculenta.

sim M. submaxillaris

$s m^{\prime}$ Hinder portion of same arising from the anterior comu of the hyoid bone.

(For other references see page 68.)

pass from one bone to the other. Below it is covered by the most anterior portion of the $m$. submaxillaris.

Its action is to approximate the sides of the lower jaw : according to Dugès (l.c., p. I 23), it assists in closing the nostrils, by drawing together the sides of the lower jaw and thus raising the premaxillae. 


\section{Muscles of the Hyoid Bone and the Tongue.}

× 19. M. geniohyoideus (Figs. $59 \mathrm{ghl}, 60 \mathrm{gh}$ ).

Cuvier, IV, I, 536.-Dugès, n. 16.-Zenker, p. 30.-M. St. Ange, l. c., Pl. XXVI, f. I, I3, p. $4^{23}$.

Arises from the lower jaw in two portions, the one from near the middle line above the $m$. submentalis, the other more externally

Fig. 59 .

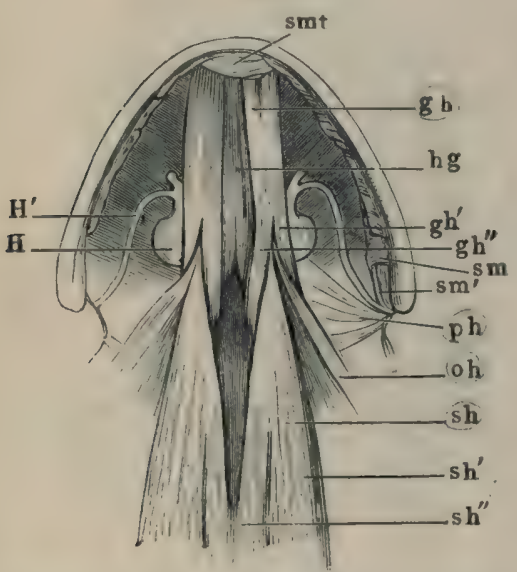

Muscles of the hyoid bone and the tongue of Rana esculenta.

The m. submaxillaris has been removed close to its insertion.

$\mathrm{cm}^{\prime}$ Origin of the hinder portion of same from the byoid bone.

$g h$ M. geniohyoideus.

$g h^{\prime}$ External portion of same.

$g h^{\prime \prime}$ Internal portion of same.

$H$. Body of hyoid bone.

$\boldsymbol{H}^{\prime}$ Anterior horn.

hg M, hyoglossus,

oh M. omolfyoideus.

ph Mm. petrohyoidei.

sh M. sternohyoideus.

$s h^{\prime}$ External origin of same.

$s h "$ Internal origin of same.

$s m$ M. submaxillaris.

$s m^{\prime}$ Origin of hinder portion of same.

smt M. submentalis. from the upper border of the lower jaw. The two parts unite to form a long, flat muscle, which lies on the ventral surface of the body of the hyoid bone, and divides posteriorly into two portions. One of these, the median (Figs. 59, 60g $h^{\prime \prime}$ ), is inserted into the inner border of the posterior horn of the hyoid bone, and is here attached to a fascia which covers the $m$. hyoglossus from beneath. By the same fascia the muscles of opposite sides are connected in the space between-the two posterior cornua. The lateral division (Figs. 59, 60 $g h^{\prime}$ ) is attached to the posterior cartilaginous process of the hyoid bone.

20. M. sternokyoidens (Figs. $59,60 s h$.

Cuvier, IV, I, 538 (pubio-hyoideus). - Dugès, n. I 7 , sterno. xipho-hyoidien.-Zenker, p. 30.

This muscle forms the cervical part of the $m$. rectus abdominis and is, in fact, a direct continuation of it. It arises by an inner portion (Fig. $59 s h^{\prime \prime}$ ) from the upper surface of the inner extremity of the coracoid and from the xiphisternum, while the 
outer portion $\left(* l^{\prime}\right)$ is an immediate continuation of the $m$. rectus abdominis, which passes into this nauscle at about the fifth inscriptio tendinea. The muscle passes forwards on the upper surface of the coracoid and of the clavicle, under the pericardium towards the hyoid bone; here the muscle, hitherto horizontal, suddenly becomes (compare Fig. 60) vertical, and passes between the two insertions of the m. geniohyoideus, and is inserted for a considerable length into the lower surface of the hyoid bone and the anterior extremity of the posterior cornu. $600 \%)$.

21. M. omohyoideus (Figs. 59,

Cuvier, l.c., p. 539.-Dugès, n. I 8 , interscapulo-hyoidien ou omohyoidien. - Zenker, p. 31. M. 8t. Ange, l. $c$.

Arises from the anterior border

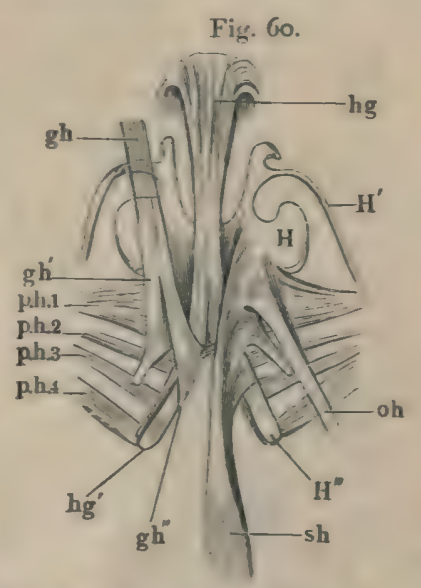

Museles of the tongue and of the hyoid bone of Kana esculenta, from below.

g) M. geniohyoideus

gh" Internal origin $\}$ or amigin $\}$

H Body of byoid.

$\boldsymbol{H}^{\prime}$ Antarior cornu.
$\boldsymbol{H}^{\prime \prime}$ Povterior cornn.

hg M. hyoghosens.

$h^{\prime}$ Hinder origin of zame.

ols M. omohyoidens.

$m h .1,2,3,4$, first, second, third, and fourth m. petrobyoidens.

a. 1. Bternohyoidens. of the bony scapula, and is inserted into the outer part of the ventral surface of the body of the hyoid: it is partially covered by the m. strmollyoidens.

22. M. petmliyoidens anterion (Ecker), (Fig. 6i plis).

Dugès, Io, rupéo-cérato-hyoidien.-Zenker, m. pelro-ceraus? p. 30.Klein, basio-hyoideres, L. $\epsilon_{0}$, p. $\eta \mathbf{I}$.

A thin, flat. muscle, narrow above, but broadening rapidly below, which arising from the outer extremity of the prootic bone, partially surrounds the pharynx below, into which some of its fibres are inserted; it is attached to the ventral surface of the body of the hyoid bone, near the lateral notch. The chief action of this muscle appears to be that of a $m$. constrictor pharyngis. 
23, 24, 25. Mm. petrohyoidei posteriores (Ecker), (Figs. 6I $p h 2,3,4)$.

Cuvier, mm. stylohyoidei, l.c., p. 537--Dugès, 20, 21,22 , masto-hyoideus (Fig. 4).-Zenker, petro-hyoideus superior and inferior.Kloin, stylo-hyoideus, $l$. c., p. 18.

These are three long, thin muscles, which lie nearly parallel to one another, and run from the prootic bone to the posterior cornu

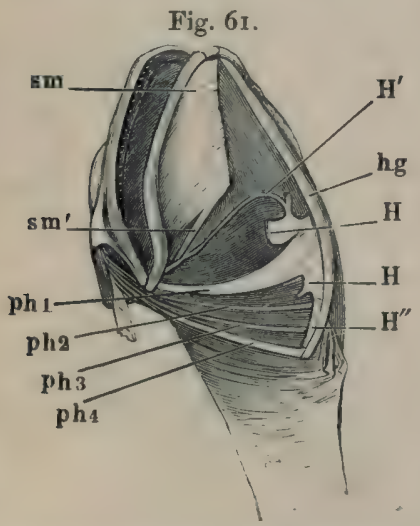

Muscles of the hyoid bone of Rnna esculentr, seen from the right side and below.

$I^{\prime}$ Anterior cornu.

$H^{*}$ Posterior cornu.

hg M. hyoglossus.

II II Body of hyoid bone.

$p h \times$ M. petrohyoideus anterior.

$p h_{2,3 .} 4 \mathrm{Mm}$. petrohyoidei posteriores.

$\mathrm{sm}$. M. submaxillaris.

$s m^{\prime}$ Hinder portion of same. of the hyoid bone. All three arise, covered by the $m$. sternocleidomastoideus, from the lateral extremity of the prootic, pass round the pharynx and are attached, the $m$. petrohyoidens posterior primus (Fig. 61 ph 2) to the anterior extremity, the secundus (Fig. 6 I $p h 3$ ) to the middle; and the tertius (Fig. 6I $y_{h} / 4$ ) to the hinder extremity of the posterior horn of the hyoid bone.

\section{26. M. hyoglossus (Figs. 59, 60; 6 I $h g)$.}

Cuvier, 1. c., p. 588.-Dugès, 24, hyo-glosse.

Arises from the bony posterior extremity of the hinder process of the hyoid bone $\left(/ \mathrm{lg}^{\prime}\right)$. The museles of the two sides pass forwards and converge to the middle line, where they unite. The azygos muscle thus formed runs forwards on the ventral surface of the hyoid bone, between the mm. geniohyoidei, over the anterior border of the hyoid, and passes into the tongue, where it turns backwards and runs to the tip. (For action, see tongue.)

\section{M. genioglossus,}

Cuvier, l. c., p. 587.-Meckel, l. c., IV, 339--Dugès, 23, genio-glosse.

Arises above the insertion of the $m$. geniohyoidens on either side near the middle line from the two anterior bones of the lower jaw. The two origins quickly unite to form a thick, very firm muscular belly, which in its course backwards rapidly thins, and is distributed by numerous bundles; decussating with the fibres of the m. lyyoglosins at an acute angle, it runs on to the anterior extremity of the tongue. 


\section{MUSCLES OF THE TRUNK.}

\section{Muscles of the Abdomen.}

In the formation of the abdominal wall the following muscles take part:-(1) m. rectus abdominis, (2) m. obliquus externus, (3) m. obliquns internus, (4) the portia ablominalis of the $m$. pectoralis. Above, the $m$. obliquus internus forms a kind of diaphragm, partially separating the abdominal from the thoracic cavity (p. 70 ).

28. M. rectus abdominis (Fig. $62 r$ ).

Duges, pubio-thoracique, M. 52 .

These muscles, situated on either side of the middle line of the abdomen, are as a rule traversed by five notched inscriptiones tendineae. Each muscle arises, by a narrow, strong tendon, from the inferior border of the pubes, passes forwards, and quickly widening, divides at the second inscriplin lendinea (counting from behind) into two portions.

(a) The Outer portion (Fig. 62r) runs into the portio ablominalis of the $m$. pectoralis, and forms the greater lateral division of that muscle.

(b) The Inner $\left(r^{\prime}\right)$ continues as the m. rectus ablominis and gradually narrows anteriorly. At the sternum some of the fibres (the median) are inserted into the dorsal surface of the eartilaginous plate of the xiphisternum, while the greater part of the muscle continues forwards over the coracoid to become the $m$. sternohyoileus at about the fifth inseriptio tenlinea (p. 64).

29. M. obliquns externus (Fig. 63 oe, ne').

Zenker, l.c., p. 3 I, m. obliquus.-Dugès, dorso-sons-sbdominal, n. इ̆4.

The m. obliquи externus arises from-

(a) The aponeurosis covering the long muscles of the back, and by this from the spinous processes. The anterior edge of the $m$. obliquns externus covers the posterior edge of the m.latissimus Iorsi, which arises from the inferior, ventral surface of the aponeurosis. The aponeurosis also divides laterally into two parts, one of which, the posterior, passes into the obliquus extermus, while the anterior forms the tendon of origin of the depressor maxillae inf: $(d m)$ (compare Fig. 66).

(b) A second, narrow portion, portin omo-abilnminalis (Fig. 63 ne') 
(m. xipho-adscapulaire, Dugès, n. 62), arises from the posterior border of the scapula by a thin tendon, and becomes broader as it

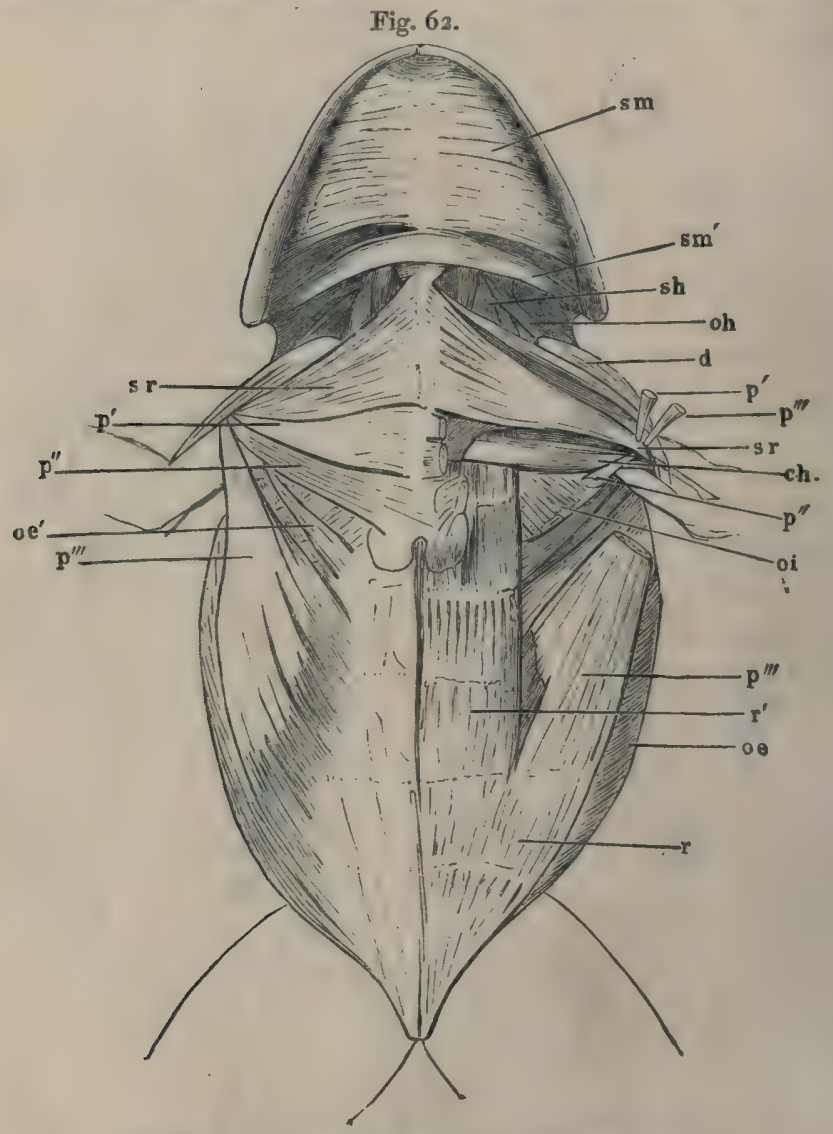

Mnscles of the chest, throat and belly of Rana esculemia.

ch M. coraco-humeralis,

d M. deltoidens,

oi M, obliquus abdom, internus.

oe M. obliq. abdom. externus. "

$\sigma e^{\prime}$ Scapular portion of same.

ol M. omohyoideus.

$p^{\prime}$ Port. sternalis anterior of $\mathrm{m}$. pectoralis,

$p^{\prime \prime}$ Port. sternalis posterior of same.

$l^{\prime \prime \prime}$ Port. abdominalis of same.

$r$ M. rectus abdominis,

$r^{\prime}$ Inner portion of same.

sh M. sternohyoidens.

sm M. submaxillaris.

$s m^{\prime}$ Hyoid origin of sane.

$s r$ M. sternoradialis,

muns downwards and backwards, to join the anterior border of the other and larger portion. 
The whole muscle is attached by its most anterior fibres to the cartilage of the xiphisternum, the rest passing into an aponeurosis

Fig. 63 .

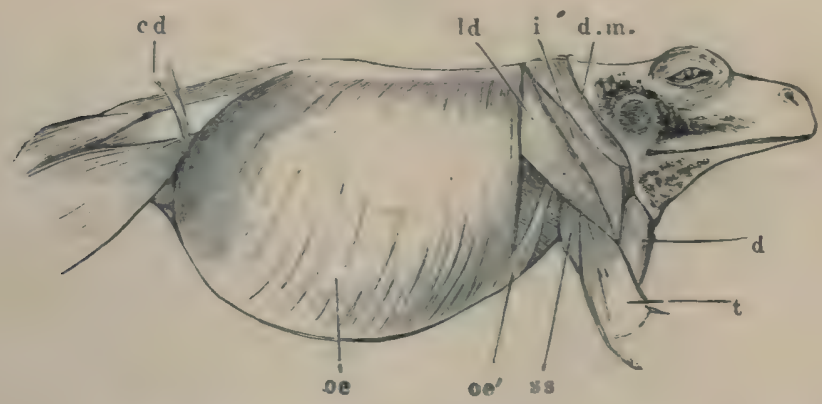

Muscles of trunk of Rana esculenta, from the right side.

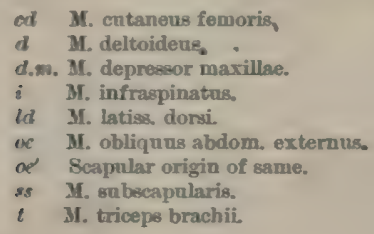

which, inseparably connected with the inscrijtiones tentineae, traverses the lower surface of the $m$, rectus abclominalis to the linea alla.

30. M. obliquus internus.(and transiersus), (Figs. 64, 65 oi).

Dugès, ilen-transverso-sous-sternal, p. 53.-Zenker, transversus, l.c., p. 31.-Kubl, transecrsus, l. e., p. Ir6.

This muscle corresponds with the combined olliquus internus and iranscersus, and has therefore been described either as the one or the other, by various authors.

The fibres arise tendinously-

a. From the transverse processes of the vertebrae from the fourth backwards, and from the fascia covering the mim. intertransrersarii.

b. From the iliac bone, by a strong tendon from its upper border, and by a few weaker fibres from its outer surface. The latter fibres are covered by the former, and these end posteriorly in a sharp concave border.

The muscular bundles diverge from these points, some running forwards, some backwards; the former are only partially covered by the portio omo-abrlominalis of the m. obliquus externus (compare 
Figs. 62, 63), in front of the anterior edge of that muscle. The posterior border of the muscle is uncovered.

Fig. 64 .

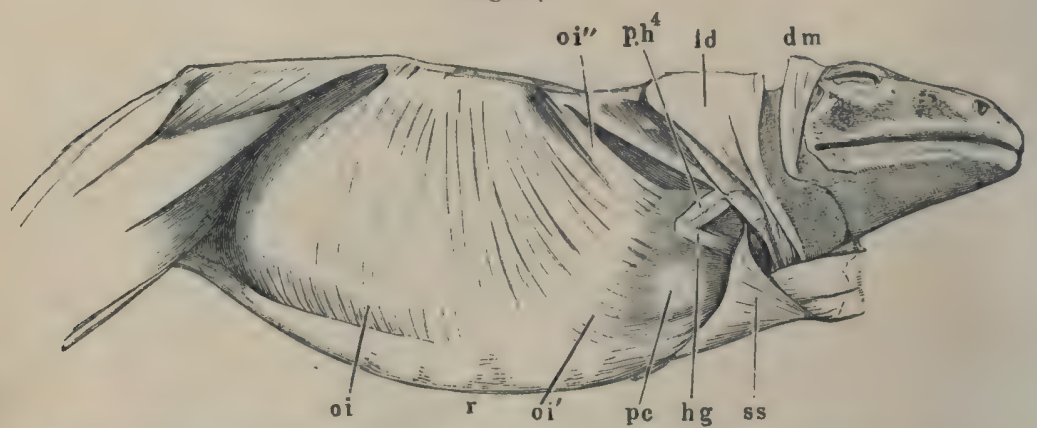

Second layer of abdominal muscles of Rana esculenta, from the right side and below. The m. obliquus externus and the right anterior extremity has been removed.

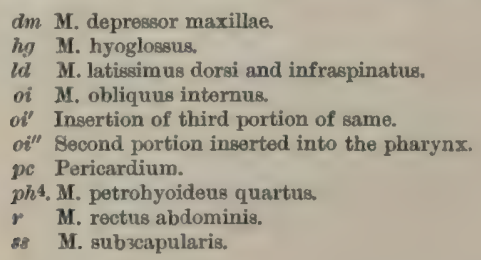

The insertions of the muscle are very various, and as a consequence very various functions are accomplished by it.

a. The most anterior part of the muscle (Fig. $\left.65 \mathrm{o}^{\prime \prime \prime}\right)$, the fibres of which run forwards, is attached-

I. Partly to the xiphisternum and the coracoid.

2. A second portion, viz. that arising from the transverse processes of the fourth vertebra (Fig. $64 o^{i \prime \prime}$ ), surrounds the pharynx like a diaphragm (Fig. $65 \mathrm{oe}$ ), and is attached to its side as far as the dorsal aspect (Fig. 65oi'). This portion is lightly separated from the following.

3. A third portion, placed behind the preceding, runs from the pharynx over the pericardium (Fig. $64 \mathrm{pc}$ ), and is attached to this nearly as far as the middle line (Figs. $640 i^{\prime \prime}$ and $650 i^{\prime \prime}$ ), resting on the sternum, the $m$. rectus and $m$. sterno-hyoideus. The lines of insertion of the muscles of opposite sides form an angle, open in front. In the thin borders of this portion the muscular bundles lie almost entirely in simple layers, and they are therefore well adapted for microseopical purposes.

b. The middle and posterior portions of the muscte pass down- 
wards and slightly backwards, towards the outer border of the $m$. rectus; there they pass into a tendon which, for the most part, runs on the upper surface of the rectus to the linea alla.

\section{Muscles of the Back.}

The muscles of the back are covered by a fascia, the fascia dorsalis (Fig. $66 \mathrm{fil}$ ), attached to the spinous processes of the vertebrae. Anteriorly, where it covers the m. temporalis, it is attached to the frontoparietal and squamosal bones, posteriorly to the superior border of the iliac bones and the extremity of the urostyle. The posterior part, which covers the origins of the m. longisimus dorsi, of the $m$. coccygeo-iliacus, and of the coccygeo-lumbaris, is especially strong. From the anterior part several muscles arise laterally, viz. a portion of the m. obliquus abdominalis exteruns, of the m. latisimus dorsi, and of the $m$. depressor maxillae inferioris. In the uppermost layer, immediately covered by the fascia dorsalis, lie the $m$. cucullaris, the m. retrahens scapulae, the $m$. latissimus dorsi arising from the fascia itself, and the scapula with its muscles; then come the long muscles of the back ; and in the third and deepest laver the short muscles of the back.

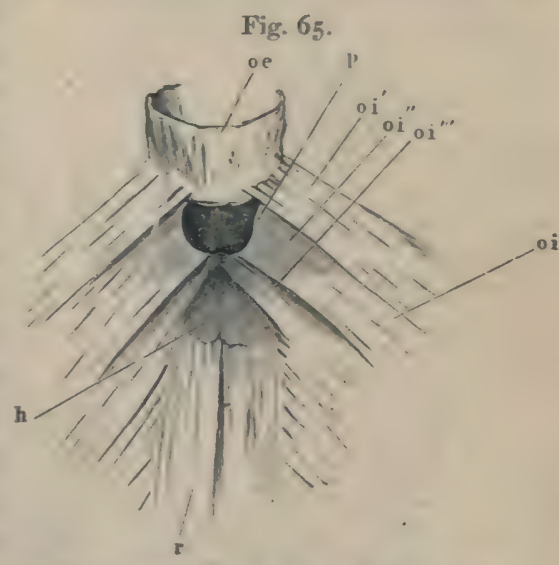

M. ubliquus internus, shuwing its attachments superiorly.

Xiphisternum.

Desophagus.

3. cbliquus internus.

Fibres of $\mathrm{m}$. ubliq. int., which are inserted into the (x) puhasus.

oi" $0 i^{\prime \prime \prime}$ Fibres of same, which are attached to coracoid and xiphisternum.

Perieardium.

M. rectus abdominis.

The individual museles are as follows :-

A. Limb Mlscles of tIIE BACK (for moving the shouldergirdle and arm).

31. M. cueullaris (Fig. $66 \mathrm{c}$ ).

Cuvier, angularis.-Dugès, n. 38, sous-occipito adscapulaire.-Zenker, levator scapulae sublimis.

In order to see this muscle, it is necessary to separate the fascia Inrsalis from the spines of the vertebrae and to turn it back with the $m$. depriessor maxillae inf. arising from it. It is then seen to 
rise from the posterior surface of the exoccipital as far as the middle line; the muscles of the two sides run backwards, diverging each from the other, so as to form an angle, and are then attached on each side to the anterior superior angle of the suprascapula at its under surface and median border.

Cuvier considers this muscle as the analogue of the $m$. levator anguli scapulae. Dugès and Meckel consider it to be the anterior part of the m. cucuilaris, the former thinking the posterior part of the muscle to be the $m$.rhomboideus. I cannot agree with these opinions, and I regard the muscle as simply representing the $m$. cucullaris of. man (Ecker).

32. M. latissimus dorsi (Figs. 56, $66 \mathrm{ld}$ ).

Dugès, n. 66, lombo-huméral.-Zenker, depressor brachii.

This thin, triangular muscle arises from the ventral surface of the fascia dorsalis, and is posteriorly covered in part by the anterior border of the m. obliquus ablominis externus. The muscle becomes narrower towards the sides, and passes into a flat tendon, which blends with that of the in. infiaspinatus, and is attached to the

Fig. 66.

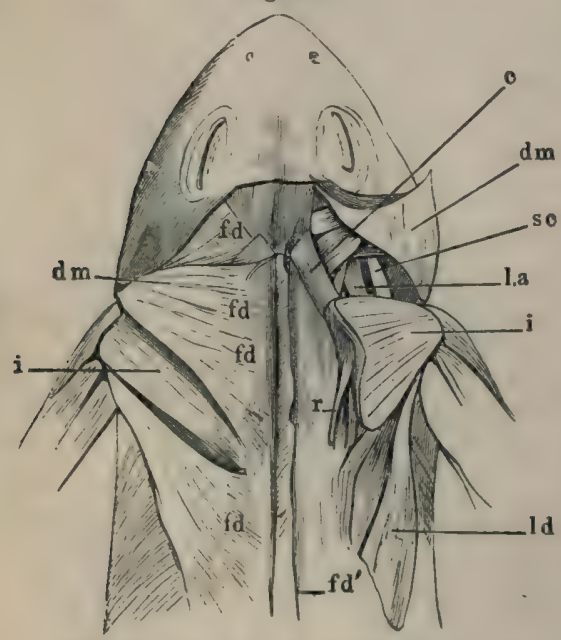

Muscles of the back and shoulder-blade.

c M. cucullaris.

dm, M. depreseor maxillae arising from the fascis dorsalis, cut through and reflected on the right side. $f d$ Fascia dorsalis

$f d^{\prime}$ Same cut through at the spines.

i. M. infraspinatus.

l.a M. levator anguli scapulae.

ld, M. Latisminus dorsi.

$r$ M. retrahens scruntac.

sc H. sternocleidomastoideus. outer surface of the crista deltoidea of the humerus by a triangular expansion.

33. M. retrahens scapulae (Ecker), (Fig. $66 r$ ).

Dugès, n. 59, lombo-adscapulaire. - Klein, m. rhomboideus, l.c., p. 26. - Zenker, omoplateus rectus ? p. 37, l.c.-Kuhl, l.c., 124 , retrahens rhomboideus.

This flat, oblong muscle arises from the transverse process of the fourth vertebra, and is connected with the third tendinous inscription (counting from before) of the m. longiss. dorsi. Posteriorly its origin forms a convex border, whence it runs forwards and to the side; it is inserterl into the ventral surface of the suprascapula, near its imner border. 
This muscle lies near the m. serratus or transt. scap. tertius (Fig. $\left.68 t s^{\prime \prime}\right)$, and has an analogous position. It would, therefore, possibly be more correct to regard it also as a $m$. serratus. It arises from parts which represent ribs, and is inserted into the seapula. It has, at any rate, no analogy to the $m$. cucullaris, with which Dugès connects it, nor with the m. rhombridleus, which Klein holds it to be, as it does not arise from spinous processes.

\section{B. Long Muscles of the Back。}

34. M. extensor dorsi communis (Fig. 67 lg.d.).

Dugès, n. 33-40, masze des muscles surspinaux devisée en huit faisceaux principaux: 1. vertebro-sus-nccipital, 2-5. transverso-spinaux, 6. transverso-coceyg., 7. sacro-coceygien, 8. ileo-coceygien. The muscles I- 7 form the lombo-costal, 8 the ischicoceyg., Cuv.-Zenker, $m$. sacrolumbaris. - Klein, longiss. dorsi, cocrygeo-lumb., coccyg-iliac.

This muscular mass is covered by the fascia clorsalis, the $m$. cucullaris and retrahens scapula, and the suprascapula : it corresponds with (I) the $m$.ileo-costalis and longissimus dorsi, llorsi and cervicis (Henle); (2) the semispinalis and spinalis (Henle).

The following separate portions may be made out:-

35. (1) M. longiss. dorsi (Fig. 67 lg.ll.).

This muscle arises from the most anterior part of the urostyle, runs forwards near the middle line, separated from the muscle of the opposite side by the spinous processes of the vertebrae. The inner portion passes over the posterior spinous processes without being connerted with them, as far as the fifth, it is then inserted into the succeeding spines as far as the exoccipital bone. The lateral portion runs outwards and forwards to be attached to the transverse processes and oblique processes of all the vertebrae, from the sixth forwards, while accessory muscular slips arise from the transverse processes and from the anterior spinous processes which, merging in the general muscle-mass, are inserted with this into the occiput.

The muscle is subdivided by a series of wavy, tendinous partitions (Fig. 67), which arise from the transverse processes, and traverse the muscle in planes, the upper surfaces of which are directed upwards and forwards. This arrangement of the muscle indicates its relation with the lateral trunk muscles of fish and fish-like amphibians.

36. (2) M. coccygeo-sacralis (Fig. 67 c.l.).

This muscle is partially covered by the preceding, it arises from the lateral surfaces of the anterior half of the urostyle; from this 
origin the fibres pass forwards and outwards to be inserted in two portions, the anterior set into the arch and the posterior set into the transverse process of the last vertebra. The former may be regarded as $m$. intercruralis, the latter as $m$. intertransversarius.

Fig. 67.

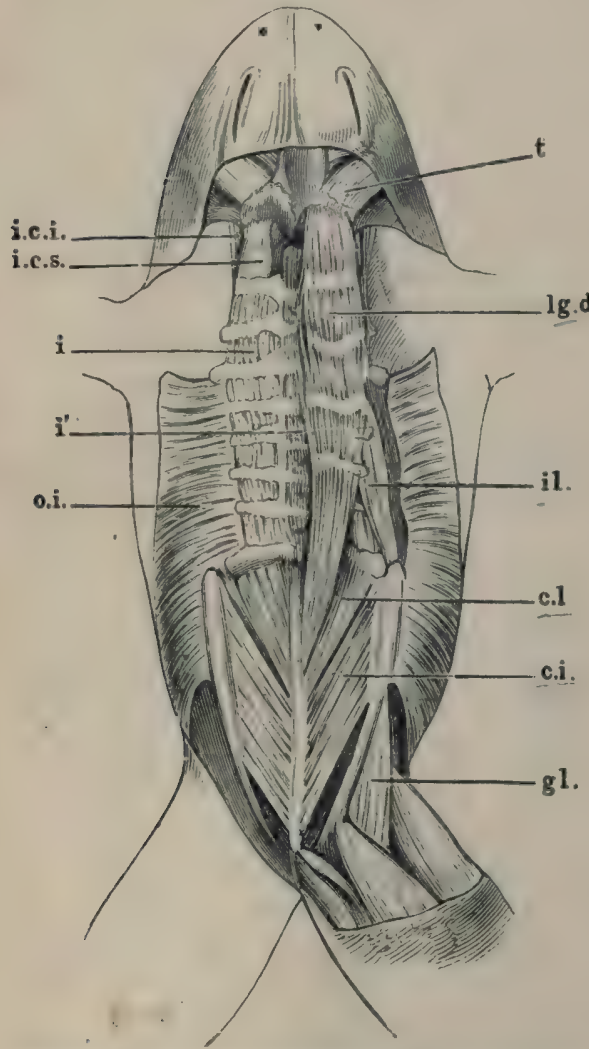

Muscles of the back and pelvic girdle of Rana esculenta.

c.i. M. coccygeo-iliacus:

c.l. M, coccygeo-sacralis.

g.l. M. glutaeus.

i MM. intertransversarii.

i MM. intercrurales.

i.c.i. M. intertransv, capitis inferior.

i.c.s. M. intertr. cap. sup.

11. M. ilio-lumbaris.

lg.d M. longissimus dorsi.

o.f. M. obliq. internus.

$t \quad$ M. temporalis.
37. (3) M. coceygeoiliacus (Fig. 67 c.i.).

This muscle arises from nearly the whole length of the lateral surface of the urostyle, the anterior portion being concealed by the preceding muscle. The fibres pass outwards and forwards to be inserted into the anterior two-thirds of the inner surface of the ilium.

38. M. ilio-lumbaris (Klein), (Fig. 67 il.).

Duges, n. 5I, transverso-iliaque.-Cuvier, Zenker, etc., quadr. lumborum.

Evidently represents the quadratus lumborum of human anatomy; it takes its origin from the anterior extremity of the ilium, and runs forwards to be inserted into the transverse processes of the vertebrae from the seventh to the fourth. 


\section{Short Muscleg of THR Back.}

39. M. intertrunstersarius capitis superior (Ecker), (Fig. 67 i.c.s.): Dugds, n. 4r, expocipito-transversaire sup.

A small muscle arising from the prootic: it lies above the lecator anguli scapulae, and is inserted into the transverse process of the second vertebra.

40. M. intertranscersarius capit is inferior (Fig. 67 i.c.i.).

Dugès, n. 42, ex-occipita-transv. inf.

This muscle lies on the rentral surface of the preceding one, but is easily separable from it; it arises from the angle of the prootic and is inserted, together with the preceding muscle, into the transverse process of the third rertebra. The $n$. vagus passes outwards between these two muscles.

41. MII. intertranstersarii dorsi (Fig. 67 i).

Dugès, n. 43 to $\mathbf{5 0}$, intertransversaires.

Seven small muscles, placed between adjacent transverse processes of the vertebrae; from the second to the last, in continuity with the muscles last mentioned.

42. MM. intererurales (Ecker), (Fig. $67 i$ ).

Klein, p. 29, interspinales, interobliqui.

Those muscular fibres found between the arches of adjacent vertebrae are so named. On account of the shortness of the spinous processes they can scarcely be named m. interipinale:

\section{MUSCLES OF THE ANTERIOR EXTREMITY.}

\section{Mescles of THe Shotlder-Girdus.}

A. Dorsal Mlacles of the Shotlder-blate.

(I.) Muscles arising from the head or trunk, and inserted into the scapulae, which they act upon primarily, and upon the shouldergirdles secondarily.

Some of these muscles, such as m. excullaris and retraliens, are situated on the back, and have already been described with the muscles of that region. Others are attached partly to the undersurfaces of the scapulae and are only visible from below; they are best seen in such a prepration as is shown in Fig. 68, made by cutting through the sternum in. the middle line, and reflecting each half outwards. 
(a) Muscles which arise from the skull.

43. M. levator anguli scapulae (Fig. $68 \mathrm{le}$ ).

Dugès, sous-occipito-adscapulaire, n. 6o.-Zenker, protracten scapulae,

Pl. I, Fig. 5--Cuvier, Leçons I, p. 379, describes this muscle as part of the m. serratus anticus maynus.

A fairly strong muscle, which has a broad origin from the prootic and exoccipital bones as far as the foramen magnum, a few fibres are also attached to the lateral portions of the parasphenoid. The fibres run backwards and outwards, first in a frontal plane and then in a sagittal plane, to be inserted into the under surface of the suprascapula near the posterior border, where it encloses the hinder border of the $m$. interscapularis.

Its action is to draw the shoulders forwards and inwards, or the head downwards.

44. M. sternocleinlomastoinleus (Fig. $68 \mathrm{sc}$ ).

Dugès, scapulo-mastoidien, n. 65.-Cuvier, sterno-mastoidien.-Zenker, protractor scapulae, P1. I, Fig. 5, 1 .

A narrow muscle placed in front of and externally to the preceding muscle; its general direction resembles that of the m. levator ang. scap.

The fibres arise from the most external part of the prootic and from the hindermost part of the squamosal, under cover of the m. digastricus maxillae, and from the hinder portion of the cartilaginous tympanic ring. Covered by these muscles, it passes backwards and downwards to be inserted into the concavity of the anterior border of the scapula; externally to the origin of the deltoid.

The action of this muscle is to draw the shoulder forwards and towards the middle line, or to bend the head downwards.

45. M. protrahens scapulae (Fig. 68 ps).

Dugès, Zenker, protractor acromii, P1. I, Fig. 5, 3 .

This muscle lies to the outer side of the rectns capitis inferior: it arises from the prootic, and runs backwards and outwards upon the levator anguli scajulae, to be inserted into the scapula.

It pulls the scapula forwards. 
(b) Muscles which arise from the vertel,ae.

46. M. transierso-scapularis major (Ecker), (Fig. 68 ts).

Dugès, transverso-interscapulaire, n. 63.-Cuvier, 1.c., p. 380, probably regarded as a portion of the servatux.,Zenker, Pl. I, Fig. 5, 3; depressor acromii, Pl. II, Fig. 3, I5--Klein, depressor scapulae.

This muscle arises by tendon from the cartilage of the transverse process of the fourth vertebra and by a slip from the cartilage of the transverse process of the third vertebra. Diminishing in size, the muscle passes outwards, forwards, and upwards to be inserted into the posterior border of the scapula, opposite the insertion of the $m$. sternocleilomastoideus. It draws the shoulder inwards, backwards, and downwards.

47. M. transverso-scapularis minor (Ecker), (Fig. 68 t8').

Dugès, transverso-adscapulaire, n. 61.-Cuvier, regarded as part of the servatus.-Zenker, P1. I, Fig. 5, 7, detractor scapulas.

This is much shorter than the muscle just described; it arises under cover of the $n$. levator scapulae, from the transverse process of the third vertebra in front of the transrerso-scapularis major; and runs outwards and forwards to be inserted into the ventral surface of the cartilage of the scapula. The action of the muscle is to draw the shoulder inwards, backwards, and outwards. Dugès regards this muscle as a portion of the serratus anticus magnus, the remainder of which he considers is to be found in the portio scapularis of the $m$. obliquns externus (xipho-adscapulaire, Dugès, $n, 62$ ).

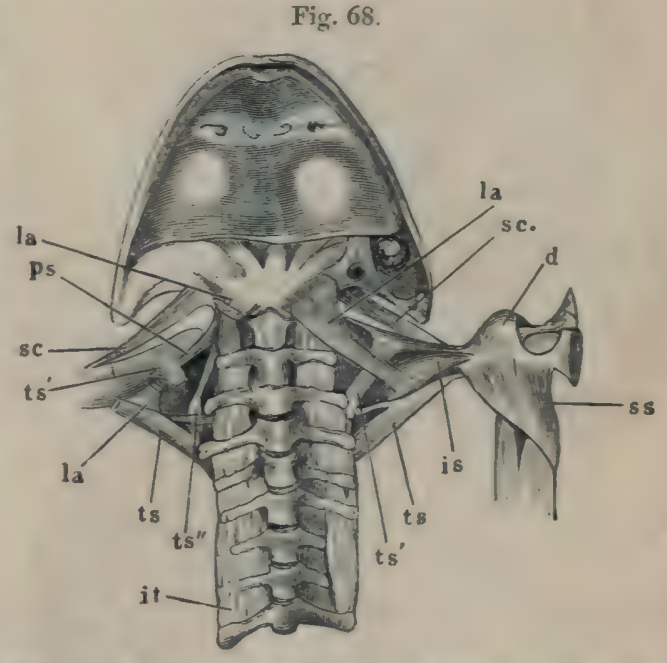

Muscles of the shoulder, from beluw ; the sternum has been cut thruugh and the sides drawn apart.

$$
\begin{aligned}
& \text { d Deltoideus. } \\
& + \text { is Interscapularis. } \\
& \text { f. il Intertransversarii. } \\
& \text { - la Ler. anguli seapulae. } \\
& \text { ps Protrahens scipulae. } \\
& \text { si Sternocleidumastoideur. } \\
& \text { ss Subscapularis. } \\
& \text { 1. is Transterso-ecap. major. } \\
& \text { 18 Transwersu-seap. minor. } \\
& 6 \text { Transverno-seap. tertius. }
\end{aligned}
$$



$\left.68 t^{\prime \prime}\right)$.

48. M. transverso-scapularis tertius s. serratus (Ecker), (Fig.

This is larger than the muscle just described; arising by a broad and flat origin from the transverse processes of third and fourth vertebrae, it runs upwards and inwards to be inserted into the ventral surface of the cartilaginous scapula near its inner border. In position, course, and action the muscle most nearly represents the m. serratus anticus of human anatomy.

(II.) Muscles on the scapula, that is, arising from the scapula and inserted into the scapula or humerus.

(a) Muscles on the deeper surface.

Fig. 69.

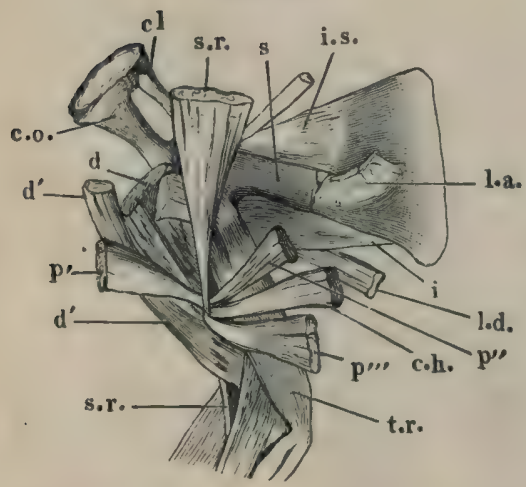

Muscles of right shoulder and upper arm. The coraeoids $(c o)$ and the clavicles $(c l)$ have been drawn apart after cutting through the sternum.

c.h. M. coraco-humeralis.

cl Clavicle.

c.o, Coracoid

d M. deltoideus.

dy Clavicular portion of $\mathrm{m}$. deltoideus.

i M. infraspinatus.

i.8. M. interscapularis,

l.r. M. levator anguli scapulae.

l.d. M. latissimus dorsi.

$p^{\prime} \quad$ Sternal portion of $m$. deltoideus.

$y^{\prime \prime}$ Anterior sternal portion of the m. pectoralis.

$p^{\prime \prime \prime}$ Posterior sternal portion of the m. pector.lis.

8 Scapula.

8.r. M. sternoradialis.

t.r. M. triceps brachii,
49. $M$. interscapularis (Fig. 69 i.8.).

Dugès, interscapulaire, n. 64 .

One end of this muscle is tendinous, and is attached to the outer extremity of the suprascapula; from this the muscle, becoming fleshy and narrower, runs towards the middle line to become attached to the ridge on the ventral surface of the scapula, from which the $m$. deltoideus and the m. subscapularis arise, and between which it passes. It approximates the scapula and suprascapula and lessens the angle between them.

$7088)$.

50. M. subscapularis (Fig.

Dugès, sous-scapulo huméral, n. 72 .

This muscle is situated on 
the apper or visceral surface of the scapula. It arises from a bony ridge found on the upper surface of the coracoid and of the proc. coracoidens of the scapula. The muscle runs outwards and is inserted, after widening, into the inner surface of the crista deltoidea of the humerus; it is antagonistic to the deltoid, and draws the raised arm backwards and towards the trunk.

Fig. 70.

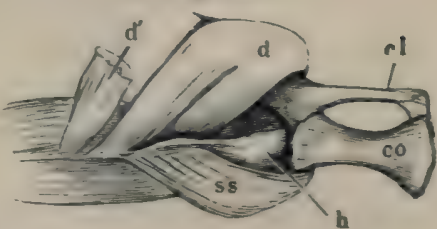

Right shoulder, from below, arm strongly abdneted.

d Claricle.

co Coracoid.

d Deltoidena.

d Clavicular portion of deltoid.

h Hamerua.

* Subecapralar muacle.

(b) Muscles on the superficial sinfarp.

51. M. infraspinatus (Fig. 57, between $l d$ and dm, Fig. $7 \mathrm{I}$ i).

Dugès, adscapulo-humérnl, n. 67 .

The $m$. infraspinatus represents the m. infraspinatus, teres major and minor of human anatomy. It is of triangular form, with the broad base directed inwards; it arises from the whole of the upper surface of the suprascapula except along the inner border which is formed of hyaline cartilage alone : from this origin the fibres converge outwards to a flat tendon which unites with that of the m. latissimus dorsi to be inserted into the crista deltoidea lunmeri, by means of a thin, triangular, tendinous expansion.
Fig. 71 .

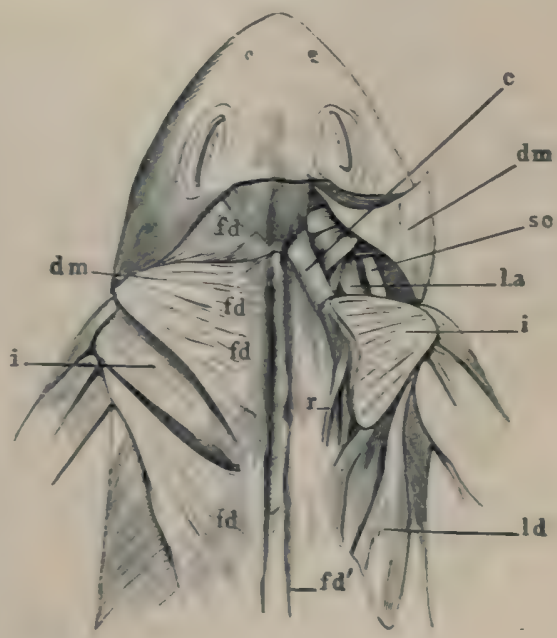

Mnoles of the back and shovider.

e M. cucullariz.

din M. depreseor maxillae.

At Fascia dursalis.

fd" Pasia dorsalis reffected.

i. M. infraspinatas

La M. levator anguli scapulae.

Id M. latissimns dorsi.

r M. retrahens scappoilae.

s $\mathbf{M}$. sternncleidomastuiletu 


\section{General arrangement of the muscles of the shoulder-blade.}

The muscles attached to the scapula and suprascapula are :

I. Muscles of the back ( $m$. cucullaris and $m$. retrahens scap.).

2. Muscles of the neck ( $m$. omohyoideus).

3. Muscles of the abdomen (portio scapularis of the m. olliquus externus).

4. True shoulder muscles (m. levator anguli scapulae; m. sternocleiromastoileus; $m$.protrahens scapulae; mm.transverso-scapularis major, minor, and tertius s. serratus; $m$. interscapularis; $m$. subscapularis ; and the long head of the $m$. triceps).

From above the following are visible: $m$. cucullaris, a portion of the $m$. subscapularis, and the transverso-scapularis maior.

From below (after cutting through and drawing aside the two halves of the sternum) may be seen: the omolyoideus, sternocleitomastoideus, levator anyuli scapulae, protrahens scapulae, transiersoscapularis minor and tertius, interscapularis and sulscapularis.

\section{B. Ventral Mescles of the Siollader (Pectoral MUSCLES.)}

These arise from the sternum or shoulder-girdle and are inserted either into the humerus or into the radio-ulnar.

52. M. pectoralis (Fig. 72).

This is placed on the ventral surface of the shoulder-girdle and consists of the following parts :

(a) Portio sternatis anterior (Ecker), (Figs. 72, $73 p^{\prime}$ ).

Dugès, clavi-huméral, n. 70 (port. clavic. du grand pectoral).

This is the anterior portion of the $m$. pectoralis, it arises from the sternum proper and the epicoracoids. Broad at the origin, it becomes narrower as it runs outwards into a tendon attached to the crista deltoidea humeri.

(及) Portio stemalis posterior (Ecker), (Figs. 72, $\left.73 p^{\prime \prime}\right)$.

Dugès, sterno-huméral, n. 7 I (port. sternal du grand pectoral).-Klein, humero-sternalis.

This muscle is placed immediately behind the portio sternalis anterior, it has a somewhat broad origin from the sternum and xiphisternum; the muscle runs outwards and slightly forwards to be inserted into the groove beside the crista deltoinlea linmeri. The tendon of the $m$. sterno-rarlialis passes between these two portions of the $m$. pectoralis. 
(r) Portio abdominalis (Figs. 72, $73 p^{\prime \prime \prime}$ ).

Dugès, abdomino-huméral, n. 69 (port. costal du grand pectoral).Zenker, brachio-abdominalis.-Klein, humero-abdominalis.

This portion represents that part of $m$. pectoralis major of human

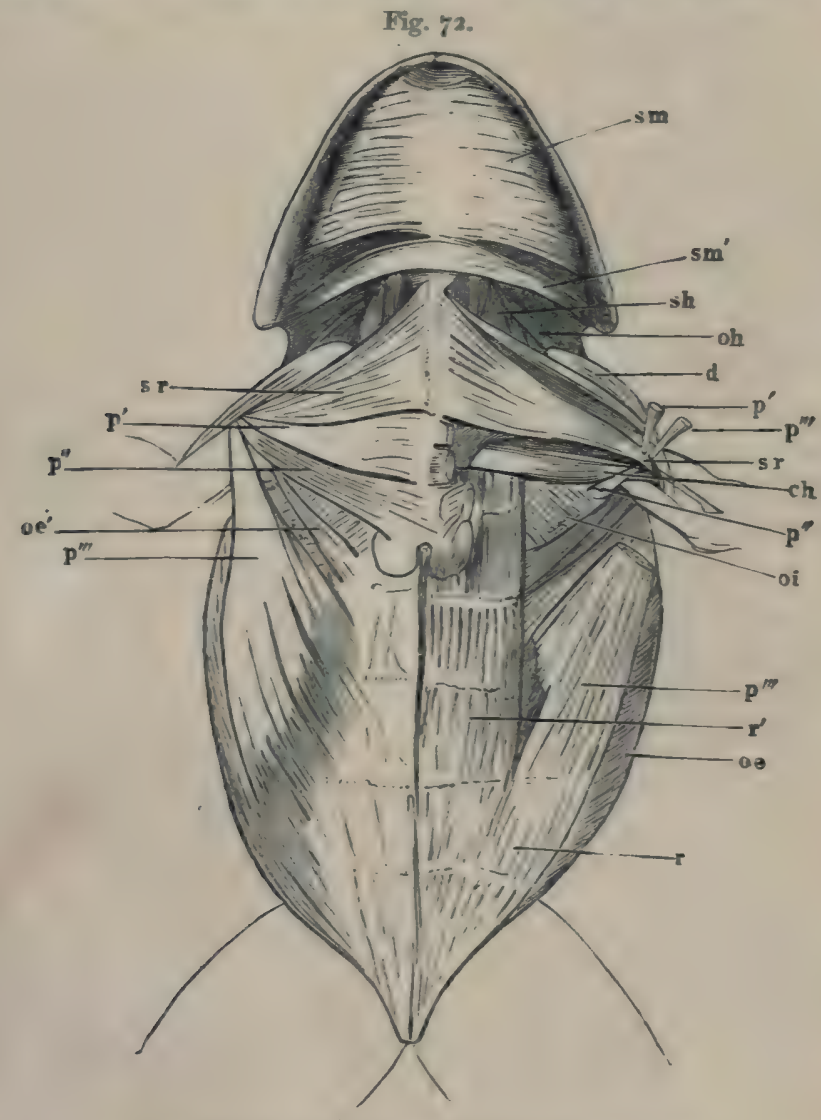

Mnecles of the chest, throat, and belly of Rana esculenta.

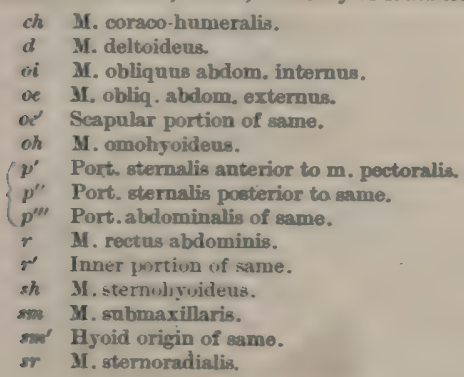


anatomy which arises from the costal cartilages, and more particularly that part which is connected with the aponeurosis of the $m$. obliquus abdominis externus. The muscle arises ( $\mathrm{I}$ ) from the m. rectus abdominis (Fig. $72 r$ ), that is, it forms a direct continuation of the outer portion of this muscle; (2) the inner, smaller part arises from the superficial surface of the aponeurosis of the $m$. obliquus abdominis. The muscle becomes narrower as it courses outwards and forwards, the outer fibres being longer and more oblique than the inner. The action of this muscle will necessarily vary according to the part or parts which are brought into action; speaking generally, the anterior extremities will be drawn downwards and towards each other.

53. M. coraco-humeralis (Dugès), (Figs. 72, 73 c.h.). Dugès, n. 72.-Klein, adductor humeri.

A long, narrow muscle, lying upon the posterior border of the coracoid and the lowest part of the m. subscapularis. By its position it corresponds most nearly with the m.pectoralis minor, although its insertion does not. It has a narrow origin from the coracoid near the sternum, whence it courses outwards, under cover of the port. sternalis anterior and posterior of the $m$. pectoralis, to be inserted into the middle of the humerus between the deltoid and internal head of the triceps. It draws the limb towards the trunk.

54. M. sternoradialis (Cuvier), (Figs. 72, 73 s.r.).

Dugès, pré-sterno-clavi-radial, n. 74 .

This muscle evidently represents the biceps of man, it lies in front of the portio sternalis anterior of the $m$. pectoralis, its hinder border being under cover of the latter muscle. It takes origin from the episternum, omosternum, and the epicoracoid; from this broad origin the fibres converge while coursing backwards and outwards to be attached to a strong tendon. This tendon plays in a groove along the crista deltoidea, and is held in position by tendinous bands arising from the insertion of the $m$. pectoralis; it then pierces the lower portion of the muscular belly of the deltoid, and is inserted into the anterior extremity of the radial side of the radio-ulnar. The muscle is a powerful flexor of the forearm.

55. M. deltoideus (Figs. 70, 72, 73d).

Dugès, pré-sterno-scapulo-huméral, n. 68.

It is placed in front of and external to the m. sternorartiatis, and represents both the $m$. deltoideus and supraspinatus of man. The muscle has two points of origin :- 
Fig. 73 .

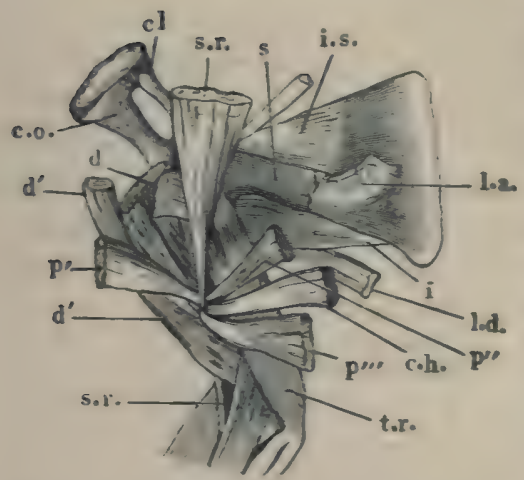

Mnsle of right shoulder and upper arm. The onracxids (ee) and the clavicles $(\cdot l)$ have been drawn asunder after cutting throngh the steraum.

c.h. M. coraco-humeralis.

d Claricle.

c.o. Coraceid.

a Y. deltuidens.

$d^{\prime}$ Clavivular jortion of $\mathrm{m}$. deltwide.

i M. infmepinatus.

i.t. M. intermatularis.

i.n. M. exater anguli scapulae.

1.d. M. lativimus dorsi.

$p^{\prime}$ sternal yortion of $\mathrm{m}$. deltwiles.

$p^{\prime \prime}$ Anteriur sternal portiun of the $\mathrm{m}$. pectoralis

1f" Pisterior sternal purtion of the m. jecturadia

\& Sexprula

s.r. M. sternoradialix

t.r. M. triceje brachii.

(a) Portio scapularis, the larger, external portion is attached to the outer end of the clavicle, and to the anterior process of the precoracoid, but it arises chiefly from the dorsal surface of the scapula (from the same ridge as the m. subscapularis), and lastly from the anterior border and ventral surface of the scapula. The fibres pass outwards over the shoulder-joint.

(b) Pars clavicularis (mus. cleilo-hwneralis, Klein) arises from the inner extremity of the clavicle and from the omosternum and joins the portio scapularis.

The muscle is inserted into the humerus, the under part of the portio scapularis being attached to the upper portion of the crista deltwillea; the outer fibres of this part, together with those of the pars clavicularis, are attached to the extremity of the crista cleltoidea and to the inner surface of the humerus as far as the distal extremity; just before its insertion the muscle is pierced by the tendon of the $m$. sternorartialis. The deltoid draws the limb forwards.

\section{Mescles of thi Fore-Limb.}

\section{A. Mescles of THE ARM.}

11. sternoradialis (bicejis). See page 82 .

56. M. triceps brachii (Fig. 73 t.r.).

Dugès, seapulo-huméro-olecranien, n. 75-Capes, Zenker, m. a nconaens.

This muscle lies on the upper or dorsal surface of the arm, and has relations similar to those of the corresponding muscle in man. The long head arises from the posterior border of the scapula at the upper border of the glenoid cavity, and is here attached to the capsule of the joint; the inner head arises from the upper and inner surfaces 
of the anterior half of the humerus as far as the extremity; the outer head arises from the outer surface of the humerus. Additional fibres, which may be regarded as a fourth origin ( $m$. subanconaens), arise from the upper surface of the hinder half of the humerus. The fibres from these several origins unite to form a strong muscle, which covers the upper, inner, and outer surfaces of the bone, and then passes into a tendon. This tendon is attached to the capsule of the elbow-joint and inserted into the proximal extremity of the radio-ulnar. A cartilage, representing the olecranon, is found in the capsule at the point of attachment of the tendon.

\section{B. Muscles of the Forearm.}

(I.) Muscles of the flexor surface.

The muscles of this surface are arranged in two groups, so as to form, at the elbow-joint, a triangular depression (plica cubiti), into which the tendon of the $m$. stemorarlialis sinks.

A. Muscles of the Inner Group.

Fig. 74

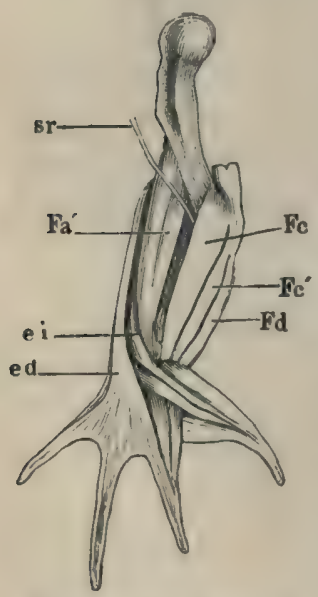

Muscles of the right arm of Rana esculenta.

ed M. extens, digitorum communis.

ei M. abductor digiti II longus. $F u^{\prime}$ M. flexor antibrachii lateralis superficialis.

Fc M. flexor carpi radial.

$F_{C}$ M, flexor carpi ulnar. munis.

$s r$ Tendon of the M. sternoradialis.
Fd M. flexor digitorum com-

57. M. Alexor carpi $I$ \& ratialis (Fig. $74 F c)$.

Dugès, sous-huméro-carpien, n. 83 .

This represents either the flexor carpi radialis longior or radialis brevior of man; it has a broad origin from the inner border of the humerus above the epicondylus medialis. It becomes narrower as it passes downwards to be inserted by a tendon into the os semilunare and naviculare. The muscle is much stronger in males than in females, and the crest from which it takes origin is correspondingly larger in the former sex (p. 42). Tendinous fibres connect it with the following muscles:-

58. M. flexor carpi II 8. ulnaris (Fig. $\left.74 F c^{\prime}\right)$.

Dugès, epitrochlo-carpien, n. 84 .

This muscle represents the flexor carpi ulnaris or ulnaris anterior, and is close to the inner side of the foregoing. It arises from the epicondylus medialis, being connected by fibres with the Hexor Nigitorum communis, and is inserted into the os nariculare. 
59. H. flexor digitorum communis (Figs. 75, 76, 77 Fil).

Dugès, epitrochlo-sous-phalangettien, n. II 8 .

This muscle lies most internally, and corresponds to the m. flex'm aligitorum sublimis of man. It arises in common with the foregning muscle from the epiconlylus metialis, and runs downwards to the palm of the hand. At its entrance into this it diminishes and passes into the flat aponeurosis palmaris. (See hand, B.)

60. M. Alexor antibrachii melialis (Ecker), (Fig. 75 Fa).

Dugès, epitrochlo-sous-radial, n. 79. (Frequently described as the pronutor rolundus, a description which cannot be retained, as the implied movement does not occur in the frog.-Ecker.)

This muscle lies deeply on the inner side of the forearm, covered by the flexores carpi; it arises tendinously from the epicondylus medialis and is inserted into the inner surface of the radial side of the radio-ulnar as far as the inferior articular extremity.

61. M. Hexor antibrachii lateralis superficialis (Ecker), (Figs. 74, $75 \mathrm{Fa}^{\prime}$ ).

Dugès, premier ex-huméro-radial, n. 76 . (Usually described as supinator longur, this, for reasons similar to those in the case of m. flexor antibrachii medialis, cannot be retained.)

The situation of this muscle corresponds with that of the supinator longus of man; it lies to the outer side of the tendon of the $m$. sternoraliulis, and arises by tro heads, the one, above from the outer edge of the humerus, the other deeper from the epiconlylus lateralis. They unite and pass into a tendon which, running over the lower articular extremity of the radioulnar, is partly attached to the carpus and partly connected with the tendon of the m. extensor digiti II proprius longus. From its position and insertion, this muscle evidently flexes the forearm and extends the hand. Fig. 75 .

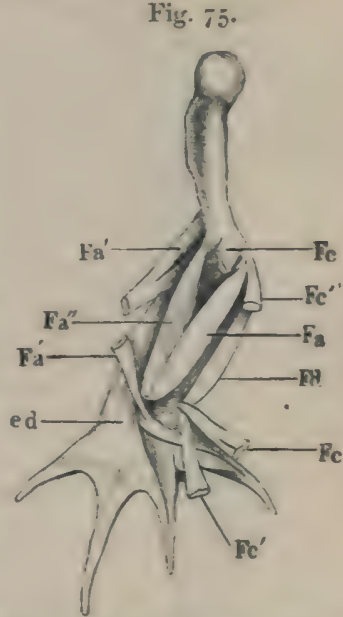

Muscles of the right arm of Rana esculenta, deep laver.

ed Extensor digit. onumunis.

$F a$ Flexwr antibrachii medialis.

Fa' Flexur antibrachii lat. super fivialis.

Fa" Flexor antibr. lat. profundus.

Fe Flexor enrpi radialis.

Fe Flexor carpi ulnaris.

Fd Flexur digitorum eomnunis.

62. M. Hexor antibrachii lateralis jprofund us (Ecker), (Fig. $75 \mathrm{Fa}^{\prime \prime}$ ).

Dugès, epicondylo-sus-radial, n. 78.-Klein, flexor antibmehoii. (S'spinat. brevis sutt.)

This muscle arises under cover of the foregoing, from the epicondylus lateralis of the outer surface of the humerus, it becomes 
broader and is inserted into the whole length of the lower (volar) ridge of the radio-ulnar. It is a powerful flexor of the forearm.

\section{(II.) Muscles of the extensor surface.}

63. M. extensor digitorum communis longus (Fig. 75 ed).

Dugès, huméro-sus-digital, n. 95 .

This muscle lies on the outer border of the forearm; it arises in common with the short head of the flexor antibr. lateralis superficialis from the epicondylus lateralis, and from the surface above it; it runs downwards along the outer side of the forearm, in order to pass into an aponeurosis on the back of the hand, which expands upon the third, fourth, and fifth fingers, and ends between them in a free concave border. This aponeurotic expansion is connected with the tendons of the extensor brevis digitorum.

\section{3*. M. abductor digiti II (i, e. pollicis) longus (Fig. 74 ei).}

*Dugès, cubito-métacarpien, n. $8 \%$.

This musele lies between the foregoing and the flexor antibrachii lateralis superficialis, and appears superficially in the interval between

Fig. 76 .

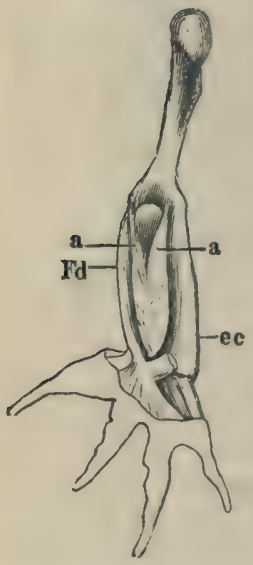

Muscless of forearm of Rana esculenta, dorsal view.

aa M. anconaei.

ec M. extens, digit. communis,

Fd M. flex, digit, them. It arises from the lateral surface of the radio-ulnar, and runs obliquely over the $m$. flexor antibracliii lateralis profundus and the hinder extremity of the radio-ulnar towards the second finger into the metacarpal bones of which it is inserted.

64. M. extensor carpi ulnaris s. ulnaris post. (Fig. $76 e c$ ).

Dugès, epicondylo-sous-carpien, n. 85.-Klein, abductor carpi internus.

This muscle has a somewhat narrow origin from the epicondylus lateralis; during its course through the forearm, where it lies between the $m m$. anconaei on the one side and the extensor digitorum communi on the other, it becomes broader and is inserted into the outer surface of the carpus in the following manner. By one tendinous slip it is attached to the palmar border of the os pyramidale, by a second slip to the outer border of the os capitato-hamatum. This latter slip is usually connected in its dorsal portion with the extensor digitorum communis brevis. 
65, 68. M. anconaei s. extensores antibrachii (Fig. 76 aa).

Dugès, epicondylo-cubital and epitrochlo-cubital, n. 80, 8 r.

Both these muscles lie on the extensor side of the forearm; they spring, the one from the epicondylus lateralis, the other from the epicondylus medialis; converging, they run downwards, enclose the olecranon, and are inserted into the upper (dorsal) border of the ulna, each forming a penniform muscle. They are extensors of the forearm and assist the m. triceps.

\section{Muscies of the Havd.}

(I.) Muscles on the palmar surface.

(I) Muscles common to all the digits.

67. M. flexor digitorum communis and m. palmaris Lrevis (Fig. $77 f d, p b)$.

The origin and course of this muscle has been described above. At its entrance into the palm it suddenly diminishes in size and passes into a triangular aponeurosis, aponeurosis palmaris. Into the outer border of this aponeurosis is inserted the m.palmaris brecis (Fig. $77 p b$ ); this latter muscle arises from the posterior or ulnar border of the lower extremity of the radio-ulnar below the insertion of the mm.anconaei, and runs obliquely downwards to this insertion.

From the lower free border of the aponeurosis a number of muscles arise which will be deseribed with the rest of the digital museles.

(2) Muscles of the rudimentary thumb.

68. M. alductor pollicis (Figs. 77, 78 ap).

Dugès, cubito-pollicien, n. Ioo.

This short muscle arises from the upper border of the lower extremity of the radio-ulnar, passes transversely outwards, and is then inserted into the anterior border of the rudimentary thumb.

69. $M$. adductor pollicis (Figs. 77,78 ad.p).

Dugès, sour-carpo-pollicien, n. IoI.

This lies more superficially than the last, it arises from the palmar surface of the os capitato-hamatum, and is inserted together with the alductor pollicis into the thumb. Several fibres of the extens. dig. II brevis are also inserted into the thumb. As this member is completely covered with skin, the motions of which it is capable are very limited. 
(3) Muscles of the second finger, which serves the purposes of a thumb.

70. M. flexor digiti 11 longus 8. sublimis (Fig. $77 f 2$ ).

Dugès, sous-carpo-phalangettion de l'index, n. 133 .

This is a flat muscle, which arises for the most part by fleshy fibres from the hinder free border of the aponeurosis palmaris, also

Fig. 77 .

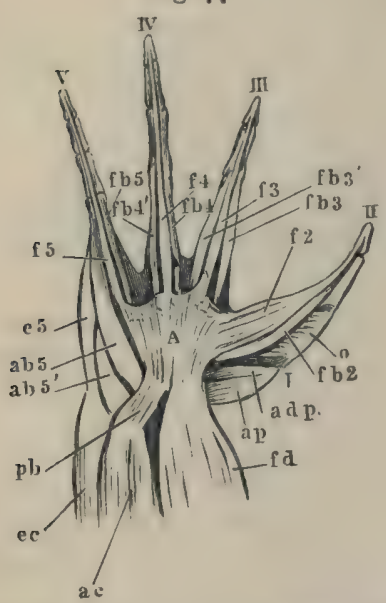

Muscles of hand of Rana esculenta, volar surface, larger than nature.

A Aponeurosis palmaris.

ab5 M. abductor dig. $V$ primus.

abs' M, abductor dig, secundus.

ac MM, anconaei.

adp M. adductor pollicis.

ap M. abductor pollicis,

ec M. extensor digitorum communis.

e5 M, extens, dig. commun. brevis.

$f_{2}$ M. flexor dig. II longus.

$f_{3}$ M. flexor dig. III longus.

$f_{4}$ M. flexor dig. IV longus,

$f_{5} M$. flexor dig. $V$ longus.

$\mathrm{fb}_{2}$ M. flexor dig. II brevis.

$f^{\prime} b_{3}$ and $f b_{3}$ MM. flexures dig. III breves.

$\mathrm{fb}_{4}$ and $f b_{4}$ ' MM. flexores dig. IV breves.

$f^{b}{ }_{5}$ M. flexor dig. V primus.

$f d$ M. flexor digitorum communis.

- M. opponens.

pb M. palmaris brevis,

I First finger, rudimentary thumb.

II Second finger, functions as thumb.

III-V Third to fifth fingers,
Fig. 78.

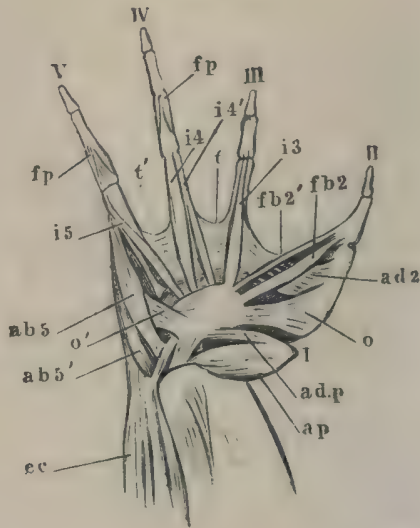

Second layer of muscles on volar surface of hand of Rana esculenta, larger than nature.

$a b_{5}$ M. abductor dig. V primus

$a b 5^{\prime}$ M. abductor dig. $\mathrm{V}$ secundus.

$a d z$ M. adductor dig. II.

$a d . p$ M. adductor pollicis.

ap M. abductor pollicis.

ec M. extensor carpí.

$\mathrm{flo}_{2}$ M. flexor dig. II brevis.

$f \circ z^{\prime}$ M. flexor dig. II tertius,

fp MM. flexores proprii phalangum.

$i_{3}$

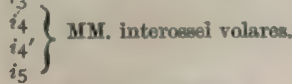

a M. oppopens dig. II.

$o^{\prime} \quad$ M. opponens dig. $\mathrm{V}$.

$t t^{\prime}$ MM. transversi metacarpi.

I-V as in Fig. 77.

by a smaller part from the palmar surface of the os capitatohamatum. It quickly passes into a thin long tendon which is inserted into the terminal phalanx of the thumb (second finger). 
71. M. flexor digiti 11 brecis s. profundus (Fig. $77 f^{\% 2}$ ).

Dugàs, sous-carpo-phalangien de l'index, n. roa.

This flat muscle, covered by the preceding, has a tendinous origin from the palmar surface of the os capitato-hamatum. together with one head of the flexor sulblimis, and is inserted into the basal phalanx.

72. H. flexor aligiti II tertius (Fig. $78 \mathrm{fl}^{\prime} \mathrm{z}^{\prime}$ ).

Dugès, tendini-phalangien de l'index, n. 103.

A small, thin muscle which arises close to the foregoing from the os rapitato-hamatum, and is inserted into the basal phalanx (see below, $m$. interossens volaris $I$ ).

73. M. alductor digiti II (Fig. 78 ad 2).

Dugès, métacarpo-métacarpien de l'index, n. 90.

This muscle represents the alliuctor pollicis of man; it arises from the base of the third os metacarpal and is inserted into the metacarpal of the second finger, which latter it draws towards the third finger.

74. $M$. opponens digiti $I I$ (Figs. 77 and 780 ).

Dugès, sous-carpo-métacarpien de l'index, n. $9 \circ$.

This muscle represents the muscle of like name in man. It arises from the palmar process of the os capitalo-hamatum by a narrow tendon and passes into a broad, flat musele, which is inserted into the under surface and outer border of the metacarpal of the second finger throughout its length. It has, undoubtedly, the same action as the corresponding muscle in man.

(4) Muscles of the third finger.

75. M. Alexor digiti III longus s. sublimis (Fig. $77 f_{3}$ ).

The smaller portion of this muscle arises from the free border of the aponeurosis palmaris, the chief portion, together with the flexor brevis, from the palmar surface of the os cajitato-hamatum. The two portions pass into one long tendon, which is inserted into the last phalanx.

76, 77. МH. flexmex digiti III breves s. profundi I, II (Fig. $77 f^{\prime} l_{3}$ and $\left.f^{\prime} 3^{\prime}\right)$.

Dugès, tendini-phalangiens du medius, n. 104, 105.

These two muscles arise in part from the free border of the aponeurosis palmaris, in part from the volar surface of the os cajitalohamatum, and pass backwards on either side of the muscle last described, to be inserted into the basal phalanx. Dugès regards these as analogues of the $\mathrm{mm}$. lumbricales. 
78. M. flexor metacarpi dig. III.

This is a somewhat strong musele, which arises by fleshy fibres from the palmar surface of the os capitato-hamatum; and is inserted into the palmar surface of the metacarpal bone.

(5) Muscles of the fourth finger.

79. M. Hexor digiti IV longus 8. sublimis (Fig. $77 f_{4}$ ).

It arises at the free border of the aponeurosis palmaris, and is inserted into the terminal phalanx by a thin tendon.

80, 81. MM. flexores digiti IV breves s. profundi I, II (Fig. $77 \mathrm{fl}_{4}$ and $\mathrm{fb}_{4}^{\prime}$ ).

Dugès, tendini-phalangiens de l'annulaíre, n. 108, rog.

Dugès regards these also as analogues of the m.lumbricales; they arise on either side of the foregoing muscle from the free border of the aponeurosis palmaris, and are inserted by tendons into the basal phalanx.

82. M. flexor proprius phalangum dig. IV (Fig. $7^{8} \mathrm{fp}$ ).

Dugès, phalango-phalangien, n. II5.

A small muscle which arises by two slips from the palmar surface of the basal phalanx, and is inserted into the base of the middle phalanx.

83. M. flexor metacarpi dig. IV (Fig. 78 i4).

This somewhat strong muscle arises from the os capitato-hamatum, and is inserted into the palmar surface of the metacarpal bone.

(6) Muscles of the fifth finger.

84. M. flexor dig. $V$ longus s. sublinils (Fig. $77 f_{5}$ ).

This corresponds exactly with the corresponding muscle of the fourth finger.

85. M. flexor dig. $V$ brevis (Fig. $77 f b 5$ ).

This muscle arises from the free border of the aponeurosis and is inserted into the basal phalanx.

86. M. flexor proprius phalangum dig. $V$ (Fig, $78 \mathrm{fp})$.

Dugès, phalango-phalangien, n. I 7 .

It corresponds exactly with the corresponding muscle of the fourth finger.

87. M. opponens dig. $V$ (Fig. $78 o^{\prime}$ ).

Dugès, deuxième sous-carpo-métacarpien du digitule, n. 92 .

This muscle has a narrow origin from the palmar surface of the 
or capitato-hamatum, it widens and is inserted into the outer border of the metacarpal of the small finger. It draws this finger towards the thumb.

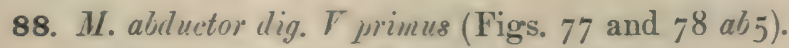

Dugès, sous-pyro-pré-métacarpien du digitule, n. 93.

This muscle arises from the palmar border and the outer surface of the os pyramidale, and is inserted into the basal phalanx by a thin tendon.

89. M. abluctor dig. $V$ secundus (Figs. 77 and $78 a^{b} 5^{\prime}$ ).

Dugès, sous-pyro-post-métacarpien du digitule, n. 94 .

It arises from the posterior part of the os pyramidale, is short, and is inserted into the outer side of the metacarpal.

(II.) Muscles on the dorsal surface.

11. extensor digitorum communis longus (Figs. $75 \mathrm{ed}$ and $77 \mathrm{ec}$ ).

90. M. extensor digitorum communis brevis (Fig. 79 e3, e4, e5).

Dugès, sous-pyro-phalangettien du III, IV, V, n. I24, I28, I3I.

Covered by the foregoing, this muscle arises from the os pyramidale in conjunction with the extensor pollicis and from the os capitato-hamatum. The part destined for the third finger, together with that for the fourth, arises from the os pyramidale, passes obliquely backwards into a tendon which runs along the inner side of the corresponding finger to be inserted into the last phalanx. That for the fifth finger arises from the inner projection of $0 . s$ capitato-hamatum being here attached to the insertion of the $m . e x-$ tensor carpi ulnaris, and is inserted in a similar manner into the terminal phalanx of the fifth finger.

91. II. abuluctor digiti II (i.e. jollicis) longus (Figs. $74 \mathrm{ei}$ and $79 a b .2)$.

For the origin and course of this muscle in the forearm see No. 63. The muscle passes obliquely over the wrist-joint from the little finger towards the inner side and from before backwards, it is inserted into the metacarpal of the second finger (thumb). The place of insertion of this muscle into the metacarpal (compare p. 47) is, in the males, developed into a ridge and process, the muscle itself is enlarged during the breeding season. This muscle abducts the thumb and by this means presses upon the chest of the female when clinging to her. 
92. M. extensor digiti 11 proprius longus (Fig. 79 e2, e2'). Dugès, cubito-radio-sous-phalangien de l'index, n. 96 .

This muscle lies obliquely on the back of the hand, parallel

Fig. 79.

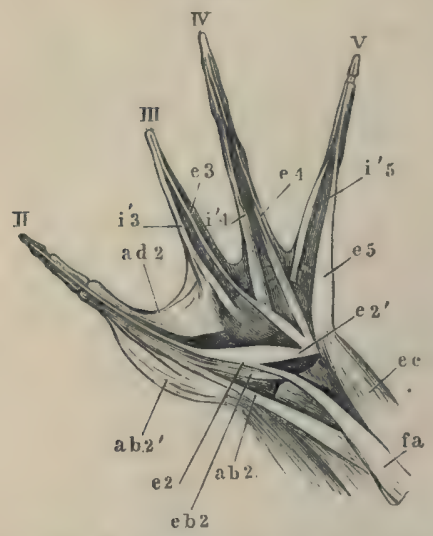

Muscles of hand of Rana esculenta. Dorsal view, twice natural size.

ab.2. M. abductor dig. II longus。 ab. ${ }^{\prime}$ M. abductor dig. II brevis. $a d_{2}$ M, adductor dig. II.

$\left.e_{2}^{\prime}\right\}$ M extensor dig. II longus,

e3 M. extensor digitorum communis e4 $\}$ brevis.

$\mathrm{eb}_{2}$ M. extensor dig. II proprius brevis.

ec M. extensor carpi uInaris.

$f a$ M. Hexor antibr. lat. superficial.

$i^{\prime} 3$

$\left.i_{4}\right\}$ MM. interossei.

II- $\mathrm{V}$ as in Fig. 77 with the $m$. alductor digiti $I I$. It arises by two heads, one from the tendon of the flexor antibr. lat. superf. (n. 60) upon the hinder extremity of the radio-ulnar. This tendon eonceals the hinder end of this bone by means of a patella-like thickening, and sends forth three tendinous prolongations; of these, the one is attached to the ulnar border of the radio-ulnar, the second to the of naviculare, while the third constitutes that portion of the $m$. extens. dig. II proprius long. which is under consideration. The second head arises from the os pyramidale in connection with the extensor digitorum communis brevis (n. 90). The heads unite to form a long muscle, which runs obliquely towards the second finger, passes into a tendon, which, after forming connections by some musctar fibres with the metacarpal, is inserted into the terminal phalanx.

. 93. M. extensor dig. II jroprius brevis (Fig. 79 eb2).

Dugès, sus-luno-phalangettion de l'indez, n. I20.

This muscle lies between the preceding muscle and the abductor dig. II longus. It arises from the os naviculare, and also includes some fibres which arise from the second metacarpal. The tendon runs along the radial side and is inserted along with the last muscle into the terminal phalanx.

94. M. abductor dig. II brevis (Fig. 79 al.2').

Dugès, sus-luno-métacarpien de l'index, n. 88.

This represents the abluct. pollic. brevis of man, lies on the outer side of the hand, arises from the os naviculare, and is inserted into the second metacarpal. 
95. M. extensor dig. III proprius.

Dugès, sus-luno-pbalangettien du médins, n. I22.

This muscle has two heads of origin, from the ns naviculare and lunatum. These form one muscular belly, which rapidly diminishes and passes into a tendon; this, after receiving a few muscular fibres from the second metacarpal, runs to the outer part of the dorsal surface of this finger as far as the terminal phalanx, where it is inserted.

96. M. extensor dig. IV proprius.

Dugès, sus-pyro-phalangettien de l'annulaire, n. 128 .

By a somewhat broad base, this muscle arises from the os nariculare and lunatum. The tendon receives fibres from the fourth metacarpal and runs on the outer half of the dorsal surface of this finger as far as the middle phalanx, where it is inserted.

\section{(III.) MM. interossei.}

97, 98. [a.] MM. transicersi metacarpi (Ecker), (Fig. $78 \ell, t^{\prime}$, all2).

These lie transversely between the metacarpals. There are three; the first has been already described as m. adluctor digiti II (n. 73); the second is stretched between the third and fourth metacarpals, and the third between those of the fourth and fifth fingers.

99, 100, 101. [b.] M.M. internasei volares.

One may regard as such, four long, thin muscles, which take origin near one another on the palmar surface of the carpal bones, and diverge from this towards the second and fifth fingers.

I. The first of these muscles (Fig. $\left.78 f^{\prime} z^{\prime}\right)$ has already been describer above as the $m$. Alexor digiti II tertius (n. 72).

2. The second (Fig. 78 i3) passes from the origin already described to the palmar surface of the basal phalanx of the third finger. finger.

3. The third (Fig. 78 i4) runs, in like manner, to the fourth 4. The fifth (Fig. $78 i_{5}$ ) to the fifth finger .

102 to 108. MM. interossei dorsales.

These arise in common from the metacarpals, and are inserted into the basål phalanx of the corresponding surface on the finger.

1 Whether these muscles may be regarded as mm. interosxei is open to discussion, as they appesr to act more as wm. opponentes. 
I. The thirl finger has two, one to the radial side (Fig. $79 i^{\prime} 3$ ), one to the ulnar side.

2. The fourth finger has three, the third (Fig. $79 i^{\prime} 4$ ) arises from the carpus, and perhaps ought rather to be regarded as an extensor.

3. The fifth finger has two.

\section{MUSCLES OF THE HINDER LIMB.}

\section{Muscles of the Thigh.}

General arrangement (Figs. 80, 8I).

a. The $m$. triceps femoris forms the outer border of the thigh, and extends on to both the dorsal and ventral surfaces. The outer border therefore corresponds with the anterior surface of the thigh of man, in consequence of the thigh in the frog being normally rotated outwards.

b. The $m$. vastus internus $\left(v . i_{0}\right)$ and a portion of the adductor longus $\left(a l^{\prime}\right)$, the sartorius (s), a portion of the adiluctor magnus ( $\left.a d^{\prime \prime \prime}\right)$, and the rectus internus major $\left(r . i^{\prime}\right)$ are found on the inner surface of the thigh.

c. The rectus internus minor $\left(r \cdot i^{\prime \prime}\right)$ forms the inner borter.

d. On the dorsal surface are to be seen, nearest the trunk, the glutaeus $(g l)$, on the outer border the vastus externus (v.e.), the pyriformis and liceps ( $p$ and $l$ ), then the semimemlianosus (sm), and lastly the rectus internus minor $\left(r i^{\prime \prime}\right)$.

e. By reflecting the rectus internus major (compare Fig. 82) there are exposed to view: the semitendinosus (st), the whole length of the arlluctor longus, magnus ( $a d^{\prime}$ and $\left.a d^{\prime \prime \prime}\right)$, and brevis $\left(a d^{\prime \prime}\right)$. By reflecting the triceps, one sees (Figs. 84, 85) the ilio proas (ip), and beneath the semimembranosus, the quarlratus $(q f)$, and capsularis femoris $(\circ)$.

\section{Description of the separate Muscles.}

(A.) Muscles of the dorsal surface.

109. M. glutaeus (Fig. $80 \mathrm{gl}$ ).

Dugès, ex-llio-trochantérien.-Zenker, glutaeus maior.

The tendinous origin of this muscle is found on the outer surface and upper border of the two hinder thirds of the iliac bone. 'T'hence it runs outwards and backwards between the head of the m. vastus externus $(v e)$ on the one side, and the ilio-proas and rectus anticus ( $1 \cdot a)$ 
on the other, to be inserted into a tubercle (trochanter) of the femur.

110. MI. Pyriformis (Fig. $80 p)$.

Cuvier, pyramidal. - Dugês, coccy-fémoral, n. 136.

A narrow, slender muscle, arising from the apex of the coccyx; it passes obliquely outwards and backwards to the thigh, to be inserted deeply between the $m$. vastur externus and the biceps, into the inner surface of the femur, but towards the ventral surface.

11. triceps femoris s. exten80s eruris communis (Fig. 80).

Dugès, pelvi-fémoro-rotulien, 1. $145,146,147$.

This is a large, strong muscle, having three heads of origin, and inserted by a tendon into the tibio fibula. The three heads are the caput longum or the rectus fenoris anticas (r.a.), the caput externum or the tastus externus(v.e.), and the caput interrum or the vostus intermus (Fig. 82 vi); of these, the first is situated on the outer border of the thigh, the second on the dorsal surface, and the third on the ventral surface.

111. [a.] M.rectus femnris anticus (Figs. 80, 82 ra).

This arises from the under (rentral) surface of the iliac bone about its middle and beneath the m. glutaens. The muscular belly quickly passes into
Fig. 80 .

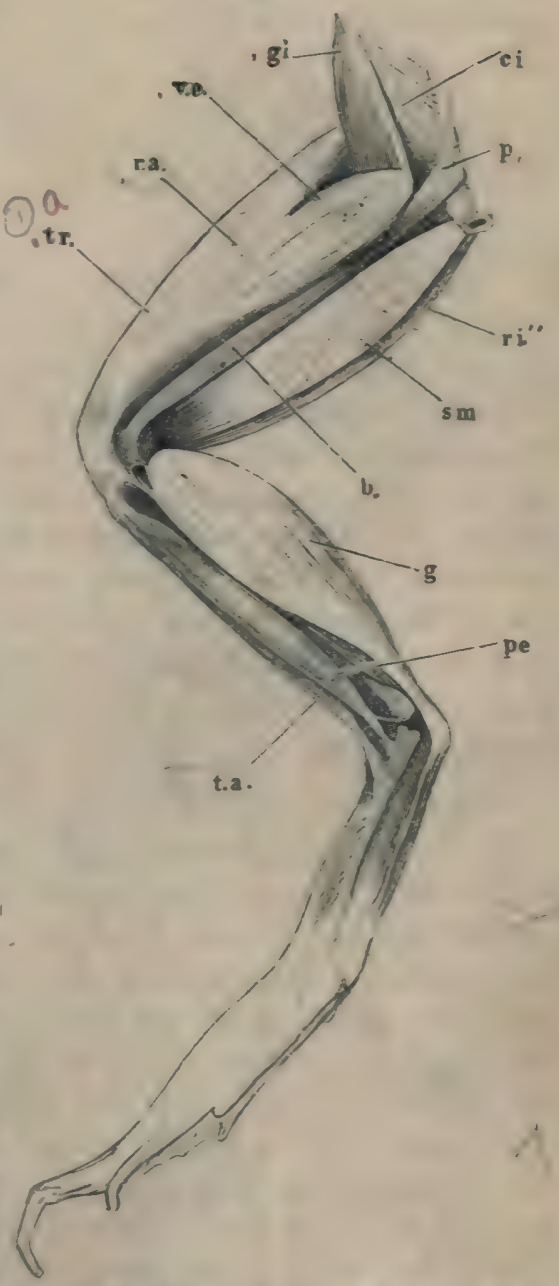

Museles of left thigh of Rama esculwio. Dorsal riew.

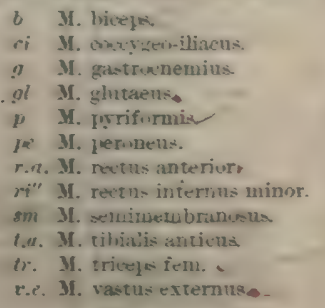

b. Micejk
ri M. shexyetiliacus.

g M. gastronemius

ol M. ghtraens,

p. M. Iyrifurmis

I2: M. jeraneths.

r.n. M. newtus anteriur.

ri" M. reetn- interrins minor.

sm X. seluimewubranusus

t.u. M. tilualis antiena.

tr. M. trive $\mathrm{k}$ fent.

ar belly quickly passes into 
an aponeurosis, which covers the other two muscular masses and combines with their tendons.

112. [b.] M. vastus externus (Fig. 80 v.e.).

It arises from the upper and hinder extremity of the iliac bone (Fig. $42 i l^{\prime}$ ) behind the glutaeus, which here sinks in between this muscle and the rectus anterior.

113. [c.] M. vastus internus (Figs. 81, 82 vi).

It arises from the whole of the under and outer surfaces of the hip-joint capsule, and from tendinous slips which pass from this capsule downwards on the under surface of the muscle, (from the pubis and the femur I have not seen any fibres of origin, as stated by others). Anteriorly the vastus may easily be separated into two heads. The two vasti unite and form one muscular belly, in the formation of which, as above stated, the rectus anticus takes no part. This united muscle passes into a tendon which, without the mediation of a patella, passes over the knee-joint to be inserted into the anterior extremity of the tibio-fibula, and is prolonged into the fascia of the leg.

\section{M. ilio-fibularis s. biceps (Fig. 80 b).}

Dugès, ilio-péronien, n. I49.-Zenker, flexor externus tibiae, p. 42.

'This is a long, somewhat narrow muscle, which lies to the inner side of, and partly covered by, the rastus externus, between which and the semimembranous it is placed. It arises by a tendon between the itio-pssoas and pyriformis from the ilium above the acetabulum and behind the origin of the rastus externus. From here it passes backwards, separated from the vastus extemus by a strong ligam. intermusculare. On the inner side of this muscle, between it and the m. semimembranosus, run the vessels of the thigh and the $N$. ischiadicus. The muscle then divides into two portions, of which one is inserted high up on the inner and under surface of the femur. This is probably the muscle which Klein (l.c., p. 61) describes as the extensor brevis. The other long muscular belly passes into a thin tendon, opposite the hinder extremity of the thigh, it divides into two portions; the anterior is inserted into the dorsal surface of the hinder extremity of the femur, the other into the dorsal surface of the tibio-fibula. Between the two is stretched an arch with the coneavity outwards. This insertion of the biceps is covered by the stronger tendon of origin of the $m$. gastrocnemins (compare Fig. 87). 
115. M. semimembrannsus (Figs. 80, $86 \mathrm{sm}$ ).

Dugès, suz-ischio-poplité, n. I48.-Klein, p. 6o, estensor fomoris sublimis.

This muscle lies on the dorsal surface of the thigh, to the inner side of the bicejs and pyriformix: it is a broad muscle, which takes a tendinous origin from the hinder and upper angle of the sympllyysis axris ilei, and is inserted by a flat tendon into the dorsal surface of the ligaments of the knee-joint, and through these into the tibio-fibula. The tendon is formed rather abruptly from the muscle, and is surrounded (Fig. 86) by the concave arch, which forms the tendon of origin of the gastrornemius $(q . v$.$) . A little behind$ its middle (compre Fig. 81 ) the muscle is divided obliquely into an anterior and a posterior portion by an aponeurotic septum. Is all the fibres are interrupted by this structure, the muscle may very easily be torn through.

(B.) Muscles on the ventral surface.

116. M. artorins (Figs, 81, 82 s).

Dugès, sous-iléo-tibial, n. I 50.-Klein, gracilis.

This long, flat muscle lies along the middle of the ventral surface of the thigh; it arises by a tendon from the anterior inferior angle formed by the symphysis of the innominate bones, and terminates in a tendon behind the knee-joint, forming a kind of pes anserinns in the fascia of the leg, similar to that of the semitendinosus?

117. W. rectus internus major (Ecker), (Figs. 8I r.i', 82 ri').

Dugès, post-ischio-tibial profond, n. 152.-Klein, semimembranosus.

This is a broad and flat muscle, thinned out at either extremity; it occupies the inner half of the ventral surface of the thigh, and is in relation with the allluctor magnus externally and anteriorly, with the sartorius posteriorly, and the rectus minor muscle internally. The muscle arises by a tendon from the pubic symphysis; it covers in its course the semitendinosus, then passes into a strong tendon, which blends with the tendon of the rectus minor, to be inserted by a slip into a process of the tibio-fibula representing the tuberositas tiliae, first passing between the tendons of the sarturius and semimembranasus, which here form an aponeurotic arch; a second slip passes under the tendon of the

I The sarterius has lately been used by Kühne in his researches on the nerveendings in muscle and on muscle contraction withont nerve supply (du Bois-Reymond's and Reichert's Archiv, 1859. Page 314). 
Fig. 81.

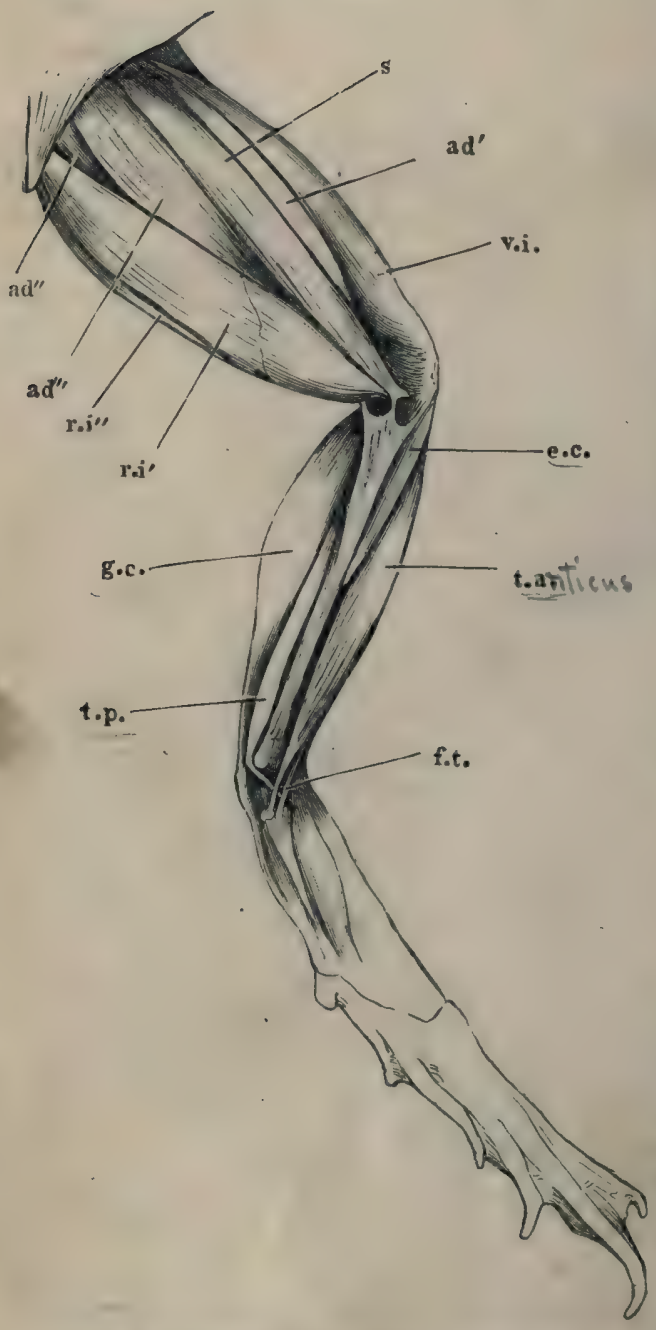

Muscles of left thigh of Rana eseulenta. Ventral surface.

ad' M. adductor longus.

$a d^{\prime \prime}$, M. adductor 'brevis.

$a d^{\prime \prime \prime}$ M. adductor magnus,

- e.c. M. extensor oruris.

f.t. M. flexor tarsi.

- g.c. M. gastrocnemins.

$r, i^{\prime}$ M. rectus internas major:

r. $i^{\prime \prime}$ M. rectus internns minou

8 M. surtorius,

t.a. M. tibialis anticus.

n t.p. M. tibialis posticus.

v.i. M. vastus internus. m. semitendinosus to be inserted into the upper surface of the tibio-fibula, under it passes the $N$. tibialis. A third thread-like tendon passes to the $m$. semimembranosus. Somewhat behind its middle (Fig. 82) the muscle is traversed by an inscriptio tendinea, by which the whole of the fibres are interrupted.

118. M. rectus internus minor (Ecker), (Figs. 80, 8I r.i").

Dugès, post-ischio-tibial superficiel, n. I51.Zenker, flexor tibiae - magnus.-Klein, ischio-tibialis.

Situated entirely on the inner surface of the thigh, this narrow muscle arises by a tendinous band which runs the whole length of the pubic symphysis, and is connected posteriorly with the sphincter ani, anteriorly with the rectus abdominis; posteriorly it passes into a thin tendon which is also connected with the muscle just described (II7). In its course 
this musce is attached to the skin by strands of vessels and connective tissue.

The vastus internus major and minor together undoubtedly correspoy thith rectus internus or gracilis of human anatomy. The rectis ternus major is, however, regarded as corresponding with the anductor magnus by Dugès, and with the semimembranosus by Klein; by considering the position and attachments of these muscles one must arrive at a different conclusion.

\section{MII. add wetores femoris.} $\left.82 a d^{\prime}\right)$.

119. [a] M. adduetor longurs (Fig. Fig. \& .

Dngès, sous-ilio-fémoral, n. I41.

Without further dissection this muscle is only partially visible between the $m$. sartorius and rastus internes (Fig. 8I $a d^{\prime}$ ). The muscle is flat and long, and arises by a tendon from the anterior inferior angle of the pubic symphysis (Fig. 42 s), partially covered by the origin of the sartorius. Thence the muscle passes between the vastus iuternus and the adductor magnus, and finally is inserted below the middle of the femur, together with the latter muscle.

120. [b] M. adductor magnus (Figs. 8I, $82 a d^{\prime \prime \prime}$ ).

- Dugès, sous-ischio-pubi-fémoral (adductor I and 2), n. 142,143 Klein, adductor nagnes and extewsor femoris profundus.

This'muscle is visible between the sartorius and rectus internus major in the anterior half of the thigh, posteriorly it is corered by these muscles. It arises by a tendon from (a) the pubic symphrsis and

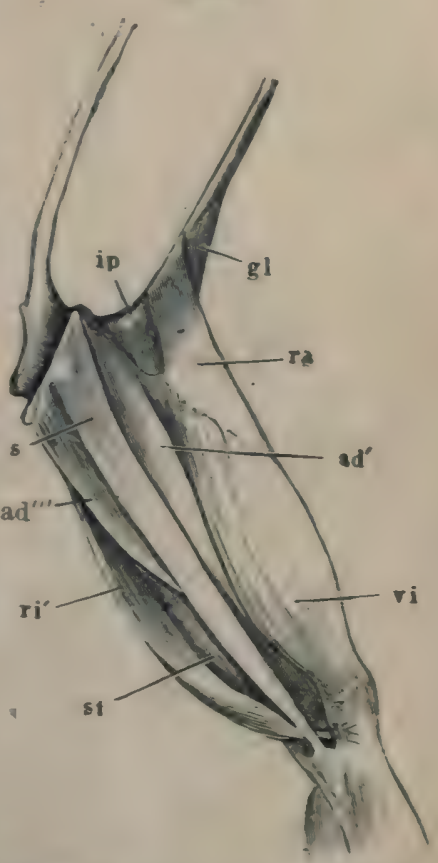

Yuseles of the left thigh of Rana escukentr. Ventral gurface.

ad' M. adthetor longuli

ad"' M. alductur magnus,

gl M. glutiens.

ij. M. illinperser.

ra M. rectus fem antives

ri' II rectls int, majur.

s M. sirtersiuk

s Y. seuitendinesus

ri M. vastus internns ixchii, and is in this position divided into two portions, between 
which passes the tendon of one head of the $m$. semitendinosus (Fig. $\left.838 t^{\prime \prime}\right)$; (b) a second part arises from this same tendon (Fig. $838 t^{\prime \prime \prime}$ ) and joins with the first part. Thus formed the muscle passes to be inserted into the distal half of the inner surface of the femur as far as the condyle. Near its hinder extremity, however, it passes on to the dorsal and outer surfaces, and thus forms a kind of muscular sheath surrounding the distal portion of the bone.

and

121. [c] M. arduetor Ireris (Figs. 8I, 83 arl"),

122. [d] M. pectineus (Fig. 83 pe).

Dugès, sous-pubio-fémoral (analogue of the pectiners, possibly of the add. brevis also).

These two small museles which lie under cover of the sartorius, adduc-

Fig. 83 .

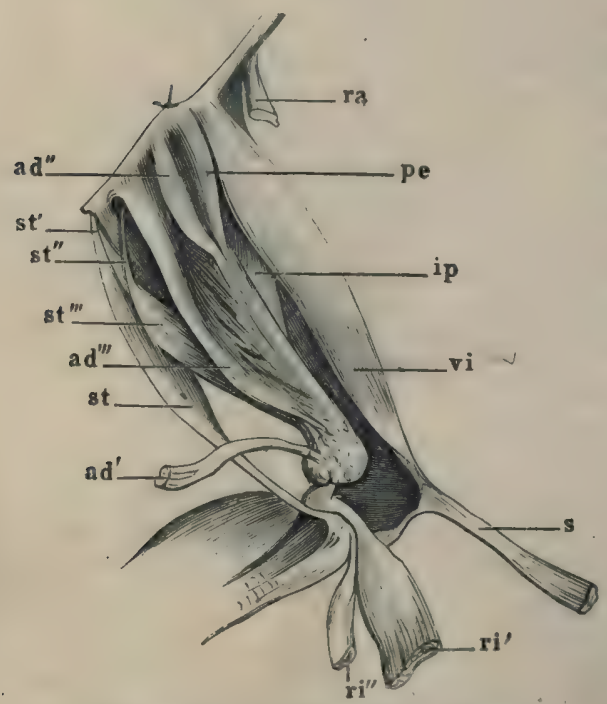

Deep muscles of left thigh of Rana esculenta.

ad M. adductor longus, Rend esc wivin's

- $a d^{\prime \prime}$ M. adductor brevis.

$a d^{\prime \prime \prime} \mathrm{M}$. adductor magnus.

5ip M. ilio-psons.

b. pe M. pectineus.

ra M. rectus anticus.

$\left.\begin{array}{ll}r i & \text { M. rectus internus maior } \\ r i \prime & \text { M. rectus internus minor }\end{array}\right\}$ ent through.

- M. sartorins.

st Belly of m. semitendinosus.

$g t^{\prime}$ M, semitendinosus (cap. posticum).

s $\ell^{\prime \prime}$ M. semitendinosus (cap. anticum).

st" Fibres passing into the sddnctor magnus.

vi M. vastus internus. tor longus and magnus, appear externally as one muscle, but may easily be separated (Fig. 83). They arise close together from the pubic symphysis, and are inserted into the inner surface of the anterior half of the femur. They are not attached to the adductor magnus.

123. M. semitendinosus (Fig. $83 s t, s t^{\prime}, s t^{\prime \prime}$ ).

Dugès, bis - ischio - tibial, n. I53. - Zenker, biceps.

This is a long thin muscle, only visible after removal of the m. rectus internus, by which it is entirely covered. It arises by two long thin tendons, one (caput posticum, $8 t^{\prime}$ ) from the pubic symphysis, the other (caput anticum, $s t^{\prime \prime}$ ) from the hollow between the symphysis and the acetabulum. The latter 
passes through a slit in the adductor magnus, and so affords this muscle another point of origin; then backwards between the adductor magnus and the rectus intermus major and under the lower third of the thigh, and unites with the posterior head of origin. The muscle so formed passes into a thin tendon, and, together with that of the sartorius, forms an aponeurotic arch, connected with the fascia of the leg, under which the tendons of the rectus internus major and minor pass.

(C.) Deep muscles of the thigh.

To these, in addition to the adductor breits, pectineus, and the portion of the biceps already described, belong also the following :

124. M. ilio-jpsoas (Figs. 82, 83, 84 ip).

Dugès, intra-ilio-fémoral (=iliacus and psoas,--Cuvier, Zenker, Kloin, iliacus internms.

The fibres of this muscle take a broad origin from the pelvic surface of the ilium, pass outwards over the lower margin of the

Fig. 84 .

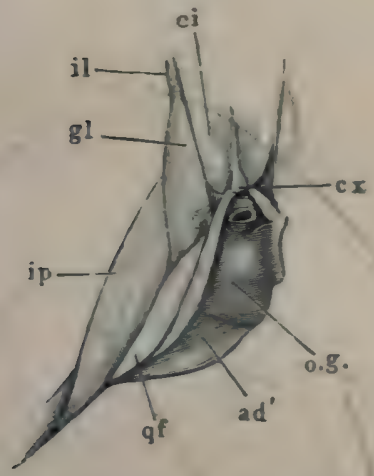

Deep musiles of the left thigh of Runes esculenta. Lursal view.

ad' M. adductor brevis.

ci M. ancegroo-iliawus.

cr Cineys.

al M. gintaeus,

il Ileum.

ij) M. illin-jooas;

ax. M. uburatoriua

if M. quadratus femoris
Fig. 85.

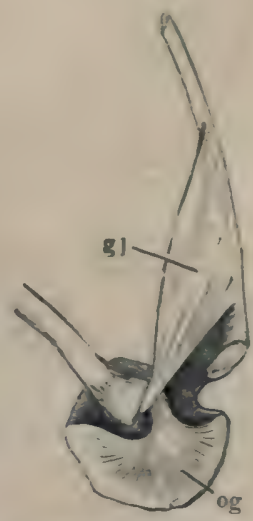

Left half of pelvis of Rana esenkenta. Thigh turned forwands under the abolomen.

ol M. glutaenk.

oy M. ubturaturias.

bone and form a flat muscle with its apex pointed posteriorly. It crosses the hip-joint between the $m$. rectus and castus internus, 
covering the hinder part of the m. glutaeus, and is inserted into the outer surface of the middle third of the femur.

125. M. quadratus femoris (Fig. $84 q f$ ).

Dugès, post-ilio-fémoral (Homologue of the glutaeus maximus), n. I97.Zenker, gletaeus minor, p. 42.

This muscle is of a somewhat elongated, triangular shape, and arises, under cover of the pyriformis, from the ilium behind the acetabulum; it passes backwards over the joint to be inserted into the inner and under surfaces of the femur, between the pyriformis and ilio-psoas; below, it is in direct relation with the adductor brevis.

126. $M$. obturatorius (Figs. $84,85 \mathrm{og}$ ).

Dugès, ischio-pubi-fémoral, n. '39 (?).-Zenker, $m$. capsularis femoris.

This small muscle is deeply situated upon the hip-joint, and covered by all the other muscles that arise from the symphysis. Its origin from the innominate bone extends from the superior posterior angle of the symph. ossis ilii to about the middle of the pubic symphysis; the muscle fills the space between the crest of the symphysis and the acetabulum. The fibres converge to pass into a strong tendon, which is inserted into the posterior and anterior surfaces of the head of the femur. The muscle appears to represent collectively the small rotators of human anatomy, $m$. obturator externus and internus and the gemelli.

\section{Muscles of the Leg.}

General description.

On the outer surface (the anterior of man), covered by the fascia cruris, into which the tendon of the extensor communis cruris or triceps is prolonged, are found the following muscles: nearest to the bone, the $m$. extensor cruris brevis $(e c)$; externally, the $m$. tibialis anticus $(t a)$ and the $m$. peroneus (pe). On the inner surface (the hinder of man) lie the gastrocnemius (gc) and tilialis posticus ( $t p)$, and deeply the flexor tarsi sup. ( $f t)$.

127. M. gastrocnemius (Figs. 80, 8I , 86).

Dugès, bi-fémoro-plantsire, n. I59.

This important muscle arises by two tendinous heads. The one (Fig. $86 g^{\prime}$ ) rather nearer the middle line of the popliteal space, is by far the stronger: it arises by a broad, tendinous expansion, which covers the knee-joint, and is attached to the femur and the tibio-fibula hy anterior and posterior bands respectively; it ends 
internally in a concave aponeurotic arch: the second head is a thin, tendinous slip, arising from the common tendon of the triceps as this lies on the knee-joint. The muscle is thickest near its origin, and then gradually diminishes in size as it passes backwards; the superficial surface is convex, the deep surface is flat. By tracing the tendons of origin, they are seen soon to unite and form a common flat tendinous surface, broad in front, contracted behind; this aponeurosis lies in a plane running obliquely from the deep surface towards the superficial surface, without, however, reaching this. The muscular fibres arise from both surfaces of the aponeurosis, the fibres of the two sides diverging slightly as they pass backwards so as to be inclined at a small angle to each other. The fibres are inserted into a fibrous expansion $(A p)$ which lies on the superficial surface of the muscle; thin and slight in front, this aponeurosis rapidly thickens posteriorly until it passes into the tendo Achillis.

128. M. tibialis posticus (Fig. 86 t.p.).

Dugès, cruro-astragalien, n. 160 .

Covered by the gastrocnemius this

Yuscles of the right leg and foot of Rana eaculenta. Dorsal view.

a.h. M. abductor hallucis.

a.li 3I. abuluetor longus eligiti I.

A.p. Aponenrusis plantaris.

$b$ M. bicejo.

e.t. M. exten*or tarsi.

Fl. M. flexor digitorum III, IV, V longus.

F.S. M. flexor digitorum I and II longus,

g. M. gastrocnemius, drawn towards the right.

If Teadon of origin of gastrocnemins.

L. Liganentum calcanei.

v M. planturis,

r.i. MM, internus main and minor.

s.m. M. semiuernhrumens.

a. M. semitendinus.

1.A. Tendo Achillis.

1.At'. Thiekening of tendo Achillia.

1.p. M. tibialis puntiens.

r.s. M. vastus externus.

r.i. M. vastus internus.

Fig. 86.

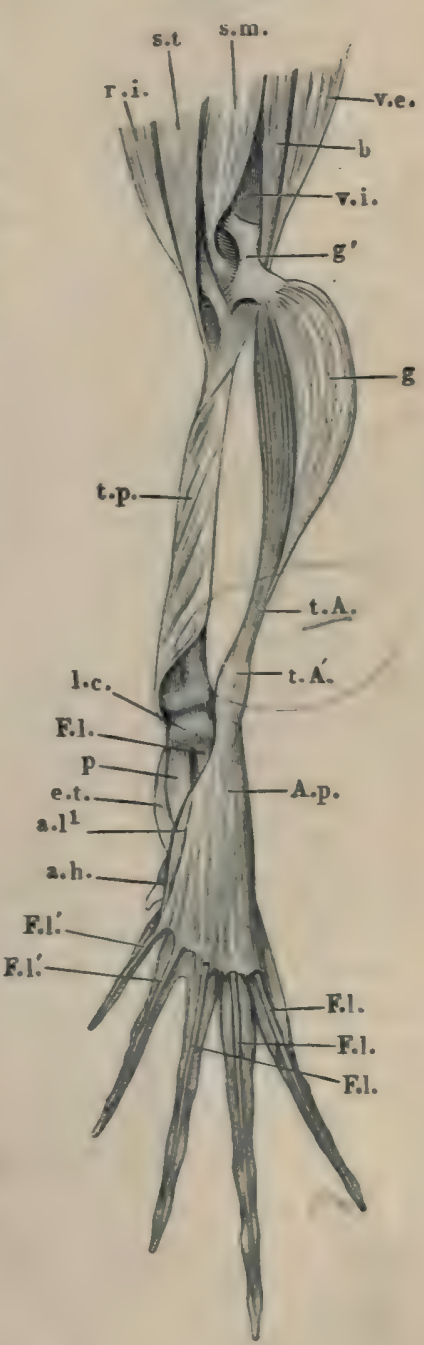


muscle occupies the whole of the inner and upper surfaces of the tibio-fibula, from which it arises by numerous fibres. Opposite the hinder extremity of the bone the muscle becomes free and passes somewhat abruptly into a tendon, which courses behind and over the malleolus internus, on to the dorsum of the foot, and is here inserted into the anterior extremity of the astragalus. I cannot agree with Dugès that this muscle corresponds with the soleus (Ecker).

129. M. extensor cruris brevis (Fig. $87 \mathrm{ec}$ ).

Dugès, pré-témoro-tibial, n. I54.

Covered by the strong fascia cruris, and lying between the m. $t_{-}$bialis anticus and the tibio-fibula, this muscle arises by a long tendon from the inner condyle of the femur; it passes backwards in the groove on the anterior extremity of the tibio-fibula, covered by the tendon of the triceps femoris, and is then inserted by muscular fibres into the outer surface of the tibio-fibula almost as far as the posterior third of the bone. (Dugès regards this muscle as the upper, i.e. anterior, portion of the tibialis anticus.)

\section{M. tibialis anticus (Figs. 80, 81, 87 ta).}

Dugès, pré-fémoro-astragalien and pré-fémoro-calcanien, n. I 56 and 157 ; the former he regards as one part of the tib. anticus, the latter as the peroneus longus $I$.-Zenker, tib. ant, biceps.

The tendon of origin of this muscle is attached to the femur near the tendon of the m.extensor cruris brevis, and to the joint-ligaments. The muscle is placed under the fascia cruris, its long tendon of origin passing beneath the tendon of the triceps in a special sheath through the joint; the tendon then gains a muscular belly . which bifurcates at about the middle of the leg, forming two muscular masses, coursing along the outer and the inner side of the leg respectively. The latter is inserted into the dorsal surface of the astragalus by a tendon, and the former into the dorsal surface of the calcaneus in a similar manner. The muscle extends the foot and flexes the tarsus; the latter movement is very distinct on account of the insertion of the muscle being so near the hypomochlion.

y 131. M. flexor tarsi anterior (Ecker), (Fin. 87 Fl).

Dugès, ex-tibio-astragalien, n. 155.-Zenker, tibializ aulicus simplex.

This musele arises where the insertion of the extensor cruris bret ceases, from the middle of the under surface of the tibio-fibula, and passes backwards between the two tendons of the m. tibialis anticus along the outer side of this muscle, to be inserted by a tendon 
into the inner side of the anterior articular extremity of the astragalus and the fascia dorsalis pedis.

× 132. M. peroneus (Figs. 80 pe, $87 p)$.

Dugès, génio-péronéo-calcanien, n. 158 .

'This is a strong muscle which is attached by a long tendon of origin to the hinder extremity of the femur and the ligaments of the knee-joint. The tendon runs in a sheath through the joint and posteriorly becomes muscular; the muscle passes downwards on the outer side of the tibio-fibula to be inserted into the malleolus externus of this bone and into the anterior extremity of the calcaneus. It has an action similar to that of the $m$. tibialis anticus.

\section{Musches or the Foot.}

A. Mugcles on the Plantar Surface.

133. Aponeurosis plantaris (Fig. 88 A.p.).

As already mentioned, the tendon of the $m$. gastrocnemius is, at the heel, continued into a strong aponeurosis, and possesses at this place a thickening ${ }^{1}$. The aponeurosis is of triangular form, the base directed towards the toes and attached to these. The lateral borders of this triangle are continued into weaker fasciae, which are attached to the two long tarsal bones. The inner border in particular gives a strong bundle of
Fig. 87 .

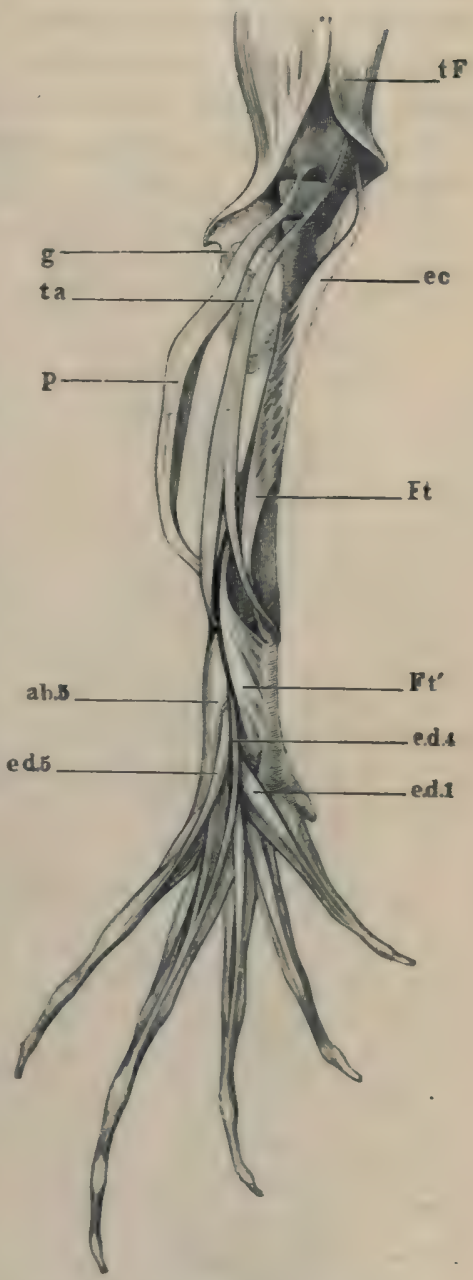

Muscles of log and foot of Rana esculenta, seen from below.

a.b.5 M. abductor dig. V longna.

ce M. extensor cruris brevis.

e.d. . M. extensor digit I longra

P.d.4 M. extensor digit IV longus,

e.d.5 M. extensor digit $r$ longus,

M. M. flexor tarsi anterior.

Fv M. flexor tarsi posterior.

$+g$ M. gastrocmemins.

p M. peroneus.

ta M. tibialis anticus.

if M. triceps femoris:

' Lehmann, Ueber den Knorpel in der Achillessehene des Frosches, Zeitschs. f.

U. Zool. XIV, p. I09. (See also literature on cartilage, Sect. VII.) 
fibres to the astragalus, and is thus connected with the fascia of the dorsum of the foot; externally this aponeurosis is attached to a cartilage (Dugès, os sesamoïde, $l . c ., n .66$ ), situated on the plantar surface of the joint between the calcaneus and the os metatarsi $I V$.

134. Ligamentum calcanei (Ecker), (Figs. 88, 89 l.c.).

If the tendo Achillis be divided and the aponeurosis plantaris

Fig. 88.

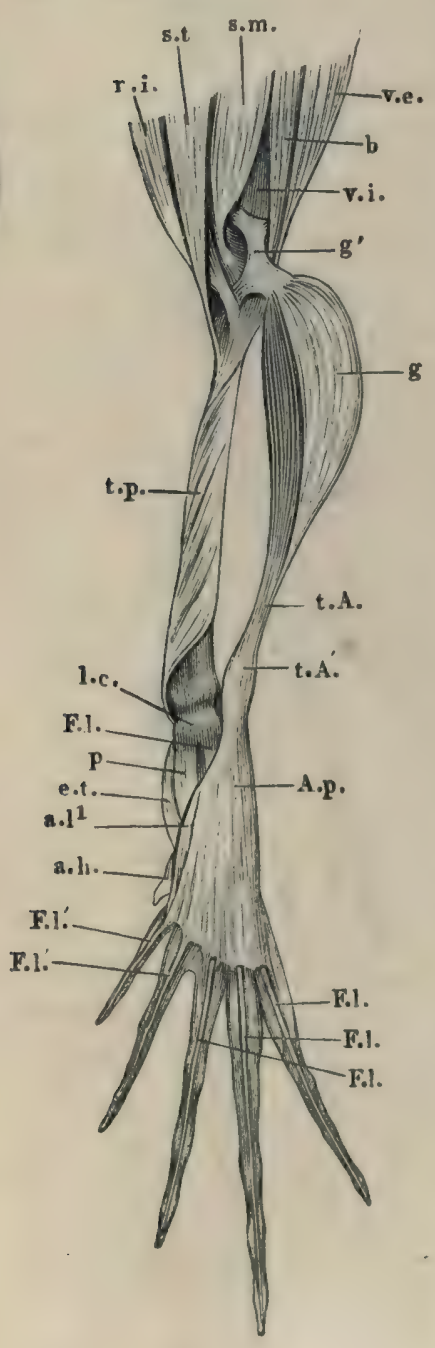
reflected towards the toes, there is seen, arising from the posterior head of the tibio-fibula, in. its whole breadth, a ligament (between the tib. posticus and peroneus). This ligament forms a firm surface on which the thickened portion of the tendo Achillis may move, and which evidently represents the tuberosity of the heel bone. I have therefore named the entire structure the ligamentum calcanei.

Several muscles arise from this ligament, viz. :-

135. $M$. extensor tarsi (Klein), Figs. 88,89 e.t.).

Dugès, tibio-sous-astragalien (regarded by him as the homologue of the tibialis posticus).

Covered by the two succeeding muscles, this muscle arises from the

Muscles of the right leg and foot of Rana esculenta. Dorsal view.

$a, h, \quad$ M. abductor hallucis.

$a, l \pi$ M. abductor longus digiti $\mathbf{I}$.

$A, p$. Aponeurosis plantaris.

b M. biceps.

c.t. M. extensor tarsi.

F.l. M. flexor digitorum III, IV, V longus.

$F . l$. M. flexor digitorum I and II longus.

$g$ M. grstroonemius, drawn towards the right.

$g^{\prime}$ Tendon of enigin of gastrocnemius.

l.c. Ligamentum calcanei.

p M. plantaris.

r.i. MM. internus maior and minor.

s.m. M. senaimembranosus.

s.t. M. semitendinusus.

t.A. Tendo Achillis.

$t, A$ ', Thickening of tendo Achillis.

t.p. M. tibialis postiens.

v.e. M. vastus externns.

$r$. M. vastus intermus. 
ligamentum calcanei, runs backwards, and is inserted into the whole length of the plantar surface of the astragalus. It extends the foot.

\section{M. plantavis (Figs. 88, 89 p).}

This takes its origin from the ligamentum calcanei to the inner side and below the last muscle. It passes backwards and is inserted into the dorsal surface of the aponeurosis plantaris.

137. 11. flexor digitorum III, IT, $V$ longus (Ecker), Figs. 88, 89 P.l.).

Dugès, péronéo-sous-phalangettien (flexor dig. longus).

This muscle also arises from the ligamentum calcane $i$ to the outer side of the m. plantaris. It runs backwards over the aponeurosis plantaris, and at the free margin of this passes somewhat suddenly into a strong tendon, which traverses an aponeurotic canal, formed by fibres of the aponeurosis passing above and below the tendon, from

Muscles of the plantar surface of foot of Rana coculenta, twico natural size.

A.p. Aponenrosis plantaris, divided.

ab.5. 11. abduetor dig. V.

ad.5. M. adductor dig. V.

ad.l.1. M. adductor longes dig. 1.

e.f. M. extensor tarsi.

$\boldsymbol{F}$.5. M. flexor brevis dig. $\mathbf{V}$.

Fl. M. flexor digitorum III, IV, V longas,

F.T. M. Alexor digitorum I, II longus.

8.1.

i.2.

L.3.

7.3\% - Mnsculi lumbricales,

i. $4^{\prime} .1$

l. $4^{\prime \prime}$

l.c. Ligamentum caleanei.

p) M. plantaris.

t.A. Tendo Achillis.

$t, A^{\prime}$. Thickening in toado Achillia

t.p. M. transversus plantas poeterior.

tp. M. transveraus plantse anterior.
Fig. 89.

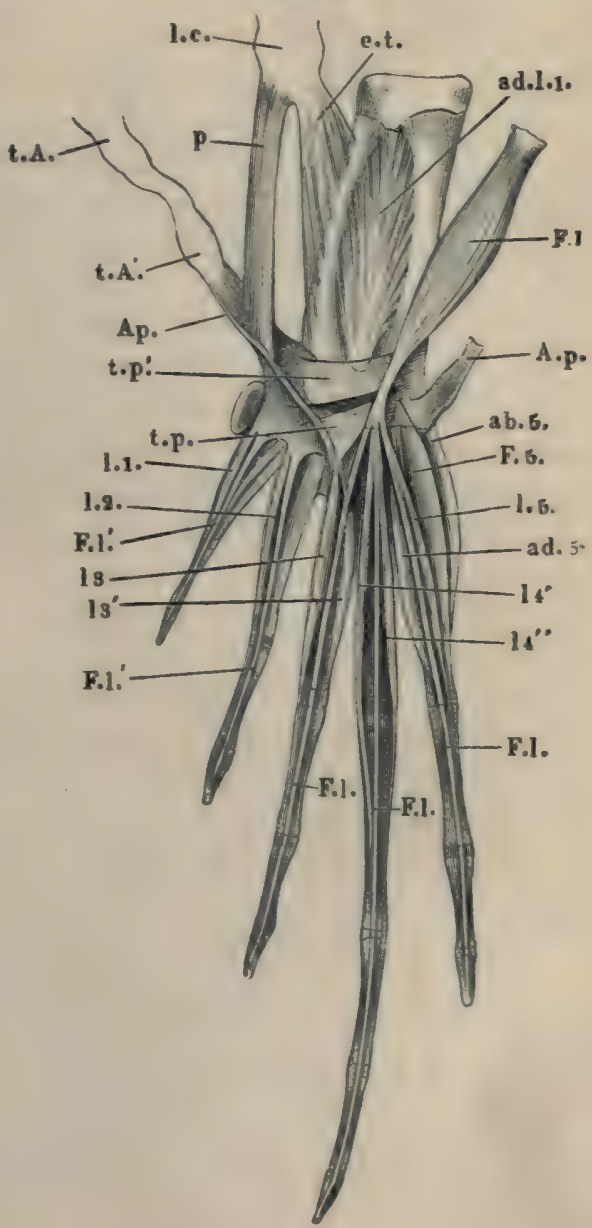


the cartilaginous enlargement in the tendon to the median border of the aponeurosis. The tendon forms three slips for the fifth, fourth, and third toes: these are slightly attached to the aponeurosis, but reach beyond its free border to be inserted into the terminal phalanges of the toes mentioned, and are held down by fibrous bands. (The small $m$. lnmbricales arising from these tendons are described below.)

138. M. flexor digitorum I, II longus (Ecker), (Figs. 88, 89 F.l'.).

The tendons, by means of which the terminal phalanges of the first and second toes are flexed, arise directly from the posterior border of the aponeurosis.

139, 140. MM. transversi plantue (Ecker), (Fig. 89 t.p., t.p'.).

The movements of the aponeurosis and through it the movements of the tendons attached to it are influenced not only by the $m$.gastrocnemius and plantaris, but also by two other museles, which together have been described as the flexor dig. longus internus (Klein), or as the tarso-sous-phalangettien (Dugès, 22 I).

a. M. transversus plantae posterior $\left(t_{.0} p_{0}\right)$.

This takes its origin from the plantar cartilage, widens as it courses backwards and inwards to be inserted into the dorsal surface of the aponeurosis plantaris; from this the tendons for the first and second toes (Hexor dig. longus $I$ and $I I$ ) arise, thus there is no direct connection between the muscular fibres of the two muscles.

\section{b. M. transversus plantae anterior $\left(t_{.} p^{\prime}\right.$.).}

This muscle is covered by the last; broader anteriorly, it arises from the calcaneum, and is inserted to the inner side of the last muscle into the dorsal surface of the aponeurosis. This muscle, like that just deseribed, is not continued directly into the tendon of the flexor of the toes, they cannot therefore be regarded as flexors of the toes.

141 to 149. Musculi lumbricales (Fig. 89 l.I-5).

(A.) From the posterior border of the aponeurosis plantaris arise :-..

(1) M. Tumbricalis digiti $I($ l.1)

Dugès, tendini-sous-phalangien de pouce, n. 185 .

This is inserted into the anterior extremity of the proximal phalanx. 
(2) M. Iumbricalis digiti II (l.2).

Dugès, tendini-sous-phal. du I doigt, n. I 86 (and 187), double scoording to Dugès.

Similarly inserted.

(3 and 4) MLV. Tumbricales digiti III (l.3).

Dugès, tendini-sous-phal. du III doigt, n. I88, single according to Dugès.

One of these $\left(l_{3}\right)$ is inserted into the anterior extremity of the basal phalanx, the other $\left(I 3^{\prime}\right)$ into a corresponding position on the middle phalanx.

(5) M. lumbricalis digiti $1 V$.

Dugès, tendini-sous-phal. du IV doigt.

Inserted into the anterior extremity of the basal phalanx.

(B.) Arising from the tendons of the flexor longus $111, I T, I^{-}$:

(6 and 7) MM. Iumbricales digiti IT (1.4'. and $7.4^{\prime \prime}$.).

Dugès, tendini-sous-phalanginien du IV doigt, n. 201, 202.

The first $\left(l .4^{\prime}\right)$ is inserted into the posterior end of the basal phalanx, the second $\left(1.4^{\prime \prime}\right)$ in a similar position into the second phalanx.

(8) M. humbricalis digiti $V(l .5$.$) .$

Dugès, tendini-sous-phalangien du $\mathrm{V}$ doigt, n. 203 .

This arises from the tendon for the fifth toe, runs backwards as a thin tendon alongside that of the flexor, and is inserted into the middle phalanx.

\section{Special Muscles of the Separate Toes.}

(I.) Muscles of the rudimentary great toe.

150. H. abeluctor halluris (Figs. 88 a.h., 90).

Dugès, tibio-sous-tarsien, n. 163 .

This muscle arises from the inner border of the aponeurnsis plantaris, at the spot where the $m$. plantaris is inserted, it may therefore almost be regarded as a continuation of this muscle; it is inserted into the anterior border of the rudimentary toe.

(II.) Muscles of the great and first toes.

151. M. ald uetor longus digiti $I$ (Figs. 89, 90 arl.l. ).

Dugès, calcanéo-scaphoidien, n. 164.

This powerful muscle arises from the plantar surface of the calcaneum and astragalus; its fibres converge towards a tendon lying in 
its middle, which becomes free towards its posterior end; the tendon passing inwards under the ligamentum tarsi transversum through a groove on the hinder extremity of the astragalus in an arched direction, to be inserted into the os naviculare, which bears the rudimentary great toe and the os metatarsi 1.

(III.) Muscles of the first toe.

152. M. abductor longus digiti I (Figs. 88 al.I, 90 a.b. I).

It takes its origin from the inner border of the aponeurosis plantaris, and lies on the plantar surface of the abiluctor hallucis. Its tendon runs in the hollow which the great toe forms, and is inserted into the inner side of the os metatarsi $I$.

153. M. flexor brevis digiti I (Fig. 90 F.b.I).

A small, thin muscle, which arises from the anterior extremity of the os metatarsi II, and is inserted into the basal phalanx of the first toe. In this small muscle, and also in the $m$. lumbrical. dig. $V$ (Fig. 89 l.5.), the nerve distribution may be very well seen.

154. M. opponens dig. I (Fig. 90 op).

Dugès, sous-metatarso-phalangien du pouce, n. $19^{2}$.

This is situated to the inner side of the preceding muscle, arises from the os metatarsi II somewhat narrow, widens in a fan-like manner towards the $o .8$ metatarsi $I$, into the anterior half of which it is inserted.

(IV.) Muscles of the second toe.

155. M. flexor metatarsi dig. II (Fig. 90 F.m.2).

Dugès, sous-tarso-metatarsien du II doigt.-Klein, extensor metatarsi.

By a narrow origin from the hinder end of the calcaneum, posteriorly this muscle becomes broader and is inserted, somewhat thinned out, into the plantar surface of the second os metatarsi.

156. M. Alexor dig. II proprius (Fig. 90 F.p.2).

Dugès, sous-metatarso-phalangien, n. I94.

It arises from the plantar surface of the os metatarsi 11 , and is inserted by a thin tendon into the plantar surface of the first phalanx.

Dugès describes this and the analogous muscles of the third, fourth, and fifth toes $(F . p .3,4,5)$ as the interossei plantares, a no- 
menclature which, to me, does not appear correct, as these muscles lie entirely on the plantar surface, and do not adduct or abduct the toes, but flex them.

(V.) Muscles of the third toe. 157. M. Alex. metatarsi dig. $I I I$ (Ecker), (Fig. 90 F.m.3).

Dugès, sous-calcaneo-métatarsien du III doigt, n. 174.Klein, extensor metatarsi.

Like the corresponding muscle of the second toe (n. I 55), this arises by a small tendon from the hinder extremity of the calcaneum, runs backwards and is inserted into the plantar surface of the os metatarsi III. The greatest portion of the muscle lies beneath the $m$. transversus metatarsi $(\mathrm{tm})$, the most anterior portion, however, lies above this. Dugès has described this latter portion as a special muscle (n. I76, metatarsométatarsien du III), the same description holds good for the second toe (n. 177, Dugès).

158. M. flexor dig. III propring (Ecker), (Fig. 91 Fp3).

Dugès, sour-métatarso-phalangien du III doigt, n, r95.

Like the corresponding muscle of the second toe, this arises from the plantar surface of the as metatarsi III, and is inserted by a thin tendon into the plantar surface of the anterior extremity of the first phalanx.
Fig. 90.

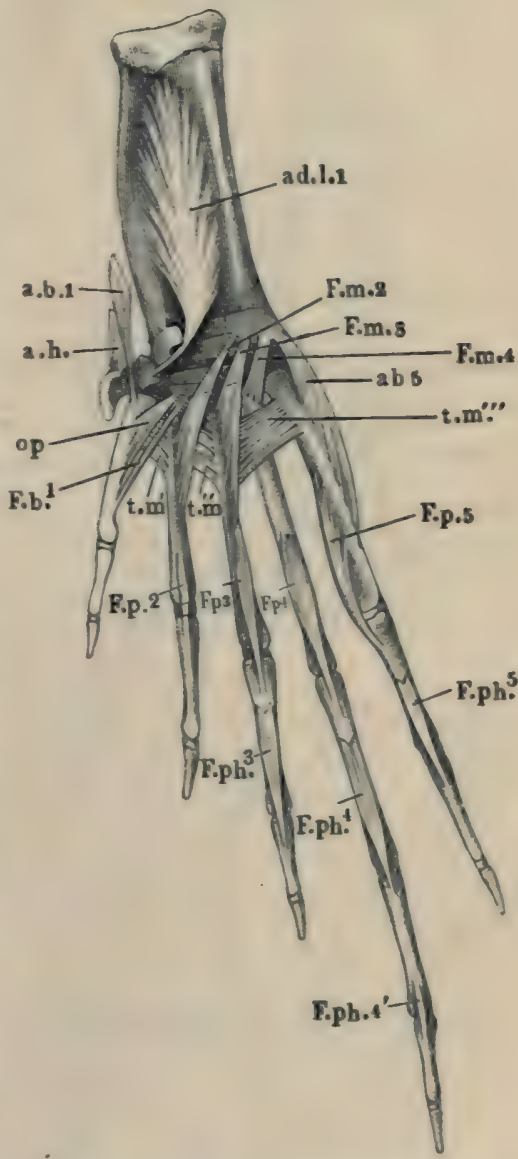

Muscles of plantar surface of foot of Bane esculente.

ab.1 M. abductor longus digiti I.

$a_{5}$ M. abductor digiti $\mathrm{V}$.

adl, 1 M. adductor longus digiti $I_{\text {. }}$

a.h, Y, abductor hallucia

F b.I M. flexor brevis digiti I.

F.s. $, 3,3,4$ M. flexores metatarii II, III, IV.

P.p.2, 3, 4, 5 MM. flexor. proprii digit, $2,3,4,5$.

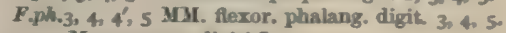
op M. opponens digiti I.

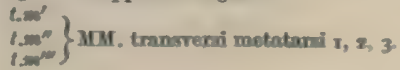


159. M. Alexor phalangum proprius digiti III (Ecker), (Fig. 9I F.ph.3).

Dugès, phalango-phalangien, n. 204 -

This arises by tendon from the plantar surface of the basal

Fig. 91.

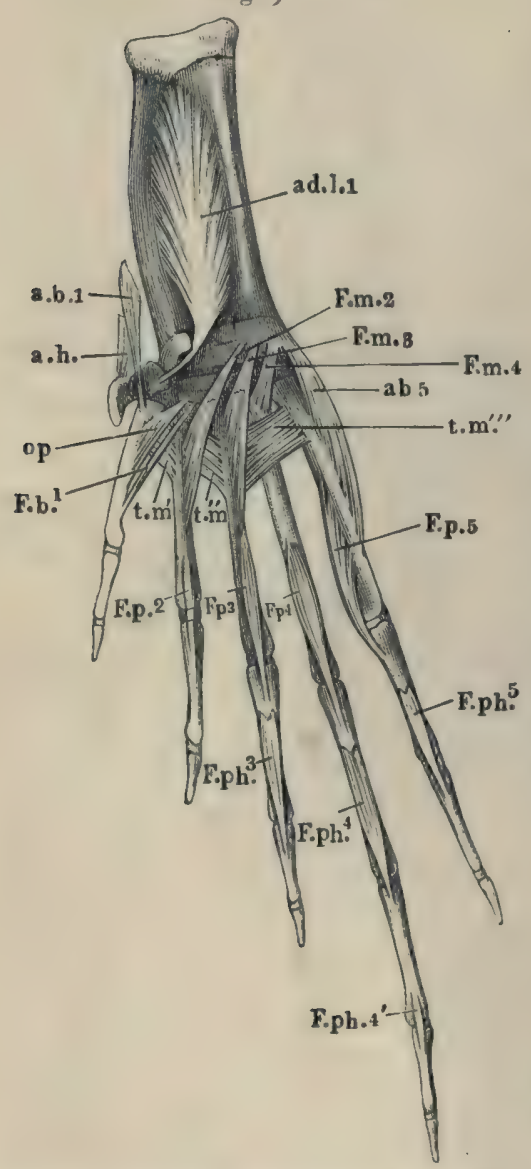

Muscles of plantar surface of foot of Rana esculenta.

a.b.1 M. abductor longus digiti I.

$a b_{5}$ M. abductor digiti V.

$a d .1 . x$ M. adductor longus digiti $\mathrm{I}$.

a.h. M. abductor hallucis.

F.b.I M. flexor brevis digiti I.

F.m.2. 3, 4 M. flexores metatarai II, III, IV.

F.p.2, 3, 4, 5 MM. flexor. proprii digit. $2,3,4,5$.

F.ph.3, 4, 4, 5 MM. flexor. phalang. digit. 3,4 , 5 . op M. opponens digiti $\mathbf{I}$.

$\left.\begin{array}{l}t . m^{\prime} \\ t . m^{\prime \prime} \\ t . m^{\prime \prime \prime}\end{array}\right\}$ MM. tranavenai metatansi $x, 2,3$. phalanx, and is inserted into the anterior extremity of the terminal phalanx.

(VI.) Museles of the fourth toe.

160. M. flexor metatarsi sig. IV (Fig. 91 F.m.4).

Dugès, métatarso-métatarsien, n. I75.

Similarly to the corresponding muscle of the third toe, this one arises from the hinder extremity of the calcaneum, and is inserted into the anterior portion of the plantar surface of the os metatargi $I V$, but not into the greater portion of this surface, as in the second and third os metatarsi.

161. M. flexor dig. IV proprius (Fig. 91 Fp4).

Dugès, sous-métatarso-phalangien du IV doigt (interosseus plantaris), n. I96.

The origin and insertion are similar to those of the muscles of the second and third toes.

162. M. flexor brevis dig. IV.

A small muscle, which arises with the $m$. flexor lrevis of the fifth toe, from enlargement of aponeurosis plantaris, and is inserted into the basal phalanx of the fourth toe. 
163. M. flexor phalangum proprius dig. IV anterior (Fig. 9I F.ph.4).

Dugès, phalango-phalanginien, n. 205.

It resembles the corresponding muscle of the third toe.

164. M. flexor phahingum proprius posterior (Fig. 9I F.ph.4').

Dugès, phalangino-phalsagettien, n. 209.

This extends from the plantar surface of the second phalanx to the anterior extremity of the third.

(VII.) Muscles of the small toe.

165. M. abductor dig. $V$ (Fig. 9 I a.b.5).

Dugès, calcanéo-ex-métatarsien du digitule, n. I69.

This muscle arises from the hinder extremity of the calcaneum, and is inserted into the outer surface of the fifth metatarsal.

166. M. arlduetor vig. $T$ (Fig. 89 a.d.5).

Dugès, sous-tarso-in-phalangien, n. I9I.

This arises from the cartilage of the plantar aponeurosis, and is inserted into the hinder end of the fifth metatarsal.

167. M. flexor brevis dig. T (Fig. 89 F.5).

Dugès, sous-tarso-ex-phalangien, n. I90.

Arising from the same place as the preceding, it extends to the basal phalanx.

168. M. flexor dig. T. proprius (Fig. 9I F.p.5).

(Analogues of Muscles, n. I56, I58, I6 1 ; see note at n. 156).-Dugès, sous-métatarso-phalangien, $\mathbf{1}$. I97 (= inteross.plant.).

This muscle arises from the plantar and inner surfaces of the fifth metatarsal, and is inserted into the basal phalanx.

169. M. flexm phalangum proprius (Fig. 9I F.ph.5).

Dugès, phalango-phalanginien, n. 206.

Its origin and insertion are as in the corresponding muscles of the second, third, and fourth toes, n. I59, I63, I64, 169 .

170 to 172. MM. interossei (Fig. 9 I t.m.).

Dugès, 1, 2, and 3, intermétatarsien, n. 1 70, 171, 172.

These are three muscles with their fibres arranged transversely, which oceupy the anterior portion of the spaces between the 
metatarsals, and approximate these. The first arises $\left(t m^{\prime}\right)$ from the edge of the plantar surface of the first metatarsal, and is inserted into the corresponding part of the second: the second $\left(t m^{\prime \prime}\right)$ passes from this point to the third, and the third $\left(t \mathrm{~m}^{\prime \prime \prime}\right)$ to the fifth.

\section{B. Muscles of the Dorsal Surface.}

173. M. flexor tarsi posterior (Ecker), (Fig. 92 F.t.).

Dugès, péronéo-sug-astragal, n. 16x.

This is a strong muscle, which has a narrow origin from the outer side of the tibio-fibula, directly over the distal extremity, and is inserted into the dorsal surface of the astragalus from the middle to the distal extremity.

Muscles of the first toe.

174. M. extensor longus dig. I (Fig. 92 e.l.I).

Dugès, calcanéo-sus-métatarsien du pouce, n. 166 .

This lies to the outer side of and near the foregoing muscle; it arises by a long, strong head from the middle of the calcaneum, runs obliquely backwards and inwards to unite with a small head which arises from the common epiphysis of the astragalus and calcaneum, in common with the $m$. extensor dig. II. The muscle so formed passes into a flat tendon to be inserted into the basal phalanx of the first toe.

175. M. extensor brevis dig. $I$ (Fig. 92 e.b.I).

A small, short musele which arises from the os naviculare and is inserted into the dorsal surface of the first metatarsal.

176. M. abductor trevis dig. I (Fig. 92 a.b.I).

Dugès, ex-tarso-métatarsien du pouce, n. 168.

This small muscle is situated near the preceding; it arises from the first bone of the supplemental toe, and is inserted into the inner side of the first metatarsal.

Muscles of the second toe.

177. M. extensor dig. II longus (Fig. 92 e.l.2).

Dugès, calcanéo-sus-phalangien du II doigt, n. 182 .

This arises from the calcaneum, in common with the m.extensor longus of the third toe, and is inserted into the basal phalanx of the second toe by a tendon. 
178. M. extensor dig. II brevis (Fig. 92 e.l.2).

Dugès, astragalo-sugphalangien du II, n. 183 .

This is partly covered by the preceding muscle: it arises from the astragalus, and unites with the tendon of the preceding muscle.

Museles of the third toe.

179. M. extensor Nig. III longns (Fig. 92 e.l.3).

Dugds, ang-astragalophalangien du médins, n. 199.

This arises with the extensor longus of the second toe from the calcaneum : its tendon unites with that of the following musele.

180. M. extensor dig. III brevis (Fig. 92 e.l.3).

Dugès, astragalo-gusphalangien du médius, n. 181 .

This muscle arises from the astragalus, and is inserted with the tendon of the preceding muscle into the dorsal surface of the basal pha$\operatorname{lan} x$.
Fig. 92.

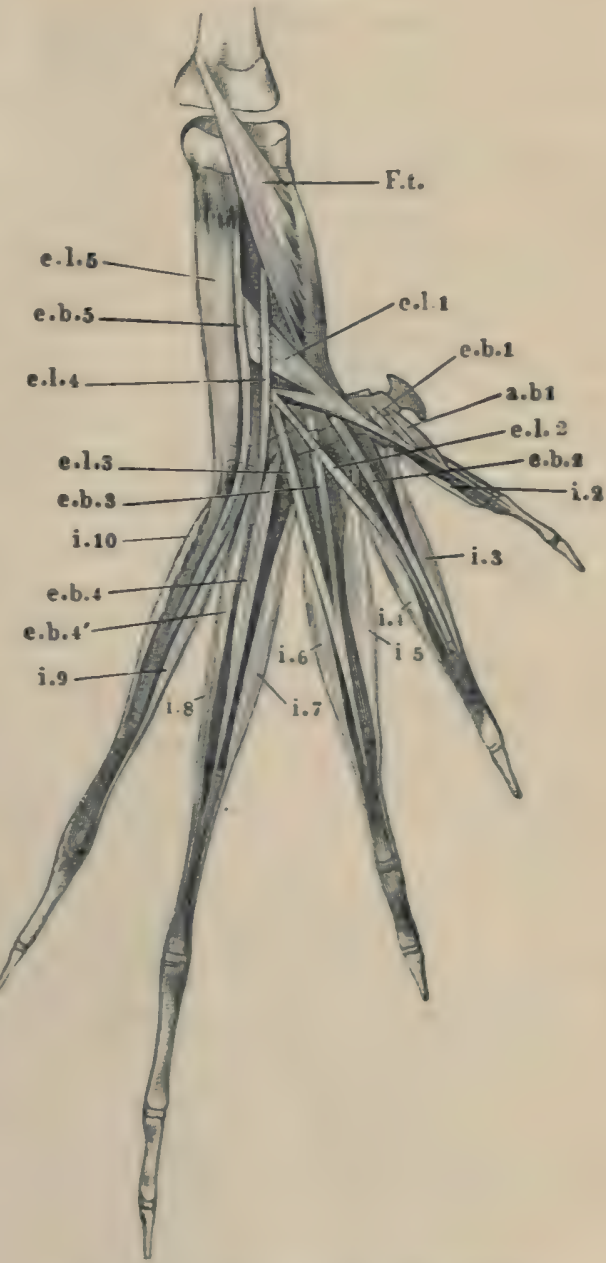

Dorsal view of muscles of foot of Rana exculecta.

a.b., M. abduetor brevis dig. I.

e.b.r M. exteneor brevis dig. I.

c.b.2 M. ertensor brevis dig. II.

e.b.3 M. extensor brevis dig. III.

c.b.4 M. extensor brevis I dig. IV.

e.6.4' M. exteneor brevia 2 dis. IV.

e.b.5 M. extemeor brevis dig. V.

e.h. I M. extensor longus dig. I.

C.L.2 M. exteneor longus dig. II.

e.l.3 M. extensor longus dig. III

e.l.4 M. extenaor longue dig. IV.

e.h.5 M. exteneor longus dig. $\mathrm{V}$.

F.I M. flescor tarki posterior.

$i .2$ to i ro MM. interoseci. 
Muscles of the fourth toe.

181. M. extensor longus dig. IV (Fig. 93 e.l.4).

Dugès, péroneo-sus-phalangien du IV, n. I 78 .

A narrow muscle arising in common with the flexor tarsi inf., but external to it. It is inserted into the tendinous expansion on the dorsum of the toe.

182. MM. extensores dig. IV breves (Fig. 93 e.b.4 and e.b.4').

Dugès, calcanéo-sus-phalangien and sus-calcanéo-phalanginien, n. I79 and 198 .

These two small muscles arise from the calcaneum: one is inserted into the basal phalanx, the other, by means of a long thin tendon, passes along with the tendon of the corresponding $m$. interosseus to the second phalanx, to which it is attached.

Muscles of the fifth toe.

183. M. extensor dig. $T$ longus (Fig. 93 e.l.5).

Dugès, calcanéo-sus-métatarsien, n. 165 .

A strong muscle which covers almost the whole length of the calcaneum ; it arises from the anterior extremity of this bone, runs backwards to the outer side of the dorsum of the foot, and is attached to the outer surface of the fifth metatarsal.

184. M. extensor dig. $V$ brevis (Fig. 93 e.b.5).

Dugès, calcanéo-sus-phalangion du $\mathbf{V}$, n. 180.

This is a long thin muscle, which, together with the muscle last described, arises from the calcaneum and is inserted into the basal phalanx of the fifth toe.

185. M. abductor dig. $T$ brevis (Fig. 93 i.10).

This, the last $m$. interosseus, arises from the outer side of the fifth metatarsal, and is inserted into the hinder extremity of the second phalanx of the same toe.

186 to 195. MM. interossei dorsales (Fig. 93 i.1 to i.10).

First toe.

(I) The analogue of the first $m$. interossens is the $m$. abductor brevis dig. $I$ (a.b.I).

(2) The second $m$. interosseus (i.2) arises from the outer side of the first metatarsal, and is inserted into the outer surface of the second phalanx of the same toe, dorsally to the $m$. opponens and flexor brevis dig. $I$. 
Second toe.

(3) The third $m$. interossens (i.3)takesorigin from the anterior part of the outer surface of the first metatarsal by a thin tendon; it is inserted into the inner surface of the second phalanx by a similar tendon.

(4) The fourth m. interosseus $(i .4)$ arises from the outer side of the second metatarsal, and is inserted into the outer surface of the second phalanx.

Third toe.

(5) The fifth $m$. interossens arises from the outer surface of the second metatarsal, and is inserted by a thin tendon into the inner surface of the second phalanx of the same toe.

(6) The sixth arises from the outer surface of the thind metatarsal, and is inserted laterally by a thin tendon into the hinder extremity of the second phalanx of the same toe.

Fourth toe.

(7) The seventh $m . i n-$ terosens $(i .7)$ arises by a thin tendon from the
Fig. 93 .

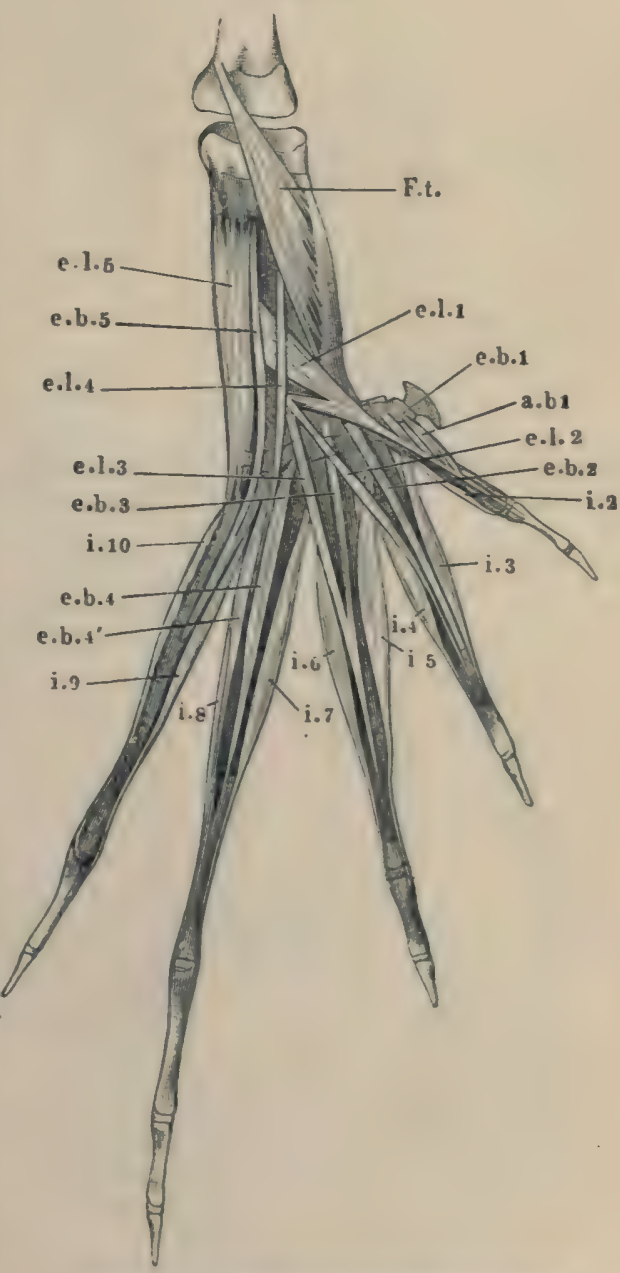

Lorsal view of nuscless of foot of Rara exculenta.

a.b. I M. abductor brevis dig. I.

c.b.1 M. extensor brevis dig 1 .

e.b.z M. extensor brevis dig. II.

c.b.3 M. extunsor brevis dig. III.

e.b. 4 M. extensor brevis $x$ dig. IV.

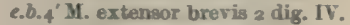

e.b.5 M. extensor brevis dig. V.

e.h.I M. extensor longus dig. I.

C.l.3 M. extensor longus dig. II.

e.l.3 M. extensor longus dig. III.

e.l.4 M. extensor longus dig. TV.

c.l.5 M. extensor longus dig. V".

F.t M. flexor tarai posterior.

i. $z$ to $i .10$ MM, interuseei. 
Fig. 94.

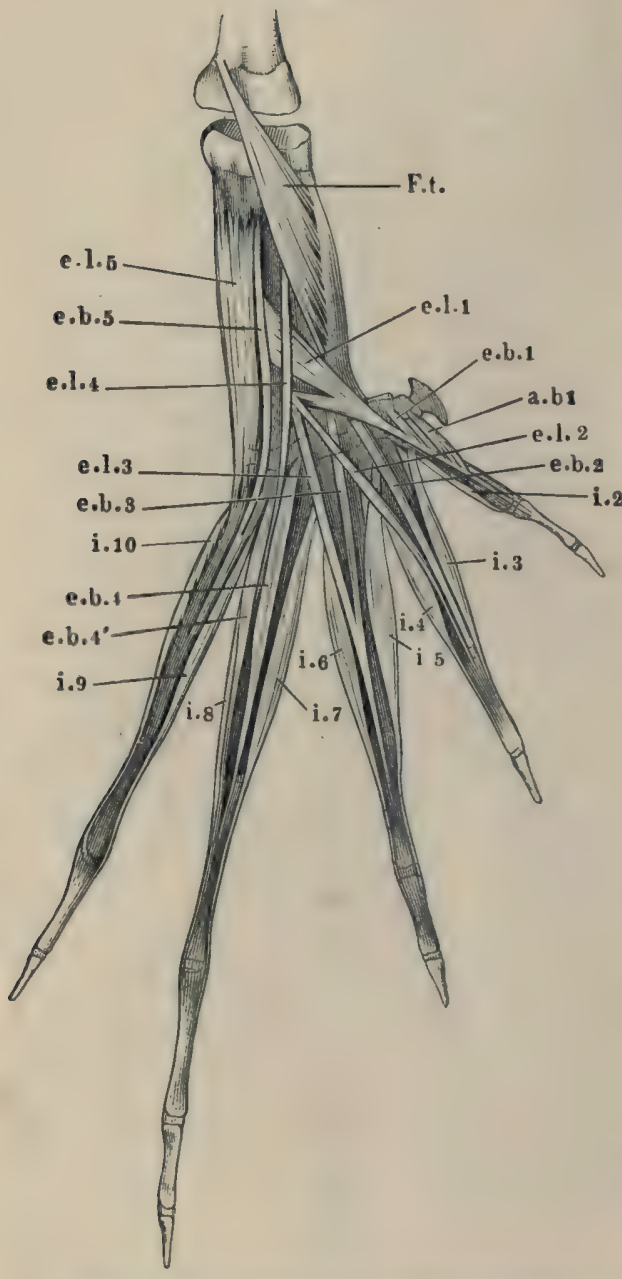

Dursal view of muscles of foot of Rance esculenta.

a.b.I M. abductor brevis dig. I.

e.b.I M. extensor brevis dig. I,

e.b.2 M. extensor brevis dig. II.

e.b.3 M. extensor brevis dig. III.

e.b. 4 M. extensor brevis $\mathrm{x}$ dig. IV.

e.b. ' $^{\prime} \mathrm{M}$, extensor brevis 2 dig. IV.

e.b.5 M. extensor brevis dig. $V$.

e.b.I M. extensor longus dig. I.

e.l.3 M. extensor longus dig. II.

e.l.3 M. extensor longus dig. III.

e.l.4 M. extensor longus dig. IV.

c.l.5 M. extensor longus dig. V.

F.t M. flexor tarsi posterior.

i. 2 to i.ro MM, interossei. hinder extremity of the astragalus, and by fleshy fibres from the hinder extremity of the fourth metatarsal; it is inserted by a thin tendon into the inner surface of the second phalanx of the same toe.

(8) The eighth $m$. interosieus (i.8) takes its origin from the outer surface of the fourth metatarsal and from the inner surface of the fifth : it is inserted into the hinder extremity of the second phalanx.

Fifth toe.

(9) The ninth $m$. interosseus (i.9) arises from the inner surface of the fifth metatarsal, and is inserted into the hinder extremity of the second phalanx.

(10) The tenth $m$. interosseus has already been described as the abductor digiti $T$ brevis (Fig. 94 i.10).

If we take the fourth toe as the axis of movement, the first, third, fifth, seventh, eighth, and tenth $m m$. interossei will abduct from an imaginary line which runs through this toe. The second, fourth, 
sixth, and ninth will adduct towards this line. If we compare them with those of man (in whose case the second toe affords the central line), those of the first group must be regarded as mm. interussei dorsales, of the latter as plantares. Dugès holds all these interossei (with the exception of the first, abuluctor lrevis dig. I) to be mm. interossei ilorsales (métatarso-sus-phalangettiens, n. 2 I0, 2 I I, $212,214,215,216,218,219)$. Those which I have described as flexores proprii digitorum, he regards as interossei volares.

\section{MUSCLES OF THE SKIN.}

196. M. cutaneus pectoris ( $\mathrm{Fig} .95$ c $\%)$.

Dugès, abdomino-guttural, n. 53.-Klein, abdomino-cutaneus.-Zenker, subcutsneus pectoris.

This is an elongated quadrangular muscle, attached by its hinder margin to the side of the xiphisternum, and to the superficial surface of the aponeurosis of the $m$. obliquus externus. The fibres course forwards and slightly outwards to be inserted, at a very acute angle, into the skin : lying between the two museles and attached to them on either side is a thin fascia, which, together with the museles and the septum thoracicum, assists in elosing a triangular space between these structures and the deeper muscles.

The thinness and transparency of this muscle render it especially suitable for the investigation of nerve-terminations ${ }^{1}$.

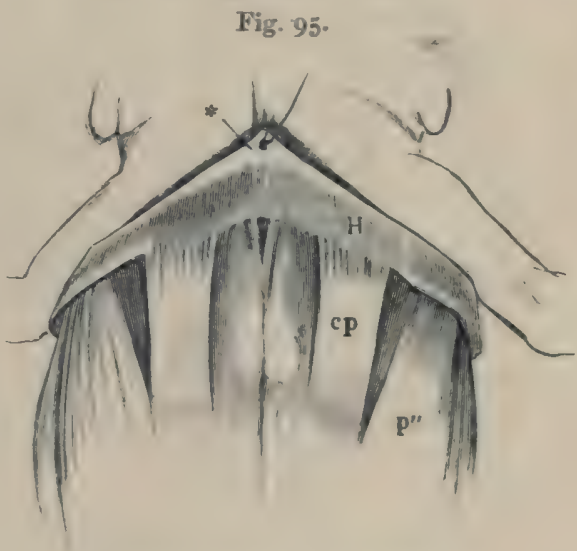

Pectural region of Rund esculioula.

ep M. cutaneus pectoris.

$f^{\prime \prime \prime}$ Port. abuominalis of the $\mathrm{m}$, pecturalis.

197. M. cutanens dorsi (Fig. $96 \mathrm{~cd}$ ).

Dugès, pubio-dorso-cutané, n. 36.-Zenker, cutaneus iliaeus.

This muscle has a narrow origin in the space between the muscles

1 Kölliker, Mikrosk. Anatomie, 1866, vol. II. I. p. 247 ; Reichert, Müller's Archiv, 1851, p. 29, Pl. I ; Källiker, Cntersuchungen über die letzten Endigungen der Nerven in den Muskeln des Frosches; Leipzig, Engelmann, 1862. 
of the belly and of the thigh, and is here inserted into the fasciae, which are attached to the pubic symphysis; it passes inwards and

Fig. 96 .

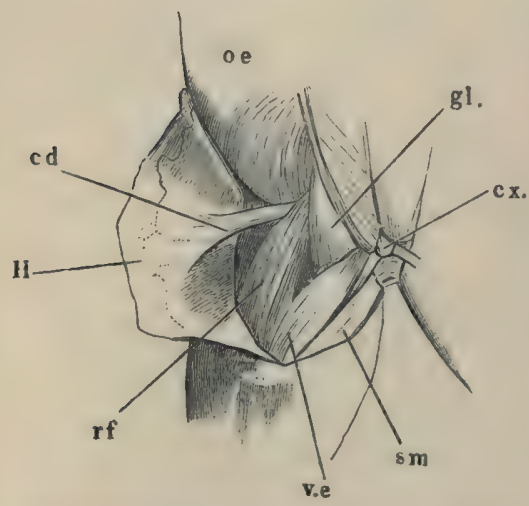

Hind portion of back and thigh of Rana esculenla.
cd M. cutaneus dorsi.
cx. Coccyx.
gl. M. glutaeus.
II Skin reflected to left side.
oe M. obliquus externus.
of M. rectus femoris anterior.
sm M. semimembranosus.
v.e M. vastus externus. upwards to the outer side of the anterior insertion of the m. rectus femoris anticus, then widens and is inserted by diverging fibres into the inner surface of the skin of the hinder portion of the back.

198. M. coccyge-cutaneus. Dugès, coccy-dorso-cutanés; n. 57 .

The muscular fibres which Dugès has described under this name, lie covered by the $m$. pyriformis, behind the $m$. coccygeo-itiacus, ete., and above the muscles of the rectum. They arise from the hinder extremity of the urostyle: they appear to be connected with the rectal muscles, and pass outwards to be attached to the skin.

Among the cutaneous muscles may perhaps be included the m. submaxillaris (p. 62).

The fibrils passing from the flexor tendons to the warty bodies on the plantar surface of the toes are described ${ }^{1}$ with the skin (p. 373).

1 Compare Klein, Beiträge zur Anatomie der ungeschwänzten Batrachier (R. temporaria, L.) : Jahreshefte des Vereins für vaterländische Naturkunde in W iurttemberg, 1850, p. 72 . 


\section{SECTION III.}

THE NERVOUS SYSTEM. 


\section{THE NERVOUS SYSTEM.}

\section{LITERATURE.}

Ahlborn, F., Ueber die Bedeutung der Zirbeldrüse. Zeit. f. wiss. Zool. I884. Vol, XL, pp. 331-337.

Allen, H., The Spinal Cord in Batrachia and Reptilia. Proc. Acad. Nat. Sci. Philadelphia. I883, pp. 56-57.

Arndt, A. W., Untersuchungen über die Ganglienkörper des Nervus sympathicus. Arch. f. mikrosk. Anat. 1874. Vol, X, pp, 208-24I.

Arndt, R., Untersuchungen über die Endigung der Nerven in den quergestreiften Muskelfasern. Arch. f. mikrosk. Anat. 1873. Vol. IX, p. 481.

Arndt, R., Untersuchungen über die Ganglienkörper der Spinalganglien. Arch.f. mikrosk. Anat. 1875. Vol. XI, p. 140.

Arnold, J., Zur Histologie der Lungen des Frosches. Virchow's Arch. 1863. Vol. XXVIII, p. 433.

Arnold, J., Histologische Verhältnisse des Frosch-Sympathicus. Centralbl. f. d. med. Wiss. 1864, p. 657 .

Arnold, J., Ueber die feineren histologischen Verhältnisse der Ganglienzellen in dem Sympathicus des Frosches. Virchow's Arch. 1865. Vol. XXXII, p. I.

Arnold, J., Die Spinalfasern im Sympathicus des Frosches. Arch. f. Anat. und Physiol. 1866, p. 398.

Arnold, J., Das Gewebe der organischen Muskeln. Leipzig, I869; and Chap. IV in Stricker's Handbook.

Arnstein, C., and Gonjaew, K., Ueber die Nerven des Verdauungskanals. Bericht. f. Physiol. u. Histologie. Mittheilung. ans. d. 4 Vers. wissensch. Naturforsch. zu Kasan. Pflüger's Arch. d. ges. Physiol. 1874. Vol. VIII, pp. 6I4-6I5.

Aubert, H., Die Innervation der Kreislaufsorgane, Hermann's Handbuch der Physiologie. Leiprig, 1880. Vol. IV, Pt. I, p. 377.

Axmann, De Gangliorum systematicis structura persitiori eiusque functionibus. Berolini, 1847.

Axmann, Beiträge zur mikroskopischen Anatomie und Physiologie des Gangliennervensystems. I 853, p. 20.

Baculo, B., Nuove ricerche intorno l'apparechio ganglionare intrinseco dei cueri linfatici. Naples, 1885 .

Balfour, F. M., Treatise on Comparative Embryology. London, I880.

Balfour, F. M., Handbuch der vergleichenden Embryologie. Aus dem Englischen von B. Vetter. Jena, I88o.

Beale, L. S., On the Structure and Formation of the so-called Apolar, Unipolar, and Bjpolar Nerve-cells of the Frog. Phil. Trans. 1863, p. 543. (Hyla arborea.)

Beale, L. S., Further observations in favour of the view that nerve-fibres never end in voluntary muscle. Proc. Roy. Soc. 1863. Abstract in Quart. Journ. Micros. Sci. 1863. Vol. XII, p. 668.

Beale, I. S., New observations upon the structure, etc. of certain nervous centres. Proc. Roy. Soc. 1860. Vol. III.

Beale, L. S., On the Distribution of Nerves to the elementary fibres of Striped Muscle. Phil. Trans. 1864, p. 6I1. 
Beale, I. 8., Of very fine nerve-fibres ramifying in certain fibrous tisstes and trunks, and plexuses consisting entirely of very fine nerve-fibres in the bladder of the frog. Beale's Archives of Medicine, 1864. Vol. IV, pp. 19-25I.

Beard, J., The Ciliary or Motor-oculi ganglion and the Ganglion of the ophthalmicns profundus in Sharks. Anatom. Anzeiger. 188;. Vol. II, p. 56j.

Beck, K., Zur Kenntniss der Herznerven. Arch. f. mik. Anat. 1885. Vol. XXIV, pp. II 19 .

Bellonci, G., Intorno alla struttura e alle connessioni dei lobi olfattorii negli arthropodi superiori e nei vertebrati. Atti Acead. Lincei Ann. 279 Mem. Accad. Bologna, Vol. XIII, pp. 555-564: and in Arch. Ital. Biol. 1883; Vol. III, pp. 191-196.

Bellonci, G., Sulla terminazione centrale del nervo ottico nei mammiferi. Mem. Accad. Bologna, Vol. VI, pp. 199-205: and in Arch. Ital. Biol. 1884, Vol. VI, pp. $405-411$.

Bidder, F. H., Die Endigungsweise der Herzzeige des $\mathbf{N}$. vagus beim Frosch. Arch. f. A nat. u. Physiol. 1839, p. I.

Bidder, F. H., Zur Lehre von dem Verhältniss der Ganglienkörper zu den Nervenfasern. Nebst einem Anhange von Dr. A. W. Volkmann. Leipzig, 1847.

Bidder, F. H., Zur Lehre vom Verhalten der Ganglienkörper, u. §. w. Leiprig, 1847 .

Bidder, F. H., Ueber functionelle verschiedene und räumlich getrennte Nervencentra in Froschherzen. Arch. f. Anat. u. Physiol. I 852 , p. I63.

Bidder, F. H., Endigungsweise der Herzzweige des N. vagus beim Frosch. Arch. f. Anat. und Physiol. 1868, p. 1 .

Bidder, F. H., Zur näheren Kenntniss des Froschherzens und seiner Nerven. Arch. f. Annt. u. Physiol. 1866, p. I.

Bidder, F. H., and Kupffer, Cntersuchungen über die Textur des Rückenmarks. Leiprig, 1857 .

Bidder, F. H., and Volkmann, A. W., Die Selbständigkeit des sympathischen Nervensystems, durch anatomische Untersuchungen nachgewiesen. Leipzig, 1842 .

Bidder and Gregory, Beiträge zur Physiologie der Herzbewegung beim Frosche. Dorpat, 1865 .

Bikfalvi, K., Ceber die Hornseheide der markhaltigen Nervenfasern. Orvostermészettudomanyi Ertesito, 1884, p. 133- Abstract in Centralbl. f. d. med. Wiss. 1886, p. 34

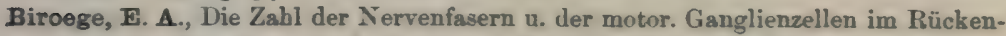
mark des Frusches. Arch. f. Anat. u. Physiol. 1882. Physiol. Abth., p. 435.

Bischoff, Nervi accessorii Willisii anatomia et physiologia. Heidelberg, 1832 .

Blasius, G., Gerardi Blasii Anatomia Animalium. Amstelodami, I68I.

Blattmann, A., Mikrosk. anatom. Darstellung der Centralorgane des Nervensystems bei den Batrachiern. Dissert. Zürich, 1850.

Boll, F., Studj sulle immagini microscopiche della fibra nervosa midollare. Atti della R. secademia dei Lincei, $1876-187 \%$. Vol. II.

Boll, F., Ueber Zersetzungsbilder der markhaltigen Nervenfasern. Arch. f. Anat. u. Physiol. 1877, p. 288.

Bojanus, Testudinis anatomis, 1819.

Bosse, De ganglior. spinal. vi in nutr. radic. poster. nervor. spinal. Dissert. 1859 .

Boveri, T., Beiträge zur Kenntniss der Nervenfasern. Abhandl. d. bayr. Akad. d. Wiss, 1885. Vol. XV, p. 421.

Bremer, D. L., Die Nerven der Capillaren, der kleinen Arterien und Venen. Areh. f. mik. Anat. Vol. XXI. 1882, p. 663 .

Bremer, L., Leber die Muskelspindeln sowie iiber Structur, Neubildung u. Innervation der quergestreiften Muskelfaser. Waldeyer's Arch. IS83. Vol. XXII, p. 2. 
Bromer, L., Ueber die Endigungen der markhaltigen und marklosen Nerven in quergestreiften Muskel. Arch. f. mikrosk. Anat. 1882. Vol. XXI, p. 165.

Brenner, A., Ueber das Verhältniss des nervus laryngeus inferior vagi zu einigen Aortenvarietäten des Menschen und zu dem Aortensystem der durch Lungen athmenden Wirbelthiere überhaupt. His u. Braune's Arch. I883, pp. 373-397.

Budge; J., Ueber den Verlauf der Nervenfasern im Rückenmark des Frosches. Arch. f. Anat. u. Physiol. 1844, p. 160.

Budge, J., Ueber die Bewegung der Iris. (Concerning ganglia of motor-oculi, p. 36.)

Budge, J., Wagner's Handwörterb. d. Physiologie. 1846. Vol. III, p. 451 .

Burdon-Sanderson, J., Circulation of the Blood. Handbook for the Physiological Laboratory. London, 1873 .

Calberla, E., Ueber die Endigungsweise der Nerven in den quergestreiften Muskeln bei Amphibien. Zeit. f. wiss. Zool. 1874. Vol. XXIV, p. I64.

Calberla, સ., Studien über die Entwicklung der quergestreiften Muskeln und Nerven der Amphibien und Reptilien. Arch. f. mik. Anat. 1875. Vol. XI, p. 443.

Carus, Versuch einer Darstellung des Nervensystems und Gehirns, Leipzig, I8I4.

Champness, F., The septum atrium of the Frog and Rabbit. Journ. of Anat. and Physiol. 1874.

Christmas-Dirokinck-Holmfeld, J., Experimentaluntersuchungen über den Bau der Regio olfactoria. Nord. med. ark. 1883. Vol. XV, No. 3.

Ciaccio, G. V., On the nerves of the Cornea, and their distribution in the corneal tissue of man and animals. Proc. Roy. Soc. 1863. Abstract in Trans. Micros. Soc. London, 1863. Vol. XI, pp. 77-93.

Ciaccio, G. V., On the distribution of nerves to the skin of the frog, with physiological remarks on the ganglia connected with the cerebro-spinal nerves. Quart. Journ. Micros. Sei. 1864, Vol. IV, pp. I5-31.

Ciaccio, G. V., Intorno alla minuta fabbrica delle pelle Rana esculenta. Giornale di Scienze naturali ed economiche. Palermo, I866. Vol. II, p. 103.

Clarke, J. Lockhart, Ueber den Bau des Bulbus olfactorius und der Geruchsschleimhaut. Zeit. f. wiss. Zool. I862. Vol. XI, p. 3 I.

Cornil and Ranvier, A Manual of Pathological Histology. London, 188o, p. 359, Fig. 199 (Ganglia of heart).

Courvoisier, G., Beobacht. über den sympathischen Gränzstrang. Arch. f. mik. Anat. I866. Vol. II, p. 13.

Courvoisier, L. G., Ueber die spinalen und sympathischen Zellen des Frosches. Centralbl. f. d. med. Wiss. 1867, p. 897 .

Courvoisier, G., Ueber die Zellen der Spinalyanglien, sowie des Sympathicus beim Frosch. Arch. f. mikrosk. Anat. 1868. Vol. IV, p' 125.

Cuvier, Leçons d'anatomie comparée. and Edit. Vol. II.

Cyon, Ueber die Nerven des Peritoneum. Berichte über die Verhandlungen d. königl. sächs. Gesellsch. d. Wissensch. zu Leipzig. Math.-physik. Classe. 1868. Vol. XX, p. I 19 .

Czermak, J. N., Ueber die Hautnerven des Frosches. Arch. f. Anat. u. Physiol. 1849, p. 252 . Leipzig, 1869.

Czermak, J. N., Ueber die Herznerven des Frosches, Rana temporaria. Arch. f. Anat. u. Physiol. 1851 , p. 160.

v. Darkschewitsch, L., Zur Anatomie der Glandula pinealis. Neurol. Cent. Bl. I886. Vol. V, p. 29.

v. Deen, De differentia et nexu inter nervos vitae animalis et vitae organicae. Diss. inaugur. Lugduni-Bat,, I834.

v. Deen, Over de zijdelingsche Takken dar swervende zenuw van den Proteus anguineus, aus Bijdragen tot de Naturkundige. Wettenschappen, 1834 .

v. Deen, Ueber den Ramus lateralis n. vagi bei den Batrachiern. Arch. f. Anat. u. Physiol. 1834 , p. 477 (abstract from Diss. inaugur. De differentia et nexu inter nervos vitae animalis et vitae organicae). Lugduni-Bat. 
Deiters, O., Tntersuchangen åber Gehirn und Rūckenmark. Braunschweig, $186 ?$.

Denissenko, G., Zur Frage über den Bau der Kleinhirnrinde bei verschiedenen Klassen von Wirbelthieren. Arch. f. mikrosk. Anat. 18\%\%. Vol. XIV, P. 203.

Dietl, M. J., Beobachtungen über Theilungsvorgänge an Nervenzellen. Wiener Sitzungsber. 1874. Vol. LXIX, Pt. III, p. 71 .

Dietl, M. J., Casuistische Beiträge zur Morphologie der Nervenzellen. Wiener Sitrungsber. 1874. Vol. LXTX, Pt. III, p. 80.

Dogiel. J., Die Ganglienzellen und Nerven des Herzventrikels beim Frosehe. Arch. f. miknoek. Anat. 1877. Vol. XIV, p. 470.

Dogiel, J., Die Ganglienzellen des Herzens bei verschiedenen Thieren und beim Menschen. Areh. f. mikrosk. Anat. 18;j. Fol. XVII, p. $4 i$ r.

Dogiel, J., Die Nervenzellen und Nerven des Herzventrikels beim Frosche. Arch. f. mikroek. Anat. 1882 . Vol. XXI, p. 21.

Duméril, A. M. C., and Bibron, G., Erpétologie générale ou histoire naturelle complete des reptiles. Paris, 184 I.

Eberth, Untersuchungen zur normalen und pathologischen Anatomie der Froschhaut. Ieiprig, 1869 .

Ecker, $\mathbf{A}$., Icones physiologicae. Ieiprig. I8:I to 1859 .

Eckhard, C., Beiträge zur Anatomie und Physiologie. Giessen, I860. Vol. II.

Eckhard, C., Experimentale Physiologie des Nervensystems. Giessen, I867, p. 208 (Ganglion cells of heart).

Idinger, Is., Nachtrag zu dem Bericht über Leistungen auf dem Gebiete der Anatomie des Centralnerrensystems. Schmidt's Jahresb. ISS;.

Egorow. W., Ceber die Nervenzellen der Lungen. Centralbl. f. med. Wiss. I8 $; 9$. Vol. XVII, p. 305.

Bichholtz, De piscium atque amphibiorum nudorum lobis opticis atque olfactoriis. Berolini, 1841.

Ingelmann, T. W., Zur Physiologie des Creter. Pflüger's Arch. f. d. ges. Ihysiol. I869. Vol. II, p. 243. (Treats alko of histological details of frog's bladder.)

Engelmann, T. W., Teber die Discontinuität des Axenerlinders und den fibrillären Bau der Nervenfasern. Pflüger's Arch. f. d. ges. Physiol. i85o. Vol. XXII, p. I.

Fingelmann, T. W.. Der Balbus aortae des Froschherzens. PAlüger's Arch. f. d. ges, Physiol. 1882. Vol. XXIX, p. 425.

Fischer, D., Teber die Endigung der Nerven im quergestreiften Muskel der Wirbelthiere, Arch. f. mik. Anat. 18-6. Tol. XIII, pp. 35:-390.

Fischer, J. G., Amphibierum nudorum nèurologiae specimen primum. Berlin, 1843 ; and Arch. f. Anat. v. Physiol. 1844, p. 57.

Fowelin, C., De causa mortis poet nervas ragos dissectos instantia. Inaug. Dissert. Dorpati, 1851.

Frenkel, 8., Xerv und Epithel am Froechlarvenschwanze. Arch. f. Anat. n. Phyviol. 1886. Physiol. Abth, P. 405.

Frey, Handb. d. Histologie u. Histochemie d. Menschen. 3rd Edit., p. 34r. (Ganglia of heart.)

Friedländer, Teber die nervösen Centralongane des Froschherzens. Cntersuch. ans d. physiol. Laborat. an Würzburg. $186 \%$.

Frommann, Leber Structur der Nerrenzellen. Virchow's Arch. 186 4 . Fol. XXXI, p. 129.

Fubini, \$., Gewicht des centralen Nervensystems im Vergleich zu dem Körpergewicht der Thiere, bei R. esculenta u. R. temporaria, Minleschott's Cntersuchungen zur Naturlehre d. Menschen. IS8I. Tol. XII, pp. $4 \Sigma 5-46$ I.

Gad, J., Ueber Centrum und Leitungsbahnen im Ra̋ckenmark des Frosches. Verhandl, der Physiol. Gesellech. zu Berlin, No. 10,18R. Arch. f. Anat. n. Physiol. 
1884, p. 304. Verhandl. d. physick. med. Gesellsch. zu Würzburg. I 884. Vol. XVIII.

Gaskell, W. H., On the augmentor (accelerator) nerves of the heart of cold-blooded animals. Journ. of Physiol. 1884. Vol. V, p. 46.

Gaskell, W. H., and Gadow, On the anatomy of the cardiac nerves in certain coldblooded animals. Journ. of Physiol. 1884. Vol. V, p. 362.

Gaskell, W. H., The Structure, Distribution, and Function of the Nerves which innervate the Visceral and Vascular System. Journ. of Physiol, 1886. Vol. VII, p. I.

Gegenbaux, C., Grundzüge der vergleichenden Anatomie. 1870. 2nd Edition, p. 728.

Gerlach, J., Ueber das Verhalten der Nerven in den quergestreiften Muskelfäden der Wirbelthiere. Sitzungsber. d. phys.-med. Societät zu Erlangen. 1873. Vol. V, p. 97 .

Gerlach, J., Das Verhältniss der Nerven zu den willkürlichen Muskeln der Wirbelthiere. Leipzig, 1874 .

Gerlach, J., Ueber die Nervenendigungen in der Muskulatur des Froschherzens. Virchow's Arch. 1876. Vol. LXVI, pp. 187 223.

Gerlach, J., Das Verhältniss der nervösen und contractilen Substanz d. quergestreiften Muskels. Arch. f. mikrosk. Anat. 1877. Vol. XIII, p. 399.

Giuliani, Sulla struttura del midollo spinale della Lacerta viridis. Memorie della R. academis dei Lincei. Roma, 1878 .

Goette, A., Kurze Mittheilungen aus der Entwicklungsgeschichte der Unke. Arch. f. mik. Anat. I873. Vol. IX, p. 396.

Goette, A., Entwickelungsgeschichte der Unke. Leipzig, 1875.

Golgi, C., Sulla fina anatomia degli organi centrali del sistema nervoso. Milano, 1866.

Golgi, C., Sui Nervi dei Tendini dell' Uomo e di altri Vertebrati e di un nuovo organo nervoso terminale muscolo-tendineo. Estr. dalle Memoire della Reale Acc. di Torino. 1880. Vol. XXXII, p. 29.

Gonjaew, K., Die Nerven des Nahrungsschlauches. Arch. f. mikrosk. Anat. 1875. Vol: XI, pp. 479-496.

de Graaf, H. W., Zur Anatomie u. Entwicklung d. Epiphyse bei Amphibien u. Reptilien. Zool. Anz. 1886. Vol. IX, No. 219.

de Graaf, H. W., Over den bouw der epiphyse bij de amphibien. Tijdschr. der Nederl. dierkundige Vereeniging. 1886. Vol. II, p. I.

de Graaf, H. W., Bijdrage tot de kennis van der bouw ende entwickkeling der epiphyse bij amphibiën en reptiliën. Inaug.-Diss. Leiden, 1886. Abstract in Centralbl. f. d. med. Wiss. 1886, p' 706.

Grant, R., Comparative Anatomy. London, 1839.

Grænt, R., Umrisse der veryleichenden Anatomie von R. E. Grant. Aus dem Englischen von C.C. Sehmidt, M.D. Leipzig, 1842 .

Gruenhagen, A., Ueber ein Endothelialelement der Nervenprimitivscheide. Arch. f. mik. Anat, 1884. Vol. XXIII, p. 380 .

Gscheidlen, R., Ueber Nervenendigung in den glatten Muskelfasern. Arch. f. mik. Anat. 1877. Vol. XIV, pp. 320-332.

Guillot, Exposition anatomique de l'organisation des centres nerveux dans les quatres

- classes d'animaux vertébrés. Paris, $\mathbf{1 8 4 4}$.

Hannover, A., Die Chromsäure, ein vorzügliches Mittel bei mikroskopischen Untersuchungen. Arch. f. Anat. u. Physiol. 1840, pp. 549-556. (Describes the connection between fine fibres and small ganglia in the central nervous system of fish, frogs, and birds.)

Hannover, A., Recherches microscopiques sur le système nerveux. Recherches aur le cerveau de la grenonille, pp. 20-22. Kopenhagen, Paris, and Leipzig, 1844 . 
Harless, Ern., Teber die Functionen verschiedener Parthien des Rūckenmarks der A mphibien. Areh. f. Anst. u. Physiol. I846, p. 74

Hartmann, D. R.. Teber die Endigungsweise der Nerven in den Papillae fungiformes der Froschzunge. Arch. f. Anat. u. Physiol. 1863: p. 634.

Heidenhain, Disquisitiones de nervis organisque centralibus cordis. Dissert. inang. Berul. 1854; and in Arch. f. Anat. u. Physiol. 1858, p. 479.

Hénoque, Du mode de distribution et de la terminaison des nerfs dans les muscles lisses. Arch de l'Anat. et de la Physiol. 1870.

Hensen, $\nabla .$, Ceber die Entwicklung des Gewebes und der Nerven im Schwanze der Froschlarve. Virchow's Arch. 1864. Vol. XXXI, p. 51.

Hensen, V., Teber die Nerven im Schwanz der Froschlarven. Arch. f. mik. Anat. 1868. Vol. IV, p. III.

Hesse, F., Zur Kenntniss der peripherischen markhaltigen Nervenfaser. His $и$. Braune's Arch. f. Anat. u. Physiol. I879. Vol. VI, p. 89. Abstraet in C'entralbl. f. d. med. Wiss. 1880, p. 324 .

His, W., Ceber die Endigung der Gefäsmerven. Virchow's Arch. 1863. Vol. XXVIII, p. 427 .

Hjelt, De nervis cerebralibus parteque cephalica nervi sympathici Bufonis cinerei adnotata quaedam. Helsingforsiae, 1852 .

Hoffmann, C. K., in Bronn's Klassen und Ordnungen des Thierreichs. Leiprig and Heidelberg, I873-1878. Vol. VI. Amphibia.

Holl, M., Ceber den Bau der Spinalganglien. Wiener Sitzungsber. 1876. Vol. LXXII, Pt. III, p. 3 I.

İorn, H., Teber die Endschlingen des Geruchsnerven (Nervus olfactorius) in Rana temporaria Arch. f. Anat. und Physiol. 1850.

Huizinga, D., Untersuchungen über die Innervation der Gefässe in der Schwimmhaut des Frosches. Pflüger's Arch. f. d. ges. Physiol. 1875. Vol. XI, pp. $207-221$.

Huxley, T. H., Article Amphibia. Encyclopaedia Britannica, 9th Edition.

Isquierdo, V., Ceber die Endigungsweise der sensiblen Nerven. Arch. f. mikrosk. Anat. 1880. Vol. XVII, p. 367.

Jacubowitsch, $\mathbf{M}$. N., Terminaisons des nerfs à la périphérie et dans les différents organes ou terminaisons périphériques du gystème nerveux en général. Comptes rendas, 1860. Vol. L, p. 859.

Jantschitz, J., Materialien zur Anatomie der Nerven des Pericardiums. Rudneff's Journ. f. normale v. patholog. Histologie u. klinische Med. St. Petersburg, 18 $\mathbf{j 4}$, pp. 4I $7-442$. (In Russian, Abstract in Centralbl. f. d. med. Wiss. 1874.)

Johnson, A., and Sheldon, I., Note on the Development of the Newt (Triton cristatus). Quart. Journ. Micros. Sei. IS86. Vol. XXVI, p. 573.

Kandarazki, M., Ueber die Nerven der Respirationswege. His u. Braune's Arch. f. Anat. u. Entwickelungsgesch. I881, PP. I - I1.

Kanhel, G., Studien über Innervation der Lymphherzen. Medic. Jahrb. 1886, pp. $392-420$.

Karabanowitsch, D., Teber den Ban des Rŭckenmarkes vom Frosche. Arbeiten der St. Petersburger Gesellsch. der Naturforscher. St. Petersbury, 1872, pp. 402-42I.

Key, A., and Retrius, G., Studien in der Anatomie des Nervensystems. Arch. f. mikrosk. Anat. 1873. Vol. IX, p. 308.

Klebs, E., Die Nerven der organischen Muskeln. Centralbl. f. wiss. Med. 1863, p. 561 .

Klebs, E., Die Nerven der organischen Muskelfasern. Virchow's Arch. 1865. Vol. XXXIH, p. 168.

Klein, E., Beiträge zur Anatomie der ungeschwänzten Batrachier. Württemberger Jahreshefte. 1850, pp. $1-84$. 
Klein, E., Auerbach's Plexus in the Intestine of Frog and Toad. Quart. Journ. Microse. Sci. 1873. Vol. XIII, pp. 377-380.

Klein, E., Some remarks on the finer nerves of the Cornea. Monthly Micros. Journ. I 872 . Vol. VII, pp. I56-164.

Klein, E., On the peripheral distribution of non-medullated nerve-fibres. Quart. Journ. Microse. Sci. 1871. Vol. XI. New Series, p. 405.

Klug, F., Ueber die Herznerven des Frosches. Arch. f. Anat. u. Entwicklungsgesch. I881, pp. $330-346$.

Klug, F., Ueber die Beschleunigungsnerven des Froschherzens. Centralbl. f. med. Wissensch. Berlin, 1881, pp. 945-948.

v. Kölliker, A., Neurologische Bemerkungen. Zeit. f. wiss. Zool. 1849. Vol. I, p. I35.

v. Kölliker, A., Handbuch der Gewebelehre. 5th Edit. 1861, p. I63. (On nervefibres of frog's heart.)

v. Kolliker, A., Vorläufige Mittheil. über den Bau des Rückenmarks bei niederen Wirbelthieren. Zeit. f. wiss. Zool. I858. Vol. IX, p. I.

v. Kölliker, A., Ueber die letzten Endigungen der Nerven in Muskeln des Frosches. Würzburger naturwissensch. Zeitschrift. Vol. III. Sitzungen, 8th and 22nd March, I862.

v. Kölliker, A., Untersuchungen über die letzten Endigungen der Nerven. Zeit.f. wiss. Zool. 1863. Vol. XII, p. 149.

v. Kölliker, A., Histologische 'Studien an Batrachierlarven. Zeit. f. wisa. Zool. 1886. Vol. XII, pp. I-4.

v. Kölliker, A., Ueber die Vitalität der Nervenrohren der Frösche. Würzburg. Verhandl. 1857. Vol. VII, p. I45.

Kollmann, J., Ueber den Verlauf des Lungenmagennerven in der Bauchhöhle. Zeit. f. wiss. Zool. 1859-r86o. Vol. X, p. 413.

Kollmann, J., and Arnstein, Die sympathischen Ganglienzellen des Frosches. Zeitschr. f. Biologie. I866. Vol. II, p. 27 I.

Königstein, I., Beobachtungen taber die Nerven der Cornea und ihre Gefässe. Wiener Sitzungsber. 1878. Vol. LXXVI, Pt. III, p. 37.

Köppen, M., Zur Anatomie des Froschgehirns. Neurologisches Centralblatt. 1888.

Köppen, M., Zur Anatomie des Froschgehirns. Arch. f. Anat. u. Physiologie, 1888.

Korybutt-Daszkiewicz, W., Ueber die Entwicklung der Nerven aus Plasmazellen beim Frosche. Arch. f. mikrosk. Anat. 1878. Vol. XV, p. I.

Krause, W., Die Nervenendigungen in den Froschmuskeln. Internat. Monats. f. Anat. u. Histologie. 1884. Vol. I, p. I94.

Krause, W., Ueber die Drüsennerven. Zeitschr. f. rat. Medicin. Dritte Reihe. Vol. XXIII, p. 60.

Krohn, A., Ueber den Ramus lateralis n. vagi bei niedrigen Amphibien. Fror. Not. 1836 . Vol. XLVIII, p. 1043.

Krohn, A., Ergänzungen der Nachricht über den n. lateralis der Froschlarven. Fror. Not. 1838. Vol. VII, n. 137.

Kühne, W., Die Endigungsweise der Nerven in den Muskeln und das doppelsinnige Leitungsvermögen der motorischen Nervenfaser. Monatsbericht der Königl. Akademie der Wissenschaften zu Berlin, I9 May, 1859.

Kühne, W., Die peripher. Endorgane der motorischen Nerven. Leipzig, I862.

Kühne, W., Zur Lehre von den Endplatten der Nerrenhïgel. Virchow's Arch. 1865. Vol. XXXIV, p. 412.

Kühne, W., Zur Histologie der motorischen Nerven. W. Kühne's Heidelberger Untersuchungen, I879. Vol. II, p. 187. Abstract in Centralbl. f. d. med. Wiss. 1879, p. 405.

Kühne, W., Ueber Nervenendigungen in den Muskeln nach Beobachtungen von M. B. von Syckel. Verhandl, des naturf. Vereins z. Heidelberg, I884. Vol. III, p. 238. 
Kühne, W., Widerlegren der Bemerkung E. du Bois-Reymonds über mehrfache Nerrenendigungen in einer Muskelfaser. Zeitschr. f. Biol. 1884. Vol. XX, pp. $531-539$.

Kühne, W., Ueber das doppelsinnige Leitungsvermögen der Nerven. Zeitschr. f. Biol. 1886. Vol. XXII, p. 305.

Kuhnt, J. H., Die peripherischen markhaltigen Nervenfasern. Arch. f. mik. Anat. 187\%. Vol. XII, p. 137.

Kupffer, De medullae spinalis textura in Ranis. I854 Dissert. inang.

Kutschin, Zur Structur des Nervengewebes. Centralbl. f. d. med. Wiss. 1865, p. 561 .

Küttner, C., De origine n. sympathici ranaram, ex nervorum dissectorum mutstionibus dijudicatar. Dorpat, 1854. Dissert. inang.

Lahousse, $\boldsymbol{P}$., Die Struetur des Nervenplexus in der Vorhofacheidewand des Froschherzens. Arch. f. Anat. u. Physiol. 1886, p. 19.

Langerhans, P., Zur Histologie des Herzens. Virchow's Arch. I873. Vol. LVIII, p. 65 .

Lantermann, A. J., Bemerkungen ǔber den feineren Bau der markhaltigen Nervenfasern. Centralbl. f. d. med. Wiss. 1874, p. 706.

Iantermann, A. J., Teber den feineren Bau der markhaltigen Nervenfasern. Areh. f mikrook. Anat. 1877. Vol. XIII, p. 1 .

Lavdowsky, N., Die feinere Structur und die Nervenendigungen der Froschharnblase. Areh. f. Anat. und Physiol. 1872, p. 55.

Iavdowsky, N., Das Saugadersystem und die Nerren der Cornea. Arch. f. mikrosk. Anat. 1872 . Vol. VIII, p. 538 .

Lavdowsky, N., Zum Nachweis der Arencylinderstructurbestandtheile von markhaltigen Nervenfasern. Centralbl. f. d. med. Wiss. 1879, pp. $86_{5}, 881$.

Lavdowsky, N., Ceber die Furtsiitze dèr Nervenzellen in den Herzganglien. Arch. f. mik. Anat. 1887. Vol. XXIX, p.609.

Lehmann, J. C., Ceber die Nervenendigungen und das Forkommen von mikroskopischen Ganglien in den Gefïsswandungen. Zeit. f. wiss. Zool. 1864. Vol. XIV, pp. $34^{6-35^{2}}$.

Ienhossek, M., Untersuchungen über die Spinalganglien des Frosches. Arch. f. mikrosk. Anat. 1886. Vol. XXVI, pp. 370-453.

Leuret, Anatomie comparée du système nerveux de l'homme et des animaux vertébrés. Paris. Vols. I, II.

Lipmann, Die Nerven der organischen Muskeln. Dissert. Berlin, I869.

Lominsky, T., Zur Frage über die Teilung der Nervenzellen. Centralbl. f. d. med. Wiss. I882, p. 434 .

Longet, Anatomie et Physiologie du système nerveux de l'homme et des animaux vertébré⿴. Paris, 1842.

Lōwit, M., Die Nerven der glatten Muskulatur. Wiener Sitzungsb. 1875. Vol. IXXI, Pt. III, p. 355.

Löwit, M., Beitrïge zur Kenntnisz der Innervation des Froschherzens. Pflüger's Arch. f. d. ges. Physiol. Tol. XXIII, p. 313; Vol. XXV, p. 399; Vol. XXVIII, p. 312 ; Vol. XXiX, p. 469.

Löwit. M. Ceber die Gegrenwart von Ganglienzellen im Bulbus aortae des Froschherzens. Pflüger's Arch, f. d. ges. Physiol. 1883. Vol. XXXI, pp. 88-94.

Löwit, M., Beiträge zur Kenntniss der Innervation des Herzens. Pflüger's Arch. $f$. d. ges. Physiol. 1881. Vol. XXV, pp. 399-496.

Luchsinger, B., Zur Innervation d. Lymphherzen. Pflüger's Arch. f. d. gres. Physiol. 1880. Vol. XXIII, p. 304

Ludwig, C., Ceber die Herznerven des Frosches. Arch. f. Anat. u. Physiol. 1848, p. I39.

Macallum, A. B., The Nerve Terminations in the Cutaneous Epithelium of the Tadpole. Quart. Journ. Micros. Sci. 1885. Vol. XXVI, p. 53. 
Maddox, On the apparent relation of Nerve to Connective-tissue Corpuscles. Monthly Microse. Journ. Vol. IX, p. 109.

Maier, R., Die Ganglien in den harnabführenden Wegen des Menschen und einiger Thiere. Arch. f. pathol. Anat. u. Physiol. I881. Vol. LXXXV, p. 49.

Marchi, P., Beobachtungen über Wimper-Epithel. Arch. f. mik. Anat. 1866. Vol. II, p. 467.

Marshall, A. M., The segmental value of the Cranial Nerves. Journ. of Anat. and Physiol. Vol. XVI, pp. 305-354.

Marshall, A. M., The Frog: an introduction to Anatemy and Physiology. Manchester and London, 1885 .

Masius and Vaulair, De la situation et de l'étendue des centres réflexes de la moelle épinière chez la grenouille. Bruxelles, I87o.

Mason, J.J., A new group of Nerve-cells in the Spinal Cord of the Frog. New York Med. Journ. I879.

Mason, J. J., Microscopic Studies on the Central Nervous System of Reptiles and Batrachia. Journ. of Nerv. and Mental Diseases. New York. I880, Vol. VII, p. 8 ; I881, Vol. VIII, p. 7.

Mason, J. J., Minute Structure of the Central Nervous System of certain Reptiles and Amphibia of America. Newport, I884.

Mayer, A. F. J. C., Ueber das Gehirn der Amphibien und ein zoologisches Gesetz. Fror. Notizen, 1833. Vol. XXXVII, pp. 49-53.

Mayer, \$., Zur Lehre der Struktur der Spinalyanglien und der peripherischen Nerven in Rana esculenta. Arch. f. Anat. u. Physiol. I858, p. 274.

Mays, K., Histo-physiol. Untersuchungen über die Verbreitung der Nerven in den Muskeln. Zeitschr. f. Biol. Vol. XX, p. 449.

Mays, K., Ueber die Nervatur des Musculus rectus abdominis des Frosches. Heidelberg, 1886.

Mays, K., Nervenfasertheilungen in den Nervenstämmen der Froschmuskeln. Zeitschr. f. Biologie. 1886. Vol. XXII, p. 354.

Meckel, A., System der vergleichenden Anatomie. Halle, 1833 .

Meckel, J. F., Beiträge zur vergleichenden Anatomie. Leipzig, I8I r.

Michel, Ueber den Bau des chiasma nervorum opticum. v. Gräfe's Arch. I864. Vol. XIX, p. 59.

Müller, J., Beiträge zur Anatomie und Naturgeschichte der Amphibien. Tiede. mann's Zeitschr. 183I. Vol. IV, pp. Ig0-275.

Namias, M., Sui ganglii miocardici della Rana. Osservazioni ed esperienze in Lo Spallanzani. I88I. Vol. X, pp. 402-4I9.

Niccolucci, G., Sul sistema nervoso e circolatorio della Salamandra aquaivola. Napoli, 1842.

Niura, M., Untersuchungen über die motorischen Nervenendigungen der quergestreiften Muskelfasern. Virchow's Arch. I886. Vol. CV, p. I29.

Obersteiner, Ueber einige Lymphräume im Gehirne. Wiener Sitzungsber. 1870. Vol. LXI, Pt. I, p. 57.

Odenias, M. W., Undersökungar öfver de sensibla muskelnervena. Nord. Medic. Arch. Vol. IV, No. 18.

Onodi, A. D., Ueber die Entwicklung des sympathischen Nervensystems. Arch.f. mik. Anat. 1886. Vol. XXVI, p. 6I.

Onodi, A. D., Ueber die Gangliengruppen der hinteren v. vorderen Nervenwurzeln. Centralbl. f. wiss. Med. 1885 . Nos. 16 and 17 .

v. Openchowski, Th., Beitrag zur Kenntniss d. Nervenendigungen im Herzen. Arch. f, mik. Anst. 1883. Vol. XXII, pp. 408-419.

v. Openchowski, Th., Histologisches zur Innervation der Drüsen. Pflüger's Arch. f. d. Ges. Physiol. 1882. Vol. XXVII, p. 223.

Osborne, H. F., Observations upon the Urodele Amphibian Brain. Zool. Anz. 1884. Vol. VII, p. 679. 
Oaborne, H. F., Observations on the presence of the corpus callosum in the brains of Amphibians and Reptiles. Zool. Anz. I886. Vol. IX, p. 200.

Osborne, H. F., Note upon the cerebral commissures in the lower vertebrata and a probable fornix rudiment in the brain of Tropidonotus. Zool. Anz. I886. Vol. IX, p. 577 .

Partsch, C., Beiträge zur Kenntniss des Vorderdarmes einiger Amphibien und Reptilien. Arch. f. mik. Anat. 1877. Vol. XIV, p. 179.

Pertik, O., Cntersuchungen über Nervenfasern. Arch. f. mik. Anat. 1881. Vol. $\mathrm{XIX}, \mathrm{p} .183$.

Pfitsmer, Nervenendigungen im Epithel. Morph. Jahrb. I882. Vol. VII, pp. $726-745$.

Popoff, N., Die Nerven der Gallenblase. Rudneff's Journ. f. normale und pathol. Histologie u. klin. Med. St. Petersburg, 1872. (In Russian. Abstract in Virchow and Hirsehfeld's Arch.)

Priestley, J., An account of the anatomy and physiology of the batrachian lymphhearts. Journ. of Physiol. 1878. Vol. I, p. I.

Ranvier, L., Recherches sur l'histologie et la physiologie des nerfs. Arch. de physiol. normale et pathologique. 1872. Vol. IV, pp. $427-44^{6}$.

Ranvier, L., Appareil nerveux terminsux des muscles de la vie organique. Leçons d'anat. générale. Paris, 1880, p. 350.

Ranvier, L., Des tubes nerveux en $\mathbf{T}$ et de leurs relations avec les cellules ganglionaires. Compt. rend. 1875 . Vol. LXXXI, p. 1274

Ranvier, L., Leçons sur l'histologie du systeme nerveux. 1878. Vol. I, pp. 98-101.

Rawitz, B., Ueber die Structur der Zellen in den Spinalganglien, etc. Arch. f. mik. Anat. 1880. Vol. XVIII, p. 283.

Rawits, B., Ueber den Ban der Spinalganglien. Arch. f. mik. Anat. I880. Vol. XVIII, p. 283 .

Rawitz, B., Ceber den Ban der Spinalganglien. Arch. f. mik. Anat. 1882. Vol. $\mathrm{XXI}, \mathrm{p} .244$

Reichert, K. F., Ueber das Verhalten der Nervfasern bei dem Verlauf der Vertheilung und Endigung in einem Hautmuskel des Frosches, Rana temporaria. Arch. f. Anat. u. Physiol. 1851, p. 29.

Roissmer, E., Der Bau des centralen Nervensystems der ungeschwänzten Bairachier. Dorpat, 1864.

Romak, R, Anatomische Beobachtungen ūber das Gehirn, das Rūckenmark und die Nervenwurzel. Arch. f. Anat. u. Physiol. I841, pp. 506-522.

Remak, R., Multipolare Ganglienzellen. Berliner Monatsberichte. 1854, p. 26.

Retzius, G., Cndersökung üson cerebrospinalganglionus nervseller and särskild häusyn till dessus ut löpare. Nord. Med. Arkiv. 1879.

Retzius, G., Untersuchungen über die Nervenzellen der cerebrospinalen Ganglien, etc. Arch. f. Anat. u. Physiol. 1880, p. 360.

Reynier, Les nerfs du coeur. Paris, 1880 (pp. 32-37, ganglia of heart).

Rosenberger, De centris motuum cordis disquisitiones anatomico-pathologicae. Inang. Diss. Dorpat, 1850.

Rouget, Note sur la terminaison des nerfs moteurs dans les muscles chez les reptiles, les oiseaux et les mammiferes. Compt. rend. I862. Vol. LV, pp. $54^{8}-555$.

Rumph, T., Zur Histologie der Nervenfaser and des Axencylinders. W. Kăhne's Heidelberger Cntersuchungen. 1879. Vol. II, p. 355.

Sachs, C., Die Nerven der Sehnen. Reichert u. du Bois-Reymond's Arch. 1875, p. 402.

Sander, J., Die Spinalfasern im Sympathicus des Frosches. Arch. f. Anat. u. Physiol. I 866, p. 398.

Sanders, A., Contributions to the Anatomy of the Central Nervous System in Vertebrate Animals. Phil. Trans. 1882. Pt. III, p. 927. 
Scheel, Ueber die Kreuzung der Sehnerven im Chiasma bei den Wirbelthieren $\mathrm{u}$. beim Menschen. Klin. Monatsbl. f. Augenheilk. Vol. XII.

Scherhej, M. L., Zur Lehre der Innervation der Lymphherzen. Arch. f. Anat. u. Physiol. 1879. Physiol. Abth., p. 227.

Scherkey, M. L., Ueber die Feststellung und Bedeutung der Centren der Lymphherzen im Rückenmark. Dissert. Berlin, 1878. Abstract in Centralbl. f. d. med. Wiss. 1879, p. II7.

Schiefferdecker, P., Beiträge zur Kenntniss des Baus der Nervenfasern. Arch. f. mik. Anat. 1887. Vol. XXX, p. 435.

Schiess, Versuch einer speciellen Neurologie der Rana esculenta. St. Gallen und Bern, 1857.

Schmidt, M., Beiträge zur Kenntniss des Rückenmarkes der Amphibien. Zeit. f. Naturwiss. Vol. IV, pp. I-45.

Schmidt, M., Beiträge zur Kenntniss des Rückenmarkes der Amphibien. Zeit. f. Naturwiss. Vol. LVIII, pp. I-44.

Schöbl, J., Ueler die Blutgefässe des cerebrospinalen Nervensystems der Urodelen. Arch, f. mikrosk. Anat. 1882. Vol, XX, p. 87.

Schöbl, J., Ueber Wundernetze und divertikelbildende Capillaren bei nackten Amphibien und in pathologischen Neoplasmen. Arch. f. mik. Anat. 1885. Vol. XXV, p. 89.

Schönn, Ueber das angebliche Epithel des Rückenmarks und Centralcanals. Stettin, 1865.

Schönn, Ueber die Entwicklung des Rückenmarks. Stettin, I865.

Schramm, Neue Untersuchungen über den Bau der Spinalganglien. Diss. Würzburg, I864.

Schulgin, M. A., Lobi optici der Vögel; vergl, anat. Studien. Zool. Anz. I885. Nos. 84 and 85 .

Schultze, H., Axencylinder und Ganglienzelle. Reichert u. du Bois-Reymond's Arch. I878, p. 259.

Schwalbe, G., Bemerkungen über die Kerne der Ganglienzellen. Jenaische Zeitschr. f. Naturwissensch. 1876. Vol. X, pp. 25-40.

Schwalbe, G., Ueber den Bau der Spinalganglien nebst Bemerkungen über die sympathischen Ganglienzellen. Arch. f. mik. Anat. 1868. Vol. IV, p. 45.

Schwalbe, G., Lehrbuch der Anatomie der Sinnesorgane. Erlangen, I 885.

Schwalbe, G., Das Ganglion oculomotorii. Jenaische Zeitsch. f. Naturwissensch. 1879. Vol. XIII, p. 173 .

Schwalbe, G., Handbuch der Neurologie. Erlangen, I881.

Schweiger-Seidel, Das Herz. Stricker's Gewebelehre, p. 177. (Ganglion cells of heart.)

Serres, C., Anatomie comparée du cerveau des quatres classes des animaux vertébrés. Paris, I824.

Sokoloff, A. A., Ueber die Nervenendigungen in den Muskeln ausgehungerter Frösche. Med. Bote. St. Petersburg, I876. Nos. II, I5, and I6.

Sokolow, Sur les transformations des terminaisons des nerfs dans les muscles de la grenouille après la section des nerfs. Arch. de physiologie. 1864, p. 308.

Solly, s., The Brain. London, 1837 .

Sommé, C. L., Recherches sur l'anatomie comparée du cerveau. Anvers, chez Ancelle, 1824 .

Spencer, W. B., On the presence and structure of the parietal eye in Lacertilia. Quart. Journ. Micros. Sci. 1886. Vol. XXVII, p. 165.

Spina, A., Untersuchungen des lebenden Bindegewebes. Oesterr. med. Jahrb. 1885 .

Stannius, Lehrbuch der vergleichenden Anatomie der Wirbelthiere. Berlin, 1856.

Stannius, Haudbuch der Zootomie, 2nd Edit., 1856. Berlin. And Müller's Arch. I 852, p. 85 . 
Stannius, Handb. der Anatomie der Wirbelthiere. 2nd Edit., 1854 .

Stieda, I., Studien über das centrale Nervensystem der Wirbelthiere. Zeitschr. f. wiss. Zool. 187a. Vol. XX, p. 273.

Stieda, L., Zur vergleichenden Anatomie nnd Histolngie des Cerebellum. Reichert u. du Bois-Reymond's Areh. 1865, pp. 407-433.

Stirling, W., On the Nerves of the Lungs of the Newt. Journ. of Anat. and Physiol. 1882, p. 96.

Stirling, W., and Macdonald, F., The minute structure of the palatine nerves of the frog and the termination of nerves in blood vessels and glands. Journ. of Anat. and Physiol. 1884. Vol. XVII, p. 293.

Swan, Illustrations of the Comparative Anatomy of the Nervous System. London.

v. Thanhoffer, I., Neuer Nervenapparat im Dünndarm. Centralb. f. d. med. Wissen. 1883, pp. 33-35.

v. Thanhoffer, L., A csigolyaküzti dúczsejtek szerkezetéhez. Értekezések á termézzettudományok köréböl. Kiadjá a. m. t. Akadémia. IS 7 .

Tiedemann, Anatomie und Bildungsgeschichte des Hirns. ISI6.

Toel, G. H., Die Ranvierschen Schnürringe markhaltiger Nervenfasern und ihr Verhältniss zu den Neurilemmkernen. Diszert. Zürich, I875.

Toloschinoff, L'eber das Verhalten der Nerven zu den glatten Muskelfasern der Froschharnblase. Arch. f. mik. Anat. 1869. Vol. V, p. 509; and in Stricker's Gewebelehre, p. 142.

Török, A., Beiträge zur Kenntniss der ersten Anlagen der Sinnesorgane und der primären Schädelformation bei den Batrachiern. Wiener Sitzungsber. 1886. Vol. LII, Pt. I, p. 646.

Traugott, Ein Beitrag zur feineren Anatomie des Rückenmarks von Rana temporaria. Dissert. Dorpat, 186r.

Treviranus, G. R., Untersuchungen über den Bau und die Functionen des Gehirns. 1820.

Treviranus, G. R., Ueber die hinteren Hemisphaeren des Gehirns der Vögel, Amphibien und Fische. Zeit. f. Physiol. von Tiedemann und Treviranus. Heidelberg and Leipzig, 1831. Vol. IV, p. 39.

Treviranus, G. R., Bemerkungen über das Nervensystem des Fisches und über einige bisher unbeachtete Theile dieses Thieres in G. R. and L. Chr. Treviranus. Verm. Schriften Anst. u. Physiol. Vol. I, 1816, p. 94

Tschiriew, S., Sur les terminaisons nerveuses dans les muscles striés. Arch. de physiul. norm. et pathol. 1879. Vol. VI, 2 zér., p. 89.

Valentin, Die letzten Enden der Nerven. Nova acta academ. caesar. Leop. 1836 . Vol. XVIII, p. 5 I.

Vignal, Recherches sur l'appareil ganglionaire du coeur des vertébrés. Laboratoire d'histologie du Collège de France. Travaux de l'année I8S1, p. I86. Also in Areh. de physiol. norm, et pathol. I881, pp. 694- 338 , and pp. 910-934

Vogt, C., Beiträge zur Neurologie der Reptilien. Neuchâtel, $18_{4}$.

Vogt, C., Zoologische Briefe. Frankfurt a. M., I $8_{5}$ I, p. I9

Volkmann, A. W., Von dem Baue und den Verrichtungen der Kopfnerven des Frosches. Areh. f. Anat. u. Physiol. 1838, p. 70.

Volkmann, A. W., Ceber die Faserung des Räckenmarks und des sympathischen Nervensystems. Arch. f. Anat. u. Physiol. 1838, p. 274.

Volkmann, A. W., Ueber das Verhältniss des Nervus sympathicus zu dem übrigen Nerrensystem beim Frosch. Fror. Not. I 4 2. Vol. XXI, p. 305.

Volkmann, A. W., Nachweise der Nerrencentra, von welchen die Bewegung der Lymph- und Blutgefässherzen ausgeht. Arch. f. Anat. u. Physiol. 1844, p. 4I9.

Wagner, R., Icones Zootomicae. Leiprig, 1841 .

Wagner, R., Sympathische Ganglien des Herzens, Handwörterbuch d. Physiol. Vol. III, p. 46r. 
Wagner, R., Lehrbuch der vergleichenden Anatomie. Leipzig, 1834-35, pp. 400403 .

Wagner, R., Icones Physiologicae. Leipzig, 1840 .

Waldejer, W., Zur Anatomie und Physiologie der Lymphherzen von Rana und Emys europaea. Studien deg physiologischen Instituts zu Breslau. I865. Vol. III.

Waller, A., On the minute structure of the Papillae and Nerves of the Tongue of the Frog and Toad. Phil. Trans. 1849, p. I39.

Waters, W. H., On the local Vaso-motor functions of the epinal nerves. Journ. of Physiol. 1885. Vol. VI, p. 460.

de Watteville, A Description of the Cerebral and Spinal Nerves of Rana esculenta. Journ. of Anat. and Physiol. 1875. Vol. IX, p. 145.

Weber, Beiträge zur Anatomie u. Physiologie. Bonn, 1832 .

Weismann, Ueber das Wachsen der quergestreiften Muskeln nach Beobschtungen am Frosch. Henle und Pfeufer's Zeitschr. I860. Vol. X, p. 264.

Wiedersheim, R., Zur Anatomie des Froschgehirns. Zool. Anz. 1881. No. 66, p. 497 .

Wiedersheim, R., Ueber das Parietal-Auge der Saurier. Anat. Anz. I886, p. I48.

Wiedersheim, R., Elements of Comparative Anatomy of Vertebrates, translated by W. Newton Parker. London, 1886.

Wiedersheim, R., Lehrbuch der vergleichenden Anatomie der Wirbelthiere auf Grundlage d. Entwicklungsgeschichte. Jena, 1886. 2nd Edit.

Wolff, W., Ueber Nervenendigungen im quergestreiften Muskel. Arch. f. mik. Anat. 1881. Vol. XIX, p. 33r.

Wolff, W., Die Innervation der glatten Muskulatur. Arch. f. mik. Anat. I882. Vol. XX, p. 36r.

Wolff, W., Ueber freie, sensible Nervenendigungen. Arch. f. mik. Anat. 1882. Vol. $\mathrm{XX}, \mathrm{p} .377$.

Wyman, J., Anatomy of the nervous system of Rana pipiens. Smithsonian Contributions to Knowledge. 1853. Vol. V.

Wyman, J., Results of microscopical examination of the structure of the brain and spinal cord in Frogs. Boston, Nat. Hist. Soc. 185I-1854. Vol. V, p. Io7. 


\section{THE NERVOUS SYSTEM.}

\section{THE CENTRAL NERVOUS SYSTEM.}

(Re-written by the translator.)

\section{A. The Spinal Cord (Fig. 97).}

1. External form. The spinal cord is, in comparison with the brain, somewhat small; the two organs are directly continuous, and present no distinct line of demarcation: the point of origin of the first spinal nerve is, therefore, arbitrarily accepted as the anterior limit of the spinal cord; posteriorly it terminates in the filum terminale.

The spinal cord is flattened dorso-ventrally, and is constricted at a point (pars media, Reissner) somewhat anterior to its middle: in consequence of this constriction the cord has two enlargements; an anterior smaller, and a posterior larger (intumescentiae anterior $v$. piosterior), from which arise the nerves of the brachial and lumbar plexuses respectively. At about the sixth o seventh vertebra, the hinder enlargement diminishes rather auruptly to form the so-ealled conus medullaris; this is continued into the filum terminale, which enters the carity of the urostyle. The hinder portion of the lumbar nerves forms a cauda equina, the constituent nerves of which surround the filum terminale.

A dorsal longitudinal fissure (sulens longitudinalis superior) is well marked in the middle line of the dorsal surface of the posterior enlargement; anteriorly and posteriorly it rapidly fades away, its position being merely indicated by a small amount of connectivetissue and a blood-vessel.

The ventral longitudinal fissure (sulcus longitudinalis inferior) is well marked throughout the length of the cord. Neither fissure can be traced in the hinder part of the conus medullaris or in the filum terminale.

Ten pairs of nerves arise from the spinal cord, each nerve arising by two roots, a ventral and a dorsal (anterior and posterior), from 
points near the ventral and dorsal longitudinal sinuses respectively: the two roots unite at their point of exit from the ver-

Fig. 97.

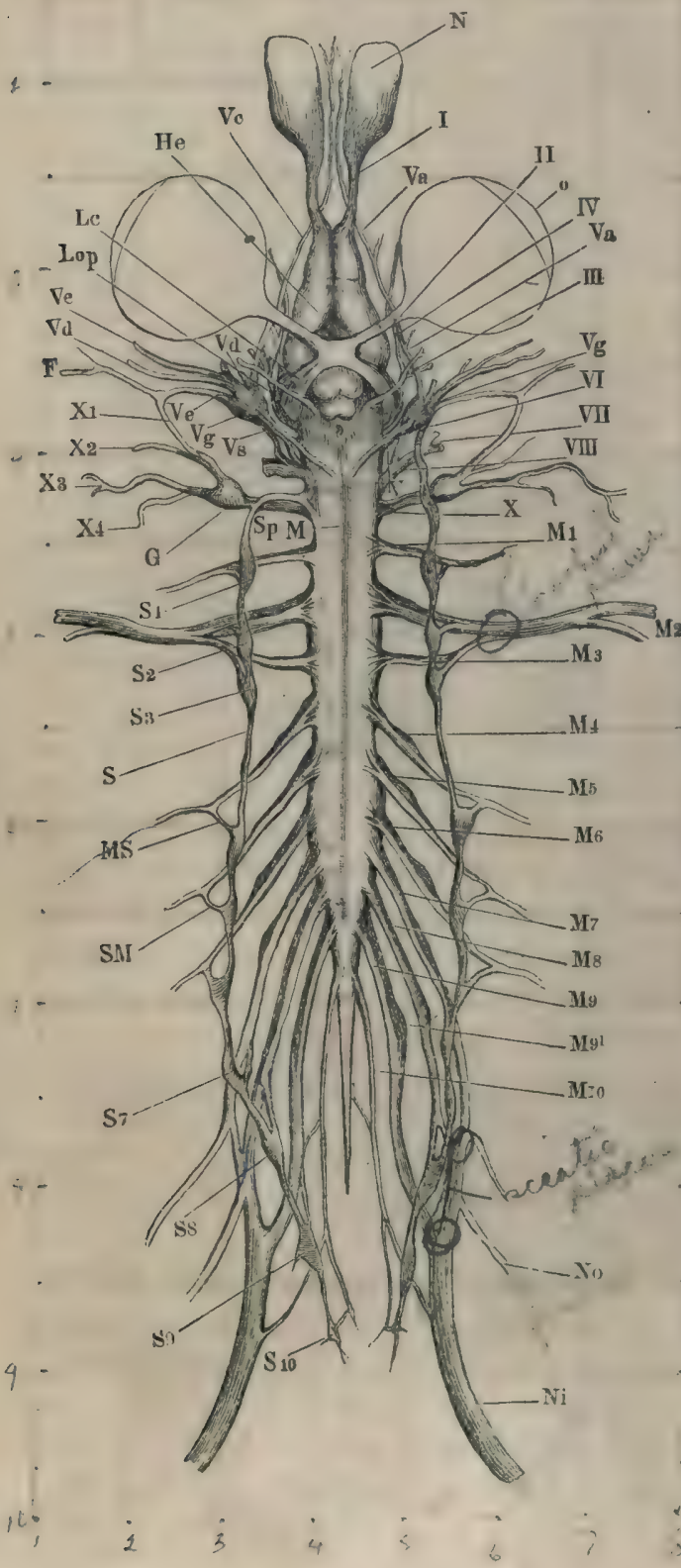

tebral canal through the intervertebral foramen; each dorsal root possesses a ganglion.

The nervous system of Rana esculenta, from the ventral surface. (From Icones physiologicae by A. Eicker. PL. XXIV, Fig. . .)

\section{F Facial nerve.}

G Ganglion of pneumogagtric nerve.

He Cerebral hemisphere.

- Lc Optic tract.

Lop Optic lobe.

$M$ Boundary between medulla oblongata and spinal cord.

$\checkmark$ Mr - Io Spinal nerves.

MS Connection between fourth spinal nerve and sympathetic chain,

$N$ Nasal sac,

Ni Sciatic nerve.

No Crural nerve.

o Eyeball,

$\sqrt{S}$ Trunk of sympathetic.

$\mathrm{S}_{\mathrm{r}-\mathrm{ro}}$ Sympathetic ganglia.

Sm Rami communicantes of sympathetic.

Sp Continuation of sympathetic into head.

- I Olfactory nerve,

II Optic nerve,

III Motor oculi nerve,

IV Trochlear nerve,

- V Trigeminal and facial nerves,

Va Ramus ophthalmicus of trigeminal.

- Ic Ramus maxillo-roandibuJaris of trigeminal.

$V d$ Mandibular branch of trigenuinal.

$\mathrm{Ve}$ Hyomandibular branch of facial.

$\nabla g$. Gasserian ganglion.

Gasserian ganglion,
Vs trunk in connection with Gasserian ganglion,

VI Abducens nerve.

VII Facial nerve.

VIII Auditory nerve.

$\boldsymbol{X}$ Glossopharyageal: and pneumogastric nerves.

$\boldsymbol{X}_{\mathbf{I}}$ Ramus unterior of glossopharyngeal.

$\boldsymbol{X}_{2}$ Rauns posterior of glossopharyngeal.

$X_{3}-4$ Branches of pneumogastric. 
2. Internal structure. As in other vertebrates, the spinal cord consists of white and grey matter, the latter being surrounded by the former; the relative amount of the one to the other varies in different parts of the cord.

A transverse section of the cord presents the same general characteristics as a similar section from a bird or mammal. The grey matter lies in the middle, surrounding the central canal, and is prolonged into each half of the section by ventral and dorsal horns or cornua. The grey matter is surrounded by the white, but is not so sharply marked off from this in amphibia as in birds and mammals.

A section through the anterior enlargement is almost quadrangular in outline, and somewhat broader below than above; the ventral longitudinal fissure is well marked and deep, while the dorsal is indistinct. The dorsal horns are narrow and short, the ventral longer and much broader. The space between the dorsal horns is narrow and deep, that between the ventral shallow; the outer boundary of the grey matter is almost straight, and the central canal is placed above the centre of the section.

In the constricted portion of the cord ( pars media) the relative proportion of the white matter is increased at the expense of the grey; the horns are less distinct, the dorsal being directed outwards and the ventral somewhat flattened. The central canal is in the centre of the section.

The posterior enlargement shows the ventral horns projecting outwards, very much enlarged, and approaching the periphery; the space between them is semilunar. The dorsal horns are well developed, especially at their upper parts; the space between them is narrow and deep. The outer margin of the grey matter is again nearly a straight line. The central canal is below the centre of the section.

The arrangement of the parts in the conus medullaris approaches that in the pars media: the horns are much diminished in size, and posteriorly they entirely disappear, the ventral horns persisting longer than the dorsal. The central canal approaches the lower surface.

No cornua can be recognised in the filum terminale behind the origin of the last pair of spinal nerves. The grey matter has here a circular outline, with the exception of a very slight indentation below; the white matter is almost absent: the central canal is on the lower border of the section in the anterior part, while posteriorly it occupies almost the entire space below the pia mater.

The Central Canal lies in the median line, and always presents a 
distinct lumen; in the two enlargements this lumen forms a vertical ellipse ${ }^{1}$, while in the pars media it is circular. The canal is lined by a single layer of ciliated columnar epithelium, the cells of which are usually conical, with their bases directed towards the lumen; but other forms may be noticed. These cells average about $0.040 \mathrm{~mm}$. in length and about $0.002 \mathrm{~mm}$. in width at their broadest part. The peripheral extremities of the cells have processes, which, in the case of the cells above and below the cord, may often be traced as far as the pia mater; the processes of the lateral cells are less distinct and seem to be shorter. Anteriorly the central canal opens into the floor of the fourth ventricle. The termination of the central canal, posteriorly, has been described by Masius and Vanlair. According to these observers, the canal towards the hinder end of the filum terminale increases very gradually in width, until its epithelial cells are immediately underneath the pia mater, its walls then converge somewhat more sharply to close the cavity. From the point where the canal commences to increase in width, a change takes place in its epithelial wall, which, instead of having a single layer of cells, now possesses two to three layers; towards the posterior end it is again thinned out to a single layer.

The grey matter varies in different parts of the cord and in different parts of the same section. In a section through the anterior enlargement a portion of the grey matter, placed immediately above the central canal, is easily distinguished by its vertically-placed, elliptical outline, and by its transparency: it is known as the substantia reticularis. It consists of a mesh-work of branched cells, through which course distinctly contoured fine commisural fibres which are derived chiefly from the dorsal cornua, the vertical from the epithelial cells of the roof of the central canal. In a seriès of sections the substantia reticulosa may be seen to originate indistinctly in the most anterior part of the cord; in the anterior enlargement it already possesses the elliptical form mentioned, and in the pars merlia it commences to send off lateral processes to either side. In the posterior enlargement it reaches its greatest absolute development, as it here surrounds the central canal; while further backwards it encroaches until, together with the remaining grey matter, it constitutes almost the whole of the filum terminale.

Immediately underneath the central canal is a narrow band, which immediately connects the grey matter of the two sides; above it is bounded by the epithelium of the central canal, below

1 v. Kölliker states that the lumen is everywhere circular. 
by medullated fibres. This septum merlium (Reissner) may be traced backwards from the anterior extremity of the cord to the posterior enlargement. It consists chiefly of transverse fibres, together with vertical fibres derived from the epithelial cells on the floor of the canal, and like the substantia reticulosa, is distinguished by its greater transparency from the rest of the grey matter.

The grey matter consists of connective-tissue and nervous elements, which are very intimately united; each of these elements including its special cells and fibres. The nerve-cells vary much in size and appearance. A prominent group of large cells in the ventral cornua, the lateral group (Stieda), is very conspicuous. The individual cells are seldom rounded, but are usually spindle-shaped or angular, and each possesses one to five processes, which may often be traced through considerable distances. These cells have an average length of $0.040 \mathrm{~mm}$., and are about $0.016 \mathrm{~mm}$. broad; they are somewhat larger in the anterior enlargement than in the posterior, and are also more numerous in a section from the anterior enlargement than in a section from the posterior. In the terminal filament they gradually disappear. Some of their processes are continued into the lateral columns (Köppen).

Smaller, spindle-shaped or triangular cells are scattered irregularly throughout the grey matter, without forming distinet groups, though for descriptive purposes those of the centre have been named the central group. In a stained, transverse section of the cord are seen numerous nuclei; these undoubtedly belong both to small nerve-cells and to connective-tissue cells, but except under the most favourable conditions the two are indistinguishable. The larger nerve-cells present the usual characters of nerve-cells : more or less granular contents, nucleus, well-marked nucleolus, more or less marked fibrillation; their processes are usually more homogeneous. The cells are frequently pigmented.

The processes of the cells belonging to the lateral group radiate in all possible directions, but certain well-marked processes directed towards the middle line can always be made out. From the lowest part of this group a few processes may be traced into the ventral roots. The small cells seem to be chiefly arranged vertically, although their processes radiate in all directions (Stieda).

The Fibres of the grey substance are nearly all non-medullated. They may be traced in all directions, but the best-marked groups are either vertical or transverse. The vertical fibres appear to arise from the central grey matter, and to ascend in larger or smaller 
bundles towards the periphery. The transverse fibres are arranged chiefly in the two commissures: the dorsal commissure (commissura superior) is the smaller; the fibres are parallel, and show no trace of decussation; externally they radiate in various directions to the dorsal horns. The ventral commissure is composed of two layers, the upper grey (commissura inferior grisea), the lower white (commissura inferior alba): both are interrupted by the septum medium. A wellmarked decussation of the fibres is seen in the middle line; the exact mode of termination of these fibres has not been made out, but many appear to communicate with the large cells of the ventral horns.

The white matter consists chiefly of longitudinal, medullated fibres, in which various columns may be distinguished. The dorsal columns are separated from the lateral by a process of neuroglia, continued from the general investment of neuroglia lying under the pia mater. The line of separation between the lateral and ventral columns is not well marked; it is about the line which would be formed by prolonging the ventral horns to the surface.

The fibres vary in size, and fibres of all sizes may be found in any particular part of a transverse section; still the fibres of the ventral columns have an average greater diameter than those of the lateral columns, and the fibres of the dorsal columns are finer than those of the lateral. The largest fibres of the ventral column are placed near the ventral fissure and on its lower border; they attain their greatest development in the posterior enlargement; these fibres frequently contain two or three axis-cylinders each. Köppen suggests that they may represent the formatio reticularis of higher animals.

In the lateral columns the larger fibres are placed close to the grey matter, these columns also receive fibres from the cells of the lateral group.

In the dorsal columns the radiating root-fibres never reach the median plane, but leave an area of purely longitudinal fibres on each side of the dorsal fissure; these represent Goll's columns, and have a club-shaped outline in transverse section.

The white matter is pierced in all directions by fine connectivetissue fibres and bundles of fibres which radiate from the grey matter; some branch and join with others to form a network, others pass almost uninterruptedly to the periphery. From the connective-tissue cells of the pia mater, processes pass into the white matter and assist in completing the connective-tissue matrix for the nervous elements.

Dorsal roots of the spinal nerves. Each root consists of a 
single bundle of nerve fibres, which suddenly bends at the periphery of the cord in order to descend vertically through the white matter towarls the dorsal horn; the fibres divide into three sets, one to the dorsal commissure, a second to the upper horn itself, and the third helps to form the dorsal columns.

Ventral roots of the spinal nerres. Each rentral root consists of three or four delicate threads, which may be traced to the ventral cornua, which they reach after a vertical or very slightly oblique course through the white matter.s Other fibres arise from the rentral columns, but these oblique fibres never extend to the median plane.

Pigment is found distributed irregularly through a section from any part of the spinal cord; it is increased in amount in those parts in which there is an increased amount of grey matter. The pigmentation is always found more marked in the lower parts of the ventral horns than in other parts.

\section{B. The Brais (Figs. 98, I02, 103, and 105).}

1. General description. From behind forwards, the dorsal surface of the brain presents the following parts for examination : the medulla oblongata, the cereljellum, the optic lobes, the thalamencephalon, the cerebral hemispheres, and the olfactory lobes.

The meslulla ollongata is a direct continuation of the spinal cord; it is wider anteriorly than posteriorly, and is separated in front from the optic lobes by a vertical plate of nervous matter, the cerebellum. The optic lobes are two symmetrical oroid bodies touching each other in the median plane, and tegether forming the widest part of the brain. In front of the optic lobes is the thalamencephalon, with a thick vascular membrane, the choroid plexus, lying on its upper surface, and connected with the pineal gland; the thalamencephalon extends forwards between the posterior ends of the cerebral hemispheres. The cerebral hemispheres are two symmetrical ovoid bodies, narrow in front, wider and slightly diverging behind: each hemisphere is prolonged forwards to form an olfactory lobe.

The ventral surface has in front the olfactory lobes, then the cerebral hemispheres, behind these the lamina terminalis, the tuber cinereum, the optic chiasma, the pituitary body, the crura cerebri, and lastly the medulla oljongata, in the order here given.

The various cranial nerves (Figs. 102 and 103) may be seen to arise as follows:-The olfactory nerve $\left(I, I, L . o l^{\prime}\right)$ arises directly 
from the anterior end and outer side of the corresponding olfactory lobe, and from the cerebral hemisphere. The optic nerve (To and II) arises, as the optic tract, from the side of the brain below the optic lobe, whence it passes to the chiasma on the under surface of the brain. The oculo-motor (III) takes its origin from the ventral surface close to the median line and between the crura cerebri. The pathetic or trochlear nerve $(I V)$ is attached to the dorsal surface between the optic lobes and the cerebellum. The trigeminal nerve $(V)$ arises from the side and anterior part of the medulla oblongata. The abducens $(V I)$ arises behind the pituitary body close to the median line from the ventral surface of the medulla halfway between the sulcus and the origin of the vagus. The facial and auditory (VII and VIII) nerves arise from the medulla ollongata behind the trigeminal nerve, the facial being in front of the auditory nerve. The glossopharyngeal $(I X)$ nerve arises, in common with the pneumogastric nerve $(X)$, behind the auditory nerve.

\section{The several parts of the brain.}

a. The medulla oblongata (Figs. 98, 102, and 103 Mo)-a. External form. The medulla is limited behind by the origin of the first pair of spinal nerves, at which point a very faint constriction is sometimes found: it extends forwards as far as the cerebellum. It gradually widens as it passes forwards until just before it reaches its anterior limit, where it presents a shallow but sharp constriction. The dorsal surface is characterised by the presence of a deep, triangular fossa, the fourth ventricle (Fig. $9^{8}$ S.r.), (ventriculus quartus, Stieda; sinus whomboidleus s. sinus triangularis, Reissner; fossa rhomboilalis); the sides of the triangle are, however, not quite straight, but are slightly bent outwards just before they converge towards the posteriorly-directed apex; the base of the triangle is formed by the cerebellum. By careful examination, the ventricle is seen to be continued for a short distance under the cerelellum, where it opens into the Sylvian aqueduct. In the floor of the fourth ventricle is a well-marked median longitudinal fissure (sulcus centralis), (Fig. $98 S$ ). Into the posterior part of the ventricle opens the central canal of the spinal cord. As the fourth ventricle is formed by the white matter passing to either side, and the simultaneous flattening of the grey matter, the floor of the fourth ventricle is composed of grey matter.

The fourth ventricle is closed in by a highly vascular membrane, the choroid plexus of the fourth ventricle (plexus cho- 
roilens ventriculi quarti, Reissner; velum medullare posterius). The blood-vessels of the plexus will be described together with the other vessels of the brain (p. I62). They are supported by a connective-tissue matrix, and the whole covered with flattened epithelium, which in the fourth ventricle is ciliated and often pigmented.

The ventral surface of the medulla oblongata (Fig. $102 \mathrm{Mo}$ ) has a median ventral longitudinal fissure, a direct continuation of that of the cord; in the anterior part of the merlulla oblongata there is also to either side of this a lateral fissure, continued on to the crura cerebri; these fissures correspond to the positions of the two rami posteriores of the internal carotid arteries; they are always well seen in microscopical sections. The merlulla ollongata is so intimately connected with the jars commissuralis (pp. I49, I50) that the minute anatomy of the two is best described at the same time.

ß. Internal structure. Examined by means of serial sections, the merlulla oblongata is seen to have, in comparison with the eord, an increased amount of grey matter; this is especially the case in its anterior part. The floor and inner parts of the walls of the ventricle are formed of grey matter, in which the largest-sized cells have disappeared, to be replaced by medium-sized cells. Traced from behind, the ventral horns of the cord are seen to increase in size and to be more widely separated until they form two isolated masses, while the dorsal horns gradually diminish; at the

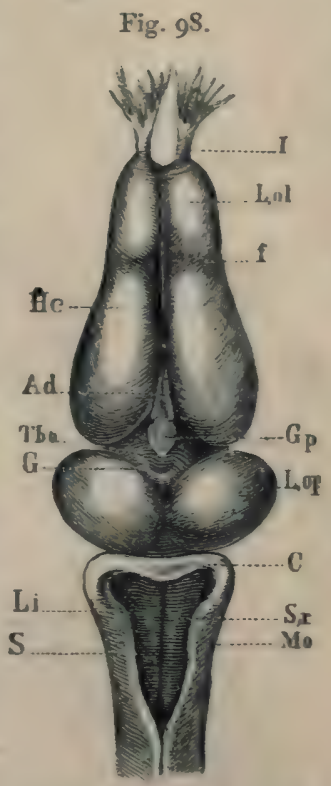

Dorsal view of brain of Ranus esculenta.

Ad Choroid plexns

c Cerebellum.

$f$ Groove between serebral hemispheres and elfactory lebes.

a Opening in the roof of the third rentricle.

Gp Pineal body.

He Cerebral hemispherea

I Olfactory nerva.

Hi Wall of fourth rentricle.

L.ol Olfactory lobe. L.op Optic lobe.

Mo Medulla oblongata.

8 Longitudinal fissure of the fourth ventricle.

S. Pourth ventricle.

Tho Thalamencephalon。 same time they are forced outwards and upwards, until they lie under the floor of the ventricle, and so extend to the pars peduncularis.

Grey matter. The sulstantia reticularis is not present, but the septum mediun extends forwards as far as the pars peduncularis. The central canal extends upwards at the expense of the tissue above it, and is here pear-shaper; at the same time the dorsal 
longitudinal fissure deepens until the two meet in the fourth ventricle; beyond this point one cannot speak of dorsal and ventral horns.

Fig. 99.

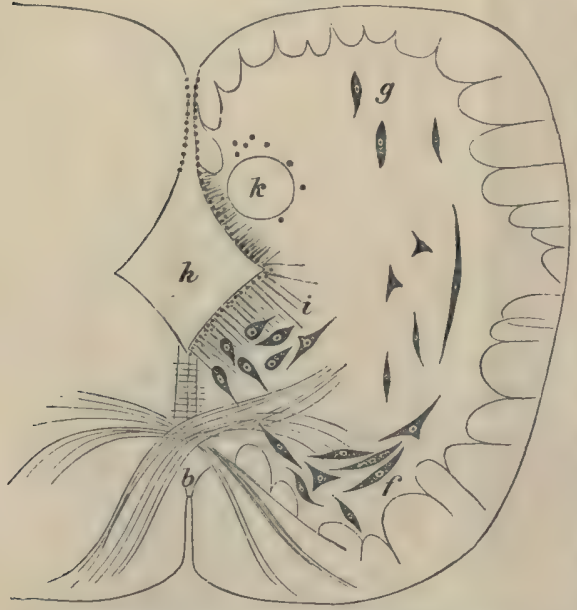

Transverse section through hinder end of Medulla oblongata (magnified 30-80)1, from Stieda.

$b$ Inferior commissure.

$f$ Dorsal horns.

$g$ Ventral horns.

h Fourth ventricle.

i Nucleus centralis.

$k$ Isolated mass of grey matter in which longitudinal fibres of the pneumogastric nerve course.
Small nerve cells are irregularly distributed throughout the whole of the grey matter and cannot be grouped; the larger cells, on the other hand, are arranged in distinct groups which have special relations with the nerves arising from the part. Occasionally these groups are not so isolated as usual; in this case processes of one group can be traced into another group (Reissner). Of these groups the chief are :

I. The nucleus centralis (upper inner group, Reissner), nucleus medullae oblongatae, Stieda (Fig. 99 i), is a group of cells found to-

wards the hinder end of the melulla ollongata, on either side of and below the central canal; the group can be traced under the floor of the fourth ventricle to about its middle. The cells are rounded or spindle-shaped, the processes directed upwards, downwards, or outwards; their average size is $0.040-0.048 \mathrm{~mm}$. long by $0.020 \mathrm{~mm}$. broad.

2. The auditory nucleus (nuclens acusticus, Reissner, Stieda), (Fig. $100 n$ ) is a large group of cells found in the wall of the fourth ventricle opposite the point of origin of the auditory nerve. The cells are rounded, pear-shaped, or of spindle form, and interspersed between the nerve fibres; these cells have an average length of $0.040 \mathrm{~mm}$, and are about half as broad. The fibres of the auditory nerve radiate from their superficial origin in all

1 In these diagrams, from Ludwig Stieda's Studien über das centrale Nervensystem der Wirbelthiere, the outline of the diagram is magnified thirty times, while the details are magnified eighty times. 
directions through the grey matter towards these cells, and evidently communicate with them (Fig. IOI $p$ ). One small group (Fig. IOI $r$ ) passes to a lower level than the rest, and is regarded by Stieda as

Fig. 100 .

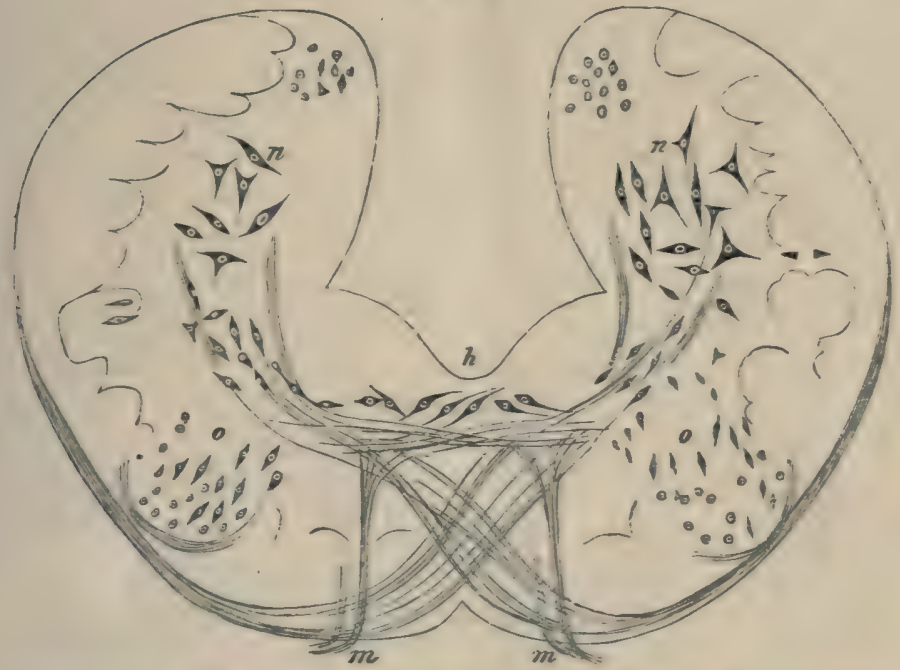

Transverse section throngh the Medulla oblongata at the point of origin of the abdncens nerve. from Stieda. Magnified $30 \times 8$ a)

$$
\begin{aligned}
& \text { n Fourth ventricle. } \\
& \text { n Abducens nerve. } \\
& \text { n Auditory Iuclens, } \\
& \text { a Abducens nuclens. }
\end{aligned}
$$

the true auditory centre. Köppen considers that the auditory nerve has a threefold origin: (I) from small cells on the median surface of the auditory area; (2) from the large cells between the above; (3) from a group of free nuclei on the dorsal surface of the auditory area.

3. The trigeminal nucleus (nucleus trigeminus), (Fig. IOI q) lies in part beneath the auditory nucleus but extends further forwards. It forms a rounded group of cells placed under the outer angle of the grey matter. The cells are somewhat crowded together, and are chiefly of an elongated spindle-form, with their processes directed obliquely downwards and outwards. The fibres of the trigeminal nerve separate into two groups; the upper group is best traced in a horizontal section, the fibres curving round to join the longitudinal fibres continued from the dorsal columns of the cord. The fibres of the lower, smaller group pass transversely inwards to the 
trigeminal nucleus. According to Reissner the latter fibres are motor, the former sensory. Probably other nerves are connected with the hinder part of this group.

4. The abducens nucleus (Fig. I00 o). From its superficial origin, the fibres of the abducens nerve may be traced vertically upwards to a small, rounded, grey mass; at this point the mass is somewhat isolated, but further forwards it may be traced as belonging to the central grey matter; it contains small spindle cells.

Fig. ror.

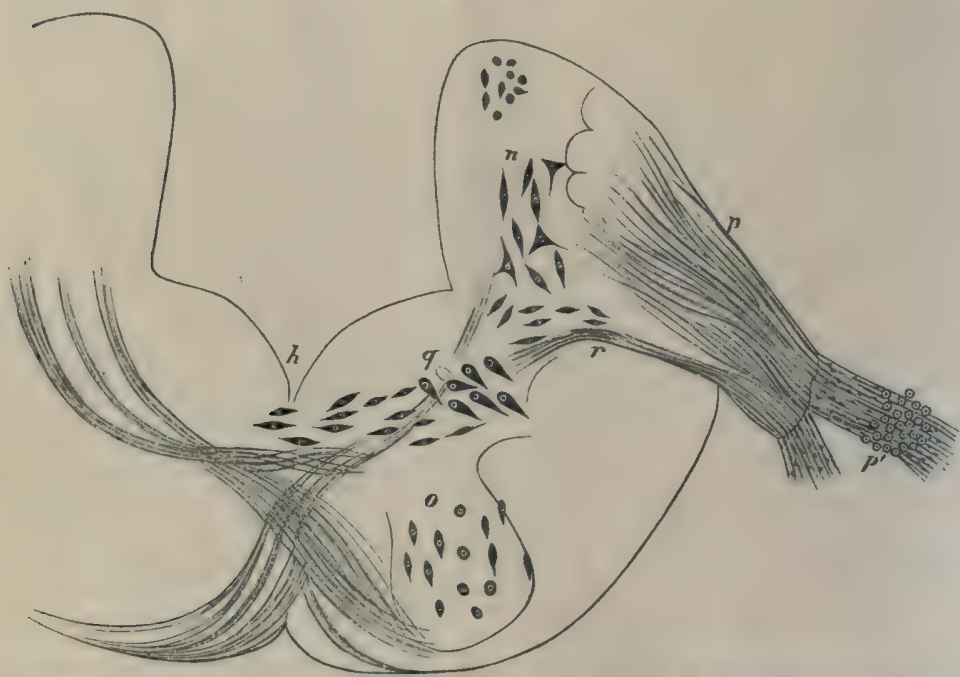

Transverse section of the Medulla oblongata, at the point of origin of the auditory nerve, from Stieda. (Magnified $30 \times 80$.

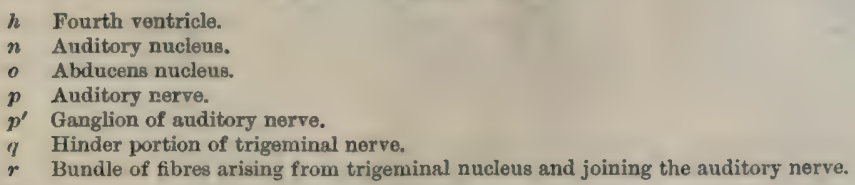

5. The pneumogastric nucleus. The pneumogastric, with its numerous irregular roots, arises from the side of the medulla oblongata. The hindermost fibres can be traced as a small bundle, passing almost transversely through the white matter to the outer margin of the grey matter. The larger portion of the fibres is placed in front of these; part of this seems to be directly continuous with the longitudinal fibres of the white matter; a second part, however, can be traced from the surface transversely 
through the white matter to the grey matter. These latter fibres, together with those of the group first described, do not arise from the grey matter in this part of the medlulla ollongata, but curve round and run backwards longitudinally through the grey matter, thus forming a rounded bundle of fibres (Fig. $99 k$ ). Between these fibres are interspersed small nerve-cells and nuclei which disappear as the fibres approach the white matter. The ragus undoubtedly receives fibres from the grey matter throughout a long course, and again receives a large bundle just before leaving the grey matter. The more exact origin of the rarious fibres has not been traced.

6. The nuclens magnus (Reissner and Stieda) is a very peculiar group of cells placed on either side, in the most anterior portion of the pars commissuralis, that is, immediately underneath the valvula cerebilli. The large cells are arranged in a transverse section in a single row so as to enclose a pear-shaped space on either side, which has its long axis directed from above, downwards and outwards, the narrower end being above. In longitudinal section the line of cells is seen to be open in front. The space enclosed by these cells is occupied by a granular ground-substance which contains only few nuclei. Bellonei is of upinion that these nuclei represent the corpora quadrigemina posteriora of higher animals.

White matter. In the hinder part of the medlulla oblongata the arrangement of the white matter resembles that of the white matter of the spinal cord; further forwards the white matter of the dorsal surface commences to pass to either side, and ultimately it forms the outer part of the walls of the fourth ventricle. The fibres of the white matter of the ventral surface are unchanged in direction as they proceed forwards. The fibres of the anterior part of the medulla are thinner than those of the posterior portion (Stieda), according to Reissner they gradually thin as they pass forwards. The fibres are nearly all longitudinal, such transverse and oblique fibres as are present being chiefly in connection with the rarious nerve-roots and the commissures.

The commissura superior is naturally lost in consequence of the opening of the central eanal into the fourth ventricle; the commissura inferior is increased in the anterior half and decreased in the posterior half of the medulla ollongata; in the latter the fibres become more and more oblique, and decussate very freely; ultimately they seem to be either continued as longitudinal fibres or to join the ganglia. 
Near the pars commissuralis is a transverse arched band of fibres, passing from the under surface of one half of the cord over the ventral longitudinal fissure through the septum medium to the under surface of the opposite half; part of the fibres are continued upwards along the periphery to the cerebellum, part to the nucleus magnus. Vertical, straight, or slightly arched fibres are found in the walls of the fourth ventricle.

A section from the medulla oblongata has a larger amount of pigment than a section from the spinal cord, and the anterior portion of the medulla oblongata contains more than the posterior portion. The pigment is chiefly found in a curved line, placed in the lower and outer parts of the grey matter; the amount present varies in different specimens.

b. The Cerebellum and Valvula cerebelli.

a. External form. The cerebellum is a thin, semilunar plate, which projects between the optic lobes and the fourth ventricle, its base covering the most anterior part of the ventricle; the posterior surface possesses a very faint median fissure (Reissner). The valmula cerebelli (Velum medullare anterius, Reissner) is the thin lamella which connects the anterior surface of the cerebellum with the optic lobes.

$\beta$. Minute structure. By means of longitudinal, vertical sections, the posterior surface of the cerebellum is seen to be covered with epithelium; in the lower part of the surface this is columnar or conical, above it is flattened: immediately beneath, that is in front of this is a finely granular layer, with very closely packed and granular nuclei. In front of these is a stratum of nerve-fibres forming the second layer of the cerebellum.

Still more anteriorly is the third layer of the cerebellum, an irregular double layer of large cells (Purkinje's cells, Denissenko); the cells have an average length and breadth of $0.040 \mathrm{~mm}$. and $0.015 \mathrm{~mm}$. respectively; they are pear-shaped or of spindle-form, and possess usually two well-marked processes, one passing into the layer behind, the other forwards into the anterior layer to be immediately described, while other less distinct processes radiate irregularly in all directions. The fourth and most anterior layer of the cerebellum is a thick stratum of nerve fibres with numerous nuclei $(0.006$ to $0.008 \mathrm{~mm}$. diameter). The fibres are for the most part arranged transversely, but some course in various directions. These fibres underlie the flattened epithelium which covers the anterior surface of the cerebellum. 
The fibres of the second layer course, for the most part, in an almost vertical plane; they connect the cerebellum with the optic lobes (proces:us cereluelli anl corjora bigemina) and with other parts of the brain.

The fibres of the fourth layer receive numerous long processes from the largre cells of Purkinje; they form a large commissural system, which can be followed ventrally on each side into the pars commissuralis. A part of the fibres ends here in the grey matter, a second portion enters the auditory area and forms a descending auditory root, a third part joins the lateral columns (in the meilulla oblongata), and more anteriorly some join the rentral columns. The descending fibres from the cerebellum, together with the filrae arcuatce found in the ventral columns, indicate the presence of a pons $\sigma_{a}$ rolii. The fibres of this ventral commissure decussate only on its dorsal surface (Köppen).

The Falcula cerebelli contains a few medullated fibres and the ronts of the trochlear nerves; these pass from the medulla oblongala into the ralvula cerebelli, eross in the median line, and then proceed forwards as the trochlear nerves.

The pigment in the pars commisonralis is arranged in a curved line similar to that found in the medulla oblongata, but the line is shortened at either extremity, and consequently does not extend into the cerelellum.

c. The optic lobes and Crura cerelit. ICorpura geminata and Pars pedumularis, Reissner; Lulus optirus, Stieda; Vierhügel, Tioxlemann; Tierhïgrel (Zweihügel) and Perlunevli cerel,ri, Schiess; Mesencephalon, Huxley.)
Fig. 102.

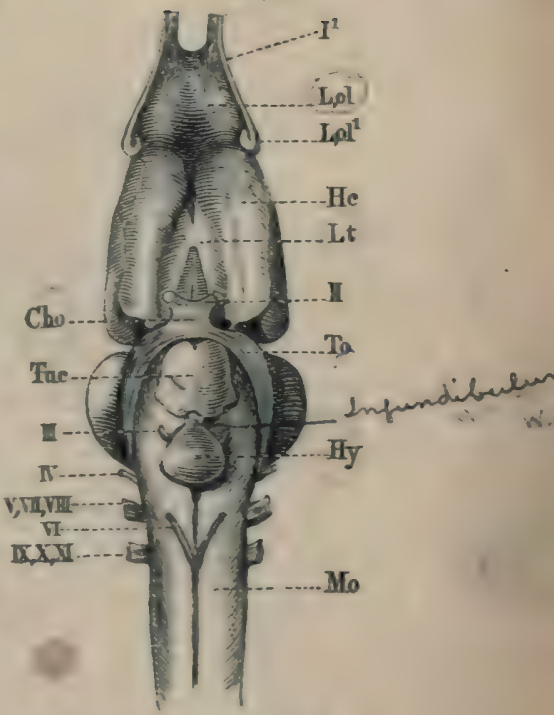

Ventral riew of brain of Ranes caculenda.

Cho Optic ahiswurL

He Cerebral heuvispheres.

Hy Pituicary body.

L ol Olfactory lobe

L.op Origin. of olfactory nerve from the cerebral hemisphere.

ll Launina terminalia,

Mo Medulla ublongratia

To Optic tract.

Tw, Tuber cinereum.

$I$ Ist 3 root of the olfactory norve.

II Optic nerve

III Oculo-motor nerve.

IV Trochlear nerve.

VI Abducens nerve.

V, VII, VIII Trigeminal, facial, and auditory nerves.

IX, $X, X I$ Gloasopharyngeal, pneumogastric, and accevoory nerves. 
a. External form (Figs. 98, 102, 103 L.op). The optic lobes Fig. 103.

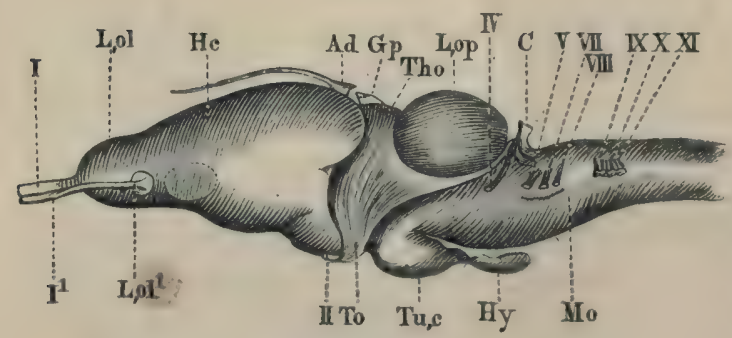
are two prominent ovoid bodies placed immediately in front of the cerebellum, and connected with it by the valvula cerebelli; posteriorly they touch each other Lateral view of brain of Rana esculents.

\begin{tabular}{|c|c|c|}
\hline$A d$ & Choroid plexus. & Tu.c Tuber cinereum. \\
\hline$C$ & Cerebellum. & factory nerve. \\
\hline$G p$ & Pineal body. & $I^{\prime} 2 n d$ \\
\hline$H c$ & Cerebral hemisphere. & II Opti \\
\hline$H y$ & Pituitary body. & erve. \\
\hline $\boldsymbol{L} .0 \mathrm{l}$ & Olfactory lobe. & Trigeminal nerve. \\
\hline L.oll & Disc at origin of seconc & t. VII Facial nerve, \\
\hline L.op & Optic lobe. & $V I I I$ A uditory nerve. \\
\hline Mo & Medulla oblongata. & $\boldsymbol{I} \boldsymbol{X}, \boldsymbol{X}, \boldsymbol{X} \boldsymbol{I}$ Glosiopharyngeal, pneumo- \\
\hline Tho & Thalamencephalon. & gastric, and accessory nerves, \\
\hline & $\mathbf{O}_{1}$ & \\
\hline
\end{tabular}
in the median plane, while anteriorly they diverge and thus constitute the widest part of the brain; in the anglethus formed

is the thalamencephalon. The optic lobes are always more darkly pigmented than any other part of the central nervous system.

The Crura cerebri are two columns of white matter, placed beneath the optic lobes, and partly hidden by the pituitary gland. At their junction with the medulla oblongata, or rather with the pars commissuralis, is a very slight transverse fissure; at the same point the ventral longitudinal fissure is interrupted by an extremely small grey tubercle (Stieda).

$\boldsymbol{\beta}$. Internal structure. From the anterior extremity of the fourth ventricle a canal, the Sylvian aqueduct (Aqueductus Sylvii, iter a tertio ad quartum ventriculum), may be traced forwards under the cerebellum, in the median line of this section of the brain. At about 'opposite the middle of the length of the optic lobes the canal is dilated and communicates with the cavities or ventricles (Ventriculi lobi optici, Stieda) enclosed by these; a general cavity is formed, which in transverse section has something of the form of the letter $T$. The roof of the cavity is thinner than the floor; this is especially the ease in the median plane opposite the superipr longitudinal fissure between the optic lobes; the floor is thinned in the middle line by the descending portion of the cavity. The cavity of each optic lobe extends both forwards and backwards beyond its point of communication with the dilated Sylvian aque- 
duct, hence in a transverse section taken in front of this point (Fig. $\mathrm{IO}_{4} h^{\prime}$ ) the cavity of either side appears to be isolated; in a horizontal and longitudinal section (Fig. $105 \mathrm{Aq}$ ) the general arrangement of the parts may be well seen.

The grey matter is chiefly arranged in a layer so as to surround the cavity (Fig. I04), this layer being deeper on either side of the descending portion of the cavity than elsewhere. For the rest the grey matter is much interspersed among the white matter, except at the circumference of the section, which is entirely formed of white matter. It contains a large number of small cells, of which the nuclei are alone visible; in the parts mentioned where the layer is most marked these cells are arranged in oblique rows, between which pass fine bundles of medullated fibres

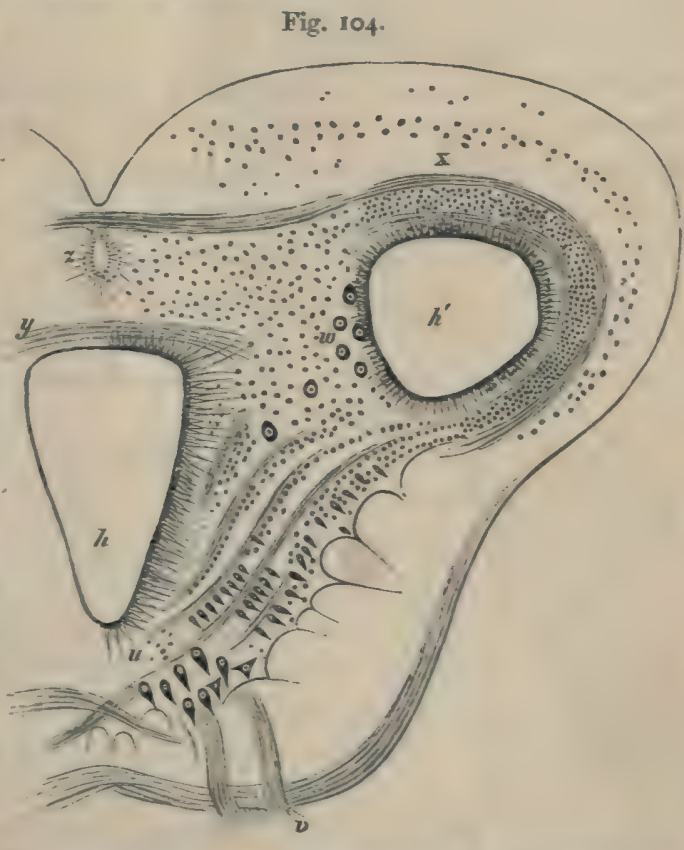

Transverse section through the anterior portion of the optic lobes opposits the origin of the motor-oculi nerve; from Stieda (mag. nified 30-80).

(Fig. 104, between $u$ and $h^{\prime}$ ). A group of large cells (Fig. $104 u$ ) is found on either side of the middle line and under the floor of the cavity; the cells are about $0.032 \mathrm{~mm}$. long, and $0.016 \mathrm{~mm}$. broad ; the oculomotor nerve may be traced to this group, which is the oculo-motor nucleus. A small commissure of decussating fibres connects the nuclei of opposite sides (Köppen).

The substance of the roof of the optic lobes (Fig. 104 $x$ ) is arranged in very distinct layers: above is a layer free from cells; 
the fibres of this layer are extremely fine and delicate, and have not been accurately traced; under this is a nuclear layer; a second layer of fine fibres follows, which is succeeded by a second layer of nuclei in a granular matrix, and lastly epithelium (Stieda). (Reissner describes three nuclear layers in Bufo variabitis, and this is also the case in $R$. temporaria, G. H. ; according to Köppen, the number is variable.) In the anterior portion of the roof a distinct bundle of fibres may be made out; externally they bend downwards, and can be traced as far as the crura cerebri.

Fibres corresponding with the commissural and arched fibres of the medulla oblongata are continued into the hinder portion of the crura cerebri, the change from pars commissuralis to crura cerebri being very gradual. The longitudinal white fibres are much increased in number in the crura cerebri, and a portion of them can be traced to the mucleus magnus.

A peculiar irregular group of large cells (Fig. 104w) is found where the roof meets the crura cerebri; these vary in diameter from 0.024 to $0.040 \mathrm{~mm}$., and their processes are very indistinct.

The fibres of the optic tracts arise, according to Köppen, from two different origins: the one lies on the hindermost part of the optic lobe ; from this point the fibres curve downwards and forwards to form longitudinal fibres; this root Köppen names the ventral ascending root, it can be traced through the entire length of the organ. The second root arises in the tectum opticum near the longitudinal fissure; it is smaller than the foregoing, and has, been named the dorsal ascending optic root. The fibres of these two roots unite anteriorly near the posterior commissure, at which point they receive additional fibres (Köppen). Bellonci traces a large proportion of the fibres of the optic tract to the nucleus magnus, which pair of nuclei, as already stated, he regards as the posterior pair of corpora quadrigemina of higher animals.

The pars peduncularis is the continuation of the pars commissu- ralis underneath the optic lobes; a gelatinous mass lying in the median plane and containing numerous isolated nuclei (Ganglion interpedunculare) divides it into two lateral hàlves. The longitudinal fibres are ungrouped posteriorly, but arranged in rounded strands in the middle, especially dorsally; anteriorly the grouped arrangement is lost and the number of fibres diminished.

The pigment of this region has, in a transverse section, an outline which has something the form of a lyre; commencing on either side of the median line, and underneath the deepest portion of the eavity, 
the pigment line passes, first, directly outwards ; then suddenly turns upwards and slightly outwards parallel with the wall of the deeper part of the cavity; it then curves outwards to pass below the cavity of the optic lobe, where it divides, one portion passing outwards, the other between the Sylvian aqueduct and the ventricle of the optic lobe.

d. The Thalamencephalon (Huxley), (Lobus ventriculi tertii, Stieda; Thalami optici, Reissner; Thalamus opticus \&. Lolus ventriculi tertii, Stannius; Ganglien der Haemisphaeren, Carus).

a. External form. From above (Fig. 98 Tho) the thalamencephalon is seen as a lozenge-shaped mass lying in front of the optic lobes, and behind and between the diverging posterior ends of the cerebral hemispheres; it is covered by a thick vascular membrane, the choroid plexus, through which passes the pedicle of the pineal body (Glanlula pinealis). On removing the choroid plexus a small aperture is seen in the roof of the thalamencephalon, connecting the hollow pedicle of the pineal gland with the third ventricle. The ventricle appears as a narrow slit in the median line, its walls being formed by the optic thalami. By pressing aside the cerebral hemispheres the posterior commissure (Commissura posterior) may be seen lying quite in front and deep in the cleft of the ventricle. Immediately behind the pedicle of the pineal body is a slight but wellmarked depression (Fig $98 \mathrm{G}$ ), the origin of which has not been investigated (Wiedersheim).

The choroid plexus 'is continued forwards between the cerebral hemispheres (Figs. 98, I03 $d d$ ) for some distance, and terminates in a fine thread of connective-tissue.

The under surface of the thalanencephalon (Fig. 102) is divided into two parts by the optic chiasma $(C h w)$ : the anterior portion $(L t)$ is the lamina terminalis (Sulstantia cinerea anterior); the posterior (Tu.c) the tuber cinereum. The lamina terminalis is bounded on either side by the cerebral hemispheres. The tuber cinereum (Figs. 102, 103 Tu.c) is a small median swelling immediately behind the optic chiasma, and caused by the depression of the floor of the third ventricle to form the infundibulium (Direrliculum infunlibuli, Reissner).

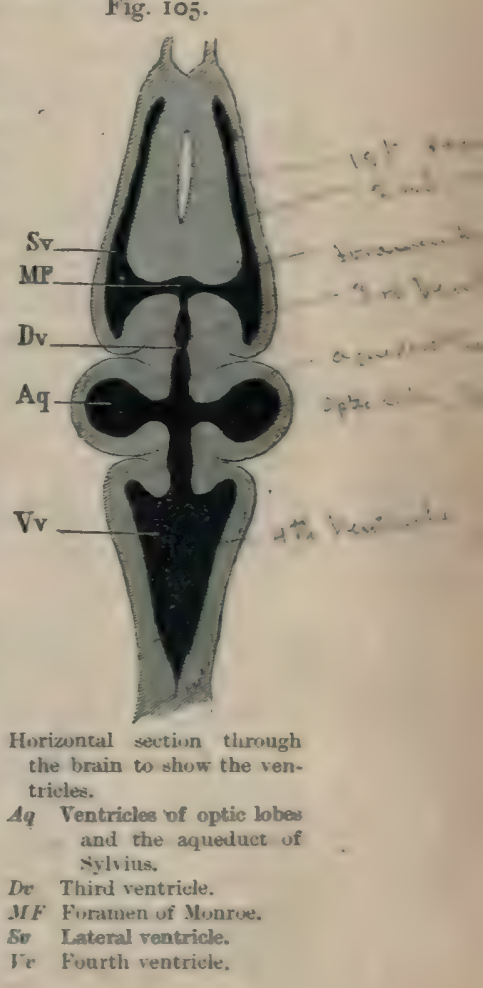


The pituitary body (Hypophysis cerebri) is a flattened sac, placed behind the tuber cinereum and continuous with it by means of the infurdibulum.

B. Internal structure. The aqueduct of Sylvius, after communicating with the ventricles of the optic lobes, again contracts (Fig. I05), but still remains somewhat larger than before. In the thalamencephalon the Sylvian aqueduct opens into the third ventricle, which gradually assumes the form of a vertical slit with the walls bulging slightly outwards in their upper parts. The thin roof of this ventricle, where complete, contains a band of transverse fibres. The floor is depressed both before and behind the part immediately above the optic chiasma, the posterior depression lying above the tuber cinereum, which here descends towards the infundibulum: a transverse section through this portion of the third ventricle has the form of a square standing on one angle, the superior angle being produced into the vertical slit of the general cavity. The anterior depression is formed by the general cavity being prolonged downwards and forwards to the lamina terminalis in the form of a narrow and shallow slit.

The white and grey matter of the thalamencephalon are only so far distinct in that the portion immediately surrounding the eavity is darker than the rest of the section. In the immediate neighbourhood of the cavity are many small cells and nuclei, which become scarcer further from the ventricle; they are arranged in rows, separated by a fibrillated matrix. On either side is a distinct bundle of longitudinal fibres, the 'round bundle' of Köppen, which come from the optic lobes but appear to arise from either the pars commissuralis or the medulla oblongata, and to receive additional fibres from the optic thalami; they pass forwards to the base of the cerebral hemispheres (Stieda). A second set of longitudinal fibres arises in the substance of the tuler cinereum and passes forwards to the hemispheres (strand of the Tuber-cinereum and Thalamus, Köppen); this band, together with the 'round bundle,' form a crus cerebri (Köppen).

The commissural fibres of the thalamencephalon are: (I) a commissura transversa Halleri in the posterior partion of the organ; (2) an optic commissure, consisting of fibres arising from the thalamencephalon (thalamencephalic root) and crossing the median line to join the optic tract of the opposite side; (3) a probable commissure between the optic nerves just in front of the chiasma opticormm; the existence of the latter is not yet proved beyond 
doubt; $(4)$ the large commissure of transverse fibres found in the roof of the third ventricle; whether the fibres decussate or not is uncertain (Köppen).

The fibres of the large commissure of the roof are, in part, continued into the strand of the Tuber-cinereum above mentioned, and thus conducted to.the posterior parts of the hemispheres (Köppen). A group of fibres (Meynert's band, Köppen) is found in each lateral wall of the third ventricle; they pass from the region of the nucleus parvus downwards in a curved course almost parallel with the external border of the thalamencephalon.

A distinct group of cells may be noted in this section of the brain, an arciform or circular group (Nucleus partus, Reissner; ganglion of the habenula, Köppen) of large spindle cells (average diameter 0.0r6 $6 \mathrm{~mm}$.), placed under the upper border close to the third ventricle; the group extends alongside the whole length of the ventricle. A second group lying in the middle and posterior parts beneath the ventricle, Köppen names the 'ventral nucleus' of the thalamencephalon.

The pigment in the posterior part of the thalamencephalon is arranged in a manner similar to that in the optic lobes and crura cerelori; anteriorly where the third ventricle is prolonged forwards and downwards the arrangement is different; the pigment lies in a curved line above the process of the ventricle, with its concavity directed downwards, each end bifurcating, in order that one branch may pass upwards, the other downwards.

The pineal body ${ }^{1}$ is a small vesicle placed underneath the skin above the fronto-parietal bones; in the embryo it is connected with the third ventricle by means of the pedicle ${ }^{2}$ already mentioned; the skin covering the body is always paler than the surrounding skin, and the usual eutaneous glands are absent in this part; the paler spot on the head may always be found, but is more distinct in Rana temporaria than in Rana esculenta. The structure on the roof of the third ventricle, which is usually known as the pineal body, is nothing more than a thickened portion of the choroid plexus, and consists of a group of convoluted vessels surrounded by pia mater, which is described by Wyman as being covered with ciliated epithelium $(R$. pipiens). The true pineal body is a small body with an outer con-

${ }^{1}$ Compare Ehlers, Ueber die Zirbel der Haifisehe, Zeit. f. wiss. Zool. I878, Vo . $\mathrm{XXX}$; and Balfour, Development of the Elnsmobranch Fishes, chap. ix.

2 Wiedersheim states that the pedicle is hollow, and regards the part formerly known as the pineal benly as a thickened portion of this pedicle. 
nective-tissue capsule, derived from the pia mater; this encloses an irregular mass of epithelial cells; according to de Graaf a twig of the ramus supramaxillaris reaches it subcutaneously, and a bloodvessel accompanies the pedicle through the foramen parietale. According to Darkschewitsch, the pedicle contains medullated nervefibres derived directly from the brain.

The pituitary body (Figs. 102, $103 H y$ ) when examined with a lens is seen to consist of two portions : an anterior, superior, and smaller white portion, and a larger, inferior, posterior, and reddish portion. The anterior portion has the form of a very small, flat disk, and is enclosed in a connective-tissue capsule which sends in larger and smaller processes. In either transverse or longitudinal section it is seen to be formed of two horizontal layers separated by a line of blood-vessels and connective-tissue. The upper layer consists of a granular and reticular matrix, containing many nuclei (averaging 0.006 to $0.010 \mathrm{~mm}$. diameter), and divided into irregular rounded or polyhedral spaces by bands of tissue derived from the capsule. This layer is more vascular than the lower. The lower layer consists of a mass of clear, nucleated rounded or polyhedral cells $\left(0^{\circ} 016\right.$ to $0.024 \mathrm{~mm}$. in diameter; nuclei from 0.008 to $0.012 \mathrm{~mm}$. in diameter, Reissner), pierced by very fine connective-tissue septa derived from the capsule. The septa are, for the most part, vertical and longitudinal (Reissner), the blood-vessels are very few.

The posterior larger portion of the pituitary body (Fig. I06) is also compressed from above downwards, and in transverse section as an oval outline. It possesses an external thin connectivetissue capsule, which sends in fine processes to support a mass of convoluted tubes, between which course a few blood-vessels; these tubes possess an outer nucleated basement-membrane, and are lined with a single layer of more or less cylindrical epithelium, which entirely fills the tube; hence the tubes possess no lumen. The tubes are from 0.04 to $0.08 \mathrm{~mm}$. in diameter; the cells are clear or granular, and possess distinct, rounded nuclei.

e. The Cerebral Hemispheres and Olfactory Lobes. The cerebral hemispheres (Lobi hemisphaerici, Stieda; Lobi cerebrales, Reissner; Centralmasse des Geruchssinns, Carus; Hemisphaeren des grossen Hirns, Tiedemann; Grosse Hemisphaeren, Schiess; Prosencephalon, Huxley). The olfactory lobes (Tubercula olfactoria, Stieda ; Lobi olfactorii, Reissner; Riechkolben, Schiess; Rhinencephalon, Huxley). 
a. External form (Figs. 98, 102, $103 \mathrm{Hc}$ and $L .0 l$ ). The two cerebral hemispheres form together the largest section of the brain; from above they are seen to be separated by a dorsal longitudinal fissure, which is here well marked: each hemisphere is an ovoid body with the smaller end directed forwards and continuous with the corresponding olfactory lobe; the posterior end forms one half of the anterior boundary of the thalamencephalon. The olfactory lobes are two elongated, rounded bodies directly continuous with the corresponding cerebral hemispheres, and likewise partially separated in the median line by a dorsal longitudinal fissure: at the point of union of the cerebral hemispheres and olfactory lobes is a faintly marked transverse depression.

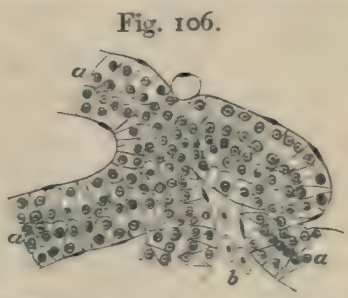

Section through the lower division of the pituitary body (magnified 360 times) ; from Stieda.

a Tubes lined with epithelium.

b Blood-resaela

On the ventral surface the parts are again marked off from one another by a corresponding ventral longitudinal fissure and a transverse groove; the two longitudinal fissures being continuous, anteriorly, between the olfactory lobes. The cerebral hemispheres appear to be more widely separated behind (Fig. 102) than is the case on the dorsal surface, and in the space so formed is the lamina terminalis $(L t)$. Seen from the side, the slight depression of the upper surface, between the cerebral hemispheres and the olfactory lobes, is seen to be continued downwards and slightly backwards to join the corresponding groove on the inferior surface.

The longitudinal fissures are shallow and do not meet, except at one point, at about the middle of the cerebral hemispheres (Fig. 105). The olfactory bulbs arise superficially (Figs. 102, $103 T$ and $L .0 l$ ) from the whole length of the olfactory lobe, between the anterior extremity $\left(l^{\prime}\right)$ and the posterior $(L . o l)$, where they are also attached to the cerebral hemispheres.

$\beta$. Internal structure. The cerebral hemispheres and olfactory lobes are hollow, the common cavity of each side being known as the lateral ventricle (Ientriculus lateralis); these ventricles communicate with each other, and with the third rentricle (Fig. I05). The narrow aperture by which the lateral ventricles communicate is known as the Foramen of Monro $(M F)$; it communicates with the third ventricle posteriorly, and with the space between the cerebral hemispheres anteriorly, and thus forms 
a common cavity (Tentriculus communis lobn'um hemisjilaericonum, Stieda).

In general terms, each ventricle may be said to be a semilunar cavity, prolonged backwards and forwards (Fig. I07 c); the outer

Fig. 10\%.

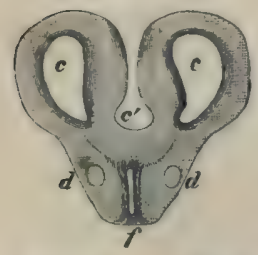

Transverse through the hinder portion of the cerebral hemispheres ; from Stieda.

c Lateral ventricle.

$c^{\prime}$ Common ventricle of Stieda.

d Longitudinal fibres.

$f$ Anterior prolongation of the third ventricle. wall is always more or less coneave, while the inner varies according to the part of the hemisphere examined. At the anterior and posterior extremities the inner wall is convex and bulges into the cavity (Fig. 107); in the middle portion of the eavity the inner wall presents a longitudinal groove (Ventriculi lateralis cornu internum, Reissner), (Fig. I08 d), and consequently the inner wall has here two rounded masses, an upper and a lower (Corpus striatum, Wiedersheim), projecting into it. By tracing them backwards and forwards, the lower swelling is seen to increase at the expense of the upper, while at the same time the lateral grooves disappear; the outline of the cavity shown in Fig. 107 is then obtained. The roof of the ventricle is arched and broader than the floor, which, in the middle part, exists only as a vertical slit (Fig. 108), (Ventriculi lateralis cornu inferius, Reissner): towards the anterior and posterior extremities it widens and becomes shallower (Fig. 107).

Fig. 108.

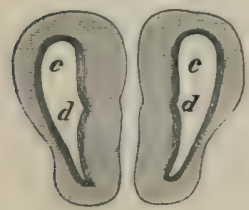

Transverse section near the middle of the cerebral hemispheres.

c Lateral rentricle.

$d$ Groove on the inner wall.

The cerebral hemispheres and olfactory lobes are composed of a fine granular matrix, enclosing spindle-shaped, rounded, or pear-shaped nerve cells and nuclei, and containing very fine fibres. The cells (Fig. $109 b$ ) are more numerous towards the ventricle, and somewhat sparse towards the superficial surface. The cells are of two chief sizes, the smaller and more numerous average $0.004 \mathrm{~mm}$. to $0.008 \mathrm{~mm}$. in diameter; they are found chiefly in the deeper portions of the section, but also form a very thin irregular layer beneath the pia mater: the larger cells have an average diameter of $0.010 \mathrm{~mm}$. to $0.012 \mathrm{~mm}$, and are placed towards the periphery, especially in the dorsal part of the inner wall.

In this irregular collection of cells the following centres have been described: (I) The nucleus, through which the corpns callosum passes (Köppen); (2) the lower internal or median cell-area 
(Osborne), situated above the foregoing nucleus in the posterior and middle portions of the hemispheres; (3) the upper internal cell-area (Osborne) is the area of large cells ir the dorsal part of the inner wall; (4) the Corpus striatum (Osborne) is a mass of cells between the corpus callosum and the commissura anterior; Köppen doubts the correctness of Osborne's opinion, and suggests that a group of cells found in the wall of the third ventricle in front of 'Meynert's band' may perhaps be a corpus striatum.

Fig. 109.

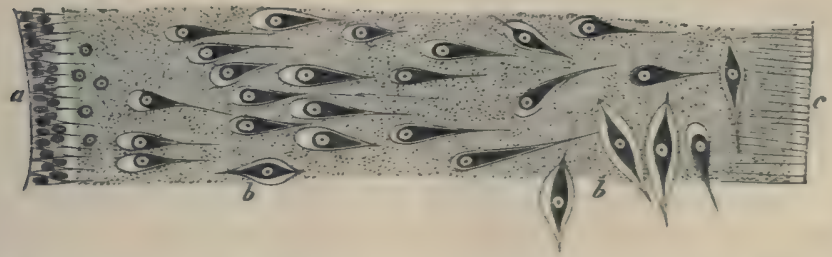

From a transverse section through one of the cerebral hemispheres; from Stieda. (Magnified 360 timea)

apithelinm of lateral ventricle.

b Nerve cells.

c Connective-tisue proceses from the Pia maler.

A bundle of longitudinal medullated nerve-fibres, the 'round bundle,' is found on either side of the median line (Fig. $107 d$ ), and near the lower border in the posterior portion of this region; these fibres can be traced from the posterior section of the thalamencephalon; they diminish in number as they course through the base of the cerebral hemispheres, and are ultimately lost in the lower anterior part of the outer walls. A second strand of longitudinal fibres is the continuation of that of the Tuber-cinerenm above described, which can be followed to the outer wall of the posterior part of the ventricles, and to the anterior commissure.

The commissures are: (I) The corpus callosum, a large bundle of transverse fibres, seen best in a transverse section, at the point of junction between the lamina terminalis and the cerebral hemispheres, forming an arch orer the roof of the anterior prolongation of the third rentricle. The fibres course to the inner and anterior parts of the hemispheres, and are situated chiefly behind the foramen Honroi. To this commissure must be added those fibres which unite the two olfactory lobes, and possibly the fibres $(\mathrm{Com}$ missura posterior) found in the roof of the third ventricle (Köppen). (2) The Commissura anterior (Stieda), a smaller set, found immedi- 
ately under the floor of the common ventricle, forming in their course outwards a curve, with the concavity directed downwards. This commissure connects the 'round bundles' of opposite sides, and those fibres coursing with the 'round bundles' to the olfactory lobes constitute the pars olfactoria of the commissura anterior. To this commissure must also be added some fibres found on the ventral surface of the commissura anterior and connecting the two strands of the Tuber-cinereum; an unusually coarse strand of these fibres can be traced to the inner wall of the ventricle, and is termed the pars olfactoria interna by Osborne.

The general structure of the olfactory lobes resembles that of the hemispheres; the olfactory nerves arise each by two roots, an outer and inner. The outer root arises from the outer wall near the groove between the corresponding hemisphere and olfactory lobe; the inner or anterior root arises from the anterior surface of the olfactory lobe. Both roots have a peculiar method of origin from the extremely fine fibrillar network of the matrix (Nerve-fibreconglomerate, Köppen), in which are rounded dark bodies known as 'glomeruli ;' in the 'glomeruli' dark points and nuclei are seen, between larger and smaller bands of nerve-fibres. Köppen holds that all the sensory nerves of the brain arise in a similar manner.

A decussation takes place between the two inner roots of the olfactory nerves; possibly the external roots are connected by means of the commissura anterior.

Very little pigment exists in the cerebral hemispheres or olfactory lobes, the greater portion is found in the upper part of the inner walls of the cerebral hemispheres.

The epithelium of the ventricles of the brain, like that of the central canal of the spinal cord, consists of conical cells with their bases directed towards the eavity, and their apices directed peripherally and prolonged into distinct processes (Figs. 104, I09 a). In such situations, as the choroid plexuses, where nervous tissue is absent and the cavity is completed by pia mater alone, the epithelial cells are flattened. Everywhere else it is ciliated ${ }^{1}$ and possesses dis.tinct round nuclei which are as broad as the cells themselves. The epithelium is somewhat irregularly and sparsely pigmented; the ventral parts of the central canal of the spinal cord, of the fourth ventricle, and of the Sylvian aqueduct are always more pigmented than the dorsal parts.

${ }^{1}$ Schmidt $(l . c$.$) states that the epithelium of the central canal of the spinal cord is$ not ciliated. 


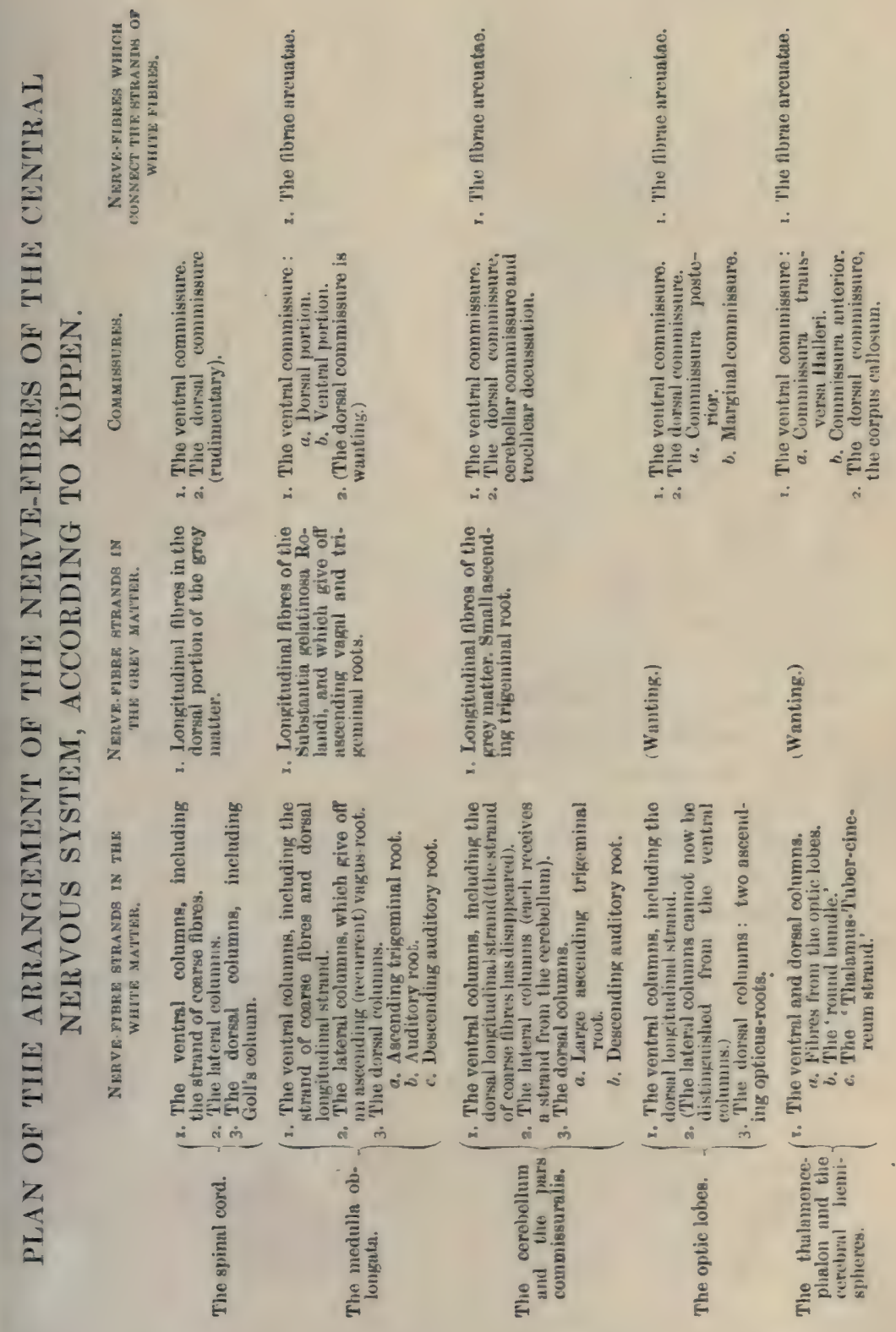




\section{The Coverings of the Brain and Spinal Cord.}

1. The Pia mater closely invests the whole of the brain and spinal cord; it may, in fact, be regarded as the flattened, outermost layer of the connective-tissue material which supports the nervous elements; fine processes (Fig. 109 c) pass radially from its inner surface to join the general connective-tissue matrix or neuroglia. It is usually pigmented, those portions covering the optic lobes and spinal cord being especially deeply pigmented: on the cerebral hemispheres it contains very little pigment; at times, indeed, in $R$. temporaria, pigment is absent from this part.

The pia mater is continued on to the choroid plexuses and pituitary body, and on to the pineal body by means of the pedicle; the membrane is very vaseular, and forms, especially for the cerebral hemispheres and the olfactory lobes, a very important source for the direct supply of blood-vessels.

2. The Dura mater, or lining membrane of the cranial cavity and vertebral canal, is a connective-tissue membrane containing many very much branched, pigmented cells. This membrane is not so deeply pigmented as the pia mater, except in that portion covering the cerebral hemispheres and the olfactory lobes, which is much darker than the corresponding pcrtion of the pia mater.

3. The arachnoid membrane is the layer of endothelial cells covering the inner surface of the dura mater: by means of the blood-vessels and nerves, ete., it is continued on to the pia mater of the spinal cord and brain, which it in like manner closely invests. Masses of calcareous crystals are found between the epineurium and the arachnoid (Wiedersheim) on each spinal nerve at its exit from the intervertebral foramen, also on the trigeminal nerves in the cranium. Additional smaller and more irregular masses are found on the dorsal part of the dura mater of the spinal cord.

\section{The Vessels of the Brain and Spinal Cord. (Fig. ilo.)}

The arteries of these organs are derived from the internal carotids and the arteriae vertebrales. As soon as the internal carotid arteries reach the cranial cavity each divides into two branches, an anterior (Ramus anterior, Schöbl ${ }^{1}$ ) and a posterior (Ramus posterior, Schöbl); the anterior branches course forwards on the lower part of

1. These names are those adopted by Schöbl for corresponding vessels in the newt, the translator has accepted them as being suitable, with slight modification, to the vessels of the frog. 
the surface of the brain as far as the anterior portion of the thalamencephalon, where they again divide; one division, arteria lobi hemisjhaerici inferior externa (Schöbl), continues forwards along the outer surface of the cerebral hemisphere and of the olfactory lobe as far as the olfactory bulb, where it may still be distinctly seen; it gives off branches to the adjacent parts in its course forwards. The vessels of the two sides communicate with each other by means of delicate transverse ressels (Arteriae communicantes anteriores). The second division, arteria lobi hemisphaerici sujerior interna (Schöbl), of the ramus anterior courses on the thalamencephalon to the dorsal surface, gives a large branch to the choroid plexus of the fourth ventricle, and runs forwards in the dorsal longitudinal fissure; it supplies vessels to all the neighbouring parts.

The rami pasteriores converge as they course backwards, and ultimately unite to form an arteria basilaris, which is continued in the median line of the under surface of the spinal cord as the arteria *jinalis anterior. The ramus posterior gives off, in its course, many small vessels to the neighbouring parts, and two larger vessels on either side, one of which, the arteria lobi opitici (Schöbl), is distributed to the optic lobes, while the other passes to the pituitary body.

The branches of these ressels form a network in the pia mater, from which the nervous tissue is supplied; they also send numerous branches directly into the brain and cord, and these have a similar arrangement for all parts of the brain with the exception of the cerebral hemispheres and olfactory lobes; more or less vertical branches arise from the posterior parts of the upper borders of the rumi anteriores, from the whole of the rami posleriores, and from the arteria basilaris; these course upwards from their place of origin into the corresponding part of the brain, give off a few branches in the white matter, and then branch freely, and at somewhat sharp angles, in the grey matter. In the pars commissuralis a large branch may be traced from the ramus josterior on either side upwards into the cerebellum almost to its upper border. The vessels of the cerebral hemispheres and olfactory lobes seem to possess no other definite arrangement than that described above. The grey matter seems, on the whole, to be more vascular than the white; the ressels of the latter are chiefly arranged radially to the surface, and run in courses which are more or less straight; the ressels of the grey matter are more irregular and sinuous.

The Arteria spinalis anterior courses along the whole length of the spinal cord, giving off lateral branches and communieating with 
rami spinales (branches of the Arteria vertebralis). These branches form a plexus in the pia mater, from which vessels pass at irregular points into the cord; one set of small vessels, described by Reissner, pass in a straight course from the superior longitudinal sinus towards the substantia reticularis, where they divide. Other branches pass directly from the arteria spinalis anterior, through the ventral longitudinal fissure, and there divide; the twigs as a rule avoiding the septum medium and passing in greater part towards the ventral

Fig. I10.

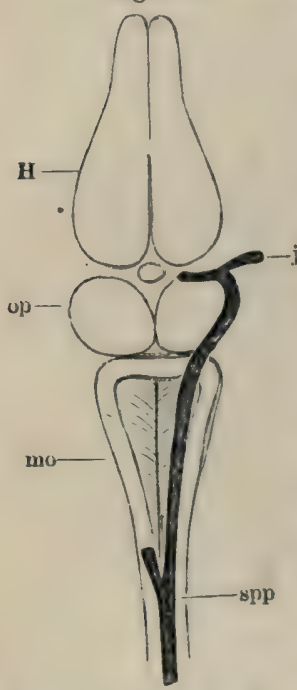

Diagram to show the Vena spinalis posterior, the $\mathrm{Ve}$ nae spinales superiores, and the origin of the Vena jugularis interna.

$\boldsymbol{H}$ Hemispheres.

ji Internal jugular.

op Optic lobes.

mo Medulla oblongata.

spp Vena spinalis posterior

horns. The vessels in the white matter are for the most part radial and straight, while in the more vascular grey matter they are irregular and more sinuous in their course.

The choroid plexus of the third ventricle (Plexus choroideus ventriculi tertii, Reissner) lies, as already described, on the roof of the third ventricle; it is somewhat triangular in form (Plexus venosus triangularis, Schöbl), and is evidently a prolongation of the pia mater, with an increased supply of vessels. It receives, at its anterior angle, veins from the cerebral hemispheres and the adjacent parts. The under surface is covered with a layer of ciliated pavement epithelium. At the posterior angles of the plexus the veins communicate on either side (Fig. IIO) with the anterior lateral prolongation of the rena spinalis superior, and with the internal jugular vein. The small body usually named the pineal body, and placed on the roof of the ventricle, is only a small thickened portion of the plexus, and consists of a group of convoluted blood-vessels. This plexus sends a considerable bunch of vessels into the upper part of the third ventricle. The choroid plexus of the fourth ventricle (Plexus choroillens rentriculi quarti, Reissner) is a triangular membrane, slightly attached to the borders of the fourth ventricle. Its upper surface is flat and bounded at either side by a large vein, the $v \in n u$ spinalis superior; anteriorly it is bounded by the cerebellum. The under surface is not flat; in the middle line is a slight furrow corresponding to the position of a median vessel, which may, when injected, be seen from the dorsal surface; from it a number of 
short vessels pass outwards and slightly backwards to the outer border. The connective-tissue between these ressels is pushed down into the cavity ; in this manner one obtains a double row of flattened villous-looking bodies, which frequently hare their tips pigmented. The under surface of the plexus is clothed with flattened, ciliated epithelium.

On either side of the pituitary body is another small venous plexus (Plexus lateralis, Schöbl); it communicates above with the posterior angle of the choroid plexus of the third ventricle; externally, with the internal jugular vein; and internally with its fellow of the opposite side by more or less irregular transverse ressels, which, together with a median rein from the fissure between the cerebral hemispheres, form an irregular circulus venosus around the pituitary body. These plexuses receive blood from the lower part of the cerebral hemispheres, the thalamencephalon, the optic lobes, and from the pituitary body. The veins of the spinal cord open into the dorsal, rena spinalis posterior (Fig. IIO spp), which bifurcates at the posterior angle of the fourth rentricle, one division passing to either side and forming, as already described, the outer border of the choroid plexus ; anteriorly it opens into the internal jugular vein (Fig. 110 ji).

The blood-ressels, both arteries and reins, are irregularly pigmented, both on the surface and in the interior of the central nervous system; those of the cerebral hemispheres and olfactory lobes have very little or no pigment. 
Fig. III. Dorsal view of the orbit, ete.; deep dissection.

c Course of the palatine nerve.

db Fibrous plate.

$d m$ M. depressor maxillae.

ef Terminal branches of the ophthalmic nerve.

F Facial with R. anterior of the glossopharyngeal.

$g, a, g$ Terminal twigs of the ophthalmic nerve.

$h$ Muscular twigs of the Ram, maxillaris.

ics M. intertransversar. capitis superior.

ii Twigs of upper eyelid.

$K$ Terminal twigs of the Ram. maxillaris.

la M. levator angruli scapulae.

pt M. pterygoideus,

sc $\quad$ M. sterno-cleido-mastoideus.

Sp Sympathetic nerve.

$t$ M. temporalis,

ir Nasal branch.

* Union of facial nerve with Ram. anterior of the glossopharyngeal nerve.

I Olfactory nerve.

Fig. I I 2. Dorsal view of the orbit, etc. ; superficial dissection.

e External branch of the ophthalmic nerve.

$f$ Internal branch of the ophthalmic nerve.

$g, g, g$ Terminal twigs of the ophthalmic nerve.

II Optic nerve.

III Motor oculi nerve.

IV Trochlear nerve.

Fig. II3. View of roof of mouth ; mucous membrane, etc., removed.

Branch of the Ram. palatinus to the Harderian gland.

$b$ Branch of the Ram. palatinus to the intermaxillary gland.

c. Inosculating branch of the Ram, palatinus,

Ch Internal naris,

d Cutaneous branch of the Ram, palatinus.

db Fibrous plate.

F Ramus mandibularis of the facial nerve.

Gl Intermaxillary gland.

HD Harderian gland.

$l \quad$ Eyeball.

$m$ M. masseter.

Ms.ob.i. M. obliquus inferior.

OK Upper jaw.

$r$ M. retractor bulbi.

$r i$ M. rectus internus.

sc M. sterno-cleido-mastoideus.

uk Mandible.

+ Terminal branch of Ram. palatinus. the glossopharyageal.

III Motor oculi nerve nerve.

Vd R. mandibularis.

$V e(\nabla I I)$ Facial nerve.

$\boldsymbol{X}$ Pneumogastric nerve.

$\boldsymbol{X}_{\mathbf{r}} \quad$ Glossopharyngeal nerve.
II Optic nerve.

III Motor oculi nerve.

IV Trochlear nerve.

Ve R. maxillo-mandibularis (of the trigeminal

$\begin{array}{ll}V c^{\prime} & \text { R. maxillaris } \\ V d & \text { R. mandibularis }\end{array}$ nerve.

Ve (VII) Facial nerve,

$V g$ Gasserian ganglion.

$V N$ Trigeminus,

VS Sympathetic nerve.

VI Abducens nerve.

VII' Facial nerve.

VIII Auditory nerve.

$\boldsymbol{X}_{\mathbf{I}} \quad \boldsymbol{R}$ am. anterior of the glossopharyngeal.

$X_{2} \quad$ Glossopharyngeal nerve.

$\boldsymbol{X}_{3}$ Pnelumogastric nerve.

$X G$ Ganglion nervi vagi.

XI Accessory nerve. $\nabla a$ Ophthalmic nerve.

Ve R. maxillo-mandibularis.

$V c^{\prime} R$. maxillaris of the trigeminal nervo.

Vd R. mandibularis of the trigeminal nerve.

$V I$ Abducens nerve.
$V \boldsymbol{P}$ Ciliary nerves.

* Union of facial nerve with Ram. anterior of

Ib Ranus palatinus of trigeminal nerve.

VC Ramus maxillo-mandibularis of the trigeminal

Yc Ramus maxillaris of the trigeminal nerve.

\section{c Cardiac nerve.}

$F$ Union of facial and Ram, anterior of the glossopharyngeal nerve.

$h$ Ram. hyoideus of the glossopharyngeal nerve.

la M. levator angi scapulae.

lgd M. longissimus dorsi.

$m$ M. masseter.

mt Ram. mandibularis of the glossopharyngeal nerve.

$\boldsymbol{M}_{\text {I }}$ Hypoglossal nerve.

$M_{2}$ Brachial nerve.

oh Anterior cornu of the hyoid bone.

oi M. obliquus internus.

phI M. petrohyoideus I.

ph2 M. petrohyoideus II.

$p h_{3}$ M. petrohyoideus III.

$\mathrm{ph}_{4}$ M. petrohyoideus IV.

Fig. II5. Disection of the floor of the mouth.

pp Pharyngeal branches of the pneumogastric nerve.

$t$ M. temporalis.

us Muscular twigs of the Ram, mandibularis of the trigeninal nerve.

$Z$ Tongue.

$V a$ Terminal twigs of the ophthaimic nerve.

Ve Ram, maxillaris of the trigeminal nerve.

Yd Ram, mandibularis of the trigeminal nerve.

$\nabla e(V I I)$ Facial nerve.

$X_{I}$ Ram. anterior of the glossopharyngeal nerve.

$\boldsymbol{X}_{2} \quad$ Glossopharyngeal nerve.

$X_{3}$ Pneumogastric nerve.

$X_{3}$ Ram. gastriei of the pneumogastric nerve.

$X_{3 l}$ Ram. laryngeus.

$X_{3} p$ - Ram. pulmonales of the pneumogastric nerve,

$X I$ Accessory nerve of the pneumngastric nerve.

din M. depressor maxillae.

$F$. United facial nerve and Ram. anterior of the glossopharyngeal nerve.

$g h$,$\} M, geniohyoideas.$

$h h^{\prime}$ Ram. hyoidens of the gloseopharyngeal nerve.

II Heart.

Lg Lung,

$m^{\prime}$ Ram, mandibularis of the gloseopharyngeal nerve.

MI Hypoglossal nerve.

$\boldsymbol{M}_{2}$ Brachial nerve.

oh Anterior cornu of the hyoid bone.

oh Momohyoideus.

phI M. petrohyoideus $\mathrm{I}_{\text {。 }}$

phe M. petrohyoidens II.

$\mathrm{ph}_{3}$ M. petrohyoideus III.

$\mathrm{ph}_{4}$ M. petrohyoideus IV.

sc M. sterno-cleido-mastoideus.

$s h$ M. sterno-hyoideus.

sm M. mylohyoideus (submaxillaris).

smt M. submentalis.

TT Thyroid.

uk Mandible.

us Mruscular twigs of the Ram. mandibularis.

$X_{2} \quad$ Glosepharyngeal nerve.

$X_{3}$ Pneumogastric nerve.

$X_{36}$ Rami cardiaci of pneumogastric nerve.

$X_{3} l$ Ram, laryngeus of the pneumogastric nerve.

$X_{3} p$ Ram. pulmonalis of the pneumogastric nerve.

1 The branches of the vagus which are represented in this figure as crossing the petrohyoid muscles ought to be underneath them.-Trans. 


\section{THE PERIPHERAL NERVOUS SYSTEM.}

\section{E. The Cravial Nerves.}

(To facilitate reference the original arrangement of this part has been altered.)

[There are ten pairs of cranial nerves in the frog, which are numbered in order from before backwards. The mode of origin of these nerves, and their deeper relations with the respective parts of the brain to which they belong, have already been described.]

1. The olfactory nerve ( $N$. olfactorius ), [(Figs. 97, 98, 102, 103, III I) runs a very short course only a few lines in length, and escapes from the cranium by an opening in the cartilage of the sphenethmoid into the nasal cavity, where it divides into two branches, each of which breaks up into a brush of filaments, to be distributed in the olfactory mucous membrane. The nerve contains no white fibres]. (See organ of smell, p. 385.)

2. The optic nerve (N. opticus), (Figs. 97, 102, 103, III II) [arises, as already described, by the optic traet, and joins with its fellow at the optic chiasma or commissure, where part of the fibres pass over to the opposite side (according to Michel all the fibres cross). Each optic nerve then courses outwards, piercing the cartilage of the cranium and so reaching the eyeball]. (See organ of sight, p. 408.)

3. The motor oculi ( $N$. oculomotorius, Oculo-motor, Motor comminis), (Figs. 102, III, II 2, II $3 I I I)$. From its origin it courses outwards and forwards, perforating with a slight obliquity the cartilaginous wall of the cranium, just in front of the Gasserian ganglion (Fig. II6 III); on reaching the orbit it divides into two branches, between the Levator bulli and the Rectus internus and inferior. One branch, Ramus snperior, runs over and parallel to the Ramus ophthalmicus Trig. and enters the under surface of the Rectus superior; the second, lower branch, Ramus inferior, supplies filaments to the Rectus internus and inferior and to the Obliquus inferior. Apparently it exchanges fibres with the ophthalmic division of the trigeminal nerve.

[That portion of the motor-oculi between its branch to the Rectus superior and to that to the Rectus internus contains a number of nerve cells; according to Schwalbe (l.c., p. 235 and Pt. XII, Fig. 4) these cells are arranged in four groups or ganglia ; 
the second group forms a very slight prominence, and is covered by a very fine layer of nerve fibres, it also gives off some extremely fine nerves to the eyeball; this is perhaps a ciliary ganglion (Ganglion ciliare, Schwalbe). Beard, however, names it 'mesocephalic ganglion.' The other three groups are simply clusters of cells between the fibres of the nerve.]

4. The pathetic or trochlear nerve ( $N$. trochlearis, patheticus), (Figs. 102, 103, and 112 IV). From its origin it courses forwards with and then crosses the motor-oculi ; it perforates very obliquely the cartilaginous lateral wall of the cranium, in front of the motor oculi but above and very slightly behind the optic foramen (Fig. I16); it runs parallel to and in company with the Ramus opthalmicus trigemini, and appears to exchange a few fibres with it, which, however, according to de Watteville, Stannius, Cuvier, and Wyman, is not really the case. In this course it lies first to the inner, then to the outer side of the ophthalmic, over which it passes to supply the Rectus superior. [The pathetic and ophthalmic nerves are sometimes enclosed in a common sheath (de Watteville).]

5. The trigeminal nerve ( $N$. trigeminus), (Figs. 97, 102, 103, III, II2, II3, and II4 $V$ ) is the largest of the cranial nerves in the frog; from its origin it runs outwards and forwards to the skull wall, and just before reaching this enters the large Gasserian ganglion. It then passes through the cranial wall immediately in front of the auditory capsule, and divides at once into two main

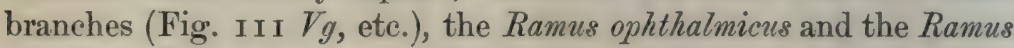
maxillo-mandibularis.

The Gasserian ganglion is a large, yellow, oval ganglion placed in a depression in the outer wall of the cranium; it is covered by a 'periganglionic gland,' which is similar in structure to that of a spinal 'periganglionic' gland (see p. I80), the fibrous capsule being stronger. This ganglion receives three other nerves besides the trigeminal, viz. the sixth and seventh nerves, and branches of the sympathetic.

According to de Watteville, these nerves are arranged on the lower surface of the ganglion, so that the sympathetic is below, the sixth above it; then the seventh, while the fifth is uppermost; the sympathetic splits into several bundles which join the various branches of the ganglion; the sixth divides into two bundles, one of which usually joins the ophthalmic, while the other makes its exit independently; the seventh splits into two bundles, one of which 
leaves the ganglion as the hyomandibular branch, the other gives some fibres to the palatine branch of the trigeminal nerve, and is then continued as the palatine branch of the facial.]

8. The Ramus ophthalmicus (Ramus nasalis, Fischer; Ophthalmic or Orbital Branch, Wyman; Orbito-nasal or Ophthalmic Nerve, de Watteville), (Figs. II I and II $2 F_{a}$ ). After learing the Gasserian ganglion the nerve is directed forwards parallel to the side of the cranium, between this and the eyeball. It lies beneath the Rectus superior, but above all the other muscles of the eyeball and the optic nerve. At the anterior end of the orbit it divides into two branches ( $e$ and $f)$ which pass through apertures (Foramen pro ramo nasali) in the eartilage of the sphenethmoid, to reach the nasal eavity, where they lie between the eartilage and mucous membrane. In this position the nerves supply branches to the mucous membrane and then pierce the skull to appear on the surface (Figs. III, I1 $g, g, g, 114 \mathrm{Fa}$ ), the skin of which they supply. The branches inosculate with each other and communicate with the anterior twigs of the Ramus maxillaris (Fig. II $4 F_{c}$ ) and with those of the Ramus palatinus (Fig. Ir3 $\mathrm{V} b$ ).

In its course through the orbit the Ramus ophthalmicus gives off :-

(I) Near the Gasserian ganglion one, two, or three small branches, which communicate with the trochlear nerve, and may then be traced to the sclerotic of the eyeball; some of the twigs enter near the optic nerve, others nearer the cornea. They are regarded as Ciliary nerves (Nervi ciliares).

(2) A large branch, the palatine nerve (Ramus palatinus), (Figs. III and II $3 b, b$ ). This nerve, after receiving the palatine branch of the facial, descends on the inner border of the Levator bulbi to the mucous membrane of the mouth, to which it gives numerous filaments; it then runs parallel and near to the median line, lying on the base of the skull; and near the front of the orbit it divides into three branches. The smallest $(a)$ supplies the Harderian gland $(H D)$; the second $(b)$ continues in the course of the original nerve, pierces the romer, and divides, giving filaments to the mucous membrane in its whole course, while the terminal twigs supply the intermaxillary gland $(G l)$ and the surrounding structures. One of these $(\dagger)$ ascends on the anterior border of the sphenethmoid to the intermaxillary (internasal, Born) space to supply the numerous glands and to inoseulate by one or two twigs with the nasal branch $(t r)$ of the trigeminal. 
The third branch of the palatine nerve $(c)$ curves directly outwards, just behind the palatine bone, to the inner surface of the maxillary bone; it then courses backwards, pierces the fibrous plate $(d b)$ between the eyeball and the pterygoid bone, and ultimately unites with superior maxillary division of the trigeminal nerve $\left(V c^{\prime}\right)$. Just before piercing the fibrous plate it gives off a tolerably large nerve $(d)$ to the mucous membrane, and in its whole course it gives off twigs to the mucous membrane and surrounding structures; many of these twigs inosculate with other terminal twigs of the trigeminal.

[This nerve has been minutely described by Stirling and Macdonald; these observers find that the branches form a very fine and close plexus in the mucous membrane, etc.; fibres were traced to blood-vessels, glands, etc., and ganglion cells were found scattered along the nerves. The fibres are both medullated and non-medullated, and many of the cells are described as 'spiral cells' (see page 20I), such as those described by Arnold in the sympathetic system of the frog.]

b. The Ramus maxillo-mandibularis (Ramus maxillaris, Ecker and Hoffmann; Supra-maxillary, Humphry; Upper Maxillary Branch, Wyman), (Figs. III, I I 2, and I I $3 V c$ ). This nerve is the largest division of the trigeminal; it runs directly outwards behind the eyeball, in front of the auditory capsule, and between the temporal and pterygoid muscles. After a very short course it divides into the maxillary and mandibular nerves. The nerve gives off before its division a few fine filaments $(i, i)$ to the hinder half of the upper eyelid and to the surrounding skin, also a branch $(h)$ [not correctly drawn in Fig. II 1] which divides to supply twigs to the temporal and pterygoid muscles.

(1) The Ramus maxillaris (Ramus supramaxillaris, Ecker; Ramus maxillaris superior, Hoffmann; Upper Maxillary Branch, Wyman ; Supramaxillary, Humphry and de Watteville), (Figs. I I I, I I 2, II 3 , and II $V_{c}$ ) runs outwards and then forwards, between the eyeball and the outer wall of the orbit, to the margin of the upper jaw $(K)$; a large portion terminates in a number of small branches for the supply of the skin of the lower eyelid, the upper lip, and of the parts between the tympanic membrane and the external nares. Some of these twigs inosculate with twigs of the palatine and ophthalmic nerves. The second portion of the nerve unites with the palatine nerve, as already described. 
(2) The Ramus manditularis (Ramus maxillaris inferior, Hoffmann; Mandibular or Lower Jaw Branch, Wyman; Inframaxillary, Humphry and de Watteville), (Figs. I I I, I I 2, I I 3, I I 4, and I I 5 $\left.V_{d}, u s\right)$. As far as the outer margin of the eyeball, this nerve runs parallel to and behind the Ramus maxillaris, in which course it supplies branches to the temporal and pterygoid muscles; it then curves backwards, outwards, and downwards to the under surface of the squamosal bone, where it supplies a twig to the Depressor maxillae, and then perforates the Masseter: in this manner it reaches the outer surface of the mandible, just behind the insertion of the temporal muscle; it then courses forwards, under the skin, to the Symphysis menti. In this course the nerve gives off numerous branches to the skin and surrounding parts, it also supplies the mylo-hyoid and submental muscles; one branch (Figs. II 4 and II $5 \mathrm{us}$ ) is larger than the rest, and supplies the under surface of the floor of the mouth and lower lip.

6. The abducens nerve (Tertus abducens, Ecker and Hoffmann; included in the trigeminal, Wyman), (Figs. I I I and I I 2 VI). This very slender nerve courses along the inner wall of the cranium from its origin to the Gasserian ganglion ( $q \cdot v$ ) which it joins, and leares this in contact with the ophthalmic division of the trigeminal nerve: the nerve then bifurcates in the orbit; the outer branch supplies the Rectus externus, the inner inosculates with small twigs of the ophthalmic division of the trigeminal, and then gives off a number of small eiliary nerves, already described, and one special branch to the Retractor bulbi.

7. The facial nerve ( $\mathrm{V}$. facialis, Ecker and Hoffmann; Faciali* (Portio dura), Wyman; Facial or Jugular Nerre, Stannius), (Figs. III, II 3 , and II $\left.4 F_{e} F I I\right)$ arises immediately behind the trigeminal, and runs forwards, first in company with the auditory nerve, then alone, to the Gasserian ganglion (q.r.), with which it unites; it again appears at the posterior angle of the ganglion, and escapes from the cranium in company with, and immediately behind, the Ramus mandibularis of the trigeminal, and divides at once into two branches.

a. The Ramus palatinus at once unites with the palatine branch of the ophthalmic division of the trigeminal nerve. Wiedersheim doubts this arrangement, and holds that the two portions arise in common from the Gasserian ganglion; neither has Wyman (Rana pipiens) described this branch of the facial. 
[De Watteville states that the Ramus palatinus and the palatine branch of the ophthalmic nerve are separated by the carotid artery. In urodeles the two nerves are distinct.]

b. The Ramus hyomandibularis (Ramus jugularis, Hoffmann; Facial Nerve, Wyman), (Figs. II 3 and Ii $4, V e V I I$ ). The nerve is directed outwards and backwards so as to pass around the bony wall of the auditory capsule, it then crosses over the inner end of the columella, with which it is in close contact, and is then joined, under cover of the sterno-cleido-mastoideus $(s c)$, by a branch (Ramus communicans) of the glossopharyngeal (see Fig. I I I *). The single trunk $(F)$ so formed is directed downwards in the posterior wall of the Eustachian tube to just above the angle of the mandible, where it divides into three branches, or sometimes into two, in which ease a third nerve is supplied by one of the others, usually by the Ramus hyoideus.

(I) The Ramus mandibularis (Ramus mentalis, Hoffmann; Third Trunk of the Facial, Wyman), (Figs. I I $4 \mathrm{mt}$ and I I $5 \mathrm{~m}^{\prime}$ ) passes inside the angle of the jaw and courses forwards, between the skin and mylo-hyoid muscle, parallel to the Ramus mandibularis of the trigeminal nerve, as far as the symphysis. It supplies small twigs to the neighbouring parts of the mucous membrane of the mouth.

(2) The Ramus hyoideus (Ramus jugularis, Hoffmann; Second Trunk of the Facial, W yman), (Figs. I I 4, I I 5 h) is the largest division of the facial; it courses forwards subcutaneously over the deltoideus and the hinder fibres of the mylo-hyoideus to the anterior cornu of the hyoid bone, supplying its muscles and the skin of the throat and sternal region.

(3) The Ramus auricularis (First Trunk of the Facial, Wyman); is a small branch, directed outwards; it supplies a branch to the walls of the tympanic cavity, and is finally distributed in the skin under the tympanic membrane and behind the angle of the mouth.

8. The auditory nerve (N. acusticus, Ecker, Hoffmann ; Auditory Nerve, Wyman). This nerve has a very short course in the cranium; it reaches the auditory organ by a foramen (Fig. 116 VIII) in the auditory capsule, and is then distributed in the ear, with which it will be described.

9. The glossopharyngeal nerve $(N$. glossopharyngeus, Ecker; Ramus glosso-pharyngeus, Hoffmann; Glossopharyngeal, Wyman; 
Glossopharyngeal of the Vagus, Müller), (Figs. 102 and I03 X, I I I, I 3 , I 4 , and I I $X^{2}$ ) arises in common with the pneumogastric nerve, and quits the skull with it through an opening (Canalis nerri vagi) immediately behind the auditory capsule, and at once divides into two branches; both of which lie under the $\boldsymbol{M}$ M. intertransversarii capitis and are covered by the Depressor mandibulae.

a. The Ramus anterior (Verbindungsast des Glossopharyngeus, Wiedersheim; Ramus communicans, Hoffmann; Uniting Branch, Wyman; Laryngeal Branch of the Vagus, Volkmann; Communicans ail facialem, de Watterille), (Figs. 11 I, I I 3 , and I I $4 X^{1}$ ). This nerve curves downwards and forwards around the auditory capsule and beneath the Depressor mantibuli to join the facial nerve, as already described.

b. The Ramus posterior (.V. glossopharyngeus, Wiedersheim; Ramus lingualis, Hoffmann), (Figs. II I, I I3, and II $4 X^{2}$ ). This nerve runs downwards and forwards to the ventral surface of the pharynx, dips underneath the Petrohyoideus IF, to appear again, after a short interval, by piereing the Petroliyoileus $I I$ or $I I I$, courses parallel to and behind the anterior cornu of the hyoid bone, and thus reaches the floor of the mouth. The nerve then runs forwards in a very sinuous course, close to the median line, and between the Geniohyoideus and Hyoglossus; in its course on the floor of the mouth it crosses the hypoglossal nerve. It supplies the petrohyoid muscles, and gives numerous small branches to the mucous membrane of the pharynx (Ramus pharyngeus, Hoffmann).

10. The pneumogastric or vagus nerve (Tagus; Ramus intestinalis nervi ragi, Fischer, Hoffmann; Vagal Trunk, Wyman; Vasosympathetic, Gaskell), (Figs. I I I, I I 3, I I 4 , and II $5 X^{3}$ ). This nerve arises in common with the glossopharyngeal; the two nerves leave the skull together by an opening in the exoccipifal bone (Canalis nervi vagi); immediately outside the skull they acquire a ganglionic enlargement (Gainglion condyluideum, Ganglion nerri ragi), (Fig. I I $X G^{\prime}$ ); in this course the glossopharyngeal lies in front of the pneumogastric, which it then leaves. The pneumogastric lies first upon the $\boldsymbol{M}$. levator anguli scapulae, then running backwards and downwards along the hinder border of the Petrahyoileus IV it comes to the side of the pharynx; it is covered by the trapezius, and passes between the hypoglossal nerve and the Aorla ascendens; arriving at the Arteria pulmonalis, it gives off its terminal branches. 
[Gaskell has proved that this nerve contains both sympathetic and vagal elements, and that it is therefore really a vago-sympathetic.]

Fig. I 6 .

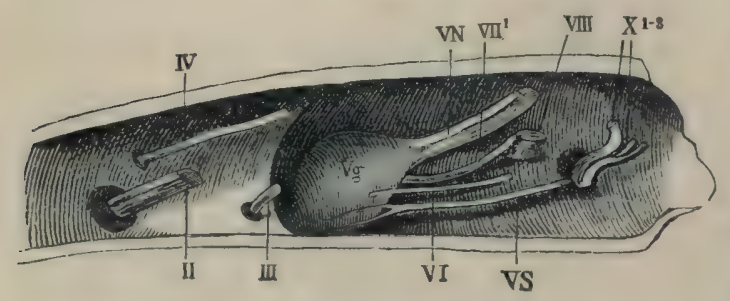

Right half of skull of Rana esculenta, seen from within.

$\begin{array}{ll}\text { II } & \text { Optic nerve. } \\ \text { III } & \text { Motor oculi nerve. } \\ \text { IV } & \text { Trochlear nerve. } \\ \text { VN } & \text { Root of the trigeminal nerve. } \\ \text { Vg Gasserian gangliun. } \\ \text { VS } \text { Sympathetic nerve. } \\ \text { VI Abducens nerve. } \\ \text { VIII Facial nerve. } \\ \text { VIII Auditory nerve. } \\ \text { XI-3 Pneumogastric and glossopharyngeal nervee. }\end{array}$

The branches and communications of the pneumogastric nerve are :-

a. Communications between the ganglion of the pneumogastric and the sympathetic system (Fig. I1I $\left.S_{p}\right)$, which again connect it with the Gasserian ganglion of the trigeminal nerve (Fig. I I I $V S, V g$ ); (see sympathetic system).

b. [The Ramus cutaneus dorsalis (Fischer) is considered by Stannius and Fürbringer to be the homologue of the Ramus auricularis; it passes outwards between the digastricus and temporalis to be distributed in the skin of the suprascapular region. This nerve is the persistent portion of the $N$. lateralis nervi vagi of the tadpole.]

c. During its course over the petrohyoidei the vagus gives off a few twigs (Fig. I 4 Pp), which form a fine plexus to supply these muscles and the pharynx [also a twig to the trachea, according to Hoffmann].

d. The Ramus accessorius (Fürbringer, Hoffmann, Ecker), (Fig. I $4 X I$ ) is usually a single small nerve which runs between the intertransversarii muscles and the trapezius: it supplies the under surface of the latter muscle.

e. The Ramus scapularis (Hoffmann) is a very slender nerve arising near the Ramus accessorius; it passes along the under surface of the trapezius to the inner surface of the interscapularis, which it supplies. 
f. The Ramus laryngens (Recurrens ragi), (Figs. II4 and II 5 $\mathrm{X}_{3} l$ ) runs for some distance parallel to the pneumogastric, separated from it by the petrohyoideus $I \Gamma$; arriving at the hinder cornu of the hyoid bone the nerve loops round the Arteria pulmonalis, and divides into two branches for the supply of the larynx.

g. The Rami gastrici (Fig. $1_{4} X_{39}$ ) are usually two in number: they pierce the partial diaphragm formed by the anterior fibres of the $M$. obliques internus and terminate in the walls of the stomach.

h. The Rami pulmonales (Figs. I 14 and I I $_{5} X_{3 p}$ ) also perforate the partial diaphragm, and then course along the pulmonary arteries to the lungs.

i. The Ramus carliacus (Figs. II 4 and I I $5 X_{3}$ ). This nerve is usually smaller on the right side than on the left; it passes along the dorsal surface of the pulmonary artery and Tena cava siljerior to the Sinus renosus; in this course it gives off two or three twigs to the roots of the lungs: the two nerres communicate just before reaching the heart and pass on to the auricular septum, whence they are distributed to the heart.

j. A slender Laryngeal nerve arises from the vagus alongside the Ramus carliacus; it courses along the hinder end of the greater cornu of the hyoid to the outer side of the pharyns, which it pierces to pass to the larynx.

\section{F. The Sptnat Nerves.}

I. General description. Ten pairs of nerves arise, as already described (p. I35), from the spinal cord; each nerve has two roots, a ventral or anterior, and a dorsal or posterior, which unite at their points of exit from the intervertebral foramen: just before, and for a short distance beyond this union, each dorsal root bears a ganglionic enlargement.

1. The length and direction of the various Nerve-roots vary greatly; the roots of the anterior spinal nerves run a very short course, almost transversely outwards, from their points of origin to the intervertebral foramina : the roots of the middle and posterior nerves, in consequence of the vertebral column being considerably longer than that part of the cord belonging to it, pass obliquely backwards to the foramina, the hinder nerves of the Cauda equina running for a considerable distance in the vertebral canal (Fig. I I6). The relations of these roots are as follows:- 
(I) The roots of the first nerve ( $N$. hypoglossus) arise from the spinal cord at a point between the first and second vertebrae; they run transversely outwards to escape between the first and second vertebrae. The dorsal root is extremely slender.

Fig. 117. •

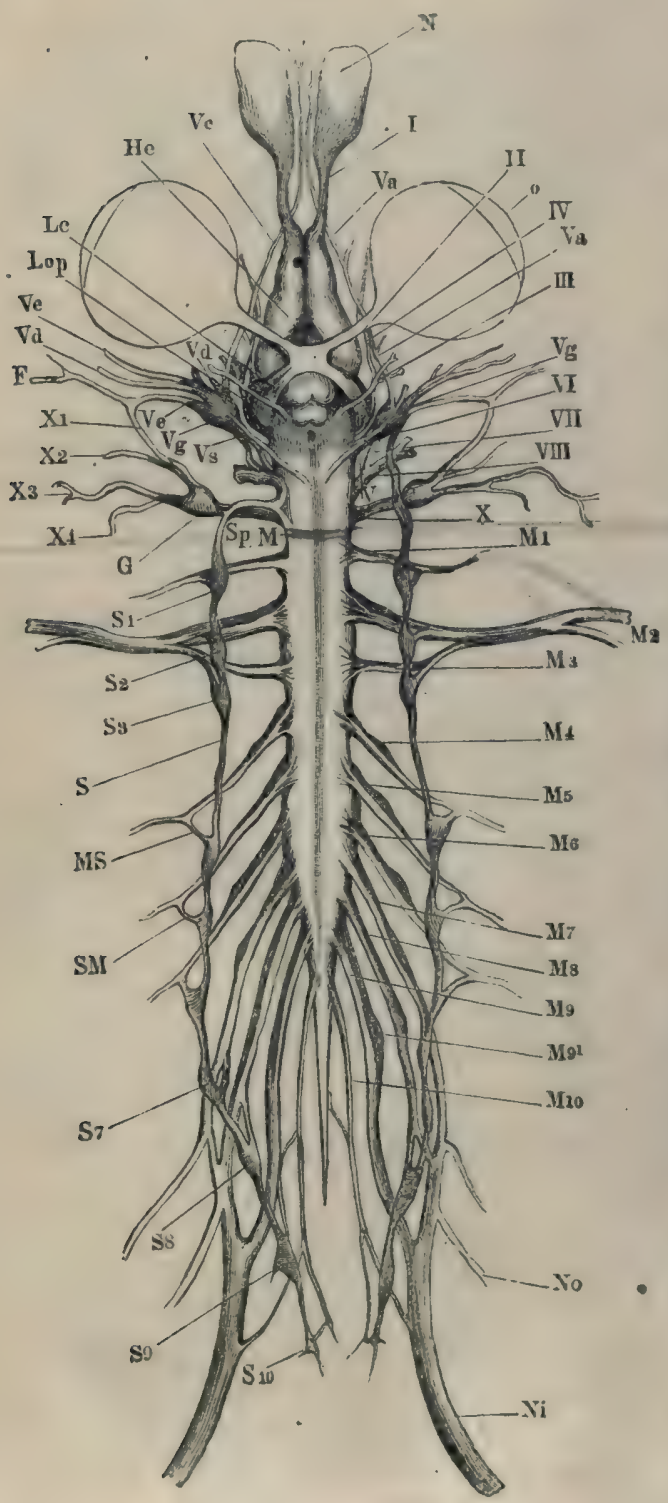

(2) The roots of the second nerve $(N$.

The nervous system of Rana esculenta, from the ventral surfaco. (From Icones physiologica by A, Ecker. Pl. XXIV, Fig. r.)

\section{F Facial nerve, \\ G Ganglion of pneumogas tric nerve.}

He Cerebral hemisphere.

Lc Optic tract.

Lop Optic lobe.

$M$ Boundary between medulla oblongata and spinal cord.

$M_{\mathbf{I}} \rightarrow$ ro Spinal nerves.

MS Connection between fourtl spinal nerve and sympathetic chain.

$N$ Nasal sac.

$\mathrm{Ni}$ Sciatic nerve.

No Crural nerve.

- Eyeball.

\& Trunk of sympathetic.

Sx-ro Sympathetic ganglia.

SMI Rami communicantes of the same.

Sp Continuation of symputhetic into head.

I Olfactory nerve.

II Optic nerve.

III Motor oculi nerve.

IV Trochlear nerve.

$V$ Trigeminal and facial nerves,

Va Ramus ophthalmicus.

Ve Ramus maxillaris.

$V d$ Mandibulgir branch of trigeminal.

Ve Hyomandibular branch of facial.

Vg Gasserian ganglion.

Vs Upper end of sympathetic trunk in connection wit l Gasserian ganglion.

VI Abducens nerve.

VII Facial nerve.

VIII Auditory nerve.

$\boldsymbol{X}$ Gloseopharyngeal and pneumogastric nerves.

$\boldsymbol{X}_{\mathbf{I}}$ Ramus anterior of gloseu. pharyngeal.

$X_{2}$ Ramus posterior of gloasopharyngeal.

$x_{3}$, Branches of pneumogastric. 
brachialis) arise at the level of the second vertebra and leave the vertebral canal between the second and third vertebrae.

(3) The roots of the third nerve arise from the cord between the second and third vertebrae, and pass out between the third and fourth vertebrae.

(4) The fourth nerve arises by its two roots at the level of the fourth vertebra, and quits the vertebral canal between the fourth and fifth vertebrae.

(5) The fifth nerve arises opposite the fourth rertebra, and passes outwards and slightly backwards to the foramen between the fifth and sixth vertebrae.

(6) The roots of the sixth nerve are attached to the cord opposite the fourth vertebra, and leave the vertebral canal between the sixth and seventh vertebrae.

(7) The seventh nerve arises from the cord at a point between the fourth and fifth vertebrae, and leaves the canal between the seventh and eighth vertebrae.

(8) The eighth nerve quits the cord at a point opposite the articulation between the fifth and sixth vertebrae, then runs backwards to the eighth vertebra, and escapes between this and the ninth vertebra.

(9) The ninth nerve arises at the level of the sixth vertebra, and passes out between the sacrum (ninth vertebra) and the urostyle.

(Io) The tenth nerve ( 1 . coccygens) arises from the cord immediately behind the ninth nerve and opposite the sixth vertebra, and courses alongside the terminal filament to pass out through a foramen in the urostyle (canalis coccygeus).

b. [The Spinal ganglia (Ganglia interverteliralia).

At their exit from the intervertebral foramen the two roots of each nerve unite and bear a ganglionic enlargement, which is in intimate connection with the dorsal root, but is merely in contact with the ventral root. The ganglia lie ${ }^{1}$ in the large intervertebral depressions, upon the under surface of the Proc. obliqui, above and behind, being in relation with the bodies of the vertebrae internally, and the Musculi intertranstersarii externally (Fig. II9); ventrally. the ganglia are, more or less, covered by the "periganglionic glands.' The ganglia vary much in size; that of the first spinal nerve is the

1 The Gangl. coceygeum is in the urostyle. 
smallest. The ganglion is not attached to the dorsal root alone but is prolonged a short distance beyond the point of union of the two roots; this is best seen in the nerves of the lumbar plexus.

Fig. 118

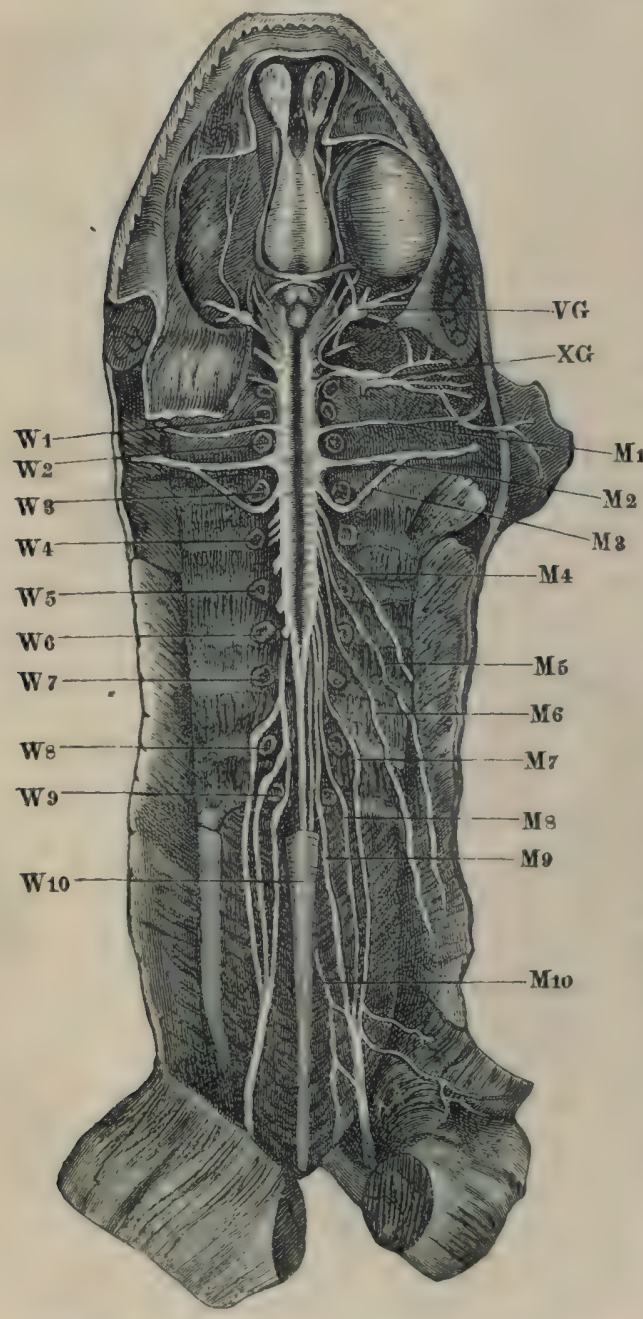

Ventral view of the brain and spinal cord, to show the points of exit of the spinal nerves.

Mr-ro Spinal nerves.

$V G$ Trigeminal ganglion.

$W_{\text {I }}$ ro Vertebrae.

$X G$ Ganglion of vagus.
Each ganglion is a yellowish-white rounded or oval body, with an outer thick (sometimes $0.15 \mathrm{~mm}$. thick) sheath of connective - tissue, connected by the epineurium of the nerve roots with the Durd mater. This sheath is composed of bundles of parallel, wavy, white, connective-tissue fibres, which enclose a large number of connectivetissue corpuseles, and here and there contains brown pigment.

By means of longitudinal and transverse sections it may be seen that the ganglion surrounds the ventral root, but that it forms a thinner layer on that side, where the dorsal root joins the ventral; although at this point the two roots and the ganglion are firmly united together, the thick fibrous sheath of the ganglion prevents any communication between the nervous elements of the ventral root and those of the ganglion. 
The sheath eontains nerve-cells and fibres, and sends in a few fine processes to support these structures. The fibres of the posterior root enter and pass out of the ganglion without suffering any changes, except that the nerve fibres are slightly separated by the presence of a few nerve-cells, and that a distinct increase in the number of nerve fibres takes place. The nerve-cells, of which the ganglion is chiefly composed, and upon the number of which its size directly depends, are arranged chiefly around the fibres of the dorsal root; such few as lie between the fibres are smaller than the rest and vary more in their relative numbers; at times one or two isolated cells are found in the capsule or even in the adjoining 'periganglionic gland.' The cells near the capsule are somewhat smaller than the deeper cells ${ }^{1}$. Each of these cells, which are usually pear-shaped, possesses only one process; the cell membrane is thick, resistant, and possessed of an external nucleated, endothelial covering, the space around being probably a pericellular lymph-space; it often contains one to three small fat-globules; the protoplasm of these has, according to $\mathrm{v}$. Lenhossék, a concentric fibrillation; the nucleus is round, clear, and distinct, and relatively larger the smaller the nerve-cell; it is usually placed in the centre of the cell.

In that portion of the cell towards the process is a portion brighter and less easily stained than the rest of the cell (Polarkernen, Courvoisier); this apparently possesses one or two nuclei, and is regarded as a cell by Lenhossék (Polarzellen); the process of each cell soon acquires a medullated sheath, and after

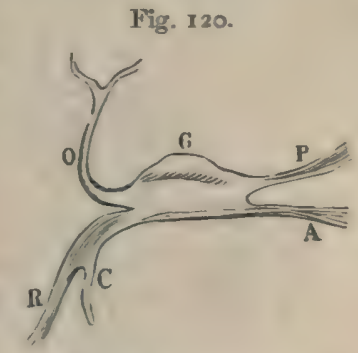

Schemg-of spinal ganglion.

A Ventral root.

f Ramus communieans.

G Ganglion.

o Doral division.

$P$ Dorsal root.

IR Ventral division.

${ }^{1}$ Larger cells of deeper layer $80 \mu$ to $90 \mu$ in diameter, sometimes one or two as large as C.I mm. v. Lenhossék. 
a short course, $0.09 \mathrm{~mm}$. to $0.35 \mathrm{~mm}$., divides usually about the third constriction (Lenhossék). These processes all pass peripherally, even those which appear at first to pass in the opposite direction curve round again ; it is chiefly due to these fibres that the spinal nerve is larger than its two roots.

In addition to the above, smaller, irregular cells from $5 \mu$ to $7 \mu$ in length are found; Rawitz regards them as young cells, Lenhossék as cells capable of (entwicklungsfühige) developing into nerve-cells. The ganglia contain only few blood-vessels.]

The above description is founded upon that of Lenhossék, and has been confirmed by the translator in every particular, except that only very indistinct and unsatisfactory indications of the concentric fibrillation so clearly delineated by Lenhossék were obtained; the structure of the Gasserian ganglion was found to correspond exactly with the description here given of the structure of the spinal ganglia. The nucleus was oftener at the side than at the centre of the cell.

c. The 'Periganglionic Glands' (Periganglionäre Kalkdrüsen, v. Lenhossék; Kalksäckchen, Ecker, and others ; Crystal capsules, Wyman; Calcareous Sacs or Masses, of other writers), (Fig. I I9). These bodies are found on the ganglia of all the spinal nerves and on the Gasserian ganglion of the trigeminal nerve; they have recently been carefully investigated by v. Lenhossék. According to his description there are usually two to each ganglion, lying on its sides and ventral surface ; each consists of a connective-tissue capsule which sends in a few fine trabeculae to support a system of glandular tubes: these usually run parallel to the long axis of the grland, and are about $14 \mu$ to I $5 \mu$ in diameter; each tube is lined with a single layer of somewhat columnar epithelium, the cells of which have sharp, distinct outlines and oval nuclei.

A membrana propria was not made out with certainty; the lumen of the tubes is wide and contains a milky fluid, which gives the whole structure its characteristic appearance; it has long been known (Blasius, 168I, mentions the fact, l.c., p. 291) that this fluid contains calcareous matter, which effervesces and dissolves in the presence of hydrochloric acid; the crystals vary in form but are chiefly oval (Wyman).

These glands bear no definite proportion to the size of the nerves to which they are attached (Fig. II 8); they already contain calcareous matter during the tadpole stage before the limbs are developed (Stannius, Wyman). No ducts have been traced to 
these glands. This description, founded upon that of Lenhossék, can be confirmed by the translator in every particular; his sections, however, would lead him to believe that the glands are far more vaseular than the description and the drawings of Lenhossék imply.]

d. The Branches of the complete spinal nerves formed by the union of the dorsal and ventral ronts with the ganglion (Fig. I20) are usually described as two, a dorsal and a ventral branch, which latter at once gives off a Ramus communicans to the sympathetic system; these tro branches are given off almost immediately beyond the ganglion.

\section{The Individual Nerves.}

\section{A. The Dorsal Branches (Fig. 121).}

The dorsal branches are smaller than the ventral; they pass upwards between the inner borders of the Muse. interfiansrersarii and the articular processes of the vertebrae to reach the under surface of the $M$. longissimus dorsi; the general course of these nerves is very similar for all; each nerve gives off--

(a) A twig to the Musc. intertransversarius and then divides into two branches.

(b) A Ramus muscularis (Fig. I2I $\mathrm{rm})$, which passes outwards to supply the $M$. longissimus dorsi. .

(c) A Ramus cutaneus (Fig. $121 \mathrm{rc}$ ); this nerve continues under the extensor muscle of the back, running on the arch of the vertebra towards the middle line; it then pierces the muscle and Fascia dorsalis to reach the large dorsal lymph-sac (Sacc. cranio-dorsalis), through which it courses to end in the skin. In its course through the sac the nerve is connereded with a small artery and rein' by a small amount of connective-tissue, the whole being enclosed

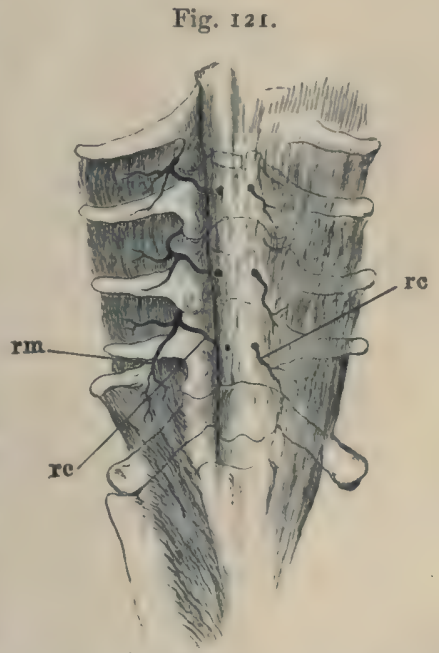

Dorsal branches of the splual nerves. The Finsia dorsalis is dissected, removed from the left side.

rc Rami cutarei.

rm Rami musculares. 
in a sheath of endothelium continuous with that of the general eavity.

The three anterior cutaneous nerves pierce the Fascia dorsalis near the spinous processes, the fourth a little to the side, the fifth perforates the $M$. coccygeo-iliacus at about the junction of its anterior and middle thirds; the sixth and seventh perforate the same muscle, but more posteriorly. There are seven of these Rami cutanei, the first coming from the second spinal nerve, the rest from the succeeding six spinal nerves.

\section{B. The Ventral Branches.}

The ventral branches of the spinal nerves are larger than their corresponding dorsal branches: each nerve gives off immediately a Ramus communicans to the sympathetic system (Figs. II 7 SM, I $20 C$ ) ; these Rami communicantes will be described with the sympathetic system; the remaining portions of the ventral divisions of the original spinal nerves are usually known as the spinal nerves; they will be described as such in detail.

1. The hypoglossal nerve ${ }^{1}(N$. hypoglossus, $N$. spinalis $I)$, (Figs. I I4, II5, and II7 MI), or first spinal nerve, is of small size; it leaves the vertebral canal between the first and second vertebrae to lie between the Musculi intertransversarii and the pharynx, where it has in front the Arteria vertebralis, behind the Arteria and Nervus brachialis; passing under the Levator anguli scapulae; it touches the Aorta ascendens and crosses the Vagus and the Carotid-gland, and thus reaches the space between the Musculi sterno-hyoidei and the Petro-hyoideus; then curving forwards sharply it turns under the Mylo-hyoideus to course between the fibres of the Genio-hyoideus to the root of the tongue, where it ends. It first lies to the inner and then to the outer side of the glossopharyngeal nerve. In its course the nerve gives off the following branches :-

(a) One or two communicating twigs (Figs. I14 and 122) to the second spinal nerve.

${ }^{1}$ [Observers have differed considerably as to the relations of this nerve : Volkmann describes it as the first nerve of the neck, and describes a ganglion on its dorsal root; Vogt denies the presence of this ganglion, and regards it as a true cranial nerve; Stannius asserts that no ganglion exists, and holds the nerve to represent the first two spinal nerves; Wyman describes the two roots and regards it as a spinal nerve; Hoffmann regards this nerve as the second spinal (N. spinalis II): Fürbringer as the representative of two spinal nerves; de Watteville describes two roots and names it first spinal nerve.-TRANs.] 
(b) Muscular twigs to the Longissimus dorsi, Intertransversarii capitis, Levator anguli scapulae, and the Retrahens scapulae.

(c) When near the glossopharyngeal it supplies twigs to the Geniohyoideus, Sternohyoileus, and Omohyoideus, where it bifurcates.

(d) One of the branches passes inwards to supply the Hyoglossus.

(e) The other terminal branch passes forwards with the Ramus Tingualis and the glossopharyngeal, between the fibres of the Geniohyoidens, which it partially supplies, and sends twigs to the neighbouring parts.

(f) [Hoffmann describes a communicating branch to the pneumogastric nerve, which the translator has not been able to discover, and which no other observer has mentioned.]

2. The second spinal or brachial nerve ( 1 . brachialis, $N$. spinalis II), (Fig. 122) is a large nerre, learing the rertebral canal between the second and third vertebrae; it then accompanies the Art. axillaris along the anterior border of the transrerse process of the third vertebra, over the hinder end of the Musc. levator scapulae and the anterior end of the $m$. transcerso-scapularis major, to the inner border of the Musc. subscapularis, under which it passes into the arm. In this course it gives off or receives the following branches :-

(a) It first receives a branch from the second spinal nerve.

(b) It gives off a large branch, the $\boldsymbol{N}$. coraco-clavicularis (Fig. 122 $C_{c}$ ), which first accompanies a branch of the Art. axillaris on the Musc. levat. scapulae, then courses forwards and outwards over the Musc. subscapularis to pass from above into the Foramen ovale between the clavicle and coracoid bones. It gives off two branches:

(I) One immediately beyond its origin, which runs backwards over the Iusc. subscapularis to supply the Musc. obliq. abdominis internus (Fig. $122 \mathrm{Ce}^{\prime}$ ).

(2) While in the Foramen oxule, the $\mathbf{N}$. coraco-claricularis bifurcates; the anterior twig runs forwards and outwards to the deltoideus and also supplies a recurrent filament to the $M$ H $\mathrm{sc}$. sterno-radialis; the posterior twig enters the upper surface of the Musc. sternoradialis.

(c) At the outer extremity of the Musc. transterso-scapularis the brachial nerve gives off a posterior branch, which at once bifurcates:

(I) The first branch passes into the under surface of the Musc. latissimus dorsi (ld), giving a twig to the Infraspinatus.

(2) The second is the Ramus cutanens axillairs (IIc); it passes on 
the under surface and posterior border of the Musc. latissimus dorsi to the skin of axilla and dorsal surface of the upper arm.

(d) Several small branches are given off from the upper and anterior surfaces of the brachial nerve near the Foramen ovale; they accompany an artery to pass forwards and upwards between the Musc. subscapularis and the M. transverso-scapularis on the one side,

Fig. 123.

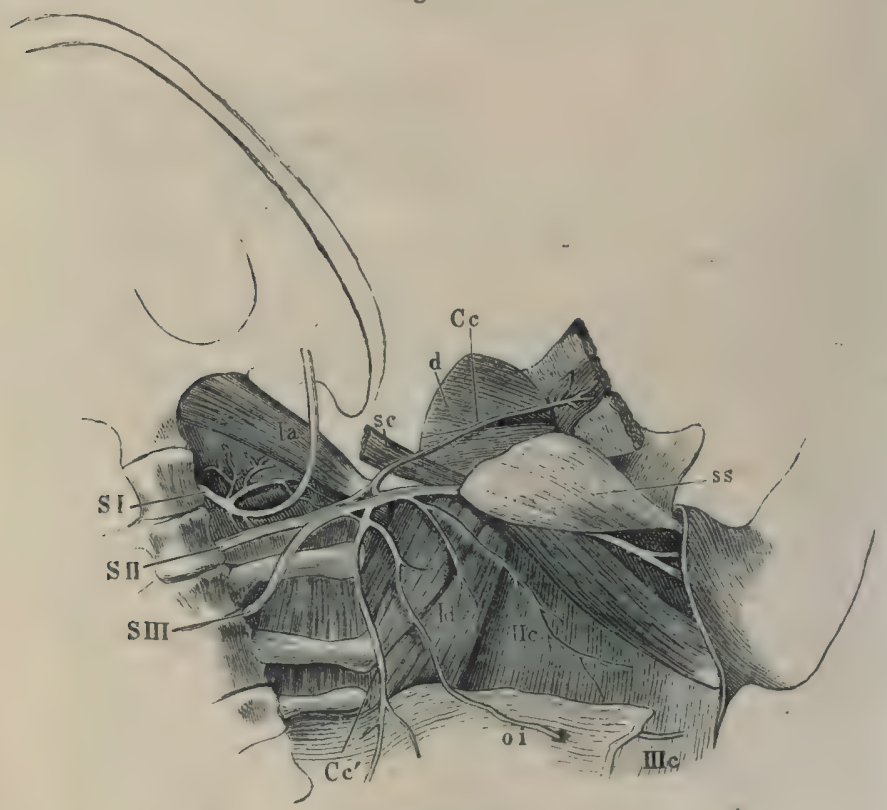

The brachial plexus.

Cc N, coraco-clavicularis

$C c^{\prime}$ Nerve to musc, obliq. abdom. internus.

d Deltoid muscle.

la Musc. lev. ang. scap.

ld Musc. lat dorsi,

of Musc, obliq. abdom, intern.

sc Mrisc, sterno-mastoid. ss Musc subscapularis.

SI Firat spinal nerve.

- SII Second spinal nerve.

- SIII Third spinal nerve.

IIC Ramus cutaneus axillaris,

IIIC Ramus cutaneus abdominalis.

and the long head of the $M$.triceps brachialis on the other, and are lost in the $M$. deltoideus and the $M$. infraspinatus.

The $N$. brachialis continues its course by passing between the long and inner heads of the $M$. triceps, reaches the arm and splits into two nerves, the $N$. ulnaris and the $N$. rallialis.

[I.] The $N$. ulnaris (Fig. I $23 U$ ) escapes from cover of the long head of the $M$. triceps and runs obliquely over its inner head 
towards the outer side of the Plica cubiti; in this course it supplies four branches :

a. The Ramus subscapularis passes dorsally to the $\boldsymbol{M}$. subscapularis.

B. A Ranus pectoFig. 123 .

ralis. (Fig. 123 up), passes forwards to the M. abdomino-pectoralis and to the skin of the pectoral region $(\boldsymbol{R}$. cutaneus pectoralis).

$\gamma$. The $N$. cutaneus antitrachii superior s. medialis (uc) passes to the-skin of the inner side of the forearm; this and the two following nerves are giren off near the Plica culiti.

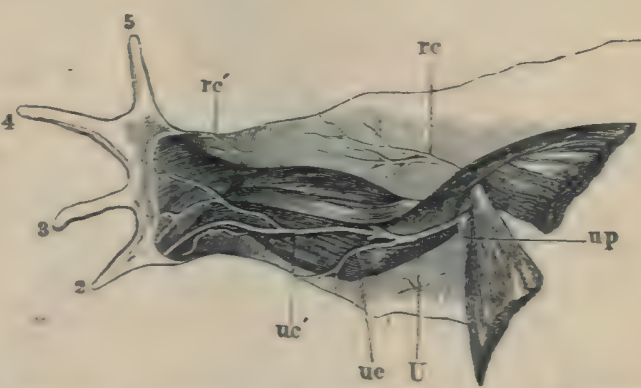

Nerres of the ventral surface of the arm. The hand promated.

$$
\begin{aligned}
& r \text { L } \quad \text { pper entaneous braneh of the } \mathbf{X} \text {. radializ } \\
& \text { re Jower cutaneous branch of the } \mathrm{N} \text {. redialis, } \\
& \text { U N. mharis. } \\
& \text { uc R. cutan. snp of the X. ulnaris } \\
& \text { ot } \mathbf{R} \text { cutan, inf. of the } \mathbf{N} \text {. ulnaris. } \\
& \text { up } \mathrm{R} \text {. pectiralis of the } \mathrm{X} \text {. ulnaris }
\end{aligned}
$$

8. The 1 . cutaneus antibrachii inferior s. dorsalis 8. musculacutaneus (u') at once supplies branches to the $\boldsymbol{M}$. flexor carpi raslialis $^{1}$, and then runs downwards upon the muscle and bifurcates :-

[I] The R. lateralis is distributed, by two twigs, in the $M$. Alexor carpis ulnaris and in the skin of the seennd finger, to which it supplies the Rami digitales valaris and dorsalis.

[2] The $R$. dorsalis, after giving a cutaneous twig to the second finger, is distributed by numerous twigs to the skin of the dorsal surface of the hand.

The. . ulnaris then passes between the $\boldsymbol{M}$. Alexor carpi ralialis and the tendon of the $\boldsymbol{M}$. sterno-radialis, sinks deeply into the Plica culiti, where it lies between the $M$. Hexor carpi radialis and the Flexor carji ulnaris, then between the latter and the Flexur antiUraclii medialis on the one side and the Flexor digitorum communis on the other: it supplies branches to all these muscles, and while still in the forearm divides into two terminal branches :-

a. The $R$. ulnaris merlialis is the smaller; it runs inwards,

1 As this muscle increases in size during the breerling sesson, it would be interesting to know whether a corresponding change takes place in the nerve. 
passes under the tendon of the $M$. extensor carpi ulnaris into the palm of the hand and ends as the $N$. volaris digiti $V$ medialis.

Fig. 124 .

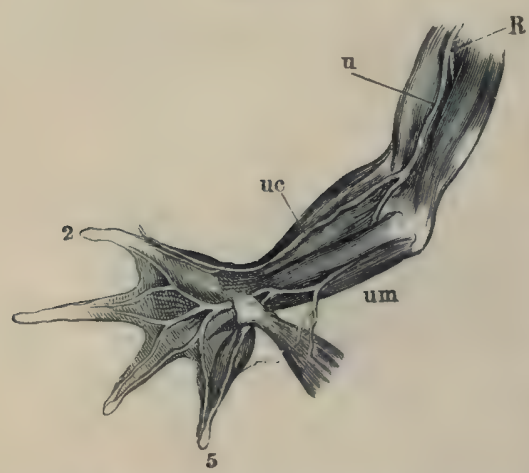

Nerves of the ventral surface of the arm. The hand supinated, and the superficial layer (Flex. carpi rad. and uln., Flex. dig. commun.) has been removed.
$\boldsymbol{R} \quad$ N. radialis,
$u \quad \mathrm{~N}$, alnaris,
uc R. cutan. inf. of the N. ulnaris.
um Bifurcation of the $\mathrm{N}$. ulnaris.

$\beta$. The $R$. unnaris lateralis passes near the thumb-rudiment, covered by the $M . a b$ ductor pollicis, deeply into the palm of the hand, and supplies by bifurcating branches the adjacent sides of the second, third, fourth, and fifth fingers ( $R$. volares); it also gives twigs to the muscles of the palm.

[II.] The $N$.radialis (Figs. 123, 124 , and $125 R$ ) passes immediately beyond its origin from the $N$.brachialis, between the humerus and the M.triceps, runs along the bone to its outer side; in this course it gives off :-

a. Rami musculares to the separate parts of the $M$. triceps.

$\beta$. The Ramus cutaneus superior (Fig. I2.5 rc) to the skin of

Fig. 125 .

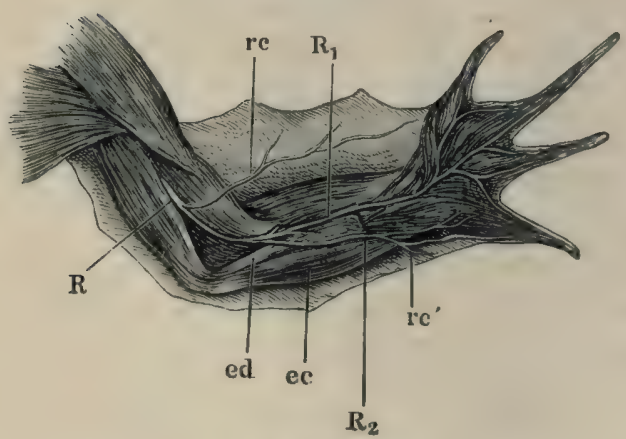

The N. radialis,

$\begin{array}{ll}e c & \text { M. extensor carpi ulnaris. } \\ e d & \text { M. extensor digit. comm. } \\ \boldsymbol{R} & \text { N. radialis, } \\ \boldsymbol{R} \mathbf{x} & \mathbf{R} \text {. lateralis. } \\ \boldsymbol{R} 2 & \mathbf{R} \text {. medialis, } \\ r \boldsymbol{c} & \mathbf{R} \text {. cutaneus superior. } \\ r c^{\prime} & \mathbf{R} \text {. cutaneus inferior. }\end{array}$

the outer surface of the upper arm and forearm.

The nerve then sinks deeply under the origins of the $\boldsymbol{M}$. extensor carpi ulnaris and the $M$. extensor digitorum communis, where it bifurcates after giving off some small twigs :-

$\gamma$. Small muscular twigs to the extensor muscles of the hand and fingers.

$\delta$. The $R$. radialis medialis $\left(R_{2}\right)$, the 
smaller terminal branch, supplies a branch to the $\boldsymbol{M}$. extensor digit. comm. longus and the skin over the earpus (Ramus cutanenz inferior, $\left.r c^{\prime}\right)$, and ends on the muscles of the little finger as the $R$. dorsalis digiti $T$ medialis.

$\epsilon$. The $R$. rarlialis lateralis $(R)$, the larger of the two branches, supplies the extensor muscles of the fingers and gives bifurcating branches, Rami digitales dorsales, to the adjacent sides of the second, third, fourth, and fifth fingers (the Ramus dorsalis lateralis of the second finger is supplied by the $N$. ulnaris).

3. The third spinal nerve (N. spinalis III) (Fig. I $22 S I I I)$ leaves the vertebral canal by the foramen between the third and fourth vertebrae, and runs outwards and forwards upon the large transverse process of the third vertebra to the brachial nerve (N. spinalis $I I)$. Its behaviour at this point is subject to considerable variation; at times it joins the brachial nerve completely, at other times the two nerves are simply in eontact; or lastly, it may send a small twig to the brachial nerve. Externally to this point the two nerves supply a number of small branches, which may belong almost entirely to either one nerve or the other ; these nerves again inosculate in a variable manner, to form an axillary plexus. The more constant branches are:-

(1) One or more twigs to the Musc. transterso-scapularis major.

(2) Several branches, usually two larger and one smaller; they course in the $\boldsymbol{M}$. obliq. abdom. internus (Fig. $\mathbf{2} 22$ oi) to the $\boldsymbol{M}$. rectus, where they give off branches, then pierce the muscle to reach the skin ( $R$. cutaneus abdominalis), (Fig. I22 IIIC).

4. The fourth spinal nerve ( $N$. spinalis $I V$ ) (Fig. I26 M/4) appears between the fourth and fifth vertebrae; it runs on the ventral surface of the transverse process of the fifth vertebra and upon the $M u s c$. intertranscersarius obliquely outwards and downwards, and reaches the deeper surface of the Musc. obliquus internus, into which it descends, about opposite the articulation between the eighth and ninth vertebrae; it then bifurcates into:-

(I) A Ramus cutaneus aldominalis, which pierces the muscle and supplies the skin.

(2) A Ramus muscularis, which supplies the broad abdominal muscle and the $M$. rectus abdominis.

5. The fifth spinal nerve ( $N$ spinalis $V$ ) (Fig. I $26 M / 5$ ) emerges through the foramen between the fifth and sixth vertebrae, runs 
obliquely downwards and outwards over the transverse processes of the sixth and seventh vertebrae and the corresponding $M$. inter-

Fig. 126.

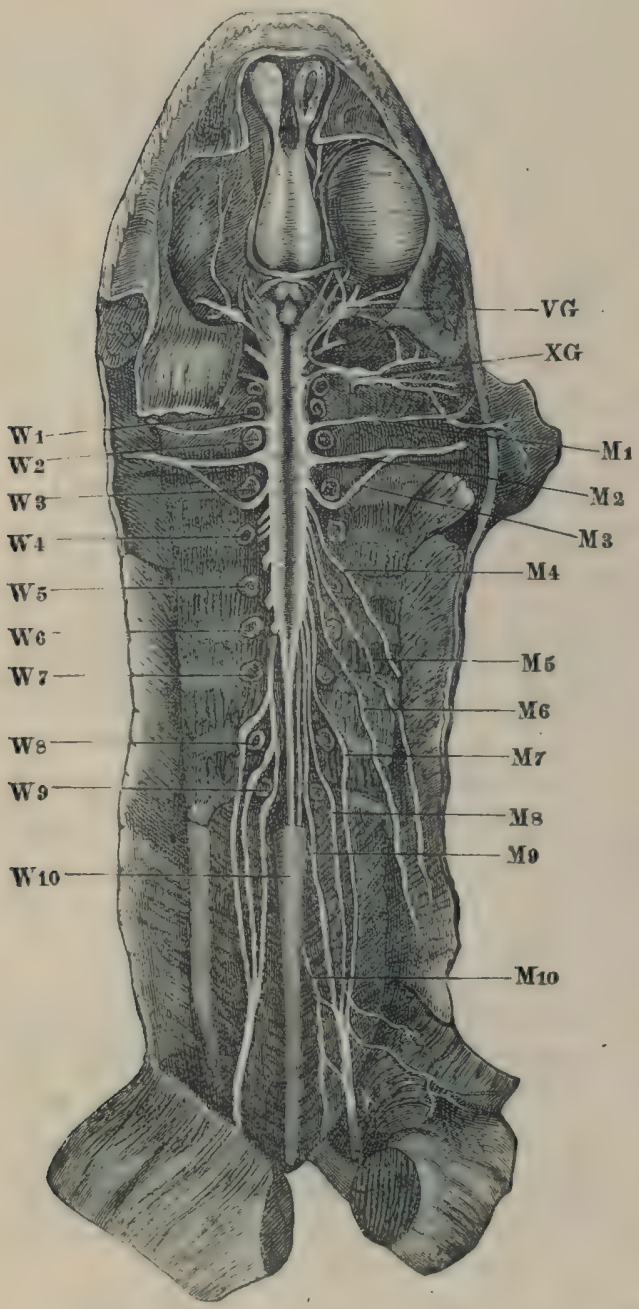

Ventral view of the brain and spinal cord, to show the points of exit of the spinal nerven.

$M_{\mathrm{x}-\mathrm{IO}}$ Spinal nerves.

$V G$ Trigeminal ganglion.

$W_{I-\text { Io }}$ Vertebras.

$X G$ Ganglion of the vagus, transversarii, and at a point nearly opposite the middle of the urostyle pierces the $M$. obliquus internus.

The rest of its course corresponds exactly with that of the fourth spinal nerve.

6. The sixth spinal nerve $(N$. spinalis $V I)$ (Fig. I 26 M6), after escaping from the vertebral canal between the sixth and seventh vertebrae, runs obliquely downwards and outwards on the under surfaces of the transverse processes of the seventh, eighth, and ninth vertebrae, then under the iliac bone to a point opposite the hinder half of the urostyle, where it descends under cover of the $\boldsymbol{M}$. obliquus abdom. internus. In the rest of its course it repeats the corresponding courses of the fourth and fifth spinal nerves.

$7,8,9$, and 10 . The seventh, eighth ninth, and tenth spinal nerves (Nervi spinales

TII, IIIT, $I X$, and $N$. spinalis $X$ s. $\lambda$. cocrygens) (Figs. 126 and 
I27 $M / 7, M / 8, M$, and $M / 10)$ are best described together, as they are intimately associated to form the sciatic plexus (Plexus ischiadicus, Plexus cruralis).

Within the vertebral canal the roots of these nerves form the Camla equina; the seventh nerve leaves the canal between the seventh and eighth vertebrae, the eighth nerve between the eighth and ninth vertebrae, the ninth between the sacrum or ninth vertebra and the urostyle, and the tenth by the Canalis merygeus in the urostyle; from these points the four nerves run olyliquely on the ventral surface of the $\boldsymbol{M}$. ilio-roryyeus to the pelvis, where they form the sciatic plexus. Although subject to some variation, the usual arrangement is that the seventh and eighth nerves unite to form a trunk, which then receives the ninth nerve; the large nerve so former is the sciatic nerve : a branch of the tenth usually then joins either the sciatic plexus or the sciatic nerve; the plexus gives eff or receives the following branches :---

(a) Like other spinal nerves, these nerves give off Rami communicantes (see Sympathetic System).

(b) The $M$. ilio-hyj,ogastricus (Fig. I $27, \mathbb{M}, a$ ). This arises from the seventh spinal nerve, before its union with the eighth spinal nerve; it runs obliquely outwards and downwards on the Musr. ilio-comygens and under the border of the $.1 \%$. obliguns ablom. internus, where it bifureates :-

(1) One branch, the Ramus cutaneus abdominalis, pierces the M. obliq. abdom. internus in the same fashion as the cutaneous branches of the fourth, fifth, and sixth spinal nerres; it supplies the skin of the abdomen.

(2) The second or Ramus muscularis supplies the flat abdominal museles and the $\boldsymbol{M}$. rectus abdominis.

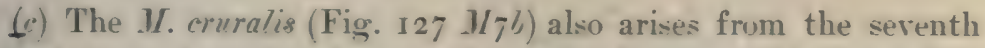
spinal nerve at or just beyond its point of union with the eighth spinal nerve. It accompanies the $A$. crusalis on the pelvic wall to the thigh, where it lies upon the $M$. illin-prosas in a triangle between the $\boldsymbol{U}$. rectus fem. anterior and the $\boldsymbol{M}$. ald luctor longus, and dirides into two main branches :-

(I) Muscular twigs to the $M$. ilio-psoas, .M. rectus femoris anticus, $M I I$. adductores longus and brevis.

(2) The Ramus cutaneus femoris, which runs downwards in the hinder wall of the Lrmph-sac (Same iliacus), and supplies the skin of the under and outer surfaces of the thigh. 
(d) The Ramus dorsalis is a very small nerve; according to Waldeyer it possesses only twenty nerve-fibres. It arises from Fig. 127 .

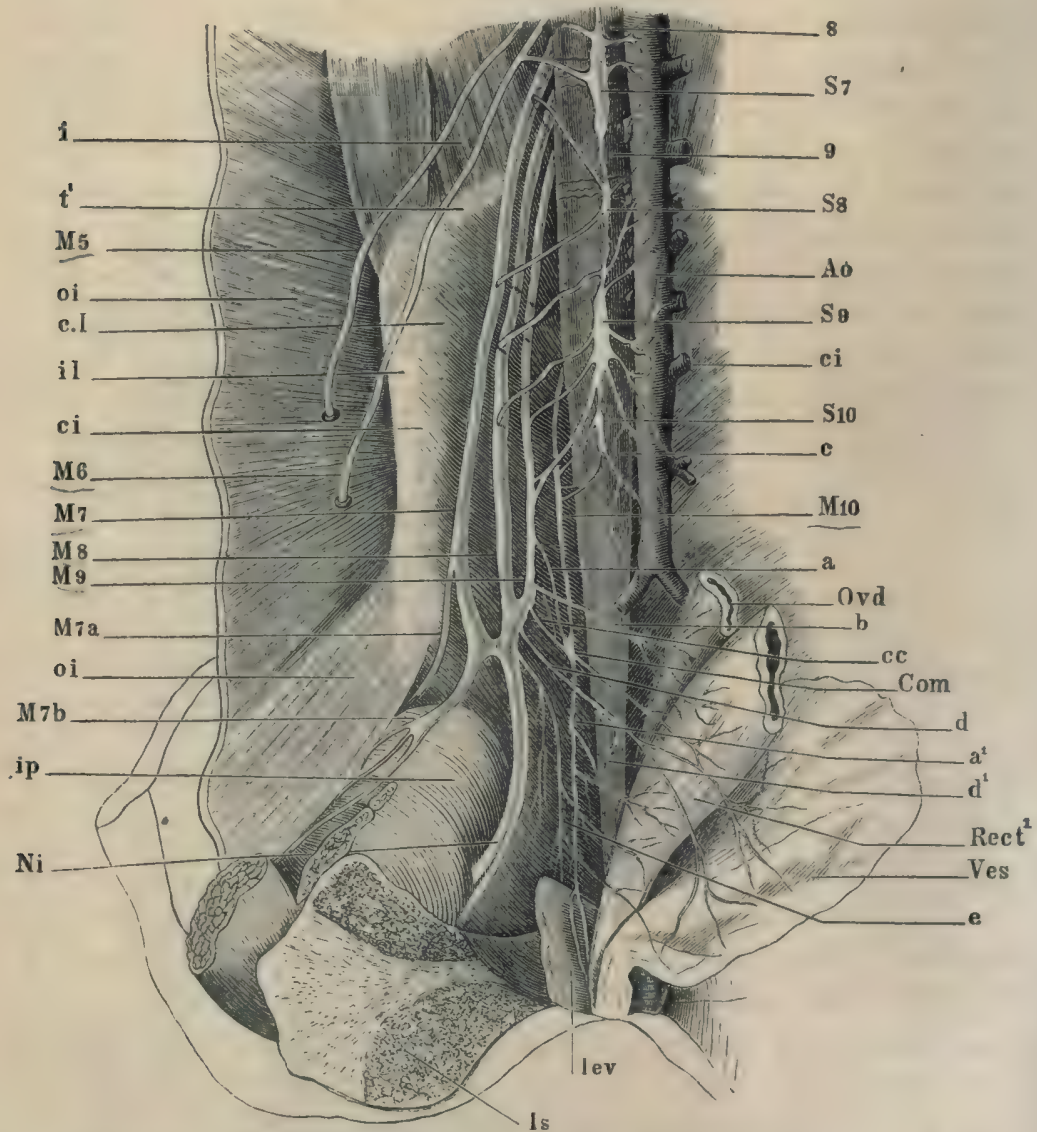

The sciatic plexts, from a drawing by Wiedersheim.

a Communicating nerve from the ninth spinal nerve.

$a^{\prime}$ Nerve to musc. lev, ani.

b Nerve to oviduct.

c Urostyle.

cc Communicating twig from the ninth spinal nerve.

ci M. coccygeoiliacus.

c.I M. cocoygeosacralis.

d Nerve to bladder.

$d^{\prime}$ Twig to the $\mathbf{m}$. iliacus.

e Twig from sciatic plexus to coccygeal plexus.

$i$ M. intertransversarius.

$i$ M. illo-coccygeus,

ip M. ilio-psoas.

lev M. lev, ani.

oi M. obliq. abdom, internus.

$t$ Transverse proceas of sacrum.
Ao Aorta.

Com Point of union of nerves $a$ and $c c$.

Is Ischium.

$M_{5} \quad$ Fifth spinal nerve.

- M6 Sixth spinal nurve.

- $M_{7}$ Seventh spinal nerve.

- M8 Eighth spinal nerve.

* $M_{9}$ Ninth spinal nerve.

- Mro Tenth spinal nerve.

M7a M. iliohypogastrieus.

$\mathrm{MI}_{7} \mathrm{~b}$ M. cruralis.

$\mathrm{Ni}$ Sciatic nerve.

Ovd Ovidnot.

Rect' Rectum.

$S_{7}, S_{8}, S_{9}$, Sro Rami communicantes of seventh, eighth, ninth, and tenth spinal nerves.

$V$ es Bladder.

8, 9 Eighth and ninth vertebrae. 
the cocergeal nerve immediately beyond the Canalis coccygeus, perforates the $M$. ilio-coccygeus, and runs on its dorsal surface obliquely over the lymph-heart, without supplying it; the nerve then pierces the fascia to supply the skin of the back and thigh.

(e) The Ramus abdominalis also arises from the cocergeal nerve; it is larger than the $R$. dorsalis, and arises at the same point; the nerve runs on the ventral surface of the $M$. itio-coccygeus towards the lymph-heart, and inosculates with the sympathetic. It is from this nerve that the branch to the sciatic plexus is usually given off ; it further supplies a varying number of branches, which with branches derived directly or indirectly from the sciatic nerve, form a plexus (Plexus cocrygeus); the two plexuses may together be regarded as a Plexus ischio-coceygens or a Plexus sacro-coceygens.

(f) In addition to the Rami rommunicantes giren off by the spinal nerves near the vertebral column, the sciatic plexus supplies a few twigs, usually two (Fig. 127).

(g) Other small twigs pass from the sympathetic system forwards and outwards to join the sciatic plexus or the sciatic nerve. Aceording to Walderer two of these are very constant.

(h) Branches to the oviduct (Fig. 127 b).

(i) Branches to the rectum (Fig. $127 \mathrm{ce}$ ).

(k) Branches to the bladder (Fig. $127 d$ ).

(l) Branches to the M. levator ani (Fig. I $27 a^{\prime}$ ).

(m) A branch to the lymph-heart, which runs along the anterior border of the $M$. lex. ani, on to its dorsal surface, and then direct to the lymph-heart.

Variations in the sciatic plexus. The arrangement of the nerres in the sciatic plexus is subject to many variations; according to $W$ iedersheim most of these rariations belong to two chief classes : either the 1 . coccygens inosculates directly with the ninth spinal nerve by one or several branches, or it joins the ninth nerve indirectly by uniting with its branches. A case of the latter arrangement is seen in Fig. 127 , and is thus described by Wiedersheim :-

'After cutting through the pelric symphrsis and drawing to one side the contained viscera, namely, the hinder end of the oviduct, the rectum, and the bladder, one sees a row of small twigs $(a, b$. $e c, d$, and $e$ ) arising from the inner, hinder, and anterior surfaces of the ninth spinal nerve: the first $(a)$ runs backwards parallel with 
the $N$. coccygeus over the $M$. ilio-coccygens to join this nerve at the point marked Com. The twig $c c$ behaves in like manner after receiving a twig from $b$. The twig $b$ arises from the inner surface of the ninth nerve between the two foregoing and close to its union with the eighth spinal nerve ; from this origin twig $b$ passes almost transversely outwards to the hinder extremity of the oviduct ("uterus"), and partly to the rectum, crossing in its course twig $a$, the sciatic nerve, and the urostyle. Its branches form a netlike plexus with the terminal branches of the last sympathetic ganglion and with a branch $c c$ from the point of union Com.

'A second branch ( $u^{\prime}$ '), arising from the point of junction Com, is a continuation of the $N$. coccygens $(H \mathrm{I} O)$; it passes vertically downwards towards the hinder end of the cloaca and at the upper border of the Levator ani, divides into two branches, which are distributed to the inner and outer surfaces of this muscle and to the cloaca. Other branches pass dorsally to the lymph-hearts, while a third set pass to the hindermost part of the bladder.

'These three sets of nerves, to the $M$. coccygeus, M. levator ani, and to the lymph-hearts, are not supplied entirely by the $N$. coccygens, as this is reinforced by one or more branches $(e)$ from the sciatic plexus: this branch $(e)$ supplies twigs to the $M$. ilio-coccygens, which is also supplied anteriorly from the trunk of the $N$. coccygeus. - 'The bladder receives a special branch $(\bar{d})$, which arises from the sciatic plexus at the junction of the eighth and ninth spinal nerves; this nerve gives a twig $\left(d^{\prime}\right)$ to the $M$. iliacus.'

I. The sciatic nerve (N. ischiarlicus) (Fig. $128 I$ ) is the largest nerve of the body; it passes under the $\boldsymbol{M}$. coccygens, between the origins of the $M$. vastus externus and of the $M$. pyramidalis : lies then between the $\boldsymbol{M}$. bicepss and the $M$. pyramidalis, and later between the M. biceps and the M. semimembranosus; lastly, it bifurcates under the $M$. bicejs to form the $N$. tilialis $(I I)$ and the $N$. peroneus $(I I I)$. In this course it gives off :-

(a) A twig to the $M$. coccygeo-iliacus, while still in the pelvis.

(b) The $N$. cutanens femoris posterior (Fig. I 28, 2), which passes between the $M$. pyramidalis and the M. vastus externus, to appear behind and beneath the former; it accompanies an artery of like name to supply the skin of the hinder and inner surfaces of the thigh.

(c) A little below the foregoing it gives off a collateral branch (Fig. 128,3 ), which passes under the M. pyramidalis and divides to form- 
(1) A branch to the upper third of the $M$. semimembranosus.

(2) A branch to the Rectus internus minor. A twig of this branch $(b b)$ pierces the muscle transversely in company with the Arteria cutanea, and passes to the skin of the middle of the inner surface of the thigh.

(3) Branches to both heads of the semitendinosus.

(4) Branches to the $M$. adductor magnus.

(d) Branches covered by the $M$. pyramidalis to the M. quadrat. femoris and $M$. obturator.

(e) A branch (5) forwards to the $M$. biceps.

(f) A branch (6) which accompanies the Art. circumflexa genu lateralis sup. forwards to the $M$. extensores cruris, the $M$. vastus externus, and the $M$. rectus anterior.

Distribution of the sciatic nerve.

I The eciatic nerve.

II $\mathbf{N}$, tibialis.

III N. peroneus.

I Branches to the M. pyramidalis,

N. cat. fem posterior.

Large collateral branch.

Branch to the M. biceps.

Branch acoompanying the art aircumfl genu lataralis sup.

7 Branch of tibial nerve to the M. gaetrocnemiua

8 5. suralis.

u(im, M. adductor magnus

8 M. bicepa.

D6 Twig accompanying the art. cutanea.

of M. coccygeo-ilineus.

QP N. cut. cruris lateralis.

a R. cut. cruris posterior.

g M. gastrocnemius.

ol M. glutaeus.

J M. pyramidalis.

pe M. peroneus.

ra M. rectus anterior.

ri' M. rectus internus minor.

sil M. seluimembranosus.

st M. semitendinosus.

ve M. vastus externus.

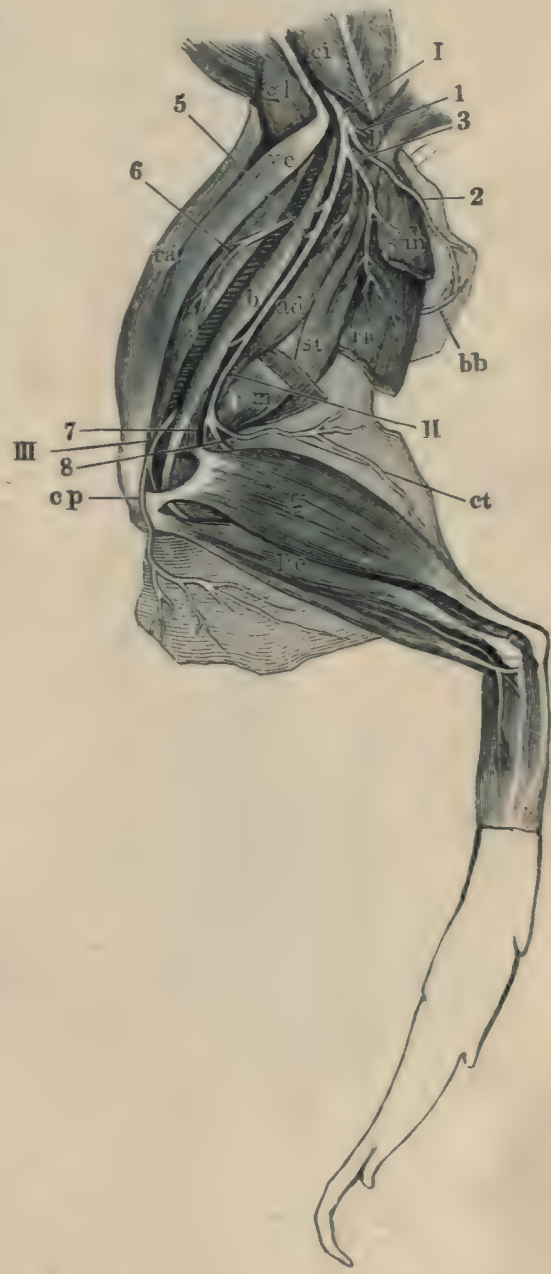


II. The Nervus tibialis (Figs. I 28 II, I $29 T$ ) passes backwards and inwards to supply the extensors of the font and the flexors of the toes. Its branches are :-

(a) The $R$. cutaneus cruris posterior (Figs. I 28 and $129 \mathrm{ct}$ ), accompanied by an artery and vein, passes to the skin of the calf.

(b) A twig to the upper part of the gastrocnemius (Fig. I $29 g^{\prime}$ ).

Fig. 129.

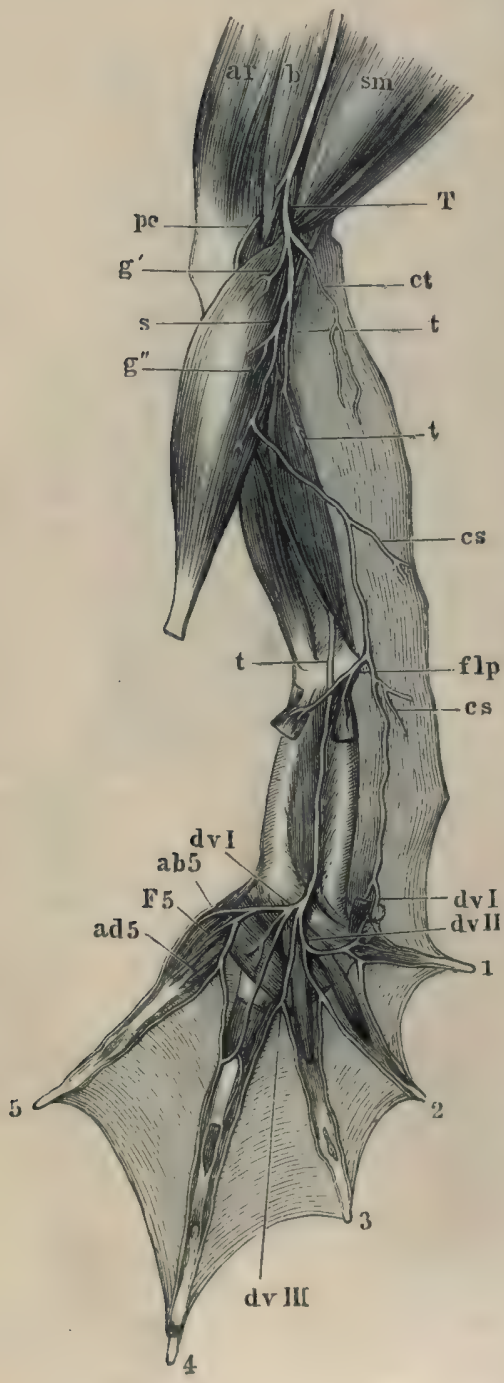

The main nerve, after supplying this twig, bifurcates to form the next two nerves.

(c) The Nervus suralis. (Figs. $128,8 ; 1298)$ runs downwards on the inner border of the $M$. gastrocnemius and gives off :-

(I) A twig $\left(g^{\prime \prime}\right)$ to the upper third of the muscle.

(2) The Ramus cutanens medius $(c 8)$ is given off below the middle of the M. gastrocnemius; it passes to the skin of the lower third of the leg. After giving off the latter branch, the $N$. suralis runs downwards along the inner aspect of the Tendo achillis to the Aponeurosis plantaris of the sole of the foot as far as the calcar, and gives off :-

Nerves of the log and sole of the foot.

$a b_{5}$ Branch to the M. abduct. digit. V.

ad's Branch to the M. adduct, digit. V.

ar M. rectus anterior.

8 M. biceps.

c8 Ramus cutaneus medius.

ct Ramus cutaneus cruris posterior.

$d v I$ Ramus digitalis volaris $\mathrm{I}$.

dvII Branch supplying $\mathbf{R}$. digit. volaris $\mathbf{I}$ and II.

dvIII Second branch of the $\mathbf{N}$. tibialis.

Fs Branch to the M. flex. brev. digit. V.

flp Branches to the M. plantaris and the M. flexor digitorum.

$g^{\prime} \quad$ Branch to the M. gastroenemius.

pc N. peroneus.

\& N. suralis.

sm M. semimembranosus.

$T, t$ Nervus tibialis, 
(3) Branches $\left(f l_{p}\right)$ to the Muse. plantaris and the $M$. flexor digitorum.

(4) A branch to the $M$. abiluctor hallucis.

(5) The $R$. Nigitalis volaris $I(n v I)$ supplies the inner side of the first toe by its terminal twig.

(il) The Nervus tibialis (Fig. I $29 t$ ) passes downwards on the hinder surface of the tibio-fibula, sinks into the $\boldsymbol{M}$. titialis pusticus to appear again at its hinder border; it then runs over the anklejoint into the sole of the foot, where it lies midway in the space between the two Ossa tarsi and between the $\boldsymbol{M}$. extensor tarsi and the M.abluctor digiti I longus; the nerve then runs downwards in the groove of the small $O_{s}$ tarsi and divides to form three branches:-

(I) The first branch ( $d v I I)$ runs to the space between the second and third fingers, where it bifurcates :-

(a) The Rami digital. volaris I run transversely over the muscles of the second toe, supply the muscles of the first toe, and bifurcate to form the $R$. Nigital. volaris $I$ and $I I$.

( $\beta$ ) The Ram. Nigit. volar. II dirides in the space between the second and third fingers to supply the Flex. phalang. and the adjacent sides of these toes.

(2) The second branch $(I / I I I)$ runs over the $M$. Mlex. metatarsi of the third toe to the space between the third and fourth toes, and bifurcates to supply the adjacent sides of these toes and the web between them.

(3) The third branch at once divides to supply :-

(a) The $M$.transt, metatarsi.

( $\beta$ ) The MII. lumbricales of the fourth toe.

(y) The $\boldsymbol{H}$. abiluctor digit. $\boldsymbol{V}\left(a b_{5}\right)$, the $\boldsymbol{M}$. flexor brevis dig. $\boldsymbol{V}$ $\left(F_{5}\right)$, and the $M$. adductor dig. $T$ (ad 5$)$; it then ends as-

( $\delta$ ) A bifurcating branch forming the $R$. digit. valar. of the fourth and fifth toes.

III. The Nerws peroneus ( $N$. peroneus communis superior, Ecker), (Fig. I $30 \mathrm{pc}$ ) is the second division of the sciatic nerve; it passes between the outer head of origin of the $M$. gastrocnemius and the tendon of insertion of the $\boldsymbol{M}$. biceps, it then lies on the tibio-fibula between the $\boldsymbol{M}$. gastrocnemius and the $\boldsymbol{M}$. peroneus, where it is accomnanied by the Tena tilialis postica, then runs downwards upon the $M$. extensor cruris and the Flexor tarsi ant., and passes under the $M$. tibial. anticus and bifurcates; its branches are:- 
a. The $N$. cutaneus cruris lateralis (Fig. $128 \mathrm{cp}$ ); which, like other cutaneous nerves, runs in a common sheath together with an artery and vein to the skin. It arises close to the sciatic nerve.

b. Muscular branches to the MM. peroneus, tibialis anticus, extensor cruris brevis, and the flexor tarsi anterior.

Fig. I 30.

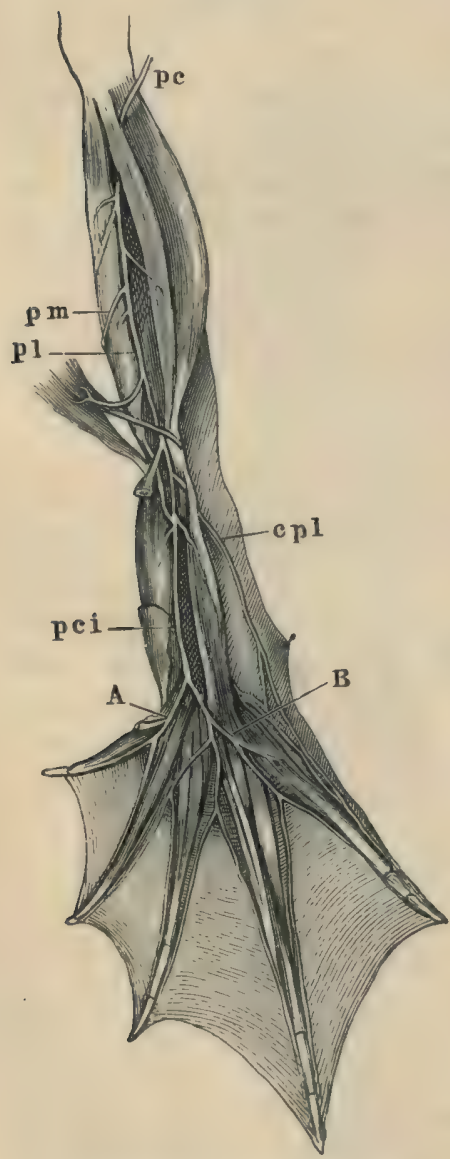

Distribution of the $N$, peroneus.

A Inner terminal twig of $\mathrm{N}$. peron. comm. inf.

$B$ Outer terminal twig of N, peron, comm, inf.

$\operatorname{cpl} \mathrm{N}$. cutaneus dorsi pedis lateralis. pc N. peroneus.

poi N. peroneus communis inferior pl N. peroneus lateralis. pm N. peroneus medialis. c. The $N$. peroneus medialis (Fig. I $30 \mathrm{pm}$ ) is the smaller of the two terminal branches of the $N$. peroneus ; it courses with the Art. tibialis antica under the $\boldsymbol{M} \boldsymbol{M}$. flexores tarsi anterior and posterior and supplies the latter.

d. The $N$. peronews lateralis (Fig. I $30 \mathrm{pl}$ ) is the larger terminal branch of the $N$. peroneus; it passes downwards between the heads of the $M$. tibialis anticus to the tendon of origin of the Flexor tarsi posterior, where it gives off two branches (Nos. I and 2); the nerve then unites with the $N$. peroneus lateralis to form a common stem, the $N$. peroneus communis inferior (Ecker). The N. peroneus lateralis gives off :-

(I) The $N$. cutaneus dorsi pedis lateralis $(c p l)$, which passes to the skin of the outer side of the dorsum of the foot.

(2) A second branch to the $M$. extensor of the fourth and fifth toes.

๑. The $N$. peroneus communis inferior (Fig. 130 pei) runs on the dorsum of the foot in company with the Art. dorsalis pedis, underneath the $M M$. extensores digiti $I$ and $I I$; it supplies several branches and then bifurcates. It gives off :-

(I) Branches to the MM. extensor longus and brevis digiti $I$. 
(2) Rami digitales dorsales to the adjacent sides of the first and second toes.

(3) Branches to the MM. extensores digiti $I I$.

(4) The inner, terminal branch (Fig. I $30 A$ ) at once divides :-

(a) The outer branch runs between the third and fourth toes as far as the commencement of the web, where it bifurcates to form two Rami cutanei, which course along the adjacent sides of these toes as far as their apices.

$(\beta)$ The inner branch passes to the extensor muscle, and, in part, to the adjacent sides of the third and fourth toes.

(5) The outer, terminal branch (Fig. I $30 B$ ) of the $I$. peroneus communis inferior passes to the muscles of the fourth and fifth toes, and supplies Rami cutanei dorsales to the outer side of the fourth and inner side of the fifth toes.

Cutaneous branches of the 1 . tilyialis supply the outer side of the fifth and inner side of the first toe.

\section{G. The Srupathetic Srstem (Sympathicus). (Re-written by the translator.)}

The sympathetic cord or chain is a row of nerrous ganglia (vertebral or lateral ganglia), connected by nerve-fibres, and lying on either side of the vertebral column (Figs. II 7 and 131); with the exception of the last spinal nerve there is usually one sympathetic ganglion associated with each spinal nerve ; in the case of the tenth spinal nerve there may be only one ganglion or as many as twelve.

The first ganglion (Figs. II I, opposite ics; I I $/ S_{I}$ ) is placed on the hypoglossal nerve just as it emerges from the first intervertebral foramen; it is large, but smaller than the second; its Ramus communicans is represented by several fine and very short fibres, which connect the ganglion with the nerve. This ganglion is connected with the second by two cr three nervous threads, between which passes the subclarian artery, a true Annulus Tieussenii being thus formed (de Watteville). The other ganglia are connected by single bands of fibres. The first ganglion supplies also branches to the axillary artery and to the cardiac plexus.

The second ganglion (Figs. II 7 and I $I I$ ) is the largest, and is closely applied to the brachial nerve; as in the case of the first ganglion and hypoglossal nerve, it is attached to the second spinal nerve without a distinctly marked Ramus communicans. 
The third ganglion (Ganglion cardiacum basale, Gaskell and Gadow) is sometimes fused with the second, but is usually close to the third spinal nerve : it has a short but distinct Ramus communicans.

Behind the third ganglion the sympathetic cord is continued backwards along the corresponding aortic arch, then parallel with and close to the abdominal aorta (Figs. I17, I27, and I3I), receiving

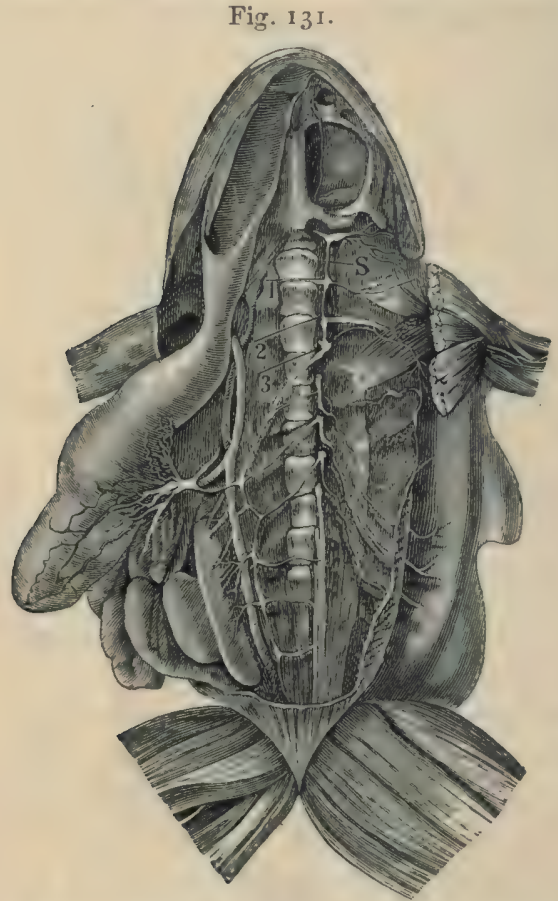

Sympathetic cord. From Ecker (Icones physiologicae, PI. XXIV, Fig. 3).

The heart, lungs, and liver have been removed; the stomach, intestine, kidneys, and testes drawn to the right side; the left sympathetic cord is thus pulled to the right side to expose the Rami communicantes.

$S$ Sympathetic cord attached to the ganglion of the vagus.

The numbers refer to the ganglia, which are enumerated from before backwards.

Rami communicantes, which are long and well marked, from each of the spinal nerves; the fourth, fifth, and sixth nerves usually supply each one Ramus communicans, the seventh two, and the eighth and ninth each two or three : from the tenth nerve it receives three or more, as many as twelve having been noted. The ganglia are usually more or less spindle-shaped or flattened and triangular; the hinder part of the cord usually receives in addition two or three branches from the sciatic plexus and twigs from the $R$. abdominalis of the $N$. coccygens.

The branches and communications of the sympathetic cords are as follows :-

a. Communicating branches between the two cords ; these are extremely numerous and irregular, forming a net-like plexus, which surrounds the abdominal aorta and other adjacent structures, and gives off numerous small twigs to the neighbouring vessels and organs.

b. Communications with the cranial nerves; these are two branches (Wiedersheim), (Figs. I I I and I 6 ) which pass from the first ganglion to the Ganglion nervi vagi, where one terminates, the other leaves the ganglion to pass on to the Gasserian ganglion 
(Figs. II I and II6 VS): according to Gaskell a single nerve passes from the first ganglion to the Ganglion nervi vagi, whence one portion of its fibres is continued to the Gasserian ganglion, the remainder accompanying the pneumogastric nerve without any connection with the ganglion; he therefore names this nerve the vago-sympathetic. (See Gasserian ganglion, p. I68.)

c. Communications with the spinal nerves; these are :-

(I) The Rami communicantes.

(2) Communications between the sympathetic ganglia or their branches and the spinal nerves or their branches (Fig. II 7 ); by means of these connections, fibres of the sympathetic system are conducted by the spinal nerves and their branches to all parts of the body.

d. Branches to the heart, which form the following ganglia :-

(I) A relatively large plexus lies on the auricles in the median plane immediately beneath the division of the $M$. hyoglossus. It supplies a network of fibres to the auricles and the adjacent large vessels. It is said to communicate at various points with the pneumogastric nerve.

(2) A smaller ganglion of oval form, supplies twigs to the neighbouring ressels and a communicating branch to the hypoglossal nerve (Wiedersheim).

e. Branches to the abdominal viscera; these form intricate plexuses by which the organs are supplied: the one best known is the solar plexus (Fig. 13I); it is formed chiefly from branches derived from the third, fourth, and fifth ganglia, and supplies the stomach, etc.; other plexuses for the various viscera are known by corresponding names, such are the Plexus hepaticus, renalis, genitalis, haemorrhoidalis, and vesicalis.

The sympathetic system is characterised by the fact that the branches form intricate plexuses, which include numerous ganglia and which are very irregular; it is also characteristic that most of its fibres are non-medullated. According to the investigations of Gaskell, the fibres of the sympathetic system arise in mammalia as very fine medullated fibres from the posterior vesicular (Clarke's) columns (Mason has recently described cells in the frog's spinal cord, which he holds to be homologous with the cells of these columns); they leave the cord by both the ventral and dorsal roots of the spinal nerves, and are thus connected with two sets of ganglia, (I) with the ganglia of the dorsal roots, and (2) 
through the Rami communicantes with the sympathetic ganglia (vertebral or lateral ganglia); these two sets of ganglia Gaskell terms proximal. By means of the branches from the sympathetic ganglia (Rami efferentes) part of the fibres pass to another set of ganglia, the solar plexus, etc., which he terms prevertebral or collateral; from these the fibres pass to be distributed to the various viscera and bloodvessels, where a fourth set of very small ganglia (terminal ganglia) is found. The prevertebral and terminal ganglia are together classed as distal ganglia. Gaskell holds that the fine medullated fibres from the cord lose their medullary sheath in one or other of these ganglia according to the function they fulfil.

The inhibitory fibres of the heart and vaso-dilator fibres of the blood-vessels continue as white fibres along the vago-sympathetic and spinal nerves to the distal ganglia (Bidder's ganglion, ete.), where the medullary sheath disappears: whereas the 'augmentor' fibres of the heart and vaso-constrictor fibres of the blood-vessels lose their medullary sheath in the proximal ganglia and pass on as nonmedullated fibres. In the same way the nerve-fibres that bring about contraction of the circular muscle fibres of the hollow viscera lose their medullary sheaths in the proximal ganglia, while those fibres, the influence of which negatives the former, become pale fibres in the distal ganglia.

Waters has demonstrated that in the frog the various spinal nerves have each a localised physiological action upon the bloodvessels and muscular walls of various parts of the alimentary canal: he shows that

The third spinal nerve supplies the oesophagus.

The fourth spinal nerve supplies the stomach.

The fifth spinal nerve supplies the upper third of the small intestine.

The sixth spinal nerve supplies the lower two thirds of the small intestine.

The seventh spinal nerve supplies the large intestine.

The eighth spinal nerve supplies the bladder, this supply being, however, not so definite as the others given above.

It has long been known that the branches of the spinal ganglia (ganglia of the posterior roots) are together larger (one-third, Lenhossék), and contain more fibres than the ventral and dorsal roots together; this is supposed to be in part due to an acquisition of new fibres derived from the ganglia. The majority of recent observers hold that each ganglionic cell has only one process, which, 
however, soon bifurcates; whether any of the fibres so formed pass as far as the cord or beyond its blood-ressels is doubted by most observers, and denied br Gaskell. These remarks and the description of the cells of the spinal ganglia (p. I $; 6$ ) hold good for the lateral or vertebral ganglia and the prevertebral ganglia (solar ganglion, etc.) of the srmpathetic system; the terminal ganglia will be described with the organs in which they are found.

\section{H. Histological Notes ox the Nervots Systfir.}

(In order to render the foregoing description of the nervous gystem more complete, the following notes have been added by the translator.)

[The histological elements of the nervous system are nerve-cells and nerve-fibres; of these the nerve-cells have been described with the parts in which they occur; it may simply be remarked that later observers have been unable to discover the 'spiral cells' described by Beale, Arnold, and others. The nerve-fibres, as in most other animals, are of two kinds, medullated and non-medullated.

1. Medullated nerve-fibres or white fibres are found in all cranial and spinal nerres, with the exception of the olfactory nerves, and in many of the sympathetic nerres (see Srmpathetic System); also in the white matter of the brain and spinal cord; examined microscopically the fibres are seen to consist of an external sheath or neurilemma, a medullary sheath, and an axis-cylinder :-

a. The neurilemma (Sheath of Schwann, Outer or Primitive Sheath) is a nucleated cndothelial laver covering the nerve-fibre; it is continuous with the corresponding coat of the nerre-cells, and is uninterrupted throughout the length of the nerre; at the nodes. however, it dips down towards the axis-crlinder, the circular groove so formed being filled with cement substance.

b. The medullary sheath (White substance of Schwann); the presence of this sheath is the chief cause of the whiteness of these nerves; the thickness of the sheath raries considerably; and towards the ultimate distribution of the nerve it is entirely lost. At more or less regular intervals along the course of the nerve-fibre the continuity of the medullary sheath is broken, and gives the fibres the appearance of being constricted at these places; such constrictions are known as nodes of Ranvier; the portion between two such nodes being termed an internode. Each internode possesses an oral, flattened, granular nucleus at about its middle 
and placed between the neurilemma and the medullary sheath; the nucleus has a nucleolus. In the fresh state the medullary sheath seems to be fluid; it is of a fatty nature.

Medullary segments are caused by breaks in the continuity of the medullary sheath, which are seen only in nerves which are no longer in their normal condition, and are especially well marked after treatment with osmic acid. The breaks are oblique; hence the conical end of one segment fits into the funnel-shaped end of the next. How far they correspond to pre-existent structures is uncertain. The segments in the frog vary in length from 0.010 to $0.040 \mathrm{~mm}$.

c. The axis-cylinder is the essential part of every nerve-fibre ; it shows a longitudinal striation corresponding to the fine fibrils (primitive fibrillae) of which it consists ; these fibrils often exhibit minute varicosities : at times it has the appearance of being invested with a very delicate structureless sheath. It is continuous through the nodes of Ranvier.

2. Non-medullated nerve-fibres (Grey or Varicose Fibres; Fibres of Remak); these occur chiefly in branches and plexuses of the sympathetic system; they consist of a neurilemma and an axiscylinder, which agree exactly with the corresponding elements found in the medullated fibres.

The nerve-fibres, whether medullated or non-medullated, are bound together by connective-tissue to form nerves. A number of fibres bound together by connective-tissue to form a slender cord is known as a funiculus; a small nerve may consist of one such funiculus; the sheath surrounding it is known as the perineurium, and sends in supporting processes between the fibres (endoneurium): when several funiculi are bound together to form a large nerve the common sheath is known as the epineurium. These sheaths support nerves (nervi uervorum) and vessels (vasa vasorum) supplying the nervous elements, and their intercellular spaces form lymph-canals. The whole nerve is surrounded by an endothelial coat, which helps to form a lymph-space, which more or less completely surrounds the nerve.

The ultimate distribution of the nerve-fibres will be included in the description of the various organs in which they end.] 


\section{SECTION IV.}

\section{THE VASCULAR SYSTEM.}





\section{THE VASCCLAR SYSTEM.}

\section{LITERATURE.}

\section{THE HEART AND BLOOD-VESSELS.}

Aeby, Ueber den feineren Bau der Bluteapillaren. Centralbl. f. d. med. Wiss. 1865, p. 209.

Altmann, R., Ceber Corrosion in der Histologie. Centralbl. f. d. med. Wiss. I8 8 , p. 245 .

Aubert, H., Die Innervation der Kreislaufsorgane. Hermann's Handbach der Physiologie. Leiprig, 1880. Vol. VI, Pt. I, p. $37 \%$.

Beck, K., Zur Kenntniss der Herznerven. Arch. f. mik. Anst. 1884. Vol. XXIV, pp. II-19.

v. Bezold, Cntersuchungen über die Innervation des Herzens. Leipzig, 1863.

Bidder, F., Ueber functionell verschiedene und räumlich getrennte Nervencentra im Froschherzen. Arch. f. Anat. u. Physiol. I852, p. I63.

Bidder, F., Zur näheren Kenntniss des Froschherzens und seiner Nerven. Arch. f. A nat. u. Physiol. 1866, p. I.

Bidder, F., Endigungsweise der Herzzweige des N. ragns beim Frosche. Arch. f. Anat. n. Physiol. 1868, p. I.

Bidder, F., and Gregory, Beiträge zur Physiologie der Herzbewegung beim Frosche. Dorpat, 1865.

Boss, J. E. V., Ceber den Conus arteriosus und die Arterienbogen der Amphibien. Morph. Jahrb. 1881. Vol. VII, pp. 271-273.

Boss, J. E. V., Beiträge zur Angiologie der Amphibien. Morph. Jahrb. I882. Vol. VIII, pp. 169-187.

Bobretzky, C., Ceber die Entwickelung der Capillargefässe. Centralbl. f. d. med. Wiss. 1885, p. 769 .

Bremer, L., Die Nerven der Capillaren der kleinen Arterien und Venen. Arch. f. mik. Anat. I882. Vol. XXI, p. 663.

Brenner, A., Ceber das Verhältniss des $\mathbf{N}$. laryngeus inferior vagi zu einigen Aortenvarietäten des Menschen und zu dem Aortensystem der durch Lungen athmenden Wirbelthiere überhaupt. Arch. f. Anst. u. Physiol. 1883, pp. 373-397.

Brūcke, E., Ceber Mechanik des Kreislaufes des Blutes bei Fröschen. Wiener Sitzungsb. 1851. Vol. VI, p. 61 ; also p. II4.

Brūcke, E., Beiträge zur rergl. Anatomie u. Physiologie des Gefaisssystems der Amphibien. Denksehriften d. Wiener Academie. 1852. Vol. III, p. 335.

Burdon-Sanderson, J., Circulation of the Blood, in Handb. for the Physiological Laboratory. London, 1873 .

Burow, De vasis sanguiferis ranarum. Diss. inaug. Regiomontani, I834.

Calori, L., Sugli organi della circulatione e della respirazione dei gyrini della Rana esculenta e della Salamandra cristata. Nuov. Ann. delle Scienz. nat. de Bologna. 1838 .

Champness, F., The Septum Atriorum of the Frog and the Rabbit. Journ. of Anat. and Physiol. 1874, p. 340.

Chapmann, 8. H., Beiträge zur Kenntniss des Baues des normalen und entzündeten Pericardiuma der Batrachier. Wiener Med. Jahrbücher. 
Chrzonzczewsky, N., Ueher die feinere Structur der Blutcapillaren. Virchow's Arch. 1866. Vol. XXXV, p. 169.

Darwin, F., Contributions to the anatomy of the sympathetic ganglia of the Bladder in their relation to the vascular system. Quart. Journ. Micros. Sci. 1874. Vol. XIV, p. rog.

v. Deen, De differentia et nexu inter nervos vitae animalis et vitae organicae. Diss. insugur. Lugduni; also in Areh. f. Anat. u. Physiol. 1834, p. 477.

v. Deen, Over de zijelingsche Takken dar zwervende van den Proteus anguinis (includes frog-larva). Bijdragen tot de Naturkundige Wetenschappen. 1834 .

Dogiel, J., Die Ganglienzellen des Herzens bei versehiedenen Thieren und beim Menschen. Arch. f. mik. Anat. 1877. Vol. XIV, p. 47 r.

Dogiel, J., Die Nervenzellen und Nerven des Herzventrikels beim Frosche. Arch. f. mik. Anat. 1882. Vol. XXI, p. 21.

Dumeril, A. M. C., and Bibron, G., Erpétologie générale, ou histoire naturelle complète des reptiles. Paris, I84I.

Eberth, C. J., Ueber den feineren Bau der Blutcaplllaren bei den Wirbelthieren. Centralbl. f. d. med. Wiss. 1865, p. 196.

Fberth, Elemente der quergestreiften Muskelfasern, bes, des Herzens. Virchow's Arch. 1866. Vol. XXXVII, p. I00.

Eoker, A., Icones physiologicae. Leipzig, I851-9.

Engelmann, T. W., Der Bulbus Aortae des Froschherzens. Physiol. Untersuch. in Gemeinsch. mit. J. Hartog und J. J. Verhoff. Pfliger's Arch. f. d. ges. Physiol. I882. Vol. XXIX, pp. 425-468.

Friedländer, Ueber die nervösen Centralorgane des Froschherzens. Unters. a. d. physiol. Labor. in Wiirzburg. 1867. Vol. II, p. 159.

Fritsch, G., Zur vergleichenden Anatomie der Amphibienherzen, Arch. f. Anat. u. Physiol. 1869, p. 654 .

Gaske11, W.H., On the augmentor (accelerator) nerves of the heart of cold-blouded animals. Journ. of Physiol. I884. Vol. V, p. 46.

Gaskell, W. H., and Gadow, On the anatomy of the cardiac nerves in certain coldblooderl animals. Journ, of Physiol. 1884. Vol. V, p. 362.

Gastaldi, Neue Untersuchungen über die Muskulatur des Herzens. Würzb. Naturf. Zeitschr. I862. Vol. III, pp. 6-9.

Gegenbaur, C., Grundzüge der vergleichende Anatomie. 2nd edit., 1870.

Gerlach, L., Ueber die Nervenendigungen in der Muskulatur des Froschherzens. Virehow's Arch. 1876. Vol. LXVI, pp. 187-223.

Golubew, A., Beiträge zur Kenntniss des Baues und der Entwicklungsgeschichte der Capillargefässe des Frosches. Arch. f. mik. Anat. 1869. Vol. V, pp. 49-89.

Gompertz, C., Ueber Herz und Blutkreislauf bei nackten Amphibien. Arch. f. Anat. u. Physiol. Phys. Abt. 1884, p. 242.

Gruby, Sur le système veineux de la grenouille. Annales des Sciences nat. 2 ntt series. Zool. I842. Vol. XXVII, p. 207.

Gruby, Recherches anatomiques sur le système veineux de la grenouille. Paris, 1842 .

Gscheidlen, R., Zur Lehre v. d. Nervenendigungen in den glatten Muskelfasern. Arch. f. mik. Anat. 1877. Vol. XIV, p. 321.

Heidenhain, Disquisitiones de nervis organisque centralibus cordis. Dissert. inaug. Berol., I854; and in Arch. f. Anat. u. Physiol. 1858, p. 479.

His, W., Ueber die Endigung der Gefässnerven (in mesentery). Virchow's Arch. 1863. Vol. XXVIII, pp. 427-428.

Hoffmann, C. K., Die Lungengefässe der Rana temporaria. Dissert. Jorpat, I875.

Hoffmann, C. K., in Bronn's Klassen und Ordnungen des Thierreichs. Leipzig und Heidelberg, 1873-1878. Vol. VI, pp. 509-514.

Hoffmann, T., Die Lungen-Iymphgefässe der R. temporaria. Dissert. Dorpat, 187.5 . 
Huizinga, D., Untersuchungen über die Innervation der Gefäse in der Schwimmhaut des Frosches. Pfluger's Arch. f. d. ges. Physiol. IS75. Vol. XI, p. 207.

Huschke, Leber die Carotidendrüse einiger Amphibien. Zeit. f. Physiol. von Friedmann u. Treviranus. 183r. Vol. IV, p. Ir3.

Hyrtl, J., Vorläufige Anzeige tuber gefisslose Herzen. Wiener Sitzungsb. 1859. Vol. XXXIII, p. 572 .

Hyrtl, J., Ueber die sogenannten Herzvenen der Batrachier. Wiener Sitzungsb. 186. Vol. L, Pt. II, p. 42.

Hyrtl. J. Teber das Verhalten der Leberarterie zur Pfurtader bei Amphibion u. Fischen. Wiener Sitzungsb. 1864. Vol. XLIX, Pt. I, p. 16\%.

Jantschitz, J., Materialien zur Anatomie der Nerven des Pericardiums. Rudneff" Journ. f. normale und patholog. Histologie u. klinisch. Med. St. Petersburg, 1874, pp. $417-41^{2}$.

Klug, F.. Ueber die Beschleunigungsnerven des Froschherzens. Centralbl. f. d. med. Wiss. 188r, p. 945 .

Klug, F., Teber die Herznerven des Frosches. Arch. f. Anat. u. Entwicklungsgesch. 1881, pp. 330-346. Abstract in Centralbl. f. d, med. Wiss. I $\$ 8 a$, p. 259.

v. Kölliker, A., Handbuch der Gewebelehre. 5th edit.

Küttner, Beitrag zu den Kreislaufsverhältnissen in der Froschlunge. Virchow's Arch. Vol. LXI, p. 21 .

Lahousse, P., Die Structur des Nervenplexus in der Vorhofscheidewand des Frosehherzens. Arch. f. Anat. u. Physiol. 1886, pp. 191-196.

Lambotte, H. A., Obserrations anatomiques et physiologiques sur les appareils sanguins et respiratoires de Batraciens anourés. Mém. cour l'A cad. de Bruxelles. 1838 .

Langer, C., Ueber das Lymphgefásssystem des Frosches. Wiener Sitzungsb. I 866. Vol. LIII, Pt. I, p. 395 ; 1867. Vol. LT. Pt. I, p. 593; 1868. Vol. LVIII, Pt. I, p. 198 .

Irangerhans, P., Notiz zur Anatomie des Amphibienherzens. Zeit. f. wiss. Zonl. 1873. Vol. XXIII, p. 457.

Langerhans, P., Zur Histologie des Herzens. Virchow's Arch. 1873. Vol. LVIII, pp. $65-83$.

Lavdowsky, M., Das Säugadersystem und die Nerven der Cornea. Arch. f. mik. Anst. 1872. Vol. VIII, p. 538 .

Lavdowsky, $\mathbf{N}$., Ceber die Furtsatze der Nervenzellen in den Herzganglien. Arch. f. mik. Anat. I887. Vol. XXIX, p. 609.

Lehmann, Leber die Nervenendigungen und das Vorkommen ron mikroskopischen Ganglien in den Gefässwandungen. Zeit. f. wiss. Zool. I864 Vol. XIV. pp. 346-352.

Ievschin, Ceber das Lymph. und Blutgefaisssystem. Wiener Sitzungsb. 18 jo. Vol. LXI, Pt. I, p. 6\%.

Leydig, Anatomisch.histologische Tntersuchungen über Fische und Amphibien. I 853 .

Leydig, F., Leber Organe e' nes sechaten Sinnes. Nora Acta Acad. Caes. I $86,8$. Vol. XXXIV, pp. I-102.

Leydig, Lehrbach der Histologie. 1857.

Lōwit, M., Beiträge zur Kenntniss der Innervation des Herzens. Pflüger's Arch. f. d. ges. Physiol. Chapters I and II, I880, Vol. XXIII, p. 3I3. Chapters III, IV, and V, I\$81, Vol. XXV, pp. 399-496. Chapter VI, I882, Vol. XXVIII, p. 312. Chapter VII, 1882, Vol. XXIX, p. 469.

Lőwit, M., Teber die Gegenwart von Ganglienzellen im Bulbus sortae des Froschherzens. Pflüger's Arch. f. d. ges. Physiol. 1883. Vol. XXXI, pp. 88-94.

Ludwig. C., Ceber die Herznerven des Frnaches. Arch. f. Anat. u. Physiol. IS48. p. 139 . 
Marshall, A. M., The Frog. Manchester and London. 1885, pp. 22-31.

Marshall, C. F., Structure and Distribution of striped and unstriped muscle. Quart. Journ. Micros. Sei. 1887. Vol. XXV.

Meckel, J. F., System der vergleichenden Anatomie. Halle, I 833 .

Milne-Edwards, Leçons sur la Physiol. et l'Anat. comparée. Vol. II, p. 407.

Namias, M., Suiganglii miocardici della Rana. Osservazione ed esperienzi in Lo Spallanzani. 1881. Vol. X, pp. 402-419.

Nicolsky, P., Ueber Flimmerendothel beim Frosche (in pericardium). Centralbl. f. d. med. Wiss, $\mathrm{x} 88 \mathrm{o}, \mathrm{p} .64 \mathrm{I}$.

Oellacher, J., Ueber die erste Entwickelung des Herzens und der Pericardial- oder Herzhöhle bei Bufo cinereus. Arch. f. mik. Anat. I871. Vol. VII, p. I57.

v. Openchowski, T., Beitrag zur Kenntniss der Nervenendigungen im Herzen. Arch. f. mik. Anat. I883. Vol. XXII, p. 408.

Owen, R., Comparative Anatomy. Vol. I, p. $5 x$.

Owen, R., On the structure of the heart in the perennibranchiate Batrachia. Trans. Zool. Society, I834. Vol. I, p. 2 I 2.

Pihlermann, R., Untersuchungen äber die angeblich präformirten Verbindungswege zwischen den Blut- und Lymphgefässen des Frosches. Dissert. Dorpat, 1876.

Pohl-Pincus, Ueber die Muskelfasern des Froschherzens. Arch. f. mik. Anat. I884. Vol. XXIII, p. 500 .

Prévost and Lebert, Mémoire sur la formation des organes de la circulation et du sang dans le batraciens. Annales des Sciences nat. 1844; Vol. I, p. 193; and in Compt. rend. 1844; Vol. XVIII, p. 88 ; and in Froriep's Notizen, 1844, Vol. $\mathrm{XXX}$, cols. $337-340$.

Ranvier, L., Leçons d'anatomie générale. Paris, 1880, p. 469.

Ranvier, L., Appareils nerveux terminaux des muscles de la vie organique; coeurs sanguins, cœurs lymphatiques; œsophagus; muscles lisses. Leçons d'anatomie générale au Collége de France. Paris, 1880. Vol. VII, p. 350.

Rawitz, B., Ueber den Bau der Spinalganglien. Arch. f. mik. Anat. Vol. XXI, p. 244 .

Reich, M., Einige microscopische Studieu mit Silbersalpeterlösung besonders an Gefässen des Auges und anderen Organen. Wiener Sitzungsb, I873. Vol. LXVII, Pt. III, pp. 8I -96 .

Rokitansky, C. Ueber die Scheidewand der Vorhöfe. Wiener Med. Jahrb. I87I, p. 340 .

Rosenberger, De centris untuum cordis disquisitiones anatomico-physiologicae. Dorpat, 1850 .

Rouget, C., Mémoire sur le développement, la structure et les propriétés physiologiques des capillaires sanguins et lymphatiques. Arch. de physiol. normale et pathologique. $1873, \mathrm{pp} .66_{2}-66_{4}$.

Rusconi, M., Observations sur le systeme veineux de la grenouille. Annales des Seiences nat. 2nd series. Zool. 1845. Vol. IV, p. $28_{3}$.

Sabatier, Etudes sur le cœur dans la série des vertébrés. Montpellier, 1873; also Ann. Sci. nat. I873, Vol. XVIII, art. 4; also Revue Cours. Scient. 1873, pp. $163-165$.

Schmuziger, F., Ein Beitrag zur Auswanderung der Blutkörperchen aus den Gefässen des Frosches. Arch. f. mik. Anat. 1873. Vol. IX, pp. 709-711.

Schöbl, D.J., Ueiser die Blutgefässe des cerebrospinalen Nervensystems der Urodelen. Arch. f. mik. Anat. I882. Vol. XX, p. 87. Also in Sitzungsb. d. k. b. Gesell. d. Wiss. in Prag. 1878, p. 25.

Schöbl, D. J., Ueber Wundernetze und divertikelbildende Capillaren bei nackten Arnphibien, etc. Arch. f. mik. Anat. 1885. Vol. XXV, p. 89.

Schraeder, M. Æ. G., Ueber das Hemmungzcentrum des Froschherzens. Strasaburg, I 886.

Schutz, C. H., Das System der Circulation. Stuttgart and Tübingen, 18,36. 
Schweigger-Seidel, Das Herz, in Stricker's Handbuch d. Gewebelehre.

Sokoloff, Ueber die Saftkanälchen (Lymphkanälchen) in den quergestreiften Muskeln des Frosches. Rudneff's Journ. f. normal u. patholog. Histologie und Klin. Med. St. Petersburg, I873, pp. 456-459.

Stirling, W., and Macdonald, The minute structure of the palatine nerres of the Frog and the termination of nerves in blood-vessets and glands. Journ. of Anat. and Physiol. 1884 Vol. XVII, p. 273.

Stricker, \$., Cntersuchungen über die capillaren Blutgefässe in der Nickhaut des Frosches. Wiener Sitzungsb. I865. Vol. LI, Pt. II, pp. I6-26.

Stricker, S., Studien über den Bau und das Leben der capillaren Blutgefässe. Wiener Sitzmingsb. 1866. Vol. LII, Pt. II, pp. 379-394.

Trevianus, G. R., Ceber die Karotidendrüse einiger Amphibien. Tiedemann's Zeitschr. 183r. Vol. IV, p. II3.

Trevianus, C. R., Beobachtungen aus der Znotomie u. Physiologie, nach dessen Tode herausgegeben von L. C. Treviranus. Bremen, 1839.

Verhoeff, J. J. W., Histologisehe en physiologische bijdragen tot de kennis ran den bulbus aortae van het kikvorschhart. Onderzoekingen gedach in het Phys. Laborat. VII, afiev 2. Utrecht, 1882.

Vignal, Recherches sur l'appareil ganglion nerve du cœur des vertébrés. Labratoire d'histologie du Collége de France. Travaux de l'année I881, p. 186; and in Arch. de Physiol. norm. et path. 1881, pp. 673-694 and 910-934.

Virchow, H., Ceber die Kopfgefässe des Frosches. Sitzungsb. Würzburg, 1880. Vol. XV, p. xxxiv.

Virchow, H., Ceber die Gefässe im Auge und die C'mgebung des Auges beim Frosche. Zeit. f. wise. Zool. 1881. Vol. XXXV, p. 247.

Volkmann, Nack:weise der Nervencentra, von welchen die Bewegung der Lymphund Blutgefässherzen auggeht. Arch. f. Anat. u. Physiol. 18+4, p. 4 I9.

Wagner, R., Lehrbuch d. vergleichenden Anatomie. Lëipzig, 1834-35.

Wagner, $\mathbf{R}$, Icones Zootomicae. Leipzig, 1841 .

Weismann, Teber die Muskulatur des Herzens beim Menschen und in dem Thierreiche. Arch. f. Anat. u. Physiol. 1861, p. 42.

Wyman, J., On the heart and respiration of the Menobranchus and Batrachians. Proc. of the Bnston Soc. of Nat. History. I 856 . Vol. T, p. s I.

Zimmermann, W., U'eber circumvasale Safträume der Glaskiorpergefaisse von Rans esculenta. Arch. f. mik. Anat. 1886. Vol. XXVII, p. 410.

\section{THE LYMPHATIC SYSTEM.}

Bacculo, B., Nuove ricerche intorno l'apparecchio gangliunare intrinsicu dei cuori linfatici. Naples, 1885 .

Fckhard, C., Zeitsch. f, rat. Med. 1850. Vol. IX.

Eckhard, C., Beiträge zur Anat. u. Physiol. I 855 . Tol. I, p. 53; 1858, Vol. II, p. $145 ; 1863$, Vol. $\Pi 1$, p. 167 .

Eckhard, C., Experimentale Physiolngie des Nervensystems. Giessen, 1867, p. 208.

Goltz, Centralbl. f. med. Wiss. I863, pp. I7, 497; I 864, p. 690.

Heidenhain, Disquisitiones de nervis cordis cordiumque lymphaticorum. Berlin, 1854 .

His, W., Ueber die Wurzeln der Lymphgefässe in den Häuten des Körpers und über die Theorien der Lymphbildung. Zeit. f. wiss, Zool. 1863. Vol. XII, p. 223.

Hoffmann, T., Die Lungen-Lymphgefäse der R. temporaria. Dissert. Dorpat, 1875 .

Hüter, C., Teber den Kreislauf und die Kreislaufsstörungen in der Froschlunge. Centralb. f. med. Wiss. 1873, Nos. 5 and 6. 
Jourdain, S., Sur les sacs sous-cutanés et les sinus lymphatiques de la région céphalique dans la Rana temporaria. Compt. rend. 1881. Vol. XCIII, pp. $597-600$.

Jourdain, s., Sur le système lymphatique des tétards de grenouilles. Compt. rend. 1883. Vol. XCVI, pp. $27 x-273$.

Jourdain, s., Recherches sur le système lymphatique de la R. temporaria. Montpellier, I883; Extr. de la Revue de Sci. nat. Montpellier, I884.

Kahrhel, G., Studien über Innervation der Lymphherzen. Medic. Jahrb. I 886, pp. $39^{2-420}$.

Key and Retzius, Studien in der Anatomie des Nervensystems. Arch. f. mik. Anat. I873. Vol. IX, p. 308.

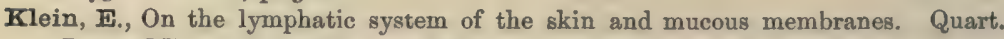
Journ. Micros. Sei. 1881. Vol. XX, pp. 379-406.

Langendorff, O., and Boll, F., Zur Kenntniss der Lymphherzen. Arch. f. Anat. u. Physiol. I883, p. 329.

Langer, C., Ueber das Lymphgefässsystem des Frosches. Wiener Sitzungsb. 1866, Vol. LIII, Pt. I, p. 395; I867, Vol. LV, Pt. I, p. 593 ; I868, Vol. LVIII, Pt. I, p. 198.

Levschin, Ueber das Lymph- und Blutgefässsystem. Wiener Sitzungsb. 1870. Vol. LXI, Pt. I, p. 67.

Luchsinger, B., Zur Lehre der Innervation der Lymphherzen. Pflüger's Arch. f. d. ges. Physiol. 1880. Vol. XXIII, p. 304.

Meyer, J., Systema amphibiorum lymphaticum. Diss. Berol., I845.

Müler, J., Beiträge zur Anatomie und Naturgeschichte der Amphibien. Tiedemann's Zeitschr. 1831. Vol. IV, pp. 190-275.

Müller, J., On the existence of four distinct hearts having regular pulsations connected with the lymphatic system in certain amphibiuus animals. Phil. Trans. 1833. Pt. I, pp. 89; also in Arch. f. Anat. u. Physiol. 1834, p. 296.

Müller, J., Bemerkungen über die Structur der Lymphherzen und der Lymphgefässe. Arch. f. Anat. u. Physiol. I839, p. I76.

Obersteiner, H., Ueber einige Lymphräume im Gehirne. Wiener Sitzungsb. 187o. Vol. LXI, Pt. I, p. 57 .

Pagliani, Ueber die Funktion der Herzganglien. Moleschott's Untersuchungen. 1876. Vol, XI, p. $35^{8}$.

Panizza, B., Sopra il sistema linfatico dei retelli. Ricerche Zootomiche. Pavia, 1833 .

Panizza, B., Ueber die Lymphherzen der Amphibien. Arch. f. Anat. u. Physiol. 1834 , p. 300 .

Pihlermann, R., Untersuchungen über diè angeblich präformirten Verbindungswege zwischen den Blut- und Lymphgefäscen des Frosches. Dissert. Dorpat, I $\&_{7} 6$.

Priestly, J., An account of the anatomy and physiology of the batrachian lymphhearts. Journ. of Physiol. I878. Vol. I, p. I.

Ranvier, L., Appareils nerveux terminaux des muscles de la vie organique; cœurs sanguins, cœurs lymphatiques; œsophagus; muscles lisses. Leçons d'Anatomie générale faites au Collége de France. Paris, r880. Vol. VII, p. 350.

v. Recklinghausen, Die Lymphgefässe und ihre Beziehung zum Bindegewebe. 1862.

Remak, R., Ueber blutlebre Gefässe (Lymphgefässe) in Schwanze der Froschlarve. Arch. f. Anat. u. Phyøiol. I849, p. I02.

Robinson, C., Ueber die Lymphgefässe der Abdominaleingeweide der Frösche, sowie deren Lymphbehälter. Froriep's Notizen, 1846. No. 807, col. 225.

Rusconi, M., Lettre du ducteur Rusconi à M. Breschet sur le système lymphatique de la Salamandra commune Arch. f. Anat. u. Physiol. I840, p. 8.

Rusconi, M., Ueber die Lymphgefässe der Amphibien. Arch. f. Anat. u. Physiol. 1843: p. $24 \mathrm{I}$. 
Rusconi, M., Einige historische Notizen die Lymphgefässe der Anphibien betreffend. Arch. f. Anat. u. Physiol. 1843, p. 244.

Rusconi, M., Sur les vaisseaux lymphatiques. Antrales des Sci. nat. Series II. Zool. 1841. Vol. XV, p. 249 .

Rusconi, M., Riflessioni sopra il sistema linfatico dei Rettili. Pavia, 1845.

Scherkey, M. L., Ceber die Feststellung und Bedeutung der Centren der Lymphherzen im Rückenmark. Dissert. Berlin, 1878 .

Scherkey, M. I., Zur Lehre der Innervation der Lymphherzen. Arch. f. Anat. u. Physiol. 1879, p. 227.

Schweigger-Seidel, F., and Dogiel, J., Ceber die Peritonealhöhle bei Fröschen und ihren Zusammenhang mit dem Lymphgefässsysteme. Arbeiten aus d. physiol. Anstalt. Leipzig, I86-, pp. 68- 76 ; Abstract in Centralbl. f. d. med. Wiss. 1867, p. 287 .

Suslowa, N., Beiträge zur Physiologie der Lymphherzen. Centralbl. f. d. med. Wiss. I 867, p. 832 .

Suslowa, Beiträge zur Physiol. der Lymphherzen. Dissert. Zürich, 1867 ; also in Zeitsch. f. rat. Med. 3rd series. I868. Vol. XXXI, p. 224.

Waldeyer, W., Anatomische und physiologische Cntersuchnngen ïber die Lymph. herzen der Frïsche. Zeitsch. f. rat. Med. 3rd series. 1864. Vol. XXI, pp. 103-124; Abstract in Centralbl. f. d. med. Wiss. 1864, p. 73 .

Waldeyer, W., Zur Anatomie und Physiologie der Lymphherzen von Rana und Emys europea. Studien des physiol. Instituts zu Breslau. 1865, pp. 71-96; Abstract in CentralbI. f. d. med. Wist. 1865, p. 32 I.

Weber, Đ. H., Ceber die Lymphherzen der Amphibien von Panizza. Arch. f. Anat. u. Physiol. 1834, pp. 300-304.

Wober, J., Beiträge zur Anatomie und Physiologie. Bonn, 1832.

\section{THE BLOOD AND LYMPH.}

Aly, W., Teber die Vermehrung der rothen Blutkörperchen bei Amphibien. Dissert. Halle, 1884 .

Arndt, R., Beobachtungen an roten Blutkörperchen der Wirbelthiere. Virchow's Arch. Vol. LXXVIII, p. I.

Beale, L. S., Observations upon the nature of the red blood-corpuscle. Quart. Journ. Micros. Sei. 1864, pp. 32-43.

Bizzozero, G., Ceber die Teilung der roten Blutkörperchen. Centralbl. f. d. med. Wiss. 1881, p. 129 .

Bizzozero, G., Ueber die Teilung der roten Blutkörperchen. Centralbl. f. d. med. Wise. 1882, p. 577 .

Bizzozero, G., and Torre, A. A., Ceber die Entstehung der roten Blutkörperchen bei den verschiedenen Wirbelthierklassen. Virchow's Arch. I884. Vol. XCV, pp. I-25.

Brücke, E., Ueber den Bau der rothen Blutkörperchen. Wiener Sitzungsb. I 867. Vol. LVI, Pt. II, pp. 79-9r.

Donders and Moleschott, Holländische Beiträge. I $\$ 48$, p. $36 \mathrm{r}$.

Fberth, C. J., Čber die Vermehrung der rothen Blutkörperchen nach Untersuchungen von W. Aly. Fortschritte d. Med. I885. Vol. III, pp. I- §.

Fuchs, E., Beitrag zur Kenntniss des Froschblutes und der Froschlymphe. Virchow's Arch. 1877. Vol. LXXI, p. 78 .

Gaule, J., Beobachtungen der farblosen Elemente des Froschblutes. Arch. f. Anat. a. Physiol. 1880, pp. 375-392. 
Gulliver, G., Measurements of the red blood-corpuscles of Batrachians. Proc. Zool. Soc. London, 1873, p. 162.

Hewson, W., On the figure and composition of the red Particles of the Blood, commonly called Globules. Phil. Trans. 1773. Vol. LXIII, Pt. I, p. $3 \circ 3$.

Home, E., On the changes the blood undergoes in the act of coagulation. Phil. Trans. I8 8 , p. I7 2 .

Kollmann, J., Bau der rothen Blutkörperchen. Zeitschr. f. wiss. Zool, I874. Vol. XXIII, p. $4^{62}$.

Kusnezoff, F., Ueber blutkörperhaltige Zellen der Milz. Wiener Sitzungsb, 1873. Vol. LXVII, Pt. III, pp. 58-67.

Moriggia, A., Ueber den Durchtritt der farblosen Blutkörperchen durch die Blutgefässwandungen, etc. Moleschott's Untersuchungen. I876. Vol. XI, p. 47c.

Neumann, E., Zur Histologie der rothen Blutkörperchen. Centralbl. f. d. med. Wiss: 1865, p. 481 .

Owsjannikow, P., Zur Histologie der Blutkörperchen. Bullet. de l'acad. science de Pétersbourg. 1865. Vol. VIII, pp. 561-572.

Peremeschko, Ueber die Theilung der rothen Blutkörperchen bei Amphibien. Centralbl. f. d. med. Wiss. I879, pp. 673-675.

Ranvier, I., Traité technique d'histologie, pp. 148-224.

Rollett, A., Versuche und Beobachtungen am Blute. Wiener Sitzungsb. Vol. XI.VI, Pt. II, pp. 65-98.

Stricker, Beobachtungen über die Entstehung des Zellkernes. Wiener Sitzungsb. 1878. Vol. LXXVI, Pt. 1II, p. 7 .

Thoma, R., Die Ueberwanderung farbloser Blutkörperchen von dem Blut in das Lymphgefäsøsystem. Heidelberg, I873.

Welcker, H., Grösse, Zahl, Volum, Oberfläche und Farbe der Blutkörperchen bei Menschen und Thieren. Henle u. Pfeuffer's Zeitschr. I864. Vol. XX, pp. $25^{8-30 \%}$. 


\section{PART I.}

\section{THE HEART AND BLOOD-VESSELS.}

\section{THE HEART.}

The original arrangement of this section has been modified.)

THE heart is situated in the middle line above the central portion of the shoulder-girdle and $\boldsymbol{M}$. sternohyoideus, and below the oesophagus; the apex is directed backwards and lies between the lobes of the liver, the base is directed forwards and lies a short distance behind the larynx. The heart is surrounded by the perieardium.

\section{A. The Pericardinm [is a} very thin membranous sac, which completely encloses the heart; it is attached, at some distance, to the large vessels passing to and from the heart, and has inserted into it some fibres of the $\boldsymbol{M}$. obliquus aldominis internus (see page 70). A fold of the pericardium extends from the dorsal surface to the truncus arteriosus, and through it courses the vena cardiaca.

The pericardium is a connective-tissue membrane, and is lined on either side with endothelium, which is in part ciliated (Lreydig); the endothelium of the inner surface is continued on to the heart
Fig. 132.

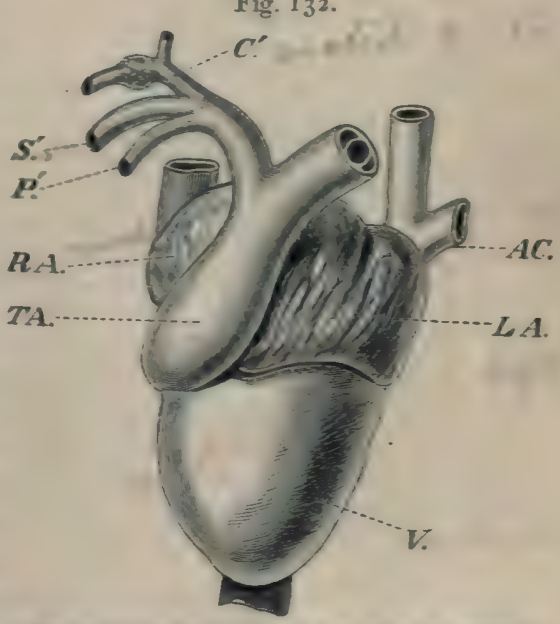

The heart and blood-ressels, geen from the ventral surface; after Howes.

AC. Left anterior caval rein.

C'. Carotid areh.

L.A. Left auriele.

P. Right pulmo-entaneous arch.

RA. Right auricle.

$S^{\prime}$. Left systemic arch.

TA. Truneas arteriosus,

V. Ventricle, 
and so forms a closed lymph-sac. The pericardium is more or less pigmented, and contains both vessels and nerves; it may contain fat-cells].

\section{B. The Heart.}

[The heart is a hollow muscular organ, composed of: (1) two auricles, forming the wider anterior portion ; (2). the ventricle, placed behind the auricles ; (3) the sinus venosus, situated dorsally; and (4) the truncus arteriosus, lying ventrally. Examined while still living, the auricles are seen to be much darker in colour than the ventricle, due to the blood being seen through their thinner walls; between the auricles and the ventricle is a distinct groove, the auriculoventricular groove. The whole organ is more or less pigmented, especially the ventricle ( $R$. temporaria has much less pigment).]

Fig. 133 .

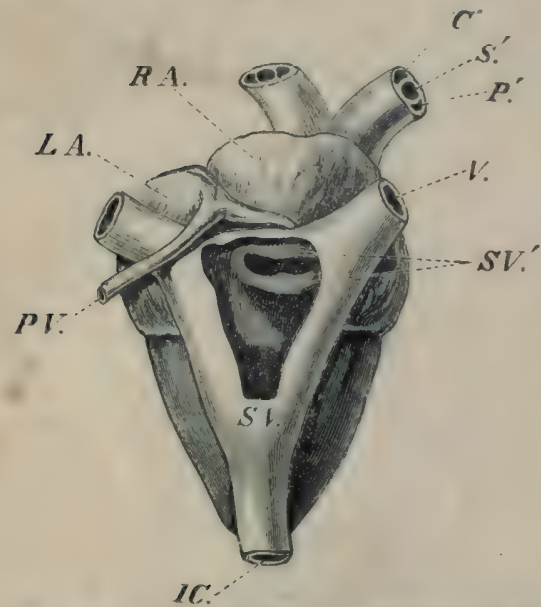

The heart, seen from above, and dissected to show the opening from the Sinus vencsus to the right auricle; after Howes.

C". Right carotid arch.

IC. Posterior caval veid

LA. Left auricle.

$P$ '. Right pulmo-outaneous arch.

$\boldsymbol{P V}$. Pulmonary vein.

RA. Right auricle.

$S^{\prime}$. Right systemic arch.

$S V$. Sinus venosus.

$S V^{\prime}$. Opening of Sinus venosus into the right auricle.

V. Right anterior caval vein. a. The Sinus venosus (Sinus venarum cavarum), (Fig. I33 $S V$.) is a thin-walled sac lying on the dorsal surface. of the heart, and very slightly to the right side (Hoffmann). It is somewhat triangular in form, receiving an anterior caval vein at each anterior angle $(V$.$) , and the posterior$ caval vein $(I C$.$) at the poste-$ rior angle. The ventral wall has a transverse opening $\left(S V^{\prime}.\right)$, by which it communicates with the right auricle; the opening possesses two valves, an anterior and a posterior, and is placed close to the auricular septum.

b. The auricles [are not always separated, as the septum which usually brings about the separation is in some cases incomplete, and in rare instances appears to be absent (Hoffmann)]; according to Ecker, the auricular septum is sometimes placed so far to the left side that it 
appears to be absent (Fig. 135). The septum is attached to the walls of the auricles so as to form two distinct carities, which communicate at the auriculoventricular opening, where the septum has a free concave border (Fig. 134). The right auricle is much lacorer than the left, and receives the systemic venous blood from the sinus venosus by the opening (Figs. 133 and $1348 V$.) already described. The left auricle receives the blood from the lungs by the pulmonary vein (Fig. I $33 P V_{0}$ ), which opens into the auricle near the septum (Fig. I34 PV.): [the openings from the sinus venosus and from the pulmonary vein may be so closely approximated as to be separated by the septum only. The septum is much thinner than the auricular walls]. Both auricles open into the ventricle by the auriculo-ventricular opening (Fig. 134).

c. The ventricle (Figs. 132, 134, and 1 $36 \tau$.), examined while still living, is seen to be bluntly conical in shape and darker on the left side than on the right; this is due to the ventricular wall of the right side, near the truncus arteriosus, being somewhat thinner. The inner wall is not smooth but possesses muscular ridges (Trabeculae). At its base the rentricle communicates with the auricles by the auriculo-rentricular opening (Figs. 134 and 136 ), and with the truneus arteriosus by a separate opening (Fig. I $3+$ B. The ventricle is lined by a laver of endocaruial endothelium.
Fig. ${ }^{134}$

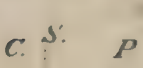

PI:

The frog's heart secen from the ventral surface, and dissected so as to show its stmeture. The venauricles and ventricle have been removed. From

A. Auricula-ventricular aperture and valve.

B. Aperture leading from rentricle to truncus arterivens.

C. Leit caritid arch.

UA. Leit auriele.

eft pulmo-cutaneovs arch.

into the truncus arteriosus, $T$

PV. Opening of pulmonary rein.

RA. Right auricle.

SA. Septum atriortum.

$\delta V$. Opening of Sinus venostus into right anricle.

$\boldsymbol{V}$. Ventricle. 
The auriculo-ventricular opening (Fig. I 34 A.) is a large aperture guarded by two valves, a dorsal and a ventral : each valve

Fig. 136 .

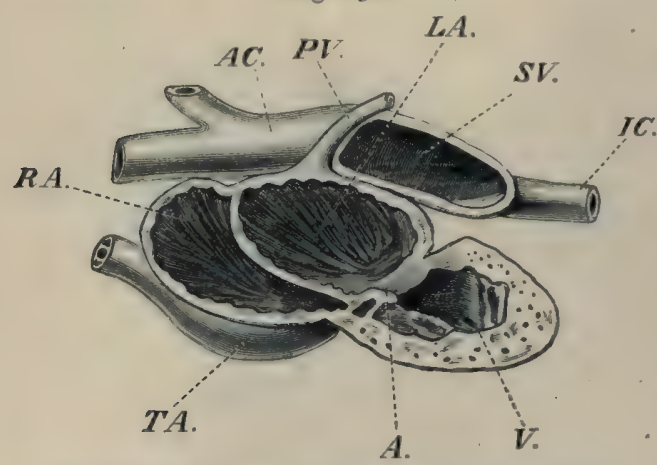

Dissection of the heart from the left side; after Howes,

A. Aurioulo-ventricular opening.
$A C$. Anterior caval veins.
IC. Posterior caval vein.
LA. Left auricle.
$P V$. Pulmonary vein.
$\boldsymbol{R A}$. Right auricle.
$S V$. Sinus renosus.
$T A$. Truncus arteriosus,
$\boldsymbol{V}$. Ventricle.
is formed by a reduplication of the endothelium, and contains a small amount of connective-tissue,; its free margin is bound down by a number (about twelve) of fibrous cords, the chordae tendineae, which are attached by their posterior extremities to the trabeculae.

d. The truncus arteriosus (Figs. I $32 T A$., I34 A.) arises at the base of the ventricle, on the right side of its ventral surface, then

passes forwards and to the left, across the auricles, to reach their anterior border near the median line, where it divides to form two vessels.

Internally it is incompletely divided into two compartments by a spiral valve (Fig. 134); the valve is attached to the dorsal surface and is free ventrally: when the vessel is fully dilated (artificially), the valve extends two-thirds of its diameter. The opening of the vessel into the ventricle is guarded by two semilunar valves (Fig. $1.34 \mathrm{~A}$.), the free margins of which are bound to the inner surface of the tube by chordae tendineae. The distal extremity has a semilunar valve in the left compartment (Fig. I34), which is attached by a delicate band to the spiral valve (Ecker).

\section{The minute structure of the Heart.}

[The heart consists chiefly of muscle, but possesses also nervefibres, nerve-cells, endothelium, and connective-tissue; the truncus arteriosus has in addition, blood-vessels.

a. The muscular structure of the heart.

(I) The arrangement of the muscle-fibres varies in the different portions of the heart. That of the ventricle will be easily understood 
by reference to Fig. I37. A layer of circular fibres $(C M I)$ extends round the whole ventricle, and from it more or less radial or trans-

Fig. 137.

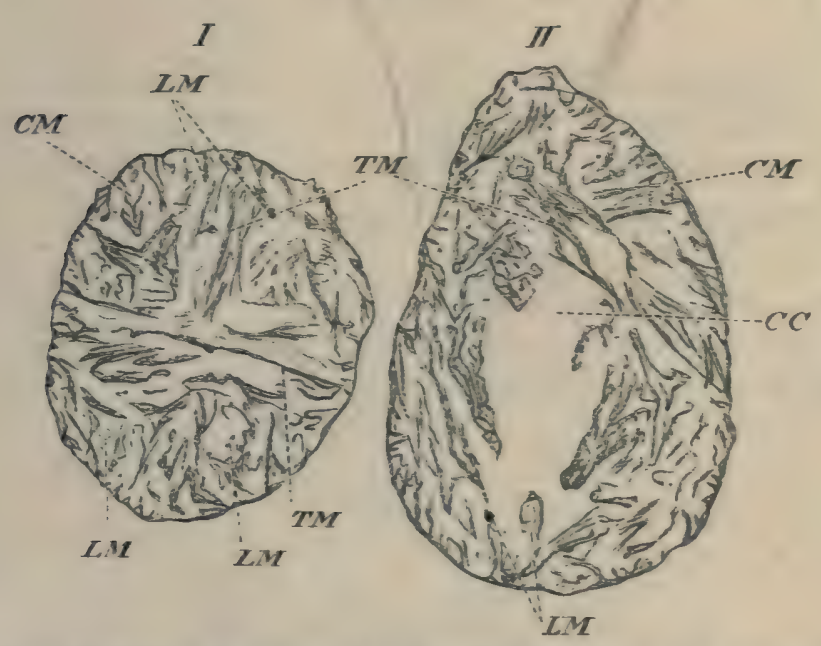

1. Transverse section through the junction of the hinder and middle thirds of the ventricle of $R$. lemporaria. II. Transverse section through junction of middle and anterior thirds of the same heart. Occ. I, Syst, r, Leitz. The heart was freely distended 1 with dilnte spirit, and so hardened. $-\mathrm{G}$. H.

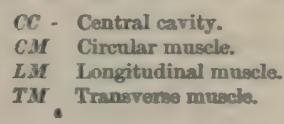

verse bands ( $T M$, also Fig. I $38 T M$ ) pass inwards; these, in the apical portion of the ventricle, seem to extend almost transversely across ; towards the base they are directed onwards and forwards towards the auricles. Of these bands some, near the apex, can be traced directly to the opposite side, others join the wall more anteriorly, and still others join bands of muscular fibres $(L M /)$, which may be described as longitudinal, and form the Musculi papillares. In the anterior portion of the ventricle the same arrangement holds good, but is modified to form a central cavity; still more anteriorly, at the junction of auricles and ventricle, the trabecular structure is much less apparent, the fibres being closer and mainly circular.

In the auricles the muscular fibres are chiefly arranged in circular rings which cross one another; on the inner surface, however, traces of an arrangement similar to that in the ventricle mar be male out. In the heart, from which the sections in Fig. I 37

1 The base of the ventricle measured, when distended, $8 \mathrm{~mm}$. by $5 \mathrm{~mm}$. 
were drawn, transverse bands (cut longitudinally), $0.33 \mathrm{~mm}$. in length, were numerous ; their central ends terminated in bands, the fibres of which were cut transversely. The auricular septum (Fig. I 4 I a $M$ ) also possesses muscular fibres which cross one another in its substance.

The fibres of the truncus arteriosus resemble those of an ordinary artery; those of the sinus venosus are arranged in rings, mostly transverse, but others oblique, and a few longitudinal.]

(2) The structure of the cardiac muscle-fibres (Figs. I 38 and I41 a).

[The cardiac musele of the frog consists of spindle-shaped cells, which as Pohl-Pincus pointed out, are of two kinds ; the main difference between the two being in the size of the nucleus, which is much broader in one than in the other.

Fig. 138 .

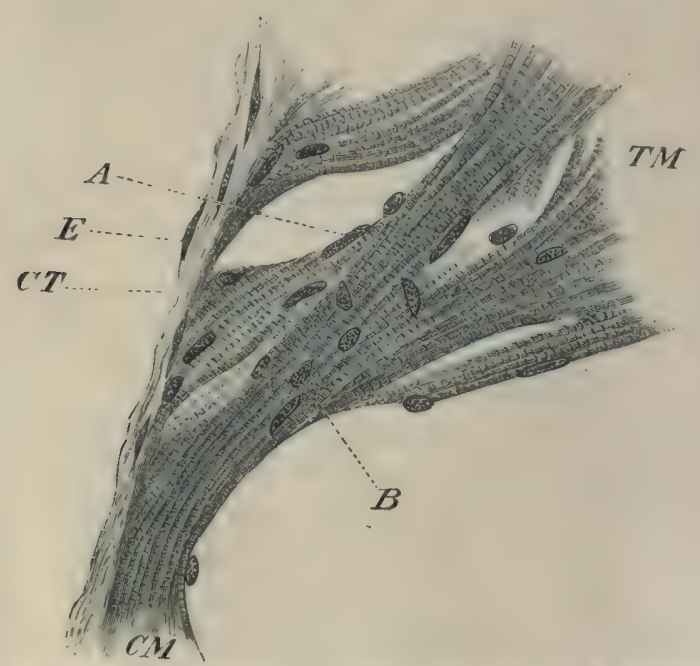

Portion of a transverse section through the middle of the ventricle of $R$. temporaria. From

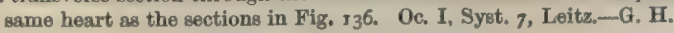
A. Rod-shaped nuelei of muscle fibre.
B Oval nuclei of muscle fibre.
CM. Circular layer of muscle.
CT Connective-tissue.
E Endothelium of the epicardium.
TM Transverse bands of muscle.

a. Cells with a broad nucleus (Fig. ${ }_{3} 8 B$ ) : the nucleus is lenticular or egg-shaped, 4 to $7 \mu$ broad, 8 to I 4 or $18 \mu$ long; the ratio of length to breadth being $I: 2$.

$\beta$. Cells with a narrow nucleus (Fig. $138 \mathrm{~A}$ ): the nucleus is 
rod-shaped, 2.5 to $3.5 \mu$ broad and 25 to $43 \mu$ in length. The ratio of length to breadth varying from $I: 8$ to $1: 16$. These cells are more frequent in the right half of the base of the ventricle than the former variety. In the trabeculae the second variety is more numerous (Pohl-Pincus).

The muscle-fibre may be simple (Fig. I 4I a $M$ ) or possess branches (Fig. 138); the fibres are all more or less spindle-shaped, and striated transversely and longitudinally, but possess no sarcolemma. The protoplasmic contents of the cell are finely granular; the nucleus much more coarsely granular and possessing one or more distinctly marked nucleoli. The striations are due to the presence of a network, which has been carefully described by Messrs. B. Melland and C. F. Marshall ${ }^{1}$, and is similar to that of ordinary voluntary muscle (see histology of muscle).]

b. The nerves of the heart.

The nervous supply of the heart is derived from the sympathetic system and from the eardiac branches of the pneumogastric nerve; the course of which has already been traced (page 175) to the roots of the anterior caval veins, where they form a simple plexus by means of a connecting link (Fig. I39). The plexus possesses nerve-cells and sends off two nerves into the auricular septum; the one $(d)$ lies dorsally and is shorter and thicker than the other $(v)$, which lies ventrally in the septum. They course backwards to the posterior border of the septom, and there distribute fine branches to the base of the ventricle and surrounding parts.

[In the whole of their course in the heart they have numerous nerve-cells, either imbedded between their fibres or attached to the nerves and their branches.

Fig. 139 .

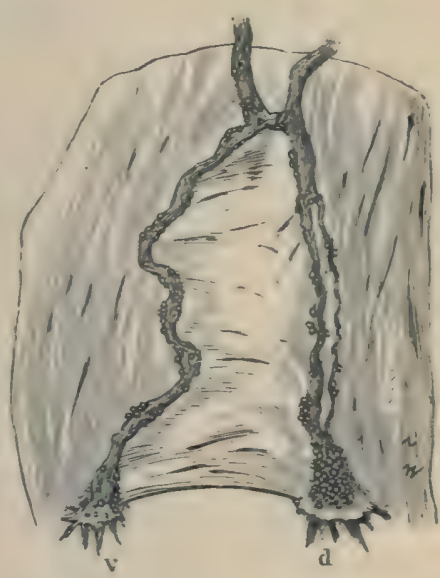

Course of the cardiac nerves in the auricular septum.

d Dorsal nerre.

$v$ Ventral nerve.

The nerve-fibres are both medullated and non-medullated. The nerve-cells (Figs. I39, 140, I4I)

1 I have had opportunity of examining Mr. Marshall's slides and have convinced myself of the correctness of his observations. 
are usually oval, and are unipolar or rarely bipolar; sometimes two cells exist in the same envelope, forming the 'twin-cells' of

Fig. ${ }^{4}$.

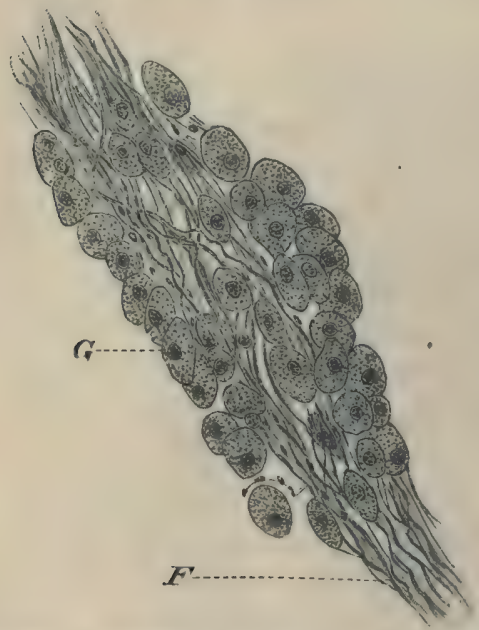

Group of nerve-cells on the cardiac nerve, from the auricular septum. Stained with picrocarmine. Occ. III, Syst. 3, Hartnack ; after Dogiel.

$F$ Fibres of the cardiac nerve.

$G$ Nerve-celle.
Dogiel (Fig. I4I b II). According to the recent observations of Lavdowsky and Dogiel each cell receives one medullated fibre and gives off a fine non-medullated fibre; the two run together for a short distance, after which the non-medullated fibre separates to supply muscle-fibres.

Two large clusters of nervecells have received special names.

Remak's ganglion is a large group of nerve-cells in the wall of the sinus venosus.

Bidder's ganglion is formed, collectively, by groups of cells in the auriculo-ventricular groove, the chief groups being attached to the two cardiac nerves.

No nerve-cells have been discovered behind that portion of the ventricle near the auriculoventricular groove, nor has a direct connection between the cells or their processes with the fibres of the pneumogastric nerve been made out.

Nerve-fibres have been described as existing in all parts of the ventricle and being connected with the muscle-fibres (Openchowsky and others); this cannot, as yet, be accepted as proved.

The truncus arteriosus also possesses nerve-fibres and nerve-cells (Pagliani, Löwit, and others), but their arrangement seems to be very irregular. Löwit did not succeed in finding the nerve-cells in all cases examined; and Engelmann denies their occurrence.]

c and d. [The endothelium and connective-tissue of the heart.

The connective-tissue of the heart exists only in very small quantity. A fine layer on the outer surface of the ventricle, especially towards the auriculo-ventricular groove, can easily be seen (Fig. I 38 CT) ; the various valves, the auricular septum, and more particularly the truncus arteriosus, all contain connective- 
tissue. In the latter part the spiral valve is wholly formed of this tissue.

Fig. $14 \mathbf{1}$ \%.

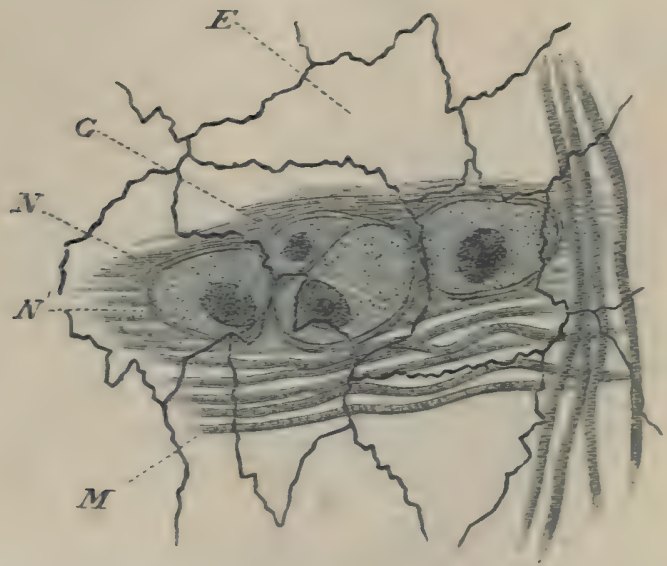

Small gronp of nerve-cells from the aurieular septum. Stained with piencarmine and silver nitrate, after Dogiel.

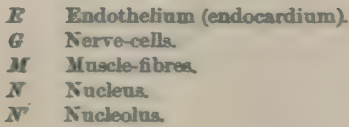

The whole of the inner surface is lined with endothelium

Fig. $14 \mathrm{I} \mathrm{b}$.
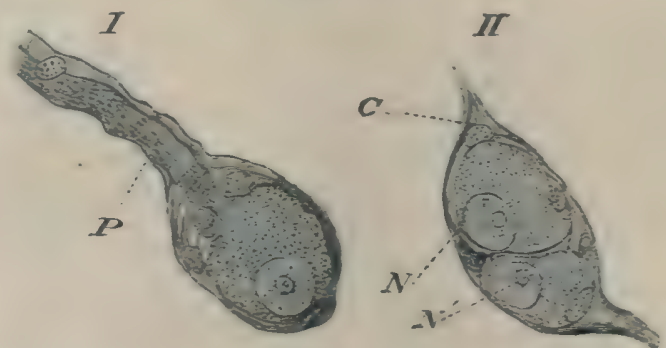

Isolated nerve-cells fnom frog's heart. I. LEual furw of kerve-cell. II. 'Twin-oell.'

$$
\begin{aligned}
& \text { C Capsule } \\
& \text { I Nucleus } \\
& \text { IV Nicleolus } \\
& \text { P Process. }
\end{aligned}
$$


Fig. 142.

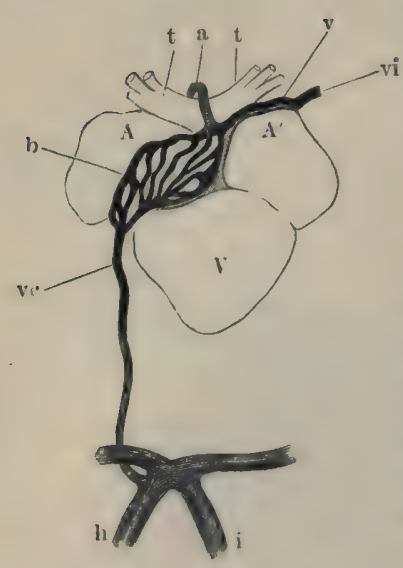

Arteries and veins of the Truncus arteriosus of Bufo vulgaris, after Hyrtl.

a Arteria bulbi.

b Truncus arteriosus.

$h$, i Hepatio portal veins.

$t \quad$ Right and left synangium.

v Vena bulbi anterior.

$v i$ Left innominate vein.

vc Vena bulbi posterior ( $V$. cardiaca).

1 Right auricle.

$A^{\prime}$ Left auricle.

V Ventricle, (endocardium), which covers the various trabeculae; the external surface of the heart is likewise covered with an epicardial layer of endothelium (Fig. $13^{8}$ E).]

e. The blood-supply to the heart.

With the exception of the truncus arteriosus, no part of the heart possesses blood-ressels (Hyrtl). [The truncus arteriosus (Fig. I42 b) has a rich anastomosis, which receives its blood by the arteria bulbi $(a)$, a branch of the carotid arch. Two veins connect this anastomosis with the systemic veins, and with the hepatic portal veins: the former, vena bulbi anterior $(v)$, passes over the auricles to open into the left innominate vein $(v i i)$; the latter, the vena bulli posterior $(v c)$ or vena carNiaca, as it is more usually named, passes from the truncus arteriosus in a fold of pericardium, and then courses backwards to open into the anterior-abdominal vein.]

\section{THE ARTERIES.}

(The original arrangement of this section has been modified.)

The Truncus arteriosus divides to form two vessels (Figs. 132, 134); each of these is divided by two partitions into three compartments, which after a short course together separate to form three distinct ressels, the carotid, systemic, and pulmo-cutaneous arches.

1. The carotid arch (C'analis carotico-lingualis, Brïcke; Juctus caroticus.s), (Fig. 14.3 I) is the most anterior of the three arches : it winds round the side of the oesophagus as far as the carotid gland, where it divides to form two branches; the right carotid arch gives off a small branch to the Truncus arteriosus, the Arteria bulbi (see above). 
The carotid gland (Fig. I $44 c^{\prime}$ ) is a dilated portion of the ressel. The interior contains bands or trabeculae of muscle, which give its

Fig. 143.

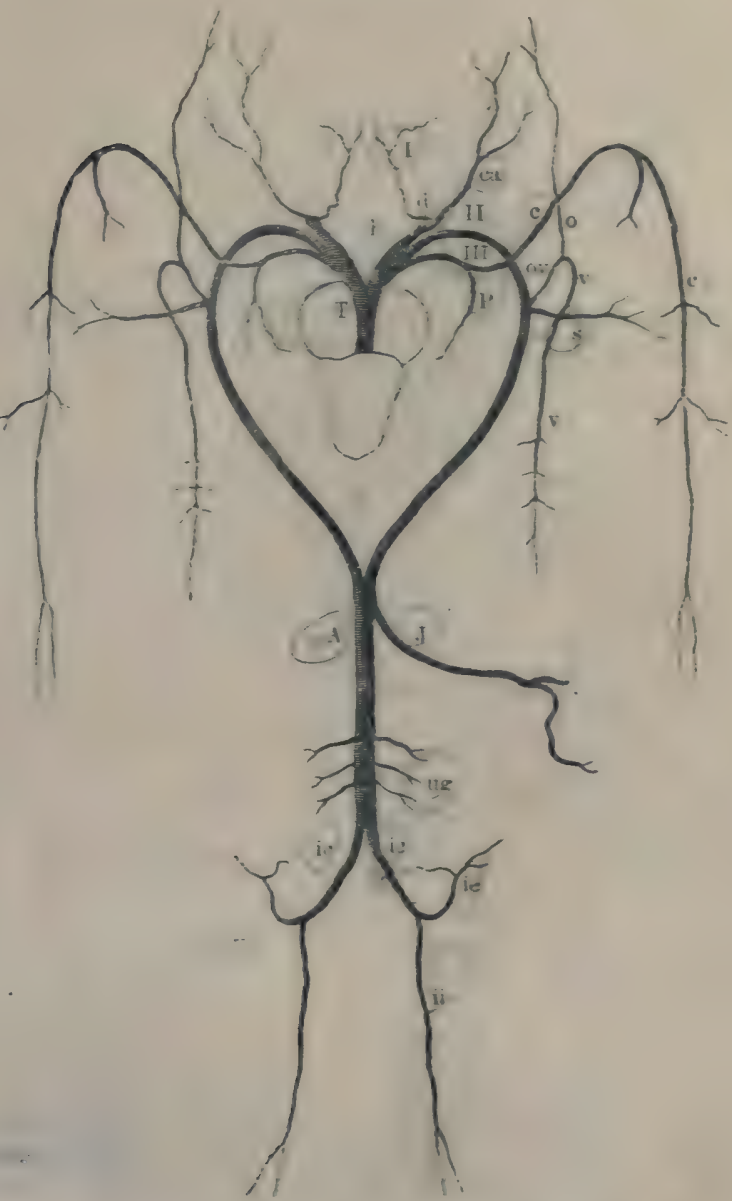

Schemn of the arterial system of Rana esculcuila.

A. Dinalacta. :

c Cutaneones artery. V

CI Car tillartery.

d Carvitiluland.

e, Iliac arterion

Tृ Exterial iliac artery.

if Intermal iliac artary.

$\vec{J}$ Meenterit artery.

Lingual artery.

Occipital artery. ox Docipito-vertebral artery.

Polomonary artery

Sulw an:an artery.

Truncis arteriosma \&

Urinogenital arterios.

Vervinar arery

Crnotid areh.

is-ientic arith

III Pulnuglusaneus anch. 
walls a more or less spongy structure; the muscle-fibres are not transversely striated (Hoffmann).

a. The lingual artery (Arteria lingualis, Arteria hyoidea-lingualis, Arteria hyoidea), (Figs. $143 l, 144 L$ ) arises by two roots from the inner surface of the carotid gland, and courses forwards and inwards, supplying branches to the thyroid gland and the Musculi genioliyoidei, to the ventral surface of the hyoid; another continues forwards on the outer border of the $\boldsymbol{M}$. hyoglossus to supply branches to the hyoid and tongue.

b. The carotid artery (Arteria carotis communis), (Figs. I 43 ca, I $44 c^{\prime \prime}$ ) arises by several roots from the outer wall of the carotid gland; and passes over the Musculus petrolyoideus $I$ to the anterior end of the oesophagus, round which it courses towards the vertebral column, and then runs forwards to the base of the skull. The artery then courses forwards, lying immediately above the mucous membrane and underneath the transverse arm of the parasphenoid, which it crosses about midway between its back and external end; [at this point the artery gives off two palatine arteries, then ascends in the orbit to the origin of the $\boldsymbol{M}$. pterygoileus, and divides into two

Fig. 144.

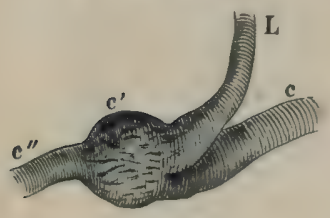

Right carotid gland.

c Carotid arch.

$c^{\prime}$ Carotid gland.

c" Carotid artery.

LL Lingual artery. branches, the internal carotid artery and the ophthalmic artery]. The branches are :-

(i) The pharyngeal artery (Arteria pharyngea ascendens), (Fig. I45 p) which runs towards the opening of the Eustachian tube, distributes branches to the pharynx, and anastomoses with the Arteria pharyngeo-maxillaris of the cutaneous artery, and with the Ramus inframaxillaris of the occipital artery.

(2) [The posterior palatine artery (Arteria palatina josterior, virchow) immediately divides into a number of small twigs to supply the mucous membrane of the hinder and outer wirts of th gums.]

(3) The anterior palatine artery (Arteria palatina anterior, Virchow; Arteria palatina, Ecker), (Fig. $145 \mu^{\prime}$ ) runs forwards, between the Musc. levator bulbi and the mucous membrane, with the Ramus palatinus of the trigeminal nerve. [On reaching the palatine bone, it curves outwards to the outer anterior angle of the orlit, where it gives off a branch backwards along the upper jaw to the hinder portion of the orbit.] In its course it supplies twigs 
to the surrounding tissues, but chiefly to the nucous membrane and Harder's gland.

Fig. 145 .
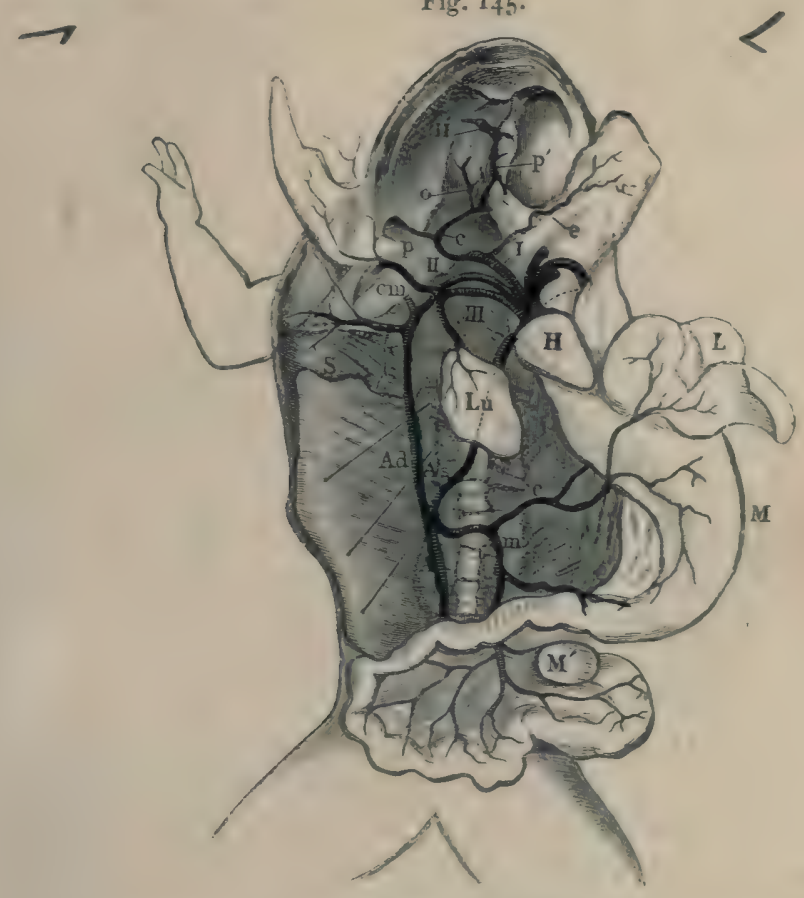

Arterial system of Rasa esculentu.

- A Domal aorta.

Ad Right systemic anch.

As Loft rystomic anch.

c (opposite fore-limb) Carotid artery.

$c$ (in abdomen) Coeliac artery.

ciu Cutaneous artery.

e Lingual artery/

H Heart.

$\boldsymbol{H}^{\prime}$ Harderian gland.

$\boldsymbol{L}$ Liver.

Lน Lung.

\author{
w Mesenteric artery. \\ M Stomach.

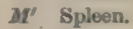 \\ - Ophthalmic artery. \\ p Pharyngeal artery. \\ $p^{\prime}$ Anterior palatine artery. \\ 8 Subclavian artery. \\ I Carotid arch. \\ II Systemic anch. \\ III Pulmo-cutaneons srah.
}

(4) The internal carntid artery (Ai. cerebralis, Virchow); see Arteries of Brain, p. 162 .

(5) The ophthalmic artery (Art. ophthatmica), (Fig. I 45 o) [is larger than the internal carotid artery at this point; it crosses the origins of the $M$. rectus externus and of the $M$. retrahens lulli $i$ and reaches the optic nerve; the artery then runs forwards along the under surface of this nerve and of the eveball, lying close to the sclerotic coat as far as a little beyond the equator, where it pierces the sclerotic coat so obliquely that the choroid coat is only 
reached at the ciliary processes. In its course the artery supplies :-

a. Muscular branches, given off at the point where the artery reaches the eyeball.

$\beta$. Two arteries ( $A A$. ciliares) to the choroid, given off at the same point as the foregoing.

$\gamma$. Two arteries to the iris.

$\delta$. The Art. hyaloidea, the terminal portion of the ophthalmic artery. (For further description of these vessels, see Eye.)].

2. The systemic arch (Ductus aorticus), (Figs. I32, 143, and $145 I I)$ is the middle arch of the three; it arises from the middle canal of the Ductirs arteriosus, and winds obliquely round the oesophagus between the $M M$. petrohyoidei $I$,and $I I$ towards the vertebral column, which it reaches at about the level of the sixth vertebra. The right systemic arch is continued as the dorsal aorta, the left arch communicates with it merely by a small opening, and is then continued as the coeliaco-mesenteric artery.

Branches of the systemic arch:-

a. The laryngeal artery (Arteria laryngea), (Fig. $146 \mathrm{lg}$ ) arises from the inner border of the systemic arch before it reaches the oesophagus; it passes forwards and inwards to be distributed in the larynx and pharynx. According to Brücke this artery possesses a valve at its point of origin.

Fig. 146 .

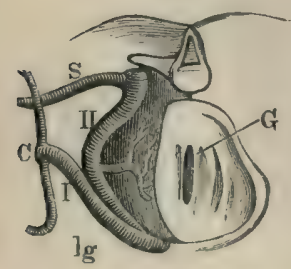

Transveree section at level of the larynx.

C Carotid gland.

G Glottis.

lg Laryngeal artery.

$S$ Subclavian artery.

I Carotid arch,

II Aortic arch.

(I) The vertebral artery (Arteria vertebralis or supra-vertelinatis

b. The oesophageal arteries (Arteriae oesophageae) pass from the upper part of the arch to the dorsal surface of the oesophagus.

c. The occipito-vertebral artery (Eeker), (Art. occipito-vertebralis), (Fig. $1470, v$ ) [arises from the systemic arch immediately in front of the transverse process of the second vertebra, and ascends immediately in contact with the body of the first vertebra, which it separates from the $M M$. intertransversarii capitis and the sympathetic cord]. Immediately under the most anterior portion of the $\boldsymbol{M}$. longisimus dorsi the artery divides into two branches, the vertebral and occipital arteries :- 
(Fig. $147 v$ ) courses backwards lying on the transverse processes of the vertebrae and on the $M I M$. intertranstersarii, under cover of the M. longissimus dorsi. In this course it is close to the oblique pro-

Fig. 147 .

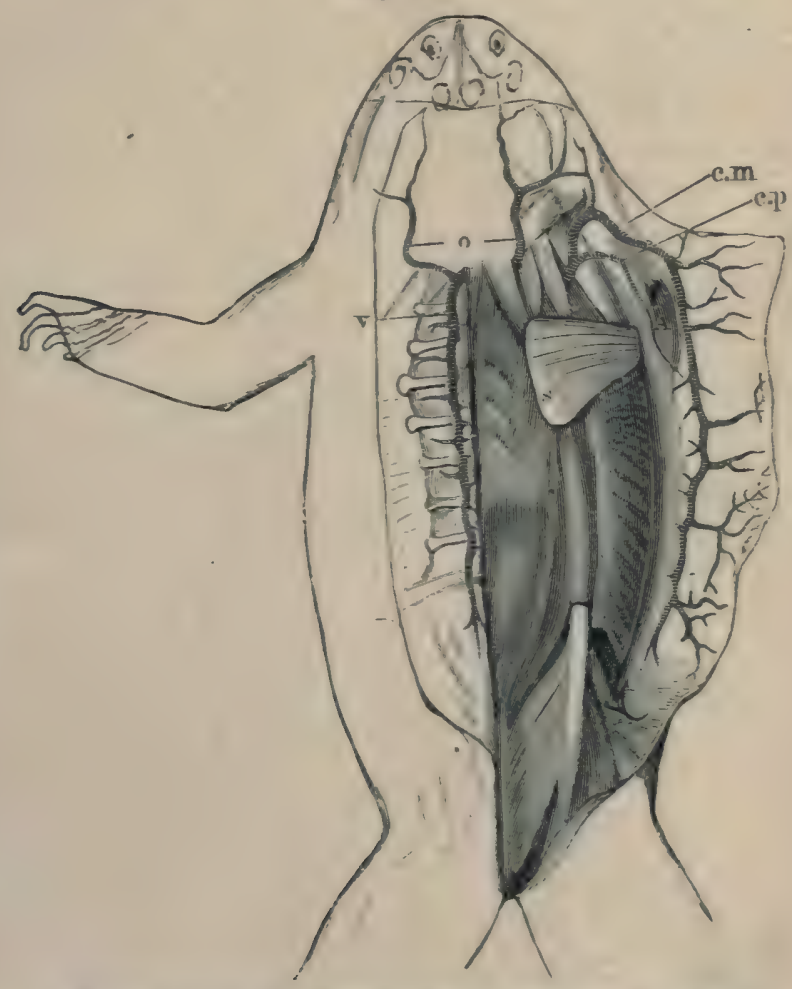

Disection to show the occipito-vertebral and the cutaneons arteries.

The skin of the back has been divided by a median incision and drawn to either side : the right arm dislocated amd removed throngh the opening in the skin (at A). Un the left side the extensor muscles of the back have been remored.

$$
\begin{aligned}
& \text { c.m. Cutaneous artery. } \\
& \text { c.p. Arteria cutanea pectoris. } \\
& \text { * Occipital artery. } \\
& \text { * Scapular artery. } \\
& \text { Vertebral artery. }
\end{aligned}
$$

cesses, and may even be partially corered by these; it extends beyond the sacrum, and gives off:

a. The Rami spinales, which pass through the intervertebral foramina to the spinal cord (see Arteries of Spinal Cord, p. 162).

$\beta$. The Rami lorsales; these supply the muscles of the back and send branches to the skin, which aceompany the cutaneous branches of the spinal nerves through the Saccus !ymphaticus cranio-dorsalis. 
$\gamma$. The Rami intercostales are distributed in part to the $M M$. intertransversarii; other twigs pass ventrally to the periganglionic glands; the longest branches accompany the anterior divisions of the spinal nerves to the muscles and skin of the belly (Fig. 145).

(2) The occipital artery (Arteria occipitalis), (Figs. 147 and 1480 ), the anterior branch of the occipito-vertebral artery, pierces the M. Tongissimus Horsi; then courses forwards under cover of the Fascia dorsalis and upon the M. temporalis, and divides, behind the eyeball [at the anterior border of the $M$. temporalis, Virchow], into two branches :-

a. The Ramus orlito-nasalis (Fig. 148 on) accompanies the ophthalmie nerve along the wall of the cranium, and passes through the sphenethmoid, with the nasal branch of the ophthalmic nerve, to the nose, where it divides into two branches supplying the mucous membrane of the nose. In its course through the orbit the artery supplies branches to the Harderian gland and neighbouring parts, and anastomoses with the ascending branch of the Arteria palatina.

$\boldsymbol{\beta}$. The Ramus maxillaris communis (Art. temporalis, Virchow), (Fig. $148 \mathrm{~m}$ ) runs downwards and outwards along the anterior border of the $\boldsymbol{M}$. temporalis, and passes under the anterior arm of the squamosal bone to course backwards on the upper jaw. At

Fig. 148.

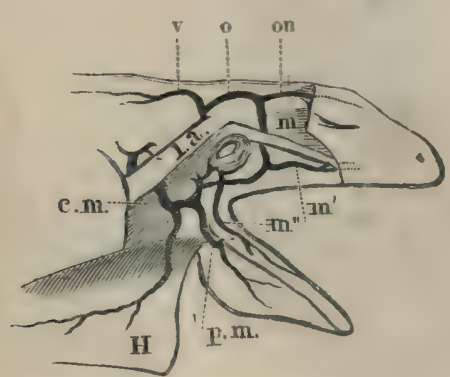

Branches of the occipito-vertebral and cutaneous arteries in the head; side view. The skin $(H)$ has been reflected downwards.

\footnotetext{
c.m. Cutaneous artery.

l.a. M. levator scapulae.

$m$ Art. maxillaris communis.

$m^{\prime}$ Art. maxillaris superior.

$m^{\prime \prime}$ Art. naxillaris inferior.

- Occipital artery.

on Art. orbito-nasalis.

p.m. Art. pharyngo-maxillaris.

v Vertebral artery.
} this point the Ramus maxillaris superior $\left(m^{\prime}\right)$ is given -off. The main artery continues its backward course to the tympanic membrane, where it divides into its three terminal branches:-

\section{[(I) The Ramus maxillaris supe-} rior (AA. maxillares superiores, Virchow), usually not a single artery but a number of small twigs, which supply the space between the eye and the upper jaw.

(2) A small ascending branch to the tympanic membrane (Virchow).

(3) A Ramusauricularis(Virchow), which forms a rich anastomosis on the hinder wall of the tympanic cavity, and supplies a twig to the tympanic membrane. This passes 
from the upper border of the membrane to the point of attachment of the Columella auris (extrastapedial), round which it forms a cireular anastomosis. The Ranus auricularis also anastomoses with the cutaneous artery.

Fig. 149.

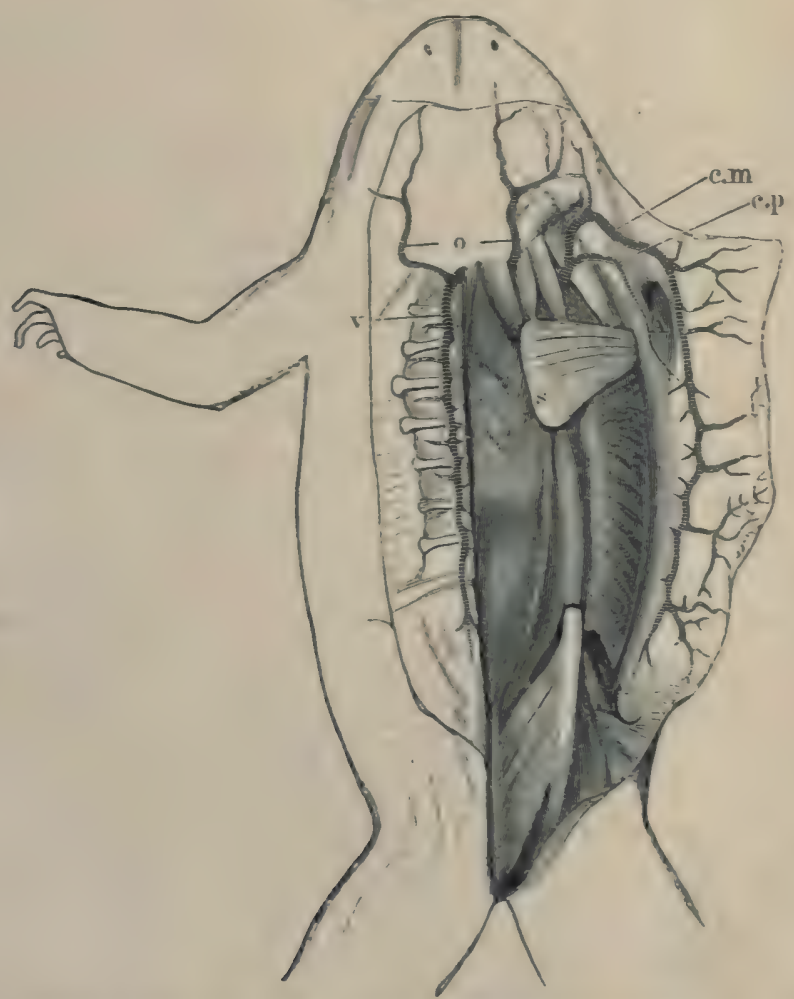

Diwection to slow the occipito-vertebral and the cutaneons arterien.

The skin of the baek has been divided by a median incision and drawn to sither side; the right arm disloratud and removed through the opening in the skin (at $A$ ). On the left side the extensor imuscles of the back have bean removed.

\section{c.m. Cutaneous artery. \\ c.p. Arteris cutanea pectoris \\ - Occipital artery. \\ y Scapular artery. \\ - Vertebral artery.}

(4) A branch passing inwards to the fat-body, and lying immediately in front of the deltoid muscle (Virchow).

(j) A small branch running on to the inner surface of the angle of the jaw and then forwards (Virchow). 
(6) A larger vessel, the Ramus maxillaris inferior (Fig. $148 \mathrm{~m}^{\prime \prime}$ ), which arises from the Ramus maxillaris superior under eover of the tympanic membrane, and accompanies the Ramus mantibularis of the trigeminal nerve through the $M$. masseter, or between this muscle and the $M$. temporalis to the mandible, and then courses forwards to the chin. A large cutaneous branch is given off halfway along the floor of the mouth. The artery gives off many small twigs to supply the neighbouring structures.]

3. The pulmo-cutaneous arch (Ductus pulmo-cutaneus), Figs. I 32, I 43, and $145 I I I$ ) is the hindmost (fifth embryonic) of the three persistent arches; it passes upwards and forwards on the oesophagus, and at the level of the carotid gland divides into two branches, the pulmonary artery and the cutaneous artery.

a. The pulmonary artery (Arteria pulmonalis) runs backwards to the root of the lung, along the outer surface of which it is continued in a sinuous course. It supplies the lung.

b. The cutaneous artery (Arteria cutanea magna), (Fig. I49 c.m.) [passes along the deeper surface of the $M$. petrohyoideus $I I I$ until near the prootic bone; in this course it travels forwards, outwards, and upwards, crosses the outer border of the muscles, and appears between the $M$. levator anguli scapulae and the $M$. sternocleidomastoideus. At this point the artery curves sharply round to reach the angle of the jaw, the hinder border of the $M$. depressor maxillae inferioris. The curve so formed and the descending limb are covered by the $\boldsymbol{M}$. depressor maxillae inferioris. The artery then passes backwards to form a rich anastomosis in the skin almost as far as the posterior end of the trunk. It supplies the following branches :-

(I) The Ramus dorsalis (Virchow) arises immediately in front of the curve of the main artery ; it ascends behind the $M$. temporalis, and passes along the anterior border of the $M$. depressor maxillae to the skin, where it curves backwards. It supplies small twigs forwards as far as the eyelids.

(2) The Ramus auricularis (Virchow) also arises in front of the curve in the cutaneous artery; sometimes it arises from the Ramus dorsalis. The artery winds around the $\boldsymbol{M}$. petrolyyoileus $I I I$ near its insertion, and so reaches the posterior wall of the tympanic cavity, where it anastomoses with the $R$. auricularis of the Ramus maxillaris communis.]

(3) The Arteria pharyngo-maxillaris (Fig. I 48 p.m.) is a small branch running forwards and outwards to supply the mucous membrane of the larynx, Eustachian tubes, gums, the lower jaw, and 
the skin under the mouth. It forms a rich anastomosis with branches of the Ramus maxillaris inferior of the occipital artery, and with others from the pharyngeal branch of the carotid artery; a large branch passes forwards to supply the skin of the throat and floor of the mouth.

(4) The Arteria cutanea pectoris (Fig. $149^{c} \cdot p$. .) is distributed to the skin of the breast.

4. The subclavian artery (Arteria subclavia), (Fig. I50 8). The subclavian artery arises from the systemic arch immediately behind the occipito-vertebral artery at the level of the second or third vertebra. The artery then runs outwards alongside and in front of the brachial nerve, between the $M$. sulsscapularis and the M. triceps to the arm, where it is known as the brachial artery; in its course it gives off:-

a. The Arteria costo-cerricalis (Fig. I50, I). This artery arises near the systemic arch, and runs backwards, parallel to the vertebral column, over the brachial nerve, and across the transverse processes of the vertebrae. It is distributed more especially to the M. obliquus internus.

b. The Arteria coraco = clavicularis (Fig. I 50, 2) arises more externally than the last artery; it accompanies the coraco-clavicular nerve on the dorsal surface of the ventral portion of the shouldergirdle, and passes between the $\boldsymbol{M}$. deltoideres and $\boldsymbol{M}$. subscapularis into the Foramen orale, where it divides to supply these muscles and the M. pectoralis.

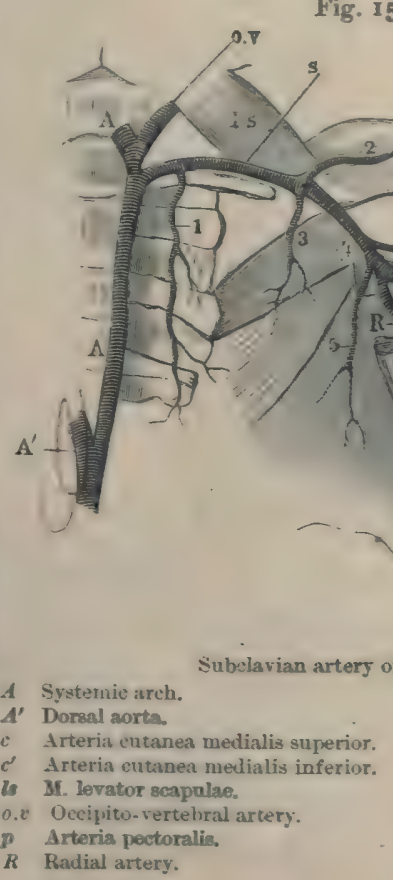

Fig. I50. 
c. The Art. scapularis posterior (Fig. I50, 3), a small branch arising opposite at the tip of the second transverse process and passing backwards over the MM. transverso-scapulares, to which it is distributed.

d. The Art. scapularis superior (Fig. I 50, 4) accompanies several nerves between the $M$. sutscapularis, $M$. transverso-scapularis major,

Fig. $15 \mathrm{~T}$.

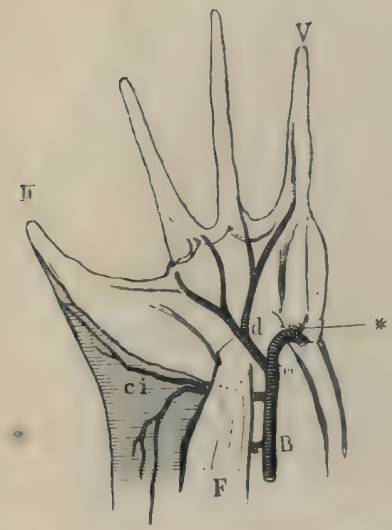

Arteries of the palmar surface of the hand.

$\begin{array}{ll}B & \text { Ulnar artery. } \\ c i & \text { R. cutaneus medialis inferior. } \\ d & \text { Digital branches. } \\ \text { F } & \text { M. flexor digitorum communis. } \\ \text { II } & \text { Thumb. } \\ \boldsymbol{V} & \text { Fifth finger. }\end{array}$
Fig. I52.

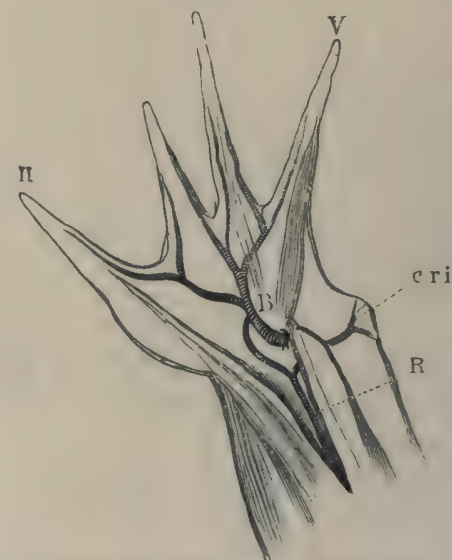

A teries of the dorsal surface of the hand.
$B$ Ulnar artery.
cri R. cutan. rad. inferior.
R Radial artery
II Thumb.
$V \quad$ Fifth finger.

and the long head of the $M$. triceps towards the dorsal surface, where it is distributed to the MM. infraspinatus, latissimus dorsi, etc.

e. The Ramus cutanens maxillaris.

f. The Art. subscapularis (Fig. I50, 6) is distributed in the subscapular muscle.

A. The brachial artery (Arteria brachialis), (Fig. I50) accompanies the brachial nerve under cover of the long head of the $M$. triceps and over its inner head to the Plica cubiti, into which it sinks near the tendon of the $M$. sternoradialis; beyond this point it is continued as the ulnar artery. In its course the brachial artery gives off: - -

a. The Arteria pectoralis (Fig., $50 \mathrm{p}$ ).

b. The Arteria cutanea medialis superior (Fig. I50 c).

c. The radial artery (Arteria radialis), (Fig. I50 R) which winds 
round the humerus with the radial nerve between the muscles of the outer side of the forearm, to which it gives branches: in the palm of the hand it passes between the $M$. extensor carpi ulnaris and the M. Alexor antibrachii to the dorsal surface of the hand, where it anastomoses with the ulnar artery. In its course it supplies:-

(I) Muscular branches to the surrounding muscles.

(2) The Ram. cut. rarlialis inferior, which arises from the radial artery towards the distal end of the forearm, and passes underneath the $M$. flexor carpi ulnaris to the skin.

B. The ulnar artery (Arteria ulnaris), (Figs. I.50 U, $151 \mathrm{~B}$ ) accompanies the ulnar nerve towards the hand, passes between the M. Alexor digitorum communis and the $\boldsymbol{M}$. anconens to the palm of the hand, and then winds round the outer side to the dorsal surface of the earpus to form its terminal branches. The branches are :-

(1) The Raw. cutan. med. inferior (Fig. I5I ci); it arises near the wrist-jont and supplies $(\alpha)$ twigs to the skin of the inner surface; $(\beta)$ a branch downwards, which courses along the inner side of the second finger to its tip; and $(\gamma)$ a branch which passes upwards to anastomose with the $R$. cutaneus medialis superior.

(2) In the palm of the hand a branch (Fig. 15 I $d$ ) is given off, which divides to form drteriae digitales volares: one for the second finger, two for the third finger, two for the fourth finger, and one for the fifth finger.

(3) Given off on the dorsum of the hand (Fig. 152) it supplies branches corresponding exactly with those of the palmar surface.

5. The dorsal aorta (Aorta communis 8. abdominalis (Fig. I53 A). The two systemic arches unite at about the level of the sixth vertebra to form the dorsal aorta : as already mentioned the union is very incomplete, the dorsal aorta being practically a continuation of the right systemic arch, and only communicating with the left by means of a small opening. The branches are as follows :-

a. The coeliaco-mesenteric artery (Arteria intestinalis communis), (Fig. 153), the true continuation of the left systemic arch, at once divides to form the gastric and mesenteric arteries.

(I) The gastric artery (Avteria gastrica \&. coeliaca) (c) immediately divides into two branches:-

a. The Ramus dexter 8. anterior; this artery gives off the Arteria hepatica to the liver and gall-bladder and passes to the right (anterior) surface of the stomach, running along the attachment of the 
mesentery and supplying branches forwards to the oesophagus and backwards towards the intestine.

$\beta$. The Ramus sinister s. posterior passes to the left (posterior) surface and behaves like the Ram. dexter.

(2) The mesenteric artery (Avteria mesenterica superior and inferior, and the Arteria splenica), (Fig. I $53 \mathrm{~m}$ ) supplies :-

a. The superior mesenteric artery, which supplies the upper part of

Fig. I53.

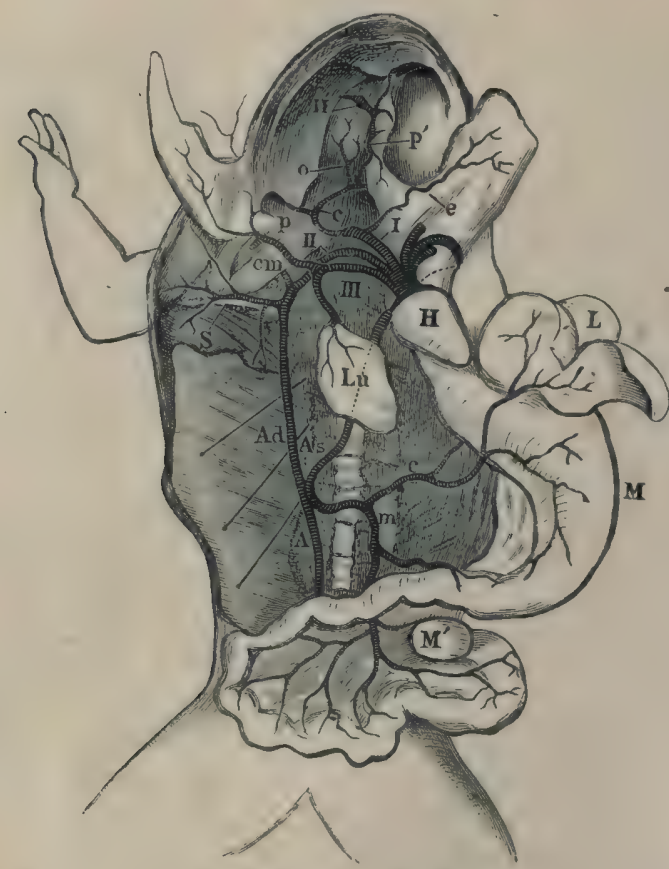

Arterial system of Rana esculenta.

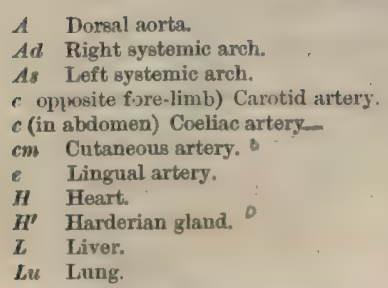

m Mesenteric artery. 6

M. Stomach.

$M^{\prime}$ Spleen.

o Ophthalmic artery:

p Pharyngeal artery.

p' Anterior palatine artery.

\& Subclavian artery.

I Carotid arch.

II Systemic ar̀ch.

III Pulmo-cutaneous arch.

the intestine, and gives off a recurrent branch to the stomach, which anastomoses with the gastric arteries.

$\beta$. The splenic artery to the spleen. 
$\gamma$. The inferior mesenteric artery to the lower part of the intestine.

All the arteries to the intestine course in lymph-spaces.

b. The urinogenital arteries (Arteriae urino-genitales), (Fig. $154 \mathrm{ug}$ ) are four to six small arteries arising from the ventral surface of the anta between the kidneys : they immediately divide into right and left branches to supply the kidneys, fat-bodies, reproductive organs, and their ducts (see kidney).

c. The lumbar arteries (Arteriae lumbales), are small paired vessels to the neighbouring muscles, and send branches through the intervertebral foramina to the vertebral canal. Sometimes these arteries arise from the Art. spinalis or Art.verteliralis, ete.; in the former case they pass outwards from the vertebral canal to the surrounding structures.

d. The haomorrhoidal artery (Art. mesenterica inf. \& Art. haemorrhoilalis s"lperior) is a small median artery running from the posterior end of the aorta to the large intestine.

\section{Bifurcation of the aorts. The} iliac arteries (Arteriae iliacae communes). Opposite the middle of the urostyle the aorta bifurcates to form the iliac arteries; each of these courses on the corresponding sciatic plexus to the thigh, beyond which it is continued as the sciatic artery. The branches of the iliac artery are:-

a. The vesico-epigastric artery (Arteria ejigastrico-vesicalis). (Fig. I 55 $e v)$; it arises near the bifurcation, passes outwards on the plexus, and divides into two branches:-

(I) The epigastric artery (Arteria epigastrica) (e) immediately gives off a recurrent branch to the iliac bone and the $M$. ilio-coccygers; it then

Fig. 154.

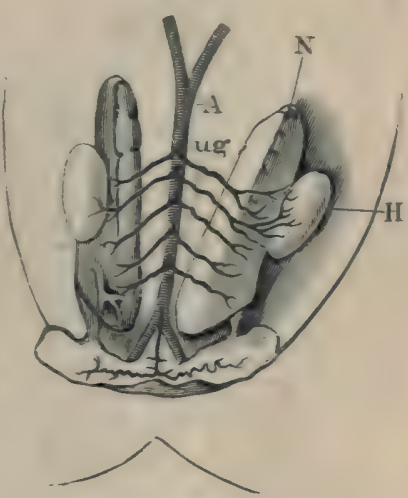

The urinugenital arteries.

A Dorasl aorta.

H Testis.

v Kilney.

ug) Urinugenital arteries. continues to the ventral muscles of the abdominal wall, where it runs forwards on the deeper surface of the $\boldsymbol{M}$. obliquus internus, and is distributed more especially to this muscle.

(2) The hypogastrie artery (Arteria vesicalis) ( 2 ) winds downwands around the sciatic plexus to reach the mesentery, along which it courses to the bladder, where it forms a rich anastomosis. 
b. The femoral artery (Arteria femoralis s. cruralis), (Fig. I $55 f$ ) is the representative of the femoral artery of man, although it does not perform the same functions. The artery passes under the hinder free border of the $\boldsymbol{M}$. olliquus internus to the thigh, where it lies upon the $M$. itio-psoas, and sends twigs to the neighbouring muscles, the skin, and lymph-sac (Lamina inguinalis), and then divides into :-

(I) A twig, which runs forwards on the ventral surface of the iliac bone and is covered by the epigastric artery.

(2) A twig, running forwards and downwards on the MM. itiopsoas, vastus internus, and sartorius, to send branches to the hip-joint.

c. The spermatic artery (Arteria spermatica), which arises, in males, from the iliac artery, and ascends to the Vesicula seminalis.

Fig. 155 .

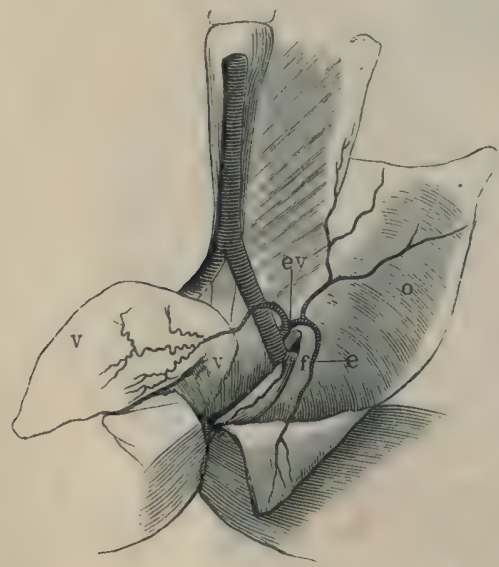

Bifurcation of the aorta and the iliac arteries.

$$
\begin{array}{ll}
e & \text { Epignatric artery. } \\
e v & \text { Vesico-epigastric artery. } \\
f & \text { Femoral artery. } \\
v & \text { Internal oblique muscle. } \\
v & \text { Vesical artery. }
\end{array}
$$

7. Arteries of the hinder extremity.

A. The sciatic artery (Arteria ischiadica), (Fig. I56 i) is the continuation of the iliac artery; it leaves the pelvis between the hinder (outer) border of the $\boldsymbol{M}$. coccygeo-iliacus and the inner surface of the origin of the $M$. ilio-proas, then lies between the former muscle and the origin of the $M$. vastus externus. It appears on the thigh between the $M$. vastus externus (in front) and the M. pyriformis (behind); it is the main arterial trunk for the hinder extremity. The artery courses backwards, lying upon the sciatic nerve and between the $M$. biceps and the $M$. semimembranosus; in this course it runs in a lymphspace placed in the Septum femorale superius (see page 259). Arrived at the popliteal space the artery bifurcates to form the peroneal and tibial arteries; near the pelvis it gives off two branches (a) and (b), and in its course along the thigh two branches (c) and (d).

a. The Art. haemorrhoidalis inferior (h) runs backwards and 
inwards under the $\boldsymbol{M}$. pyriformis to be distributed in the $\boldsymbol{M}$. sphincter ani and the skin of the anus.

b. The Art. cutanea femoris posterior $r$ superior $\left(c f^{\prime}\right)$ runs with the corresponding nerve and the $\boldsymbol{M}$. pyriformis, and over the $\boldsymbol{M}$. semimembranosus to the skin of the inner and hinder surfaces of the thigh.

c. The Rami musculares supply the $\boldsymbol{H}$. semimemlranosus, the $M$. lireps, and the M.M. extensores auris; the branch to the $M$. rectus inferior major pierces the muscle in company with the nerve, and is continued as :-

d. The Art. cutane femoris media $\left(c f^{\prime \prime}\right)$ to the skin of the middle of the inner surface of the thigh. Several small twigs pierce the M. rectus internus minor, reach the skin, and communicate with this artery.

Arteries of the hinder extremity.

ci Art cutanea calcanei.

cf Cutaneous branch of the femoral artery.

cf Art. cutanea fem. post. superior.

cf' Art. cutanea femoris media.

col Art eut. genin lateralis superior.

cyl' Art. circumflexa genu lateralis inferior.

cyn Art. circumflexa genn superior medialis.

com' Art. circumflexa genu inforior medialis.

ci M. corcygeu-iliacus.

$g$ M. gastrucneruins.

ul M. glutaens.

h Art. hwemorrhoidalis inferior

$i \quad$ Seiatic artery.

$m l$ Art. malleularis lateralis.

$m m$ Art, malleolitris nedialis.

$p$ Art. peronea.

$\mu^{\prime}$ Museular branch to the M. peruneas.

$P$ M. pyramidalis。

$r$ M. rectus anterior.

$r i$ M. reetus internu.

$s m$ M. semimembranusus.

su Irt. suralis.

$t$ Tibial artery.

to Aperture in tibio-fibula.

tr Art. tarses.

$v$ M. vastus externus.

Fig. 1,6 .

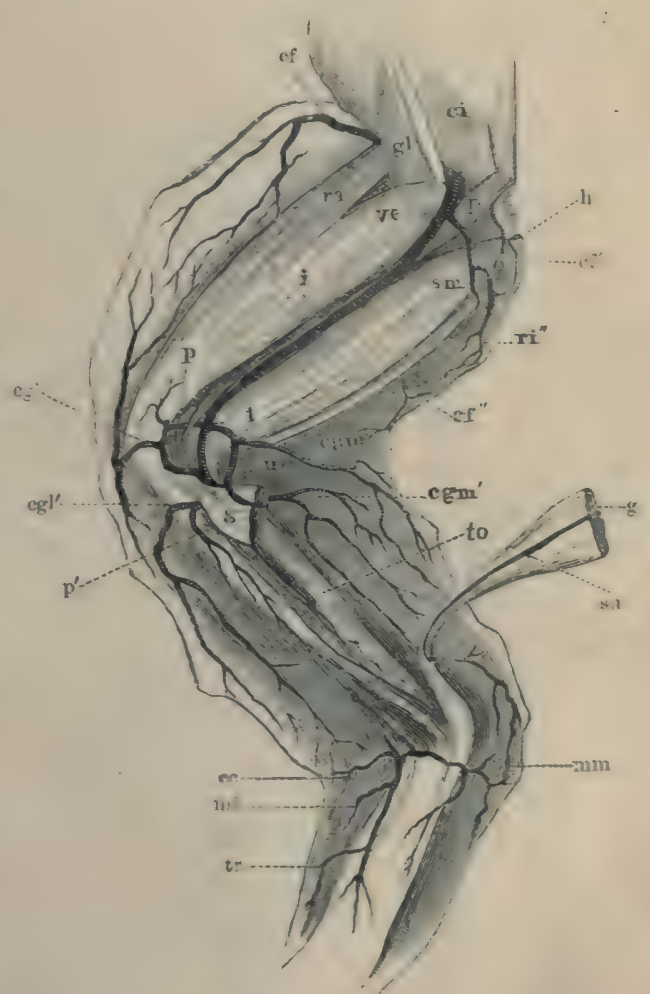

B. The peroneal artery ( $A \%$ peronea), (Fig. $156 \mu)$ runs out- 
wards under cover of the tendon of the $M$. biceps femoris, and accompanies the peroneal nerve downwards to give off :-

a. The Art. circumflexa genu lateralis superior, which runs forwards on the outer side of the knee, gives a twig to the joint, and is continued as :-

b. The Art. cutanea genu lateralis superior (cgl) to the skin of the anterior and outer sides of the knee. It anastomoses with branches of the Arteriae circumflexae genu merliales to form a rich anastomosis (Rete articulare genu): other branches pass upwards to inosculate with the Art. cutanea femoris anterior ( $f f)$, and others downwards to anastomose with the next artery.

c. The Art. circumflexa genu lateralis inferior ( $\left.c g l^{\prime}\right)$ runs under the tendon of origin of the gastrocnemius to the outer side of the knee, and terminates in the skin as the Art. cutanea genu lateralis inferior. Some of the cutaneous twigs pass upwards to anastomose with the Art. cut. genu lat. superior, others downwards to anastomose with the AA. malleolares.

d. A muscular branch $\left(p^{\prime}\right)$ for the $\boldsymbol{M}$. peronens; it is the real continuation of the peroneal artery, and runs behind the outer tendon of origin of the gastrocnemius to be distributed in the M. peroneus.

C. The tibial artery (Arteria tilialis), (Fig. ${ }_{5} 6 t$ ), arises at the bifurcation of the sciatic, and runs inwards, meeting the tibial nerve between the tendons of origin of the $M$. gastrocnemins, and deep in the popliteal space under cover of the calf-muscles. It then pierces the $\boldsymbol{M}$. tilialis posticus, and leaves this to perforate the tibio-fibula (see p. 50), appearing again on the anterior surface as the anterior tibial artery. Before meeting the tibial nerve this artery gives off the following branches:-

a. The Art. circumflexa genu superior medialis (cgm), which winds round to the front of the knee-joint, and gives off a cutaneous branch, the Art. cutanea genu medialis superior, which is distributed in the skin of the inner side of the knee and anastomoses above with the Art. cutanea femoris metia, below with the following branches (b, c, and d).

b. The Art. circumflexa genu inferior merlialis (cgm' $)$ supplies twigs to the knee-joint, and passes to the skin of the knee and inner surface of the calf as the Art. cutanea inferior medialis.

c. Muscular twigs to the $\boldsymbol{M}$. gastrocnemine. 
d. The Art.suralis ( $8 u$ ); this accompanies the $N$. suralis downwards along the calf-muscle, and is distributed in the skin of the inner side of the heel.

e. While passing between the fibres of the $\boldsymbol{M}$. tibialis posticus, the tibial artery gires off muscular twigs; one larger than the rest is known as che Ramus descendenes.

D. The anterior tibial artery (Arteria tibialis antica), (Fig. I.57 t.a.) is the continuation of the tibial artery after piercing the tibio-fibula. It runs downwards on the anterior surface of the leg, then between the two heads of the DI. tibialis anticus to the dorsum of the foot, where it is continued as the Arteria dorsalis pedis. It supplies :-

a. Rami musculares to the $M$. peroneus, 11. extensor cruris, and to the $M$. flexor tarsi ante or.

b. The Art. cutanea crurl inferior (c.c.i.) passes between the two heads of the M. tibialis anticus to the skin of the anterior and outer sides of the leg.

c. The Art. cutanea calcanei (c.c.) is given off at the ankle-joint; it runs outwards on the lower end of the

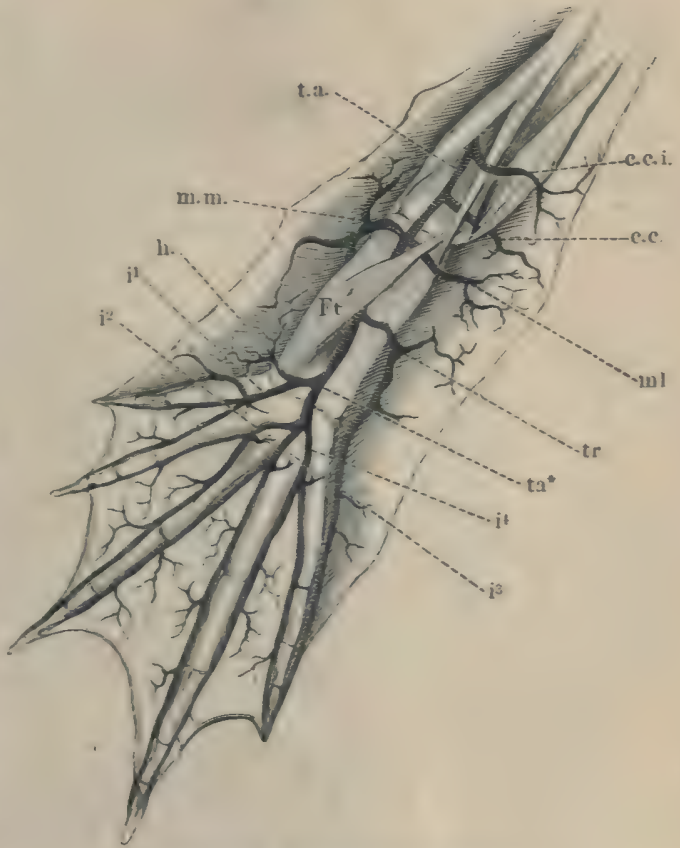

Arteries of the donsal surface of the foot.

c.c. Art, cutanea calcaned.

c.c.l. Art. cutanea cruris inferior.

Pl' M. flexor tassi.

h Art. cutanea hallucis

ir Art. interossea dorsalis I.

is Art interoseea donsalis II.

$i_{3}$ Art interussea forsalis III

4 Art interoeses doraalis IV.

$m l$ Art. mallewluris lateralis.

$m, m$. Art. mallerilaris medialis.

t.a. Anterior tibial artery.

$a^{*}$ Biruration of the dorsalis pedis artery.

tr Art tarsea tibio-fibula, giving branches to the joint, then backwards between 
the tibio-fibula and the $M$. peroneus to be distributed to the skin of the heel. Above it anastomoses with the A. circumflexa genu inf. lateralis, and below with the malleolar arteries.

d. The Art. malleolaris lateralis $(m l)$ arises a little beyond the last artery; it runs outwards under the origin of the $M$. Alexor tarsi, gives branches to the joint and muscles, and terminates in the skin of the outer border and dorsal surface of the foot.

e. The Art. malleolaris medialis $(m, m$.$) arises at about the$ same level as the Art. malleolaris lat. from the inner border of the anterior tibial artery. It supplies branches to the joint, gives numerous branches to the skin, which anastomose with the Art. suralis, and passes to the inner border of the foot, where it ends by distributing branches to the $M$.plantaris, the extensor aponeurosis, and, as the Art. cutanea plantaris, to the skin of the sole of the foot.

E. The dorsal artery of the foot (Art. dorsalis perlis), (Fic. I 57 t.a.) runs under the $M$. flexor tarsi posterior to the point $t a^{*}$,

Fig. 158.

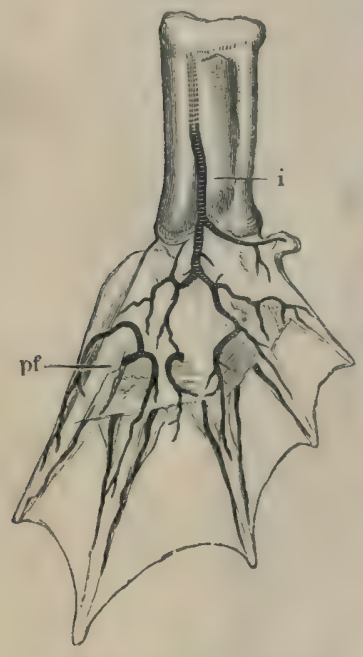

Arteries of the sole of the foot.

$i$ Art. interossea.

pf Rami perforantes, where it is superficial; the artery then bifurcates; the branches are:-

a. The Art. tarsea $(t r)$ which arises from the dorsal artery of the foot while under cover of the $\boldsymbol{M}$. Alexor tarsi posterior ; it passes to the $M$. extensor digiti $V$ and to the skin of the dorsum and outer border of the foot. One branch courses along the outer border of the fifth toe to its tip; another passes upwards to anastomose with the neighbouring vessels.

b. The inner branch, formed by the bifurcation of the dorsal artery of the foot, at once divides to form :-

(1) The Art. cutanea hallucis (h) to the supplemental great toe.

(2) The Art. interossea dorsalis $I\left(i^{1}\right)$, which at once bifurcates to form two Rami digitales for the first and second toes; these inosculate with the $A r t$. cutanea plantaris, and send twigs to the skin of the inner border of the font.

c. The outer branch formed by the bifurcation of the dorsal artery divides to form the Aiteriae interossei dorsales $I I, I I I$, and $I V$ $\left(i^{2}, i^{3}, i^{4}\right)$; they are distributed in a rich anastomosis to the web. 

d. The Aiteria interossea (Fig. I 58 i) arises from the dorsal
artery of the foot at the tarsus, and perforates the membrane
between the astragalus and calcaneum to reach the between the astragalus and calcaneum to reach the sole of the foot. It forms a rich subcutaneous plexus on the calcar, and anastomuses with the Rami perforantes (Fig. I58 pf'), which pass above the upper borders of the Musculi interossei to reach the plantar anastomose with the $A$. interosseae dorsales.

\section{THE VEINS.}

The blood, distritoment of this section has been modified.) returned to the heart by the body by means of the arteries, is rectly or indirectly to the veins, which conduct the blood didirectly into the left the auricles. The pulmonary vein opens Sinus venosus.

\section{A. Vein opening into the left auricle.}

The pulmonary vein (Tena pulmonalis communis), (Fig. I59 w). The blood returning from each lung is gathered into a the right side is the inner side of the root of the lung. That of (Tenae pulmonales dext longer than the left; the two vessels anterior caval veins to finistra) run above the corresponding which opens into the left a common trunk, the pulmonary vein,

B. Veins opening into

The reins opening into the Simus renosus.

veins; of these the into the Sinus venosus are the three caval the Sinus venosus, the anterior open into the anterior angles of

1. The Anterior posterior into the posterior angle.

I59 $\mathrm{C} \mathrm{a}$ ) are a pair of Veins (Tena cava superior), (Figs. I33 $\mathrm{F}$, and returning to it blood fe veins opening into the Sinus venosus Each rein is formed by the the fore-limbs and sides of the head. lar, with two large veins, the union of a small vein, the external jugu-

a. The external jugular innominate and the subclavian veins. I $59 j e$ ) is formed, at the outer (Tena jugularis externa), (Fig. union of two veins :- the hyoid bone, by the

(I) The lingual vein ( $T$ ena lingualis) (Fig. 16rl). This originates the ventral surface of and passes in a very tortuous course along from the tongue and hyoid muscles it receives numerous branches 
(2) The mandibular vein (Tena maxillaris inferior), (Fig. $161 \mathrm{~m}$ ) runs along the insertion of the $M$. submaxillaris, and turns inwards at its hinder border to join the lingual vein.

b. The innominate vein (Vena anonyma), (Fig. $160 \mathrm{~A}$ ) is formed

Fig. 159.

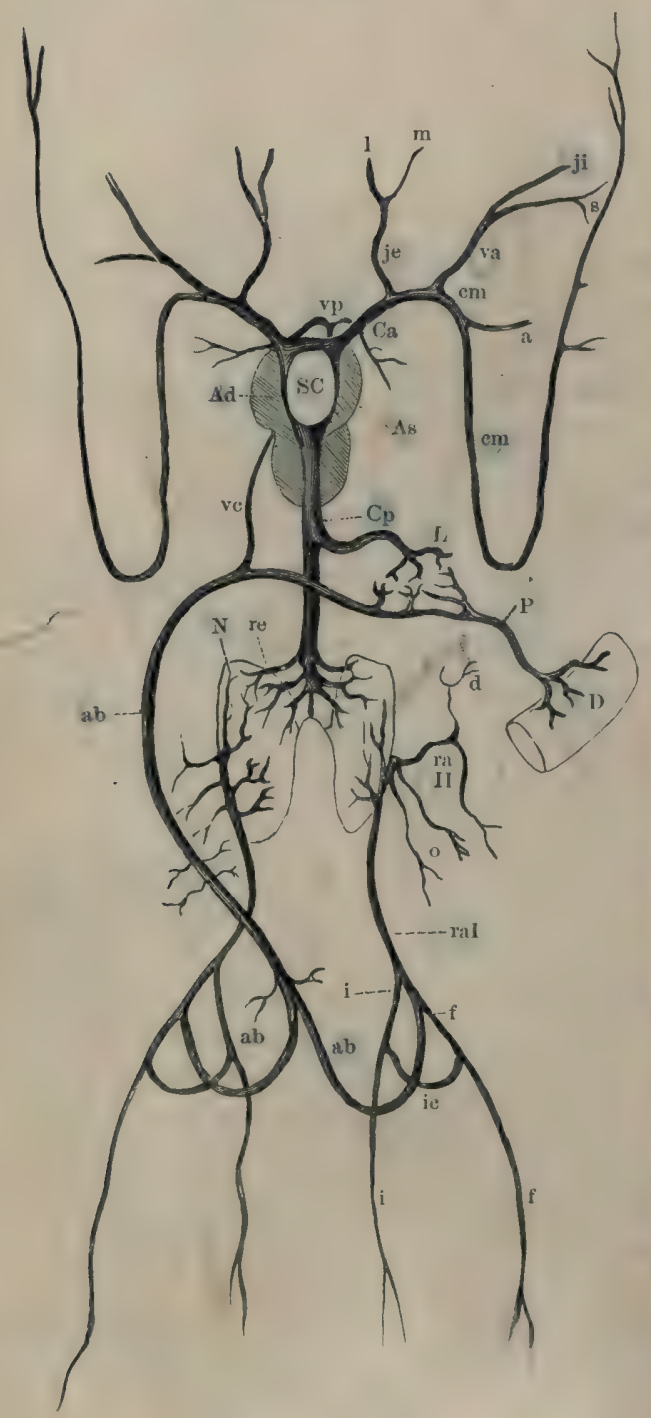
by the union of the internal jugular and the subseapular veins. By tracing the innominate vein upwards between the suspensorium and the shouldergirdle, the internal jugular vein will be seen to receive the vertebral vein at the outer border of the $\boldsymbol{M}$. levalor scapulae. The left innominate vein receives the Tena bulli anterior from the Truncus arteriosus (p. 222).

\section{Schema of the veins of Rand esculenta.}

Subelavian vein.

Anterior ahdominal vein.

Right auricle.

Left auricle.

Ca Anterior vena cava.

Cp Postevior vena cava.

cms Cutaritous rein.

d Vena dorso-lumbalis.

$n$ Intestíne.

$f$ Femoral vein.

$i \quad$ Sciatic vein.

ic Vena communicans iliaca.

je Externaljugular vein formed by lingual and maxillary veins $l$ and $m$.

i. Internal jugular vein.

$L$ Hepatic reins.

$N$ Kidney.

() Oviducal veins.

p. Hepatic jortal vein.

ral Renal portal vein.

rail Secondipy renal prortal veins.

Tre Renal joins.

z. Subscapular vein.

76 sinus venosus.

va Innominate vein.

te Vena bribl posterior (cardiac vein

vp Pulmonąry veins. 
(1) The internal jugular vein (Tena jugularis), (Fig. 160 J) can be traced from the border of the $\boldsymbol{M}$. levator scapulae upwards and forwards to the hinder part of the prootic bone: it then passes forwards under the lateral process of the prootic, in a groove on the anterior surface of the same bone, towards the hinder angle of the orbit, where it receives the veins from the cranial cavity (see vessels of brain, p. 165), and also a branch from the orbit.

Fig. 160.

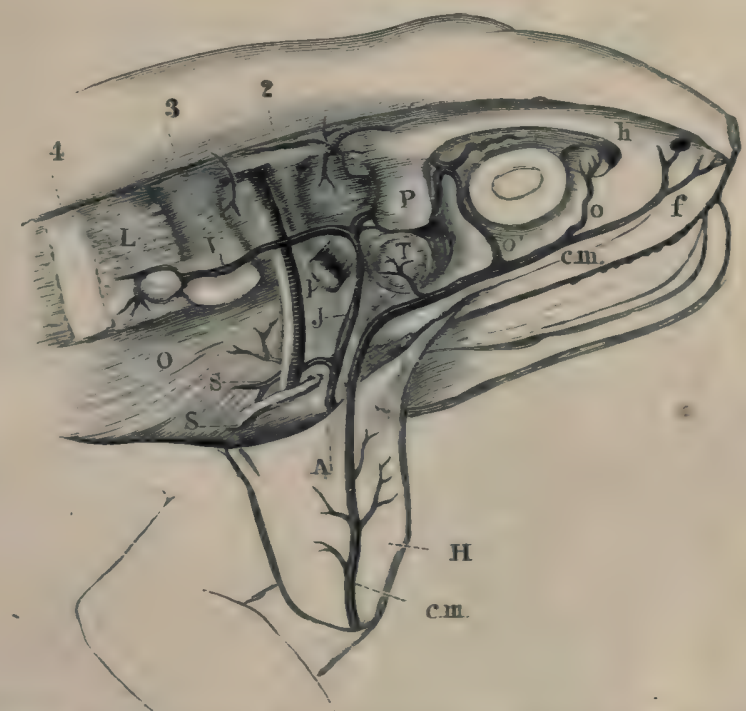

Distribution of the internal jugular vein and the anterior portion of the cutaneous vein.
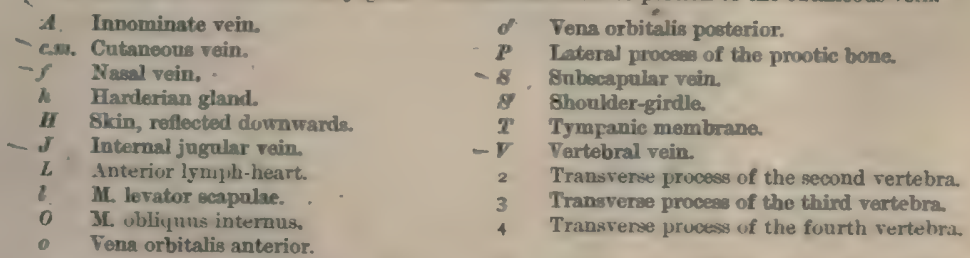

a. [The Tena orlitalis merlia (Virchow); it arises from the anterior internal angle of the orbit, from the Harderian gland, the nasal cavity, or from other veins on the anterior wall of the orbit. The ressel lies close to the cranium, immediately underneath the Arieria nasalis, and sinks under the $M$. rectus sujerion to join the internal jugular vein. It its course it receives the Vena bulli injuevior (see eye), and near its termination communicates with the Vena orbitalis pasterior.] 
$\boldsymbol{\beta}$. The Vena vertebralis (Fig. 160 $/$ ) arises posteriorly and runs forwards over the transverse processes of the vertebrae, the Musculi intertransversarii, and the $M$. levat. scapulae, to join the internal jugular vein. In its course it receives branches ( $V$ enae spinales) from the vertebral canal through the intervertebral foramina, and cutaneous branches which accompany the corresponding arteries and nerves through the dorsal lymphatic sac. The vein pulsates in consequence of its connection with the anterior lymph-heart (Müller).

(2) The subscapular vein (Tena subscapularis), (Fig. I60 S). This vein arises in

Fig. 161 .

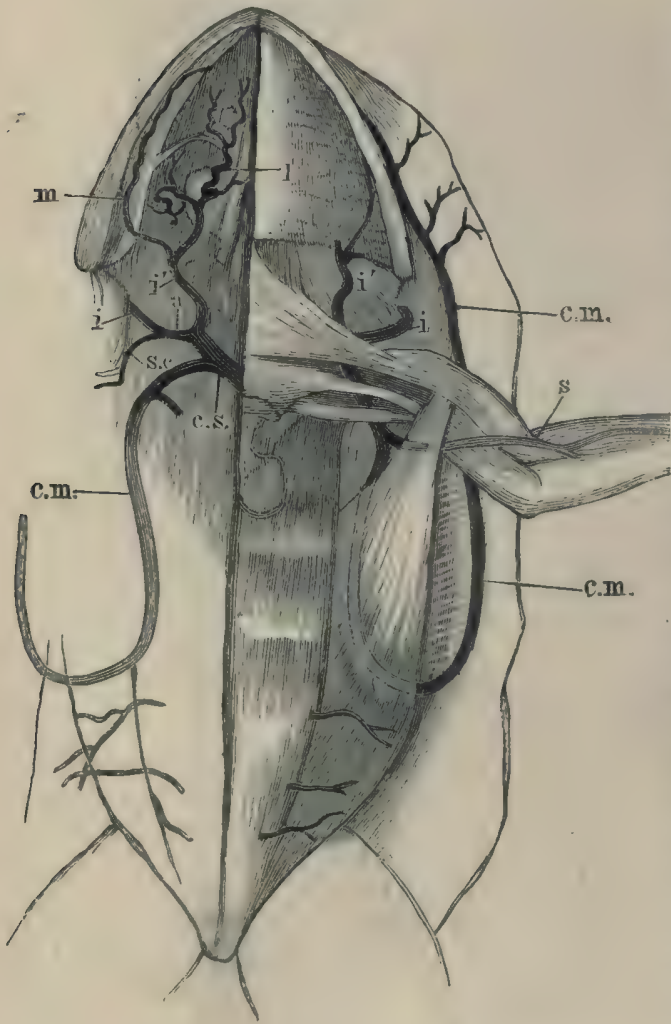

The anterior caval vein and its branches.

a Innominate vein.

c.m. Cutaneous rein.

c.s. Anterior cava vein.

i Internal jugular vein.

i) External jugular vein. the transverse abdominal museles and the muscles of the shoulder girdle; it unites with the internal jugular vein under the shouldergirdle.

c. The subclavian vein (Vena subclavia), (Fig. I59) passes backwards from the anterior caval vein on the dorsal surface of the coracoid bone and the clavicle, and then under cover of the Portio sternalis of the $M$. pectoratis major, to the internal border of the Portio abdominalis of the $M$. pectoratis major, where it is formed by the union of the cutaneous vein and the brachial vein.

(I) The eutaneous vein (Vena cutanea magna, Ecker; Vena 
musculo-cutanea, Gruby), (Figs. I60, 16I, and $162 c . m$.$) . This vein$ arises by small branches in the head; these are:-

a. The Tena nasalis (Virchow); it arises by an upper and a lower branch from around the nostril, and courses backwards along the superior maxillary bone to about the middle of the orbit, where it joins the facial vein.

$\beta$. The Tena orbitalis anterior (Virchow), (Tena oplithalmica antevior, Ecker), (Fig. I60o) commences at the Harderian gland from a rich anastomosis, receives branches from the floor and anterior wall of the orbit, and joins the facial vein with the Tena nasalis.

$\gamma$. The Tena orbitalis posterior (Virchow), (Tena ophthalmica posterior, Ecker), (Fig. 1600') arises on the posterior wall of the Fig. 162.

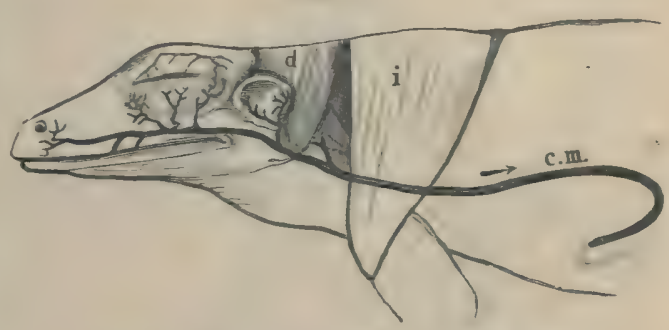

Conrse of the cutaneots vein as seen from the side.

$$
\begin{aligned}
& \text { c. } \text {. Cutaneons vein. } \\
& \text { d M, depressor maxillae. } \\
& \text { i M. infraspinatus. }
\end{aligned}
$$

orbit on the $M$. pterygoileus; it passes under the Processus zygomaticus to join the facial vein, and in its course receires the Tena ophthalmica (see eye), and communicates with the Tena orbitalis medialis and the internal jugular vein.

8. The Tena facialis (Fig. I60) is formed about the middle of the orbit by the union of the Tena nasalis and the Tena ortitalis anterior; it courses backwards towards the angle of the jaw. On reaching the $\boldsymbol{M}$. depressor maxillae, about $4 \mathrm{~mm}$. in front of the angle of the jaw, it passes on to the skin. It receives in its course the Tenae palpjebrales (Fig. 162) and the Tena orbitalis posterior.

The musculo-cutaneous vein is the direct continuation of the Tena facialis after this has left the upper jaw; it immediately receives one or more twigs (Tenae tympanicae), (Fig. 162) from the tympanic membrane and the tympanic cavity.

The vein then courses backwards in the outer wall of the lateral lymph-sac as far as the middle of the trunk, where it passes, by means of the Septum abdominale, to the outer border of the Portio 
abdominalis of the $M$. pectoralis; here the vein curves round to pass forwards between the fibres of this muscle to its inner border where it terminates by joining the brachial vein. In the whole of this lengthy course the vein receives numerous branches from the neighbouring parts.

Fig. 163.

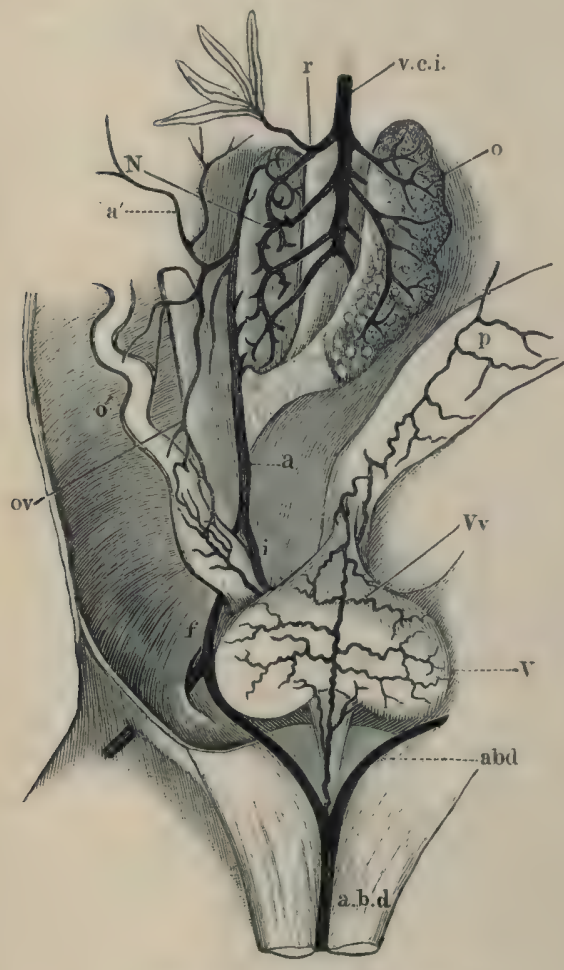

Veins in the region of the kidney.

$\begin{array}{ll}a & \text { Renal portal vein. } \\ a^{\prime} & \text { Dorso-lumbar veins. } \\ a b d & \text { Anterior abdominal vein. } \\ d & \text { Intestine. } \\ f & \text { Femoral rein. } \\ i & \text { Sciatic vein. } \\ N & \text { Kidney. } \\ o & \text { Right ovary, drawn to the left. } \\ o^{\prime} & \text { Oviduct. } \\ o v & \text { Oviducal veins. } \\ p & \text { Mesenteric veins. } \\ r & \text { Renal veins, } \\ V & \text { Bladder. } \\ v, c, i . & \text { Postiorior, vena cava. } \\ v v & \text { Vesical veins. }\end{array}$

(2) The brachial vein (Vena brachialis) is formed in the Plica cubiti by the union of two veins.

a. The radial vein (Vena radiatis) arises on the dorsum of the hand from a venous arch, the distal convexity of which d receives the $V$ enae digitales dorsales: the vein courses superficially along the outer side of the forearm to the elbow.

B. The ulnar vein (Vena ulnaris) arises from the veins in the palm of the hand, and courses towards the elbow, lying deeply between the muscles of the inner and outer surfaces of the forearm. In the elbow the vein becomes superficial near the tendon of the $\boldsymbol{M}$. sternooleidoradialis, and joins the radial vein to form the brachial vein.

The cutaneous veins of the fore-limb follow courses corresponding with those of the arteries.

2. The Posterior Caval Vein (Vena cava inferior), (Fig. $159 C p, 163$ v.c.i.). 
The posterior caval vein is a median vein which, commencing between the kidneys, runs forwards to open into the posterior end of the Simus cenosus. It receives the hepatic, renal, and ovarian or spermatic veins.

a. The hepatic veins (Venae hepaticae), (Fig. I64 r.h.) are two in number, one from either side of the liver; they open into the posterior caval vein near the Sinus renosus.

b. The renal veins (Tenae renales or Tenae revehentes), (Fig. ${ }_{1} 63 r$ ) are fuur or five small vessels on each side; they pass from the inner border of the kidney inwards and forwards, to form, by their union, the posterior caval vein. The must anterior receive branches from the fat-bodies (see kidney).

c. The spermatic or ovarian veins are four or five in number on each side; they open into the posterior eaval vein between the renal veins.

\section{The Portal Systems.}

[There are, in the frog, two portal systems; the renal and the hepatic. Each of these receives vessels which are derived, directly or indirectly, from the reins of the hinder extremity.

The femoral vein on entering the pelvis divides to form two branches; an iliac vein placed dorsally, and a pelvic vein placed ventrally; the two pelvic veins converge to the middle line of ventral wall of the abdomen, where they unite to form the anterior abdominal vein.]

a. The renal portal voin (Vena renalis arlehens princeps), (Fig. $163 a$ ). This vein is formed by the union of the sciatic and the iliae veins; it courses forwards to the outer border of the kidney, and is distributed, by numerous branches, to that organ, chiefly on its dorsal surface. It receives the following veins :-

(I) The iliac vein (Vena iliaca externa); this is the dorsal branch formed by the bifurcation of the femoral vein.

(2) The sciatic vein (Tena ischiadica), (Figs. 163 and 165 i) arises at the popliteal space, courses upwards in company with the sciatic nerve between the $M$. semitentinosus and the $M$. biceps, then passes, still with the nerve, between the $M$. vastus externus and the M. pyramilalis into the pelvis. It continues forwards to join the iliac vein. At the root of the thigh this vein communicates with the femoral vein by the Ramus communicans iliacus. 
(3) The dorso-lumbar vein (Tena dorso-lumbalis), (Fig. I6 $3 a^{\prime}$ ) is a vein (or more usually several) arising by twigs in the dorsal and outer walls of the abdomen; it joins the renal portal vein opposite the kidney.

(4) The oviducal veins (Fig. 163 ov) are irregular veins from the oviducts, which open either into the dorso-lumbar vein, or into the renal portal vein.

b. The hepatic portal system.

The liver receives blood from two sources: (I) from the hind-

Fig. 164 .

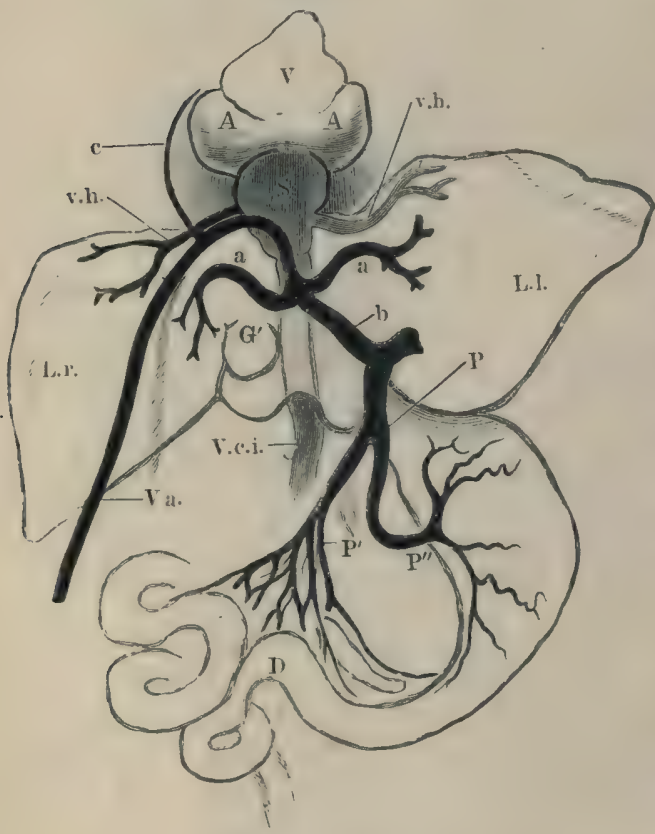

Veins of the liver.

AA Auricles.

aa Right and left branches of anterior abdominal vein.

b Ramus descendens.

c Vena bulbi (Vena cardiaca).

$D$ Intestine.

$G$ Gall-bladder.

$L, l$. Left lobe of liver.

$\boldsymbol{L} . r$. Right lobe of liver. limbs by means of the anterior abdominal vein, and (2) from the alimentary canal by the hepatic portal vein.

The anterior abdominal vein (Vena abdominalis),(Figs.I 59 $a b, \mathrm{I} 64 V a$ ) is formed, a little in front of the symphysis pubis, by the union of the two pelvie veins. It courses forwards along the middle line of the ventral body-wall until opposite the liver, where it ascends and divides into three branches, of which two enter the right and left lobes of the liver respectiveyl. The third, the Ramus descendens, joins the hepatic portal vein. The anterior abdominal vein receives the following veins :-

a. The vesical vein ( $V$ ena vesicalis), (Fig. I63 $V v$ ); a median vein arising in the groove between the lobes of the bladder from lateral branches, which extend outwards on the bladder. This vein 
communicates abore with other resical twigs which open into the haemorrhoidal vein.

ß. Parietal reins, which join the anterior abdominal vein in its course along the ventral body-wall.

$\%$. A cardiac vein (Tena carliaca), (Figs. I42, I59vc, 164c), which joins the anterior abdominal vein just before its division (see p. 222).

The hepatic portal vein (Tena portarum), (Figs. I59, I64 $P$ ) is formed by the union of the gastric, intestinal, splenic, and one of the haemorrhoidal reins. The large vein so constituted passes forwards towards the liver, receives the Ramus descendens from the anterior abdominal rein, and then passes into the left lobe of the liver. Its branches are the following:-

(I) The gastric veins. The stomach has three veins :-

a. [The Tena coronaria rentriculi, which receives blood from the hinder end of the oesophagus and anterior portion of the stomach.

$\beta$ and $\gamma$. Two other veins which form an Arcus coronarius on the concave surface of the stomach; the hinder receiving in addition the small Tenae pancreaticae and the Tena duorlenalis; the trunk so formed receives the Tena coronaria ventriculi (Hoffmann).

(2) The intestinal veins; the veins of that portion of the alimentary canal between the middle of the duodenum and the anterior end of the large intestine open into a common vein which joins the hepatic portal vein.

(3) The splenic vein joins either the hepatic portal vein or one of the intestinal veins.

(4) The haemorrhoidal veins are three in number; the anterior opens into the splenic rein, the remaining two into the portal veins through the agency of the intestinal veins.]

\section{The Veins of the Hinder Extremity.}

The hinder extremity has two renous trunks, the sciatic rein and the femoral vein.

a. The femoral vein (Tena femoralis), (Fig. $165 f$ ) is the larger venous trunk of the hinder extremity. It arises in the popliteal space as a direct continuation of the posterior tibial vein, courses upwards in company with the sciatic artery and nerve, then leares these to wind forwards and outwards, and appears between the origins of the $M$. vastus externus and of the $M$. rectus anterior. 
The vein here gives off the Ramns communicans iliacus to the sciatic vein, and turns forwards and downwards around the $M$. glutaens

Fig. 165 .

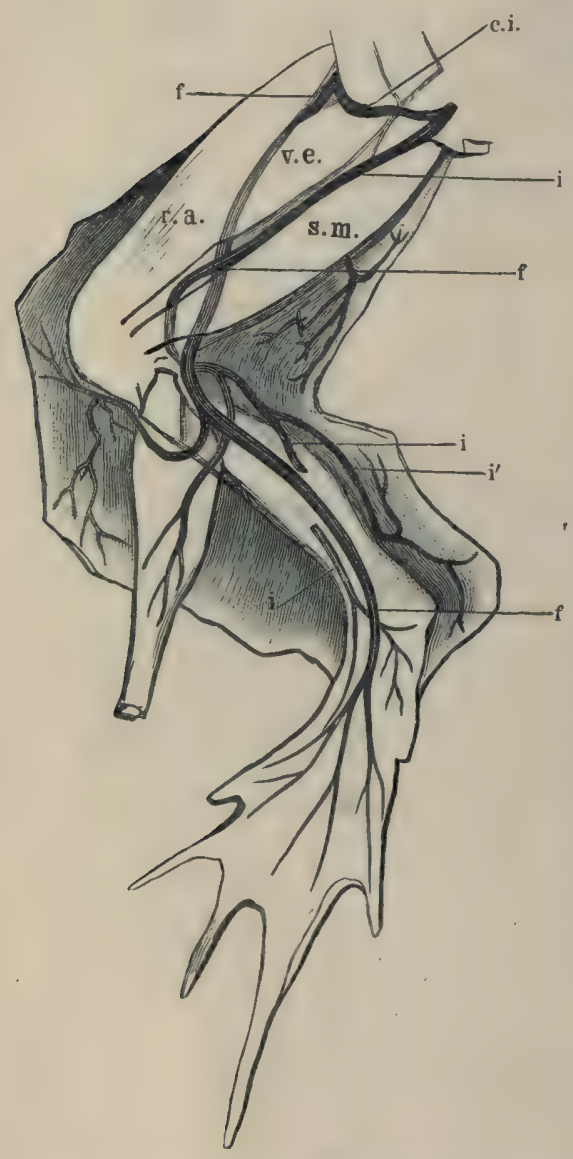

Veins of the hinder extremity, half schematic.

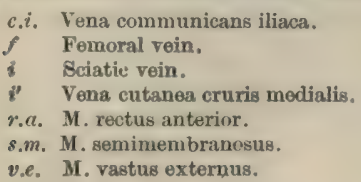
maximus to reach the floor of the pelvis, near the femoral artery. The vein then bifurcates to form the pelvic and iliac veins.

(I) The Ramus communicans itiacus (Fig. I6 5 c.i.) forms a communication with the sciatic at the base of the thigh.

(2) The posterior tibial vein (Vena tibialis postica), of which the femoral is a continuation, arises on the dorsal surface of the toes and foot. It runs superficially on the $M$. extensor longus digiti primi over the ankle-joint, courses upwards and winds round the outer surface of the tibio-fibula to the flexor surface. It receives, in its course, muscular branches, and at the knee a large cutaneous branch.

b. The sciatic vein: this vein has already been described (see p. 247), but the vein from which it arises requires description.

The anterior tibial vein (Tena tibialis an(ica) arises on the dorsum of the foot by twigs from

the toes; it courses under the $\boldsymbol{M}$. extensor longus digiti primi, then upwards on the anterior surface of the leg, and enters the canal in the tibio-fibula to appear on its hinder surface. The vein then 
receives twigs from the $M$. peroneus, the $M$. tibialis posticus, the $M$. gastrocenemius, and a large cutaneous branch.

a. The Tena culanea cruris medialis (Fig. $165 i^{\prime}$ ) receives branches from both above and below, and enters the popliteal space to join the anterior tibial vein.

3. The anastomosis on the dorsum of the foot, from which the anterior tibial vein arises, receives perforating twigs from the plantar surface.

\section{PART II. \\ THE LYMPHATIC SISTEY.}

(The arrangement of this section has been considerably alteret.

[The lymphatie system of the frog may, for descriptive purposes, be advantageously treated of in four parts :

1. The subcutaneous lymph-sacs.

2. The lymph-hearts.

3. The lymph-spaces of the body, and those lying between the various organs.

4. The lymph-ressels of the separate organs.

The first two parts will be deseribed in this section; the remainder with the organs or parts of the body with which they are more intimately associated. The spleen will be described with the abdominal viscera.

\section{The Subcutaneous Lymph-Sacs.}

A number of large spaces exist between the skin and the muscles, in which there is no direct attachment between these parts. These spaces are separated from each other by thin connective-tissue septa, stretehed between the museles and the skin, and by attachments of the skin to the underlying structures.

Joh. Müller first demonstrated that these spaces were connected with the lymphatic system, and that the contained fluid was lymph. Although this fact was contradicted by Meyer it received confirmation from Stannius, Levdig, and especially from Recklinghausen, who showed that the fluid of the lymph-saes was carried away by the lymphaties, and that later it entered the blood-stream. 
A. The Lymph-sacs of the Head and Trunk.

a. The septa. The connective-tissue septa themselves contain sinuses which occupy the space between their two surfaces (Fig. x66): these septal sinuses receive the contents of the cutaneous lymph-vessels and forward their contents into lymph-vessels situated in the septa. Such a sinus is shown in transverse section in Fig. $x 66$, which is a section of the ventral septum. The same sinus, in plan, is seen in Fig. 167 .

(I) The dorsal septum (Septum dorsale), (Figs. I69 and I 7 I d) of each side commences at the tympanic membrane; it is then attached to the $M$. depressor maxillae, $\boldsymbol{M}$. infraspinatus, and $\boldsymbol{M}$. longissimus

Fig. 167 .

Fig. 166.

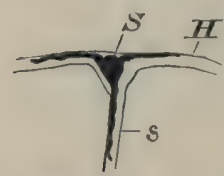

Transverse section of a septum with the attached skin, its contained sinus injected with blue injection mass.

H Skin.

s Septum.

$S$ Sinus contained in the septum.

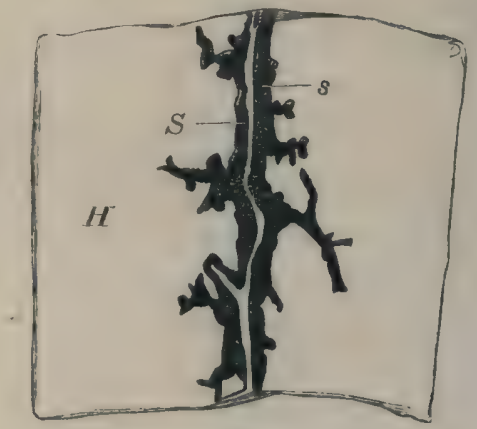

The sinus abdominalis lateralis (Ecker) injected with blue mass.

H Bkin with its lymph-veseels.

8 Sinus of the septum with Iymph-vessels opening into it.

\& The septum cut parallel with the skin.

dorsi; and continued backwards over the M. obliquus ablominis externus to the anterior end of the $M$. glutaeus, whence it extends along the iliac bone, where it is connected with the posterior lymph-heart and the $\boldsymbol{M}$. pyriformis, to the tip of the urostyle. At the tip of the $M$.glutaeus it is joined by the iliac septum. The posterior part of the septum is horizontal, and forms the roof of the iliac lymph-sac.

(2) The ventral septum (Septum abdominale), (Figs. I69, I 70, and I7I $a$ ), commencing at the Symphysis pubis, runs forwards and outwards, on either side, along the outer border of the $M$. rectus abdominis to the Portio abdominalis of the M. pectoralis $\left(p^{\prime \prime \prime}\right)$, where it is attached, at a right angle, to the pectoral septum; it then extends" forwards, after attachment to the axillary septum, to the outer 
angles of the maxillary septum. At the root of the anterior extremity it divides to enclose the root of the limb, and so form the axillary septum.

(3) The pectoral septum (Sejtum pectorale), (Figs. I 70 and I 7 I $p$ ) is attached to the superficial surface of the $\boldsymbol{M}$. pectoralis (Portin sternalis, anterior and josterior); it runs transrersely across the body, and is attached at its outer end to the rentral and to the maxillary septa. The septum passes obliquely backwards and downwards to be attached to the skin, and so forms a very acute angle with the $\boldsymbol{M}$. cutaneus jectoris $(\%)$ : a vertical band of connective-tissue, broad behind, narrow in front, extends in the middle line from the septum to the body wall; from it a certain amount of loose connective-tissue extends in all directions, and forms open lymph-spaces between the M.M. cutanei pectorales and the vertical septum.

(4) The perineal septum (Septum perineale), (Fig. I 70 pe). This median septum extends from the attachment of the dorsal septum to the tip of the urostyle, backwards to the symphysis pubis, where it joins the ventral septa. In its attachment it follows the middle line of the perineum.

(5) The maxillary septum (Septum maxillare), (Figs. 170, $171 \mathrm{~m}$ ) is attached by either extremity to the dorsal septum, near the tympanic membrane, is continued downwards to unite with the Fig. I68.

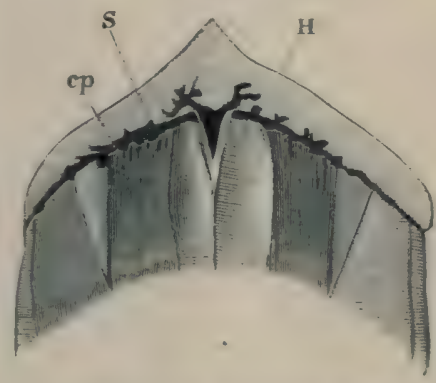

Sinus thuracieus transversus (Ecker).

cp M. cutaneus pectoralis.

II Skin reflected forwaris.

- Sinus with its afferent resoels. anterior end of the ventral septum, and then runs across the anterior pectoral region, forming a curve with the convexity forwards. It has inserted into it fibres of the $\boldsymbol{H}$. sulfimaxillaris. The septum is formed of very loose tissue, and frequently contains deposits of fat; it encloses a well-marked septal sinus, the Sinux thoracicus transversus (Ecker).

(6) The iliac septum (Figs. $169,17215,173 S^{\prime}$ ) is a septum extending from the dorsal septum to the inguinal septum. It is attached to the dorsal septum opposite the anterior end of the II. glutaeus, and extends outwards and downwards to the inguinal 
Fig. 169 .

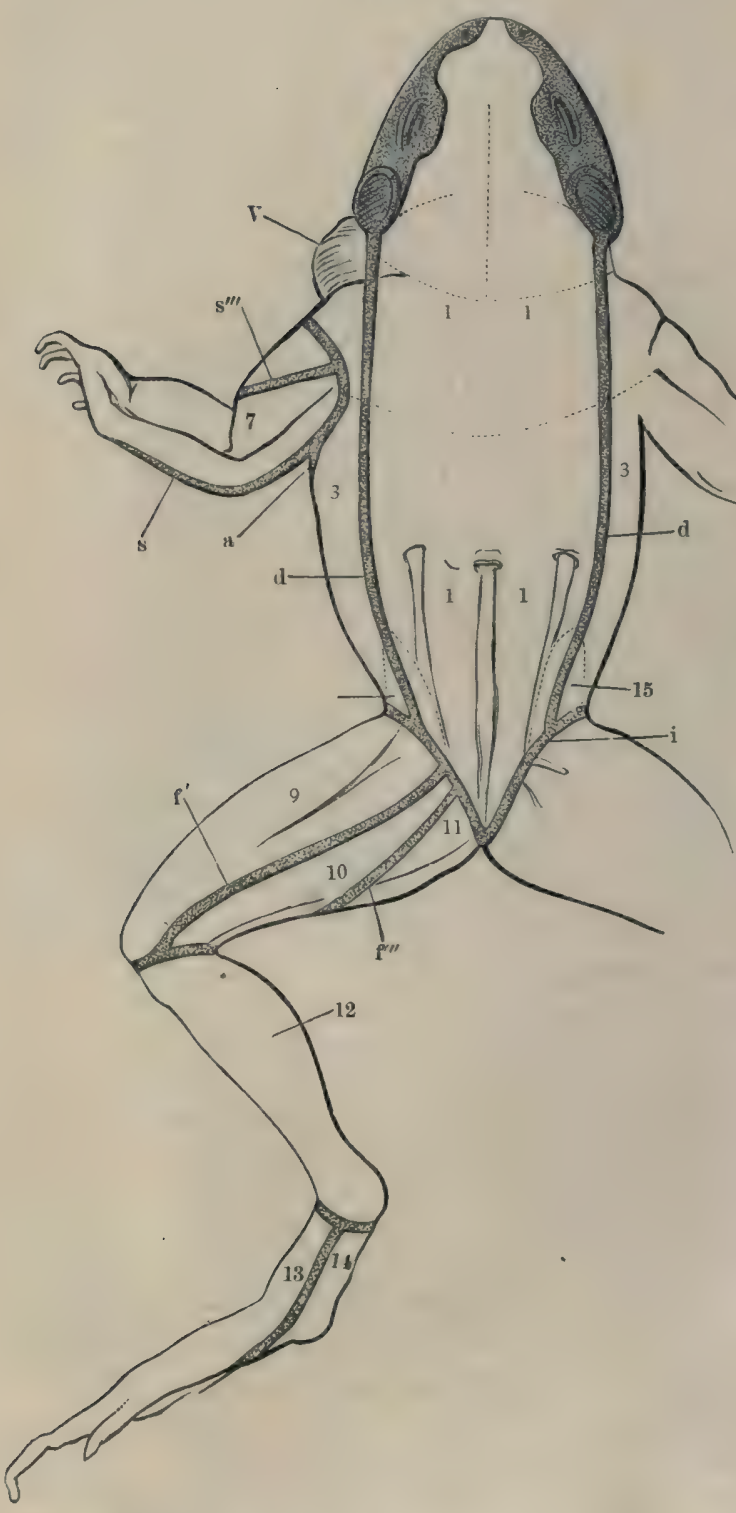

septum. In it the $M$. cutaneus itiacus passes from the trunk to the skin.

(7) The inguinal septum ( $L a-$ mina inguinatis, Ecker), (Figs. 169, I 7I, the dotted line near 15, Fig. 172, separates the belly from the thigh ; on the ventral surface it is attached to the groove which

The 1ymph-sacs of Rana esculent $u$, seen from the dorsal surface.

I Dorsal lymph-Bac.

3 Lateral lymph-sac,

7 Brachio-radial lymphsac.

- Femoral lymph-sac.

ro Suprafemoral lymphsac.

xx Interfomoral lymphsac.

I2 Crural lymph-sac.

r3 Dorsal lymph-sac of the foot.

14 Plantax lymph-sac of the foot.

$x_{5}$ Iliac lymph-sac.

a Ventral septum.

d Dorsal septum.

$f^{\prime \prime}$ Superior femoral septum.

f"I Intermediate femoral septum.

i Inguinal septum.

s Posterior brachial septum.

$8^{\prime \prime \prime}$ Anterior brachio-radial septum.

V Vocal sac.

${ }^{1}$ In Figs. 168, 169, and 170 the dotted lines denote the boundaries of the various lymph-racs. 
forms the boundary between the belly and thigh; on the dorsal surface it is more posterior, and is attached to the dorsal surface of the muscles of the thigh at some little distance from the trunk. It completely surrounds the root of the hinder limb. It has attached to it the rentral, dorsal, and iliac septa, together with the septa of the thigh.

\section{b. The lymph-sacs.}

(i) The dorsal lymph-sac (Saccus cranio-dorsalis), (Figs. Ito and I I I I). This is a large lymph-sac, extending from the tip of the snout to the tip of the urostyle; it is bounded in front by the attachment of the skin to the premaxillary bones; the line of attachment is continued, on either side, along the inner border of the external nares, then forms a pouch towards the jaw and in front of the eye, and runs backwards along the upper border of the orbit, where it is attached to the upper evelid, to the inner border of the tympanic membrane. In this course the skin is firmly attached to the underlying parts. The lateral boundary of the lymph-sac, behind this point, is formed by the dorsal septum, which separates it from the lateral lymph-sac.

(2) The ventral lymph-sac (Saceus abdlominalis), (Figs. 170, 171 2) is triangular in form, with the base forwards at the breast, and the apex behind at the pelvic symphysis; it occupies the space between the skin below and the belly muscles and part of the $M$. pectoralis above. It is bounded anteriorly by the pectoral septum (j) and laterally by the ventral septa $(a)$.

(3) The lateral lymph-sac (Saceus lateralis), (Figs. 169, 170, and I II 3) exists on either side; below, the sac is bounded by the ventral septum (a), above by the dorsal septum (d), anteriorly by the maxillary septum ( $m$ ), and posteriorly by the inguinal septum (i) and the wall of the iliac lymph-sac.

(4) The submaxillary lymph-sac (Sacens submaxillaris), (Figs. 170 and $17 I_{4}$ ) is a space between the $M$. sulmaxillaris and the skin; the sac is bounded behind by the maxillary septum, which separates it from the pectoral lymph-sac, and more laterally from the lateral lymph-sac. In front and at the sides the skin is firmly attached to the margin of the mandible.

(5) The pectoral lymph-sac (Saccus thrracicus), (Figs. 170 and I 7 I s) lies between the submaxillary and ventral lymph-sacs. The 


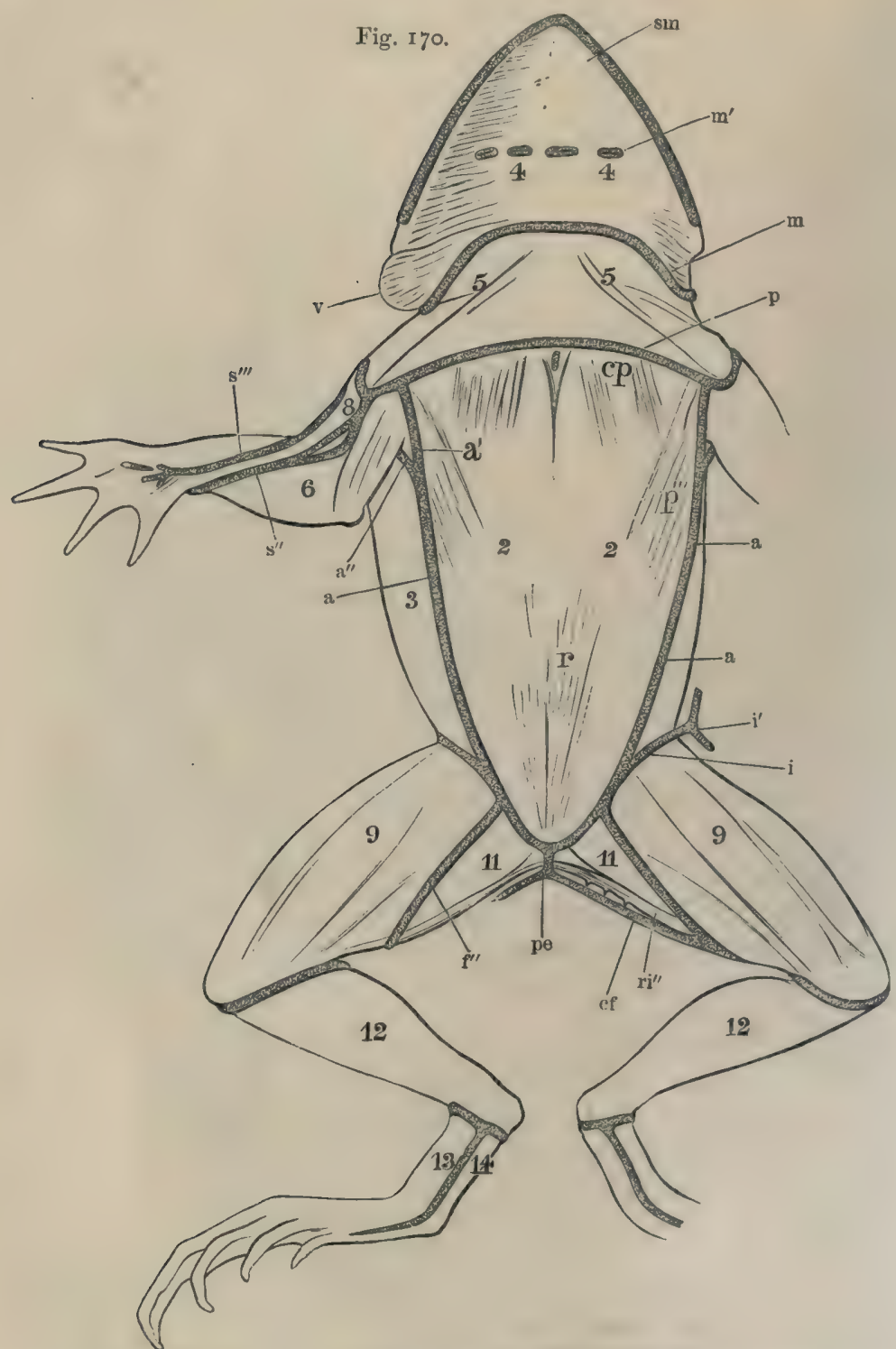

Lymph-sacs of Rana esculenta, seen from the ventral surface.

\section{Ventral lymph-sac.}

Lateral lymph-sac.

4 Submaxillary lymph-8ac.

5 Thoracic lymph-sac.

6 Brachio-ulnar lymph-sac.

8 Anterior brachial lymph. sac.

Femoral lymph-sac.

II Intèrfemoral lymph-sac.

12 Crural lymph-sac.

13 Dorsal lymph-sac of the foot.

I4 Plantar lymph-sac of the foot. a Ventral septum.

$\boldsymbol{a}^{\prime}$ Anterior division of ventral septum.

$m^{\prime}$ Attachment of maxillary soptum to skin.

p Pectoral septum.

$a^{\prime \prime}$ Posterior division of ventral $p^{\prime \prime \prime}$ Port, abdom. of the M. pectoseptum.

cf Intermediate femoral septum. pe Perineal septum.

cp M. cutaneus pectoris.

$f^{\prime \prime}$ Inferior femoral septum.

i. Inguinal septum.

i Attachment of inguinal septum to skin.

$m$ Maxillary septum. $r$ M. rectus abdominis.

$r i$ " M. rectus internus minor.

$g^{\prime \prime}$ Anterior brachio-ulnar aeptum.

e"l Anterior brachial-radio septum.

sm Musc, submaxillaris, 
sac is bounded behind by the pectoral septum $(p)$, and in front by the maxillary septum $(\mathrm{m})$.

(6) The iliac lymphsac (Saccus iliacus), (Figs, I7I and I72 15, 173) does not really belong to the subcutaneous lymph-sacs, as it does not lie directly under the skin except by a very narrow border. It is bounded in front by the iliae septum, above by the dorsal septum, and posteriorly by the inguinal septum. By these boundariesa space is enclosed, which lies under the dorsal septum and dorsal sac, and at the same time partly under the lateral sac. In this sac the $M$. glutaens, the anterior ends of the $M$. vastus externus, $M$. rectus anterior, and $M$. cutaneus itiacus, lie free together

\footnotetext{
The lymph-sacs of Rana exculenta, seon from the side.

I Dorsal lymph-sac.

Veutmal lyzaph-sac.

Lateral lymph-sac.

Submaxillary lymph-sac.

Pectoral ly mpli-sae.

Fenoril lymph-sac

Silumferuiral ly mph-sac

Crural lvmph-sac.

llia lo kuph-sac.

Ventral septum.

Ihomal septum.

Inguinal sерtum.

w Maxillary septum.

$m^{\prime}$ Attachment of M. submaxillaris to the skin.

p Pectoral septum.

sm M. submaxillaris.

$v$ Tocal sac.
}

Fig. I\% I.

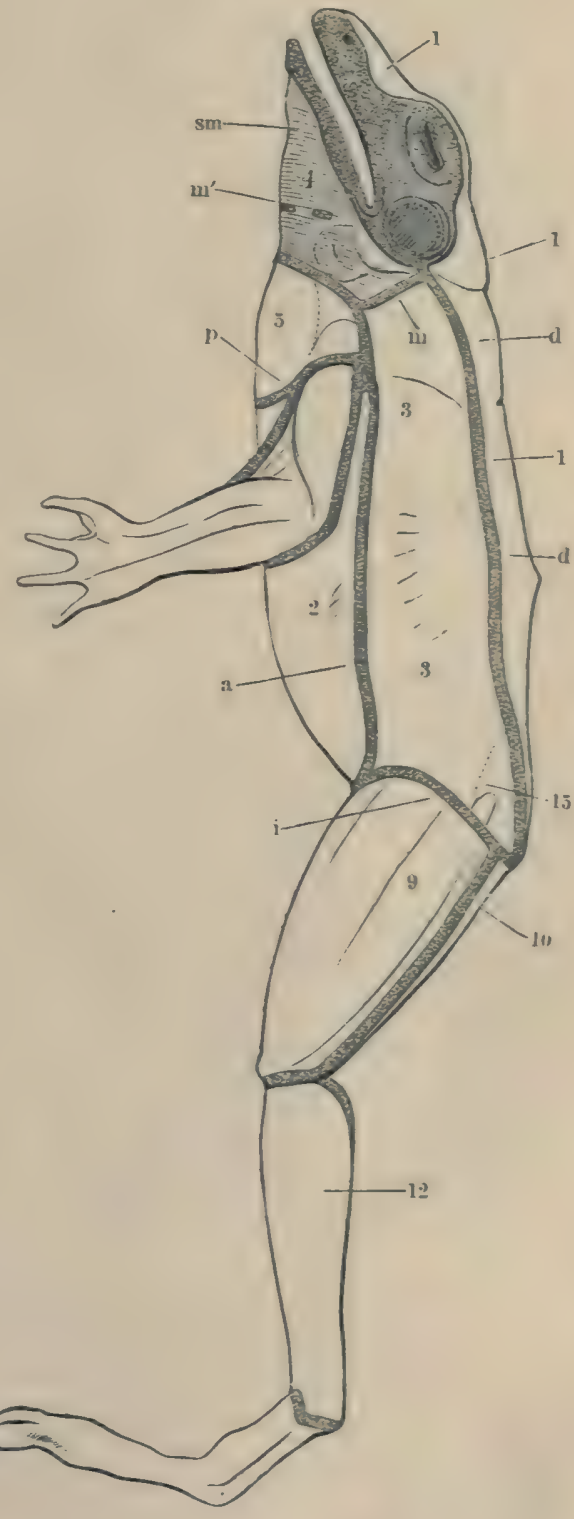


with the hindmost part of the $M$. obliquus abulominis externus, and the hinder portion of the posterior lymph-heart. Anteriorly the floor is depressed between the $M$. obliquus ablominis and the M. glutaeus, the depression leading to a canal, which communicates with the abdominal cavity.

B. The Lymph-sacs of the Anterior Extremity.

a. The septa.

(1) The axillary septum (Septum axillare), (Figs. I $70 a^{\prime}, a^{\prime \prime}$, I71) is practically a portion of the ventral septum, which divides at the root of the arm to enclose it. The dorsal and ventral portions of this circular septum have received special names.

Fig. 172.

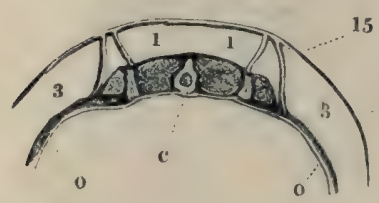

Transverse section throngh the trunk in the region of the iliac lymph-sac.

$$
\begin{aligned}
& c \text { Urostyle. } \\
& c^{\prime} \text { Skin. } \\
& \text { o } \text { Mnscles of abdominal wall. } \\
& \text { I Dorsal lymph-sac. } \\
& 3 \text { Lateral lymph-sac. } \\
& \text { 15 } \text { Iliac lymph-sac. }
\end{aligned}
$$

a. The dorsal axillary septum (Septum axillare dorsale) crosses the M. triceps and joins the pectoral septum.

$\boldsymbol{\beta}$. The ventral axillary septum (Septum axillare dorsale) passes through the axilla and joins the pectoral septum.

The circular axillary septum has attached to it the following :-

(2) The posterior brachial septum (Septum brachiale posticum (Fig. $1698)$; it is attached along the middle line of the extensor surface of the arm (long head of the $M$. triceps $)$ to the elbow and to the forearm ( $M M$. anconaei $)$, then passes obliquely over the volar surface of the hand to the fourth finger.

(3) The anterior brachio-ulnar septum (Septum bracliale anticum ulnare), (Fig. I $70 s^{\prime \prime}$ ) commences at the same point as the foregoing, passes obliquely over the outer head of the $M$. triceps, and is continued over the $M$. flexor antibrachii lateralis, $M$. supinator longus, and $M$. extensor digitorum communis, to the dorsal surface of the fourth finger.

(4) The anterior brachio-radial septum (Septum brachiale anticum radiale), (Fig. I $70 s^{\prime \prime \prime}$ ) passes from the outer angle of the wall of the pectoral lymph-sac, over the inner head of the $M$.triceps and $M$. flexor carpi radialis to the thumb.

b. The lymph-sacs are enclosed by these three septa; they are four in number :- 
(1) The brachio-ulnar lymph-sac (Sarcus brachialis ulnaris), (Fig. 1706) is situated between the first and second septa along the extensor and ulnar surfaces.

(2) The brachio-radial lymph-sac (Sacens brarlialis ralialis), (Fig. I69 $i$ ) is placed along the extensor and radial surfaces.

(3) The anterior brachial lymph-sac (Sacms brashialis antirus), (Fig. I 70 8) lies on the flexor surface between the second and thind septa ; it is a long carity and interrupted by connective-tissue bands, in which the tendon of the $\boldsymbol{M}$. sterno-railialis and the nerre and ressels are situated.

(4) The axillary lymph-sac (Sacens axillaris) corresponds to the iliae lymph-sac; it is bounded br the divisions of the rentral septum.

In the hand no large lymph-space exists ; the skin is attached by numerous bands to the underlying structures.

C. The Lrmph-saes of the Hinder Extremity.

a. The septa.

(1) The superior femoral septum ( $S e p-$ tw $m$ femorale superius). (Figs. 169 and $175, f$ ) is attached abore to the inguinal septum near the posterior lymph-heart; and is Fig. 173-

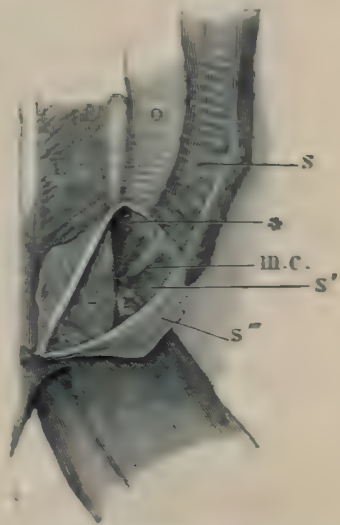

Disection to show the ilim. lytoph-zas:

2) M. glnzacus

i.c. M. ilimerey zens.

a.e. M. entaneas iliwers

- M. obliq. abilom externms.

$r$ M. nectus.

5 Dursal septum.

S" Dize sepum.

Sw Portion of dissal septum. which forms the noof of the iliax lowph-sic.

* M. saserls externus.

- Apernre. by which "the ilita Iymith-sue emrumniates with the abdiminal carits. continued, from this point, over the M. vastus estermus and along the $M$. triceps to the knce.

(2) The inferior femoral septum (Sptum femorale inferims), (Figs. $I 70$ and $\left.175 f^{\prime \prime \prime}\right)$ runs from the inguinal septum near the point of insertion of the $\boldsymbol{M}$. rectus ablominis, along the II. rectus internus minom to the knee.

(3) The intermediate femoral septum (Septum femorale intermedium), (Figs. I 69 and $175 f^{\prime \prime \prime}$ ) passes from near the posterior lymph-heart over the M. semimemlsanasus and the $\dot{H}$. rectus internus minor to join the inferior femoral septum.

Fig. 174

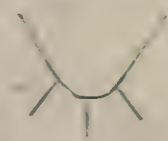

Plan of atcaehment: of the inferien fe. moral, inguinal. and perineal septe- 
(4) The tibio-femoral septum (Septum femoro-crurale) is a circular band, separating the lymph-sacs of the thigh from the leg sac.

(5) The septa of the foot. At the ankle joint the skin is closely attached all round to the underlying parts. Along the outer border of the foot a septum is attached to the skin externally, and to the underlying parts, especially the $M$. abductor longus digiti primi, internally. A similar but weaker band is attached along the outer border of the foot, especially to the $M$. adductor digiti quinti.

b. The lymph-sacs.

(1) The femoral lymph-sac (Saccus femoralis), (Figs. I69, 170, I $7 \mathrm{I}, 1759$ ) covers the lower and outer surfaces of the thigh; it is

Fig. 175 .

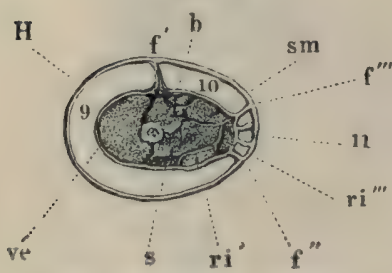

Transverse section of the thigh.

b M. biceps.

$f^{\prime}$ Superior femoral septum.

$f^{\prime}$ Inferior femoral septum.

$f^{\prime \prime}$ Intermediate femoral septum.

II Skin.

ri' M, rectus internus major.

$r i^{\prime \prime \prime}$ M. rectus internus minor.

8 M. Sartorius.

sm M. semimembranosus.

ve M. vastus externus.

9 Fernoral lymph-sac.

ro Suprafemoral lymph-sac.

II Interfemoral lymph-sac. bounded by the superior femoral and inferior femoral septa, and in front by the inguinal septum.

(2) The suprafemoral lymph-sac (Saccus suprafemoratis), (Figs. 169, I7I, I75 ro) lies on the upper surface of the thigh, between the superior and intermediate femoral septa; above it is bounded by the inguinal septum.

(3) The interfemoral lymph-sac (Saccus interfemoralis), (Figs. I69, $\mathrm{r} 70,175 \mathrm{II})$ is a narrow sac on the inner surface of the thigh, between the inferior femoral septum and the intermediate femoral septum. It covers the $\boldsymbol{M}$. rectus internus minor,

and is interrupted by numerous bands of tissue which pass from the surface of the muscle to the skin. It is, therefore, not a simple sac, but a very wide-meshed trabecular structure of connective-tissue. The sac is triangular in shape, with the base directed forwards at the inguinal septum.

(4) The lymph-sac of the leg is a simple sac enclosing the whole leg, bounded above by the tibio-femoral septum, and below by the attachment of the skin to the ankle.

(5) The lymph-sacs of the foot. On the dorsum of the foot the skin is free, and there is consequently a lymph-sac. On the plantar surface the skin is attached by numerous connective-tissue bands and thread-like tendons, particularly to the flexor tendons. The 
skin of the dorsal and plantar surfaces meet on the web and enclose a very rich anastomosis of lymph-capillaries.

2. The Lymph-Hearts.

The frog has two pairs of lymph-hearts, one pair anterior, the other posterior.

A. The anterior lymph-hearts (Fig. 176). These organs lie, one on each side, behind the broad transverse processes of the third vertebra (Müller, Panizza, Priestley), in a deep triangular space formed by the separation of the fibres of the $\boldsymbol{M}$. intertranscersarius, between the transverse processes of the third and fourth vertebrae. Each heart is a rounded sac, slightly elongated anteriorly where

Fig. 176 .

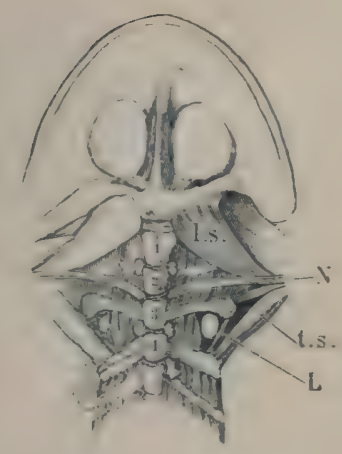

The anterior lymph-bearts.

L The left anterior lymphheart.

l.8. M. levator scapulae.

N Brachial nerve.

1.8. M. transverso = scapularis maior.

I-4 Vertebrae numbered from before backwards.
Fig. 177 .

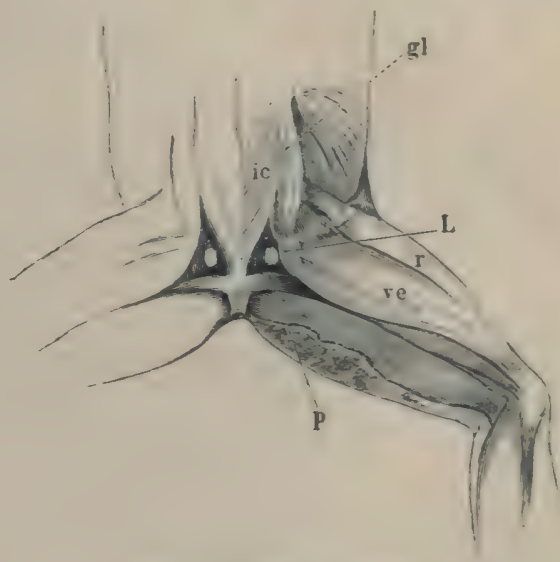

The posterior lymph-hearts.

gl M. glutreus
ic M. ilio-coceygens,
L Posterior lymph-hearts,
$p$ M. pyriformis.
ve M. rectuss
M. vastus externus.

it is connected with the subscapular vein. [The hearts receive lymph from the anterior part of the body and the surrounding parts, and empty their contents into the vertebral vein. Each of these hearts is supplied by a branch from the second spinal nerve (Volkmann, Eckhard, Schiff, Priestley).]

B. The posterior lymph-hearts (Fig. I 77) are situated on either side of the urostyle in the triangular spaces (Müller, Panizza, Priestley), bounded externally and above by the $M$. glutaeus, 
internally and above by the $\boldsymbol{H}$. cocrygen-iliacus, below and externally by the origin of the $M$. vastur externus, and below by the M. pyramilalis. Each posterior heart is about two lines long and one broad, with its long axis placed antero-posteriorly; the outer surface is uneven and appears to be unequally dilated. The lymphheart is closely attached to the surrounding parts, especially to the fascia covering the $\boldsymbol{I}$. ilii-coccygea, and posteriorly to the M. levator ani and the M. pyramilalis. [The posterior lymph-hearts receive lymph from the parts surrounding them, and from the hinder extremities, and forward it into the $V$. iliaca communicans.

The posterior lymph-hearts are each supplied by a branch from the corresponding coceygeal nerve (Waldeyer) by its dorsal branch. The lymph-hearts are also in close connection with the sympathetic system (Waldeyer).]

\section{PART III.}

\section{THE BLOOD, LYMPH, AND HISTOLOGY OF THE VESSELS.}

[The parts described in this section will be considered very briefly, and only from an anatomical point of view.

\section{A. The blood ${ }^{1}$.}

The blood varies in colour, according as it is obtained from an artery or from a vein; from an artery it has a bright red or searlet colour; from a vein a darker shade: in the pulmonary vessels these colours are reversed. The blood consists of a fluid plasma which contains red and white corpuseles: the whole forming a slightly alkaline, opaque, and somewhat sticky fluid.

a. The plasma or liquor sanguinis is a transparent, clear, slightly yellow fluid, faintly alkaline in reaction.

1 Mr. Hurst has noticed a frog (R. temporaria) in which the blood was perfectly colourless. 
b. The corpuscles are of two kinds, colourless and coloured.

(1) The colourless or white corpuscles are subspherical masses of protoplasm, endowed with the porver of spontaneous motion. They are much fewer than the red corpuscles, though the proportion of white to red varies considerably. Three chief varieties of colourless (orpuscles can be distinguished, all of which are true cell forms, and behave like other cells with staining or other reagents. They have no cell-wall, but are simply nucleated masses of protoplasm. These corpuscles possess the power of passing through the walls of the blood-vessels, and are then known as migratory cells; such migratory cells can be found in nearly all tissues, but more especially in the connective-tissues.

a. Ordinary large colourless corpuscles are large transparent masses of protoplasm containing one or two nuclei, rarely three or more. The cell contains few granules, and usually has one or more vacuoles or clear spaces containing fluid.

$\beta$. Granular corpuscles are less numerous than the foregoing, but larger, and are distinguished by the numerous large dark granules which they contain. The processes such a corpuscle sends out are hyaline.

$\gamma$. Smaller corpuscles also occur varying much in form: they may consist of a nucleus with a very small amount of hyaline or granular protoplasm, or of several nuclei with an extremely small amount of protoplasm.

(2) The coloured corpuscles are much more numerous than the colourless corpuscles; each is a bi-concave, oval disc, about $0.0255 \mathrm{~mm}$. in length, and $0.017 \mathrm{~mm}$. in breadth (Gulliver) ${ }^{2}$ (R. temporaria, 0.0235 and $0.0145 \mathrm{~mm}$. respectively). Each corpuscle possesses an oval nucleus (Hewson) ${ }^{2}$, which projects into either concave surface of the whole corpuscle. These corpuscles do not possess the power of spontaneous movement; and have no cell-wall. The corpuscles are of a reddish-yellow colour, and give the blood its characteristic hue. The colouring matter is haemoglobin, and when separated it crystallizes in prisms (Preyer). The corpuscles show a well-marked intracellular and intranuclear network.]

'Gulliver, Proc. Zool. Soc. London, I \&45, Vol. XIII, p. 93 seq.

${ }^{2}$ Hewson, Phil. Trans, I 773, Vol. LXIII, p. z10 seq. 


\section{B. [The Lymph and Chyle.}

The lymph is that portion of the blood which has filtered from the blood-vessels, through the tissues, into the lymphaties. It is a clear, transparent fluid, containing colourless corpuseles, which agree in all particulars with the colourless corpuseles of the blood. During digestion the lymph from the alimentary canal contains particles of fatty matter, and is then known as chyle.] The colourless corpuscles of the lymph frequently contain portions of red corpuscles or granules of pigment. Non-nucleated masses of protoplasm and decolourised red corpuseles (slightly diminished in size) have also been described as occurring frequently in the lymph $\left(\right.$ Fuchs $\left.^{1}\right)$.]

C. [Histological Remarks on the Vascular System.

a. The heart has already been described (pp. 216-222).

b. The blood-vessels present the same structure as the corresponding vessels in higher animals. The arteries and veins have each the three walls or layers usually described-Tunica adventitia, Tunica media, and Tunica intima. The only characteristic to be mentioned is that the Tunica adventitia contains branched, pigmented corpuseles. The Nervi vasorum, especially of the smaller arteries, are arranged in two plexuses, one in the Tunica adventitia (His) ${ }^{2}$, the second in the muscular coat (J. Arnold) ${ }^{3}$. The fibres of both plexuses are non-medullated, and have the usual beaded appearance; they communicate freely with each other. The capillaries present, as a rule, the usual structure: such special arrangements of the capillaries or peculiarities in structure as occur will be described with the organs in which they are found.

c. The subcutaneous lymph-sacs are lined with a layer of endothelium resembling the endocardium shown in Fig. 140; the endothelial layer possesses stomata (see peritoneum), through which the lymph-sacs communicate with the underlying lymphaties. The endothelium is continued on to the vessels, nerves, etc., which course through the sacs, and excludes these from the cavities. As a rule an artery, vein, and nerve are enclosed in a common sheath.

d. The lymph-hearts are small saccular bodies with thin transparent walls, which contain obscurely striated muscle-fibres. The vessels communicating with the hearts appear to possess valves

1 Fuchs, Virchow's Arch. 1877, Vol. LXXI, p. 78 seq.

${ }^{2}$ His, Virchow's Arch. 1863, Vol. XXVIII, p. 427.

${ }^{3}$ Arnold, in Stricker's Handbuch d. Gewebelehre, p. I37. 
(Miiller). The walls of the hearts are formed of three layers; an external, compared by Waldeyer to an alventitic, a muscular layer, and an endothelial lining. The museular fibres form a close interlacing mass, the fibres being small, branched (Leydig), and possessed of many nuclei. Among the muscular fibres are pigmented corpuscles, together with medullated and non-medullated nervefibres, but no ganglion-cells (Volkmann, Waldeyer, Priestley). The adrentitia is a connective-tissue layer with many pigment cells (Leydig, Hyrtl, Waldeyer).] 



\section{SECTION $\mathrm{V}$.}

THE ALIMENTARY TRACT WITH ITS APPENDAGES, THE SPLEEN, AND THE PERITONEUM. 


\title{
THE ALIMENTARY TRACT, ETC.
}

\author{
LITERATURE.
}

THE MOUTH.

(Except the mucous membrane of the tongue, for which see organ of taste.)

Ducrotay de Blainville, H. M., Ostéographie ou deseription iconographique comparée du squelette et du système dentaire des cinq classes d'animaux vertébrés. Paris, I84I.

Frdl, Ueber den Bau der Zähne bei den Wirbelthieren, etc. München, I84 I.

Fixen, C., De linguae raninae structura. Dorpat, 1857.

Heincke, F., Untersuchungen über die Zähne niederer Wirbelthiere. Zeitsch. f. wiss. Zool. 1873. Vol. XXIII, p. 495.

Hertwig, O., Ueber das Zahnsystem der Amphibien, etc. Suppl. to Vol. XI, Arch. f. mik. Anat. 1874 .

Hoffmann, C. K., Bronn's Thierbuch. Leipzig and Heidelberg, 1873-1878. Vol. VI, p. 379.

Holl, M., Zur Anatomie der Mundhöhle vou Rana temporaria. Wiener Acad. Sitzungsb. 1887. Vol. XCV, Pt. III, p. 47.

Hoyer, Ueber die Epithelzellen der Froschzunge, sowie über den Bau der Cylinderund Flimmerepithelien und ihr Verhältniss zum Bindegewebe. Arch. f. Anat. u. Physiol. 1858 , p. $16_{3}$; also Deutsche Klinik, 1857 .

Langer, C., Ueber das Lymphgefässsystem des Frosches. Wiener Acad. Sitzungsb. 1867. Vol, LV, Pt. I, pp. 6r 4 -62I.

Ioydig, Die Anuren Batrachier der deutschen Fauna. Bonn, 1877 .

Owen, R., Odontography. London, I840-1845, p. 187 .

Reichel, P., Beiträge zur Morphologie der Mundhöhlendrüsen der Wirbelthiere. Leipzig, 1882 ; also in Morph. Jahrb. I882, Vol. VIII, pp. I-72.

Santi Sirena, Untersuchungen über den Bau und die Entwicklung der Zähne bei den Amphibien und Reptilien. Verhandl. d. phys.-med. Gesellsch. in Würzburg, 1872. Vol. II, new series, p. I 25.

Schöbl, J., Ueber divertikelbildende Capillaren in der Rachenschleimhaut nackter Amphibien. Sitzungsb. d. k. b. Gesellsch. d. Wiss. in Prag. 1878, p. 25 ; also in Arch. f. mik. Anat. 1885, Vol. XXV, p. 89.

Schultze, F. E., Das Drüsenepithel der schlauchförmigen Drüsen des Dünn- und Dickdarms und die Becherzellen (of the pharyngo-oral cavity). Centralbl. f. d. med. Wiss. 1866, p. 6r.

Schultze, F. E., Epithel- und Drüsen-Zellen. Arch. f. mik. Anat. 1867. Vol. III, p. 137 .

Smith, W. J., Beitrag zur differentiellen Diagnose der Rana fusca s. platyrrhinus und Rana arvalis s. oxyrrhinus auf Grund der an den Gaumenzähnen nachweisbaren Unterschiede. Pflüger's Arch. f. d. ges. Physiol. 1883. Vol. XXXII, pp. 58I-588. 
Tomes, C. $\mathbf{8 . , ~ O n ~ t h e ~ d e v e l o p m e n t ~ o f ~ t h e ~ t e e t h ~ o f ~ t h e ~ n e w t , ~ f r o g , ~ s l o w w o r n , ~ a n d ~}$ green lizard. Phil. Trans. 1874, p. 285.

Török, Tntersuchungen über die Entwickelung der Mundhöhle, etc. Wiener Sitzungsb. 1866. Vol. LT, Pt. I, p. 75.

Waller, A., Microscopic examination of the principal tissues of the tongue, etc. Phil. Mag. 1846, pp. 273-290.

Waller, A., On the development of the mouth and tongue of the frog. Phil. Mag. 1850. Vol. I, pp. 38-43.

Zeller, A.. Die Abscheidung des indig.-schwefelsauren Yatrons in den Drisen 'Intermaxillary gland). Virchow's Arch. IS 78 . Vol. LXXIII, p. $25 \%$

\section{THE OESOPHAGUS AND STOMACH.}

Biedermann, Tntersuchungen über Magenepithel. Wiener Acad. Sitzungsb. IS ; Vol. LXXI, Pt. III, p. 377 .

Bischoff. Ceber den Bau der Magrenschleimhaut. Arch. f. Anat. u. Phrsiol. I $\delta_{3} \delta_{\text {, }}$ p. 503 .

Bleyer, E., Magenepithel und Magendrïsen der Batrachier. Dissert. Künigsberg, 1874 .

Braun, Zum Vorkommen ron Flimmerepithel im Magen. Zoul, Anzeiger. ISSo. No. 69, p. 568.

Brinton, in Cyclopaedia of Anat. and Physiol., edited by R. B. Todd. IS 59 . Tol. I, p. 320.

Cobelli. Le gliandole acinnse del cardia. Wiener Acad. Sitzungsb. 1866. Tol. LIII, Pt. I, p. 25 I.

Ebstein. W, Beitrige zur Lehre rom Bau und den phrsiologischen Funktionen der sogenannten Magenschleindrüzen. Areh. f. mik. Anat. 18jo. Vol. VI, p. \$15.

Ecker, A., Teber die Drüsen der Magenschleimhaut. Zeitsch. f. rat. Med. 1 $\$: 2$, p. 243 .

Foster, M.. On some points in the epithelinm of the frog's throat. Journ. of Anat. and Physiol. 1869. Vol. IV, p. 394.

Frerichs, On the Stomach, in Wayner's Handwörterbuch d. Physiol. 1 448 . Fol. II, p. 748 .

Glinsky. A., Zur Kenntniss des Bauez der Magenschleimhaut der Wirbelthiere. Centralbl. f. d. med. Wiss 1883, p. 225 .

Gonjaew, K., Die Nerven dez Nahrungzechlauches. Arch. f. mik. Anat. 18-5. Vol. $\mathrm{XI}, \mathrm{pp} \cdot 479-496$.

Hebold, O., Ein Beitrag zur Lehre ron der Sekretion und Regeneration der Schleinzellen, Dissert. Bonn, 1879, Pp. 2T-27.

Heidenhain, R.. Cutersuchungen über den Bau der Labdrüsen. Arch. f. mik. Anat. 1870. Vol. VI, p. 368.

Hoffmann, C. K., Bronn's Klassen und Ordnungen des Thierreichs. Leipzig und Heidelberg. 1873-1878. Vol. VI, pp. 408-412.

Just. A., Zur Histolugie und Physiologie des Flimmerepithels. Breslauer ärztliche Zeitsch. 1885. No. 18, pp. 205-206.

Klein, E., Darmkaual, in Stricker's Gewebelehre, p. 385 , etc.

v. Kölliker, A., Mikroskopische Anatomie. I8 $\$$. Vol. II. p. I 4 ;

4

Langley, J. N., and Sewall. $\mathbf{H}$, On the changes in pepsin-forming glands during secretion. Journ. of Physiol. 1880. Vol. II, pp. 26r, 28r.

Langley. J. N., On the histolngy and physinlogy of pepsin-forming glands. Phil. Trans. 1881. Vol. CIXXII, Pt. III, pp. 66j-7I2. 
Langley, J. N., On the structure of secretory cells and on changes which take place in them during secretion. Internat. Monatschr. f. Anat. u. Histol. Vol. I, pp. $69-76$.

Leydig, Lehrbuch der Histologie. 1857.

Nussbaum, M., Ueber den Bau und die Thätigkeit der Drüsen. Arch. f. mik. Anat. I882, Vol. XXI, p. 296 ; 1882, Vol. XXVIII, p. 296; 1877, Vol. XIII, p. 721 .

Partsch, C., Beiträge zur Kenntnisz des Vorderdarmes einiger Amphibien und Reptilien. Arch. f. mik. Anat. 1877. Vol. XIV, p. I79.

Regéczy, E. N., Ueber die Epithelzellen des Magens. Arch. f. mik. Anat. I88o. Vol. XVIII, pp. 408-4II.

Robinson, C., Ueber die Lymphgefässe der Abdominaleingeweide des Frosches, etc. Froriep's Notizen, 1846. No. 807 , col. 225.

Rollett, Bemerkungen zur Kenntniss der Labdrüsen und der Magenschleimhaut. Untersuch. in d. Institut f. Physiol. u. Histol. zu Graz. $187 \mathrm{r}$.

Schultze, F. F., Epithel- und Drüsenzellen. Arch. f. mik. Anat. I867. Vol. III, p. I74; abstract in Centralbl. f. med. Wiss. I866, No. 4.

Schmidt, C., Ueber eingenthümliche aus dem Flimmerepithel hervorgehende Gebilde. Arch. mik. Anat. 188I. Vol. XX, p. I23.

Sewall, H., A note on the processes concerned in the secretion of the pepsin. forming glands of the frog. Studies in the Biol. Laborat., Johns Hopkins Univers. Vol, II, pp. 13I-I 34 .

v. Swiecicki, H., Untersuchungen über die Bildung und Ausscheidung des Pepsins bei den Batrachiern. Pflüger's Arch. f. d. ges. Physiol. 1876. Vol. XIII, p. 444 .

Trinkler, N., Zur Kenntniss des feineren Baues der Magenschleimhaut, insbesondere der Magendrüsen. Centralbl, f. med. Wiss. 1883, pp. I6I-163.

Trinkler, N., Ueber den Ban der Magenschleimhaut. Arch. f. mik. Anat. 1885. Vol. XXIV, p. 74 .

Trütschel, Ueber die Endigung der Nerven in der Schleimhaut des Magens. Centralhl. f. d. med. Wiss. I870, p. I15.

Valatour, Recherches sur les glandes gastriques et sur les tuniques musculaires du tube digestif dans les poissons ossieux et les Batraciens. Annales de Sc. nat. I861. Series IV. Vol. XVI, p. 2 ז..

\section{THE INTESTINE.}

Arnstein, C., Ueber Becherzellen, etc. Virchow's Arch. 1867. Vol. XXXIX, p. 527 .

Arnstein, C., and Gonjaew, K., Ueber die Nerven des Verdauungskanals. Pflüger's Arch. f. d. ges. Physiol. 1874. Vol. VIII, pp. 614-615.

Auerbach, L., Fernere vorläufige Mittheilung über den Nervenapparat des Darmes. Virchow's Arch. 1864. Vol. XXX, p. 457.

Auerbach, L., Untersuchungen tiber Lymph- und Blutgefässe. Virchow's Arch. 1865. Vol. XXXIII, p. 340 .

Auerbach, I., Organologische Studien.

Billroth, T., Ueber die Epithelzellen der Froschzunge; der Bau, Cylinder- und Flimmerepithel und ihr Verhältniss zum Bindegewebe. Arch. f. Anat. u. Physiol. 1858, p. I 59 .

Billroth, T., Einige Beobachtungen über das ausgedehnte Vorkommen von Nervenanastomosen im Tractus intestinalis. Arch. f. Anat. u. Physiol. 1858 , p. 148 . 
Brettauer und Steinach, Cntersnchungen über das Cylinderepithelium. Wiener Akad. Sitzungsb. 185i. Vol. XXIII, p. 303. Moleschott's Zeitsch. 1857. Vol. III, p. I57.

Darsch, O., Beiträge zur Kenntniss des feineren Baues des Dünndarmes. Wiener Sitzungsb. 1880. Vol. IXXXII, Pt. III, p. 168.

Dornitz, Leber die Schleimhaut des Darmeanals. Arch. f. Anat. u. Physiol. 1864, p. 367 .

Dönitz, L'eber Darmzotten. A reh. f. Anat. u. Physiol. 1866, p. 757 .

Iberth, C. J., Ceber den feineren Bau der Darmschleimhaut. Würzb. naturw. Zeitschr. 1864. Vol. V, p. 23.

Dimer, T., Zur Fettresorption, etc. Virchow's Arch. 1867. Vol. XXXVIII, p. 428 .

Đimer, T., Ceber Becherzellen. Virchow's Arch. 1868. Vol. XLII, p. 490.

Dimer, T., Zur Geschichte der Becherzellen. Dissert. I86\%.

Eimer, T., Die Wege des Fettes in der Darmschleimhant bei seiner Resorption. Virchow's Arch. 186g. Vol. XLVIII, p. II9.

Fimer, T., Zur Becherfrage. Virchow's Arch. 1867. Vol. XL, p. 282.

Erdmann. Die Resorptionswege in der Schleimhaut des Dünndarms. Dissert. Dorpat, $186 \%$.

Fries, E., Ceber die Fettresorption und die Entstehung der Becherzellen. Virchow's Arch. 1867. Vol. XL, p. 519 .

Gerlach, L., Ceber den Auerbachschen Plexus mysentericus. Arbeiten aus d. physiol. Anstalt. Loiprig. 1872, pp. 102-112.

Gonjaew, K., Die Nerven des Nahrungsschlauches. Arch. f. mik. Anat. 1875. Vol. XI, pp. 479-496.

Gruby and Delafond, Résultats des recherches faites sur l'anatomie et les fonetions des villosités intestinales, etc. Compt. rend. 1843. Vol. XVI, p. 1194 .

Grugenhagen, A., Ueber Fettresorption und Darmepithel. Arch. f. mik. Anat. 1887. Vol. XXIX, p. 139.

Heidenhain, R., Die Absorptinnswege des Fettes. Moleschott's Untersuchungen. 1858. Vol. IV, p. 251.

Henle, J., Symbolae ad anatomiam villorum intestinalium impr. eorum epithelii et vasornm lacteorum. Berolini, 1837 .

Hoffmann, C. K., Bronn's Klassen und Ordnungen des Thierreichs. Leipzig und Heidelberg, 1873-1878. Vol. VI, pp. 412-424.

Klein, E., Der Darmkanal in Stricker's Gewebelehre, Article XVI.

Klein, E., Contributions to the anatomy of Auerbach's Plexus in the intestine of the frog and toad. Quart. Journ. Micros. Sei. 18;3. Vol. XIII, p. 37\%.

Klein, E., and Verson, E., Der Darmcanal, in Stricker's Gewebelehre, $18 ; \mathbf{I}$, p. 355 .

Klein, E., Der neue Nervenapparat v. Thanhoffer's. Centralbl. f. d. med. Wiss. I 883, p. 82 .

v. Kölliker, A., Nachweis eines besonderen Baues der Cylinderzellen des Dünndarms. Verhandl. d. phys.-med. Gesells. Würzburg, 1856. Vol. VI, p. I 53.

v. Kölliker, A., Handbuch der Gewebelehre.

Lambl, Ueber die Epithelialzellen der Dünndarmschleimhaut. Wiener med. Wochenschr. 1859. Nos. 24 and 25.

Langer, C., L'eber das Lymphgefässsystem des Frosches. Wiener Acad. Sitzungsb. 1866. Vol. LIII, Pt. I, p. 395.

Letzerich, L., Ceber die Resorption der verdauten Nährstoffe im Dünndarm. Virchow's Archiv. 1866, Vol. XXXVII, p. $22^{2} ; 186 \%$, Vol. XXXIX, p. 435 .

Lipsky, A., Beitrag zur Kenntniss des feineren Baues des Darmeanals. Wiener Akad. Sitzungsb. 1865. Vol. LV. Pt. I, p. 183 . 
Oeffinger, Einige Bemerkungen über die sogenannten Becherzellen. Arch. f. Anat. u. Physiol. I867, p. 337 .

Partsch, C., Beiträge zur Kenntniss des Vorderdarmes einiger Amphibien und Reptilien. Arch. f. mik. Anat. 1877. Vol. XIV, p. I79.

Remak, R., Ueber peripherische Ganglien an den Nerven des Nahrungsrohrs. Arch. f. Anat. u. Physiol. 1858 , p. 189 ; also in Zeit. d. Vereins f. Heilkunde in Preussen. 1840.

Renzoni, Osservazioni e ricerche sul epitelio intestinale. Rendiconti dell Acad. di Napoli. 1868.

Rusconi, Riflessioni sopra il sistema linfatico dei rettili. Pavia, 1845 .

Sachs, J., Zur Kenntniss der sogenannten Vacuolen oder Becherzellen im Dünndarm. Virchow's Arch. I867. Vol. XXXIX, p. 493.

Schultze, F. F., Das Drüsenepithel der schlauchförmigen Driisen des Dünnund Dickdarms und die Becherzellen. Centralbl. f. d. med. Wiss. 1866, p. 160 .

Schultze, F. E., Epithel- und Drüsen-Zellen. Arch. f. mik. Anat. 186\%. Vol. III, p. 145 .

Thanhoffer, I., Beiträge zur Fettresorption und histologischen Structur der Dünndarmzotten. Pfiiger's Arch. f. d. ges. Physiol. 1874. Vol. VIII, pp. $39 \mathrm{I}-443$.

จ. Thanhoffer, I., Ein neuer Nervenapparat im Dünndarm. Centralbl. f. d. med. Wiss, 1883, p. 33 .

v. Thanhoffer, L., Antwort auf Herrn Prof. Klein's 'Der neue Nervenapparat etc.' betitelte Bemerkungen. Centralbl, f. d. med. Wiss. 1883 , p. I76.

Valatour, M. M., Recherches sur les glandes gastriques et sur les tuniques musculaires du tube digestif dans les poissons et les Batraciens. Annales des Sci. nat. $4^{\text {th }}$ Series, Vol. XVI. Zool. 186r, pp. 219-285.

Watney, H., The minute anatomy of the alimentary canal. Phil. Trans. 1877. Vol. CLXVI, Pt. II, p. 45I.

Wiegandt, Untersuchungen über das Dünndarmepithel. Dissert. Dorpat, 1860.

v. Wittich, Beiträge zur Frage über Fettresorption. Virchow's Arch. 1857. Vol. XI, p. 37 .

\section{THE LIVER, GALL-BLADDER, AND PANCREAS.}

Barfurth, D., Vergleichend-histochemische Untersuchungen iiber das Glycogen. Arch. f. mik. Anat. 1885. Vol. XXV, p. 369.

Brotz, J., and Wagenmann, C. A., De amphibiorum hepate et glandularum ductu excretio carentium structura deque earundem functionibus experimenta. Berolini, 1841 .

v. Brunn, A., Flimmerepithel in den Grallengängen des Frosches. Zool. Anzeiger. 1883. No. 148, p. 483 .

Æberth, C. J., Die Pigmentleber der Frösche und die Melanämie. Virchow's Arch. 1867: Vol. XL, p. 305.

Eberth, C. J., Zur Kenntniss der Verbreitung glatter Muskeln. Zeitschr. f, wiss. Zool. s 863 . Vol. XII, p. 360 .

Fberth, C. J., Ueber den feineren Bau der Leber. Centralbl. f. d. med. Wiss. I 866, p. 897 .

Eberth, C. J., Untersuchungen über die Leber der Wirbelthiere. Arch. f. mik. Anat. 1867. Vol. III, p. 423 .

Eberth, C. J., Untersuchungen über die normale und pathologische Leber. Virchöw's Arch. 1867. Vol. XXXIX, p. 7o. 
Eberth. C. J., Teber die Pigmentleber der Frösche. Virchow's Arch. I862. Vol. XXIX, p. 70 .

Gerlach, L., Leber die Nerven der Gallenblase. Centralbl. f. d. med. Wiss. I873, p. 562 .

Hering, E., Teber den Bau der Wirbelthierleber. Wiener Acad. Sitzungsb. 1886. Vol. LIV, Pt. I, p. 335.

Hering. E., Leber den Bau der Wirbelthierleber. Arch. f. mik. Anat. 186\%. Vol. III, p. 88.

Hering, E.. On the liver. Stricker's fewebelehre. I $8 \tau^{2}$, p. 429 .

Hoffmann, C. K., Bronn's Klassen und Ordnungen des Thierreichs. Leiprig und Heidelberg, 1873-1878. Vol. VI, p. 424 .

Jones, C. H., On the structure and development of the liver. Phil. Trans. 1849. Pt. I, p. 122 .

Langley, J. N., On rariations in the amount and distribution of fat in the liver-cells of the frog. Proc. Roy. Soc. 1886. Vol. XXXIX, p. 234.

Leydig, $\mathbf{F}$., Lehrbuch der Histologie. 1857.

Leydig, F., Die Leber der Fische und Batrachier.

Nussbaum, M., Ceber den Bau und die Thätigkeit der Drtisen (Pancreas). A reh. f. mik. Anat. 1877 . Vol. XIII, p. 752.

Popoff, M., The nerres of the gall-bladder (in Russian). Rudneff's Journ. f. normal. u. pathol. Histol, ete. 1872 .

Remak, R., Ceber runde Blutgerinnsel und über pigmenthaltige Zellen. Arch. f. Anat. u. Physiol. 1852, p. 115.

Weber, E. H., Ceber die periodische Farbenänderung welche die Leber der Hiihner und Frösche erleidet. Bericht von Verhandl. K. Säch Gesell. Leipzig, 1850, p. 15.

Zeller, A., Die Abscheidung des indig.-sehwefelsauren Natrons in den Drüsen (Pancreas). Vinchnw's Arch. 1878. Vol. LXXIII, p. 257.

\section{THE SPLEEN.}

Billroth, T., Beiträge zur vergleichenden Anatomie der Milz. Arch. f. Anat. u. Physiol. 1857, p. 88.

Billroth, T., Beiträge zur vergleichenden Anatomie der Milz. Virchow's Arch. I86r, Vol. XX, p. 410, and 1862, Vol. XXIII, p. 457; also Zeitschr. f. wiss. Zonl. 1862, Vol. XI, p. 325.

Ecker, Blutgefässdriisen, in Wagner's Handwörterbuch der Physiologie. 1849. Tcl. IV.

Gray, H., On the strueture and use of the spleen. London, I 854 .

Hoffmann, C. K., Bronn's Thierbuch. Leipzig und Heidelberg, 1873-18-8. Vol. VI, p. 509.

v. Kolliker, A., Ceber den Bau und die Verrichtungen der Milz. Mittheil. d. naturf. Gresell. in Zürich, 1847. Vol. I, p. 120.

Kusnezoff, F., Leher blutkörperchenhaltige Zellen der Milz. Wiener Sitzungsber. 1873. Vol. IXXVII, Pt. III, pp. 58-67.

Müller. W., Teber den feineren Bau der Milz. Leipzig und Heidelberg, $186_{5}$.

Remak, R., T'eber runde Blutgerinnsel und uber pigmenthaltige Zellen. Arch. f. Anat. u. Physiol. 1852, p. II5.

Schweigger-Seidel, F., Untersuchungen iiber die Milz. Virchow's Arch. 1862. Vol, XXIII, p. 526.

Stieda, L., Zar Histologie der Milz. Dorpat, 1862. 


\section{THE PERITONEUM.}

Alltmann, R., Ueber die Veränderungen des serösen Epithels am blosgelegten Froschmesenterium. Arch. f. mik. Anat. 1878. Vol. XVI, p. III.

Arnold, J., Ueber die Durchtrittsstellen der Wanderzellen durch entzündete seröse Häute. Virchow's Arch. 1878. Vol. LXXIV, p. 245.

Batelli, A., Dello addaltamento di alcune cellule endotiali nelle membrane serose. Lo Sperimentale. $\mathrm{J} 88_{4}, \mathrm{p}$. I32.

Cyon, Ueber die Nerven des Peritoneum. Bericht über d. Verhandl. d. Kön. Sïih. Gesell. d. Wiss. z. Leipzig, I868. Vol. XX, p. ז19. Leipzig, I869.

Grunau, H., Ueber das Flimmerepithel auf dem Bauchfell des weiblichen Frosehes und über den Eileiterbau desselben. Dissert. Königsberg, I875.

Hoffmann, C. K., Bronn's Klassen und Ordnungen des Thierreichs. Leipzig und Heidelberg, 1873-1878. Vol. VI.

Hoffmann, T., Dic Lungen-Lymphgefässe der Rana tempuraria. Dissert. Dorpat, 1875 .

Kapff, Untersuchungen über das Ovarium und dessen Beziehungen zum Peritoneum. Arch. f. Anat. u. Physiol. I872, p. 553 .

Klein, E., On Remak's ciliated vesicles and corneous filaments of the peritoneum of the frog. Quart. Journ. Mic. Sci. New Series, 1872. Vol, XII, p. 43.

Klein, E., On the peripheral distribution of non-medullated nerve-fibres (nerves of the peritoneum). Quart. Journ. Micros. Sci. I872. Vol. XII, p. 32.

Loydig, Lehrbuch der Histologie. 1857, p. 325 .

Mayer, Ueber die Flimmerbewegung. Froriep's Notizen, 1836. Vol. XLVII, p. 179 .

Neumann, E., Die Beziehungen des Flimmerepithels der Bauchhöhle zum Eileiterepithel beim Frosch. Arch. f. mik. Anat. I875. Vol. XI, pp. 354-377.

Nicolsky, P., Ueber das Flimmerepithel beim Frosche. Centralbl. f. d. med. Wiss. 1880, p. 64 I.

Paladino, G., Dell' endotelio vibratile nei Mammiferi ed in generale di alcuni dati sulla fisiologia delle formazioni endoteliche. Estr. dal Giornale intern. delle Scienze Mediche. 1882. Vol. IV.

Schweigger-Seidel and Dogiel, Ueber die Peritonealhöhle der Frösche. Arbeiten aus d. physiol. Anstalt zu Leipzig. 1866, p. 68.

Solger, B., Ueber einige Entwicklungsstadien des Peritonealepithels der Amphibienlarven. Manusc. d. Naturf. Versamml. zu Freiburg. I884.

Thiry, Ueber das Vorkommen eines Flimmerepitheliums auf dem Bauchfell des weiblichen Frosches. Göttinger Nachrichten. I86i, pp. I 7 I-174.

Tourneux, Recherches sur l'épithelium des sereuses. Journ. de l'anat. et de la physiol. I874.

Waldeyer, Eierstock und Ei. Leipzig, I87o, pp. 7 and 122.

Wolff, W., Ueber freie sensible Nervenendigungen. Arch. f. mik. Anat. 1882. Vol. XX, pp. $377-3^{8} \mathbf{I}$. 


\section{THE ALIMENTARY TRACT, ETC.}

\section{THE ALIMENTARY TRAC'T.}

THE alimentary tract consists of the mouth or pharyngo-oral cavity, the oesophagus, the stomach, the small intestine and the large intestine; these together forming a tube extending from the mouth to the cloaca. From the commencement of the oesophagus, at the entrance to the larynx, to the end of the cloaca, the length of the tube is about $31.5 \mathrm{~cm}$, that of the various parts being :

\begin{tabular}{|c|c|}
\hline From glottis to pylorus & $55 \mathrm{~cm}$. \\
\hline From pylorus to large intestine & $\mathrm{em}$. \\
\hline Large intestine to end of cloaca & $4^{\circ} 0 \mathrm{~cm}$. \\
\hline
\end{tabular}

\section{A. The Mouth.}

The mucous membrane covering the tongue will be described with the sense-organs (see organ of taste).

a. General description. The mouth of $R$. esculenta, as in all other amphibia, with the exception of the lowest (Siren, Proteus, etc.), is of considerable width, and extends backwards as far as the middle of the tympanic membrane. The upper margin of the mouth possesses a lip or fold of the skin $\left(S S^{1}\right)$, which projects sufficiently to prevent the teeth being seen from the front or from the sides. This lip-like rim is most prominent in the premaxillary and superior maxillary regions, but can be traced along the whole length of the upper jaw, and on to the lower jaw, by means of a wellmarked fold at the angle of the mouth. Beyond this point the lip is absent, as the skin is closely attached to the bony mandible.

On the roof of the mouth the following structures can be made 
out: immediately within the lip is a deep, well-marked groove, the outer boundary formed by the lip, the inner by a fold of the mucous membrane (Fig. $178 \mathrm{~F}$ ); this fold increases from behind forwards as far as the premaxillary bones, where it forms two prominences $\left(F^{1}, F^{1}\right)$ with an interval between. These correspond to the palatine processes of the premaxillary bones: immediately behind them are openings of the ducts of the intermaxillary glands.

Fig. 178 .

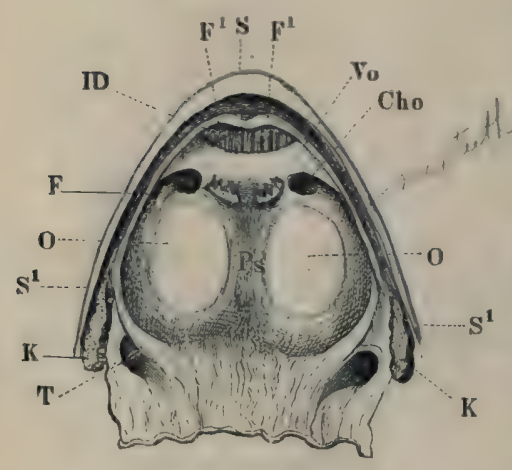

The roof of the mouth.

Cho Posterior naris,

ID . Opening of intermaxillary glands.

$\boldsymbol{F}$ Fold of mucous membrane.

F1, F Prominences of mucous nembrane.

$\boldsymbol{K}$ Muscles.

o Floor of the orbit.

8 Lip.

\$1 Lip.

T Eustachian tribes

Vo Vomer.

In the groove so formed are placed a single row of simple teeth, which, though subject to many variations, are usually about fifty in number.

A little further back and to either side of the median line is a small group of vomerine teeth $\left(T_{0}\right)$; each group has from five to ten teeth; external to these is on each side a transversely-placed oval opening, the posterior nares $(C h o)$. These apertures are directed outwards and backwards into a shallow groove, bounded anteriorly by a fold of mucous membrane.

According to Wiedersheim the mucous membrane immediately around the vomerine teeth is supplied with taste-bulbs; the epithelium strrounding these being non-ciliated.

The roof of the mouth underneath the parasphenoid is somewhat vaulted and on either side depressed by the eyeballs, which project downwards more or less prominently $(O, a)$. Still further back are the openings of the Eustachian tubes (Fig. $178 \mathrm{~T}$ ), one on each side, and almost surrounded by the limbs of the pterygoid bones.

On the floor of the mouth (Fig. I 79$)$ the tongue $\left(Z, Z^{1}\right)$ forms the most prominent object; its shape varying according to the state of contraction of its muscles. Behind it, in the middle line, is a transverse groove $(\dagger)$, corresponding to the posterior border of the hyoid bone, and still further back is the opening to the larynx $\left(I_{L}\right)$, 
a longitudinal slit about $3 \mathrm{~mm}$. in length. The mucous membrane to either side of the tongue is only slightly folded, and a little in front of the angle of the mouth is depressed into an aperture (S), opening into the rocal sac. This opening is sur(1) rounded by small radiating folds of mucous membrane, and is oval in shape.

Towards the oesophagus the mucous membrane of both the roof and the floor of the mouth is thrown into numerous longitudinal folds.

b. The minute structure of the several parts.

(1) The mucous mombrane of the mouth. At the junction of the skin and the mucous membrane there is a gradual transition from the stratified epithelium of the skin to a single layer of columnar epithelium. On the floor of the mouth this condition is reached at the tongue; on the roof the transition takes place more quickly. The columnar epithelium of the mouth (that of the tongue is excluded from this

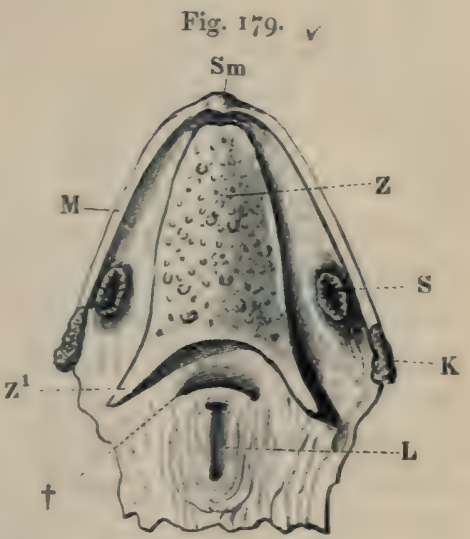

The floor of the mouth.

$$
\begin{array}{ll}
\boldsymbol{K} & \text { Mcusoles, } \\
\boldsymbol{L} & \text { Opening to larynx. } \\
M & \text { Mandible. } \\
\text { S } & \text { Opening to voice-bac (in males only) } \\
\text { Sm } & \text { Chin. } \\
Z & \text { Tongne. } \\
Z 1 & \text { Left curnu of bifid tongue. } \\
+ & \text { Fulds opposite hinder border of the } \\
& \text { hyoid. }
\end{array}
$$
description) is ciliated; scattered cells, which are not ciliated, are found here and there irregularly, but are not numerous. The cylindrical cells are very finely granular in their upper parts, clearer in the middle portion, more coarsely and darkly granular in their deeper portions ; each cell is possessed of a large, well-defined, oval nucleus, which contains one or sometimes two nucleoli. The non-ciliated cells usually present a sharply differentiated, structureless, hyaline, free border (Schultze). The epithelium towards the margin of the mouth, where it is stratified, is also ciliated.

Goblet-cells occur in every part of the epithelium, whether ciliated or non-ciliated, and their forms vary very greatly.

[The submucous layer is a fibrous connective-tissue matrix, very rich in nerves and blood-ressels. The eapillaries are arranged in small, somewhat polygonal meshes (Fig. I80), and are peculiar, with those of the anterior part of the oesophagus, in having small 
dilatations. This arrangement was first ${ }^{1}$ described by Langer, and later by Schöbl. The dilatations are placed quite irregularly on the capillaries, sometimes only on one side, sometimes on both sides of the vessel ; a slight constriction occurs at the neck of each dilatation, where it opens into the capillary ${ }^{2}$. The nerves of the mucous membrane underneath the orbits have nerve-cells attached to them (Stirling and Macdonald, page I 70). The lymphaties are very numerous, and for the most part follow the course of the bloodvessels to their finest twigs, beyond which they follow an independent course (Langer).]

(2) The toeth are wanting in the lower jaw; on the roof of the mouth they are found in two situations: as a single row in the groove within the lip, and a group on each vomer. Each tooth has the form of an elongated cone, which in the case of the jaw-teeth is curved, in that of the vomerine teeth straight. The teeth are fixed to the jaw so as to project upwards and slightly inwards, those at the front of the mouth projecting backwards, and those on the vomers project backwards. Each tooth has a small, sharp projection, or secondary crown on its outer surface (Fig. I8I), placed near the mucous membrane. The teeth are fixed to the bones by means of Crusta petrosa, which is again united to the bones of the mandible by a matrix of spongy bone, continuous for the several teeth. Between the tooth and the mucous membrane is a layer of flattened epithelium $(H)$, which extends more deeply on the inner side of the tooth than on the outer; the layer is continuous with the epithelium of the mouth, and is two to three cells in thickness. Each tooth has fine longitudinal grooves on the basal part of its outer surface, and consists of two parts, a crown and a root. The teeth possess large cavities, the wall being thin and almost of even thickness, except on the inner surface of the basal portion of the root, where the wall is wanting, and so forms a large aperture to the root.

The general skeleton of the tooth is formed of dentine, this is covered on the crown by a layer of enamel, and the Cuticula dentis on the socket by a layer of Crusta petrosa.

1 Beale, Phil. Trans., 1863 , p. I53, shows dilatations in his drawing, but makes no reference to them in the text.

2 The vascular supply of the mucous membrane of the dorsal surface of the mouth and oesophagus is shown (after Schöbl) in Plate II, Fig. I80, I. Arteries red, veins blue. II. in the same figure represents the dilatations on the capillaries; after Schöbl. 
a. The dentine is a homogeneous substance pierced by numerous tubules $(D)$, which arise at the pulp-carity and course in a parallel direction to the surface of the dentine, where they form a rich network with irregular, interglomerular spaces. The inner surface of the dentine is rough, through the presence of numerous small, dark tubereles.

$\beta$. The enamel covers the dentine on the apical portion of the tooth. It has tubes coursing through it, which are continuous with those of the dentine, and presents also circumferential striations (Fig. I 8 I III).

$\gamma$. The tooth cuticle (Cuticula dentis) is colourless and covers the enamel. It is highly refractive, very transparent, and very resistant to chemical reagents. From the apex, towards the Crusla petrosa, it thins very rapidly, but is continued sufficiently far to cover a portion of the Crusta petrosa.

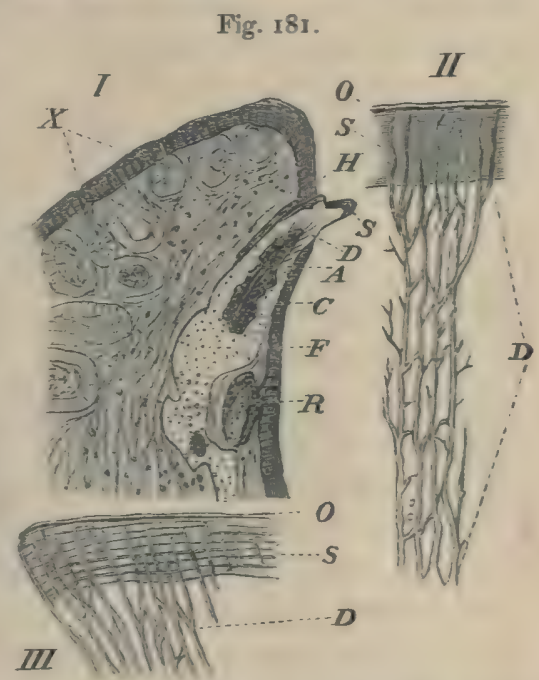

I. Transverse section of the premaxillary bone to ghow attachment of the teeth; sfter Hertwig. Magnified 22 times.

II. Dentine and enamel; after Hertwig. Magnified soo times.

III. Enamel : after Hertwig. Magnified 500 times.
C Crusta petroea.
L) Dentine.
F Provessus dentalis.
$H$ Laver ui epithelium.
D Tixuth cuticle.
R Reserve.
8 Enamel.
I Cntaneous glands.

A Blond-ressicl of the pulp-cavity.

ס. The Crusta petrosa resembles bone, except that it contains no Haversian canals ; it possesses cells which resemble bone corpuscles, and are usually somewhat rounded or oval and communicate with each other by their processes; for the most part it is homogeneous and free from cells (Hertwig).

є. The pulp-cavity contains a connective-tissue very rich in cellular elements; those cells adjacent to the dentine are arranged in a layer (Membrana eloris) which has somewhat the appearance of a layer of epithelium. The cells (odontoblasts) of this layer are spindle-shaped, and send processes (dentinal fibres) into the dentinal tubules. A small blood-vessel can be traced into each cavity, but as yet no nerve has been found in the pulp-cavities. 
[Smith $(l . c$.$) has, after careful investigation, come to the$ conclusion that the teeth of $R$. esculenta and $R$. temporaria are practically alike, therefore the methods of differentiating the two species by means of the teeth, as given by Leydig, are not to be relied on.]

(3) The intermaxillary glands (Glandula intermaxillaris) consist of a mass of convoluted tubes, lying chiefly between the premaxillary bones and the capsule of the nose, and opening by about twenty to twenty-five ducts at the fore-part of the mouth (Fig. I 78 ID). A portion of the glands extends high into the nasal cavity (Born), while dorsally another portion lies under the skin and the $M$. dilatator and $M$. lateralis narium, which together act as compressors to the subjacent glands : a small, elastic, cartilaginous rod, placed between the anterior margin of the nasal capsule and the under surface of the ascending limb of the premaxilla, opposes these muscles on either side by its spring-like action (Wiedersheim).

In a fresh skull the openings of the ducts can easily be seen after washing away the mucous secretion; they are, however, seen to better advantage by treatment with Müller's fluid and subsequent staining with carmine. With sufficient magnifying power, they are then seen as a row of bright dots. The tubules are of uniform thickness, placed closely side by side, and surrounded by a nervous plexus, which contains numerous branching nerve-cells. The epithelium of the tubules is cylindrical, with a rounded, finely granular nucleus; processes from the peripheral ends of the cells are continued to a Membrana propria. The ducts are lined with columnar, ciliated epithelium.

The secretion of the glands is remarkably adhesive, and is wiped off by the tongue when it is projected; by this means the tongue becomes a particularly efficacious instrument for capturing prey. The glands are, both histologically and chemically, pure mucous glands. In urodeles the homologous glands are placed in the hollow septum of the nose, between the nasal cavities.

(4) The tongue (Figs. I79, I82, I 83) is a broad, fleshy flap on the floor of the mouth, to which it is attached by the anterior half of its ventral surface as far forwards as the chin. Seen from above it has a wedge-like form, being narrow in front and wider behind, where it is prolonged at each angle to form two cornua.

By raising the tongue one obtains a view of a portion of the 


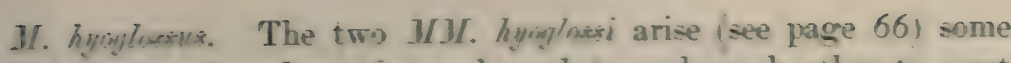
distance apart, and run forwands and towards each other to meet on the ventral surface of the hyoid bone; they now assume a longitudinal direction, and course forwards parallel to each other until ther reach the 11. grnim-glowins (Fig. $18_{2} G$ ). Each muscle now diviles to form coarse bundles, which ascend on either side of the 11. gewio-glasms towands the dorsum of the tongue. In this conrse they are encircled by a strong, elastic, connective-tissue sheath. The sheath is incomplete at the hinder end of the M. gevianglassm, where it possesses rounded apertures, through which the glossopharyngeal nerves $(N, N)$ disappear, to be distributed, after a sharp curve backwards, in the substance of the organ.

The 1 . gevio-gloses arises, in two parts on either side, at the side of the chin. One part (Fig. I82 $G$ ) is dorsal and median, the other (Fig. I82 $G^{1}$ ) ventral and external.

The first part, with its fellow of the opposite side, forms an arched commissure in the form of muscular rings, which decrease in

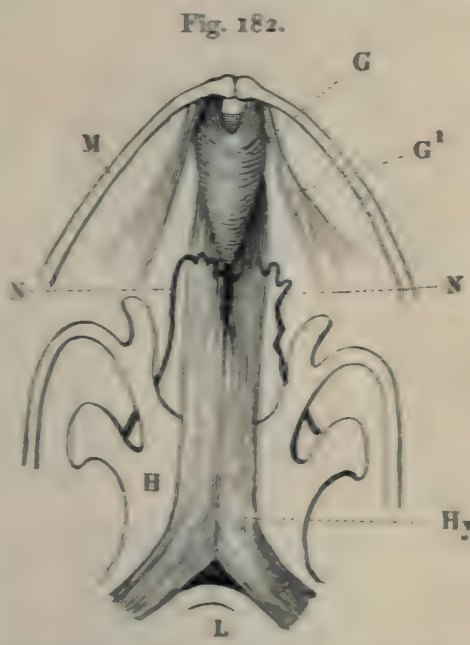

Macios of the tonicure, seen froas the reatral क्षriace.

\begin{tabular}{|c|c|}
\hline s. & 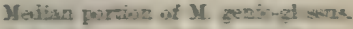 \\
\hline$G \mathrm{I}$ & 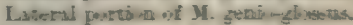 \\
\hline $\boldsymbol{H}$ & H \\
\hline $\mathrm{Hy}_{\mathrm{y}}$ & Y. lynogloentes \\
\hline $\boldsymbol{L}$ & Latysex. \\
\hline $\mathbf{M}$ & Masilinge. \\
\hline 5 & Glowentiarygeal nerve. \\
\hline
\end{tabular}

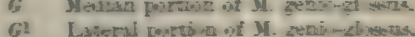

H H H

Hy M. byogloentes

I Glowopharngeal nerve. second, external portion, extends backwards, with a slight obliquity. as a thin, fan-like expansion, to the mucous membrane, where it is inserted. This arrangement can easily be seen after dissecting away the sheath (Fig. I $83 / I y$ ); the binderunst fibres curve sharply into the tongue $\left.\left(H_{y}\right)^{1}\right)$; the anterior fibres pass obliquely forwarls and blend with the straight fibres of the dorsal portion of the

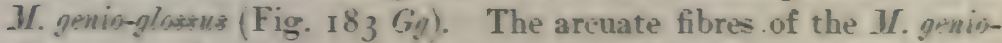
glwask pass, for the most part. upwards and outwards to the tipe of the posterior bifid borler of the tongue; in this course ther lie as a rule above the $\boldsymbol{M}$. lingiglosins, but here and there the two muscles internix (Fig. $I_{3}\left(y_{y^{1}}\right.$ ), and it is by no means easy to separate them. 
Fig. 183 .

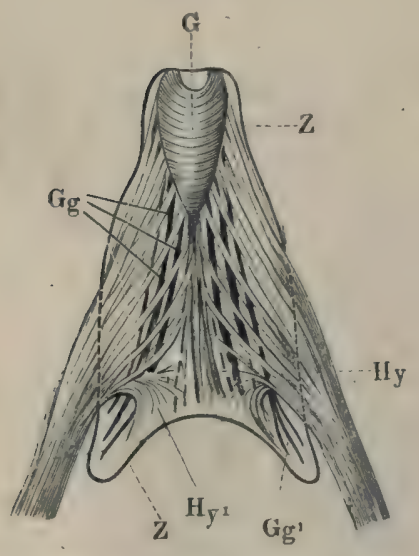

Muscles of the tonzue, from the ventral surface.

C M. genio-glossus,

Gg Straight fibres of the M, genio-glossus.

G $q 1$ Curved fibres of the M. genio-glossus. $H y$ and $H y^{2} \mathrm{M}$. hyoglossus.

$Z$ Borders of the tongtie.
The $M$. hyoglossus is the retractor of the tongue, the $M$. genio-glossus the protractor.

(For mucous membrane of the tongue, see organ of taste. The vocal sacs are described with the organs of voice and respiration.)

B. The Oesophagus and Stomach (Figs. I84, 185, I89, I94, 195, I 99).

a. General description. The oesophagus is not separated from the pharyngo-oral cavity by a sharp line of demarcation. It has a length of only a few $\mathrm{mm}$. in medium-sized frogs (Fig. $184 O_{t}$ ), and lies in the middle line of the body, supported on either side by the cornua of the hyoid bone. The oesophagus lies on the dorsal wall of the larynx, is smooth externally, and is thrown into well-marked longitudinal folds internally.

The transition from oesophagus to stomach is somewhat indefinitely marked by a slight dilatation of the tube, often searcely perceptible, still it can always be recognized by an abrupt curvature to the left (Fig. I $84 M$ ), which becomes more prominent when the stomach is distended. Externally the stomach is seen as an elongated, slightly curved cone, smooth externally and of equal diameter throughout.

The oesophagus and stomach are held in position by folds of peritoneum (mesentery), which attaches them to the dorsal wall of the abdominal cavity, to the lungs, pericardium, and liver; and by the blood-vessels.

b. Minute structure. The walls of these viscera are composed of four layers or coats.

(I) The serous coat (Fig. I 86) is a layer of endothelium, lying on a very thin stratum of connective-tissue; the whole derived from the peritoneum, which encloses the organs.

(2) The muscular coat (Fig. $186 \mathrm{LM}$ and TMI) is arranged in 
two. lavers, one $(L, M)$ longitudinal, the other (TMI) transverse. The longitudinal layer is thicker in the oesophagus, and thins as it is continued to the pyloric end of the stomach. The circular layer, on the other hand, gains in thickness; both layers are of unstriated muse'ular fibre.

(3) The submucous coat (Fig. $186 A, B$, and $S M$ ) is better developed in the stomach than in any other part of the alimentary canal. It is formed of a wide-meshed, loose connective-tissue, which supports numerous blood-vessels and lymphatics. Towards the mucous coat it possesses a well-differentiated Muscularis mucosa, which is arranged in two layers, a longitudinal $(B)$ and a transverse $(d)$.

(4) The mucous coat is possessed of numerous tubular glands, which vary in structure according to the part of the membrane examined. They have been the subject of much investigation (Heidenhain, Nussbaum, Partsch, Langley, and others), and are best described in three groups: those of the oesophagus, of the first part of the stomach, and of the pyloric end of the stomach the pyloric end of the stomac.
groups are transitional forms.

a. [The oesophageal glands are complete tubular glands lined by a single layer of epithelium, which very closely resemble the

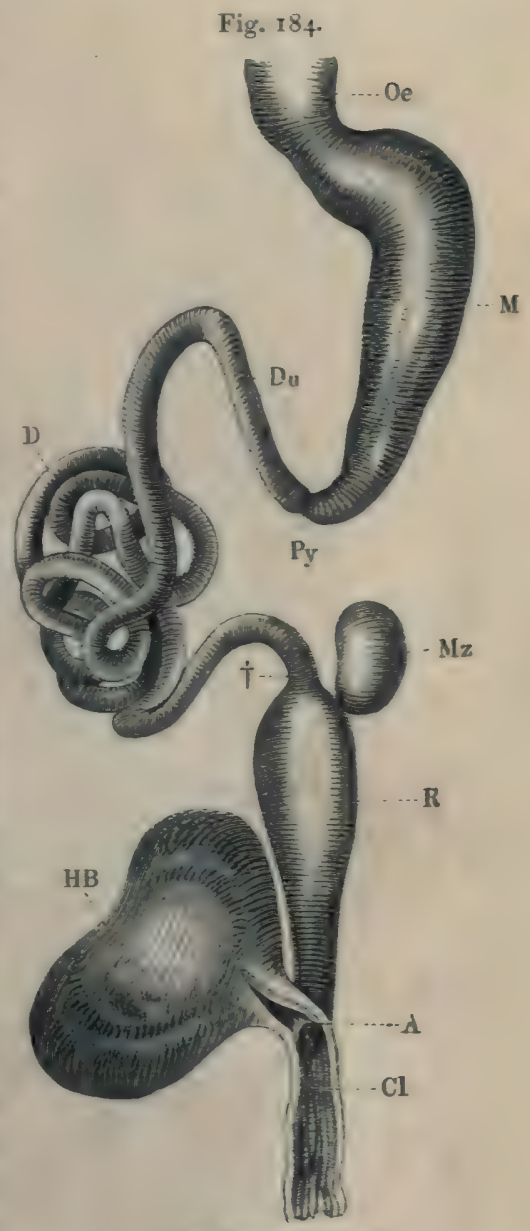

The alimentary canal.

A Opening of large intestine into cloaca.

cl Closca.

D Small intestine.

Du Du denum.

HB Urinary bladder.

N1 Stomach.

Hz Spleen.

Oe Oesiphagns.

Py Pylorus.

R Large intestine (rectum).

+ Junction of small and large intestine. 
glandular cells of the fundus of the stomach (Plate II, Fig. I 87). The cells are conical or cylindrical, the protoplasmic contents

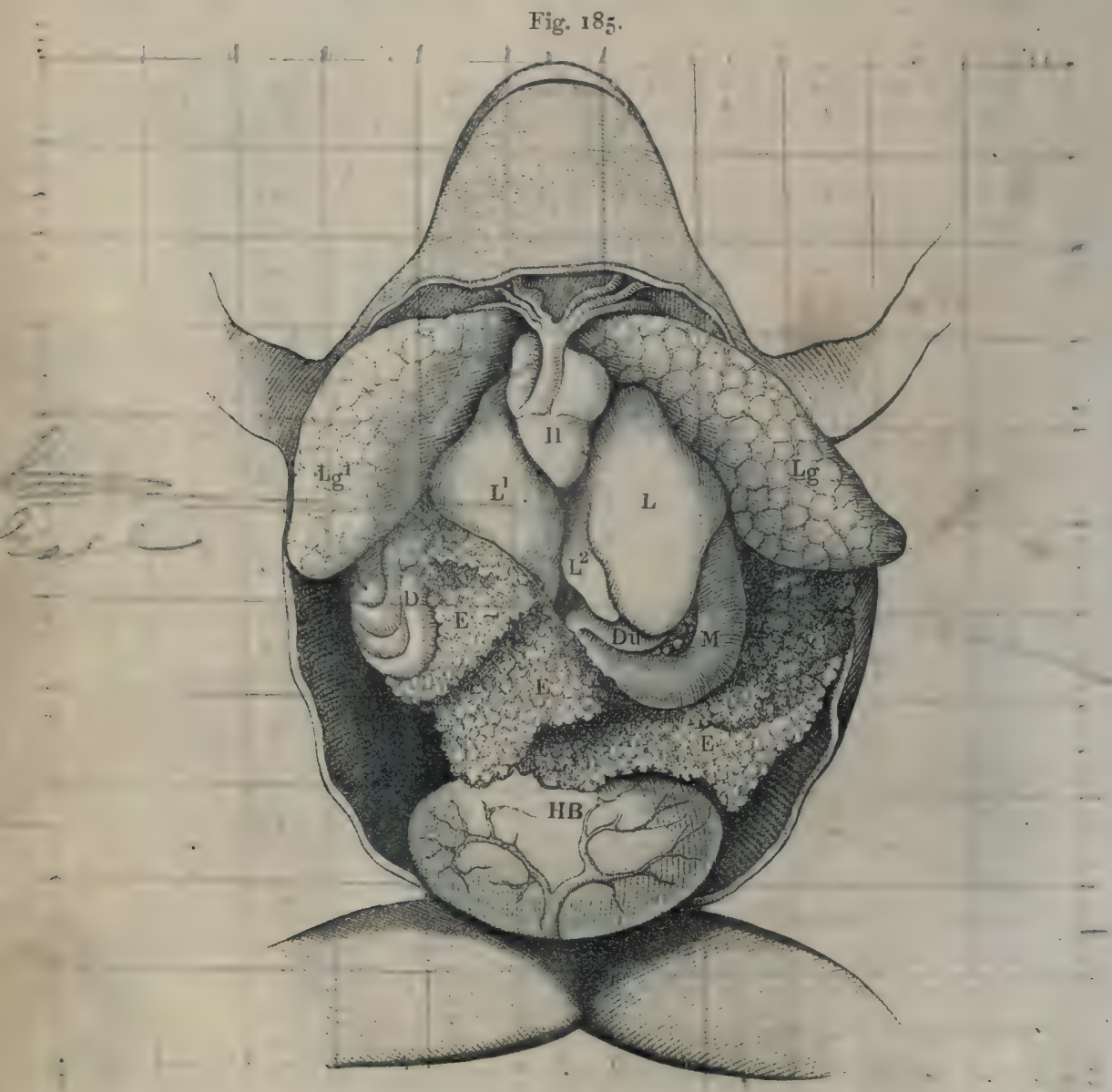

The abdominal viscera of Rana esculenta (female).

$\begin{array}{ll}D & \text { Snall intestine. } \\ \text { Du } & \text { Duodenum. } \\ E E & \text { Ovaries. } \\ H & \text { Heart. } \\ \text { HB } & \text { Urinary bladder. } \\ \text { L } & \text { Left lobe of liver. }\end{array}$

LI. Right lobe of liver.

$L^{2}$ Middle lobe of liver.

Lg Ieft lung.

Lgl Right lung.

M. Stomach.

granular, the granules being larger than those of the corresponding cells in the stomach (Langley). Mucous cells are found among the true secretory cells. The cells of the ducts are sometimes, but rarely, ciliated (Langley).] 
$\beta$. [The glands of the fundus of the stomach ${ }^{1}$ are not so complex as the typical glands of the oesophagus. The cells at the mouth of the gland are continued into fine processes (Fig. 187), and their. outer parts contain mucigen. The cells of the neck of the gland are more cubical, and towards the lower part of the neck are mucous cells. The cells of the body of the gland are of irregular shape, and so placed that the nucleus of one cell faces the junction of two cells on the opposite side (Langley). These cells are very finely granular.]

$\gamma$. [The glands of the pyloric end of the stomach have been compared with the mouths and necks of the glands of the fundus (Partsch, Langley). The cells are of two kinds only (Fig. I88). The cylindrical cells of the surface of the stomach are continued into the gland, where they become shorter and sub-cubical; these form the greater part of the gland. The rells at the

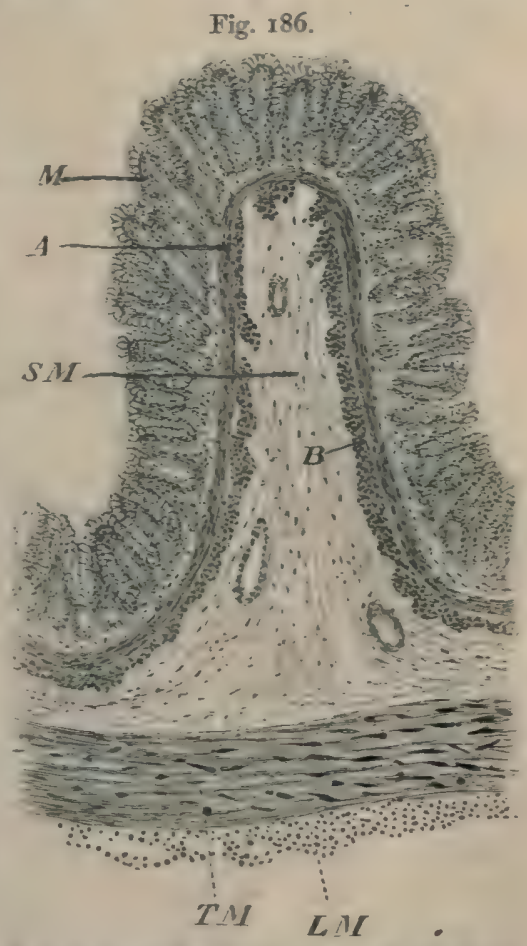

Trannverse sectiun through one of the longitudina folds of stomach of Reun temperuria. To show general arrangement of the walls. -G. H.

A Transvere layer of muzcularis mucoeae.

B Longitudinal laser of musiularis mucosae.

L.JI Longitudinal imeseular mat.

II Muems ntembrant.

S.I Subinuerns ent.

T. T Transrewe museular onat.

deepest portion of the gland are more rounded, and resemble the mucous cells in the neck of the glands of the fundus.]

$\delta$. [Between these well-marked groups of glands are various transitional forms. The transition from oesophageal to gastric glands is not a continuous one, as glands resembling those of the stomach can be found nearer the oesophagus than other glands, which

1 A transrerse section through the mueons membrane of the fundus of the stomach of Rana eseulenta is shown in Plate II, Fig. 18\%. Aleohol preparation, doulbly stained with carmine and anilin blue. After Biedermann. Obj. II, Srst. ;, Hartnack.) 
more nearly resemble oesophageal glands. At the same point the mucous membrane is thinner than either in front or behind. In

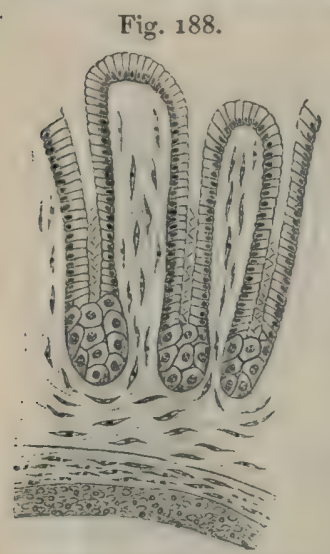

Transverse section through the mucous membrane of the pyloric end of the stomach of Rrina esculenta. After Partsch. (Obj. 11, Syst. 7, Hartnack, ) the same way an intermediate zone exists between the typical glands of the fundus and pylorus of the stomach.]

In both oesophagus and stomach the mucous membrane is thrown into longitudinal folds when the organs are empty. The epithelium of the surface of the oesophagus is mostly ciliated, and possesses numerous goblet cells; according to Klein the cells are not set vertically on the subjacent submucosa, but obliquely.

[The epithelium of the surface of the stomach is, at least in part, ciliated (Regéczy, Trinkler, and others), and has numerous goblet-cells (Schultze, Heidenhain, Bleyer, Eimer, Oedmonson, and others).]

(5) [The nerves of these organs, according to Gonjaew, contain both medullated and non-medullated fibres, which have nerve-cells attached to them. From these fine branches pass, either with the blood-ressels or alone, to the mucous coat, losing their medulla on the way. In this course they inosculate very freely, and are then distributed as very fine, beaded fibrils to the glands and epithelium, which are very richly supplied.]

(6) [The blood-vessels and lymphatics very closely resemble the corresponding structures in the small intestine ( $p .290)$; the bloodvessels form a rich anastomosis in the submucous membrane; the lymphatics are arranged in two systems, one under the serous coat, and a larger system in the mucous and submucous coats. The oesophagus lies free in a peri-oesophageal lymph-sac (Robinson).]

\section{The Small Intestine.}

a. General description. The small intestine commences behind the middle of the abdomen at the pyloric end of the stomach, from which it is marked off by a slight constriction. The first portion of the small intestine is the duodenum (Figs. 184 and $194 D u$ ); by means of an abrupt turn it winds directly forwards, parallel to the long axis of the stomach; the pancreas is placed in the loop so formed.

The whole of this portion of the intestine, together with the 
greater part of the stomach, is, in the normal condition, under cover of the liver (Figs. 185, 194): whlle under the liver the intestine is firmly attached to the deep surface of that organ by a short but strong Ligamentum hepato-duoulenale; it then turns suddenly backwards, increases in size, and by means of numerous convolutions occupies a considerable portion of the right half of the abdomen (Fig. 184 D). It is held in position by a well-developed mesentery.

b. Minute structure. Like other portions of the alimentary canal, the small intestine is formed of four lavers:-

(1) The serous coat presents no peculiarities; it consists simply of a larer of endothelial cells, with a small amount of sub-endothelial connective-tissue.

(2) The muscular coat is in two layers, the outer longitudinal layer being very thin, the inner circular layer thick.

(3) The submucous layer resembles that of the stomach, but is not so thick; the muscularis mucosae is well developed and arranged, as in the stomach, in two layers.

(4) The mucous coat (Fig. 189) is thrown into folds, which differ in various parts of the tube.

The longitudinal folds of the stomach are compressed together towards the pyloric end of the stomach $(a)$ and diminish in size; at the commencement of the duodenum they end abruptly $\left(a^{1}\right)$, but without any indication of a valvular arrangement.

Immediately beyond the pylorus the mucous membrane is folded so as to form an irregular network of folds which inclose irregular alveoli; the folds are thicker on the concave surface of the duodenum, and form a longitudinal ridge $(b)$; in this ridge the alveolar spaces are much smaller than those to either side. The irregular folding extends through two to three $\mathrm{cm}$., when a more regular arrangement commences in the form of two adjacent series of transverse folds $\left(c, c^{1}\right)$. Each fold is semi-lunar in shape, with the convexity attached to the wall of the tube and directed forwards, while the concave free border and pocket-like space enclosed are directed backwards.

The arrangement of these folds reminds one of the semi-lunar valves of the human heart, and probably one of their functions is to prevent the regurgitation of the chyme (Wiedersheim).

The corresponding valves of opposite sides meet at each end at an angle, the apex of which is directed away from the stomach. On 
Fig. 189 .

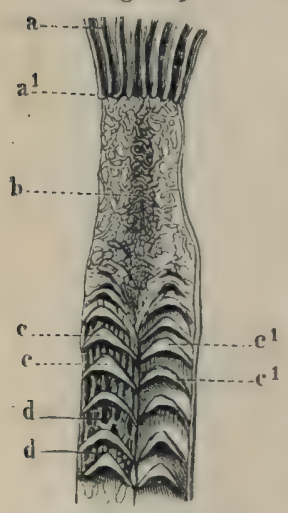

Mucous membrane of the pyloric end of the stomach and the duodenum.

a Mucous membrane of the stomach.

a Conmencement of duodenum.

$l \quad$ Duodenal nucous membrane arranged in irregular network.

$c$, Semi-lunar folds of the

$c^{i}$ i mucous membrane.

d Longitudinal folds of the mucous membrane.

these folds and between them are smaller, secondary folds, partly irregularly arranged, partly longitudinal $(d d)$.

Towards the middle of the small intestine this valvular arrangement is lost, to be replaced by an irregular net-like folding; beyond this longitudinal folds arise, which proceed in a sinuous course towards the large intestine.

The whole mucous membrane, both on the folds and otherwise, is covered with a simple layer of columnar epithelium, which is continued into numerous simple follicles (glands of Lieberkühn) found throughout the mucous membrane of the small intestine. The cells are placed on a basement membrane, which rests on a thin layer of loose connective-tissue, intervening between the epithelial coat and the muscularis mucosae. The epithelial cells are intermixed with a large number of gobletcells, and have between them fine processes from the connective-tissue corpuscles of the subjacent layer; many of these processes extend to or even beyond the free margin of the epithelial cells.

The individual cells are columnar, possessed of a well-marked cell-wall, and have distinct, large, oval nuclei, containing one or more nucleoli. The protoplasmic contents are granular, and with proper treatment show a very distinct intracellular network. The free margins of the cells are sharply marked off from the cell-contents, and are more firmly attached to the corresponding portions of adjacent cells than the rest of the cell-wall. This margin has a longitudinal striation, which owing to the important function performed by this part of the intestine, namely, absorption of the fat, has been the subject of many important investigations.

[In the following brief summary of the earlier researches on the minute structure of the intestinal epithelium, in which the intestine of the frog was chiefly used, the memoirs in which these investigations are recorded are referred to in the order of time.

1837. Henle first described the border as a thickened, highly refractive portion of the cell-wall.

1855. Kölliker and Funke, after independent research, described the longitudinal 
striation : Funke offered no explanation of the fact, while Kölliker considered it due to the presence of fine tubules. Later Funke gave a modified support to Küliker's view by admitting the presence of tubules around the circumferential part of the border.

I856. Donders gare a description corresponding with that of Henle.

I857. Brettauer and Ste nach gave it as the result of their investigations that the border was composed of closely-applied fine rods : $v$. Wittich first showed that the borders of adjacent cells were more firmly attached than the rest of the cell; he admitted the presence of apertures, but considered the whole appearance to be due to post-mortem changes.

Welcker and Friedreich agreed with the riews of Brettauer and Steins.ch, but traced the striation throughont the length of the cells, in fact traced the tubules to the connective-tissue below.

1858. In this year Heidenhain published his results; he held the striation to be due to the pregsence of fine rods, and was the first to show that processes of the connectire-tissue corpuscles passed up between the epithelial cells; he found fat globnles in the epithelial cells, in the ennnectire-tissue, and in the lacteals.

Friedreich described the striation as continued through the whole length of the cells, and as due to tubules.

1859. Lambl denied the presence of the rods, and considered the whole phenomenon an optical appearance due to the cell-wall; in this view he was supported by Vlakovich of Padua and Amici of Florence.

1860. Wiegandt held the border to be an independent covering, and the striation to be due to folding or wrinkling.

Col. Balogh deseribed the border as formed of rods, but denied that these existed except when brought about by the action of fats; in support of this riew he showed that the striation was wanting when fat was absent.

1865. Lipsky held the border to be composed of rods.

1866. Henle described the cells as in his former work, but now held the border to be composed of rods, in fact to represent a ciliated border.

186\%. Erdmann described the border as being of two layers, an upper, thicker layer, with both longitudinal and transverse striation, and a lower, thinner layer, the true cell-wall. The upper layer he described as capable of splitting in the directions of both striations.

Schultze deseribed the horder as not teing in intimate connection with the protoplasm of the cell. Arnstein and Wiegandt supported Heidenhain's description.

1868. Albini e Renzoni described the part as resembling resting eilia.

1869. Eimer traced fat-globules into all the partz, eyt thelium, connective-tissue, and vessels; and held that the fat could pass from a lacteal to a branch of the Vena porta. 18\%. Heidenhain, after further investigation, supported his earlier views.

IS 7 . Thanhoffer described the membrane as perforated, and the protoplasm of the cells as actively sending protoplasmic processes through these apertures; this he hal seen in frogs in which all connection with the spinal nerres had been serered.

I $S_{75}$. Benjamins could not find the stristion to be a constant occurrence, and failed

to find the processes described by Thanhoffer.

18;6. Krause found rod-like bodies ruund the margin of the border.

1877. Fortunatow supported Thanoffer's view.

188I. Landois observed appearances in Spelerpes fuscus, which led him to support Thanofier's views.

1883. Wiedersheim supported Thanhoffer's views.

1884. Wiemer supported Thanhoffer's observations.

1858. Paneth failed to find any contractile protoplasmic processes, and asserts that the circumference of the border, when examined under certain conditions, is composed of rods.

From the same causes the goblet- or chalice-cells, already mentioned, have been the subject of much speculation and investigation.

I846. Frerichs drew and deseribed these cells as empty cells.

In $\mathrm{I}_{4} 8$ these cells were first described as epithelium capitatum by Gruby and Delafond. 
In 1856 Donders described the cells as being open, and as discharging their contents into the canal; the cell-walls being then pressed together by the neighbouring cells, and the cell-contents being then gradually reformed.

In the same year Kölliker published results closely agreeing with those of Donders, and he traced the various stages of the process.

I 857 . Brettauer and Steinach held them to be cells which had lost their contents, and as the 'cuticular border' was absent, concluded that the cell-contents were in closer connection with the 'border' than with the rest of the cell-wall.

1865. Lipsky and Sachs both doubted the presence of such cells, and considered them due to the action of reagents or post-mortem change.

1866. Letzerich described the cells as open, and regarded them as the commencement of the lacteal system, while Dönitz thought the whole appearance due to reagents.

1867. Schultze and Eimer, independently, described them as unicellular glands.

Erdmann, however, again denied their occurrence under normal conditions.

Oeffinger held the goblet-cells to be mudified ordinary cylindrical epithelium cells ;

in which view he was supported by Arnstein.

1868. Schultze and Eimer, after renewed investigations, reiterated their former opinions.

1869. Eimer described the goblet-cells as secreting mucin, and as capable, by division, of throwing out pus-like cells.

I876. Krause described the cells as containing granular contents, which under certain conditions are thrown out.

1877. Tolldt considered them artificial productions. Edinger asserted that they are formed from the cylindrical cells.

1877-1885. Partsch (1877), Klein and Hebold (1879), Stöhr (1880), Patzelt (1882), Haller (1883), Holl (1885), support the last view.

1878. Hoffmann supported Schultze's views.

1886. List describes these organs as unicellular mucous glands.

I887. Paneth described them as secreting mucous and as being derived from the cylindrical cells.]

(5) [The blood-vessels of the small intestine (p. 234) have been described by Langer; he finds the vessels arranged in networks, one a subserous network, placed underneath the serous coat, and formed of elongated, irregular, four-cornered meshes. When the intestine is distended the meshes are rectangular.

The vessels to the mucous membrane divide and anastomose very freely in the submucous layer, and then form an irregular network on the inner surface of the Muscularis mucosa; this network follows all the foldings of the mucous membrane, and thereby supplies a double layer to each villous fold of the mucous membrane. The meshes are usually four-sided or five-sided.]

(6) [The lymphatics of the small intestine (Figs. I9o, 19r). The lymphatic vessels on reaching the intestine usually bifurcate; the two branches, as a rule, follow and enclose an arterial twig. From the serous layer they receive the contents of a very fine lymphatic plexus, the lumens of which are slightly greater than that of the corresponding capillaries; from the mucous layer they receive the contents of the lacteals: between these two layers the lymphatics anastomose very freely by means of numerous branches (Langer).

The lacteals are lined with an epithelioid laver and traversed by connective-tissue trabeculae, which have a like covering. The 
lacteals are not simple but in the form of a coarse network (Fig. 189), (Langer).]

(7) [The nerves of the small intestine (p. 200) usually follow the arteries to the muscular coats, between which they form a plexus (Auerbach's plexus); from this numerous twigs are given off, which course alone or in company with ressels to the mucous coat, where a second plexus (Meissner's plexus) is formed. Auerbach's

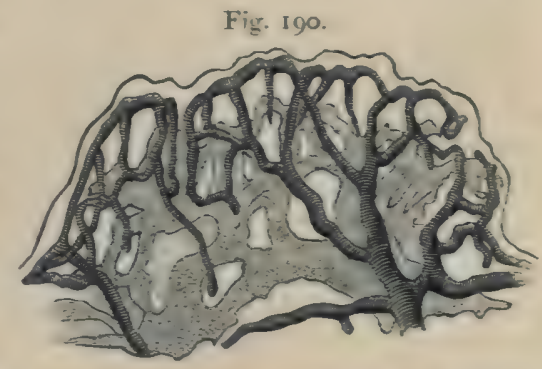

Isolated fold of nuerus membrane of small intestine of Rana temporiria; after Langer. Funty times natural size. Blood-ressels striped, lacteals shaded. plexus, according to Klein, consists of bands of nervous fibrils in endothelial sheaths; they branch and inosculate, and thus form a plexus. Where sereral such branches meet, a more or less complicated decussation of the bands of fibres takes place. Along these nerrous bands are ganglion cells, either isolated or in groups. The cells are large, generally spherical, and contain a sharply outlined nucleus with a single or double nucleolus. The smaller cells generally appear to possess only one process, which can be traced from the protoplasm of the cell between the fibrils of the nerve-trunk. The larger cells are distinctly multipolar, their protoplasm being provided with a number of fine processes, or, as is oftener the case, with one large and several small processes. In many instances Klein was able to distinguish around the ganglion-cells a capsule of a spherical or ovoid shape. In these cases the body, as well as the processes of the ganglion-cell, were lying within the capsule. This system of ganglioncells is in connection with the individual bundles within the nerve-trunks.

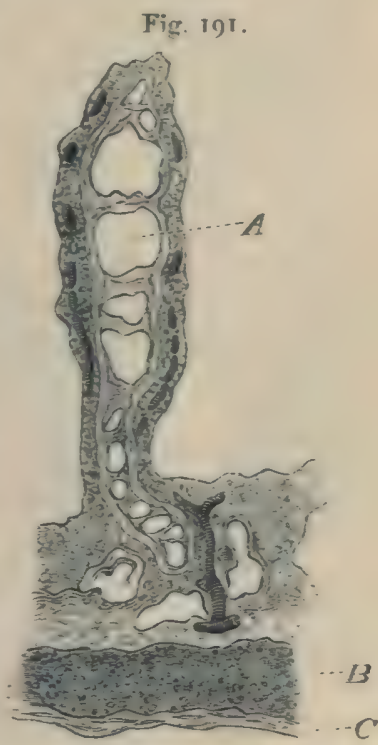

Transverse section of a fohl of the muevtus nembrane of Rant tampnrarin: after Langer. Sixty times natural size.

1 Lactoals with transverse trabeculae.

$B$ Cireular masenlar laver.

C I.mgitudinal unuseular layer. Blowhl-vewels strijed. 
Klein describes a second system of ganglion-cells, situated in meshes, which are formed by the nerve-trunks of the plexus itself. These ganglion-cells are much larger than the former, and are multipolar; their protoplasm, which is distinctly fibrillar, with granules between the fibrils, is provided with one or two long, thick processes and several short and thin ones; generally the processes are branched. The general shape of the cells is oblong, the thick, long processes being commonly at the two opposite poles. The cells are generally isolated, sometimes situated in the centre of a mesh, or more commonly near a nerve-trunk that borders the mesh on one side. Each ganglion-cell

Fig. I92.

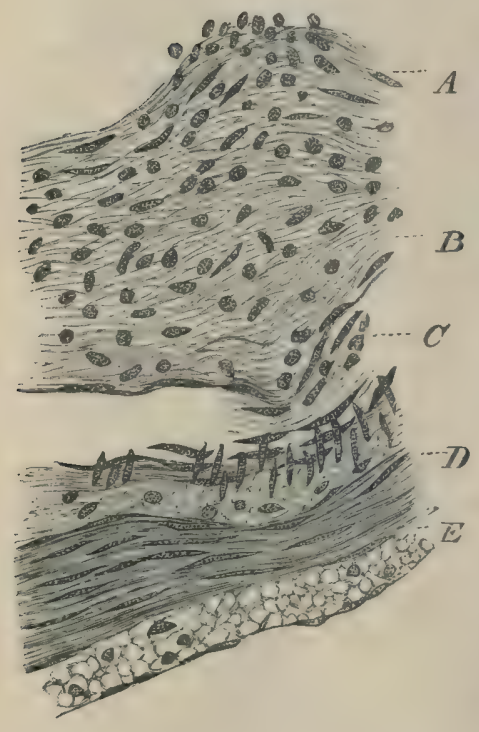

From a transverse section of the large intestine of Rena temporaria, moderately distended. -G. H.

$A$ Denser portion of submneus coat.
$B$ Looser portion of submucous coat.
$C$ Artery, cut obliquely.
$D$ Circular muscle-layer.
$E$ Longitudinal muecle-layer. is connected with a nerve-trunk of the plexus by at least one process. In a few of the nervetrunks of the general plexus, isolated medullated nerve-fibrils are seen to pursue an almost straight course from one trunk into another and divide into two. There is no connection between these medullated fibres and the ganglion-cells.

Auerbach's plexus is a much finer plexus than that just described, and the ganglia are much smaller. It supplies twigs to the Muscularis mucosa; these break up into fine fibrils, which follow the direction of the muscle-fibres; other twigs supply the bloodvessels, with which they can be traced into the bases of the folds of mucous membrane. Thanhoffer has recently $\left(l . c_{*}\right)$ described nervefibrils, which terminate in the mucous epithelium.]

\section{The Large Intestine (Fig. $\left.{ }_{1} 84 R\right)$. m}

a. General description. The large intestine is a flask-shaped viseus, lying in the median line. The small intestine opens into it 
by an abrupt curve at its anterior end. The large intestine is the widest part of the alimentary canal, is thin-walled, and diminishes in width towards its hinder end, where it opens into the cloaca above the opening of the bladder.

b. [Minute structure.

(I) The serous coat resembles that of the small intestine, ete.

(2) The muscular coats resemble those of the small intestine, but are thinner; the longitudinal layer is, however, proportionally thicker (Wiedersheim).

(3) The submucous coat (Fig. I92) resembles that of the small intestine in its general structure; the portion lying immediately beneath the mucous membrane $(B)$ is denser in structure.

This layer has no Murcularis mucosa.

(4) The mucous coat $(A)$ is a simple layer of large, columnar, epithelial cells, with large oval nuclei. The cells have a hyaline free border, but this possesses no striation. The mucous membrane is usually described as possessing numerous simple follicles (glands of Lieberkühn); in those specimens which I have examined they have been entirely absent (Figs. 192, 193). At six to eight points in a transverse section of a rectum moderately distended the submucous coat is thinner, and so throws the mucous coat into slight, longitudinal grooves; but these do not in the least resemble the glands of Lieberkühn.

(5) The epithelium possesses gobletor chalice-cells (Hoffmann), the number of which probably depends upon the period of the year and the state of digestion. In the rectum, from which the section for the figures 192 and 193 were cut, not one goblet-cell was found in a complete series of sections.

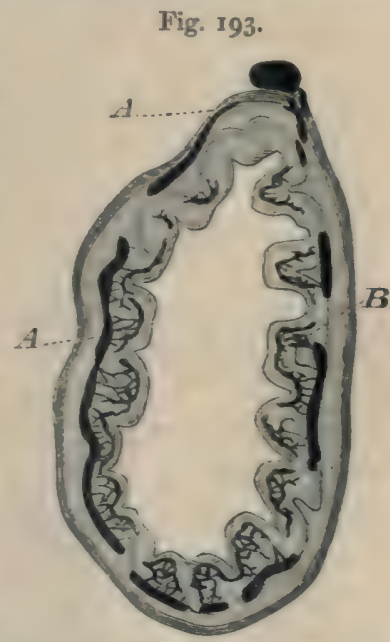

Transverse section of large intestine of kunu esculentu; the mutous membrane thrown into longitudinal folds in conseyuence of the urgan being contricted. Arteries injected with carnine. - G. H.

4 Large cirvular vessels within the musenlar coats.

$B$ Fine anastumusis to the mucons cont.

If the rectum be contracted, the mucous membrane is thrown into longitudinal folds. 
(6) The blood-vessels (Fig. 19.3) have a simple arrangement. The arteries are large, and form oblique loops around the intestine, lying under the peritoneum; from these branches are given off to form a series of rings in the submucous membrane (Fig. I93 $A$ ); from these fine twigs are given off to form a fine anastomosis under the mucous membrane $(B)$.

(7) The lymphatics of the large intestine are arranged in two chief systems : one under the serous coat resembles the corresponding system of the small intestine. The second set forms a network of rounded loops in the submucous coat, which give rise to a secondary set of smaller vessels towards the mucous membrane; this secondary system forms a sort of trellis-work standing on the rounded loops, and so maps out small blocks of the thick submucous coat. Towards the cloaca the arrangement is simpler; the secondary lymphaties are lost, while the primary lymphaties tend to form elongated, longitudinal loops (Langer).]

\section{THE GLANDS CONNECTED WITH THE INTESTINAL CANAL.}

\section{A. The Liver and Gall-bladder,}

a. External form.

(1) The liver (Figs. 185, 194) is a large, reddish-brown organ, occupying a large part of the anterior abdominal region. It consists of three or more lobes, which present many individual variations ; as a rule there are two larger lateral lobes $\left(L\right.$ and $\left.L^{1}\right)$, and a smaller median lobe $\left(L^{2}\right)$. Each lobe has a superficial or ventral surface, which is convex, and a deep or dorsal surface, which is concave and directed towards the other abdominal viscera lying above the liver. The two surfaces of each lobe meet to form a sharp border around the lobe, except where the three lobes are more intimately attached, opposite the apex of the heart (Figs. 185 , 194); at this place each lobe possesses a small, flat, or slightly concave anterior surface.

The left lobe $(L)$ hides the greater portion of the stomach, and has near its inner border a deep fissure, which runs forwards and 
so marks off a more or less well-marked fourth lobe: The anterior portion of the left lobe is attached to the corresponding portion of the right lobe by a narrow commissure.

The median lobe $\left(l^{2}\right)$ extends backwards as far as the pylorus, and covers the commencement of the intestine together with the pancreas; these organs can, therefore, not be seen until this lobe is displaced. A fifth lobe is sometimes found on the dorsal surface of the median lobe, and to it or to the dorsal surface of the median lobe the small intestine is attached by the ligamentum hepato-duodenale (Fig. $195 \quad$ Lhp ). The Vena portarum enters the liver behind this ligament.

The right lobe extends much further dorsalwards than the left lobe, and even comes in contact with the lung, the

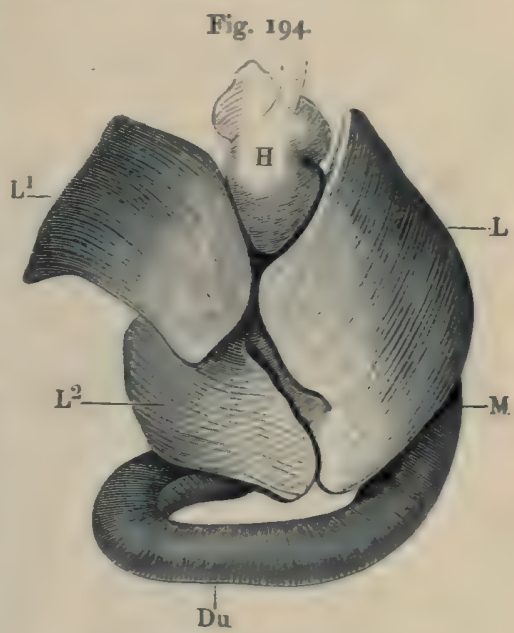

The liver, soen from the ventral surface.

$$
\begin{array}{ll}
\text { Du } & \text { Duodepum. } \\
\boldsymbol{H} & \text { Fleart. } \\
L & \text { Left lobe of liver. } \\
L_{1} & \text { Right lobe of liver. } \\
\boldsymbol{L}^{2} & \text { Middle lobe of liver. } \\
M & \text { Stomach. }
\end{array}
$$
vessels of which sometimes indent its surface in spirit specimens. This lobe is also in contact with the base of the fat-body, and in females with the oviduct.

By drawing the lobes of the liver to either side and displacing the heart towards the head, the posterior caval vein is seen passing from the liver to the heart, and the hepatic commissure joining the lateral lobes is brought into view.

(2) The gall-bladder (Fig. 195 G) is placed on the dorsal surface of the liver in the deep niche between the right and left lobes; it is attached to the liver by connective-tissue and peritoneum.

The gall-bladder is round or oval in form; when moderately full it has a smooth, outer wall, which is thin and allows the green colour of the bile to be seen. It possesses a duct $\left(D_{c y}\right)$, the cystic duct (Ductus cysticus), which bifurcates near its origin.

The two cystic ducts (Fig. $195 \dot{D} c y$ ) join the larger hepatic ducts, as shown in the figure, and so form a simple anas- 
tomosis, from which three branches (3) of varying size unite at the anterior extremity of the pancreas to form the common bile-duct

Fig. 195.

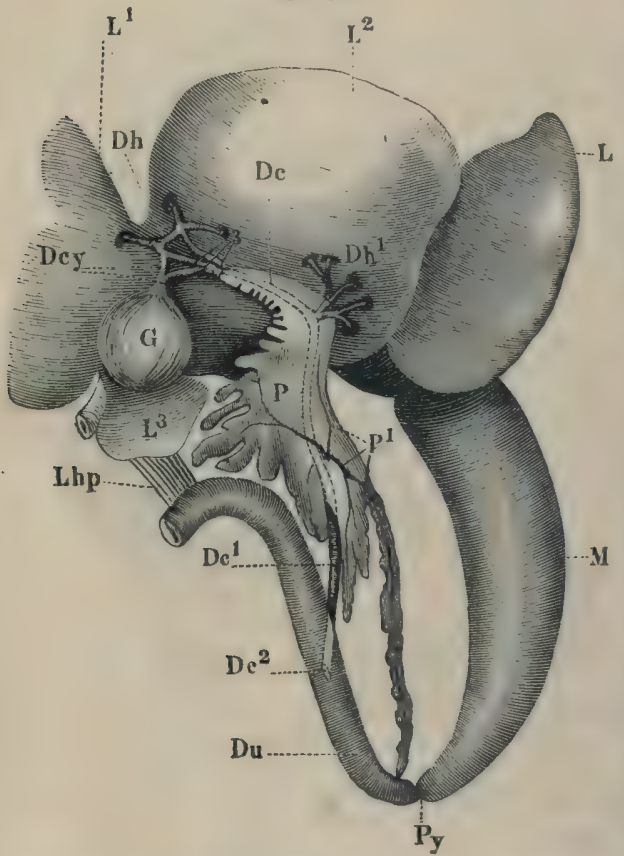

The pancreas and bile-canals. The liver has been displaced towards the head.

Dc Common bile-duct.

$D c^{1}$ Common bile-duct after leaving the pancreas.

$D c^{2}$ Opening of the common bile-duct into the duodenum.

Dey Cystic ducts.

Dh Hepatic ducts.

Dh1 Supplementary hepatic ducts from the middle lobe of the liver.

Dhe Duodenum.

$G$ Gall-bladder.

$L \quad$ Left lobe of the liver:

L1 Right lobe of the liver.

$L^{2}$ Middle lobe of the liver.

$\boldsymbol{L}^{3} \quad$ Fourth lobe of the liver.

Lhp Gastro-hepatic ligament.

MI Stomach.

$P$ Pancreas.

$\boldsymbol{P} y$ Pylorus.

P1 Ducts of the pancreas.
(Ductus choledochus, Dc). The common bile-duct runs through the whole length of the pancreas, receiving near its origin additional hepatic ducts $\left(D \iota^{1}\right)$ from the middle lobe of the liver. . In this course the duct lies either on the ventral surface of the pancreas or under a thin layer of the glandular tissue; it receives the ducts of the pancreas and leaves that organ at its posterior border as a round and strong canal $\left(D c^{1}\right)$. The duct courses in the gastro - duodenal ligament, and reaches the dorsal surface of the duodenum at a very acute angle; it then pierces the wall obliquely and terminates with a slit-like or elongated oval opening.

b. Minute structure.

(I) The liver is composed of various tisiues : it possesses a peritoneal covering, a fibrous covering, which supplies trabeculae to support the various other tissues, blood-vessels, hepatic cells or true liver parenchyma, and bile-canals.

a. The peritoneal covering of the liver encloses the organ almost completely, the only exceptions being where the various 
attachments of the liver are found (see peritoneum). The peritoneal covering of the liver is for the most part composed of flattened, ciliated cells (Neumann and Grunau); on the middle lobe these are, however, more or less replaced by non-ciliated cells. The thickness of these cells varies considerably, according to the amount of distension to which the liver is subjected.

$\beta$. The flibrous covering of the liver is very thin and very difficult to demonstrate; it consists of connective-tissue fibres with very few corpuseles. This covering is prolonged into the liver along the portal canals, where traces of connective-tissue can always be made out.

From these processes and from the whole of the inner surface of the general connective-tissue capsule are given off fine trabeculae, in which it is rery difficult to find any nuclei; these trabeculae are everywhere extremely delicate and difficult to demonstrate; nowhere do they form distinct boundaries between lobuli: the structure closely resembles the sustentacular tissue of a lymphatic gland (Eberth).

$\gamma$. The blood-vessels to the liver are the portal ressels (p. 249), the hepatic veins (p. 247), and the hepatic $\operatorname{artery}^{-1}$ (p. 233).

(1) The portal vessels pass into the liver on its ventral surface; they divide into branches which course along the middle parts of each lobe and give off smaller branches in all directions towards the periphery; the interlobular branches (Fig. I96 I) forming a very complex capillary network. As compared with the hepatic reins (Fig. I96 II), the interlobular reins do not give off their capillaries so abruptly, but tend to supply these from small lateral branches. The portal veins are accompanied in their course by branches of the hepatic artery, and often by larger bile-ducts, and thus form portal canals. In no part do the portal (interlobular) veins or their branches limit the lobules by distinct rings of vessels, as seen in many higher animals. The interlobular veins and intralobular veins simply interdigitate with each other.

\section{See Plate II, Fig. Ig6.}

1. Partial injection of the liver from the portal rein (blue) : Rana isculenta, -G. H.

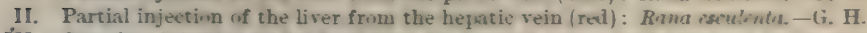

III. Cormplete injection of the liver frum the hepatic artery (rod) and from the portal vein (blue) : Rana caculenta. -G. $\mathbf{H}$.

\footnotetext{
1 Portal (interlobalar) veins and their branchea.

$\boldsymbol{B}$ Hepatic (intralobular) veins and their branches.

C Hepatic arteries and their branchea
} 
(2) The hepatic veins (Fig. I96 I and II) also course chiefly in the middle parts of the lobes of the liver; they branch, and ultimately supply intralobular veins which interdigitate with the interlobular veins (I and II). The capillaries arise very abruptly from an intralobular vein, and form a network of vessels communicating very freely with the corresponding capillaries of the interlobular veins.

(3) The hepatic arteries (Fig. I96 III) break up into small branches which, as a rule, course along the portal canal until near the surface of the liver, when they leave the portal veins and pass to the surface to supply the coverings of the liver. In their course along the portal canals they supply a few very small twigs to the structures forming the canals. At the surface of the liver the branches of the hepatic artery form capillaries, which empty themselves into the general eapillary anastomosis beneath (Fig. 196 III).

8. The liver-cells (Figs. I97, I98) are large, and of compressed spheroidal or polygonal shape. They possess no cell-wall, have usually one but sometimes two large nuclei, each with a distinct nucleolus. The cells often contain granules of glycogen or fatglobules. The main fibrillae of the intercellular network are arranged so as to extend between a bile-capillary and a bloodcapillary (Fig. I97).

є. The bile-ducts (Fig. I 98) commence as fine tubes between the liver-cells, where they are simply small spaces enclosed by the hepatic cells; they are usually enclosed by three or four cells, possibly sometimes by only two cells (Hering). Such bile-capillaries are usually separated from a blood-capillary by the thickness of one liver-cell only (Fig. 198).

As a number of such bile-capillaries run together to form a larger duct, the cells enclosing them change their character, becoming flattened and broader; these cells may, however, be traced continuously into the true hepatic cells (Hering and Eberth). The bileduct so formed then obtains a slight covering of fibrous tissue, which rapidly increases in quantity, courses along a portal canal, and receives other ducts on the way; the epithelium lining it gradually becomes more elongated, and ultimately resembles that found in the common bile-duct or the gall-bladder.

In the larger ducts the epithelium is, according to v. Brumn, 
ciliated; they also possess a layer of unstriated muscle-fibre (Eberth).

ऽ. The pigment of the liver varies very much in amount and character, according to the time of the year and state of health of the animal. According to Eberth the pigmentary masses are of about the same size as the white bloodcorpuscles, andare possessed of the power of amoeboid movement (in young animals): The cells possess two

Fig. 197.

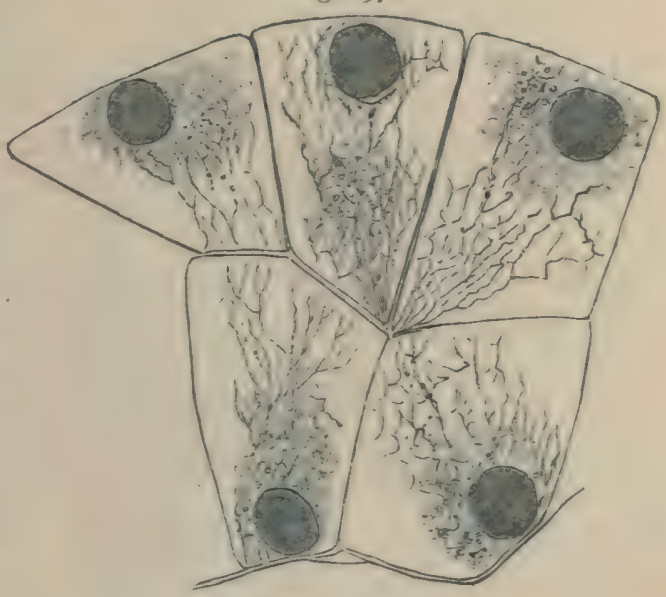

Liver-cell, after Kupfier.

to seven nuclei and vary much in colour and distribution. As a rule the larger the amount of pigment in a given liver the

Fig. $19^{8}$.

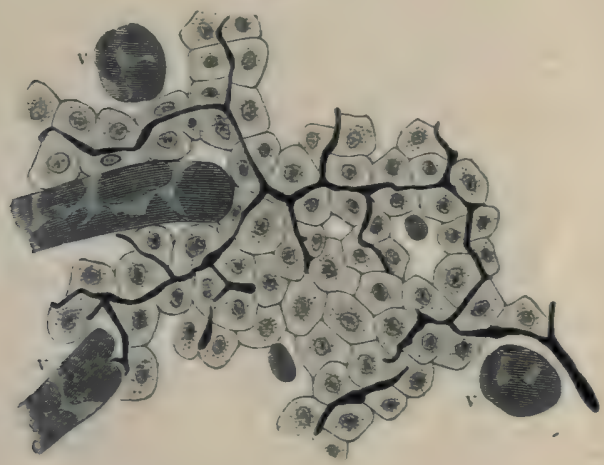

The bile-capillaries; natural injection with sulphindigotate of sodium: $v v$ represent blood-capillarien,-G. H.

smaller is the number of fat-globules found in the individual liver-cells (Eberth).]

(2) [The gall-bladder and bilo-ducts. The gall-bladder has four coverings. 
a. A serous coat of peritoneal endothelium.

$\beta$. A muscular coat, containing unstriated muscle-fibres and connective-tissue.

$\gamma$. A sub-mucous coat of areolar-tissue.

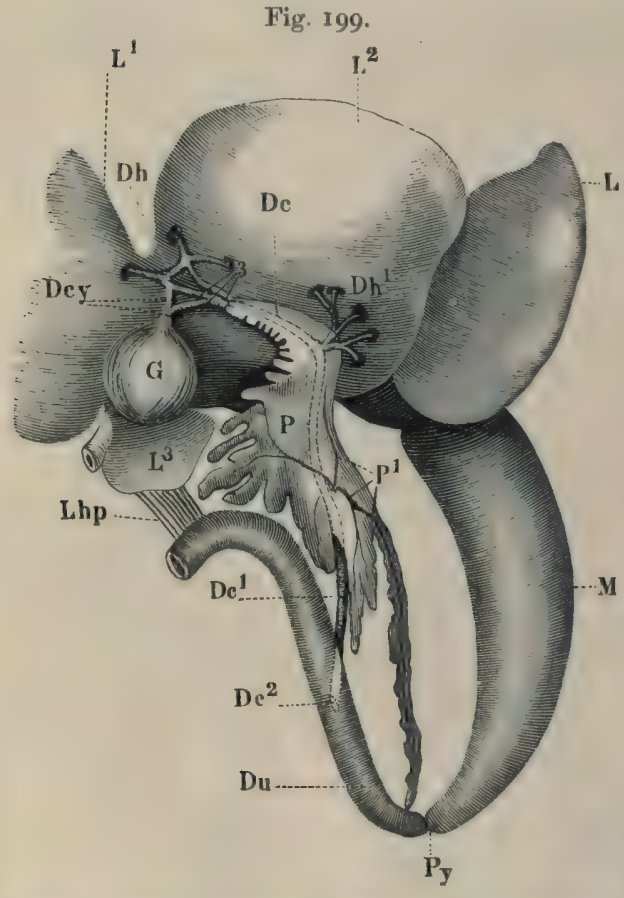

The pancreas and bile-canals. The liver has been displaced towards the head.

Dc Common bile-duct

$D c^{1} \quad$ Common bile-duct after leaving the pancreas.

$D c^{2}$ Opening of the common bile-duct into the duodenum.

$D c y$ Cystiv ducts.

Dh Hepatic ducts,

DhI Supplementary hepatic ducts from the middle lobe of the liver.

Du Duodenum.

$G$ Gall-bladder.

L1 Right lobe of the liver.

$L^{2} \quad$ Middle lobe of the liver.

$\boldsymbol{L}^{3} \quad$ Fourth lobe of the liver.

Lhp Gastro-hepatic ligament.

M. Stomach.

$P$. Pancreas.

PI Ducts of the pancreas.

Py Pylorus.
$L$ Left lobe of the liver.

8. An internal lining of columnar epithelium.

є. The walls of the gall-bladder are richly supplied with blood-vessels from the cystic arteries (p. 233); these form a close network in the submucous coat.

$\zeta$. The muscular and submucous coats also possess a rich nervous plexus, which contains ganglia and resembles Auerbach's plexus of the intestine (Popoff, Gerlach).]

B. The Pancreas (Fig. I99 $P$ ).

a. General description. The pancreas is a flattened, light yellowish - brown organ, placed in the loop of the duodenum between this latter and the stomach. The whole organ is within the gastro-duodenal ligament, and is attached to the liver; hence it is little influenced by changes in the amount of distension of the stomach or intestine.

The organ may be completely exposed by either of two methods: in the former, the liver, stomach, and duodenum are drawn towards the head and 
the dorsal surface of the organ so exposed. In the second method the liver is drawn backwards, the various peritoneal folds which connect the duodenum with the posterior border of the liver cut through, and the three organs then separated; the pancreas ean then be conveniently examined.

The size and shape of the pancreas are subject to great variations in different specimens. The usual shape of the organ is somewhat triangular (Fig. I99), the left border being usually unbroken, while the other two shorter borders are broken into lobes. The longest lobe stretches as far as the pylorus $(P y)$, to which it is attached by connective-tissue : the opposite extremity of the gland is attached to the liver.

The exeretory duct of the pancreas (Ductus Wirsurgianus) opens into the common bile-duct at about the middle of the pancreas $\left(P^{\mathrm{I}}\right)$; other smaller ducts may open into the same canal.

b. Minute structure. [The pancreas consists of a number of lobes loosely held together by connective-tissue ; each lobe is composed of a number of lobules attached to each other much more intimately. The lobules are made up of tubes lined by a single layer of glandular epithelium. This epithelium is, as a rule, broadly columnar, but in the smaller tubes may be cubical or polygonal. Each cell has a cell-wall, nucleus, and very granular protoplasm; the latter shows two zones (in the inactive condition), a granular zone near the lumen, and an outer, clear, and finely striated zone (Nussbaum). The lumen of each alveolus is very small, and in many cases difficult to make out.

The smallest ducts have no special lining, and are therefore bounded by the glandular cells; the darger ducts have a flattened, cubical epithelium, which when seen from the surface has an appearance as if the individual cells were widely separated from one another; these ducts have a considerable layer of connective-tissue around them. The largest ducts are lined with a layer of columnar, ciliated epithelium; the cilia are very long, usually of about the same length as the cell, sometimes appearing to be even longer. This epithelium is continuous with the ciliated, epithelial layer of the common bile-duet, which it resembles. These largest ducts have an extremely thick layer of connective-tissue around them.

The pancreas and its ducts are very richly supplied with vessels and nerves; the nerves forming everywhere a fine plexus, the larger strands of which usually, but not always, course with the larger 
blood-vessels. The larger ducts have an especially rich supply of nerves, of which fibrils may be traced towards the ciliated epithelium; an anatomical connection between the two has not, however, been made out.]

\section{THE SPLEEN.}

a. General description. Although the spleen belongs to the lymphatic system; it is considered here in order to complete the description of the abdominal viscera. It is a small, rounded-oval body, of a reddish-brown colour, suspended in the mesentery near the anterior end of the large intestine (Fig. $184 \mathrm{M} z$ ). In mediumsized animals the longer diameter is about $6 \mathrm{~mm}$., and is parallel with the long axis of the body; the shorter diameter is about $5 \mathrm{~mm}$., and the thickness varies from about $3 \mathrm{~mm}$. to $4 \mathrm{~mm}$. The dorsal surface is flat or slightly concave (Hilus lienis), and receives the relatively large afferent and efferent vessels; the rest of the organ is smooth and rounded, and with its greatest convexity directed towards the left side.

b. [Minute structure. The structure of the spleen resembles that of higher animals. It possesses a serous coat of peritoneum, under which is a flbrous coat; the latter sends in trabeculae, which divide and form a fine meshwork of supporting-tissue; the finest trabeculae are formed by the processes of the connective-cells of the sustentacular structure. According to Hoffmann, the thickness of the fibres averages $0^{\circ} 00 \mathrm{I}$ to $0^{\circ} \mathrm{Or} \mathrm{I} \mathrm{mm}$; the intervening spaces measure 0.002 to $0.012 \mathrm{~mm}$. The spaces are filled by the spleen pulp, which eonsists of true spleen-corpuscles, blood-corpuscles, and pigment-corpuscles.

The spleen-corpuscles have an average diameter of $0.006 \mathrm{~mm}$., and are round or of a rounded oval form. Each consists of a nucleus, with a very small amount of adherent protoplasm; the nucleus possesses one or two nucleoli. Some of these cells contain a brownish or black pigment in granules, but most of them are colourless (Hoffmann).

'The pigment-cells equal the white blood-corpuscles in size, and exactly resemble the corresponding pigment-cells of the liver.

The blood-corpuscles are found in various stages of disintegration and regeneration. 
The arteries, on entering the spleen, at once break up into branches which pass in all directions, giving off twigs on all sides and at varying angles; from these capillaries are supplied, which traverse the parenchyma in all directions. The capillaries empty themselves partly into veins, partly into the splenic spaces.

The veins commence either as capillaries in connection with the arteries or by communicating with the splenie spaces. This communication is brought about by small twigs of about $0.015 \mathrm{~mm}$. diameter, which have incomplete walls, and so open into the splenic spaces (Hoffmann).

Malpighian bodies are represented by collections of splenic cells on various arterial twigs; they are, however, not so sharply defined as is the case in some higher animals.]

\section{THE PERITONEUM.}

a General description. The peritoneum is a thin, pigmented membrane lining the abdominal eavity. Tracing it forwards from the ventral wall of the abdomen (Peritoneum parielale), it can be followed along the deeper surface of the muscles to the pericardium. The middle portion leaves the abdominal wall by accompanying the anterior abdominal vein ; the lateral portions are continued further forwards, and then ascend on the pericardium and the deeper surfaces of the lateral walls in the thoracic region.

The peritoneum passes thence to the ventral surface of the liver (Ligamentum coronarium), covers this surface and passes on to the dorsal surface of the organ, which, together with the gall-bladder, it completely encloses. The membrane thus reaches the dorsal wall (Ligamentum suspensorium hejatis et pericarlii); from the lateral borders of the liver it passes upwards to the dorsal wall, and thus forms a pocket-like pleuro-peritoneal cavity on either side.

From the dorsal wall and above the attachment of the coronary ligament of the bladder the peritoneum reaches the root of the lung on each side, and completely invests the organ: while in the middle line it covers the outer surface of the oesophagus and attaches it to the dorsal wall, thus forming the first part of the mesentery 
Just behind the root of the lung, the peritoneum, in female specimens, has an opening on each side (Ostium aludominale tubae F'allopiae), by which the oviduct communicates with the peritoneal cavity.

Tracing the peritoneum backwards, it passes over the ventral surface of the kidneys so as to exclude them from the peritoneal sac: in the middle line, between the kidneys, the peritoneum descends to form the mesentery for the small intestine. At the inner borders of the kidneys, the testes or ovaries are pushed into the abdominal sac, and so possess well-marked mesenteries; the mesovarium becomes longer towards the cloaca, but attains its greatest development in the breeding season, when it is arranged in numerous folds. Along the outer borders of the kidneys, in females, the peritoneum again descends into the abdominal cavities to enclose the oviducts, which have broad mesenteries. Towards the rectum these mesenteries are shorter and attached to either side of the bladder by a well-marked free border: as the middle line of the bladder is attached by the peritoneum to the rectum, two distinct pouches (Cava recto-resicalia) are formed, which descend deeply into the pelvic cavity. The upper walls of these pouches are pushed in between the urostyle and the rectum, and together form a strong meso-rectum, which is longer near the Valvula Baulinii and continuous with the mesentery of the small intestine. The hinder portion of this mesentery is very short, and only covers the lateral walls of the rectum.

With the exception of a small portion of its dorsal surface, which is attached to the rectum, the whole surface of the bladder is covered with peritoneum.

The mesentery of the alimentary canal commences in connection with the oesophagus between the roots of the lungs; it is attached to the dorsal surface of the liver, covering the posterior caval vein, and is attached to the gall-bladder. From this point it extends, as a free, arched fold, to the concave right border of the stomach, which is completely surrounded by peritoneum.

The gastro-duodenal fold (Ligamentum gastro-duodenale) extends from the stomach to the pylorus and includes the pancreas. The hepato-duodenal fold (Lig.hejato-rholenale) extends from the portal fissure of the liver to the duodenum.

The mesentery of the small intestine is broad and arranged in folds, which follow the curves of the intestine; and is attached in the middle line, immediately beneath the vertebrae, where it encloses the aorta. 
The varions folds and mesenteries carry the blood-ressels and nerves to the different organs; in this course the vessels are surrounded by large lymphaties, which communicate with each other.

Fig. 201.

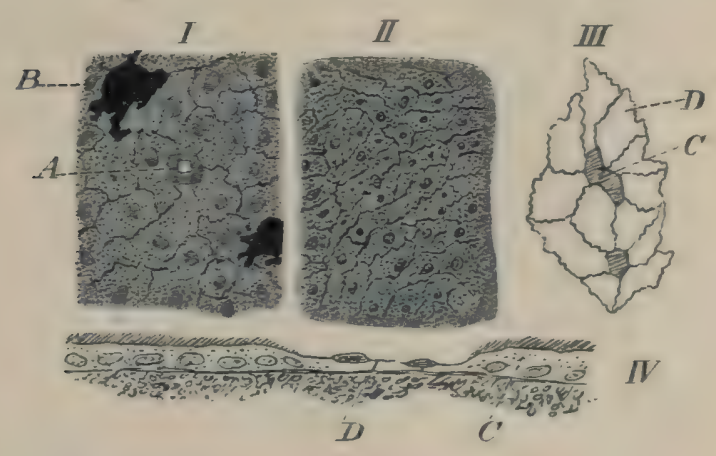

Preparations from the peritoneum of Rana eaculenla--G. H.

I. From peritunenm of the ventral wall of abdumen, stained with silver and lonwoud (Hartnaek, Oc. I, Sysat. 7).

II. From mesentery of small intestine of Rana esculentu, stained with silver (Hartnack, Uc. I, Syst. 7).

III. Preparation to show ciliated cells between non-eiliated cells; after Netumann.

IV. Vertical section at border of liver to show ciliated epithelium; after Nenmann.

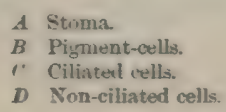

b. Minute structure (Fig. 20I).

[The peritoneum is a serous membrane, formed for the most part of a layer of irregular endothelial cells, arranged on a thin layer of subserous, connective-tissue (Fig. 201 I, II, and III).

The endothelial cells are attached to each other by cement-substance, easily stained by silver nitrate. The cells covering the general surface of the peritoneal cavity are larger and broader than those covering the mesentery of the small intestine (compare I and II, Fig. 20I).

At various points stomata are found, bordered by smaller and more deeply staining epithelium $(\mathrm{I}, \boldsymbol{A})$. The membrane covering the general cavity is also much more pigmented than that covering the mesentery (compare I and II).

Various portions of the peritoneal surface possess ciliated cells, 
and these cells are usually thicker than the surrounding non-ciliated cells. Such cells are found especially near the openings of the oviducts and on the liver. The dimensions of the cells vary; according to Neumann the average dimensions of ciliated cells on the liver are : $0.006 \mathrm{~mm}$. depth (without the cilia); nucleus, $0.012 \mathrm{~mm}$. long and $0.003 \mathrm{~mm}$. broad. The cells are five- or six-sided and bounded by straight sides (Neumann).] 


\section{SECTION VI.}

\section{THE LARYNX, LUNGS, TOCAL SACS, THYMUS AND THYROID GLANDS, AND THE LYMPHATIC GLANDS (TONSIIS ?) OF THE HYOID REGION.}





\section{THE LARYNX, LUNGS, VOCAL SACS, ETC.}

\section{LITERATURE.}

\section{THE LUNGS AND LARYNX.}

Arnold, J., Zur Histologie der Lungen des Frosches. Virchow's Arch. 1863. Vol. XXVIII, p. 433.

Auerbach, L., Ueber den Bau der Blutcapillaren in den Lungen des Frosches und an einigen andern Orten. Amtlicher Bericht über die vierzigste Vergamminung deutseher Naturforscher und Aerate. 1886, p. 241.

Brittan, Brit. and Foreign Medico-chirurgical Review, I857. Vol. XX.

Eberth, C. J., Ceber den feineren Bau der Lunge. Zeitsehr. f. wiss. Zool. 1863. Vol. XII, p. 427 .

Eberth, C. J., L'eber den Bau und die Entwicklung der Blutcapillaren. Würzburger naturw. Zeit. 1866-67. Vol. VI, pp. 27-32.

Egorow, W., Ceber die Nerven der Lungen. Centralbl. f. med. Wiss. 18 $₫ 9$, p. 305.

Elenz, E., Ceber das Lungenepithel. Würzburger naturw. Zeit. 1864. Vol. V, pp. 66-84.

Frommann, C., Ceber die spontan, wie durch Durchleiten inducirter Ströme, an den Blutzellen v. Salamandra maculata und an den Flimmerzellen von der Rachenschleimhaut des Frosches eintretenden Veränderungen. Jenaische Sitzungsb. 1880 .

Gegenbaur, C., Ueber Drüsenzellen in der Lungen-Schleimhant bei Amphibien. Arch. f. Anat. u. Physiol. 1863, p. 157.

Griffini, L., Contribuzione alla patol. del tessuto epiteliale cilindrico. Arch. per le scienze mediche, 1884. Vol. VIII, pp. I-43.

Grütener, Physiologie der Stimme und Sprache. Hermann's Handb. d. Physiol. Vol. I, Pt. I, p. 146.

Henle, J., Vergleichende Anatomische Beschreibung des Kehlkopfes. Leipzig, I839.

Hoffmann, C. K., in Bronn's Klassen and Ordnungen des Thierreichs. Leipzig and Heidelberg, I873-78. Vol. VI, PP. 514-531.

Hoffmann, T., Die Lungengefässe der Rana temporarja. Dissert. Dorpat, 1875.

Holmgren, F., Cpsala Läkareförenings Förhandlingar, 186\%. Vol. III, pp. 389-399.

Howes, G. B., On a hitherto unrecognised feature in the larynx of the anurous amphibia. Proc. Zool. Soc. London, I887, p. 491.

Hūter, C., Ueber den Kreislauf und die Kreislaufsstörnngen in der Fruschlunge. Centralbl. f. med. Wiss, 1873. No8, 5 and 6.

Kandarazki, M., Ueber die Nerven der Respirationswege. Arch. f. Anat. u. Phys. I $88 \mathrm{I}$, p. I.

Küttner, Beitrag zu den Kreislaufsverhältnissen in der Froschlunge. Virchow's Arch. 1874 Vol. LXI, p. 2I.

Leydig, Anatomische-histologische Cntersuchungen über Fische und Reptilien. I853. 
Malpighi, De pulmonibus. Oper. omn. Lugd. Batav. I687. Vol. II, p. 328.

Müller, H., Ueber das Vorkommen glatter Muskelfasern in den Lungen der Amphibien. Wïrzburger naturw. Zeit. 186I.

Pertik, O., Untersuchungen über Nervenfasern. Arch. f. mik. Anat. I88I. Vol. XIX, p. 183 .

Ranvier, L., Leçons sur l'histologie du système nerveux. Vol. I, pp. 98-ror.

Schestopol, A., Ueber die Durchlässigkeit der Froschlunge für gelöste and körnige Farbstoffe. Virchow's Arch. 1879. Vol. LXXV, p. I99.

Schultze, F. E., Epithel und Drüsenzellen. Arch. f. mik. Anat. 1867. Vol. III, p. I45.

Schultze, F. E., Die Lungen, in Stricker's Handbuch der Gewebelehre.

Stirling, W., On the nerves of the lungs of the newt. Journ. of Anat. and Physiol. I 882 , p. 96.

Treviranus, C. R., Beobachtungen aus der Zootomie u. Physiologie; nach dessen Tode herausgegeben von L. C. Treviranus, Bremen, 1839.

\section{THE THYMUS GLAND.}

Ecker, Blutgefässdrüsen, in Wagner's Handwörterbuch der Physiologie, 1853. Vol. IV, p. II 4 .

Fleisch, చ., Ueber den Bau einiger sogenannten Drüsen ohne Ausführungsgänge. Wiener Akad. Sitzungsb. 1870. Vol. LX, Pt. II, p. 55.

Gegenbaur, Vergleichende Anatomie.

Hoffmann, C. K., Bronn's Klassen und Ordnungen des Thierreiches. I873-1 878 . Vol. VI, p. 503.

Leydig, Lehrbuch der Histologie, 1857, p. 422 .

Tolldt, Ueber lymphoide Organe der Amphibien. Wiener Acad. Sitzungsb. 1868. Vol. LVIII, Pt. II, p. I 7I.

Watney, H., The minute anatomy of the thymus. Phil. Trans. I882. Vol. CLXXIII, p. II00.

\section{THE THYROID GLAND.}

Baber, E. C., Researches on the minute anatomy of the thyroid gland. Phil. Trans. I $88 \mathrm{r}$. Pt. III, p. 577 .

Ecker, Blutgefässdrüsen, in Wagner's Handwörterbuch der Physiologie, 1853. Vol. IV.

Fleisch, E., Ueber den Bau der sogenannten Schilddríse des Frosches. Wiener Acad. Sitzungsb. 1868. Vol. LVIII, p. 57 .

Hoffmann, C. K., Bronn's Klassen und Ordnungen des Thierreiches. 1873-1878. Vol. VI, p. $5 \circ 3$.

Huxley and Martin, Practical Biology. 4th edit., 1877, p. 181 .

Leydig, Lehrbuch der Histologie. 1857, p. 376 .

Müller, J., Ueber die Entwicklung der Schilddrísen des Frosches. Wiener Sitzungsb. 1871. Vol. VI, pp. 428-553,

Müller, W., Ueber die Entwicklung der Schilddrüse. Jenaische Zeitschr. 187 I. Vol. VI, p. 438.

Ponicaré, Zur Anatomie der Glandula thyroidea. Journ. de l'anat. et de la physiol. 1877. Vol. XUI, pp. 123-143.

Rolleston, Forms of Animal Life. 2nd Edit. 1888, p. 77.

Zeiss, O., Mikroskopische Untersuchungen über den Bau der Schilddruise. Dissert. Strassburg, 1877 . 


\section{THE LARYNX, LUNGS, VOCAL SACS, ETC.}

\section{THE LARYNX.}

THE larynx (Fig. 202) is a short wide tube placed between the posterior cornua of the hyoid, to which it is attached by connective-tissue. The long axis of the tube lies in the median line and almost horizontally, but the posterior end is on a slightly lower level than the anterior, when the animal is in the natural sitting position (Fig. 202). The anterior end of the larynx opens into the mouth by a longitudinal slit (Fig. I79 $L$ ), and is placed in a slight depression caused by the folding of the mucous membrane; the posterior end communicates with the cavities of the lungs.

The larynx is Fig. 202.

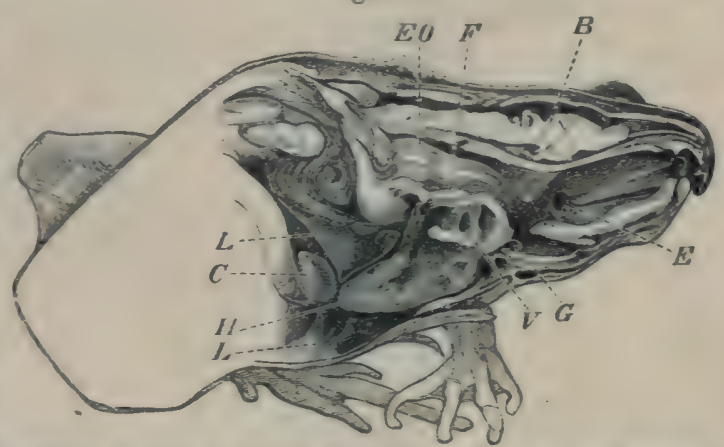

Dissection to show the pusition and relations of the larynx. The animal (Rama esculenta) is in the natural sitting position; the toes of the fore.foot are, however, too much flexed.-G. H.

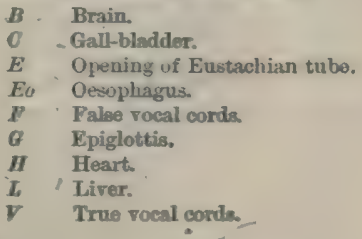

lined with mucous membrane, which is continuous, in front with that of the mouth, behind with that of the lungs. The organ has a skeleton of cartilage, and possesses special muscles, 
by which the supply of air to the lungs, and the voice can be regulated.

\section{a. The cartilages of the larynx.}

The cartilages of the larynx are five in number, of which four are paired and one is single.

(I) The cricoid cartilage (Figs. 203, 204) is an oval ring of cartilage with various processes. The ring-like portion of the cartilage is placed in a plane which is almost vertical, but which is directed slightly upwards anteriorly, and slightly downwards posteriorly (the animal being in the usual sitting position).

Fig. 203 .

I.

\section{C.1. $\mathrm{C}_{0}{ }^{1}$}

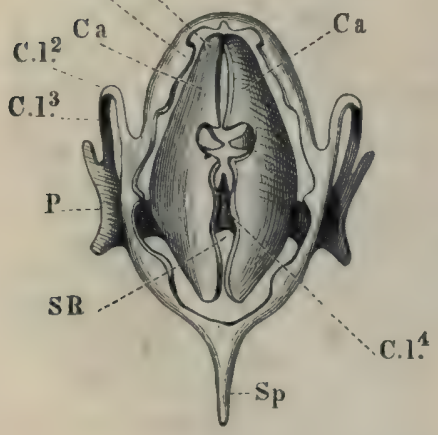

11.

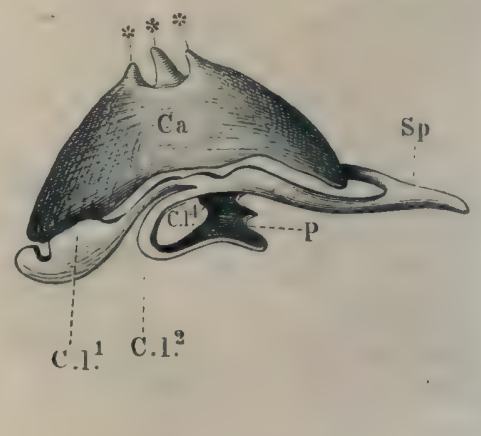

The cartilaginous skeleton of the larynx.

I. Seen from in front; the spinous process would normally be more curved.

II. Seen from the left side; the spinous process should be more curved.

Ca Right arytenoid cartilage.

Ca1 Left arytenoid cartilage.

C.l.L C.l.4 Cricoid cartilage.

P Lateral plate of cricoid cartilage.

Sp Spine of cricoid cartinlinge.
SR Opening to larynx.

* * * The two outer asterisks are above the two apices of the left arytenoid cartilage; the middle one above the pre-arytenoid carti. lage.

The sides of the ring are slightly curved inwards on the anterior surface, and possessed of irregular enlargements $\left(C . l_{0}{ }^{1}-C . l_{0}{ }^{4}\right)$, the space enclosed by this portion of the cartilage is occupied by a membrane $(M)$, which forms the floor of the body of the larynx.

From each side of the body of the cartilage, a process $\left(C . l_{*}^{2}\right)$ is given off, which curves backwards and inwards to join its fellow of the opposite side, the two forming a blunt spinous process $\left(S_{j}\right)$, which projects backwards, and is intimately attached to the oesophagus. Between these processes and the lower portion of the body of 
the cricoid cartilage are the apertures of the roots of the lungs (Fig. 203), which, by their attachments to these cartilages, are kept open.

(2) The arytenoid cartilages (Fig. 203 I, II, Ca, Call) are a pair of cartilages placed in front of the cricoid cartilage, one on each Fig. 204. side. Each cartilage is semilunar in shape, concave internally, and convex externally. The cartilages are placed almost vertically, with their posterior borders or bases parallel to the body of the cricoid cartilage. The superior borders (Fig. 204) are directed upwards and forwards, the inferior downwards and forwards. The superior and inferior borders are separated by a semicircular noteh, bounded by two sharp apices. The superior and inferior angles of the two cartilages are close together, and movably attached to each other by connective-tissue.

These cartilages vary very greatly in the two sexes. In the males they are thick, strong, and large ; in the female the cartilages are very thin, more hollowed and much smaller.

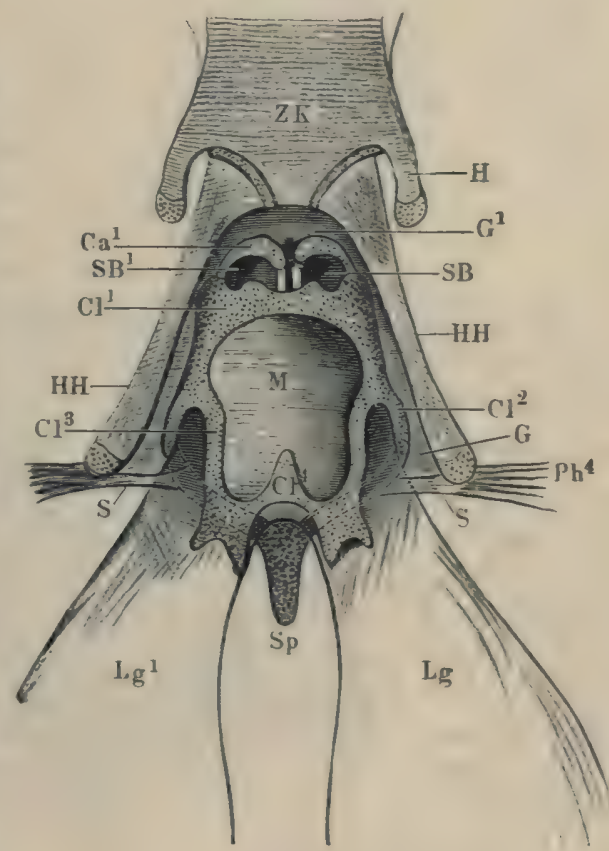

The larynx and surrounding parts, scen from the ventral surface.

Cal Arytenoid cartilages.

CA-CH Cricoid cartilage.

G, Gl Fibrous tisure connecting the laxynx with the posterior-cornua of the hyoid.

II Laser cormua of the hyoid.

HI Greater cornua of the hyoid.

Ly Right lung.

$L_{y j} 1$ Left lung.

ir Fibrulus membrane fill-

Pht The M. petrobyoideus tertius.

8 Part of tendon of $\mathbf{M}$. petrohyoidens. tertius.

$S B, S B 1$ Mncotus membrane bulging from the anterior ventricle of the larynx.

Sp Spinous process of the cricoid cartilage.

ZK Body of the hyoid. 
(3) [The pre-arytenoid cartilages (Fig. $206 \mathrm{I}, P$ ) are two small elongated cartilages placed in the semicircular notch between the superior and inferior borders of the arytenoid cartilages. They are subject to much variation in size, sometimes being merely a very slender rod, at others a moderately thick oval mass. In female specimens they appear to be, at times, absent, or to unite with the arytenoid cartilages, as in these cases a third very small apex is found on each arytenoid eartilage; but it is always much smaller than the two neighbouring apices.]

b. The attachments of the cartilages to each other.

The cartilages do not articulate directly with each other, but are connected by connective-tissue only; there are, therefore, no synovial sacs.

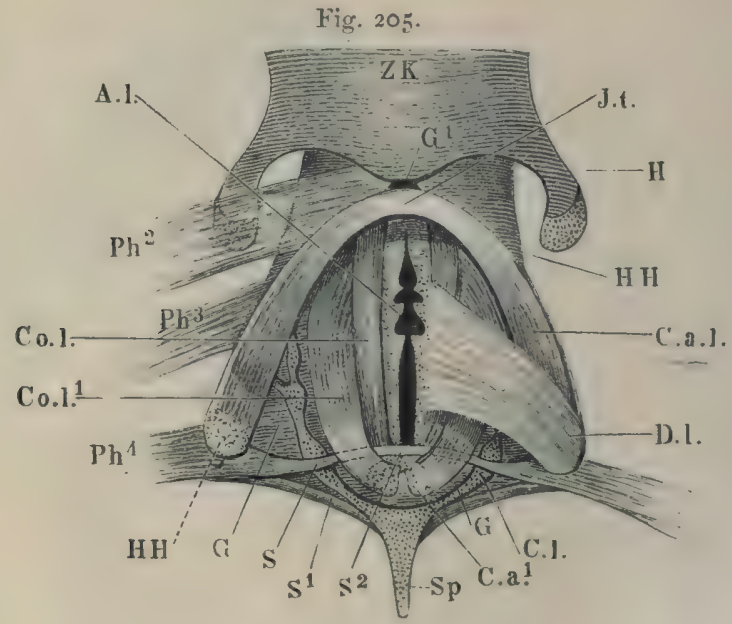

The muscles of the larynx.

A.l. Aperture batween the arytenoid cartilages.

C.l. Cricoid cartilage.

C.a. 1 Superior angle of the arytenoid cartilage,

C.a.l. M. constrictor aditus laryngis.

C.o.l. M. hyo-arytenoidens anterior.

C.0.l.1 M. hyo-arytenoideus postorior.

D.b. M. dilatator laryngis.

G Connective-tisene.

G1 Connective-tissue.

$H$ Smaller posterior cornua of the hyoid.
HH Greater cornua of the hyoid.

Jt Fibrous tissue into which the two constrictions are inserted.

Ph2 Seend petrohyoid umsele (M. petrohyoid.I).

$P^{3}$ Third petrohyoid muscle (M. petrohysid. II).

$P h *$ Fourth petrohyoid muscle (M. petrohyoid. III).

$S_{,}, S^{2}, S^{2}$ Tendon of the fourth petrohyoid musole.

Sp Spinous process of the cricoid cartilage.

$Z K$ Body of the hyoid.

c. The muscles of the larynx ${ }^{1}$.

The muscles of the larynx appear in the following order, when dissected from the mouth :-

1 The nomenclature adopted is that of Henle and Hoffmann. 
(1) The 1I. dilatator aulitus laryngis (Henle), (Fig. 205 D.l.) arises on either side from the hinder end of the larger posterior cornu of the hyoid: the fibres diverge slightly to be inserted into the middle portion of the outer surface of the arytenoid cartilage; a smaller bundle of fibres is attached to the deeper-lying constrictor muscle and to the cricoid cartilage.

(2) The M. constrictor arlitus laryngis (Henle), (Fig. 205 C.a.l.), arises on either side from the hinder half of the dorsal surface of the posterior cornu of the hyoid. The two muscles enclose the larynx, and are inserted into a median tendinous raphe on the under surface of the larynx $(J t)$. The raphe is connected with the skeleton of the larynx by connective-tissue.

(3) The .M. hyn-arytenoideus anterior (Fig. 205 C.o.l.) arises on each side from the inner border of the anterior end of the cornu of the hyoid; the muscle lies close to the anterior border of the arytenoid cartilage, and is inserted into a fibrous lamella on the dorsal surface of the larynx. The $\boldsymbol{M}$. pietrohyoinleus tertius is also partially inserted into this lamella.

(4) The M. petrohyouleurs tertius (Fig. $205 P h^{4}$ ), (see also p. 66). The greater part of this muscle is inserted into the end of the posterior cornu of the hyoid $(H H)$; a smaller portion $\left(S, S^{2}\right)$ is prolonged to be inserted into the cricoid cartilage and into the fibrous lamella into which the $\boldsymbol{\Pi} \boldsymbol{H}$. hyo-arytenoinei anteriores are inserted.

(5) The H. liyn-aryfenoilenx pusterior (Fig. 205 C.0.l. ${ }^{1}$ ) arises on each side from the superior angle of the corresponding arytenoid cartilage, under cover of the tendon of the $\boldsymbol{M}$. petrohynideus tertius. The muscle is inserted into the inferior angle of the arytenoid cartilage.

d. The interior of the larynx (Figs. 202, 206, 207). The cavity of the larynx is constricted at two points: anteriorly it is constricted by the true vocal cords (Figs. $206 \mathrm{~T}, 207 \mathrm{SB}$ ), posterio.ly by the false rocal cords. The whole cavity is lined with myous membrane, which is continuous with that of the mouth anteriorly, with that of the lungs posteriorly.

(I) The true vocal cords are two vertical flat bands of connective-tissue, attached above to the superior angles of the arytenoid cartilages, below to their inferior angles; their anterior borders are thin and free; near their posterior borders they are attached by mucous membrane to the internal surfaces of the arytenoid cartilages. 
The anterior and posterior borders are not parallel but are each concave (Fig. 202 $V$ ).

Fig. 206.

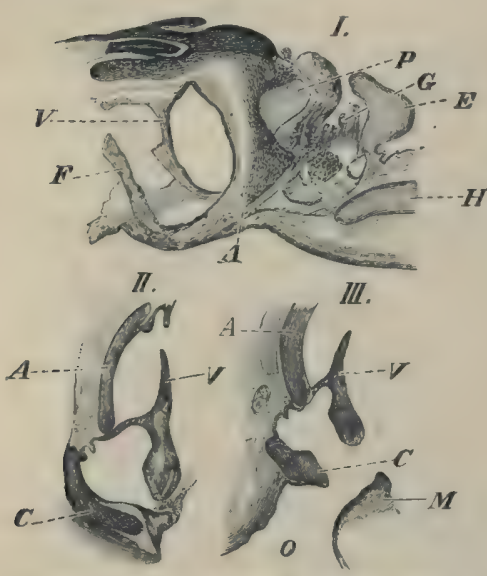

Three sections through the larynx of Rana esculenta. - G. H.

I. Sagittal section near the median plane through the larynx.

II. Oblique transverse section through larynx.

III. Almost horizontal section through larynx.

$A$ Arytenoid cartilage.

C Cricoid cartilage.

E Epiglottis.

$\checkmark F$ False rocal cords.

- E Epiglotidean glands,

$-I I$ Hyoid.

$\boldsymbol{M}$ Membranous floor of the larynx, cut obliquely.

o Opening into root of lung.

$P \quad$ Pre-ary tenoid cartilage.

- V Vocal cord.
The anterior border is thin, the posterior thick and rounded.

Seen from in front (Fig. 206), the opening between the cords (Rima glottidis) is slightly wider at each end than in the middle. The ends of the concave posterior border are prolonged backwards and enclosed in a fold of mucous membrane. Part of the tissue enclosed is unstriated muscular fibre, which may be traced to the cricoid cartilage.

(2) [The false vocal cords (Figs. 202 and $206 \mathrm{~F}$ ) are simply folds of mucous membrane, which extend vertically on each side of the larynx behind the true vocal cords; they do not extend so far towards the median plane as do the true vocal cords.]

(3) [TheVentricles of the larynx (Figs. 202 and 206) are two on each side. The anterior ventricles are between the true

vocal cords and the arytenoid cartilages; they are open anteriorly, and closed by mucous membrane posteriorly.

The posterior ventricles open towards the median plane, each presenting an oval opening (Fig. 202), which widens outwards into a large cavity (Fig. $206 I I$ ). The cavity is bounded in front by the base of the true vocal cord, and the mucous membrane attached. to it; posteriorly by the false vocal cord, and externally by the cricoid cartilage and the connective-tissue capsule of the larynx.]

(4) [The mucous membrane of the larynx varies in structure in various parts of the organ. From the anterior opening of the larynx to the posterior borders of the vocal cords it is lined with stratified epithelium, which is firmly attached to the underlying structures by a small amount of sub-epithelial 
tissue. This is especially well marked on the rocal cords themselves.

Behind the vocal cords the mucous membrane is much more loosely attached to the surrounding structures by an extremely vascular areolar tissue. The epithelium is arranged in a single layer of columnar cells, among which are numerous goblet-cells. In the more external parts of the posterior ventricles, the mucous membrane is thrown into deep folds and so forms polygonal acini. In the median line of the floor of the larynx and behind the false vocal cords is a vertical fold of mucous membrane, which increases in height and breadth as it proceeds backwards towards the roots of the lungs. The mucous membrane behind the true vocal cords is extremely vascular, in the most posterior portion of the larynx the blood-ressels form a capillary network exactly like that of the lungs.]

e. [The epiglottis (Fig. $206 \mathrm{E}$ ) is a small bilobed fold of mucous membrane placed on the floor of the mouth in the median plane and immediately in front of the aperture to the larynx. Between it and the mucous membrane covering the arytenoid cartilages are a number of large mucous glands $(G)$. The epiglottis does not contain cartilage; it is, however, constant in its appearance and sharply marked off from the surrounding mucous membrane.]

\section{THE LUNGS.}

a. General description. The lungs are two large thin-walled sacs (Figs. 185 and $204 L g$ and $L g^{1}$ ). The roots of the lungs are contracted at their origin from the larynx and then expand to form two ellipsoid saes, which terminate posteriorly in bluntly-pointed ends. With the exception of their roots they lie entirely free in the pleuro-peritoneal cavity, and are covered by the pleuro-peritoneal membrane. In the recent state they have a bright red colour due to the large supply of blood-vessels.

b. Minute structure.

(I) The muscular tissue of the lungs is for the most part arranged in large bands, which form a coarse network on the deeper 
surface of the organ; when seen in section ${ }^{1}$ (PI. II, Fig. $208 A, B$ ) these bands are found to be composed of well-developed involuntary muscular fibres. Between the larger bands are smaller bands having a similar arrangement. From these networks of muscular bands finer processes of muscular tissue pass peripherally towards the surface of the organ, and are attached to the thin and incomplete muscular layer found in the wall of the lung $(C)$.

(2) The connective-tissue of the lungs is present in only small quantity, but is still sufficient to fill in the spaces between the various muscular bands and the surface of the lung, and to invest the whole of that surface. There is thus formed a series of pits, the mouths of which open into the general cavity of the lung, while their bases are at the surface. Through this connectivetissue course the blood-vessels, nerves, and lymphaties. It contains numerous yellow elastic fibres.

(3) The blood-vessels of the lungs. The pulmonary artery courses along the outer surface of the lung to the apex, giving off, at right angles, lateral branches in the whole of its course; these show a tendency to be alternately larger and smaller. The lateral branches divide and form a rich capillary network ( $T$. Hoffmann).

The capillary network has very small meshes; the diameter of a given mesh being frequently less than that of the eapillary bounding it. The meshes are rounded or polygonal in shape.

The pulmonary vein arises by lateral branches from this capillary network; the branches join, at right angles, the main vein, which courses from the apex of the lung along its inner surface to the root of the organ.

(4) The epithelium of the lungs. Externally the lungs are covered with a layer of endothelium derived from the peritoneum. Internally the surface is covered with an epithelium which varies considerably in different positions.

On the free borders of the muscular trabeculae forming the

${ }^{1}$ See Plate II, Fig. 208.

Two sections from the lung of Rana temporaria ; stained with borax carmine.-G. H.

I. The lung dilated (Hartnack, Oc. I, Syst. 3).

II. The lung contracted (Hartnack, Oc. I, Syst. 7).

A Band of muscle cut transversely.

$B$ Band of muscle cut lungitudinally.

c Mnscular layer of surface. 
borders of the alveoli is a short columnar ciliated epithelium (Fig. 208); such epithelium is also found in the root of the lung; it contains goblet-cells.

The alreoli, for the most part, are lined with a single layer of tesselated epithelium; the cells are polygonal in outline, with finely granular contents and a distinct nucleus: the average diameter of the cells is from 0.0074 to $0.0108 \mathrm{~mm}$., that of the nucleus $0.005 \mathrm{~mm}$., that of the nucleolus $0.0009 \mathrm{~mm}$.; four to eight of such cells occupy the space enclosed by one mesh of the capillary network (Eberth).

The epithelium rests on a structureless basement membrane, which is continuous over the whole inner surface of the lung, whereas the epithelium does not pass over the capillaries, and is therefore only found in isolated patches in the areas enclosed by the capillaries (Eberth).

In rarious isolated spots, small groups of short columnar or goblet-cells are found in the tesselated epithelium (Eberth, Hoffmann).

(5) [The lymphatics of the lungs have been described by T. Hoffmann; they form a network of vessels surrounding the larger blood-ressels: from this branches are given off, which form a network of fine canals through the whole of the lung; part of this secondary network accompanies the blood-capillaries, but other portions run a separate course. They communicate with the pleuro-peritoneal cavity.

(6) The pigment-cells are very numerous, branched, and large; they accompany the lymphatics, and not the blood-vessels (T. Hoffmann).

(7) The nerves of the lungs (p. 172) course along the larger bloodressels, under the serous coat; the fibres are chiefly medullated fibres (Egorow, Kandarazki). Non-medullated branches, which form a plexus in each alveolus, are given off. The branches have small triangular enlargements (ganglia), where they unite. The nerves are accompanied by nerve-cells, which occur either singly or in groups.

Egorow describes the nerves as being distributed in three networks : one for the mucous membrane and muscular trabeculae; a second for the superficial muscular layer; and a third for the serous membrane.] 


\section{THE VOCAL SACS.}

a. General description. The vocal sacs are a pair of sacs

Fig. 209.

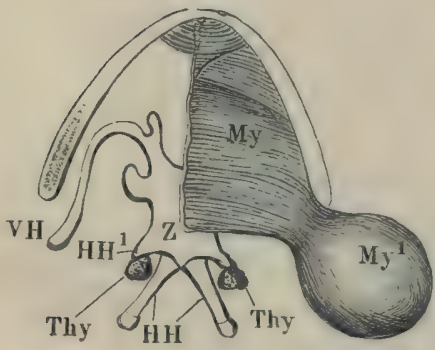

Dissection to show the vocal sac of the right side.

HH Larger pasterior cornua of the hyoid.

$H_{H}{ }^{1}$ Smaller posterior cornua of the hyoid.

My Mylo-hyoid muscle.

Myl Mylo-hyoid muscle continued on to the vocal sac.

Thy Thyroid glands.

VH Anterior cornua of the hyoid.

$Z \quad$ Body of the hyoid. which open in the floor of the mouth (Fig. I $79 S$ ); they are found only in the males. When the animal croaks these sacs are dilated and act as resonators; when so dilated the sacs force up the skin under the angle of the mouth and tympanic membrane. In welldeveloped specimens they are about as large as an average sized cherry. The skin covering the sacs is extremely elastic, but is not directly attached to the sacs.

b. Minute structure. The sac consists of connective-tissue, with a large proportion of yellow elastic fibre. Internally it is lined with a flattened epithelium, and externally is covered with a layer of striated muscular filvre, derived from the mylo-hyoid muscle (Fig. $209 M y, M y^{1}$ ).

\section{THE-THYMUS GLAND.}

a. General description. The thymus gland (Fig. $210 T h$ ) is placed on each side behind the angle of the jaw; it is best exposed by removing the skin behind the tympanic membrane and the angle of the jaw, and then reflecting the $M$. depressor manclitulae $(D . m$.). The gland is then found as an elongated, oval body, not quite $3 \mathrm{~mm}$. long, lying in the space between the $M$. depressor manditulae and the $M$. sternocleirtomas toideus $(S t)$; it extends slightly beyond the posterior border of the former muscle. The space also includes connective-tissue, fat, and numerous vessels.

In Rana tempioraria this gland is spherical, much smaller, and placed further behind on the $M$. stemocleilomastoileus, between the M. latissimus dorsi and the M. leltoideus (Wiedersheim). 


\section{b. Minute structure (Fig. 2II).}

[The gland is surrounded by a connective capsule, which is indented on the inner surface to form a hilus through which blood-vessels. course into the organ.

The capsule sends in numerous fine trabeculae, which form a connectivetissue skeleton such as is found in all lymphatic glands. The corpuscles of the trabeculae possess elongated nuclei from 0.019 to $0.028 \mathrm{~mm}$. in length, and 0.010 to $0.015 \mathrm{~mm}$. in breadth (Tolldt). The trabeculae support a network of blood-vessels.

The meshes of this sustentacular tissue are filled with cells; these are:

Fig. 210

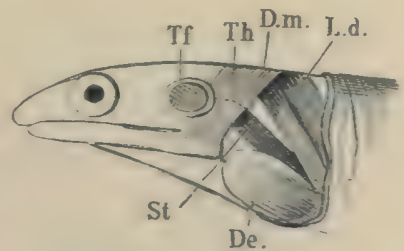

Dissection to show relations of the thymas gland.

De. M. deltoideus

D.m. M, depreseor mandibulant.

L.d. M. latissimns dursi.

S* M. sternocleidomastoideus.

Ty Tympanic membrane.

Th Thymus gland.

(a) Lymphoid cells, rounded or oval, possessing a round nucleus and nucleolus, and an extremely small amount of adhering protoplasm; the size of the nucleus is from $0.0 \mathrm{II}$ to $0.015 \mathrm{~mm}$. (Tolldt).

Fig. 211.

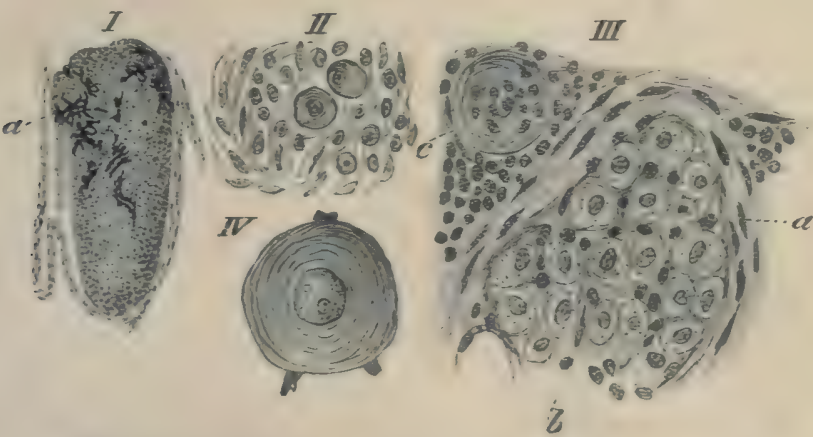

From rarious sections from the thymus gland of Rana esculenfit,-F. H.

I. Complete gland (Hartanck, Oa. I, Syot. 3). a Pigment-cells.

II. Portiun uf a section (Hartnack, Oe. I, Syst. 7) showing small corpmseles of Harsall.

11L. Portion of a section showing lobules with degenerating cells.

a Capsule of lobe.

b Lobules,

c Large corpuscle of Hassall, surrounded by normal tisue.

IV. Nerve-cell? (corpuscle of Hassall), after Fleischl.

(ß) Corpuseles of Hassall (Fig. 21I II, III, and IV) are, as a rule, large bodies, but are subject to much variation in size. Their 
general appearance is seen in Fig. 2 I I III; they show a concentric striation and usually enclose one or more smaller cells. They therefore closely resemble similar corpuscles found in higher animals.

$(\gamma)$ In many frogs the cellular structure of at least a part of the gland seems to have undergone a degenerative stage (III). In such cases the connective-tissue is increased in quantity, and marks off portions of the section into small lobules (III) which are filled with cells containing mucus or sometimes fat (III). Under what conditions this degeneration, if such it be, takes place has not yet been determined ${ }^{1}$.

( $\delta$ ) Large branched pigment-cells are found in the course of the larger blood-vessels.

(є) Watney describes also four varieties of 'granular cells:' I. polygonal or rounded; 2. vacuolated; 3. spheroidal masses; 4. club-shaped masses attached to the blood-vessels. I have, however, not been able to distinguish them.]

[Tolldt (l.c. I 868) described the lymphoid tissue and the blood-vessels of this gland but did not find the corpuscles of Hassall.

Fleischl (l.c. 1870) disputed Tolldt's description; he evidently found the corpuseles of Hassall (see Fig. $2 \times 1$ IV), but he held them to be nerve-cells, and described them as such. He was also of opinion that the blood-vessels open into the intercellular spaces (as in the spleen). This has not been found to be the case by any other observer. Watney (l.c. I882) first described the concentric corpuscles of Hassall as such.

Most writers describe the parenchyma as arranged in lobules. This I have only seen in a part of the gland and under what I believe to be pathological conditions.]

\section{THE THYROID GLAND.}

a. General description. A thyroid gland (Fig. 209 T/y) is found on either side as a small, triangular, or oval, reddish-coloured body on the dorsal surface of the $M$. sternolyoideus, just before it passes between the $M M$. genio-hyoidei. It lies in the angle formed between the larger and smaller posterior cornua of the hyoid $\left(H H, H H^{1}\right)$. It is easily found by the presence of a large number of vessels in its neighbourhood, and especially by the large jugular vein, to the ventral surface of which it is intimately attached.

2. Only winter-frogs were at my disposal (translator). 
Not uncommonly several smaller supplemental glands are found in the rich anastomosis surrounding the organ.

The dorsal surface of the gland is lobulated, the ventral surface flatter and convex. The glands of opposite sides are seldom symmetrical.

b. Minute structure (Fig. $212 \mathrm{I}$ and II). [The gland possesses a connective-tissue capsule, which sends in trabeculae to support the vesicles of which the gland is composed.

The vesicles ( $\mathrm{I}$ and $\mathrm{II}$ ), which vary greatly in size, are closed cavities, usually of a rounded or oval form, but sometimes branched (Baber). Each vesicle is lined with a single layer of cubical or slightly columnar epithelium (II, a), which rests on a delicate basement-membrane of connective-tissue, placed between the epithelium and the surrounding lymphaties (Baber).

Zeiss describes a delicate reticulum between the epithelial cells.

The vesicles always contain mucus (b), and are surrounded by a fine anastomosis of bloodvessels $(c)$.]

Fig. 212.

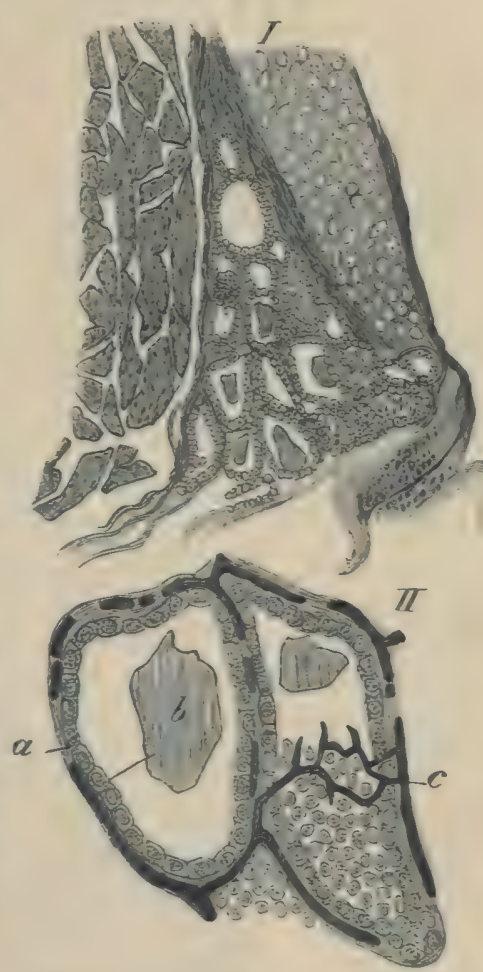

Minute structure of the thyruid gland of Rum esculenta.-G. H.

I. Section through the gland (Hartnack, Oc. I, Syst. 3).

II. Small portion of abure (Hartnack, UE. I, Syst. 7).

a Epitbelium lining the resicles.

b Mucus.

c Blood-reasels, injected with blue masa

\section{THE LYMPHATIC GLANDS OF THE HYOID REGION (TONSILS?).}

a. [General description. These are two oval, reddish-coloured, soft lymphatic glands, placed one on each side of the larynx. Frequently they are divided into two or three lobes by more ur less 
deep fissures. They are constant in their occurrence, and are frequently supplemented by one or more smaller glands; each

Fig. $2 x 3$.

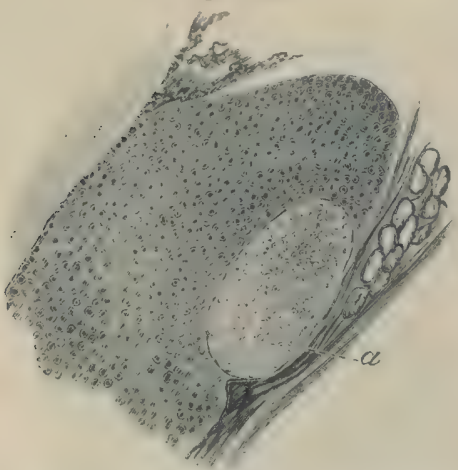

Part of section through the lymphatic gland (tonsil ?) of Rance erenclenta (Hartnack, Uc. I,

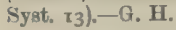

a Extremely large lymphoid follicle. gland has the larynx on its inner side, the Vena jugularis externally, the $\boldsymbol{M}$. omohyoideus in front, and above the mucous membrane of the pharynx (Tolldt).

b. Minute structure. The glands consist of dense lymphoid tissue (Fig. 2I3), but possess in addition one or more large bodies (a) which resemble lymphoid follicles in structure. Each is composed of a dense mass of small cells; and the whole follicle is, as in similar follicles of higher animals, sharply differentiated from the rest of the organ.

The glands possess an extremely rich vascular supply, and are frequently pierced by one or more large arterial trunks.

The mucous membrane covering the glands is thinner than that immediately around, but is not perforated.]

[As far as I am aware, Tolldt is the only observer who describes these glands: he makes no mention of the lymphoid follicles.] 


\section{SECTION VII.}

THE URIN0-GENITAL STSTEU, THE ADRENALS, AND THE FAT-BODIES. 


\section{THE URINO-GENITAL SYSTEM, ETC.}

\section{LITERATURE.}

\section{THE URINO-GENITAL ORGANS.}

Adami, J. G., On the nature of glomerular activity in the kidney. Journ. of Physiol. I886. Vol. VI, p. 382.

Ankermann, De moturo et evolutione filorum spermaticorum. Regimonti, 1854 .

Ankermann, Einiges über die Bewegung und Entwicklung der Samenfäden des Frosches. Zeitsch. f. wiss. Zool. 1857. Vol. VIII, p. 129.

Beale, I. S., On very fine nerve-fibres ramifying in certain fibrous tissues, and of trunks and plexuses consisting entirely of fine nerve-fibres in the bladder of the frog. Beale's Archives of Med. 1864. Vol. IV, pp. 19-25I.

Bergmann, C. G., De glandulis suprarenalis. Dissert. Göttingae, 1839.

Bidder, Vergleichende Anat. und histol. Untersuchungen über die männlichen Geschlechts- und Harnwerkzenge der nackten Amphibien. Dorpat, I846.

Biondi, D., Die Entwicklung der Spermatozoiden. Arch. f, mik. Anat. 1885. Vol. $\mathrm{XXV}, \mathrm{p} .594$.

Bloomfield, J. E., The development of the Spermatozoa. Quart. Journ. Micros. Sci. 188r. New Series. Vol. XXI, p. 415.

Böttcher, A., Ueber den Bau und die Quellungsfähigkeit der Froscheileiter. Virchow's Arch. I866. Vol. XXXVII, p. I74.

Bouillot, J., Sur l'épithélium sécréteur du rein des Batrachiens. Compt. rend. I882. Vol. XCV; No. I4, pp. 603-604.

Bourne, A. Gibbs, On certain abnormalities in the common frog, Rana temporaria. Quart. Journ. Micros. Sci. I884. New Series. Vol. XXIV, pp. 83-86.

Bowman, W., Sur la structure et fonctions des glandules des reins ou corpuscules de Malpighi. Annal. des Sci. Zool. 1843. Series II. Vol. XIX, pp. 108-145.

Bowman, W., On the structure of the Malpighian bodies of the kidney, etc. Phil. Trans. 1842. Pt. I, pp. 57-80.

Bowman, W., Ueber die Structur und den Nutzen der Malpighischen Körper in den Nieren. Froriep's Notizen, I842. Vol. XXII, No. 21, coll. 321-324.

Bowman, W., Ueber die Structur und Functionen der Malpighischen Körper in den Nieren. Froriep's Notizen, 1843. Vol. XXV, No. 12, col. I77.

Brandt, A., Fragmentarische Bemerkungen iiber das Ovarium des Frosches. Zeitsch. f. wiss. Zool. 1877. Vol. XXVIII, p. 575.

Budge, Harnreservoir der Wirbelthiere. Mittheil. aus d. naturw. V. v. Neu-Pommern und Rügen. I875, p. 103.

Carus, C. G., and Otto, A. W., Erläuterungstafeln zur vergleichenden Anatomie. Leipzig, I840.

Crivelli e Maggi, Alcuni cenni sovra lo studio dei corpi piangiati delle Rane. Rendiconti del Reale Istituto Lombardo de scienze e lettere. 1869. Second Series. Vol. II, p. 7 I6.

Della Chiaje, Esistenza della glandule renala ne Batruci et ne Pisci. Napoli, 1837 . Drasch, O., Ueber das Vorkommen zweierlei verschiedener Gefässknäuel in der Niere. Wiener Sitzungsb. 1878. Vol. LXXVI, Part III, p. 79.

Duncan, J., Ueber die Malpighischen Knäuel in der Froschniere. Sitzungsb. d. Acad, zu Wien, 1867. Vol. LVI, Pt. II, p. 6. 
Duval, M., and Wiet, Teber die Wanderung der Eier in die Bauchhöhle beim Frosche. Gaz de Paris, 1880. No. 17, p. 219.

Duval, M., Recherches sur la Spermatogénèse chez la grenouille. Revue Sci. nat. Montpellier, 1880. Vol. II, pp. I 2 I-I43.

Ecker, Dor feinere Bau der Nebennieren, ete. 1846.

Eimer, T., Cntersuchungen über den Ban und die Bewegung der Samenfäden. Verhandl. d. phys.-med. Gesell. in Würzburg, 18 7 . Tol. VI, New Series, p. 93.

Engelmann, Zur Physiologie des Ureter. Pflüger's Arch. f. d. ges. Physiol. 1869. Vol. II, p. 243.

Fürbringer, M., Zur rergleichenden Anst. und Entwicklangsgesch. d. Fxcretionsorgane der Vertebraten. Morph. Jahrb. Vol. IV.

Fürbringer, M., Zur Entwickltng der Amphibienniere. Heidelberg, I877.

Gerlach, J., Beiträge zar Structurlehre der Niere. Arch. f. Anat. u. Physiol. $1 \varepsilon_{4}$, p. 378 .

Gibbes, H., On the structure of the Syermatezoon. Quart. Jnurn. Micros. Sei. 1880. Vol. XX, p. 318 .

Goette, A., Entwicklungsgeschichte der Cnke. Leipzig, 1875 .

Goette, A., Kurze Mittheil ungen aus der Entwicklungsgeschichte der Tinke. Arch. f. mik. Anat. 1873. Vol. IX, p. 396.

Grunau, H., Ceber das Flimmerepithel auf dem Bauchfell des weiblichen Frosches und über den Eileiterbau desselben. Dissert. Königsberg, I $8 \% 5$.

Grünhagen, A., Cntersuchungen über Samenentwickelung. Centralbl. f. d. med. Wies. I885. Vol. XXIII, p. $4^{81}$.

Grünhagen, A., Ceber die Spermatogenese bei Rana fusca (temporaria). Centralbl. f. d. med. Wiss. 1885. Vol. XXIII, p. 737.

Gscheidlen, R., Zur Lehre . d. Nervenendigung in den glatten Muskelfasern. Arch. f. mik. Anat. 1877. Vol. XIV, p. 321.

Heidenhain, R., Mikroskopische Beiträge zur Anatomie und Physiologie der Nieren. Arch. f. mik. Anat. 1874. Vol. X, p. I.

Holmann, Ceber die Entwicklung der Spermatozoen der Wirbelthiere. Dissert. Dorpat, 1879 .

Henle, J., Zur Anatomie der Niere. Nachrichten v. d. k. Gesell. d. Wissensch. z. Göttingen, I862. Fol. X, pp. 4-12; and in Abhandlungen, 1861-62, Vol. X, p. 223.

Hoffmann, C. K, in Bronn's Klassen und Ordnungen des Thierreichs. Leipzig and Heidelberg, 1873-1879. Vol. VI.

Hüfner, Zur vergleichenden Anatomie und Physiologie der Harncanälchen. Diss. Leiprig, $\mathbf{1 8 6 6 .}$

Hyrtl, Ueber die Injection der Wirbelthierniere, etc. Wiener Acad. Sitzungsb. I863. Vol. XLVII, Pt. I, p. I 72.

Jensen, O. s., Recherches sur la spermatogénèse. Archives de Biologie, I883. Vol.IV.

Jensen, O. S., Ueber die Struktur der Samenkörper bei Säugethieren, Vügeln, und Amplibien. Anat. Anzeiger. 1886.

Knappe, E., Das Biddersche Organ. Morph. Jahrb. I\$86. Vol. XI, pp. 4\$9-548.

Kolessnikow, N., Ceber die Eierentwicklung bei Batrachiern und Knochenfischen. Arch. f. mik. Anat. 1878. Vol. XV, p. $3^{82}$.

v. Kölliker, $\mathbf{\Lambda}$, Gewebelehre. Fifth Edition.

Iranger, C., Teber das Lymphgefässsystem des Frosches. Wiener Acad. Sitzungsb. 1867. Vol. LV, Pt. I, p. 621.

Lavdowsky, M., Ceber die Endigung der Nerven in der Harnblase des Frosches. Centralbl. f. d. med. Wiss. IS -1, p. 33.

Lavdowsky, M., Die feinere Structur und die Nerrenendigungen der Froschharn. blase. Arch. f. Anat. u. Physiol. 1872, p. 55.

Lereboullet, A., Recherches sur l'anatomie des organes génitaux des animsux vertébrés. Nor. acta Acad. Leop. Car. I851. Tol. XXIII, pp. 1-226. 
Leydig, F., Anatom.-histol. Untersuchungen über Fische und Reptilien.

Leydig, F., Lehrbuch der Histolngie des Menschen und der Thiere. Frankfurt, 1857, p. 508.

Leydig, F., Untersuchungen zur Anatomie und Histologie der Thiere. Bonn, I883.

List, J. H., Ueber Becherzellen im Blasenepithel des Frosches. Wiener Sitzungsh. I884, Vol. LXXXIX, Pt. III, pp. 186-2Io; also in Arch. f. mik. Anat. I887, Vol. XXIX, p. I47.

List, J. H., Ueber Becherzellen im Blasenepithel des Frosches. Zool. Anzeiger, 1884. No. 169, p. 328.

List, J. H., Ueber einzellige Drüsen im Blasenepithele der Amphibien. Biol. Centralbl. I885. Vol. V, p. 499.

Loos, P. A., Die Eiweissdrüsen d. Amphibien und Vögel. Zeitsch. f. wiss. Zool. I881. Vol. XXXV, pp. 478-504.

Maier, R., Die Ganglien in den harnabführenden Wegen des Mensehen und einiger Thiere. Virchow's Arch. I881. Vol. LXXXV, pp. 49-7 I.

Marcussen, J., Ueber die Cloake und Harnblase der Frösche. Bull. der phys.-math. Acad. de St. Pétersbourg, 1853. Vol. XI.

Marshall, A. M., On certain abnormal conditions of the reproductive organs in the frog. Journ, of Anat. and Physiol. 1884. Vol. XVIII, p. I2I.

Marshall, A. M., The frog. Manchester and London. 2nd Edit. I885.

Mecznikow, F., Zur vergleichenden Histologie der Niere. Göttinger Nachrichten, I866, p. $6 \mathrm{r}$.

Meyer, F., Beitrag zur Anatomie des Urogenitalsystems der Selachier und Amphibien. Sitzungsb. d. nat. Gesellsch. Leipzig. I874, p. 38 ; published 1875 .

Moleschott, Ein histochemischer und ein histologischer Beitrag zur Kenntniss der Nieren.

Miescher, Die Spermatozoen einiger Wirbelthiere. Verhandl. d. naturf. Gesell. in Basel. 1878. Vol. VI.

Neumaun, E., Untersuchungen über die Entwickelung der Spermatozoiden. Centralbl. f. d. med. Wiss, r868. No. 24.

Neumann, E., Untersuchungen über die Entwickelung der Spermatozoiden. Arch. f. mik. Anat. 1875. Vol. XI, p. 292.

Neumann and Grunau, Drüsen der Froscheileiter. Arch. f. mik. Anat. 1875. Vol. $\mathrm{XI}, \mathrm{p} .37^{2}$.

Nussbaum, N., Ueher die Niere der Wirbelthiere. Sitzungsber. Bonn, I87o.

Nussbaum, N., Ueber die Endigung der Wimpertrichter in der Anurenniere. Sitzungsb. d. niederrheinischen Gesell. in Bonn, 1877. Vol. XXXIV, p. I22.

Nussbaum, N., Ueber den Baı und die Thätigkeit der Drüsen. Arch. f, mik. Anat. 1886. Vol. XXVII, p. 442.

Nussbaum, N., Ueber die Secretion der Niere und über die Verbindung der Samen und harnhereitenden Driisenschliuche in den Nieren der Batrachier. Sitzungsb. d. niederrheinischen naturf. Gesell. in Bonn, 1877. Vol. XXXIV, p. 277 .

Nussbaum, N., Fortgesetzte Untersuchungen über die Secretion d. Niere. Pflüger's Arch. f. d. ges. Physiol. 1878. Vol. XVII, p. 580.

Nussbaum, N., Ueber die Endigung der Wimpertrichter der Niere der Anuren. Zool. Anzeiger, 1880. No. 67, pp. 514-517.

Nussbaum, N., Zur Differenzirung des Geschlechts im Thierreich. Arch. f. mik. Anat. 1880. Vol. XVIII, p. 73.

Peltier, Sur les zoospermes de la grenouille. L'Institut. I838. Vol. VI.

Perrault, C., De generatione ranarum fusca et bona dissertatio, in Actis Eruditorum, 1687 .

Próvost, Note sur les animalcules spermatiques de la grenouille et de la Salamandre. Mémoires de la société phys. et d'hist. nat. de Genève. Geneva and Paris, I84I-I842. Vol. IX, p. 289. 
Rathke, H., Beiträge zur Geschichte der Thierwelt, III Abth.; and Neueste Sichr. d. naturf. Gesell. in Danzig. 1825 . Vol. I.

Reger, R., Teber die Malpighischen Knäuel der Nieren und ihre sogenannten Capseln. Arch. f. Anat. u. Physiol. 1864, p. 537.

Reichert, On kidney. Jahresbericht über Anatomie in Arch. f. Anat. u. Physiol. I 843, p. 220 , etc.

Remak, Untersuchungen über die Entwicklung d. Wirbelthiere, p. 128.

Retzius, G., Zur Kenntuiss der Spermatozoen. Biol. Untersuchungen. I 88 I.

Rideward, W. G., On an abnormal genital system in a male of the common frog. Anat. Anz, 1888. Vol. II, p. 333.

Robinson, C., Teber die Lymphgefasse der abdominal Eingreweide des Frosches. Froriep's Notizen, 18 46 . No. 807 , enl. 225.

Rösel, A. J., Historia naturalis ranarum nostralium. $\mathbf{1}_{758,}$ p. 28.

Roth, Cntersuchungen über die Drusensubstanz der Niere. Bern, 1864; and Schweiz. Gresellsch. f. Heilkunde, I864. Vol. III, pp. I-34.

Schiefferdecker, Ueber einzellige Drüsen in der Blase der Amphibien. Bericht. d. naturf. Ges, in Rostock, I883.

Schultze, F. E., Das Drüsenepithel der schlauchförmigen Drïsen des Dünn-und Dickdarms und die Becherzellen (Cloaca of frog' Centralbl. f. d. med. Wiss. 1866 , p. $16 \mathrm{r}$.

Schultze, M., Observationes nonnullae de ororum ranarum segmentatione. Bonn, I 863 .

Schultze, O., Tntersuchangen über die Reifung und Befruchtung des Amphibieneies. Zeitsch. f. wiss. Zool. 1887. Vol. XLV, pp. 177-226.

Schweigger-Seidel, F., Ceber die Samenkörperehen und ihre Entwicklung. Arch. f. mik. Anat. 1865. Vol. I, p. 309 .

Bolger, B., Beiträge zur Kenntniss der Nieren und besonders der Nierenpigmente der niederen Wirbelthiere. Abhandl. d. naturf. Ges. zu Halle, 1882. Tol. XV.

Spengel, J. W., Die Siermentaloryane der Amphibien. Verhandl. d. phys.-med. Gesells. Würzbung. Vol. X, pp. 89-92.

Spengel, J. W., Das Urogenitalsystem der Amphibien. Arbeiten aus d. Zool. Inst. in Würzburg, $18 ; 6$. Vol. III, pp. I-1 14 .

Spengel, J. W., Wimpertrichter in der Amphibienniere. Centralbl. f. d. med. Wis8. 1875, p. 369 .

Swammerdam, J., Bibblia naturae. Levdae, $173^{8}$. Vol. II, p. 796.

Thompson, A., Article 'Orum ' in Todd's Cyclopæedia of Anatomy and Physiology, London, I879. Vol. V, p. 9r.

Tolotschinoff, Leber das Verhalten der Nerren zu den glatten Muskelfasern der Froschharnblase. Arch. f. mik. Anat. 1869. Vol. V, p. 509.

Tornier, O., L’eber Bürstenbesätze am Drüsenepithel. Areh. f. mik. Anat. IS š́. Vol. XXVII, p. I8I.

จ. la Valette St. George, Spermatologische Beiträge. Arch. f. mik. Anat. 1886, Vol. XXVII, p. $3^{8} 5$; and in Stricker's Gewehelehre, Article 'Hoden.'

Valentin, On kidney. Repertitorium, 1845. Vol. VIII, p. 92.

Waldeyer, W., Eierstock und Ei. Ein Beitray zur Anatomie und Entwicklungsgesch. der Sexualorgane. Leiprig, 18;0.

Weldon, W. F. R., On the suprarenal bodies of rertebrata. Quart. Journ. Mieros. Sci. I885. Vol. XXV, p. I37.

v. Wittich, W., Beiträge zur morphologischen und histologischen Entwicklung der Harn- und Geschlechtswerkzeuge der nackten Amphibien. Zeitsch. f. wiss. Zool. 1853. Vol. IV, p. I52.

Wolff, W., Die Innervation der glatten Muskulatur. Areh. f. mik. Anat. I882. Vol, XX, p. 36r. 


\section{THE ADRENALS.}

Bergmann, De glandulis suprarenalibus. Dissert. Göttingen, I839.

Ecker, A., Der feinere Bau der Nebennieren beim Menschen und den vier Wirbelthierklassen. Braunschweig, 1846 .

Frey, H., On the suprarenal capsules, in Todd's Cyclopædia. London, 1849, p. 827 . Giles, A. E., On the development of the fat-bodies in the frog. Quart. Journ. Micros. Sci.

Hoffmann, C. K., Bronn's Klassen und Ordnungen des Thierreichs. Heidelberg und Leipzig, I873-1878. Vol. VI, p. 506.

v. Kölliker, A., Handbuch der mikroskopischen Anatomie. Leipzig, 1854. Vol. II, p. 386.

Loydig, Lehrbuch der Histologie. Frankfurt a. M. I857.

Moers, Ueber den feineren Bau der Nebennieren. Virchow's Arch. 1864. Vol. XXIX, p. 336.

Nagel, Ueber die Structur der Nebennieren. Arch. f. Anat. u. Physiol. 1830, p. 377.

\section{THE FAT-BODIES.}

Carus, Lehrbuch der Zootomie. Leipzig, 1818 (describes the fat-bodies as suprarenals).

Hoffmann, C. K., Bronn's Klassen und Ordnungen des Thierreichs. Heidelberg: und Leipzig, 1873-1878. Vol. VI.

Marshall, A. Milnes, The frog. Manchester and London, 1884.

v. Wittich, W., Beiträge zur morphologischen und histologischen Entwicklung der Harn- und Geschlechtswerkzeuge der nackten Amphibien. Zeitsch. f. wiss. Zool. 1853. Vol. IV, p. I52. 


\section{THE URINO-GENITAL SISTEI, THE ADRENALS, ETC.}

\section{THE URINO-GENITAL SYSTEM.}

$\mathrm{Br}$ cutting thrc.:gh the meso-rectum the posterior caval vein is seen, as a large vessel, arising by numerous transverse branches from the ventral surfaces of the kidneys and testes (Fig. $2 \mathrm{I}_{4} \mathrm{Cv}$ ), lying in the median line between the kidneys; by drawing it to one side the dorsal aorta is brought into view (Fig. 214 Ao). The testes are placed on the ventral surface of the kidneys', and together with the fat-bodies conceal the anterior portions of these organs. The posterior portions of the kidneys are covered by peritoneum only, and may by seen without further dissection. The kidneys lie dorsal to the peritoneum, and have this membrane on their ventral surfaces only; their dorsal surfaces are in contact with the lumbosacral plexus.

The ureters extend from the anterior border of the eighth vertebra to the middle of the urostyle, where they terminate by two orifices in the dorsal wall of the cloaca (Fig. I 84).

The testes are entirely surrounded by peritoneum, except a small part (Hilus) of the inner surface, where the vessels and ducts enter.

Fig. 214

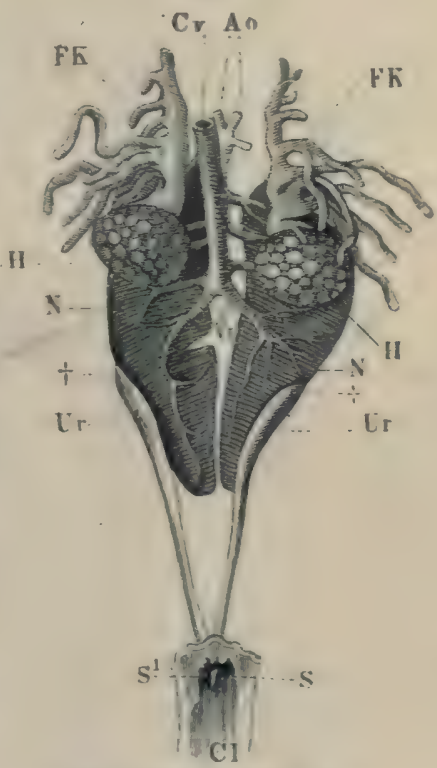

The male urino-genital organs,

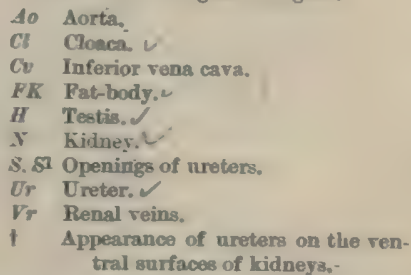

The urino-genital organs are arranged in the same manner in the two sexes; the ovaries corresponding in position with the 
testes (Fig. 2I4), that is, they are bilaterally symmetrical, and placed on the ventral surfaces of the kidneys.

The oviducts (Fig. $224 O v$ ) lie externally to the kidneys and ovaries, and course through the whole length of the trunk from the roots of the lungs to the cloaca. The size of the ovaries and oviducts varies very greatly according to the season of the year ; at times, the kidneys may be entirely hidden by them.

\section{THE URINARY ORGANS.}

\section{A. The kidneys.}

a. General description. Each kidney (Fig. 2I.5) is a reddishbrown, elongated organ, almost semilunar in shape; the inner

Fig. 215 .

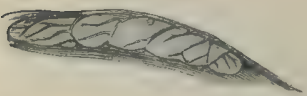

The right kidney, seen from the ventral surfroe. border being straight and the outer convex. The organ is flattened from above downwards, and decreases in thickness towards either end. In animals of average size the kidney is about $16 \mathrm{~mm}$. long, and from 6 to $7 \mathrm{~mm}$. broad. The kidneys lie parallel to the vertebrae.

The outer border is smooth and even, except at its posterior third, where a slight depression for the ureter exists; the inner border has usually two or three well-marked notehes, the hindermost of which is the deepest (Fig. 2I5). Each notch is continued outwards as a groove, traversing the whole breadth of the ventral surface and containing a branch of the renal portal vein. The ventral surface is, as a whole, slightly concave, grooved, and lobulated; the dorsal surface is smooth and slightly convex.

b. [Minute structure. The kidney is enclosed in a thin capsule of fibrous tissue (Fig. $220 \mathrm{Bg}$ ), which sends in fine trabeculae to support the glandular structures and the blood-vessels.]

(1) The blood-vessels of the kidney are the renal veins, the renal arteries, and the renal portal vein.

a. The renal portal vein (p. 247) courses along the outer border of the posterior part of the kidney, and then along the outer margin of the dorsal surface; in this course it gives off large branches, which course inwards and forwards and supply numerous lateral twigs. These anastomose to form a network of vessels on the dorsal surface of the organ, from which very numerous large branches course downwards and somewhat inwards to join ('orresponding branches of the renal veins (Fig. $216 \mathrm{I}$ ). 
Fig. 216 .

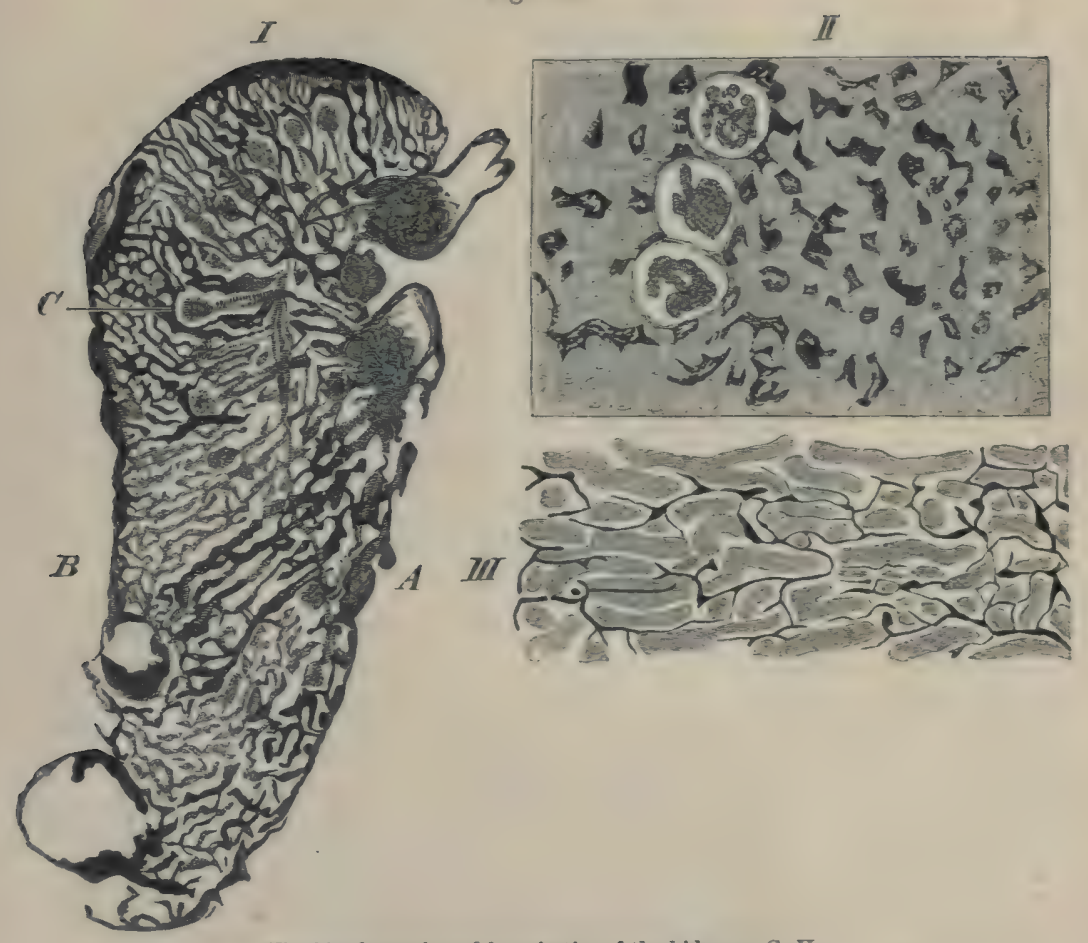

The blood-ressels and lymphatics of the kidney.-G. H.

1. Transvene vertieal seetion thruugh kilney. Yenous system bluc; arteries rel (Hartnick, Oc. I, Syst. 3).

11. Part of a horizontal section through kidney. Venons system blue; arteries reti (Hartnack, Oc. I, Syst. 3).

III. Part of a transverse vertieal seetion throngh kidney; lymphatics blue (Hartnitk, Oc. I, Syst. 7). 4 Ventral surface.

B Dorsal surface.

C Two arterial twigs uniting before entering the Malpighian body.

$\beta$. The renal veins (p. 247) form a coarse plexus on the ventral surface of the kidney, from this numerous large branches (Fig. 2 I 6 I) course upwards and outwards.

The venous system between the renal portal veins on the dorsal surface, and the renal veins on the ventral surface, are so large that they can scarcely be named capillaries (Hyrtl).

$\gamma$. The renal arteries $(p .233)$ are distributed to the ventral surface of the kidney; their mode of distribution varies in different parts of the organ. A simple arrangement is that shown in Fig. 216 I, where a branch traverses the breadth of the kidney and gives off branches to the Malpighian corpuscles; in one case (C) 
I have seen two twigs passing to the same corpuscle; as a rule, however, each Malpighian corpuscle receives only one twig. A more general arrangement is that the artery courses nearer the ventral surface and in a more winding course, several twigs are then given off close together, from the convex surface of one of the curves, and these course to their respective corpuscles.

In the Malpighian corpuscle the arterial twig forms a series of loops and then passes out to open abruptly into one of the branches of the neighbouring venous anastomosis ( $\mathrm{Hyrtl})$.

(2) [The Malpighian corpuscles and their capsules (Figs. 216 I, 2 I 8 III). The corpuseles lie nearer the ventral than the dorsal surface. They are rounded oval bodies, formed of loops of an arterial twig, held together by a small amount of connective-tissue. Each corpuscle is enclosed in a capsule, which it incompletely fills (Fig. 217$)^{x}$.

The capsules are formed of connective-tissue and lined with a flattened epithelium (Fig. 2 I 8 III) : according to Duncan the fibrous coat is arranged in two layers (III $a$ ). Towards the opening of the uriniferous tube the epithelium increases in thickness.

According to Hyrtl, the corpuscles are arranged in two layers, a more superficial one and a deeper one; and are of two sizes, the larger being as a rule the more superficial (ventral).]

(3) [The uriniforous tubes (Figs. 217 and 218 ). Each tube originates at a narrow opening on the dorsal surface of a Malpighian capsule. The tube gradually widens and is lined with a short rounded or cubical epithelium (Roth), (Fig. 2 I 8 III); each epithelial cell bearing a small number of extremely small cilia (Bowman, Kölliker, Duncan, and others). The cilia of the cells nearest the capsule are directed towards it (Heidenhain), those of the cells further away have an opposite direction (Spengel). This portion of the tube is known as the neck; it courses dorsalwards.

The second portion of the tube (Tululus contortus), (Fig. 218 III, IX, and XII) has a very tortuous course in the dorsal part of the kidney, and then winds towards the ventral surface. This portion is lined with columnar epithelium, which has granular contents, and possesses large distinct nuclei. The cells of this part

\section{See Plate II.}

Portions of two transverse vertical sections through the kidney, $-\mathrm{G}$. H.

I. Kidney of Rana eseulenta, partial injection of the uriniferous tubes with silrer nitrate (Hartnack, OQ I, Syst, 7).

II. Kidney of Rana temporaria, stained with burax-carmine (Hartnack, Oc. 1, Syst. 7). 
Fig. 218.
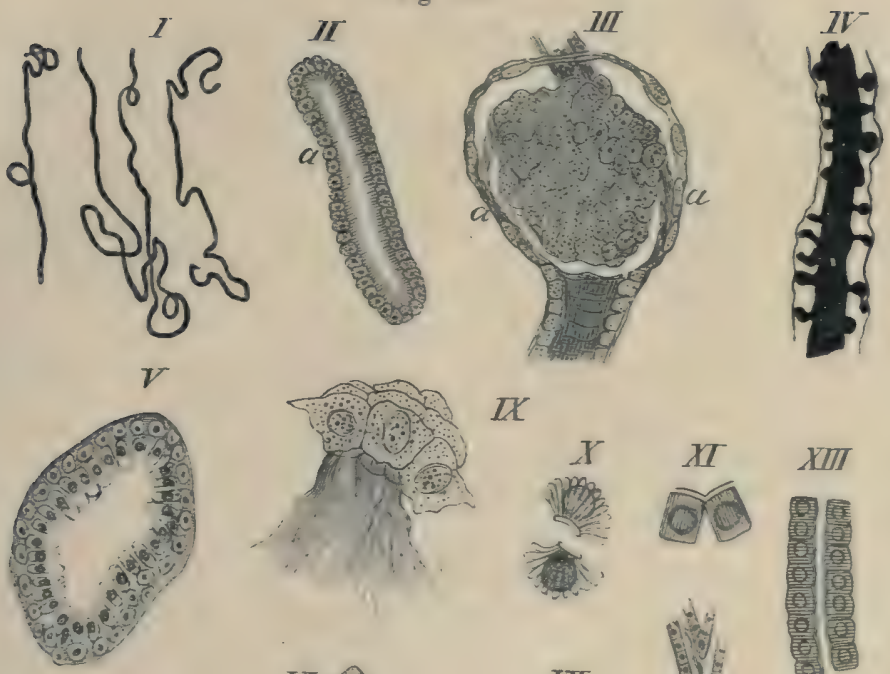

$I X$

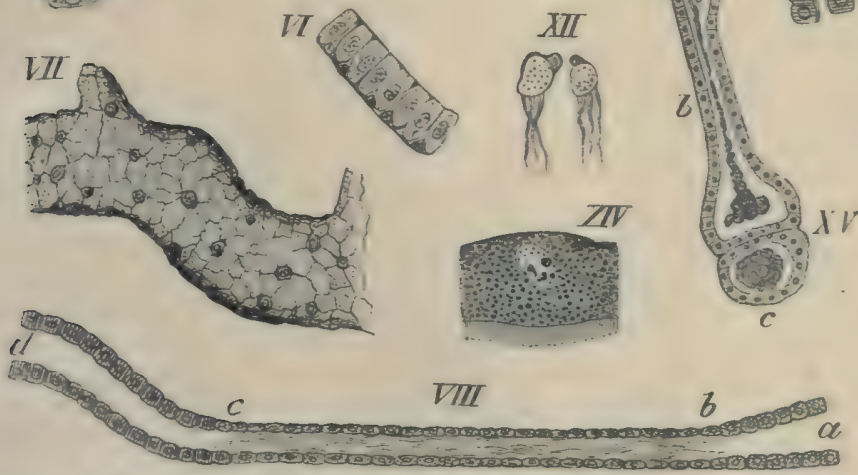

Various preparatiuns to shuw the strncture of the uriniferuns tubes, etc.

I. Three portions of the uriniferous tubes fren Rana esculentu, from a natural injection with sulphinuligutate of sedium (Hartnack, Oc. I, Syst. 3) - G. H.

II. From the third part of a uriniferuus tube; short ciliated epithelium, borax-carmine (Hart-

nack, Oc. I, Syst. 7$)-G$. H.
III. A Maljighian corpnsele and calseule; shows the capsule of two layers at $a$. After Duncan.

IV. Part of urinifermus tube after natuxal injection with sulphindigotate of sodium (Hartnack. Oc. I, Syst. 3) - G. H.

V. Transverse section of one of the larger branches of the ireter, from Rana esculenta (Hartnack, Oc. I, Syst. 7).-G. H.

VI. Epithelial lining of the ureter itself while still in the kidnev (Hartnack, Oc. I, Syst. 7). - G. H.

VII. Purtion of a uriniferwus collecting-tube from section in Fig. 217 I, stained with silver (Hartnack, Oc. I, Syst. 7)-G. H.

VIII. Renal epithelium; $a$ to $b$, tubulus contortus; $b$ to $c$, third portion of uriniferous tube; $c$ to $d$, fourth portion of tube. After Heidenhain (enlarged zro times).

IX. Ciliated cells of the neck, after Duncan.

X. Isolated rod-cells of Trilon taeniatus, after Heidenhain.

XI. Isolated rod-calls, after Hoidenhain (enlarged 300 times).

XII. Isolated cells of the neck, after Heidenhain (enlarged 2 ro times).

XIIT. Portion of the fourth part of a uriniferuus tube, after Heidenhain (enlarged 300 times).

XIV. Ciliated epithelium of tubulus contortus, af ter Tornier (magnified 550 times!;

XV. From kidney of Rana temporaria, after Spengel.

a Uriniferous tabe opening into seminiferous duct.

b Dilated seminiferotus duct cut longitudinally.

c Vas efferens cut transversely. 
of the kidney are usually more or less coloured with a goldenyellow pigment. According to 'Tornier it bears short cilia (Fig. 2 I 8 XIV).

The third portion corresponds with the narrow limb of Henle's loop; it is lined with ciliated epithelium (Fig. 218 VIII, $b$ to $c$ ), similar to that in the neck of the tube.

The fourth portion (Fig. $218 \mathrm{VIII}, c$ to $d$, and XIII) represents the wider limb of Henle's loop. It has a winding course in the ventral part of the kidney, and then ascends dorsally to open into a collecting-tube. The fourth part of the tube is lined with a short, columnar epithelium (Fig. 218 VIII, $c$ to $l$ ), which has a clear, cuticular, free border, large nucleus, and a peculiar arrangement of the protoplasm, which shows a rod-like structure (Fig. $218 \mathrm{XI}$ ).

The collecting-tubes course transversely near the dorsal surface of the kidney (Fig. 217), and the uriniferous tubes meet them at right-angles. They are lined with a short polygonal epithelium (Fig. 218 VII).

The peritoneal funnels of the kidney (nephrostomes). Spengel, Meyer, and Hoffmann describe these funnels as existing in the frog; according to them they open on the ventral surface by narrow apertures, and each is connected, by a vertical tubule, with the fourth part of the uriniferous tube (Spengel), but according to Nussbaum, with the neck of the tube. According to Spengel and Meyer the number of these funnels is in Rana from 250 to 360 .

According to Wiedersheim the funnels hang free from the ventral surface like so many parasites attached by fine filaments, and do not open on the surface.

Heidenhain (Arch. f. mik. Anat., Vol. X) was unable to find these organs.

Being unable to find any trace of these organs in the kidneys of either $\mathbf{R}$. temporaria or $R$. esculenta, in microscopic sections or in teased preparations, $I$ inserted canulae into the ureters of both male and female specimens of both species, and injected the uriniferous tubes with a solution of Berlin blue. Although the tubules were, in some cases, completely injected, in no case could I find any trace of a peritoneal funnel, nor was there any escape of the sulution from the kidney as would be the case if the funnels were open and communicated with any part of the uriniferous tubes. Even when the pressure was increased to the extent of a column of $25 \mathrm{~cm}$. high of the injection-mass, no escape took place from the surface of the kidney, though in numerous cases the uriniferous tubes were ruptured by the abnormally high pressure.

Properly dissected frogs were placed in $0.6 \%$ sodium chloride solution, in which finely divided gamboge was suspended. No trace of ciliary action was, in any case, found on either surface of the kidneys.

One may therefore conclude that if the perituneal funnels exist in the adult frog (I) they are very difficult to find; (2) they do not form a free communicating path between any part of the uriniferous tubes and the abdominal cavity; (3) their superficial terminations have no free cilia. As before stated I have found no trace of any such organs. 
The lobules of the kidney. When treated with proper reagents the kidney shows a marked tendency to separate into lobules (Fig. 2 I9 I).

The lymphatics of the kidney (Fig. 216 III $^{1}$ ) form an irregular network of fine canals with elongated meshes. They run chiefly in the direction of the blood-vessels. The large vessels, which supply the kidney, are surrounded by large lymphatics.]

The nerves of the kidney (Fig. 2 I9 II) ${ }^{3}$. Little is known of these. Nerve-fibres have been traced alongside the larger bloodvessel through the greater part of the kidney.

\section{B. The ureters.}

a. General description. In the males the ureters are, at the same time, the seminiferous ducts. Each ureter commences on the dorsal surface of the kidney by bifurcating branches, which are continuous with the collecting-tubes of the kidney. In the anterior two-thirds of the kidney the ureter is wholly on the dorsal surface; at the junction of the middle and posterior thirds it winds round to the outer border of the kidney (Fig. $21+(r)$, and there lies in a groove accompanied by the renal portal vein (Fig. $220 V_{r}$ and $T^{*} a$ ), the two organs being intimately attacher to the kidney substance and enclosed by the fibrous capsule $(B g)$.

This portion of the ureter possesses a spindle-shaped enlargement, which represents the Receptaculum seminis. In Rana temjoraria the Recejtaculum seminis forms a large saccular dilatation.

In its further course the ureter runs backwards and slightly inwards, converging with its fellow of the opposite side; the ureters lie free in the abdominal cavity, and terminate by two openings placed side by side in a groove on the dorsal wall of the cloaca (Fig. $214 S, S^{1}$ ).

In females the ureters are intimately attached to the dilated oviduct, immediately after leaving the kidney; they pursue a similar course to those of the males, but are attached to the oviduct in the whole of their course to the cloaca.

b. Minute structure. The ureter is a tube composed of connective-

1 See Plate II.

Two portions from a gold preparation of the kidney of Rana esculentu.-- (j. H.

I. Showing the tendency to split into lobules,

II. Nerve-fibres accompanying the blood-reesels.

a Blood-veasicls.

b Nerres, 
tissue and involuntary muscular fibre, and lined with a mucous membrane. The mucous membrane is thrown into longitudinal folds, and consists, in the larger tubes, of two or three layers of epithelium (Fig. $218 \mathrm{~V}$ ), that on the

Fig. 220.

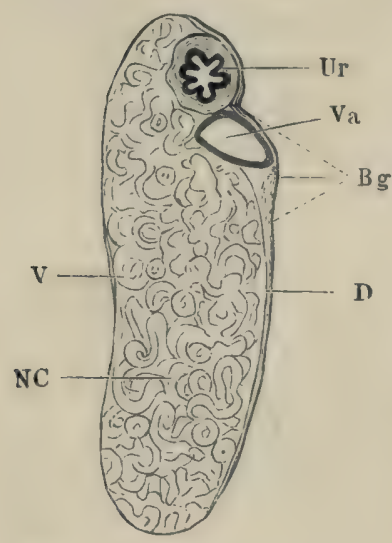

Transverse section of the kidney, enlarged.

$B g$ Connective-tissue capsule.

1) Dorsal surface.

NC Renal parenchyma.

$\mathrm{Ur}$ Ureter.

$V$ Ventral surface.

Fa Renal portal vein. free surface is columnar; the deeper cells being rounded or polygonal. The larger branches of the ureter are lined with columnar epithelium (Fig. $218 \mathrm{VI}$ ), with small intervening cells. In some parts of the branches the columnar epithelium bears short cilia.

No glands have been found in the ureter or Receptaculum seminis; in Rana temporaria, however, the Receptaculum seminis possesses large, branching mucous glands (Wiedersheim).

\section{The bladder.}

a. General deseription. The urinary bladder (Fig. I $85 H B$ ) is elosely attached to the ventral wall of the cloaca and is easily distended from that organ. In relation to the animal it is of very large size; in consequence of its being contracted in the middle it has two lobes, which may be of unequal size. The organ is somewhat heart-shaped (Figs. 184 and I 85), with the narrow neck attached to the cloaca, into which it opens by a smaller aperture on the ventral surface. The aperture is surrounded by a small fold of mucous membrane.

b. Minute structure. The urinary bladder is bounded by a thin, transparent wall, lined internally with mucous membrane, and covered externally by peritoneum.

(I) The muscular coat is formed of a network of fine bands of unstriated muscular fibre (Fig. 22I ); it is supported and completed by a connective-tissue layer, rich in connective-tissue corpuscles and yellow elastic fibres.

(2) The peritoneal coat is a single layer of endothelial cells derived from the peritoneum and resting on a very thin layer of subperitoneal tissue. 
(3) The mucons coat is formed of epithelium resting on a layer of loose, areolar tissue. The epithelium (Fig. $221 \mathrm{I}$, II, and IV) is

Fig. 221.

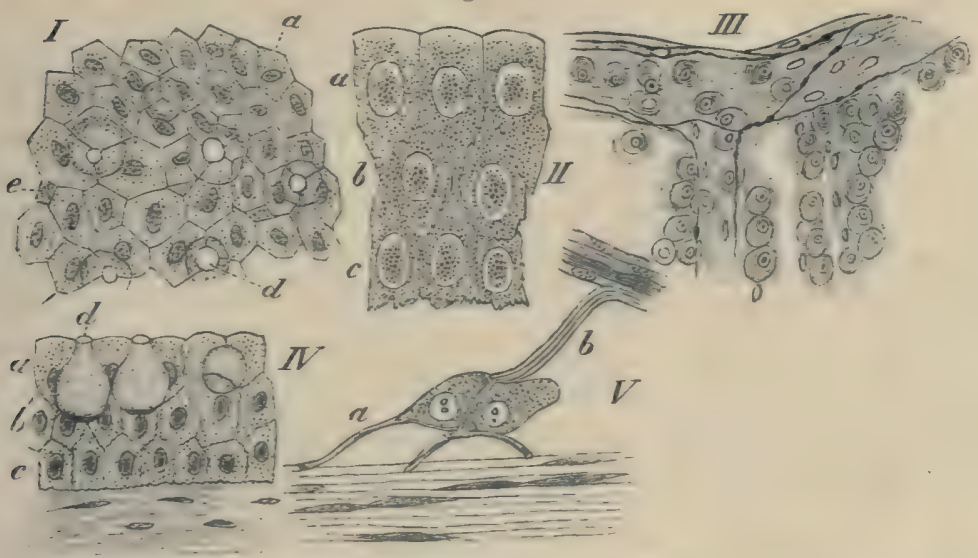

Tarions preparations from the bladder.

1. Silver preparation of the mucuus membrane; seen fnu the surface. After List (enlarged 400 times).

$$
\begin{aligned}
& \text { a Colls of the gurface } \\
& \text { d Goblet-cells. } \\
& \text { e Young cells. }
\end{aligned}
$$

11. Vertical section of the muens membrane; after Lixt (enlargerl 600 times).

$$
\begin{aligned}
& \text { a Cells of npper layer. } \\
& \text { c Cells of middle layer. } \\
& \text { Cells of lower layer. }
\end{aligned}
$$

III. Large multicellular ganglion; after Wolf.

IV. Vertical section froun a silver preparation of the mueons membrane; after fist (enlanged 600 times).

$$
\begin{array}{ll}
\text { a } & \text { Upper layer. } \\
\text { C } & \text { Middle layer. } \\
\text { c Lower layer. } \\
d \text { Goblet-cells. }
\end{array}
$$

V. Small ganglion of bladder; after Wolfi.

\section{a Non-medallated nerve-fibre leading to ganglivn.}

b Proceas of a ganglion $\cdots l l$.

arranged in three layers: the cells of the uppermost (II and IV, a) always present a flat or convex border to the cavity of the organ; seen from their free surfaces (I) they have polygonal outlines intermixed with round apertures belonging to goblet-cells, the remaining surfaces of these cells are serrated. The cells of the middle layer (II and $I V, b)$ are polygonal in outline, they are not so tall as the cells of the laver alove ; all their borders are serrated. The cells of the deepest layer (II and IV, c) are more or less pointed above where they project between the cells of the second layer; their lowest surfaces are flattened towards the subepithelial tissue, and all their surfaces are serrated. 
The cells of all three layers possess a cell-wall, and finely granular contents, and each cell has a large oval nucleus (List).

The goblet-cells (Fig. 22I I and IV, d) vary very much in shape; they are always more or less rounded in outline: they vary greatly in size (from $190 \mu$ to $54 \mu$ in length); some possess 'feet' or basal prolongations, in others these are absent. They usually open freely by rounded apertures on the surface of the mucous membrane, but are sometimes closed. The nucleus is placed towards the base of the cell and surrounded by a smaller or larger amount of protoplasm. These cells usually extend into the middle layer of the epithelium, and they probably constitute unicellular mucous glands (List).

(4) The blood-vessels of the urinary bladder (p. 235) are very numerous and run in very tortuous courses; they are accompanied by large lymphatics and by nerves.

(5) The nerves of the urinary bladder (p. I9I) are of both medullated and non-medullated fibres, which course together towards their points of distribution; the non-medullated fibres are, however, much more frequent than the medullated fibres (Wolff).

The non-medullated nerve-fibres stand in close relation with the nerve-ganglia of the bladder. These ganglia may be unicellular, or composed of groups of nerve-cells; the cells vary considerably in shape, round, oval, triangular, and other forms being equally frequent in their occurrence; to some extent the form appears to depend upon the number and position of the processes of the cells. The diameter of the cells varies from $0.05 \mathrm{~mm}$. to $0.1 \mathrm{~mm}$; the nucleus has a diameter of $0.025 \mathrm{~mm}$., that of the nucleolus measures $0.005 \mathrm{~mm}$. (Wolff).

The cells may be unipolar or multipolar ; the former are however rare. The processes of these cells supply the muscle-fibres (Fig. $22 \mathrm{I} \mathrm{V}, a$ ), and other non-medullated processes connect the cells with the nerves (V, $b$ (Wolff) ).

The number of muscular fibres is far in excess of the number of the fibres of distribution of the ganglia; Wolff hence concludes that the nervous impulse may pass from one muscle-fibre to another.] 


\section{THE REPRODUCTIVE ORGANS.}

A. The male reproductive organs are the testes and their ducts.

a. General description. The relations of the testes have already been given (p. 234 ); the organs vary much in shape and size in different individuals and with the different seasons; when greatest they are spherical, or of a rounded oral form, oceasionally cone-shaped or pear-shaped. The surface of the testes is not

Fig. 222.

I.

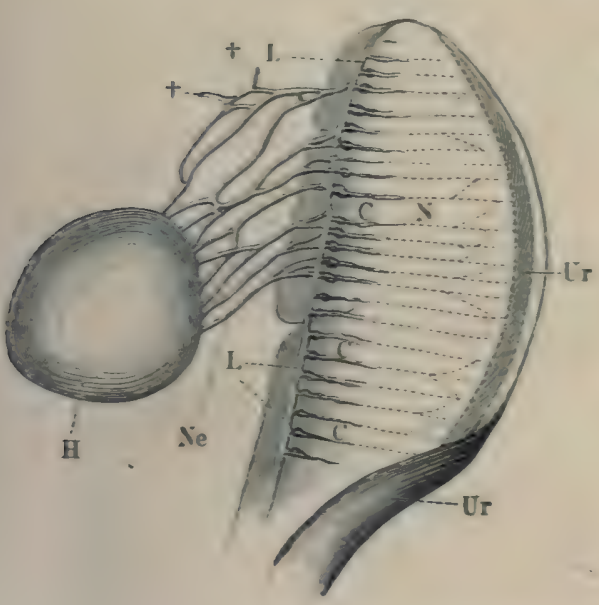

II.

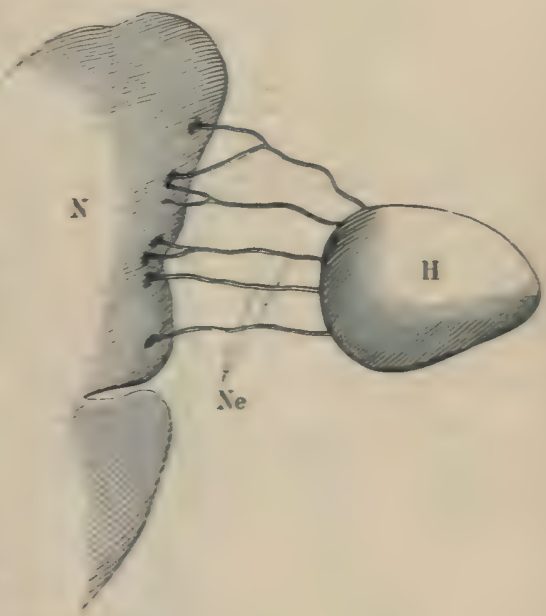

The male repnoductive organs (enlareed)

\begin{tabular}{|c|c|}
\hline & with \\
\hline & Teris. \\
\hline & Cullecting-tabe at inner border of kidner. \\
\hline & Kidney. \\
\hline Ne & Vasa efferentia within the mesorchium. \\
\hline $\boldsymbol{E}_{\mathbf{r}}$ & Lreter. \\
\hline t1 & Vass eiferentia ending blindly. \\
\hline
\end{tabular}

smooth, but presents a series of convexities, each corresponding to a lobule of the gland. At the hilus on the inner border the ressels pass to and from the organ, and the Fasa efierentia leave the testis.

The number of Tasa efferentia (Fig. $222 \mathrm{I}$ and II) is subject to considerable rariation, not only in different animals, but on the two sides of the same animal. In some cases these ducts form a network (I), in other cases this is absent (II); usually the ducts 
bifurcate at acute angles, just before entering the kidney. Most of the tubes so formed open into the collecting-tube; a few, however,

Fig. 223.

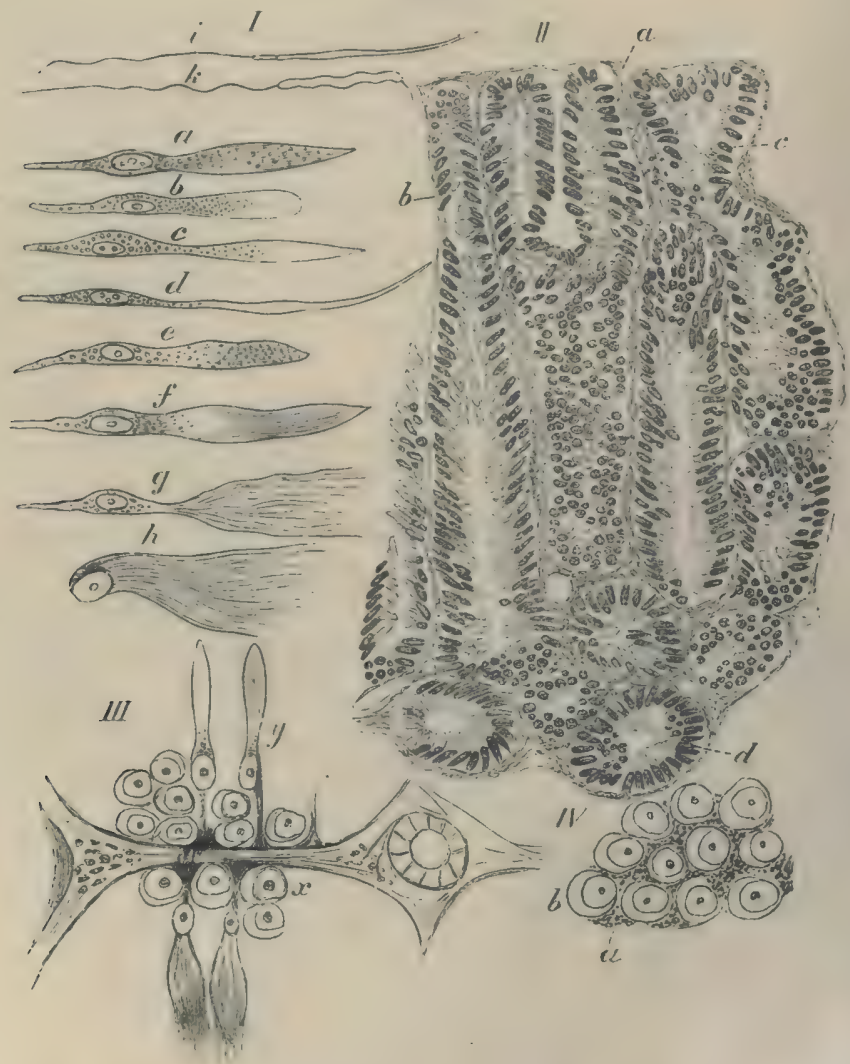

Various preparations from the testis.

I. Various stages of the spermatozoa; from testis of Rana temporuriu. After Neumann.

II. Section from testis of Rana eseulenta (Hartnack, Oc. I, Syst. 7).-G. H.

$$
\begin{aligned}
& a \text { Thin connective-tiesue capsule. } \\
& b \text { Trabeculae. } \\
& c \text { and } d \text { Seminiforous tubs. }
\end{aligned}
$$

III. From testis of Ranu temporaria. After Neumann.

$$
\begin{aligned}
& x \quad \text { Rounded epithelium of seminiferous tubes. } \\
& y \quad \text { Spermatohlasts. }
\end{aligned}
$$

IV. Surface view of Beminiferous tube of Rana temporaria. After Neumann.

$$
\text { a Granular protoplasmic feot of spermatoblasts. }
$$

end blindly in the mesorchium $(\mathrm{I},+)$. The course of the Tasa efferentia from the testis is first inwards, within the mesorchium; on reaching the kidney they curve dorsalwards between that organ and the- 
corresponding testis: the ducts then travel in the ventral surface of the kidney towards its inner border, where they open into a longitudinal canal (Bidder), (Fig. 222 I, L). Just before their terminations each duct has an enlargement $(I, C)$, the exact import of which is unknown (see also Fig. $218 \mathrm{XV}$ ).

The collecting-tubes open into the ureter at the hinder extremity of the kidney.

b. Minute structure. The testis possesses a thin connectivetissue capsule underneath its peritoneal covering (Fig. 223 II, a); this sends in trabeculae $(b)$ towards the centre of the organ, and so encloses the separate lobules. Each seminiferous tube arises from an elongated irregular sinus placed towards the middle of the organ; the tubes $(c)$ are slightly convoluted in their course towards the periphery, near which they branch (Spengel). The tubes are from $0.16 \mathrm{~mm}$. to $0.12 \mathrm{~mm}$. in diameter (Kölliker), and are lined with two kinds of cells (Fig. 222 III); the cells $(x)$ nearer the periphery are rounded and have large rounded nuclei, the diameters of which vary from 0.013 to $0.02 \mathrm{~mm}$; these again possess large and distinct nucleoli. The other cells $(y)$ are of elongated, spindleshaped form; and have oral nuclei, with an arerage length of $0.016 \mathrm{~mm}$. and an average breadth of $0.005 \mathrm{~mm}$. (Neumann).

The rounded cells lie in groups which vary in thickness and arrangement, and are often compressed so as to have polygonal outlines. The spindle cells are arranged so as to radiate from the lumen of the tube to the periphery, at an angle which varies from +5 to co degrees; these are the spermatoblasts.

s The various changes which the spermatoblasts undergo in the formation of spermatozoa will easily be understood by reference to Fig. 223 I, $a$ to $k$, where $i$ and $k$ represent the fully developed spermatozoa. These have three parts, head, middle part, and tail, the respective lengths of which in the two species are, according to Neumann, the following:-

\begin{tabular}{llll} 
& \multicolumn{1}{c}{ Head. } & Middle part. & \multicolumn{1}{c}{ Tail. } \\
Rana esculenta & $0.0140 \mathrm{~mm}$. & $0.0025 \mathrm{~mm}$. & $0.040 \mathrm{~mm}$. \\
Rana temporaria & $0.0066 \quad$, & 0.0330, & $0.045 \quad$,
\end{tabular}

At the hilus of the testis the rounded cells of the seminiferous tubes are gradually modified to form short cylindrical cells ( $0^{\circ} \mathrm{OI}$ $\mathrm{mm}$. long and $0.006 \mathrm{~mm}$. broad), the spindle cells being absent (Neumann). The Tasa efferentia are also lined with a similar columnar epithelium (Spengel).] 
B. The female reproductive organs.

The position of these organs has already been given ( $\mathrm{p}$. 335).

\section{The ovaries.}

Fig. 224.

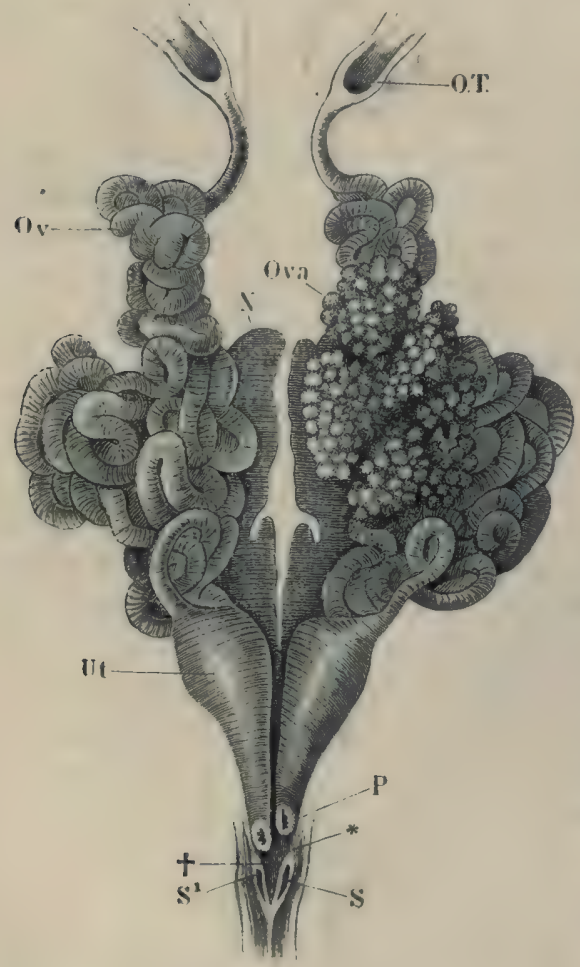

The female reproductive organs; the ovary of the right side has been removed.

$\boldsymbol{N}$ Kidnoy.

O.T. Opening of the oviduct into pleuro-peritoneal cavity. ov Oviduet.

leva Ovary.

$\boldsymbol{P}$ Opening of oviduct into the cluaca.

$S, S 1$ Openings of the ureters.

Ut Dilated hinder portion of the oviduct.

+ Groove in which areters lie:

* Fold in grodve separating the openings of the ureters a. General description. Each sac-like ovary (Fig. 224 ) is subdivided by thinwalled septa into numerous complete chambers, to the inner walls of which the ova are attached. The walls of adjacent sacs aire intimately attached to each other, and the subdivision corresponds with the external lobulated appearance of the organ. According to Spengel the number of lobules is about fifteen (Rathke nine to thirteen, Brandt nine). Whether this segmentation of the ovary corresponds with the segmentation of the body has not been determined (Spengel). No part corresponding with Bidder's organ has been found in Rana esculenta.

During the breeding season the ovaries undergo an extraordinary increase in size so as to occupy the greater part of the bodyeavity and to displace the other viscera. The ovaries are entirely surrounded by peritoneum.

b. Minute structure. [The layer of peritoneum covering the ovary possesses cilia (Thiry), the ciliated cells being arranged in isolated patches (Schweigger-Seidel, Waldeyer) on the ventral surface of the organ, and on the mesovarium; these patches are some- 
times united by very fine connecting lines of ciliated epithelium; the ciliated epithelium is always sharply marked off from that surrounding it (Kolessnikow). Under the peritoneum is a thin layer of connective-tissue, which is prolonged inwards to form the septa above-described. To these septa are attached the ova.

Between the counective-tissue layer and the peritoneum are isolated patches of germinal epithelium (Fig. 22.5 IV); these are easily distinguished, by the rounded outlines of their cells, from the surrounding epithelial cells (Walderer, Kolessnikow). These patches of germinal epithelium measure from $0.093-0.186 \mathrm{~mm}$. in diameter; the germinal cells average $0.0139-0.0232 \mathrm{~mm}$. in diameter (Kolessnikow). The patches are most numerous on the outer surface of the ovary, and particularly so near the mesovarium.

The follicles contained in the ovary have a connective-tissue coat developed in a manner similar to that of higher animals; the primordial ova which they contain have large nuclei $(0.0325 \mathrm{~mm}$.). The epithelium of the follicles has an average diameter of 0.0232 $0.0325 \mathrm{~mm}$. (Kolessnikow).

Schultze's description of the ovaries (7.c.) varies considerably from that of Walderer and Kolessnikow. Briefly he describes the ovaries as a series of sacs separated by and lined externally and internally by endothelium; between these two layers are found the germinal epithelium and follicles: the structures being held together by an extremely minute quantity of connective-tissue.]

II. The oviducts.

a. General description. In young animals the oviducts are quite straight, thin-walled, and of small calibre. During the breeding season, however, ther undergo an immense increase in size, and become much convoluted; in this state they are forced in between the other abdominal viscera, and usually cover the whole of the kidneys, and sometimes even part of the ovaries (Fig. $224 \mathrm{Or}$ ).

The openings of the oviducts into the pleuro-peritoneal cavity (p. 304) are semilunar slits, directed inwards and lined with ciliated epithelium (p. 306).

Immediately behind this opening (Ostimm ablominale) the oviduct is contracted, and is there narrower than in the rest of its length; beyond this it expands, and then retains an even size nearly to its hinder extremity, where it suddenly expands (Fig. $224(t)$. This dilatation gradually diminishes in size as it proceeds backwards towards the cloaca, into which each tube opens on a small papilla. The dilated portions of the tubes lie close together, 
but do not communicate with each other; the opening of the right tube is always slightly behind that of the left side (Fig. $224 P$ ). From the papillae, into which the oviducts open, a fold of mucous membrane extends backwards on the dorsal surface of the cloaca to meet its fellow of the opposite side at an acute angle (Fig. $224^{*}$ ). The orifices of the ureters are placed within these folds.

\section{b. Minute structure.}

(I) The tubular portion of the oviduct has three walls: a peritoneal covering with sub-peritoneal tissue $(a)$; a glandular layer $(b)$; and an epithelial lining $(c)$. Of these the glandular layer forms by far the thickest layer, especially during the breeding season, when it is much increased in thickness. It consists of long cylindrical glands, often bifurcated at their blind, peritoneal ends. The epithelial cells, with which they are lined,

Fig. 225.

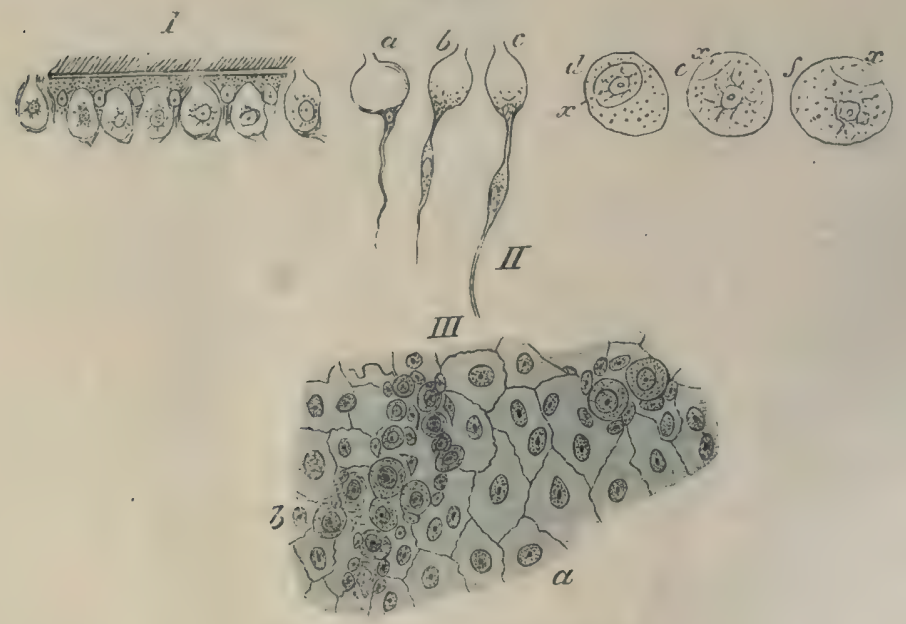

Preparations from ovary and oviduct.

I. Ciliated epithelium and goblet-cells of the oviduct; after Neunann.

II. Isolated goblet-cells and secretory cells from oviduct; after Neumann. $\boldsymbol{a}, \boldsymbol{b}, \boldsymbol{c}$ Goblet-cells.

$d, e, f$ Secretory cells after treatment with Müller's fluid.

$x$ Stoma of secretory cells.

III. Surface view of the ovary ; after Kolessnikow.

a Peritoneal endothelium.

$b$ Germin 1 l epithelium.

have the power of absorbing more than a hundred times their own weight of water (Boettcher). This layer is absent at the anterior opening of the oviduct. 
The cells have an average diameter of $0.012 \mathrm{~mm}$., the lumen of the individual glands $0^{\circ} 1 \mathrm{~mm}$. (in spirit-hardened specimens, Neumann). The cells contain small rounded bodies of very varying size, which may exist singly, grouped, or even arranged in rows; they swell on the addition of water. Each cell possesses, in addition, an oval, granular, distinct nucleus. When treated with Muller's fluid many of the secretory cells have the appearances shown in Fig. 225 II, $d, e, f$; they each possess an opening ( $x),($ Neumann).

According to Neumann the great power of absorbing water, which the oviducts possess, is due to the presence of these bodies, which he names 'colloid granules.' The mucous secretion of these glands passes into the oviduct and surrounds the eggs on their passage towards the cloaca : it is due to this secretion that the egg-spawn is so extremely slippery and difficult to handle.

The inner surface of the oviducts is lined with a ciliated, columnar epithelium (Fig. 225 I), containing numerous goblet-cells (I and II).

(2) The dilated portion of the oviduct has much thinner walls than the anterior, narrower portion; the glands cease abruptly at the junction of the two parts. The outer coat also contains unstriated muscular fibre; the inner surface is lined with ciliated epithelium similar to that of the anterior portion.

The lymphatics of the oviducts form a net with polygonal meshes on their outer surfaces; from this branches pass inwards in the spaces between adjacent glands to the inner surface, where a network with elongated meshes is formed (Langer).

\section{C. [The Cloaca.}

a. General description. The cloaca is a short tube lying beneath the urostyle; anteriorly it receives the openings of the ureters, rectum, and bladder; and in the female the openings of the oviducts, in addition : posteriorly it terminates at the anus.

b. Minute structure. The cloaca is lined internally with a mucous membrane resembling that of the rectum, e.g. a simple layer of columnar epithelium, which rests on a submucous, areolar layer.

The outer walls consist of a thick superficial, longitudinal muscular layer, and a deeper, ill-developed, transverse muscular layer.

\section{c. Special muscles of the cloaca.}

(1) The M.sphincter ani surrounds the end of the cloaca from the anus to the tip of the urostyle. It consists of striated muscle. 
348 THE URINO-GLNITAL SYSTEM, THE ADRENALS, ETC.

(2) The $M$. compressor cloacae arises from the tip of the urostyle, and is inserted into the hinder end of the rectum; it is also attached to the symphysis of the iliac bones; from this point a few fibres pass to the anus (Hoffmann).]

\section{THE ADRENALS.}

a. General description. The adrenals are small yellow bodies

Fig. 226.

C $v$ in

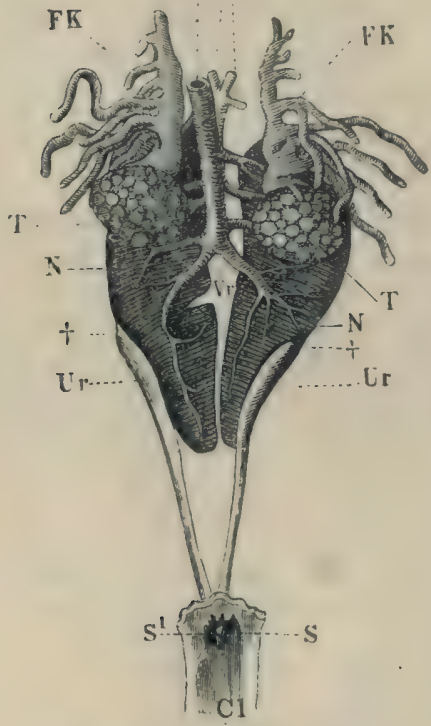

The male urino-genital urgans.

Ao Aorta.

Cl Cloaca.

Cv Inferior vena cava.

FK Fat-body.

$\boldsymbol{N}$ Kidney.

S, S1 Openings of ureters.

T Testis,

Ur Ureter.

Vro Rehal veins.

+ Appearance of ureters on the ventral surfaces of kidneys. attached to the renal veins on the ventral surface of the kidney, towards its outer border.

b. Minute structure. The superficial layer of the adrenals consists of solid, rounded, or elongated groups of polygonal cells, containing numeroùs fatgranules; these represent the cortical substance of the corresponding organs of higher animals. The medullary part is present only in small quantity; it consists of small groups of polygonal cells, placed between trabeculae of connective-tissue; both trabeculae and cell-groups are covered with an endothelium. The whole organ is surrounded by a connective-tissue capsule, which sends in trabeculae to support the parenchyma (Hoffmann).

No nerves have been traced into these organs (Eberth).]

\section{THE FAT-BODIES.}

a. General description. The fat-bodies (Fig. 226) are bright yellow, lobulated bodies, placed in front of the testes and ovaries respectively. The greater portion of each organ lies parallel to the long axis of the body, and from its anterior, posterior, and external 
borders are given off finger-like processes; these may divide dichotomously either near the base or more peripherally. The external processes are much the longest, and in the male often conceal the greater part of the testis (Fig. $226 F K$ ). The organs vary greatly in size with the season of the year.

Fig. 227 .
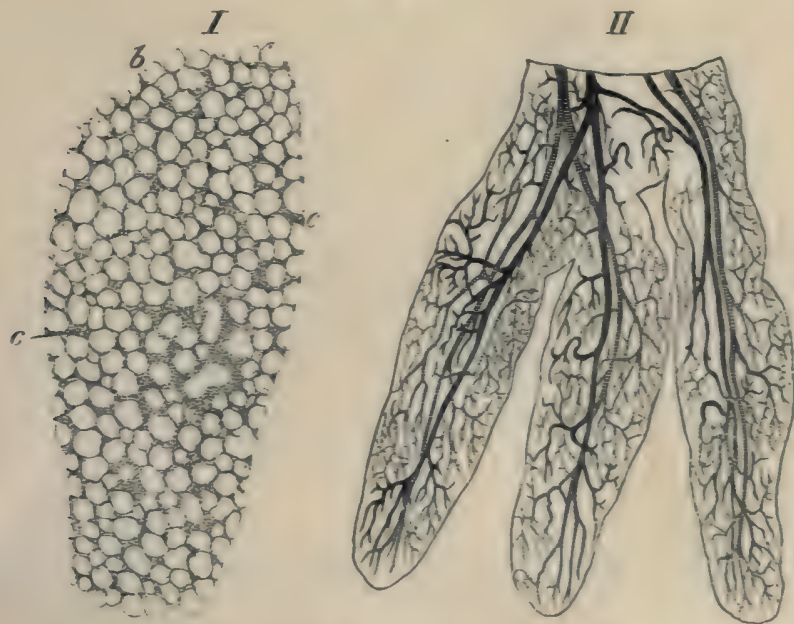

Two preparations from the fat-body of Rana esculenta 1,-G. H.

1. Section of fat-budy, stained with borax-carmine (Hartnack, (Ne. I, Syst. 7). $b$ Fat-cells.

c Adenoid tisere.

II. Three lobes of fat-body of Ranu esculenta ; coarsely injected (Hartnack, Oc. I, Syst. 3). Arteries striped. Veins shaded.

b. [Minute structure. Each organ is completely surrounded by peritoneum, under which is a very fine layer of connective-tissue. The interior of the organ (Fig. 227 I) consists of large fat-cells with small patches of adenoid tissue interspersed. The organs are extremely vascular; each lobe has a main artery which gives off lateral branches: each of these immediately divides to form two vessels, which run in opposite directions and almost parallel with the main stem; the ressels then break up into a fine network of capillaries.] 



\section{SECTION VIII.}

\section{THE SKIN AND THE SENSE-ORGANS.}





\title{
THE SKIN AND THE SENSE-ORGANS.
}

\author{
LITERATURE.
}

\section{THE SKIN.}

Ascherson, Teber die Hsutdrüsen der Frösche. Arch. f. Anat. u. Physiol. I810, p. I5.

Axmann, Beiträge zur mikroskopischen Anatomie und Physiologie des Gangliennervensystems, 1853 .

de Betta, Erpétologia delle provincie Tenete e del Tirolo meridionale. 1857 .

Biesiadecki, Ceber Basenbildung und Epithelregeneration an der Schwimmhat des Frosches. Catersuchungen aus d. Krakauer path.-anatom. Institut. 1872, pp. 60-84. Abstract in Centralbl. f. d. med. Wiss. 1873, No. 7, p. 106.

Bimmermann; F. H., Ueber den Einfluss der Nerven auf die Pigmentzellen des Froeches. Diseert. Strasbung, 1878.

Bimmermann, E. H., Ueber den Einfluss der Nerven auf die Pigmentzellen des Frosches, Centralbl. f. d. med. Wiss. 1879, p. 545.

de Blainville, M. H. M. Ducrotay, De l'Organization des animsux. Paris, 1822, Pp. I42, 225 .

Bolaw, Beitrag zur Kenntnisg der Amphibienhaut. Güttingen, 1866.

Bruch, Beiträge zur Naturgeschichte und Classification der nackten Amphibien. Würzburger naturwise. Zeitseh. 1864. Vol. III.

Brücke, Untersuchungen über den Farbenwechsel des afrikanischen Chamaeleon. Sitzungsb. der Wiener Acad. I852. Vol. IV, p. 196.

Bugnion, Recherches sur les organes sensitifs qui se trouvent dans l'épiderme du Protée et de l'A rolotl. Dissert. Zürich.

Canini, A., Die Endigungen der Nerven in der Hant des Froschlarvenschwanzes. Arch. f. Anat. u. Physiol. 1880, pp. 143-153.

Ciaccio, J. V., Intorno alla minuta fabbrica della pella della Rana esculents. Palermo, 1866. Giornale di Scienze naturali ed economiche. Vol. II, pp. 103-158.

Cisccio, J. V., On the distribution of the nerves to the skin of the frog, with physiological remarks on the ganglia connected with the cerebro-spinal nerves. Trans. Micros. Soc. London, 1864. Vol. XII, pp. I5-31.

Czermak. J. N., Leber die Hautnerven des Frosches. Arch. f. Anat. u. Physiol. I $849, \mathrm{p} .252$.

Da Collin, Danemarks Froer og Tudser. Naturhist. Tidsskrift. 18 \% .

Dewitz, Ceber das rerschiedene Aussehen der gereizten und ruhenden Drūen im Sehenballe des Laubfrosches. Biol. Centralbl. I\$83, p. 558.

Dogiel, Neue Cntersuchungen ăber den papillenerweiterden Muskel, etc. Arch. f. mik. Anat. 1886. Vol. XXVII, p. 403.

Dumbril et Bibron, Erpétologie générale. 18.41. Vol. VIII. 
Eberth, C. J., Untersuchungen zur normalen und path. Anatomie der Froschhaut. Leipzig, $\mathbf{1} 869$.

Eberth, C. J., Zur Entwickelung der Gewebe im Schwanze der Froschlarven. Arch. f. mik. Anat. 1866. Vol. II, pp. 490-503.

Eckhard, Ueber den Bau der Hautdrüsen der Kröten und die Abhängigkeit der Entleerung ihres Secretes vom centralen Nervensystem. Arch. f. Anat. u. Physiol. 1849.

Ehrmann, S., Ueber Nervenendigungen in den Pigmentzellen der Froschhaut. Sitzungsb. der Wiener Acad. I 882. Vol. LXXXIV, Pt. III, pp. $165^{-1} 70$.

Engelmann, T. W., Pfüger's Arch. f. d. ges. Physiol. 1871, Vol. IV, p. 32r, and

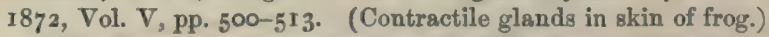

Harless, E., Ueber die Chromatophoren des Frosehes. Zeitsch. f. wiss. Zool. 1854 , Vol. V, p. 372 ; also in Münchener Gelehrten Anzeiger, 1853, No. 35.

Harley, G., On the organs of cutaneous respiration; principally on those of Rana temporaria. Tran8. Micros. Soc. London, I857. Vol. V, p. I48.

Hensche, A., Ueber die Drüsen und glatten Muskeln in der äusseren Haut von Rana temporaria. Zeitsch. f. wiss. Zool. 1856. Vol. VII, p. 273.

Henslow, Way in which toads shed their skin. Annals of Nat. History, 1850, p. 69 .

Hoffmann, C. K., Bronn's Klassen und Ordnungen des Thierreichs. Leipzig und Heidelberg, $1873-187^{8}$. Vol. VI.

Huber, O., Ueber Brustwarzen bei Rana temporaria, L. Zeitsch. f. wiss. Zool. I 88 7 . Vol. XLV, p. 664.

Huizinga, D., Untersuchungen über die Innervation der Gefäse in der Schwimmhaut des Frosches. Pflüger's Arch. 1875. Vol. XI, p. 207.

Huxley, H. T., Tegumentary organs. Todd and Bowman's Cyclopædis of Anat. and Physiol. p. 500.

Klein, E., On the lymphatic system of the skin and mucous membranes. Quart. Journ. Mieros. Sei. 188r. Vol, XXI, pp. 379-406.

Kölliker, A., Stiftchenzellen in der Epidermis von Froschlarven. Zoolog. Anzeiger. I 885 .

Krause, Handbuch der Gewebelehre. I862.

Krukenberg, C. F. W., Die Hautfarbstoffe der Amphibien, in Vergleich. physiol. Studien, by same author, 1882, pp. 43-49.

Kutschenko, N., Ueber die Krappfäbung der Froschgewebe. Arch. f. mik. Anat. 1882. Vol. XXVIII, pp. $360-364$.

Langer, Ueber das Lymphgefässsystem des Frosches. Wiener Sitzungsberichte. 1867. Vol. LV, pp. 593-636.

Langerhans, Anat.-hist. Untersuchungen iiber Fische und Reptilien. Berlin, 1853. Journal de Medicine. Vol, XI.

Leboucq, H., Recherches sur le développement et la terminaison des nerfs chez les larves des Batraciens. Bull. de l'acad. roy. de Belgique. 18;6. Vol. XLI, p. 4 .

Ieydig, F., Histologisch-anatomische Untersuchungen über Fische und Reptilien. 1853.

Loydig, F., Tastkörperchen und Muskelstruktur. Arch. f. Anat. u. Physiol. 1856 , pp. 150-159.

Ioydig, F., Lehrbuch der Histologie. 1857.

Leydig, F., Ueber die Nervenendigung in den sogenannten Schleimkanälen der Fische und über entsprechende Organe der durch Kiemen athmenden Amphibien, Arch. f. Anat, u. Physiol. 186r.

Leydig, F., Ueber die Organe eines sechsten Sinnes. Nov, act. acad. Leop. Carol. 1868. Vol. XXXIV, pp. $\mathrm{x}-102$.

Loydig, F., Ueber die allgemeinen Bedeckungen der Amphibien. Arch. f. mik. Anat. 1875. Vol. XII, p. 119.

Løydig, F., Ueber die Sehleichenlurehe. Zeitseh. f. wiss, Zool. Vol. XVIII. 
Leydig, F., Teber die Schwanzflosse, Tastkörperchen und Endorgane der Nerven bei Batrachiern. Arch. f. mik. Anst. IS 6 . Vol. XII, pp. 513-52\%.

Leydig, F., Die snuren Batrachier der deutschen Fauna. Bonn, 18\%, p. I 23.

Lister, J., On the cutaneous pigmentary system of the frog. Phil. Trans. 1857. Vol. CXLVIII, p. 62\%.

Macallum, A. B.; The nerve terminations in the cutaneous epithelium of the tadpole. Quart. Journ. Micros. Sci. I8\$6. Tol, XXVI, p. 53.

Mayer, A., Ceber das Epithelium bei den Amphibien. Froriep's Notizen, 1839. Vol. IX, coll. 49-51.

Menke, Rans rubita, Linn. Zeitschr. Isis von Oken. I82;. Tol. XX, p. I72.

Merkel, Teber die Endigungen der sensiblen Nerven in der Haut der Wirbelthiere. Rostock, 1880.

Meyer, Ceber die Abhängigkeit der Gefässe und Pigmentzellen beim Frosch von dem Nerveneinfluss. Virchow's Arch. 1854. Vol. VI, p. 581.

Openchowski, T., Histologisches zur Innervation der Urüsen. Pfläger's Arch. 1882. Vol. XXVII, pp. 223-232.

Pfitsner, W., Die Epiderunis der Amphibien. Morph. Jahrb. I8So. Vol. VI, p. 469 .

Rainey, On the structure of the cutaneous follicles of the toad. Quart. Journ. Mieros. Sci. Vol. III, p. 257.

Roesel, Historia natur. rana. nostrat. Nürnberg, 1758, p. 3, etc.

Rudneff, Leber die epidermiodale Schicht der Froschhaut. Arch. f. mik. Anat. 1865. Vol. I, p. 295.

Sattler, E. E., Die Verwendung des Lapisstiftes zur Cntersuchung der Epithelien. Arch. f. mil. Anat. 1882. Vol. XXI, p. 672.

Schneider, Historia amphibiornm. 1739.

Schultze, F. E., Epithel und Drüsenzellen. Arch. f. milk. Anat. 186\%. Vol. III, p. 145 .

Schultze, F. E., Ceber cuticulare Bildungen und Verhornung von Epithelzellen bei den Wirbelthieren. Arch. f. mik. Anst. 1869. Vol. V, p. 295.

Schultze, M., Ceber die Nervenendigung in der Netzhaut des Auges bei Menschen und Thieren. Centralbl. f. med. Wiss. 1869, p. 885 .

Stieda, I., Leber den Bau der Haut des Frosches. Arch. f. Anst. u. Physiol. I865, pp. 52-66.

Stricker, S., and Spins, A., Cntersuchungen über die mechan. Leistungen d. acinüsen Drüsen. Wiener med. Jahrb. I880, p. 355 ; und Wiener Sitzungsb. 1880. (Skin and Membrans nictitans.)

Swemmerdam, J., Biblia naturae. Vol. II, p. 808.

Szcesny, Beiträge zur Kenntniss der Textur der Fruschhaut. Dissert. inang. Dorpat, 1867.

Turner, Way in which toads shed their skins. Annals of Nat. History, 1850, p. 430 .

Wagner, R., Handwörterbuch der Physiologie. Vol. III, p. 389.

Walter, Leber die Drüsen des Daumenballens des Froschmännchens. Verhandl. d. naturf. Vereins der pr. Rheinlande und Westphalen. IS 51, p. 351.

v. Wittich, Die grüne Farbe der Haut unserer Frösche, etc. Arch. f. Anat. u. Physiol. 1854, p. 4 r.

v. Wittich, Entgegnung auf Herm. Harless's ūber die Chromatophoren des Frusches. Arch. f Anat. u. Physiol. I854, p. 264. 


\section{SPECIAL ORGANS OF TACTILE SENSATION.}

\section{a. The lateral sense-organs.}

Beard, J., On the segmental sense-organs of the lateral line and on the morphology of the vertebrate auditory organs. Zool. Anz. 1884. Vol. VII, p. I62.

Bugnion, E., Recherches sur les organes sensitifs qui se trouvent dans l'épiderme du Protée et de l'Axolotl. Dissert. inaug. Zürich. Tire du Boll. No. 7, de la société vaucloise des Sc. nat. Vol. XII. Lausanne, I873. Verhandl. d. sehweiz, naturforsch. Gesells. Zürich, I873. Vol. LVI, p. 49.

Froriep, A., Ueber Anlagen von Sinnesorganen am Facialis, Glossopharyngeus und Vagus. Arch. f. Anat. u. Physiol. I885.

Hoffmann, C. K., Bronn's Klassen und Ordnungen des Thierreichs. Leipzig and Heidelberg, $1873^{-1} 878$.

v. Kölliker, A., Ueber neue Sinnesorgane von Frosehlarven. Sitzungsb. Wtirzburg. 1885, p. 79.

Krause, W., Die Nervenendigung innerhalb der terminal Körperchen. Arch. f. mik. Anat. 1880. Vol. XIX, pp. 53-I37.

Leydig, F., Ueber die Organe eines sechsten Sinnes. Nova acta Acad. Leopold. Carol. Dresden, 1868. Vol. XXXIV, pp. I-TO2.

Leydig, F., Ueber die allgemeinen Bedeckungen der Amphibien. Arch. f. mik. Anat. I875. Vol. XII, pp. 513-527.

Leydig, F., Ueber Tastkörperchen und Muskelstructur. Arch. f. Anat. u. Physiol. 1856, p. I 50 .

Malbranc, M., Bemerkung betreffend die Sinnesorgane der Seitenlinie der Amphibien. Centralbl. f. med. Wiss. 1875, p. 5 .

Malbranc, M., Von der Seitenlinie und ihren Sinnesorganen bei Amphibien. Zeitsch. f. wirs. Zool. 1876. Vol. XXVI, pp. 24-86.

Schultze, E E., Ueber die Nervenendigung in den sogenannten Schleimkanälen der Fische und über entsprechende Organe der durch Kiemen athmenden Amphibien. Arch. f. Anst. u. Phyiol. 1861, p. 759.

Schultze, F. E., Ueber die Sinnesorgane der Seitenlinie bei Fischen und Amphibien. Arch. f. mik. Anat. 187o. Vol. VI, p. 62.

\section{b. The touch-corpuscles of Golgi.}

Golgi, C., Della terminazione dei nervi nei tendini e di un nuovo apparato nervoso terminale museulo-tendineo. Atti della Società Italiana di scienze naturali. Milan, 1879. Vol. XXI; and abstracted in Centralbl. f. med. Wiss. 1879 , p. 725 .

Golgi, C., Intorno alla distribuzione e terminazione dei nervi nei tendini dell' uomo e di altri vertebrali. Estratto dai Rendiconti del R. Istituto Lombardo. Serie II. Vol. XI. Fasc. IX. Milan, 1878. Abstract in Centralbl. f. med. Wiss. 1879. Vol. 4I, p. 725 .

Löwe, L., Ueber eine eigenthümliche Art von Gelenknervenkörperchen beim Frosch. Arch. f. mik. Anat. 1880. Vol. XVI, p. 613.

\section{THE ORGANS OF TASTE.}

Beale, I. S., New observations upon the minute anatomy of the frog's tongue. Phil. Trans. 1865, p. 443 .

Biedermann, W., Ueber morphologische Veränderungen der Zungendrüsen des Frosches, ete. Wiener acad. Sitzungsb. I $88_{2}$. Vol. LXXXVI, Pt. III, p. 67. 
Billroth, T., Ueber die Epithelzellen der Froschzunge, etc. Arch. f. Anat. u. Physiol. 1858, p. 159.

Engelmann, T. W., Leber die Endigungsweise der Geschmacksnerven des Frosches. Centralbl. f. med. Wiss. 1867, p. 785 .

Ingelmann, T. W., Ueber die Endigungen der Geschmacksnerven in der Zunge des Frosehes. Zeitsch. f. wiss. Zool. 1868. Vol. XVIII, p. 142.

Fngelmann, T. W., Die Geschmacksorgane. Stricker's Handbuch der Gewebelehre. 1872 .

Fixsen, C., De linguae raninae structura. Dorpat, 1857 .

Gottschau, M., Ceber Geschmacksorgane der Wirbelthiere. Biol. Centralbl. I882, pp. $240-24^{8}$.

Hartmann, R., Ueber die Endigungsweise der Nerven in den Papillae fungiformes der Frosehzunge. Arch. f. Anat. u. Physiol. 1863, p. 634 .

Hoyer, Mikroskopische Cntersuchungen über die Zunge des Frosches. Arch. f. Anat. u. Physiol. 1859, p. $4^{81 \text {. }}$

Hoyer, Ueber die Epithelzellen der Froschzunge, etc. Arch. f. Anat. u. Physiol. 1858 , p. 163; also in Deutseher Klinik, 1857. No. 21.

Hyrtl, Ceber abwickelbare Gefässknäuel in der Zunge der Batrachier. Wiener Acad. Sitzungsb. 1863. Vol. XLVIII, Pt. I, p. 437.

Key, E. A., Ueber die Endigungsweise des Geschmacksnerven in der Zunge des Frosches. Arch. f. Anat. u. Physiol. 186r, p. 339.

Lépine (On the nerve supply of the glands of the tongue). Arbeiten aus d. physiol. Anstalt zu Leipzig, 1870, p. I13.

Molin, R., Ceber die Theilung der Nervenprimitivröhren in den Papillae fungiformes der Froschzunge. Wiener acad. Sitzungsb. 1849. Vol. III, p. 183 .

Schultze, F. E., Die Geschmacksorgane der Froschlarven. Arch, fo mik. Anat. 187o. Vol. VI, p. 407.

Waller, A., Minute structure of the organ of taste in vertebrate animals. Proc. Roy. Soc. I848. Vol. V, p. 75 I.

Waller, A., Minute structure of the papillae and nerves of the tongue of the frog and toad. Phil. Trans. 1848. Pt. I, p. 139.

Waller, A., Microscopic examination of some of the principal tissues of the tongue, ete. Phil. Mag. 1847. Vol. XXX, p. 277.

\section{THE NOSE.}

Babuchin, Das Geruchsorgan, in Stricker's Handbuch der Gewebelehre. I872, p. 964 .

de Blainville, M. H. M. Ducrotay, L'Organisation des animaux. Paris, I822, p. 328.

Blaue, J., Untersuchungen über den Bau der Nasenschleimhaut bei Fischen und Amphibien, namentlich über Endknorpel als Endapparate des Nervus olfactorius. Arch. f. mik. Anat. 1884. Vol. XXX, pp. 231-309. Zool. Anzeiger. Vol. V, pp. $657-680$.

Born, G., Ueber die Nasenhöhlen und den Thränennasengang der Amphibien. Morph. Jahrb. 1875. Vol. II, p. 4.

Born, G., Ceber die Nasenhöhlen und den Thränennasengang der Amphibien. Breslan. Habilit.-Schrift. 1877.

Born, G., Die Nasenhöhlen und der Thränennasengang der amnioten Wirbelthiere. Murph. Jahrb. 1879. Vol. V, p. 62. 1882. Vol. VIII, pp. 188-232.

v. Brunn, Die Membrana limitans olfactoria. Centralbl. f. med. Wiss. 1874, p. 709 .

v. Brunn, Untersuchungen über das Riechepithel. Arch. f. mik. Anat. 1875. Vol. $\mathrm{XI}, \mathrm{pp} \cdot 4^{68-478}$. 
v. Brunn, Weitere Untersuchungen über das Riechepithel u. sein Verhalten zum N. olfactorius. A rch. f. mik. Anat. I880. Vol. XVII, p. I4I.

Cisoff, Zur Kenntniss der Regio olfactoria. Centralbl. f. med. Wiss. I874, pp. $689-691$.

Cisoff, Zur Frage über die Endigung der Riechnerven beim Frosche. Arbeiten der naturf. Gesells. an der Universität Kassan. 1879. Vol. VIII (in Russian).

Clarke, J. Lockhart, Ueber den Bau des Bulbus olfactorius und der Geruchsschleimhaut. Zeitsch. f. wiss. Zool. 1862. Vol. XI, p. 31.

Colossanti, Untersuchungen über die Durchschneidung des $\mathrm{N}$. olfactorius bei Fröschen. Arch. f. Anat. u. Physiol. 1875.

Dirkinck-Holmfield-Christmas, J., Experimentalle Undersögelen Bijgningen. Nordiskt medicinskt Arkiv., 1883. Vol. XXVI, pp. 50-60.

Dogiel, A., Ueber die Drǔsen der Nasenschleimhaut, besonders die Bowmanschen Drüsen, Arch. f. mik. Anat.

Dogiel, A., Ueber den Bau des Geruchsorgans bei Garroirren, Knochenfischen, und Amphibien. Arch. f. mik. Anat. 188\%. Vol. XXIX, p. 74.

Dogiel, A., Ueber den Bau des Geruchsorgans bei Fischen und Amphibien. Biol. Centralbl. Vol. I, pp. 428-43I.

Dogiel, A., Ueber die Drüsen d. Regio olfactoria. Arch. f. mik. Anat. 1885. Vol. XXVI, p. 50.

Đcker, E., Bericht über die Verhandl. der Gesellschaft für Beförd. der Naturw. zu Freiburg, 1855, p. 199; and in Zeitsch. f. wiss. Zool. 1856, Vol. VIII, p. 303.

Eckhard, C., Beiträge zur Anatomie und Physiologie. Pt. I, I855, p. 77 .

Eckhard, C., Ueber die Endigungsweise der Geruchsnerven. Beiträge zur Anat. u. Physiol. Giessen, 1882. Vol. I, p. 77 .

Đrichsen, J., De textura nervi olfactorii ejusque ramorum. Dissert. inaug. 1857 .

Exner, s., Untersuchungen iber die Riechschleimhaut des Frosches. Sitzungsb. der Wiener Acad. 1871. Vol. IXIII, Pt. II, p. 44.

Exner, S., Weitere Studien über die Structur der Riechschleimhaut bei Wirbelthieren. Sitzungsb. der Wiener Acad. 1872. Vol. LXV, Pt. III, p. 7 .

Fxner, S., Fortgesetzte Studien über die Endigungsweise des Geruchsnerven. Sitzungsb. der Wiener Acad, 1878. Vol. LXXVI, Pt. III, p. I 7 I.

Gastaldi, Nuove Ricerche sovra la terminazione del nervo olfatt. Mem. della reale Acad. della scienze di Torino. 1858 . Vol. XVII, Series II, p. 369.

Hoffmann, Lehrbuch der Anatomie der Sinnesorgane.

Hoffmann, C. K., Ondersockingen over den anat. bouw van de membrana olfactoria en het periph. uitiende van den Nervus olfactorius. Dissert. inang. I866.

Hoffmann, C. K., Amphibia in Bronn's Klassen und Ordnungen des Thierreichs. Leipzig und Heidelberg, 1873-1878. Vol. VI, pp. 335-347.

Horn, H., Ueluer die Endschlingen des Geruchsnerven (nervus olfactorius) der Rana temporaria. Arch. f. Anat. u. Physiol. 1850.

Hoyer, H., De tunica mucosa narium textura. Dissert. inaug. Berol., 1857 .

Hoyer, H., Ueber die mikroskopischen Verhältnisse der Nasenschleimhaut, etc. Arch. f. Anat. u. Physiol. I860, p. 50.

Langer, C., Ueber das Lymphgefässsystem des Frosches. Wiener Acad. Sitzungsb. r867. Vol. LV, Pt. I, p. 6r5.

Legal, E., Die Nasenhöhlen und der Thränennasengang der amnioten Wirbelthiere. Morph. Jahrb. 1882. Vol. VIII, p. 353.

Martin, Studies from the physiological laboratory in the University of Cambridge. Pt. I. 1873 .

Paschutin, V., Ueber den Bau der Schleimhaut der Regio olfactorio beim Frosch. Medicinisky Wjestnik. 1872. Nos. 38-40.

Paschutin, V., Ueber den Bau der Schleimhaut der Regio olfactoria des Frosches. Arbeiten aus d. phys. Laborat. Leipzig, 1873 . 
Paulsen. E., Ceher die Druisen der $\mathbf{N}$ asenzchleimhaut besonders die Bowman'schen Drisen. Arch. f. mik. Anat. Is\$6. Vol. XXVI, pp. 307-321.

Piersol. G. A., Beiträge zur Histologie der Harderschen Drtisen der Amphibien. Arch. f. mik. Anat. 1887. Vol. XXIX, p. 594.

Reichert, B., Arch. f. Anat. u. Phveiol. 18:\%, p. 39. Bericht.

Schultze, M., Leber die Endigungsweise des Geruchsnerven und die Epithelialgebilde der Nasenschleimhaut. Monatsb. Aead. z. Berlin. 18 56 , p. 504.

Schultze, M., Cntersuchungen über den Bau der Nasenschleimhaut, namentlich die Structur und Endigungsweise der Geruchsnerven bei dem Menschen und den Wirbelthieren. Halle, 1862. Fol. VII. pp. 32-4I ; also published in Berlin, 1875. Abstract in Centralbl. f. med. Wis8. 1863, p. 97 .

Seeberg, Disq. microsc. de textura membr. pitnit. nasi. Dorpat, 1855. Dissert. inang.

Stirling, W., and Macdonald, The minute structure of the palatine nerres of the fring and the termination of nerves in blood-vessels and glands. Journ. of Anst. and Physiol. 1884. Vol. XVII, p. 293.

Wiedersheim, R., Ceber die Kopfurüsen der Amphibien. Sitzungsb. d. phys.-med. Gesell, in Würzburg, 1876. Febr. 5.

Wiedersheim, R.. Die Kopflrüsen der geschwänzten Amphibien und die Glandula intermaxillaris der Anuren. Zeitseh. f. wiss. Zool. 18;6. Vol. XXVII, PP. 1-50.

Wiedersheim, R., Lehrbuch der vergl. Anatomie der Wirbelthiere. Pt. I. Jema, 1882 .

\section{THE EAR.}

Chatin, J., Recherches pour servir a l'histoire du noyau dang l'épithelin auditif des batrachiens. Annales des seiences nat. Zoul. 1883. Vol. XVI, Series VI, Art. No. 2.

Comparetti, A., in gymnasio patarino observationes anatomicae de aure interna comparatae. Patavii, 1789 .

Crumbie, J. M., On the membrans tympani. Journ. of Anat. and Physiol. 1883, pp. $523-536$.

Cuvier. G., Leçons danatomie comparée. Paris, I800. Vol. II.

Deiters, O., Ceber das innere Gehörorgan der Amphibien. Arch. f. Anat. u. Physiol. 1862, p. 277 .

Fberth, C. J., Zur Kenntnise der Verbreitung der glatten Muskelfasern (Tympanic membrane'. Zeitsch. f. wiss. Zool. 1863. Vol. XII, p. 364.

Ferré, Étude sur la créte auditive chez les vertébrés. Ann. Sei. Nat. Bordeaux. Vol. I, No. III.

Hasse, C., Die Histologie des Bogenapparates und des Steinsacks der Frösche. Zeitsch. f. wise. Zool. 1868. Vol. XVIII, p. 7 1.

Hasse, C., Das Gehürorgan der Früsche. Zeitsch. f. wiss. Zool. 1868. Vol. XVIII, p. 359 .

Hasse, C., Das knücherne Labyrinth der Prüsche. Anatomiache Studien, and Pt. 1873, p. 377 .

Hasse, C.. Die vercleichende Morphologie und Histologie des häutigen Gehörongans der Wirbelthiere. Supplement to the Anatomische Studien. Vol. I, 18-3.

Hasse, C., Die Lymphbahnen des inneren Ohres der Wirbelthiere. In the Anatomische Studien of Hasse, IF 73 . No. XIX.

Hasse, C., Das Gehürorgan der Wirbelthiere ron Gustav Retzius. Arch. f. Ohrenheilk. I884. Vol. XXI, pp. $314-324$.

Hoffmann, Lehrbuch der Anatomie der Sinnesorgane.

Hoffmann, Bronn's Klassen und Ordnungen des Thierreichs. Leipzig and Heidelberg, 1873-1878. Vol. VI, pp. 304-335. 
Ibsen, J., Anatomiske Undersögelser over orets Labyrinth. Udgivet vet P. L. Panum. Kjöbenhawn, 1846 (abstract in Virchow and Hirsch's Jahresb. I88 I, p. 88).

Kuhn, Ueber das häutige Labyrinth der Amphibien. Arch. f. mik. Anat. 1880. Vol. XVII, pp. 479-550.

Kuhn, Zur Anatomie des inneren Ohres der Wirbelthiere. Compt. rend. du III Congrès internat. d'Otologie à Bâle, 1884, pp. 228-238.

Loydig, F., Lehrbuch der Histologie des Menschen und der Thiere. Frankfurt a. M. 1857 .

Leydig, F., Ueber neuere den Aquaeductus vestibuli des Menschen und der Thiere betreffende Forschungen. Sitzungsb. d. Niederrheinischen naturf. Gesellsch. in Bonn, 1874. Vol. XXXIV, p. 124.

Moldenhauer, Vergleichende Histologie des Trommelfells. Arch. f. Ohrenheilk. 1878 , p. 1 .

Pappenheim, S., Ueber Verbreitung der Flimmerbewegung. Arch. f. Anat. u. Physiol. 1840, p. 533 .

Retzius, G., On hörselnervens ändningssätt i maculae och cristae acusticae. Nordiskt medicinskt arkiv. 187 I. Vol. III.

Rotzius, G., Zur Kenntniss der Morphologie des inneren Ohres bei Wirbelthieren. Nord. Med. Ark. 1880. Vol. XII, No. 12.

Retzius, G., Zur Kenntniss des Gehörorgans der Wirbelthiere. Arch. f. Anat. u. Physiol. 1880, pp. 235-244.

Retzius, G., Das Gehörorgan der Wirbelthiere. Pts. I and II, 1881. Stockholm.

Retzius, G., Das Gehörorgan der Wirbelthiere. Congr. internat. de Copenhagen. Anatomy, p. 29.

Retzius, G., Das Gehörorgan der Fische und Amphibien. Pt. I, 1881. Stockholm.

Retzius, G., Zur Kenntniss der Morphologie des inneren Ohres bei Wirbelthieren. Nord. Med. Ark. I880. Vol. XII, p. 6.

Retzius, G., Ueber die peripherische Endigungsweise der Gehörnerven. Biol. Untersuch. Stockholm and Leipzig, pp. 5I-61.

Schultze, F. E., Zur Kenntniss der Endigungsweise der Hörnerven bei Fischen und Amphibien. Arch. f. Anat. u. Physiol. 1862, p. $38 \mathrm{I}$.

Stannius, H., Handbuch der Zootomie von v. Siebold und Stannius. Berlin, I856. and Edit., Pt. II.

Tafani, A., L'organo dell' udito. Firenze, $\mathbf{1} 885$.

Waldeyer, W., Hörnerv und Schnecke. Stricker's Handbuch der Gewebelehre, pp. $91_{5}-963$.

Weber, E., Amtlicher Bericht über die neunzehnte Versammlung deutscher Naturforscher und Aerzte in Braunschweig im Sept. 1841. Printed Braunschweig, 1842 .

Wizdischmann, De penitiori auris in amphibiis structura Lipsiae, 1831 .

\section{THE EYE.}

\section{a. The cornea and sclerolic.}

Angelucci, A., Ueber den Bau u. die Entwickelung des vorderen Uvealtractus der Vertebraten. Centralbl. f. d. med. Wiss, 1879. No. 24, p. 417.

Altmann, R., Ueber die Verwerthbarkeit der Corrosion in der mikroskopischen Anatomie. Arch. f. mik. Anat. 1879. Vol. XVI, p. 47 (Corneal corpuscles).

Arnold, J., Die Vorgänge bei der Regeneration epithelialer Gebilde. Virchow's Areh. 1869. Vol. XLVI, p. 168.

Arnold, J., Experimentale Untersuchungen itber die Entwicklung der Blutcapillaren. Virchow's Arch. 1871. Vol. LIII, p. 70. 1872. Vol. LIV, p. I. 
Boddsert, Zur Histolugie der Cornes. Centralbl. f. med. Wiss. 1871, p. 337.

Cisccio, J. V., On the nerves of the cornea and of their distribution in the curneal tissue of man and animals. Trans. Micros. Soc. London, 1863. Vol. XI, p. 77.

Clasow, E., Om corneal epithel. C psala läkareforenings förhandlingar. 1869. Vol. IV, p. 4 II.

Cohnheim, J., Ceber die Endigung der sensiblen Nerven in der Hornhaut. Virchow's Arch. 1867. Vol. XXXVIII, p. 343.

Durante, F., Sulla terminazione dei nervi della cornea. Richerche fatte nel laborat. di anat. normal. Roma, pubbl. dal dott. F. Tocharo. 1873, pp. 81-87.

Engelmann, T. V., Ueber die Horahaut des Auges. Leipzig, 1867.

v. Ewetsky, Ceber das Endothel der Membrana Descemeti. Untersuch. aus d. pathol. Institut. Zürich, 1875. Vol. III.

Frey, H., Handbuch der Histologie und Histochemie.

Generisch, Zur Lehre von den Saftkanälchen in der Cornea. Med. Jahrb. der Gesellsch. d. Aerzte in Wien. 187 I, p. I.

Guye, A. G., Over bekercellen en in het byzonder over de bekercellen in de membrana nictitans van den Kïkvouch. Nederl. Tydschrift v. Gewesh. I868. Vol. II, p. 135 .

Hansen, A., Cntersuchungen über die entzïndlichen Veränderungen der Hornhautkörper. Wiener Med. Jahrb. 1871, p. 210.

Harpeck, C., Ceber die Bedeutung der nach Silberimprägnation auftretenden weissen lücken- und spaltähnlichen Figuren in der Cornea. Arch. f. Anat. u. Physiol. 1864, p. 222.

Hartmann, R., Ceber die durch den Gebrauch der Höllensteinlösung künstlich dargestellten Lymphgefässanhänge, Saftcanälchen und epithelähnlichen Bildangen. Arch. f. Anat. u. Physiol. 1864, p. 235.

Heiberg, H., Ceber die Neubildung des Hornhaut-Epithels. Wiener Med. Jahrb. 187 I.

Heisrath, F., Ceber d. Zusammenhang d. vordern Augenkammer mit d. vord. Ciliarvenen. Arch, f. mik. Anat. 1878. Vol. XV, p. 209.

Helfreich, Teber die Nerven der Conjunctira und Sclera. Würzburg, I 8 7o.

Henle, J., Handbuch der systematischen Anatomie, I866. Vol. II.

His, W., Cntersuchungen über der Bau der Hornhaut, in Verhandlungen der phys. med. Gesellschaft in Würzburg. 18;6. Vol. IV, p. 90.

His, W., Ueber die Einwirkung des salpetersauren silberoxydes anf die Hornhaut. Schweizerische Zeitsch. f. Heilkunde. 1864. Vol. II, p. I.

Hoffmann, F. A., Ceber Contractilitätsvorgänge im vorderen Epithel der Frosch. hornhaut. Diss. Berlin, 1868.

Hoffmann, F. A., Epithelneubildung auf der Cornea. Virchow's Arch. 18\%o. Vol. LI, p. 373.

Hosch, F., Leber die angebliche Contractilität der Knorpelzellen und Hornhautkörperchen. Pflüger's Arch. f. d. ges. Phyziol. 1873. Vol. VII, p. 515.

Hoyer, H., Ueber den Austritt von Nervenfasern in das Epithel der Hornhaut. Arch. f. Anat, u. Physiol. I866, pp. 180-195.

Hoyer, H., Ueber die Nerven der Hornhaut. Arch. f. mik.Anal. 1873. Vol. IX, p. 220.

Klebs, E., Das Epithel der hintern Hornhautfläche. Centralbl. f. d. med. Wiss. 1864, p. 513 .

Klein, E., Some remarks on the finer nerves of the cornea. Monthly Journ. Micros. Sei. 1872. Vol. VII, pp. 156-164.

Klein, $\mathbf{E} .$, Beiträge zur Kenntniss der peripherischen Verzweigung markloser Nervenfasern. Centralbl. f. d. med. Wiss. 1871, p. 594 .

Klemensiewiez, R., Karyokinese in den fixen Hornhautzellen bei Entzündung. C'entralbl. f. d. med. Wiss. $188_{4}$, p. I63.

v. Kölliker, A., Leber die Nerven der Hornhaut. Mittheilungen der naturforschenden Gesellschaft in Zürich. 1849 . 
v. Kölliker, A., Ueber die Nervenendigungen in der Hornhaut. Wärab. naturw. Zeitschr. 1866. Vol. VI, p. 121.

Königstein, L., Histologische Notizen. Arch. f. Ophthalmologie. 1881. Vol. XXVII, p. $5^{6}$.

Königstein, L., Beobachtungen ïbér die Nerven der Cornea und ihre Gefässe. Wiener Sitzungsber. I877. Vol. LXXVI, Pt. III, p. I7.

Königstein, L., Beobachtungen über die Nerven der Cornea und ihre Gefässe. Wiener Sitzungsber. 187\%. Vol. LXXVI, Pt. III, p. 37 .

Krause, W., Ueber das vordere Epithel der Cornea. Göttinger Nachrichten, 1870. Arch. f. Anat. u. Physiol. I87o.

Krause, W., Anatomischer Jahresbericht für 187r in Prager Vierteljahrsschrift.

Kühne, W., Untersuchungen über Protoplasma und die Contractilität. I864.

Lavdowsky, M., Das Saugadersystem und die Nerven der Cornea. Arch. f. mik. Anat. 1872. Vol. VIII, p. 538.

Leber, T., Zur Kenntniss der Imprägnationsmethoden der Hornhaut und ähnlicher Gewebe, Arch. f. Ophthalmologie. 1867. Vol. XIV, p. 300.

Leydig, $\mathbb{F} .$, Lehrbuch der Histologie. 1857.

Lightbody, W. H., Observations on the comparative anatomy of the cornea of vertebrates. Journ. of Anat. and Phys. I867. Vol. I, p. I5.

Lipmann, H., Ueber die Endigung der Nerven im eigentlichen Gewebe und im hinteren Epithel der Hornhaut des Frosches. Virchow's Arch. I \$69. Vol. XLVIII, p. 218.

Lott, G., Ueber den feineren Bau und die physinlogische Regeneration der Epithelien, insbesondere des Cornea-Epithels. Centralbl. f. d. med. Wiss. 1871.

Moseley, H. N., Some remarks on the nerves of the cornea of the rabbit and frog. Quart. Journ. Micros. Sei. 187r. Vol. XI, p. 26r.

Müller, C. F., Histologische Untersuchungen tiber die Cornea. Virchow's Arch. 1867. Vol. XLI, p. IIO.

v. Recklinghausen, F., Notiz über Silberimprägnation. Virchow's Arch. I860. Vol. XIX, p. 45 I.

v. Recklinghausen, F., Die Lymphgefässe und ihre Bedeutung zum Bindegewebe. Berlin, 1862.

Robinski, Die Kittsubstanz auf Reaction des Argentum nitricum. Arch. f. Anat. u. Physiol. 187 I, p. 184 .

Rollett, A., Ueber das Gefüge der Substantia propria corneae. Sitzungsb. Wiener Akad. I859. Vol. XXXIII, p. 516.

Rollett, A., Ueber die Contractilität der Hornhautkörper und die Hornhauthöhlen. Centralbl. f. d. med. Wiss. I871, p. I93.

Rollett, A. Ueber die Hornhaut. Stricker's Gewebelehre. I872, p. I091.

Saemisch, T., Beiträge zur normalen und pathologischen Anatomio des Augers (Nerves of Cornea). Leipzig, 1862.

Sattler, E. E., Die Verwendung des Lapisstiftes sar Untersuchung der Epithelien. Arch. f. mik. Anat. 1882. Vol. XXI, p. 672.

Schalygen, C., Ueber Hornhautepithel und besonders über Vermehrung der Zellen desselben. Arch. f. Ophthalmol. 1866. Vol. XII, p. 83.

Schneider, A., Ueber die Vermehrung der Epithelzellen der Hornhaut. Würzb. naturw, Zeitsch. 1862. Vol. III, p. 105.

Schwalbe, G., Ueber ein mit Endothel bekleidetes Höhlensystem zwischen Choroidea und Sclerotica. Central. f. d. med. Wiss. Berlin, 1868. No. 54.

Schweigger, Ueber den Bau der Hornhaut. Allg. med. Centralzeitung. Berlin, 1862. No. 4.

Schweigger-Seidel, F., Ueber die Grundsubstanz und die Zellen der Hornhaut des Auges. Berichte d. math.-physik. Classe der Königl. Sïchs. Gesellsch. d. Wissenschaft. 1869. Vol. XXI, pp. 305-359. 
Stricker, \$., Conjunctiva und Sclerotica im Handb. der Lehre von den Geweben des Menschen und der Thiere. 1872, p. II42.

Swaen, M. A., Des eléments cellulaires et des canaux plastiques dans la cornée de la grenouille. Bulletin de HAcad. roy. de Belgique. 18;6. and Series, Vol. XLII, pp. $144^{-183}$.

Tamamscheff, T., Ceber die Membrana Demoursiana. Centralbl. f. d. med. Wiss. Berlin, 1869.

Waldeyer, W., Microscopische Anatomie der Cornea, Sclera, Lider und Conjunctiva, in Handbuch der gesammten Augenheilkunde. $18 ; 4$.

Wolff, W., Die Terven der Cornea. Arch. f. mik. Anat. I8\$2. Vol. XX, p. 373.

Zielonko, J., Ceber die Entwicklung und Proliferation ron Epithelien und Endothelien. Arch. f. mik. Anat. I874. Vol. X, p. 351 .

\section{The lens, choroid, iris, apjendages, anterior and posterior chambers.}

Altmann, R., Ceber Corrosion in der Histologie. Centralbl. f. d. med. Wiss. I8;8, p. 245 .

Altmann, R., Leber die Terwerthbarkeit der Corrosion in der mikroskopischen Anatomie. Arch. f. mik. Anat. 18\%9. Wol. XVI, p. 47I (Blood-ressels of the choroid).

Angelucci, A., Ceber den Bau und die Entwickelnng des vorderen Cveatractus der Vertebraten. Centralbl. f. d. med. Wis8, 18 \%9, p. 417 .

Arnold, Die Linse. Handbuch der gesammten Augenheilkunde. 1874 .

Barkau, A., Beiträge zar Entwicklungsgeschichte des Auges der Batrachier. Wiener Sitzungsber. 1866. Vol. LIV, Pt. I, pp. 70-75.

Becker, Cntersuchungen über den Bau der Linse bei dem Menschen und den Wirbelthieren. Arch. f. Ophthalmologie. 1863. Vol. IX, Pt. II, pp. I-t2.

Biedermann, W., Zur Histologie und Physiologie der Schleiusekretion (Membrana nictitans). Wiener Sitzungsber. 1886. Vol. XCIV.

Born, G., Ceber die Nacenhühlen und den Thränennasengang der Amphibien. Morph. Jahrb. 1875. Vol. II, p. 4.

Bubuchin, Die Linse. In Stricker's Handb. der Gewebelehre. $18 \gamma^{2}$.

Burow, De rasis sanguif. ran. Diss. Regiomonti, 1838 .

Ciaccio, C. V., Benbachtungen über den inneren Bau des Glaskörpers im Auge des Menschen und der Wirbelthiere im Allgemeinen. Moleschott's Lntersuchungen. 1870. Vol. X, p. 385 .

Faber, C., Der Bau der Iris des Menschen und der Wirbelthiere. Leipzig, 18;6.

Frey, Handbueh der Histologie und Histochemie des Menschen. 18 7 .

Fubini, s., Beiträge zum Studium der Krystallinse. Moleschott's Lntersuchungen. I876. Vol, XI, p. 291.

Golubew, Peiträge zur Kenntniss des Baues und der Entwicklungsgeschichte der Capillargefasse des Frosches. Arch. f. mik. Anat. 1\$69. Vol. V, p. 49.

Grünhagen, Ueber das Vorkommen eines Dilatator pupillae in der Iris. Zeitsch. f. rat. Med. Vol. XXVIII, pp. 178, I86.

Heisrath, F., Ceber den Zusammenhang der vorderen Angenkammer mit den vorderen Ciliarvenen. Ar.h. f. mik. Anst. I8;8. Vol. XV, p. 209.

Henle, J., Zur A natomie der Crystalllinse. Abhandl. Gesells. d. W iss. zu Güttingen. 1878. Vol. XXIII.

Henle, J., Zur Entwicklungsgeschichte der Krrstalllinse und zur Theilung des Zellkerns. Arch. f. mik. Anst. 1882. Vol. ẊX, p. 413 .

Hirschberg, Zur Dioptric und Ophthalmologie der Amphibienangen. Arch. f. Anat. u. Phyriol. I887, p. 493 .

Iwanoff, Peiträge zur normalen und pathologischen Anatom:e des Frosehglaskorpers. Centralbl, f, d. med. Wiss. 1868 , p. 129. 
Klein, E., On the peripheral distribution of non-medullated nerve-fibres (Nerves of the nictitating membrane). Quart. Journ. Micros. Sci. 1872. Vol. XII, pp. $21-32$.

Koganeï, J., Untersuchungen über den Bau der Iris des Menschen und der Wirbelthiere. Arch. f. mik. Anat. 1885. Vol. XXV, p. I.

Koganeï, J., Untersuchungen über den Bau der Iris. Sitzungsber. d. Acad. d. Wiss. Berlin, 1885 , p. 105.

v. Kolliker, $\mathbf{A}$., Handbuch der Gewebelehre. $\quad 186 \%$.

Langer, C., Ueber das Lymphgefässsystem des Frosches. Wiener Acad. Sitzungsb. 1867. Vol. LV, Pt. I, p. 603 .

Leydig, F., Anatomisch-histologische Untersuchungen äber Fische und Reptilien, 1853.

Leydig, F., Lehrbuch der Histologie des Menschen und der Thiere. 1857.

Manz, W., Ueber den Mechanismus der Nickhautbewegung beim Frosche. Berichte über d. Verhandl. d. naturforsch. Gesell. Freiburg, 1862. Vol. II, p. 39I.

Moriggia, A., Ueber die beste Darstellungsweise und die Entwicklung der Röhrchen der Krystallinse. Moleschott's Untersuchungen. 1870. Vol. X, p. 658.

Openchowski, T., Histologisches zur Innervation der Drüsen. Pflüger's Arch. f. d. ges. Physiol. 1882. Vol. XXVII, pp. 223-232.

Petit, Sur l'œil de la grenouille. Mém. de l'académie d. Sciences, I 737 ; see also Lehrbuch d. vergleich. Anatomie, Stannius, Berlin, 1846, p. I98.

Robinski, S., Zur Anatomie, Physiologie und Pathologie der Augenlinse des Menschen und der Wirbelthiere. Arch. f. Anat. u. Physiol. I872, p. I 78.

Robinsky, s., Die Augenlinsensterne des Menschen und der Wirbelthiere. Centralbl. f. d. med. Wiss. 1877, p. 5 I.

Sattler, Ð. 円., Die Verwendung des Lapisstiftes zu Untersuchungen der Epithelien. Arch. f. mik. Anat. I882. Vol. XXI, p. 672.

Stricker, s., Untersuchungen über die capillaren Blutgefässe in der Nickhaut des Frosches. Wiener Sitzungsb. 1865, Vol. LI, Pt. II, pp. 16-27; and Moleschott'g Untersuchungen, I866, Vol. X, pp. I68-180.

Stricker, s., Untersuchungen über die mechan. Leistungen d. acirrösen Drüsen. Wiener med. Jahrb. 1880, p. 355 ; also Wiener Sitzungsb. I880 (Membrana nictitans and skin); also in Moleschott's Untersuchungen. 1870. Vol. X, p. 237.

Stricker, s., Studien über den Bau und das Leben der capillaren Blutgefisse. Wiener Sitzungsb. 1866. Vol. LII, Pt. II, p. 379.

Stricker, s., Untersuchungen uiber die capillaren Blutgefässe in der Nickhaut des Frosches. Moleschott's Untersuchungen. 1870. Vol. X, p. I68.

Thin, G., Contribution to the anatomy of the lens. Journ. of Anat. and Physiol. I876. Vol. X, p. 223.

Valentin, Handbuch der Physiologie v. Wagner. 1842.

Virchow, H., Ueber die Gefässe im Auge und in der Umgebung des Auges beim Frosche. Zeit. f. wiss. Zool. 1881. Vol. XXXV, pp. 247-281.

Virchow, H., Ueber die Gefässe des Kopfes und des Auges des Frosches. Verhandl. Würzburg. 1881. Vol. XV, p. zxxiv.

Virchow, H., Mittheilungen zur vergleichenden Anatomie des Wirbelthierauges. Versamml, deutsch. Naturf, und Aerzte. Strassburg. 1885, pp. 409, 410.

Virchow, H., Ueber den ciliaren Muskel des Frosches. Verhandl. d. physiol. Gesell. zu Berlin, 1885, p. 57 I.

Virchow, H., Ueber die verschiedenen Formen des Ligamentum pectinatum iridis. Veramml. d. Naturf, und Aerzte. 1885, p. 409.

Zimmermann, W., Ueber circumvasale Safträume der Glaskörpergefässe von Rana esculenta. Arch. f. mik, Anat. 1886. Vol. XXVI, p. 4 Io. 


\section{c. The retina.}

Babuchin, Vergleichende histolngische Studien. Würzburger naturwissensch. Zeitsch. I864, Vol. V, p. 127.

Besuregard, M. H., Contribution à l'étude du rouge rétinien. Journ. de l'anat. et de las physiol. 1879. Vol. XV, p. 16r.

Boll, F., Zur Anatomie und Physiologie der Retins. Berlin. Acad. Monatsber. 1876, p. 783 .

Dennissenko, G., Vorläufige Bemerkungen zur Lehre über den Bau der Netzhaut. Mitt. aus dem embryolug. Institut. d. Wiener C'niversität, I8So, Vol. II, p. I ; Abstract in Centralbl. f. d. med. Wiss. 1880, p. 739.

Dennissenko, G., Ceber den Bau der äusseren Körnerschicht der Netzhaut bei den Wirbelthieren. Arch. f. mik. Anat. 1891. Vol. XIX, p. 395.

Dietl, M. J., Beitrag zur Kenntniss dez feineren Baues der Stäbchenaussenglieder in der Netzhaut des Frosches. Arch. f. Augen- u. Ohrenheilkunde. I8 $; 8$. Vol. VII, pp. 17-24.

Dobrowolsky, Die Doppelzapfen. Arch. f. Anat. u. Physiol. 1 87 r.

Dobrowolsky, Zur Anatomie der Retina. Arch. f. Anat. u. Physiol. 1871.

Ewart, J. C., Notes on the minute structure of the retina and vitreous humour. Joum. of Anat. and Physiol. 1875. Vol. IX.

Ewart, J. C., and Thin, G., On the structure of the retina. Journ. of Anat. and Physiol. 1876. Vol. IX, p. 166.

Frisch, Gestalten des Choroidalpigments. Wiener Sitzungsber. 1868. Vol. LVIII, pp. $3^{16-320 .}$

Heinemann, C., Beiträge zur Anatomie der Retina. Arch. f. mik. Anat. 1877. Vol. XIV, p. 409 .

Helfreich, Ophthalmoscopische Mittheilungen über den Purpur der Retina. Centralbl. f. d. med. Wisk, 1877 , p. 113 .

Henle and Merkel, Ueber die sogenannte Bindesnbstanz der Centralorgane des Nervensystems. Zeitsch. f. rat. Med. 3rul Series, i 869. Vol. XXXIV.

Hensen, Ceber das Sehen in der Fovea centralis. Virchow's Arch. 1867. Vol. XXXIX, p. 75 .

Hoffmann, Lehrbuch der Anatomie der Sinnesorgane.

Hoffmann, Bronn's Thierbuch. Leipzig and Heidelberg, 1873-I878. Vol. VI, pp. $274-297$.

Hulke, J. W., A contribution to the anatomy of the smphibian and reptilian retina. Quart. Journ. Mierno. Sei. I864, Vol. IV, p. 236 ; and London Ophthalmic Hospital Reports, 1864 .

Hulke, J. W., On the retins of amphibia and reptiles. Journ. of Anat. and Physiol. 1867. Vol. I, p. 94.

Kühne, W., Ueber den Sehpurpur. Centralbl. f. d. med. Wiss. I877, p. I93.

Kühne, W., Fortgesetzte Cntersuchungen über die Retina und die Pigmente des Anges. Heidelberger physiol. Untersuch. 18 7 , Vol. II, p. 89; Abstract in Centralbl. f. d. med. Wiss. 1879 , p. 276.

v. Kolliker, A., Zur Anatomie und Physiologie der Retina. Verhandl. d. phys.-med. Gesellsch. Würzburg, 1852. Vol. III, p. 316.

v. Kölliker, A., Microscopische Anatomie. 1854. Vol. II.

v. Kölliker, A., Handbuch der Gewebelehre. $186 \%$.

Krause, W., Die Nervenendigung in der Retina. Arch. f. mik. Anat. 18-6. Vol. XII. pp. 742-790.

Krause, W., Die Nervenendigung innerhalb der terminalen Kürperchen. Arch. f. mik. Anat. 188I. Vol. XIX, p. 53.

Landolt, Beitrag zur Anatomie der Retina rom Frasch, Salsmander und Tritın. A reh. f. mik. A nat. 18jr. Vol. VII, p. 81. 
Leydig, F., Anatomisch-histologische Untersuchungen über Fische und Reptilien. 1853 .

Loydig, F., Die Farbe der Retina und das Leuchten der Augen. Arch. f. Naturgesch. 1877. Vol. XXXIII, p. 8.

Manz, W., Ueber den Bau der Retina des Frosches. Zeitsch. f. rat. Med. 3rd Series, I86r. Vol. X, pp. 30I-322.

Manz, W., Die Ganglienzellen der Froschnetzhaut. Zeitsch. f. rat. Med. 3rd Series, 1866. Vol. XXVIII.

Merkel, Zur Kenntniss der Stäbchenschicht der Retina. Arch. f. Anat. u. Physiol. 1870, p. 642.

Morano, F., Die Pigmentschicht der Retina. Arch. f. mik. Anat. 1872. Vol. VIII, p. 8I.

Morano, F., Stomata in der Pigmentschicht der Retina. Centralbl. f. d. med. Wiss. 1875, p. 67 .

Müller, H., Histologie der Netzhaut. Zeitsch. f. wiss. Zool. 18 $\vdots_{1-52}$. Vol. III, p. 234.

Müller, H., Ueber sternförmige Zellen der Retina. Würzb. Verhandl. 1852. Vol. II, pp. $216-218$.

Müller, H., Ueber einige Verhältnisse der Netzhaut bei Menschen und Thieren. Würzb. Verhandl. I853. Vol. IV, p. 96.

Müller, H., and Kolliker, A., Retina-Tafel. Plate XIX in Ecker's Icones Physiol. Leipzig, 1854 .

Müller, H., Observations sur la structure de la rétine de certains animaux. Compt. rend. I 8 56, Vol. XLIII, p. 743 ; and Annales hist. nat. 1856, Vol. XVIII, p. 492 .

Müller, H., Anatomisch-physiologische Untersuchungen über die Retina des Menschen und der Wirbelthiere. Zeitsch. f. wiss. Zool. 1857. Vol. VIII, p. 27.

Müllex, W., Ueber die Stammentwieklung des Sehorgans der Wirbelthiere. Leipzig, 1874, Festgabe an Carl Ludwig; Abstract in Centralbl. f. d. med. Wiss. 1877 , pp. $37^{2}$ and 388 .

Ogneff, J., Histogenese der Retina. Centralbl. f. d. med. Wiss. 1881, p. 64I.

Ogneff, J., Ueber die moleculäre Schicht und die sogenannte reticuläre Substanz der Retina. Centralbl. f. d. med. Wiss, I883, p. 801 .

Oppenheimer, L. S., Die Stäbchen in der Netzhaut der Froschembryonen. Schenk's Embryol. Mitt. Wien. 1878 , p. 163.

Ranvier, L., Traité technique d'histolngie, sixième fasicule. I882.

Ritter, Ueber den Bau der Stäbchen und äusseren Endigungen der Radialfasern an der Netzhsut des Frosches. Arch. f. Ophthalmol. 1859.

Ritter, Zur Histologie des Auges. Arch. f. Ophthalmol. I868. Vol. XI.

Schifferdecker, Studien zur vergleichenden Histologio der Retina. Arch. f. mik. Anat. 1886. Vol. XXVIII, p. 305.

Schultze, M., Zur Anatomie und Physiologie der Retina. Arch. f. mik. Anat. 1866. Vol. II, pp. $175^{-2} 28$.

Schultze, M., Ueber Stähchen und Zapien der Retina. Arch. f. mik. Anat. 1867. Vol. III, p. $2 I_{5}$.

Schultze, M., Bemerkungen zu dem Aufsatze des Dr. W. Steinlin. Arch. f. mik. Anat. I868. Vol. IV, pp. IO-2I.

Schultze, M., Die Retina. Stricker's Handbuch der Gewebelehre. I871.

Schultze, M., Ueber die Nervenendigung in der Netzhaut des Auges bei Menschen und bei Thieren. Arch. f. mik. Anat. 1869. Vol. V, p. 380.

Schwalbe, Lehrbuch der Anatomie der Sinnesorgane. Erlangen, 1885, p. 392, etc.

Steinlin, W., Zur Anatomie und Physiologie der Retina. Arch, f. mik. Anat. I868. Vol. IV, p. Io. 


\section{THE SKIN AND THE SENSE-ORGANS.}

\section{THE SKIN AND ITS APPENDAGES.}

THE general characters and the colouring of the skin have already been described (pp. 4 to 7). The skin consists of the cutis vera or corium, and the cuticle or epidermis, and is possessed of numerous glands.

a. The epidermis (Figs. 228, 230) consists of several lavers of epithelial cells, those of the deepest laver being more or less columnar in form, those of the middle layer shorter and polygonal, while those of the superficial laver are flattened, very transparent, and horny.

All the surfaces of these cells are serrated, the serrations being, however, with difficulty seen on the free surface of the superficial cells (Leydig). Each cell has a distinct nucleus; in the deeper cells the Fig. 228.

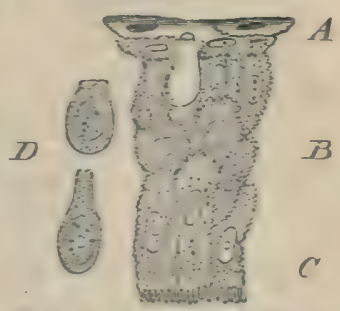

Vertiual section throngh the eqidermis from the head of Remen ceculemta : after F. E. Sichultze. Magnified 600 times
At Hornv laver.
B Midile laver.
$C$ Deer, hayer.
b Lolated mincous-cells. nucleus is oval, broad, and rounded, in the superficial cells flattened and thin.

The surface of the epidermis (Fig. 230) forms a very beautiful mosaic of flat cells, chiefly hexagonal in form, with pale, central, oval nuclei. Here and there two adjacent cells appear to enclose a semilunar space (Fig. $228 \mathrm{D}$ ); these spaces are occupied by peculiar cells (goblet-cells, E. Schultze; mucous cells, Leydig), which do not belong to the superficial cells but the layer of cells immediately beneath the horny layer (Schultze, Pfitzner). The cells are rounded or flask-shaped, and closely resemble the epithelial goblet-cells or chalice-cells. According to Rudneff they open on the free surface by stomata; this is, howerer, denied by Schultze and others. 
According to Pfitzner these cells secrete a substance, which has

Fig. 229.

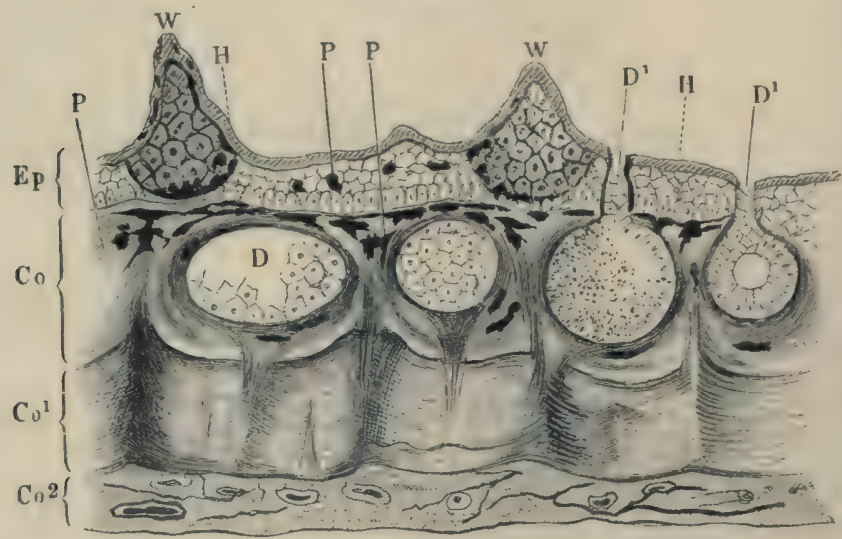

Vertical section through the skin of the back; after Wiedersheim.

$\begin{array}{llll}C o & \text { Superficial layer of cntis. } & E p & \text { Epidermis. } \\ C 0^{1} & \text { Middie layer of cutis. } & H & \text { Horny layer of epidermis. } \\ C 0^{2} & \text { Deep layer of cutis. } & \boldsymbol{P} & \text { Pigment-cells. } \\ D & \text { Cutaneous glands. } & W & \text { Papillae. } \\ D 1 & \text { Ducts of cutansous glands, } & & \end{array}$

an important function in connection with the process of casting the skin, which consists in the separation of the upper layer from that

Fig. 230.

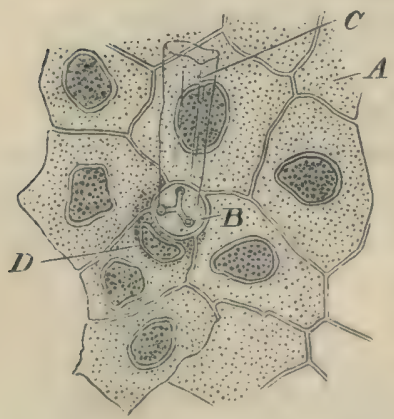

Fig. 231.

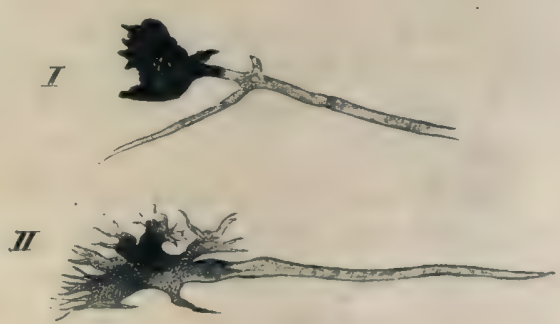

Surface view of epidermis of Rana temporaria ; Nerre terninations in the branched pigment-cells after Eberth. of the cutis; after Ehrmann. Hartnack, Obj. 8, Oc. 3 .

A Epidermal cell,

B Stoma-cell.

$C$ Attached cuticle from duct of gland,

I) Protoplasm and nucleus of stoma-cell.
I. Pigment ceasing abruptly at junction of nerve.

II. Pigment gradually ceasing along the nerve.

below brings about a complete sherlding of the skin (Wiedersheim). 
[The horny layer is, for the most part, very thin, as it consists of one or two layers of flattened cells only (Schultze), but in some situations, as on the back and especially on the under surface of the toes, it is much thickened, and is then rough.

Deeply pigmented, branched cells, capable of contractile movements, are also found, somewhat sparsely distributed, in the epidermis (Leydig, H. Müller, Schultze).]

b. The cutis (Fig. 229, $C o, C o^{1}, C o^{2}$ ). The epidermis is generally attached to the corium by means of a continuous layer of branched cells, which is deeply stained when the animals are fed with madder (Katschenko). Many of these cells are pigmented. This layer is seldom flat, but is raised into papillae and folds, which are repeated by the superimposed epidermis. In addition to this layer the corium has, except in the webs and supplemental toes, three distinct layers of connective-tissue, together with much unstriped muscle-fibre (Eberth).

The superficial layer (Fig. 229 Co) is a loosely-meshed, much pigmented, vascular layer; it forms a loose support for the numerous glands, and is traversed by numerous nerves.

The middle layer $\left(\mathrm{Ca}^{1}\right)$ forms the groundwork of the eutis; it is much firmer and more compact than the superficial layer; in section it appears as a broad band, bounded superficially by a sharp line. It is chiefly composed of closely packed connective-tissue fibres, which have, for the main part, a horizontal or wavy course ; at certain points, however, vertical fibres are seen passing towards the surface and hiding the sharp contour (between $C^{\prime} o$ and $C_{0}{ }^{1}$ ). At such points the two sets of fibres form a sort of basket-work arrangement.

The deepest layer (Fig. $229 \mathrm{Co}^{2}$ ) is composed of very delicate, white and yellow elastic fibres, and ressels and nerves; it attaches the whole integument to the underlying organs. By the looseness of its structure it forms an important lymph-space.

[The muscle-fibre of the cutis is very unevenly distributed. It is found somewhat freely in the region of the back, the dorsal surface of the head, and the neck; less freely on the dorsal surfaces of the extremities, very sparsely on the abdomen, breast, and rentral surfaces of the extremities; in the feet it appears to be absent (Eberth).

The pigment of the skin. As already mentioned pigmented cells B b 
occur in the epidermis, but by far the greater quantity of the cutaneous pigment is found in the cutis, and more especially in the loose layer of branched cells, which form the boundary between epidermis and true cutis. These cells, known as chromatophorecells, have been carefully investigated by Harless. They play an extremely important part in bringing about the well-known changes in the colouring of the skin. Bimmerman has proved that these cells are influenced by stimulation of the nerves supplying the region in which they occur. Ehrmann has been able to trace a direct connection between the nerve-fibres and the pigment-cells (Fig. 23I I, II). In such cases the pigment was sometimes sharply marked off, at others was gradually lost along. the nerve.]

c. The papillae and ridges of the skin are classified by Leydig as follows: (1) Small ridges, (2) larger ridges, (3) papillae with touch-bodies, (4) papillae without touch-bodies, (5) papillae with the ducts of glands, (6) capillaries in the form of papillae, (7) small elevations, including the lateral organs.

[All these structures are derived from the cutis, the epithelium above simply repeating the elevation, and being itself either not increased in thickness or only to a slight degree. (For further description of some of these papillae, see Organs of Tactile Sensation, p. 380.$)$

Peculiar wart-like papillae are found on the articulations of the first phalanges with the metatarsus, on the same articulations and on the articulations between the first and second phalanges of the third and fifth toes, and on the articulations between the first, second, and third phalanges of the fourth toe. These papillae are connected with the long flexor tendons by fine tendinous bands (Klein).

Temporary papillae are developed in the females of Rana temporaria during the breeding season; according to $\mathrm{O}$. Huber $(l . c$.), who has described them, their distribution and structure is as follows:-

During the breeding season the skin of the sides of the trunk of female specimens of Rana temporaria is rough; the small elevations, to which this roughness is due, are each about the size of the head of a pin, and have the appearance of small, rounded, white or pale rose-coloured, warty growths. The papillae reach their greatest development and are most numerous on the sides of the trunk (Fig. 232 I) ; they may be traced on to the tympanic membrane, where they are arranged in a ring, and in some cases under the eyes to the sides of the snout.

Anteriorly the papillae are absent from the median portion of the dorsal surface of the trunk, but posteriorly, behind a line joining the anterior extremities of the two iliac bones, the papillae cover the whole surface. 
The papillae are large and very numerous around the arms, and pass by gradual, transitionary stages into the ordinary papillae of the region. Further they may be traced backwards along the anterior or extensor surface of the thigh, the upper surface

Fig. 232.

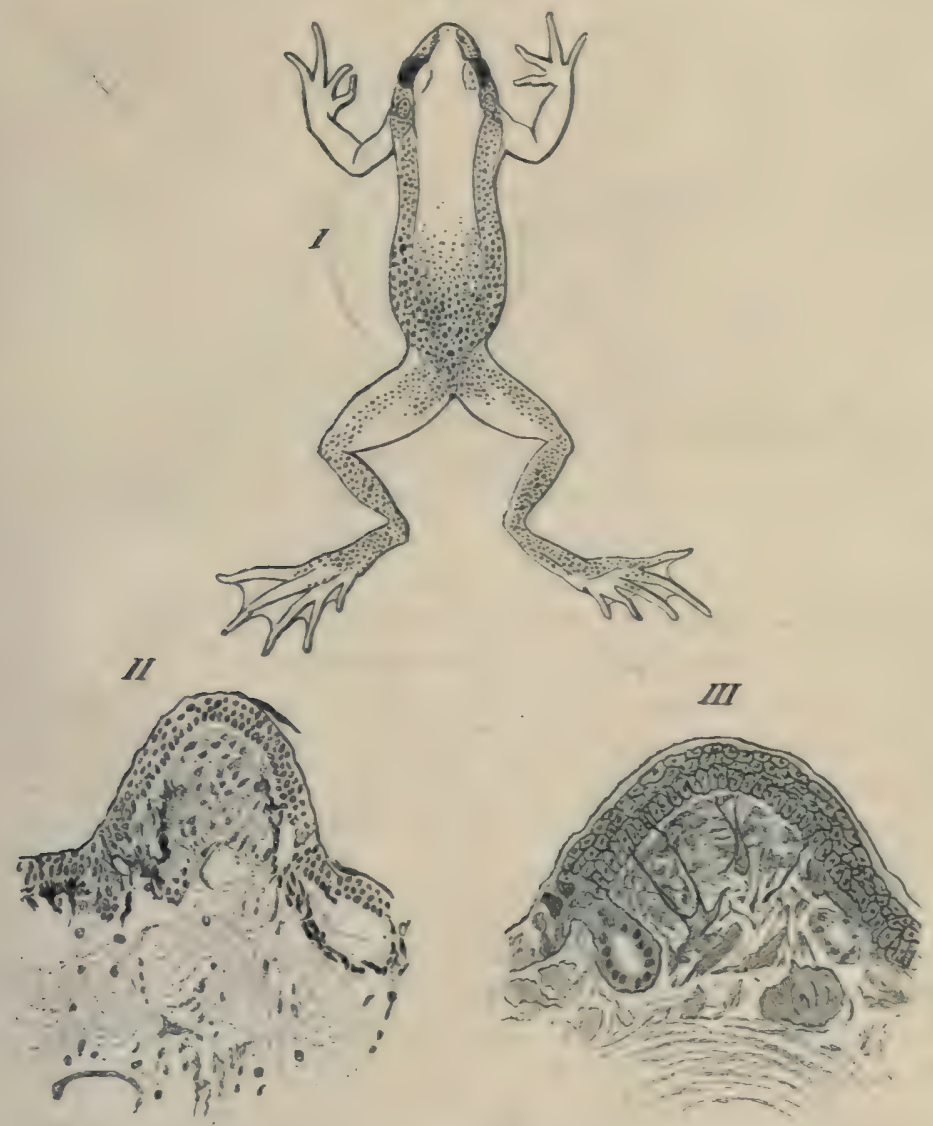

I. Diagram to show the distribution of the temporary papillae in Rama temaporaria; after Huber.

II, III Vertical sections through a temporary papilla; after Hnber.

of the leg, foot, and fifth toe. Occasionally a few papillae were found on flexor surfaces of the third and fourth metatarsus, and rery rarely were any discovered on the fore-limbs. They vecur in no other batrachian of Germany (Huber).

Each papilla (Fig. ${ }^{2} 3^{2}$ II and III) consists of a hemispherical elevation of the cutis, and is covered either by a layer of normal pyidermis or in scme very rare cases the epidermis was slightly thickened. The papilla consists of a firm connective-tissue stroma, and is from $0^{\circ} 2-0_{4} \mathrm{~mm}$. in height, $0_{4}-0^{\circ} 3 \mathrm{~mm}$. broad (after hariening in alcohol. Such glands as exist in the papilla usually open laterally (Fig. 232 III; , and the blood-vessels are numerous. 
The epidermis covering the papilla is well supplied with nerve-fibres, derived from large ganglion-cells in the papilla (Fig. 232 III). The branched pigment-cells, so numerous in the rest of the skin, are absent from the upper parts of the papillae (Fig. 232 II); the pignent-cells may cease either abruptly or gradually.

The rose-colour of the papillae is due to the presence of a golden red pigment. After the breeding aeason the papillae are gradually lost, and the pigment-cells wander into the unoccupied parts.

Huber compares the arrangement of the nerves to that of the 'tonch-spots' of Merkel.

d. The glands of the skin are of two kinds, serous and mucous; they have been fully described by Engelmann and Openchowski.

(I) The serous glands (Körnerdrïsen, Engelmann) are large, averaging in diameter $0.2-0.4 \mathrm{~mm}$., but others vary in size from $0.13-0.8 \mathrm{~mm}$. in diameter. They are found chiefly on the dorsum of the trunk and arranged in groups, which vary in dimensions from $3-20 \mathrm{~mm}$. in length and $2-4 \mathrm{~mm}$. in breadth. They may be found in any part between the ear-region and the anus, on the dorsal surface of the thigh, especially towards the outer and inner borders. They are found very sparsely distributed on the ventral surface of the trunk and on other parts of the extremities, though as a rule a few are found on the dorsal surface of the feet and near the phalanges. They are wanting in the nictitating membrane.

The glands have a rounded form, with the ducts placed at their superficial poles. The glands possess three coats; externally is a coat of connective-tissue, the fibres of which are arranged closely together, and cross one another at acute angles: these fibres are continuous with the connective-tissue of the surrounding cutis. Inside this coat is a thick layer of muscle-fibre $(0.005-0.015 \mathrm{~mm}$.); the muscle-cells are arranged meridionally, with the one pole towards the superficial surface of the gland, the other pole at the deep surface (Hensche). Many of the fibres, however, extend only one-fourth or one-third of this distance.

- The innermost coat is a simple layer of epithelial cells, which rests directly on the muscle-layer; no basement-membrane or space of any kind having been discovered between the two layers. When examined in the recent state these cells are conical or cylindrical in shape, and have the appearance of goblet-cells: they possess a delicate but distinct cell-wall, but are open towards the lumen of the gland. One or sometimes two rounded nuclei are found towards the base of the gland, and surrounded by a small amount of granular protoplasm ; the rest of the cell is occupied by a mass of small, rounded, highly refractive granules of about $0.002-0.01 \mathrm{~mm}$. in 
diameter. These granules are also to be found in the protoplasm of the cell; they contain a substance capable of swelling freely, and preseut many points of resemblance to the granules found in the cells of the oviducts.

These glands represent the poison-glands or lateral glands of toads, and the earglands or parotids of Caecilia (Leydig). According to Leroux ${ }^{1}$, Gratiolet and Cloëz ${ }^{\text {, }}$ the reaction of these glands in toads varies; according to du Bois-Reymond ${ }^{3}$ the reaction is, in frogs, acid; Engelmann " found the reaction of these glands, in frogs, to be neutral, frequently, however, with a teudency to either acidity or alkalinity.

These glands correspond with the 'large glands' of Hensche, the 'contractile glands" of Stieda, the 'large, dark glands' of Eberth, and the 'large contractile glands ' of Leydig's earlier publicatiuns.

(2) The mucous glands are, as a rule, smaller, more numerous, and more evenly distributed than the serous glands. Usually they lie in such close proximity as almost to touch one another; aceording to Engelmann an average number of sixty is found in one square millimeter; on the abdomen 62-68; flexor surfaces of the posterior extremities in some places 76 , but in others only $30-40$; on the webs only $2-6$ to the square millimeter. On the nictitating membrane they are arranged in two or three parallel rows, are large, and closely applied to each other. They are wanting on the deeper surface of the nictitating membrane.

The glands are generally rounded in form and have a short neck (Fig. 229). Glands in the recent condition, and not fully contracted, have a diameter of $0.06-0.21 \mathrm{~mm}$., the majority measure $0.12-0.16 \mathrm{~mm}$. in diameter. The upper pole of the gland is usually placed directly under the boundary between epidermis and cutis, and, as a rule, about $0.06-0.1 \mathrm{~mm}$. beneath the superficial surface of the skin. The duct usually passes directly to the surface, in a straight line.

The structure of the glands corresponds, in general, with that of the serous glands. Externally is a coat of connective-tissue, which is, however, more firmly attached to the muscular coat than in the case of the serous glands, and may easily be mistaken for a structureless basement-membrane ${ }^{5}$ (Eberth). The muscular coat is very thin, and consists of $16-20$ flat, spindle-shaped fibres; extending from the upper to the lower pole as in the serous glands. At a

1 Journal de Médicine, Vol. XI, p. 75.

2 Comptes rendus, 1851, Vol. XXXII, p. 582.

${ }^{3}$ Cntersuchungen über thier. Electricitat, 1830 , Vol. I, p. I7.

- Arch. f. d. ges. Physiol., 1852, Vol. V, p. 505 .

3 Openchowski $\left(l, c_{0}\right)$ describes a basement-uembzane. 
short distance $(0.015-0.022 \mathrm{~mm}$.) from the upper or superficial pole each fibre has an ellipsoid thickening, composed of granular protoplasm, and containing a clear oval nucleus.

The inner coat is composed of a single layer of epithelium, placed directly on the muscular coat. The epithelium has a thickness of about $0^{\circ} \mathrm{OI}-0^{\circ} .22 \mathrm{~mm}$; it is, however, usually thicker towards the base than towards the duct. The boundaries between the cells are very indistinct, and so give the epithelium the appearance of a continuous layer of protoplasm. The glandular epithelium is not directly continuous with the epithelium of the duct.

The shape of the cells depends upon their physiological condition. In a state of semi-contraction of the gland, the cells are cubical, and their free borders pushed into the lumen in a slight convexity; when the gland is fully distended the cells are two or three times as broad as deep; in a fully contracted gland the cells are conical or cylindrical. In the first-mentioned condition their diameter varies from $0.006-0.018 \mathrm{~mm}$. The larger glands are estimated to possess about I 50 cells, the smaller only thirty to forty (Engelmann).

The cells appear to have no cell-wall, certainly they possess none on their free surfaces. Their protoplasm distends very freely on the addition of water. As a rule some cells are much more granular than others of the same gland; each cell has a rounded oval, clear nucleus, and vacuoles are frequently met with.

The lumen of the gland contains a colourless, transparent, watery fluid, which contains mucous material.

The ducts of the glands are thick-walled cylinders, circular in section. Their diameter varies from $0.02-0.05 \mathrm{~mm}$, their length is equal to the depth of the superimposed epidermis. The wall of the duct is lined with two or three concentric layers of highly refractive, nucleated cells. The cells are arranged parallel to the length of the duct: in transverse section they are sickle-shaped or semilunar. In the upper third or fourth of the duct the inner wall is lined with a cuticle, very resistent to the action of acids or alkalies : it is thrown off with the skin in the process of casting. In the horny layer of the epidermis this cuticle is partially elosed by a stomacell (Eberth), (Fig. 230), which possesses a tri-radiate opening.

The glands correspond with the 'non-contractile glands' of Hensohe, the 'dark and bright glands' of Stieda, the ' glandule mezzane, piccole e piccolissime (ad epitelio pavimentoso)' of Ciaccio, and the 'small, dark, and medium-sized, bright glands' of Eberth.

e. The peculiarities of the skin of the supplemental toe and 
webs. The supplemental toe presents, in the male, a rounded, oval swelling (Fig. $234 \mathrm{I}, D$ ), with the end of the digit projecting from the distal end.

Normally this swelling is usually of a grey colour; during the breeding season, however, the swelling enlarges, and becomes of a black or deep brown colour (Leydig).

The epidermis covering this swelling (Fig. 233) is much thickened and produced into projecting papillae. The cutis also shows a marked thickening and an increase in vascularity; the glands are of the kind deseribed as mucous glands (Engelmann). Fig. 233.

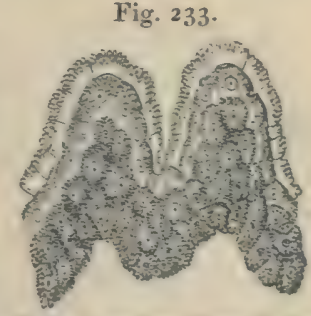

Vertical section through the epidernis of the supplemental tone of Runa esiulenta; after E. Schultze Magnitied 400 times.

They present, however, an immense increase in size, and at the same time are so closely applied to one another as to form

Fig. 234.

I.

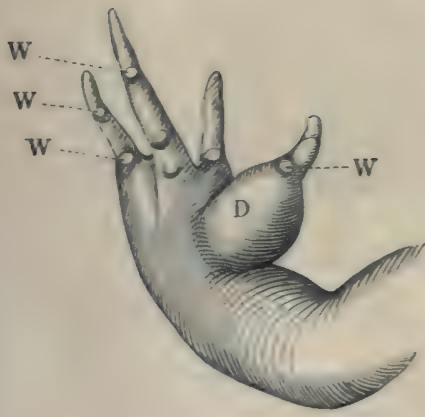

Fure-fout of a male frog.

D Glandular swelling on the expplomental toe.

W Warty papillae on the inter-phalangeal joints
II.

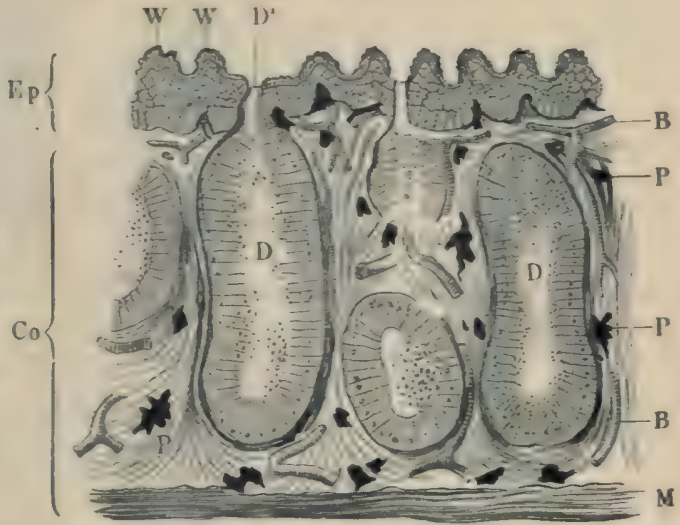

Vertical section thrungh the swelling on the supplemental toe of a male frog.
$B$ Blond-ressels.
Co Cutis
D Glanda
Ep Epidermis.
M Muscles.
P Pigment-cells.

the main part of the enlargement (see also Organs of Tactile Sensation).

In the webs the various layers of the corium are more or less 
fused together, and cannot be distinguished from each other; the glands are, as a rule, smaller than on the general surface of the skin.

f. The blood-vessels and lymphatics of the skin.

(I) The blocd-vessels of the skin are arranged in two networks; the one is situated immediately beneath the epidermis, and consists of fine capillaries, forming a fine-meshed network, which enclose the ducts of the glands. The meshes vary considerably in size and

Fig. 235 .
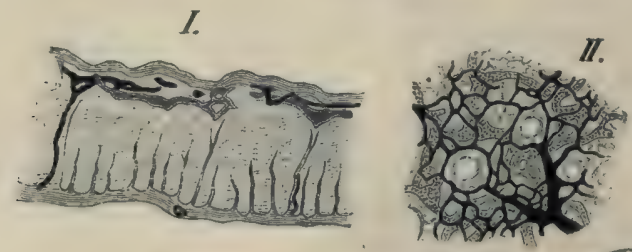

W.
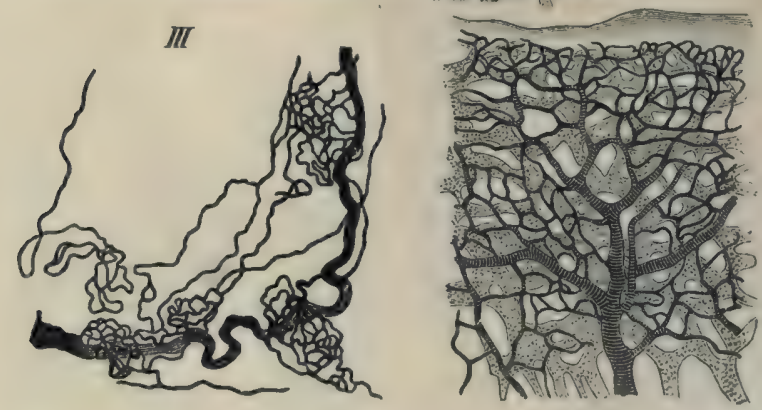

The bloud-vessels and Iymphatics of the skin; after Langer. Arteries striped, lymphatics shaded.
I. Vertical section through skin of thigh.
II. Horizontal view of arteries and lymphatics of the akin.
III. Peculiar tortuous arteries of tho lamina inguinalis.
IV. Arteries and lymphatics of the web.

shape (Hyrtl and Langer). The second network of vessels is situated under the cutis; the vessels forming it are small, and the meshes formed are large. From this network vertical branches pass to form the superficial network ; these branches usually course along the strands of vertical fibres already described, and break up to form capillaries only when they reach the deeper surface of the epidermis (Langer), (Fig. 235 I).

In some situations, however, the vertical branches divide earlier; this is especially the ease in parts where the glands are very closely packed, as in the nictitating membrane, the upper lip, and the 
swelling of the supplemental toe (in the male). In these parts the division takes place at the deeper surface of the glands (Langer).

A peculiar arrangement of the cutaneous blood-vessels is found in the lamina inguinalis, where a chain of reddish points can be made out with the naked eye; examined more carefully (Fig. 235 III) each reddish point is found to be a complex loop of capillaries. They extend from the skin to the hinder lymph-hearts, where they form a close network which partially invests the lymph-hearts (Langer).

(2) The lymphatics of the skin (see also p. 252), like the arteries, reach the deeper surface of the epidermis by coursing along the bands of vertical fibres; they then form a network of capillaries with rounded meshes (Fig. 235 I, II, IV), and lying immediately under the epidermis, and a network which surrounds the various glands. The lymphatic-capillaries are as a rule larger than the blood-capillaries. The lymphatic network lies beneath the blood network, and the vessels of the two systems branch independently (Langer).

In those parts where the glands are placed closely together this arrangement is modified, and corresponds with the modifications found in the blood-capillaries in these regions. The vertical branches divide so as to form a network below the glands, and from this vertical branches pass in the same direction between the glands to form a secondary network on the superficial surface of the glands (Langer).

g. The nerves of the skin. The cutis is very richly supplied with both medullated and non-medullated nerves. In the subcutaneous tissue the nerres destined for the skin branch freely to form numerous fine twigs, which, without actually inosculating, form a fine meshwork. From the larger trunks numerous vertical branches pass vertically to form a secondary network, from which both coarse and very fine twigs pass to encircle the glands. The fine fibres which supply the glands are non-medullated and possess oval nuclei; their diameter varies from $0.00 \mathrm{I}-0.002 \mathrm{~mm}$. The number of nerve-fibres is not much smaller than that of the muscle-fibres (Engelmann). (See also Organs of Tactile Sensation.)]

\section{THE ORGANS OF TACTILE SENSATION.}

The organs of tactile sensation are the nerve-plexus of the epidermis, the touch-spots of Merkel, the lateral sense-organs, and the touch-corpuscles of the tendons. 
a. [The nerve-plexus of the epithelium is very incomplete as compared with the plexus found in the epithelium of the cornea; here and there a few non-medullated fibres have been traced a short distance between the epithelial cells. No such mode of nerveterminations in the epithelium as is described by Eberth and Macullum in the tadpole can be found in the adult.]

b. The touch-spots. What knowledge we possess of these organs is due to the labours of Leydig, Ciaccio, Eberth, and more particularly those of Merkel.

At the base of each papilla, which contains such a touch-organ, is found a number of colourless, flattened cells, arranged either in a single layer, or heaped up and connected with very fine nerve-fibres.

Fig. 236.

I.

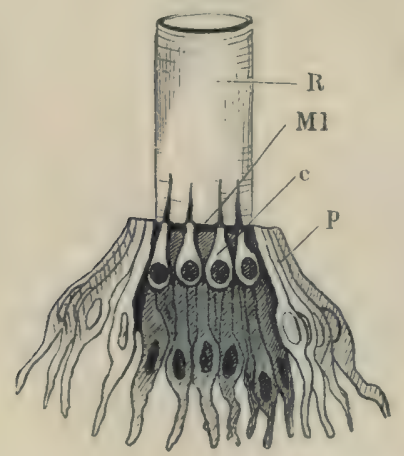

II.

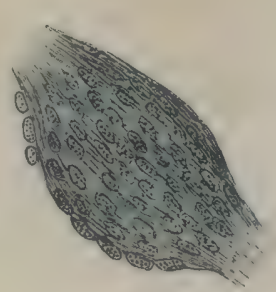

I. Lateral sense-organ of tadpole of frog. Half-schematic.
e Central zone (nerve-epithelium).
Ml Membrana limitans.
p Peripheral zone (sustentacular cells).
$\boldsymbol{R}$ Hyaline tube.

II. Touch-corpuscle from the sheath of a digital tendon of the frog ; after Löwe. Schieck, Oc, O., Obj. 9.

The flat surface of the cells is parallel to the surface of the body, and they do not form a separate or circumscribed body, they are therefore better spoken of as touch-spots than as true touch-bodias (Merkel). The larger organs are found in the papillae, but smaller ones may be found on any part of the skin.

These organs are best seen in the prominence or swelling upon the supplemental toe during the breeding season; they are numerous on the dorsal surface of the trunk, but oceur most frequently on the under surface of the hinder feet (Planta pedis). After the 
breeding season the organs of the thumb undergo a retrogressive change, which results in a network of spindle-shaped and branched cells with fibres (Wiedersheim).

c. The lateral sense-organs attain their highest derelopment in the tadpole; in the adult the organs have undergone a retrogressive change, the result of which is that the organs are diminished in size; the whole organ sinks by the formation of a tube, which is then closed by a mucous secretion, consequently the organ is functionless: with this loss in function and change in position of the organs a corresponding diminution of the ramus lateralis nervi vagi occurs (Merkel).

Each lateral organ (Fig. 236 I) consists of a slightly elevated papilla, with the centre depressed, and in each may be distinguished a central and a peripheral zone $(c, p)$. The central zone consists of a group of pear-shaped cells, with the narrower ends directed towards the free surface; each is connected below with a nerve-fibril, while above it bears a short, stiff cilium. The cilia are enclosed in a delicate hyaline tube $(R)$, which is open superficially, closed by the papilla below; consequently the cilia are in direct contact with the surrounding medium. The peripheral zone is a layer of pale, flattened, cylindrical cells $(p)$; they possess, at their upper borders, a perforated membrana limitans $(\mathbf{I} l)$, through which the cilia pass. These cells serve as a support to the central cells, and are themselves surrounded by ordinary epithelial cells.

The distribution and arrangement of the lateral organs is alike in fish and larval amphibia. They are most numerous on the head, where they surround the eve, and are continued forwards to the snout and on to the lower jaw. All these organs on the head are in connection with the trigeminal nerve. A line of these organs paszes from the hinder part of the circumference of the eye along the gill-cover to the neck, where the lines of opposite sides are usually, though not constantly, joined by a transverse line of the same organs; thence the lines are continued along the trunk to the tip of the tail. In fish there exists, as a rule, only one pair of such longitudinal lines (Linea lateralis); in anura-larvae, proteus, and in all salamanders there are three pairs: of these one pair lies near the vertebral column, the second at the junction of the flank with the abdomen, and the third corresponds to the lateral line in fish (Malbranc).

At an early derelopmental period each metamere posseases one pair of such lateral organs; in later life, however, this simple arrangement is lost, and each segment usually possesses a group of organs.

The organs of the trunk and tail are supplied by branches of the Ramus lateralis nervi ragi. Both in fish and amphibia a reparative process, by means of fission, occurs; as a consequence the organs are found in various stages of development.

d. [The touch-corpuscles of Golgi and Löwe (Fig. 236 II) are found on the joints of the digits. They are surrounded by con- 
nective-tissue and are spindle-shaped; the two ends of the spindle are glassy in appearance, the middle portion is fibrous. In the thickest part of the corpuscle is a zone of nuclear bodies.

They are regarded as touch-bodies (Golgi and Löwe). Golgi (l.c.) describes two kinds of touch-organs in connection with muscle and tendon; one class correspond with those just described, he names them 'nervous muscle-tendon organs.' The second class he compares with the touch-bodies found in the conjunctiva.]

\section{THE ORGANS OF TASTE.}

The organs of taste are not confined to the surface of the tongue, but are also found on the mucous membrane of the roof of the mouth, especially in the neighbourhood of the vomerine teeth; on both roof and floor of the mouth these organs can be traced to the commencement of the oesophagus.

[The mucous membrane of the tongue possesses two kinds of papillae and numerous glands.

a. The filiform papillae are the more numerous ; they are conical or thread-like in form, and consist of connective-tissue, with a few striated muscle-fibres; they include blood-capillaries, but no nerves have been traced into them (Leydig). They are covered with ciliated epithelium and goblet-cells.

b. The fungiform papillae are much larger, and are paler than the filiform papillae. The free ends of these papillae are broader than the bases, and when the epithelium is removed the free ends present a concavity. From the base to the border of the free surface each papilla is covered with the usual oval, ciliated epithelium, but at this border an abrupt transition takes place. The epithelium covering the end of the papillae is of three kinds: goblet-cells, cylindrical cells, and forked cells; the three forms of cells are quite characteristic, and no intermediate transitionary forms are met with.

(I) The goblet-cells (Fig. 237 I) are arranged vertically to the free surface of the papilla; they are from $0.020-0.024 \mathrm{~mm}$. in length, and from $0.01-0.02 \mathrm{~mm}$. in diameter. In the lower third of the cell is found a nucleus of about $0.008 \mathrm{~mm}$. in diameter, and this encloses a nucleolus of about $0.001 \mathrm{~mm}$. in diameter. Close underneath the nucleus the cell is contracted to form an irregular process or foot. The contents of the cells are a very finely granular, 
transparent protoplasm. These cells form the outermost part of the epithelium, covering the end of the papilla; all the cells belonging to the same papilla are of the same size. In consequence of the mutual pressure which they exert on each other they present, in transverse section, six-sided outlines (Fig. 237.2). The nuclei of adjacent cells are placed at almost exactly the same level. $\mathrm{B}$ y the

Fig. $23 \%$.
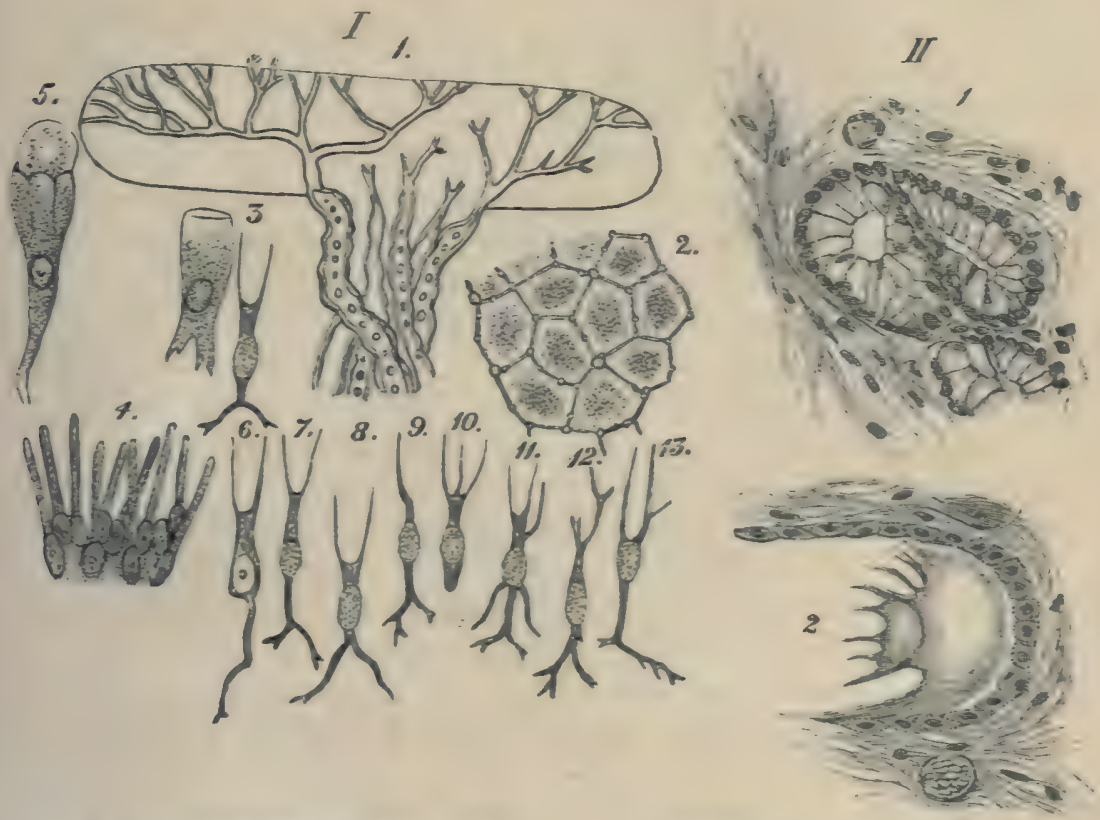

1. Various parts from tlie fungiform payillae; after Rngolmann.

₹. Nerves of a fungiform jayilla Magnified $f \equiv 0$ times.

2. Surface view of the epithelinm. after five minutes' action of io lized serum. Magnified 600 times,

3. Goblet-oell with adjacant forked oell." Magnified 450 times

4. Purtion of the papilla, after removal of the gublet-and forked cells ; only vylindrical cells rermaining. Magnified 400 tinnea.

5. Gublet-cell, with swollen contentz. Magnifiod 450 times.

6-r3. Tarious furmus of isolated forked celli. Maguified 4 50 times.

IL. Sections of two glands of the tongne ; after Biederznan.

1. Resting-gland.

2. Gland after stimulation.

action of reagents on these cells very remarkable forms are obtained, in consequence of the protoplasm swelling and being forced upwards (Fig. 237, 5).

(2) The cylindrical cells (Fig. 237 I) have rounded free extremities, which reach to the general surface of the epithelium; the remainder of the cell is cylindrical except towarls its lower ex- 
tremity, where it is slightly dilated and encloses an oval nucleus : the protoplasm of the cells is very finely granular. These cells rest on the connective-tissue of the papilla, and are in close juxtaposition, so that several hundreds of them are found on one papilla.

The spaces between the upper parts of the cylindrical cells are occupied by the goblet-cells and by the forked cells.

(3) The third form of cell found on the fungiform papillae are named forked cells (Fig. 237 I) by Engelmann. The body of the cells has an ellipsoidal form, is from $0.006-0.008 \mathrm{~mm}$. in its longer diameter, and $0^{\circ} 003^{-0.004} \mathrm{~mm}$. in the shorter diameter. Processes arise from both poles. The peripheral processes arise by a short common stem, which then divides into two or rarely three branches ; the whole process is from $0.004-0.008 \mathrm{~mm}$. in length, and is always just sufficiently long to reach the general surface of the epithelium : when the peripheral process is long the central is usually shorter, and vice versá.

The central processes arise by a stem from $0.001-0.002 \mathrm{~mm}$. in thickness, which usually divides dichotomously. The length of this process may be as much as $0.025 \mathrm{~mm}$. or almost nil.

The forked cells are about twice as numerous as the goblet-cells, they occupy the spaces between the cylindrical cells and the gobletcells. The branched central processes form a network on the connective-tissue of the papilla, which is, at this point, perforated by a rich plexus of fine non-medullated nerve-fibrils. It is not decided whether the processes of various cells inosculate. Engelmann regards these forked cells as the taste-cells and as the sensory nerve-endings.

The bodies of the fungiform papillae contain blood-vessels and nerves, the latter enter as medullated nerves, but lose the medulla somewhat abruptly towards the upper end of the papilla, where they form a sort of nerve-cushion (Nervenkissen, Engelmann).]

Taste-organs are also found on the roof and other parts of the mouth, and present many points of resemblance to the lateral senseorgans. Like them they present a peripheral zone and a central zone; the cells of the latter, however, are not longer than the peripheral cells, and possess no cilia (J. van der Hoeven, Merkel). 


\section{THE NOSE.}

The anterior nares or nostrils are two small openings, placed directly in front of the anterior angle of the eye ; the distance between the eye and the corresponding nostril being, in the case of adult animals, about five or six millimeters. The anterior nares are surrounded by rims, which are contracted below, and so form very short, tentacular-like prominences.

The posterior nares (choanae) are about four millimeters from the anterior nares, consequently the long axis of the nose is, approximately, of this length. (For the external muscles of the nose, see p. 59.)

The boundaries of the nasal cavities are as follows:--the roof of each cavity is formed by the dorsal plate of the sphenethmoid, the nasal bone, and the premaxillary bone; the floor is formed by the vomer and the palatine bone, the inner wall by the vertical septum of the sphenethmoid, the outer wall by the premaxillary and maxillary bones, the anterior wall by the premaxillary bone, and the posterior wall by the sphenethmoid. The cartilaginous portion of the nasal skeleton (see also p. 27) projects into the greneral cavity and subdivides it into various sinuses, which have been the subject of careful investigation by Born and Wiedersheim.

a. The nasal cavities are best examined by means of serial transverse sections; in a section through the anterior nares (Figs. 238 , 239) there will be seen three sinuses on either side :-

(I) The superior sinus (on) is large, rounded, and placed against the cartilaginous septum ; the sinus is lined with olfactory epithelium. Posteriorly the sinus extends beyond the posterior nares, and is bounded by the anterior surface of the sphenethmoid. In front it ends in a rounded concavity, likewise lined with olfactory mucous membrane. Opposite the anterior nares the cavity is partially subdivided, by a longitudinal process on the floor, into two cavities; the anterior nares open into the external chambers, and therefore not directly into the main eavity of the superior sinus. The superior sinus communicates with the inferior sinus by a narrow, almost vertical, slit.

(2) The inferior sinus (un) is narrow and flattened from above downwards; it is placed against the maxillary bone, and represents the maxillary sinus of the frog. Externally it possesses a descending arm.

The inferior sinus is continued backwards and opens on its 
inner side into the posterior nares, or rather into the mouth. The descending arm extends only a short distance forwards, to terminate near the point where the superior and inferior sinuses communicate by only a narrow opening. This sinus is on the whole broader in front than behind, and has a general direction from without, inwards and forwards underneath the superior sinus.

Fig. 238.

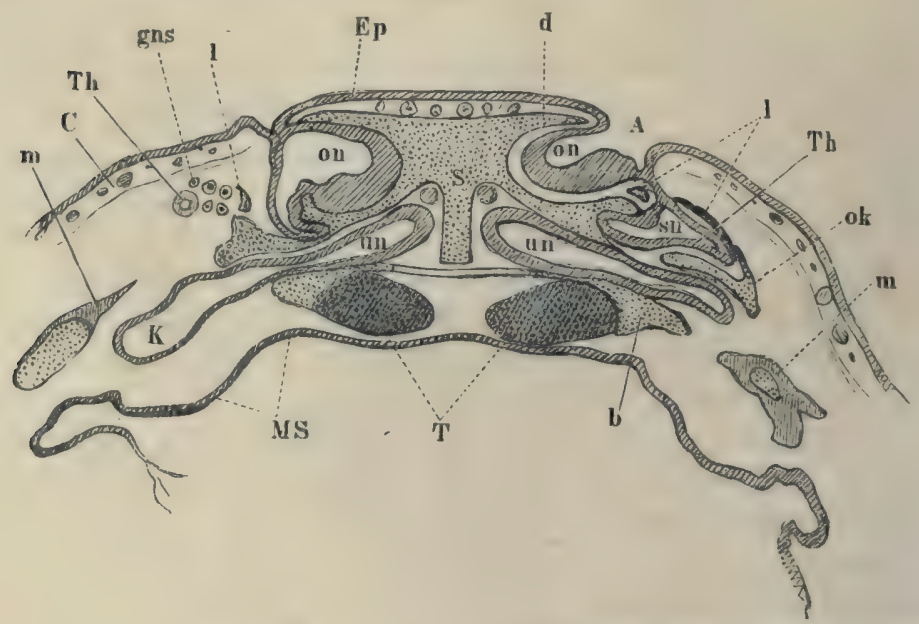

Frontal sections through the nose of two tadpoles; after G. Born.

Fig. 239.

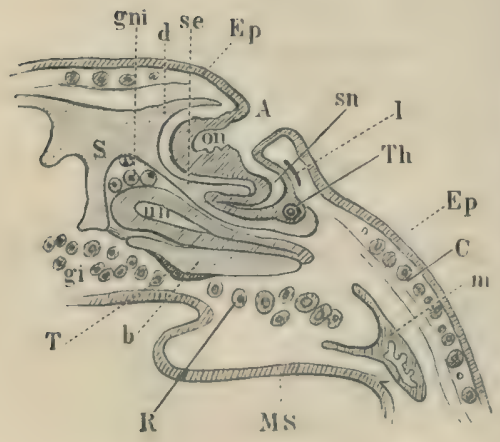

A Anterior naris.

Anterior naris,

Cutis.

Cartilaginous roof.

E E Lpidermis.

$g i \quad$ Intermaxillary gland.

gni Lower nasal gland.

gns Upper nasal gland.

$\boldsymbol{K}$ Maxillary sinus.

l Concha narium (os lachrymale).

m Maxillary bone.

MS Oral mucous membrane.

ok Cartilage.

on Upper blind sac.

$\boldsymbol{R} \quad$ Pharyngeal gland.

$S$ Nasal septum.

se Septum between the upper and lower nasal cavity.

External blind sac.

Trabeculae,

Lachrymal duct.

Lower blind sac.

(3) The lateral sinus $(s n)$ is situated in the partition between the superior and inferior sinuses, or rather between the external chamber of the upper sinus and the inferior sinus. The lateral sinus is triangular in form, being narrow in front and broad behind; at its 
inner posterior angle it opens on the free border of the horizontal partition between the superior and inferior sinuses; this opening is, however, continued along its roof, so that the lateral sinus opens also into the superior sinus.

b. The nasal cartilages. The two nasal cavities are completely separated by the cartilaginous septum (Figs. 238 and 239 S), and are for the most part lined by cartilage. The anterior end is formed of concave cartilages, while the posterior, being situated in the sphenethmoid, is usually more or less ossified in the adult. The posterior wall has two openings : a larger near the septum for the olfactory nerve, and a smaller, more externally, for the nasal branch of the trigeminal nerve.

The anterior wall is more complex than the posterior, being thicker in the middle than at the sides, and possessing three blind sacs for the three sinuses. From the anterior wall two processes project backwards between the saes and enclose them more or less completely.

Of the three sacs or cavities only the lower is completely surrounded by cartilage. The upper sac is in part bounded by a shellshaped, concave cartilage (Concha narium, of various authors; $O_{s}$ lachrymale, Born), which covers it anteriorly and externally, and is attached by a small base to the roof of the lower sac (Fig. 239, l), its upper border bounding the anterior naris (Fig. I5). The upper and external parts of the upper sac have no cartilage. The cartilages of the outer wall of the lower, blind sac extend backwards to the point where the maxillary sinus commences to descend: the roof, however, is prolonged further backwards by two small cartilaginous processes; the inner is short, the outer forms the roof of the descending arm of the sinus, and joins a cartilaginous process, which commences at the anterior portion of the roof of the nasal cavity, passes backwards and downwards to a broad plate, and forms an incomplete outer wall to the nasal cavity. There are also three cartilaginous processes - $a$. One arising from the outer side of the floor at the level of its junction with the anterior wall; it is a flattened process and passes outwards, and bifureates at its end to meet the premaxillary and maxillary bones (this is the Oberkieferfortsatz of Ecker), (p. 28, Fig. I4 $\left.n^{\prime \prime}\right)$ ). $\quad$. A delicate process on either side, deseribed by Wiedersheim (see p. 280). $\gamma$. The third pair of processes are fully described for the first time by Born; each arises at the lower border of the corresponding Concha narium, passes forwards and downwards under the ascending process of the premaxillary to 
the point where process $\beta$ is attached to this bone. The processes are flat and approach one another obliquely; in older animals they are united at the point of contact.

At the junction of the anterior wall, the septum, and the floor is a large aperture in the cartilaginous capsule, through which passes the chief nasal branch of the trigeminus, which supplies numerous branches to the intermaxillary gland.

c. The glands of the nasal region are Bowman's glands, the intermaxillary glands (Wiedersheim), the lower nasal gland (Born), the upper nasal gland (Born), the pharyngeal gland (Born), and the lachrymal duct.

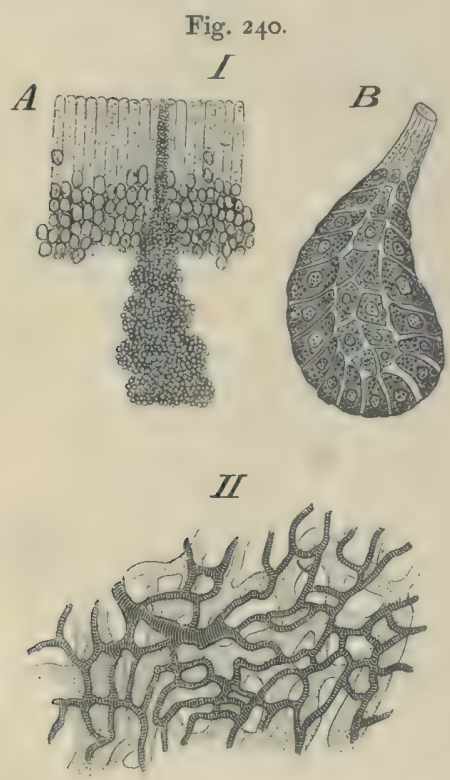

1. A. Bowman's glands in situ from Rana temporaria ; after C. K. Hoffmann. Magnified 150 times.

B. Section of Bowman's gland; after C. K. Hoffmann. Magnified 300 times.

II. Vessels of nasal mucous membrane of Rana esculenta; after Ianger. Bloodvessels striped, lymphatics shaded.

(I) The intermaxillary gland (see p. 280).

(2) The lower nasal gland is placed along the septum and extends as far back as the posterior nares, opening by its ducts (Figs. 238 and 239 gni) into the inferior blind sac of the nasal cavity. In histological structure it corresponds with the intermaxillary glands, except that the glandular tubes are somewhat smaller, and the glandular epithelium stains somewhat less easily with carmine (Born).

(3) The upper nasal gland occupies the space between the Concha navium (Os lachrymale, Born) and the neighbouring eartilages, it also surrounds the anterior naris and the opening of the lachrymal eanal (Figs. 238 and 239 gns). The numerous ducts open on the mucous membrane covering the oblique cartilage (above described, as passing from in front, downwards and backwards, and forming an incomplete outer wall of the eavity), and its hinder prolongation.

(4) The pharyngeal gland is placed transversely behind the posterior nares, and surrounds the vomerine teeth. A portion of the 
ducts open into the posterior nares, the remainder on the mucous membrane of the pharyngo-oral cavity at two symmetrically placed points (Fig. $23^{8} R$ ).

(5) The lachrymal duct (see p. 428) opens into the nasal cavity at the point where the lateral sinus opens into the external chamber of the superior nasal sinus.

(6) [The glands of Bowman (Fig. 240 I) are freely distributed in the nasal mucous membrane. Each gland is usually rounded or flask-shaped, and consists of a single layer of large epithelial cells possessing distinct nuclei and nucleoli. The epithelium of the glands possesses no basement membrane (M. Schultze and Hoffmann ${ }^{1}$ ), but is bounded externally by a layer of nerve-fibres and connective-tissue.

The glands situated more superficially have straight ducts opening on the surface; those placed more deeply have usually curved ducts (Paschutin).]

d. The mucous membrane of the nasal cavities. That part of the superior sinus immediately around the anterior naris is lined with stratified epithelium; the rest of the nasal carity is lined with columnar ciliated epithelium. The epithelial layer rests on a subepithelial network, and this again on a submucous connectivetissue layer possessing numerous ressels and nerves.

(1) The epithelial layer (Fig. 24I) consists of columnar cells, which in the olfactory region are of two kinds; in other regions the epithelium consists of closely-applied ciliated, thick cells, possessing large oval nuclei, and having irreyular, branched bases or 'feet.' The cells are $0.032-0.048 \mathrm{~mm}$. long; the nuclei $0.016-0.018 \mathrm{~mm}$. long, and $0.006-0.008 \mathrm{~mm}$. broad. The free borders of the cells bear a number of fine cilia.

In the olfactory region a second set of cells, olfactory cells, are met with; these cells (Fig. 24I II) possess each an oval hody, enclosing a large nucleus, and a peripheral and central process. The peripheral processes reach to the general surface of the surrounding epithelium and there terminate in a number $\left(5^{-8}\right)$ of stiff cilia; these cilia are sometimes $0.09 \mathrm{~mm}$. long, they are thicker at their bases than the ordinary cilia (Schultze); according to Hoffimann, a second system of stiffer and longer cilia is met with; of which each olfactory cell possesses as a rule only one. The bodies of the olfactory cells are $0.009-0.010 \mathrm{~mm}$. long, and $0.007-0.008 \mathrm{~mm}$. broad; the peripheral 
processes vary considerably in length, according to the position of the body $(0.03-0.05 \mathrm{~mm}$.). The central processes vary from $0.02-$ $0.03 \mathrm{~mm}$. in length. The peripheral processes are considerably thicker than the central processes. No membrana limitans olfactoria has been discovered in the frog.

(2) The second layer consists of a network of processes belong to the bases of the central processes of the superimposed epithelial and olfactory cells. Numerous highly refractive nuclei possessing nucleoli are situated in the meshes of this network; they correspond

Fig: $24^{\mathrm{I}}$.

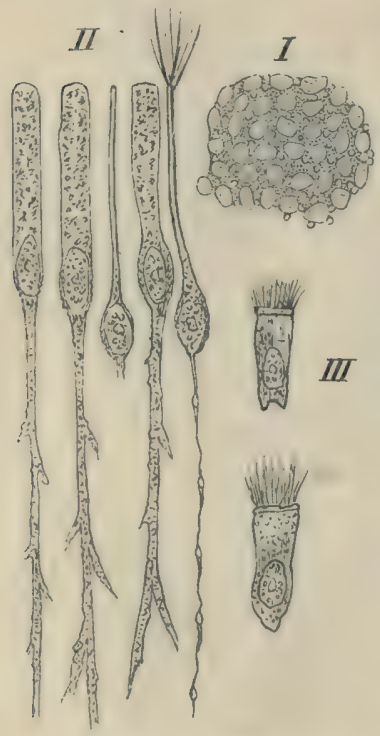

Separations from the olfactory mucous nembrane of Rana temporaria ;

1. Surface view of the olfactory mucous nembrane. Magnified 350 times.

II. Epithelial and olfactory cells. Magnified 600 times.

III. Epithelial cells. Magnified 600 times. after C. K. Hotfmann.

in all particulars with the huclei of the olfactory cells (M. Schultze). According to Exner the branched processes of the epithelial cells and of the olfactory cells unite to form a complex plexus. Other observers, Paschutin, Cissoff, v. Brunn, Schultze, and Hoffmann oppose this view, and hold that the central processes of the olfactory cells do not unite with the processes of the epithelial cells, but that they are in direct continuity with the fibrils of the olfactory nerve. This view is probably correct.

The submucous layer has a loose connective-tissue matrix, which encloses the glands, nerves, and vessels; according to Paschutin two pigment-layers may be distinguished: the one, immediately under the middle layer of this mucous membrane, is continuous and deeply pigmented; the second is deeper and does not form a continuous layer. This layer is extremely rich in blood-vessels and lymphatics (Langer and Paschutin), (Fig. 240 II). The lymphaties are relatively very large and are very numerous (Langer).

In this layer the central processes of the olfactory cells form bundles of fibres, lying parallel with the surface of the mucous membrane (Paschutin, Cissoff, and Schultze).] 


\section{THE EAR.}

(Tie-written by the translator from Das Gehörorgan der Wirbelthiere, ' by G. Retziug, 1881.)

The organ of hearing is divisible into two parts, the tympanum or middle ear, and the labyrinth or internal ear; an external ear is absent, unless a very slight depression of the tympanic membrane be regarded as such.

A. The tympanum (Carum tympani) is a cavity, bounded externally by the tympanic membrane and internally by the eapsule of the internal ear; it communicates by means of the Eustachian tube (tuba Eustachii) with the pharyngo-oral eavity (Fig. I 78).

a. The tympanic membrane lies immediately underneath the skin, but can be separated- from that structure; externally it possesses a very slight depression, the only trace of an external ear found in the frog.

The tympanic membrane is of a rounded oval form, being a little wider in the transverse than in the longitudinal diameter; the membrane is directed outwards.

After detaching the skin (Fig. $2+2$ I) the membrane is seen to be attached by its eircumference to a ring of cartilage (Annulus membranae tymjani; see also p. 26) (at); the ring is attached anteriorly and above to the squamosal bone $(\& q)$, and in the rest of its circumference to the surrounding soft parts, i.e. the $M$. depressor maxillae (dm), the $\boldsymbol{M}$. temporalis $(t)$, and their fasciae. In the middle of the membrane is a small, rounded, white part (col) which can be traced backwards and upwards towards the circumference.

The membrane consists of fibres of connective-tissue which radiate peripherally from the central point of attachment of the colu-

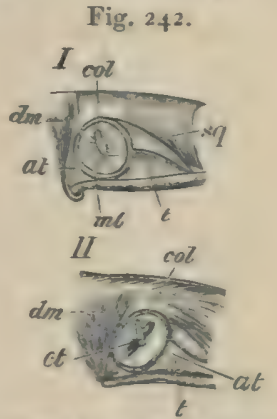

I. The tympanic memhrase of Rana esculentir; natural size. After Retzius

II. The tympanum as seen after renaving the tympanic nembrane; natural size. After Retzius.

at Annulus membranae tympani.

cal Columella.

d Fissure-like cavity.

dm M. depreseor maxillate.

$m \ell$ Trmpanic membrane.

F) Squamineal.

$t$ M. temporalis. mella; in the peripheral portion unstriated muscular fibres are also found (Leydig).

Internally the tympanic membrane is covered by columnar epi- 
thelium, a continuation of the mucous membrane lining the tympanic cavity.

b. The tympanic cavity (Fig. 242 II) is seen, after removing the tympanic membrane, as a flattened, funnel-shaped cavity. The walls of the cavity are lined with a pigmented mucous membrane, under which the cartilaginous ring (annulus membranae tympani) extends internally to form the greater part of the wall of the cavity. The eavity is an elongated oval slit (Fig. 242 II, ct), with its longer axis directed from above and in front, downwards and backwards, and leading inwards; it is bounded above, below, and in front by the squamosal, behind by the soft parts; above in the roof is the cartilaginous part of the columella. The inner or deeper portion of the tympanic cavity is bounded in front by the squamosal, and by the squamous process of the prootici (mroc. squamosus prootici) in front and above; internally by the cartilage (primordial-cranium) between the prootic and the exoccipital; behind by the $\boldsymbol{M}$. depressor maxillae. This part of the cavity is rounded and covered with mucous membrane, and has in its roof the bony part of the columella, which covers the foramen ovale (fenestra ovalis) by its oval, widened endpiece. This deeper portion of the cavity communicates by a short, wide Eustachian tube with the pharyngo-oral cavity; the tube is wide and is of a rounded oval form in section : anteriorly, externally, and internally it is bounded by the pterygoids, posteriorly by soft parts, in which is embedded the styloid process.

The tympanic cavity can be examined from without after removing the tympanic membrane, or from below by means of the Eustachian tube.

c. The columella auris (Figs. I 2, 243) is described by Retzius as consisting of three portions, of which the middle is bony, the external and internal cartilaginous. Parker divides it into four parts (see pp. 25, 26).

The extrastapedial (Fig. $243 a^{\prime}, a^{\prime \prime}$ ) is attached to the middle of the tympanic membrane by the oval surface opposite $a^{\prime}$, and is attached by the process $a^{\prime \prime \prime}$ to the annulus tympanicus; this process of Retzius is the suprastapedial of Parker.

The mediostapedial (Parker), or middle bony piece of Retzius (Figs. $12 a^{\prime}, 243 l, l^{\prime}$ ), is narrow externally but widens internally to articulate with the interstapedial. Just before reaching the latter it gives off a process $\left(l^{\prime}\right)$, to which are attached a few fibres of striated muscle $(m)$. 
The interstapedial (Figs. I $2 a, 243$ c) is cartilaginous; it is thick with a sharply cut-off, slightly concave end, which is placed against the fenestra ovalix. The inner surface of the interstapedial is, however, distinetly larger than the opening Fig. 243. of the fenesira ovalis, consequently it does not fit in accurately, but is attached to the border of the opening by means of connective-tissue; the margins of the fenestra oralis are hollowed (Fig. 245 II) so as to form a fossa fenestrae oralis, and it is really to the margin of this fossa that the connective-tissue capsule of the interstapedial is attached.

B. 'The labyrinth or in- ${ }_{b}^{b}$. ternal ear is contained in a capsule formed of bone , and cartilage.

a. The capsule of the labyrinth (Fig. 244) is formed of two bones, the prootic and the exoccipital (according to Hasse this includes the opisthotic), which are united by cartilage belonging to the primordial-cranium. The fronto-parietal, squamosal, and parasphenoid take only an indirect part in its formation.

On the whole the anterior half of the capsule is formed by the prootic, and the hinder half by the exoceipital ; the cavity has its long axis directed from within and above, downwards and outward; the eavity is comparatively large and rounded, and contains the membranous ear.

Four surfaces can be distinguished : a supero-external, an internoinferior, an anterior, and a posterior (Retzius).

(I) The supero-external surface is divided into two parts by a strong, transverse, bony ridge, the processus squamosus prootici. The upper half is concave, is directed upwards and outwards, and is formed by the prootic; it is separated from the anterior surface 
by a bony ridge, which marks the position of the anterior semicircular canal. Posteriorly and medianly it is separated from the posterior surface by a cartilaginous ridge, running from above, downwards and outwards, which marks the position of the posterior

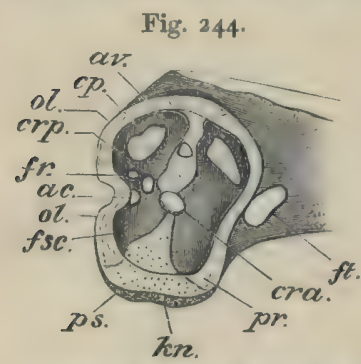

Antero-posterior section through he capsule of the right labyrinth of Ranu esculenta; after Retzius. Enlarged five times.

\footnotetext{
ac. Aquaeductus cochleae.

av, Aquaeductus vestibuli.

cp. Posterior semicircular canal.

cra. Canalis ranui anterioris acustici.

$c p$. Canalis rami posterioris acustici.

fr. Fenestra rotunda.

fst. Fovea sacculi et cochleae.

fi. Trigeminal foramen.

$k n$. Cartilaginons suture.

ol. Exoccipital.

mr. Prootic.

ns. Parasphenoid
}

covered by the columella.

semicircular canal. The eartilaginous hinder root of the processus squamosus prootici arises in the cartilaginous ridge just mentioned, and runs outwards and forwards, covering the external semicircular canal.

The lower half of the supero-external surface (under the processus squamosus) is irregularly concave; immediately under the proc. squamosus is a shallow groove in the prootic; it is continued on the exoccipital to the jugular foramen. The remaining part of this surface consists of a rounded cartilage, and is part of the primordial-cranium cartilage between the prootic and the exoccipital; posteriorly it has a small oval aperture, the foramen ovale (fenestra vestibulare), which with the groove is Above the aperture the cartilage narrows and is continued to the processus squamosus.

(2) The posterior surface is directly continuous with the superoexternal surface, and is formed by the exoccipital. This surface lies behind the ridge formed by the posterior semicircular canal, it is concave, and has two small apertures, separated by a narrow, bony process, and situated near the jugular foramen; these are the foramen rotundum $\left(f r_{0}\right)$ and the aquaeductus cochleae (ac.).

(3) The anterior surface is altogether bony and formed by the prootic $(p r$.$) ; the anterior surface of this part of the wall is continuous$ with the surface of the cranium, and abuts on to the large trigeminal foramen $(f t$.$) ; below it is continuous with the under$ surface of the cranium, below and externally it articulates with the pterygoid.

(4) The interno-inferior surface is as a whole hollowed internally, the upper part being pushed in towards the cranial eavity. It is formed by the prootic anteriorly, by the exoceipital posteriorly, and is completed by the cartilage lying between these bones. In 
the middle of the upper part of the cartilage is a small oval opening (ar.), the ap. aquaeductus vestibuli: about midway between this aperture and the jugular foramen is a second opening in the cartilage (cra.), the opening of the canalis rami anterioris (restibularis) acustici: a little behind and above this is the opening of the canalis rami posterioris (cochlearis) acustici, situated in the exoceipital. The cartilage between the prootic and exoceipital in the lower half of the interno-inferior surface rests on the parasphenoid.

b. The position of the soft parts in the capsule. The large outer, rounded part of the cavity contains the saccule and cochlea (focea sacculi et cochleae) ( $f s c$. .). Above, the cavity is more irregular, and contains the utricle and the sinus utriculi superior. In front and externally, imbedded in a deep groove, are the anterior and external ampullae (forea ampullae anterioris et amp. externae); to these are attached the corresponding semicircular canals. The anterior semicircular canal opens above and externally into the canal of the sinus utriculi superior; the posterior passes into a groove for the posterior ampulla (forea ampullae pasterioris), and opens above and internally into the posterior semicircular canal. The external semicireular canal courses in the processus squamosus prontici, the posterior in the eartilage (Fig. $244 c p$ ) between the prootic and exoccipital, and the anterior in the prootic. The upper and posterior part of the anterior semicircular canal is imbedded in cartilage, on which rests the parasphenoid.

c. The perilymphatic space (Fig. 245 I and II. The membranous labyrinth does not necupy the whole space enclosed by the hard parts but is surrounded by the perilymphatic space, which contains the perilymph. The periosteum and perichondrium form the outer lining of the space, and are for the most part pigmented.

The perilymphatic space is widest in the lower part of the organ, in the region of the forea sacculi et cochleae, especially externally and behind (per); in front it is much narrower (perl). A little higher, in the region of the tegmentum rasculosum, the space is wanting, as the membranous labyrinth is here attached to the periosteum.

Around the utricle and saceule the space is comparatively wide; it is continued into the bony canals and ampullae. In the semicircular canals the space is wider on the concave side than on the convex side, the membranous canals being placed eccentrically, as are also the ampullae, though to a less extent. The periosteum and 
perichondrium lining this eavity form a very delicate, pigmented membrane, formed of numerous fine elastic fibres which cross each other irregularly; its inner surface is lined with an incomplete layer of branched protoplasmic cells with large oval nuclei. From

Fig. 245 .
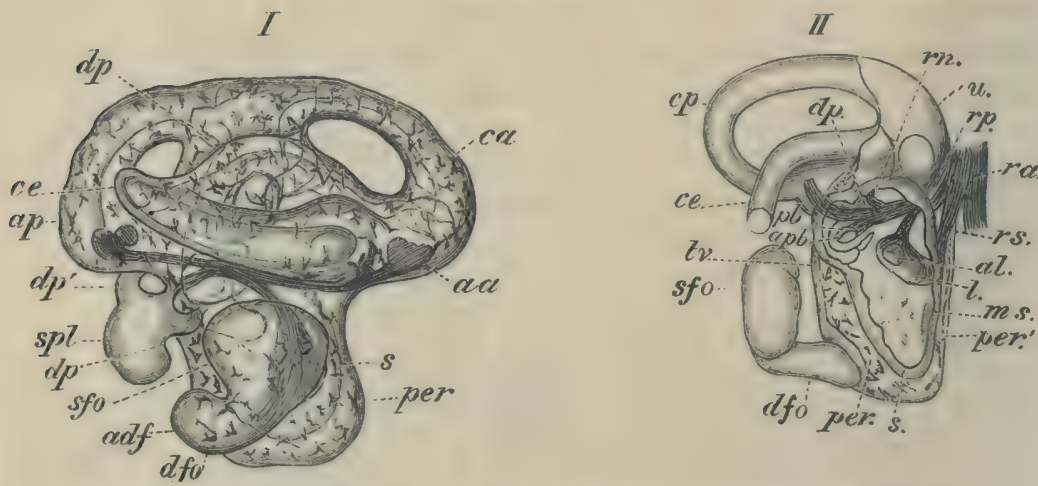

The membranous labyrinth of Rana esculenta, within its natural covering of periosteum ; after Retzius.

I. Seen from the side; magnified ten times.

II. The hinder half; magnified ten times. Seen obliquely from above, and in front, and from the side.

$\begin{array}{ll}a a & \text { Anterior ampulla. } \\ \text { adf Apertura fenestraie ovalis. } \\ \text { al. Apertura lagenae. } \\ \text { ap. Posterior ampulla. } \\ a p b \text {. Opening into the pars basilaris. } \\ c a & \text { Anterior semicircular canal. } \\ c e & \text { External semicircular canal. } \\ c p & \text { Posterior semicireular canal. } \\ d \text { o } & \text { Ductus fenestrae ovalis. } \\ d p & \text { Ductus perilymphaticus. } \\ d p^{\prime} & \text { Saccus perilymphaticus. } \\ l . & \text { Lagena cochlea. } \\ m s . & \text { Macula sacculia. }\end{array}$

pb Pars basilaris cochleae.

per Wider part of perilymphatic space.

per' Narrower part of perilymphatic spewo.

ru. Ramus anterior.

$m$; Ramulus neglectus.

rp. Ramus posterior.

r8. Ramulus sacculi.

8. Saceule.

sfo Saccus fenestrae ovalis.

spl Saccus perilymphaticus.

tv Tegmentum vasculosum.

$m s$. Macula sacculia.

this membrane numerous irregular bundles of fibres, in the form of trabeculae, pass into the space and form a rich network, which is attached internally to the outer surface of the membranous labyrinth and holds it in position. Free nucleated leucocytes are occasionally met with in the meshes of this network. The perilymphatic space is prolonged into two subsidiary eavities:-

(I) The ductus fenestra ovalis (Retzius), (Fig. 245 dfo) commences as an opening (arlf) immediately opposite the foramen ovale of the hard capsule, which leads into a moderately large canal, the structure under consideration. It passes forwards and outwards through the fenestra oralis between the interstapedial and the outer wall of the capsule into the oval depression (fossa fenestrae ovalis), 
and rapidly widens to form a short, flattened, blind sac (saccus fenestrae oralis), which is lodged in the fossa ( $f \circ)$. Its walls are thin and pigmented.

(2) The ductus perilymphaticus (Hasse), (Fig. 245 dp) passes above and behind the ductus fenestrae ovalis, behind the auditory nerve, and near the cochlea, then behind and above the lagena to the aquaeductus cochleae (Fig. 244 ac), where it forms a short, wide tube, which passes backwards and inwards through this eanal to the canalis juguTaris; here it lies close to the nerves and forms a short oval Fig. 246.

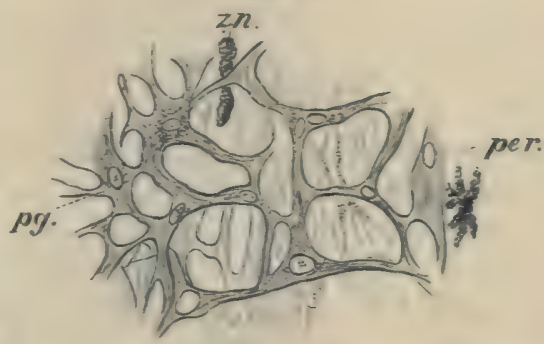

Part of the onter wall of the perilymphatie spewe: aiter Retrius. Térick's S'st., Ubj. III, Oc. 3. per. Perinsteum.

pg. Perilymuhatic network.

zir. Leuerestes. sac (saccus perilymphaticus) (dip'), which communicates with the subarachnoid space of the cranial eavity by means of a tube from the neck of the sac. The walls of this structure are thin and formed of connective-tissue with rery few pigment-cells. The other extremity of the tube passes to the jurs lusilaris and under the sinus post. utri., between it and the pars neglecta; it then courses to the outer side of the hinder end of the external semicircular canal: the tube then bends downwards to the outer side of the utricle and saccule to open into the general perilymphatic space.

d. The membranous labyrinth (Figs. 247, 248) has the following parts: the utricle and sinus superior, the recessus ulriculi, the anterior semicircular canal and anterior ampulla, the external semicircular canal and external ampulla, the posterior semicircular canal and the posterior ampulla, the saceule, ductus endolymphaticus, and saccus endolymphaticus, the pars neglecla, the lagena cochleae, the pars basilaris corleleae, and the so-called tegmentum vasculasum.

In addition the following nerve-terminations can be distinguished : (I) The macula ac. recessus utriculi, (2) the three crislae acusticae ampullorum, (3) the macula ac. sacculi, (4) the macula ac. neglectu, (5) the papilla ac. lagenae cochleae, and (6) the pajilla ac. basilaris cochleae.

The auditory nerve dirides immediately beyond its origin from the medulla oblongata to form a ramus unterior and a ramus posterior, which course alongside each other for a short distance, the latter lying behind and above the former. The $R$. anterior runs forwards 
and outwards under the utricle, giving off the $R$. sacculi, which runs downwards and outwards; the $R$. rec. utriculi is then given off as a number of fibres, which run upwards and forwards; the main nerve then divides to form the $R$. ampullae anterioris and the $R$. ampullae externae, which course together for a short distance and then separate to reach their respective ampullae. The $R$. posterior runs backwards and outwards, gives off the $R$. lagenae, and then divides to form the $R$. neglectus, running upwards, the $R$. basilaris running downwards and backwards, and the $R$. ampullae posterioris which courses backwards and outwards.

(1) The utricle (utriculus) (Figs. 247 and $248 u$ ) is irregularly cylindrical in form: commencing at the recessus utriculi it passes forwards and outwards; then backwards, inwards, and upwards, to terminate at the sinus posterior, where it is slightly contracted. At about its middle it is divided into an anterior and a posterior part by an incomplete, sickle-shaped partition, formed by the posterior semicircular canal opening obliquely into the utricle, and so causing a fold in the posterior wall : on the anterior wall there is no fold; the aperture left in the partition is the apertura utviculi.

The posterior part of the utricle receives the sinus superior, which is formed by the junction of the two vertical semicircular canals. The anterior part of the utricle receives the hinder dilated end of the external semicircular canal by an opening in its posterior wall, close to the apertura utriculi. In the lower wall or floor is the narrow opening leading into the saccule (canalis utriculo-saccularis) : this opening is placed with its long axis parallel to the long axis of the utricle, with its broader end posterior, and the narrower end anterior.

(2) The recessus utriculi (Figs. 247 and $248 \mathrm{rec}$ ). The anterior end of the utricle widens and curves downwards and outwards to form the recessus utriculi; on its floor is a thin, kidney-shaped plate or otoliths, resting on the macula ac. recessus utriculi (mu), which receives the ramulus rec. utriculi; under it the ramulus amp. anterioris and the ramulus amp. externae run forwards and close together to reach their respective ampullae, which are close together at the antero-external wall of the recessus utriculi. The otolith is a glassy, homogeneous plate, with numerous vacuole-like spaces and striated borders; it covers the whole of the macula.

(3) The anterior ampulla and semicircular canal (Figs. 247, $248, a a, c a)$. The anterior ampulla is a rounded, oval vesicle, with a depressed roof (Fig. $250 \mathrm{I}$ ); on the floor is a transverse 
low septum, which bears the crista acustica (cr) on its free border; seen from above the erista acustica (Fig. 249 II, aa, cr) has concave

Fig. 247.

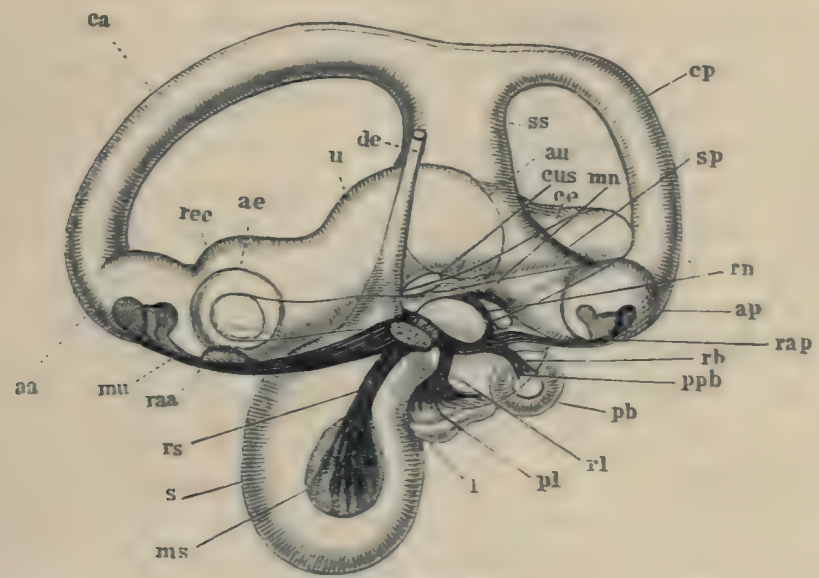

Fig. $24^{8}$.

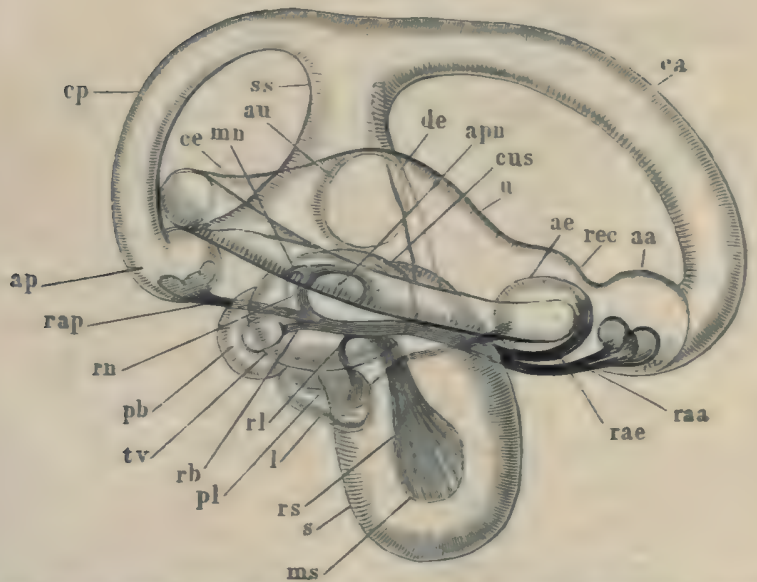

The right membranous labyrinth of Rund esculenta; after Retzinß. Magnified zo timea Fig. 247 soen from the inner side; Fig. 248 seen from the onter side.

aa Anterior ampulla.

te External anifiulla

up Pusterior ampulla.

apn Apertura partis neglectae.

au Apertura utrieuli.

cu Anterior semicireular canal.

ie External senicircular canal.

cp Posterior semieircular canal

cus Canalis ntrieulo-saceularis.

de Ductus endolymphaticus.

$l$ Lagena cuchleae.

\begin{abstract}
mn Macula acustica neglecta.
rb Ramulus basilaris.
\end{abstract}

ms Macula acustiea saceuli.

mu Macula acustica recessus utriculi.

pb Pars basilaris cochleae.

pl Payilla ac. lagenae.

ppb Papilla ac. basilaris

raa Ramulus ac. anterioria

rae Rarnulus amp, externae.

rap Ramulus amp. pusterioris. rec Recessus utriculi.

rl Ramnlns Lagenae.

rn Ramulus neglectns.

rs Ramulus saceuli.

- Raccule.

sp Sinus utriculi posterior.

ss Sinus utrieuli superior.

tv Tegmentum vasonlustum.

v Ctriculna

borders anteriorly and posteriorly; the ends are broad, rounded, and 
somewhat raised; and in the middle it presents a small elevation (Fig. $249 \mathrm{cr}$ ). On the crista acustica rests the cupula terminalis (Fig. $250 \mathrm{I}, c u$ ); this is arched above but of the same form as the crista acustica below, from which it is separated by an even slit-like space; the ends are not rounded but hollowed out. The substance of the cupula is very soft and has parallel striations, formed of fine fibres and running from above downwards ; it separates very easily from the crista acustica. The anterior ampulla is directed forwards, outwards, and slightly upwards, to open into the anterior semicircular canal (cunalis m. anterior) (ca), which curves first upwards and forwards, then backwards, inwards, and upwards, to open by means of a slightly dilated end into the sinus superior utriculi.

(4) The external ampulla and semicircular canal (Figs. 247, $248 \mathrm{ae}, \mathrm{ce}$ ). The external ampulla lies immediately external to the anterior ampulla; it also is an oval vesicle, and corresponds with the anterior ampulla in size and shape, except that the roof is higher. The roof is directed backwards, the floor forwards; the septum transiersum is low, placed vertically, and bears a triangular, slightly depressed crista acustica : the broader, rounded end of the crista is directed upwards, the apex downwards. The corresponding "cupula terminatis is relatively high, and is of the same shape as the crista, and is striated. The external ampulla is continuous with the external semicircular canal (canalis m. externus) (ce), which courses outwards and backwards; then backwards, inwards, and slightly upwards, touches the roof of the posterior ampulla; then curves forwards and inwards to terminate by a slightly dilated end in the anterior part of the utriculus.

(5) The posterior ampulla and semicircular canal (Figs. 247, 248 , and $249 a p, c p)$. The posterior ampulla commences at the posterior end of the sinus post. utriculi, and is directed outwards and backwards. It corresponds in all other points with the anterior ampulla. The posterior semicircular canal (ce) (canalis m. post.), into which the ampulla opens, curves upwards, inwards, and forwards, to open into the upper end of the sinns superior.

(6) The saccule $(s)$, ductus endolymphaticus (de), and the saccus endolymphaticus (Figs. 247, 248, 249). The saccule (s) is an oval vesicle, placed under the anterior part of the utricle and directed outwards and downwards; below it is flattened in a direction from in front and within, outwards and backwards; above it is wider. In the inner and anterior surface is the rounded, oval macula acustica sacculi (Figs. 247 and $248 \mathrm{~ms}$ ), to which is distri- 
buted the $R$. saceuli ( 78 ) from above; a large otolith rests on the macula and occupies a large portion of the carity, more especially the lower portion. The tubular iluctus endolymphaticus (de) arises by a narrow oval opening placed in the upper and inner part of the

Fig. 249.
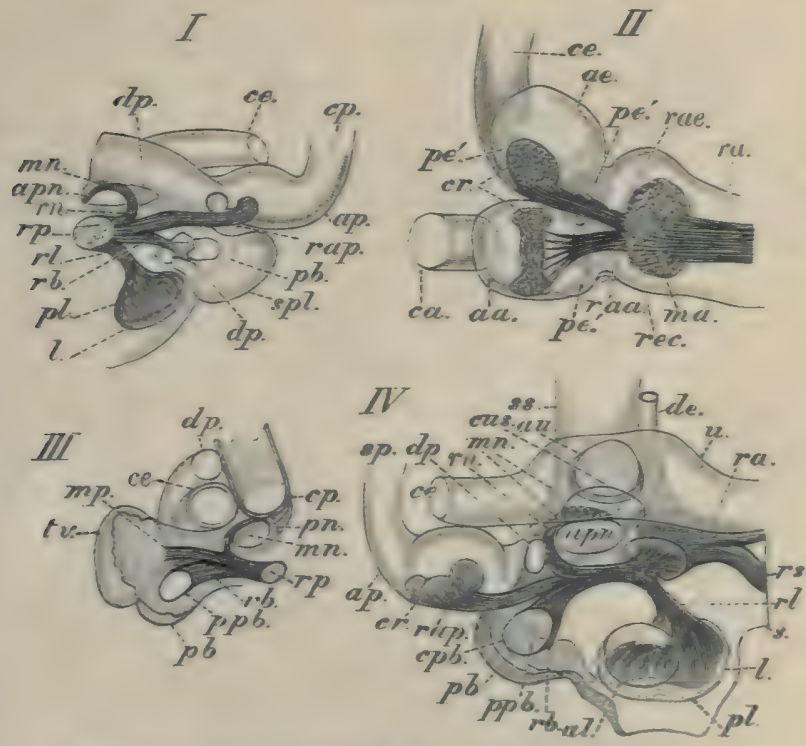

The membranposs labyrinth of Rona caculevia ; after Retzins.

I. Part of membranous labyrinth to show relations of the ductus and sacras endiglymphatiens to the cochlear part; magnitied.

II. The recensus utriculi and the external ampalls ; magnified.

III. To show tegmentum rasenlosnm, pars bilsilaris, pars neglecta, ete.

IV. To ahow relations of the cochlear part to the pars neglecta

aa. Ampulla anterior.

ac. Ampulla externa.

al. Aperturn lagenoe.

ap. Posterior ampulal.

apn Apertura partis neglectae.

au. Apertura utriculi.

ca. Canalis $m$. anterior.

ce. Rxternal semicircular cansl.

$c p$. Poeterior senicircular caral.

cpb. Opening into pars basilaris.

cr. Crista aenstien.

cus. Canalis utrieulo-sacenlarix.

de. Duetus endisnmphatiens.

dp. Ductus perilymphaticus b. Lagena erchleae.

ma. Yactula ac. recessus utricali.

mn. Maumlia ac, neglecta.

мsp. Mecubrana basilaris

pb. Pars basilariz cohlewe.

pe: Dark s[ntt on either side of ereot of ampoilla

jil. Pars ac. hirenae.

pn. Pars neglecta

ppb. Papilla ae. hasilarix.

ra. Ramus anterior.

raa. Ramulus amp. anterioris.

rece Ramulas amp. externa. rup. Ramnius anıp poterioris.

rh. Ramulns hasilaris.

nee Recususes utriceli.

rl. Ramulus lazedac.

rn. Ramulns negleetna

rp. Ramus poterior.

r*. Ranulus saceuli.

i. Sacorile.

sp. Pecterior semieireular eanal.

sh. Saevus perilymphaticus.

3s. Sinus ntrieuli superior.

tv. Tegmentum vaseulveum.

ש. Utricle.

wall, runs upwards and to the angle between the utricle and the sinus superior, continues in the same direction for a short space, and then curves inwards to pierce the apertura aquaesluctus vestituli, and so reach the cranial cavity. It then forms a large, thin-walled sac 
(saccus endolymphaticus), placed between the brain and cranium. The sac is very vascular and contains crystalline otoliths.

(7) The pars neglecta (Figs. 247, 248, 249) was described by Hasse as the 'first part of the cochlea' ('Anfangstheil der Schnecke'), but according to Retzius it does not belong to the cochlea. It is placed above and in front of the pars basilaris cochleae, above and a little behind the lagena cochleae, therefore above the upper and posterior part of the saccule, and under the middle part of the utricle. It is really a prolongation of the saccule, with which it communicates by an elongated oval opening placed externally and immediately below the opening of the canalis utriculo-saccularis. It is an oval vesicle, with its roof intimately united with the lower wall of the utricle; anteriorly it is broad, posteriorly narrowed. The macula acustica neglecta is attached to the roof of the vesicle and consists of an anterior heart-shaped and a posterior semilunar portion united by a narrow connecting piece (Fig. 250 III and VII), The ramulus neglectus divides into two branches, which supply the two parts of the macula. On the macula acustica neglecta rests the membrana tectoria (Deiters); the membrane is S-shaped, with the anterior end narrow, the posterior broad (Fig. $250 \mathrm{VII}$ ); the borders of the membrane are pierced by numerous small round holes, the central part has smaller and fewer perforations, and is finely striated. From the middle of the posterior part of the upper surface a thicker portion projects downwards into the cavity of the pars neglecta; it has a narrow, deep notch for the nerve at about its middle; anteriorly it points towards a sickle-shaped piece, which is curved inwards. Canals run obliquely downwards and inwards from the apertures on the superior surface. The membrane is clear, homogeneous, partly finely striated, and corresponds with the membrana tectoria of the pars basilaris, etc.

(8) The lagena cochleae (Figs. 247,248 , and $249 l$ ) is an oval swelling of the membranous labyrinth; it lies close to the saceulus with its broader end forwards, the narrower directed backwards. By a large rounded opening at the posterior end it communicates with the saccule by means of a rounded space common to the lagena cochleae and the cochlea. The papilla acustica lagenae $(p l)$ is situated in the posterior wall of the lagena; it is elongated, oval, and supplied by the ram. lagenae. The papilla is covered by a plate-like otolith formed of numerous rounded particles.

(9) The pars basilaris cochleae (Figs. 247,248 , and $249 p$ ) is placed on the posterior thickened wall of the saccule and lies above 
and behind the lagena. It forms a small, oval, pocket-like protuberance, with the long axis directed from in front and above, backwards and outwards, its opening being directed forwards and

Fig. 250.
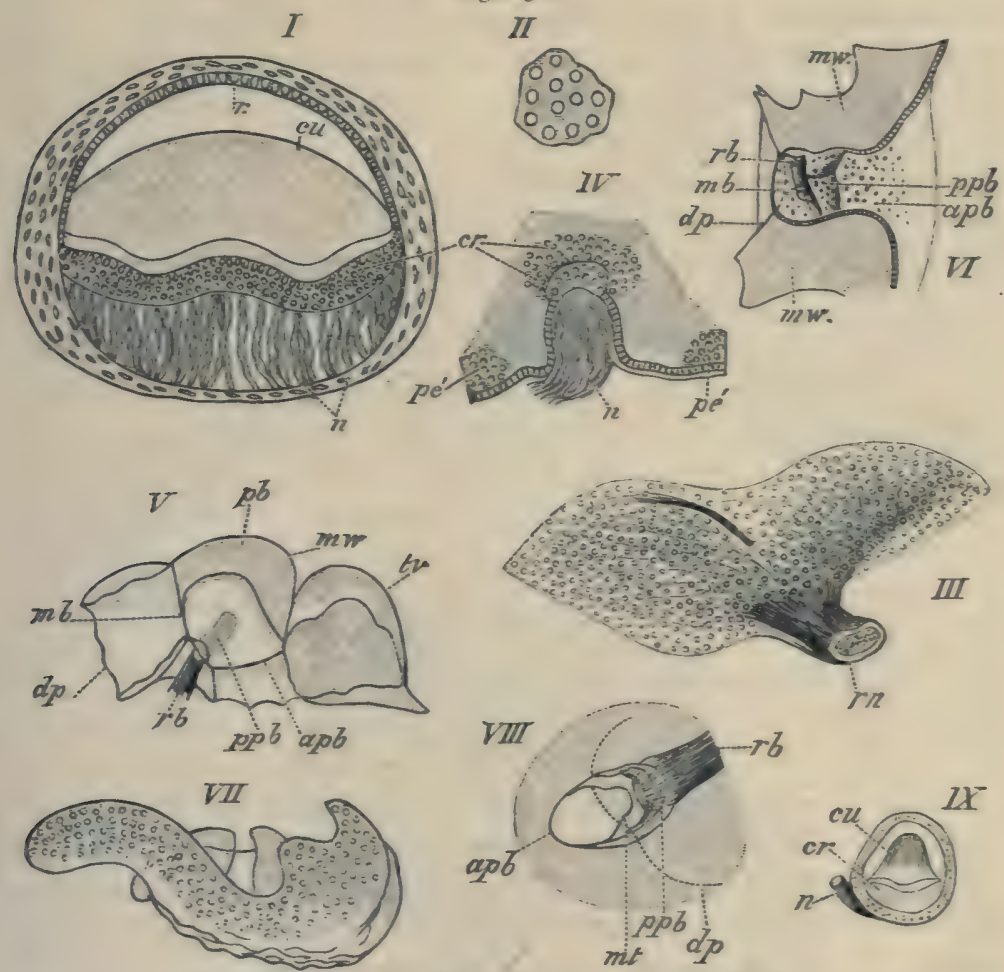

The membranous labyrinth of Rana eseulenta; after Retribs.

I. Transveree section of the anterior ampulla. Magnified go times.

II. Piece from under surfate of the eupula from the anterior ampalla, Vérick's Syst., Obj. VIII. Oc. 3.

III. The macula acustica negleeta, seen from below. Vérick's Srst., Ubj. IV, Oe. 3 .

IV. Part of wall of the anterior ampulla.

T. Part of the cochlea, the pars basilaris cut longitudinally. Térick's Syst., Obj. I, Oc. 3.

VI. Longitudinal seetion of the pars basilaris. Vérick's Syst., Obj. I, Oe. 3 .

VII. The macula ac, neglecta, seen from below. Vériek's Syst., Obj. IV, Oc. 3 .

VIII. The pars basilaris, seen from behind and the outer side. Vérick's Svst., Obj. I, Oc. 3.

IX. Transverse section of the external ampullh Magnified 175 times.
apb Oral opeuing into sacculo-cochlear space.
n Nerve-fibres.
cr Crista acustica.
ce Cupula terminalis
dp Ductas perilymphaticum,
nom basilaris
pe Area of coarealy granular cells.
ab Soction of thinner wall of pars bad-
ppb Papilla acustica basilaris. laris
- Tectorial meunbrane.
me Thickened membranous wall.
Bpithelium on raphe.
sb Ramulus bassilaria
rs Ramulus neglectus
b. Tegmentum rasculosum,

outwards. The short ram. basilaris passes in from above to supply it. The walls of this dilatation are thick and stiff, with the exception D d 
of a small portion, the membrana basilaris (Hasse) (ml), which closes the opening into a small dilatation on the anterior inner wall. The ramulus basilaris $(r b)$ divides into, at least, two branches, and passes close to the membrana basilaris $(m b)$, where the elongated and oval papilla ac. basilaris (Fig. $250 \mathrm{pp}$ ) is placed. The papilla is covered by a membrana tectoria (Fig. $250 \mathrm{mt}$ ), which is often found separated from the papilla, probably by the action of the

Fig. 251 .
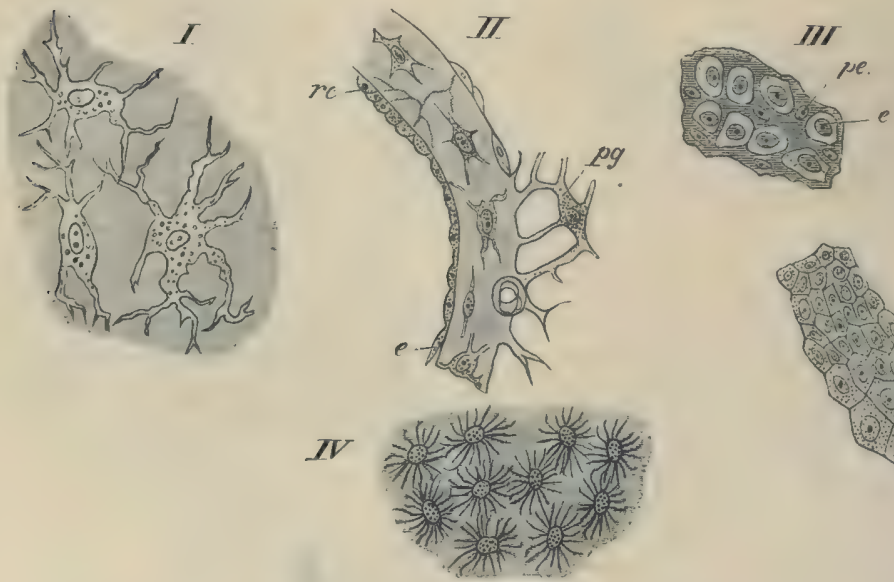

Preparations from the ear of Rana esculenla ; after Retzius.

I. Part of the membranous wall seen from the surface. Vérick, Obj. VI, Oc. 3.

II. Transverse section of the membranous wall. Vérick, Obj. III, Oc. 3 .

III. Epithelium from the neighbourhood of the macula ac. rec. utriculi. Vérick, Obj, III, Oc. 3.

IV. Branched cells from the yellow spot on the floor of the anterior ampulla. Verick, Obj. III, Oc. 3 .

V. Epithelium from the roof of the anterior ampulla. Vérick, Obj. III, Oc. 3.

re Epithelium of raphe.

e Pavement epithelium. pe Protoplasmic cells.

pg Perilymphatic tissue.

reagents used. The form of this membrane is peculiar but will easily be understood from the figure (Fig. $250 \mathrm{mt}$ ). In structure it is similar to the corresponding structures found in other parts of the ear.

(10) The tegmentum vasculosum (Deiters) (Figs. 245, 248, and $250 \mathrm{tv}$ ) is an oval, shell-shaped dilatation of the membranous labyrinth; its long axis is directed from above and in front, downwards and backwards. The walls of the tegmentum are thin and intimately attached to the periosteum.

e. The minute structure of the membranous labyrinth (Figs. $251,252)$. 
(I) The walls of the membranous labyrinth have the same general strueture throughout: the walls are usually thicker at the nerve terminations, in the ampullae, semicircular canals, pars neglecta, and especially the pars basilaris; the wall of the tegmentum fympani are the thinnest. The walls are transparent, homogeneous, refractive, and, at places, show a faint striation, which is, as a rule, not due to the presence of fibres; in parts of the recessus utriculi, and in the outer wall of the saccule, especially near the tegmentum vasculosum, more or less distinct fibres can be made out. Sections of the wall show spindle-shaped cells, with the processes usually arranged parallel to the surfaces; seen from the surface, the cells are seen to branch in all directions (Fig. 251 I, II). In the thinner parts of the walls the cells are few or altogether absent. The outer surface of the membranous labyrinth is uneven, in consequence of the attachment of the perilymphatic network. Bloodvessels are also attached to the outer surface, and pierce the wall, especially near the nerve-terminations.

The whole of the inner surface is lined with a layer of polygonal, tesselated epithelium-cells. The size and height of the epithelium varies in different parts. On the outer wall of the saccule the cells are large, but on the inner wall small; they are also large in the semicircular canals, except on a small raphe on the inner and outer side, where they are smaller but higher (Fig. $25 \mathrm{I} \mathrm{re}$ ); in the ampullae the cells are large, except on the roof. In the utricle and sinus superior they are also moderately large. In addition to the places mentioned, a smaller epithelium is found on the floors of the ampullae, in the recessus utriculi, and near all the nerve-terminations and on the sides of the ampullar septa. Surrounding the nerveterminations of the macula rec. utriculi, macula sacculi, and papilla lagenae are found narrow, branched, yellowish cells (Fig. 25I pe) with spindle-shaped nuclei. Cells of a third kind, first described by Deiters, Hasse, and Kuhn, in the tegmentum rasculosum, and in the ampullae by Hasse and $\mathrm{Kuhn}$, are also found in the utricle. They contain a yellowish pigment, and are collected into two sharply differentiated groups in each ampulla (Hasse has one placed before and one behind the septum on the floor). The cells are cyliudrical, the upper parts striated, the lower narrower, and the bases again widened to a polygonal, more homogeneous plate, which is fixed to the wall. On the tegmentum rasculosum the corresponding cells are not so high.

(2) The nerve-terminations. The larger branches of the auditory D d 2 
nerve contain medullated fibres of various dimensions and bipolar, spindle-shaped ganglion-cells. The nerves pierce the walls obliquely or vertically, and retain their medullary sheaths until near their final distribution. On each of the nerve-terminations is found nerve-epithelium, which varies in height in different parts. In the crista acustica it measures $0.075 \mathrm{~mm}$. in height in the middle part, $0.06 \mathrm{~mm}$. at the sides; on the macula rec. utriculi $0.09 \mathrm{~mm}$., on the macula sacculi $0.075 \mathrm{~mm}$., on the papilla lagenae $0.06 \mathrm{~mm}$., on the papilla part. basil. $0.045 \mathrm{~mm}$., on the macula neglecta $0.075 \mathrm{~mm}$. The epithelium is of two kinds, hair-cells and sustentacular cells.

Fig. 252.
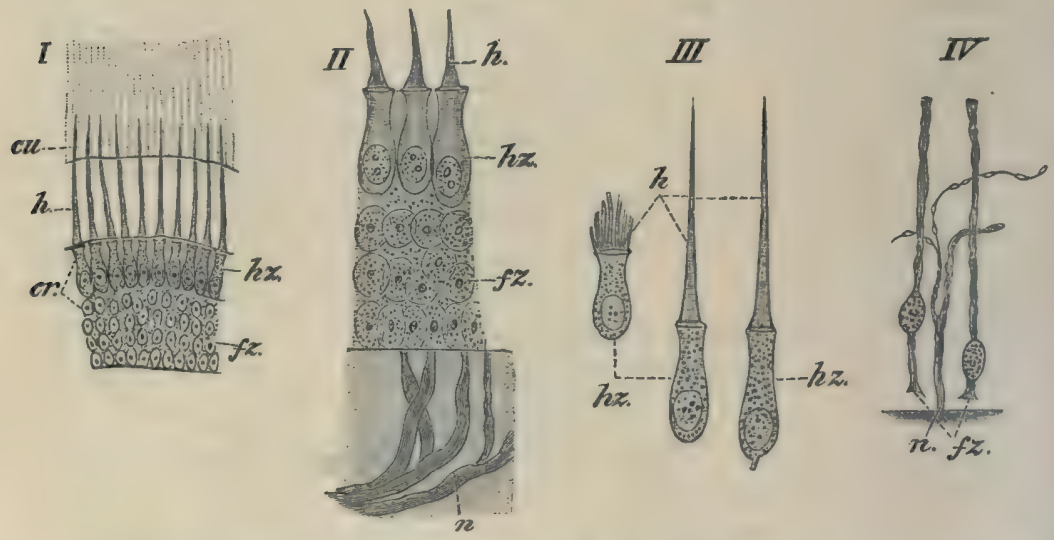

The nerve-terminations in the membranous labyrinth of Rana esculenta; after Retzins.

I. Vertical section through the crista acustica of the anterior ampulla. Vérick's Syst., Obj, III, Oc. 3 .

II. Vertical section through the macula ac. recessus utriculi. Vérick's Syst., Obj. VIII, Oc. 3 .

III. Three isolated hair-cells from the crista ac. of the anterior ampulla. Vérick's Syst., Obj. VIII, Oc. 3 .

IV. Two isolated sustentacular cells from the crista ac. of the anterior ampulla. Vérick's Syst, Obj. VIII, Oc. 3 .

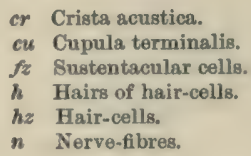

a. The hair-cells (Fig. $252 h z$ ) have, on the whole, elongated, flask-like forms, but are not all of the same length $\left(0^{\circ} 024-0^{\circ} .4 \mathrm{~mm}\right.$.). The free ends of the cells are rounded, flattened, and yellowish, and each bears a stiff cilium, which is fixed by a broad base to the cell, and thins out towards its free end : the eilia vary in length; in the ampullae their greatest length is $0.13 \mathrm{~mm}$, on the macula rec. utriculi $0.01 \mathrm{Imm}$, and on the papilla lagenae $0.017 \mathrm{~mm}$. The 
cells are granular, possess rounded oval nuclei, and are fixed by a fine, narrow process (Fig. $252 \mathrm{hz}$ ), though they usually seem to be rounded off without possessing a process.

$\beta$. The sustentacular cells. Under the hair-cells is a finely granular substance, possessing numerous rounded oral nuclei, which are placed in superimposed rows (Fig. $252 f z$ ), the deepest row being placed close together and immediately on the membranous wall. After proper treatment and isolation these nuclei are seen to belong to narrow, elongated cells, which rest by a slightly widened base on the wall, and are continued upwards between the hair-cells to reach the surface of the epithelium, where their upper processes are again slightly widened.

$\gamma$. The nerve-fibres (Fig. $252 n$ ) lose their medullary coats, ascend towards the epithelium, and frequently divide to form two unequal branches, which ascend to the level of the hair-cells, and curve so as to course horizontally as extremely fine varicose fibrillae; these frequently form a network, of which the exact method of termination has not been made out. In some cases a fine fibril may be traced to the base of a hair-cell, but a direct continuation of the one into the other has not yet been traced.

\section{THE EYE.}

(Re-written by the translator.)

The organ of sight, the eyeball (bulbus oculi), together with its appendages (tutamina oculi), will be described in this chapter.

A. The Eye is flattened on the outer surface, more convex on the inner or deeper surface. Its principal axis is directed from behind, forwards and outwards.

The outer transparent portion of the eyeball is the cornea, which forms the outer boundary of the anterior chamber. The larger, white, opaque, and inner portion is the sclerotic coat, which, together with two deeper tunies, the choroid coat and the retina, enclose the posterior chamber of the eye. The pigmented ring placed behind the cornea is the iris, and the aperture it encloses the pupil. The lens is placed immediately behind the iris. On the inner side the optic nerve pierces the sclerotic to enter the eyeball.

a. The sclerotic coat (sclerotica \&. sclera) forms about three- 
fourths of the surface of the eyeball; posteriorly it is pierced by the optic nerve at a point (porus opticus) nearer the temporal side than the nasal. The sclerotic coat consists of fibrous tissue externally, with a layer of hyaline cartilage internally (Helfreich). The fibrous layer

Fig. 253.

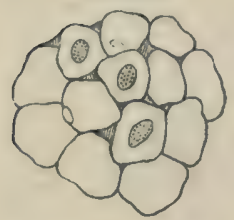

Endothelium from the inner surface of the selerotic coat; after Hoffmann. is formed of bundles of parallel fibres, which cross each other, chiefly at right angles (Hoffmann). The cartilaginous layer ends just behind the line of insertion of the extrinsic muscle of the eye, and is thickest at the point of entrance of the optic nerve (Helfreich).

The sclerotic coat is rich in nerve-fibres, which form a close network; the fibres, however, do not unite but form the meshes of the network by simply crossing each at acute angles.

The deeper surface of the sclerotic coat is lined with a layer of large endothelial cells (Hoffmann), (Fig. 253), which form the outer wall of the capsule of Tenon.

b. The cornea and the anterior chamber. The cornea forms about one-fourth of the surface of the eyeball and is directly continuous with the selerotic. In it five layers can be distinguished: a layer of stratified epithelium or conjunctiva, an anterior hyaline membrane, the true corneal substance, a posterior hyaline membrane, and a layer of endothelium.

(I) The corneal epithelium is a layer of stratified epithelium covering the superficial surface of the cornea. The superficial layer forms a beautiful mosaic of polygonal cells; the middle layers are polygonal in all sections, while the deepest layer is more or less columnar. Except in the most superficial layer, all the cells have serrated surfaces. Smaller cells possessing each two nuclei are also found between the columnar cells, and are evidently cells in process of division; according to Waldeyer, cell-proliferation may also take place in the middle layers.

'The basal or deeper portions of the columnar cells possess a clear border, which reminds one of the hyaline border found on the free border of columnar epithelium in other parts. The cells are here so rlosely applied to one another that these borders have the appearance of a continuous, highly refracting membrane (Rollett); according to Henle, the border consists of a network of very fine processes from the cells above.

(2) The true corneal substance, and (3) the anterior hya- 
line membrane. The corneal substance consists of flat bundles of fibres arranged in laminae, with cement-substance and connective-tissue corpuseles interposed. The fibrils are extremely fine ( $0.0001 \mathrm{~mm}$., Engelmann), and bound together into bundles by cement-substance. The bundles of the laminae are arranged at various angles, though many are placed at right angles to each other (Waldeyer).

Between the laminae are flattened spaces, which seen in section are spindle-shaped. By proper treatment they are seen to be irreg-

Fig. 254

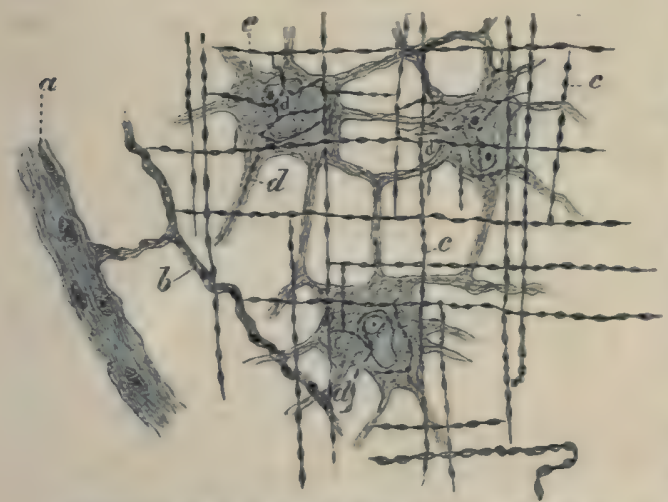

Proparation from cornea of Rana esculenta ; after Klein. Hartnack's Syst., Obj. VII, Oc. 3.

a Nierve of firat order.

$b$ Nerve of secund order.

c Nerve of third order.

d Nerve of fourth order.

e Corneal corpuncles. ular, branched spaces, which communicate by fine canals and form part of the Recklinghausen-canals or lymph-system. These spaces contain branched, connective-tissue corpuseles (Toynbee), and a colourless fluid.

The corpuscles (Fig. $254 e$ ) do not fill the spaces which they oceupy. They possess large nuclei, surrounded by granular protoplasm.

The canals by which these spaces communicate ('Saftcanälchen' of Recklinghausen) lie, in general, parallel to the surfaces of the cornea, and communieate by joining at acute angles or by short transverse branches. According to Lardowsky, these canals have a distinct lining membrane.

The anterior hyaline ${ }^{1}$ layer (Bowman's or Reichert's lamella) is not so well seen in the frog as in some higher animals; it is simply a portion of the corneal substance, of somewhat denser structure than the rest, into which it passes by a gradual transition.

(4) The posterior hyaline membrane (Descemet's membrane) is a highly elastic, very transparent layer, placed behind the true corneal substance; in the frog some few bundles of fibres

1 Tamanscheff and Schweigger-Seidel consider the anterior and posterior hyaline membranes to be composed of fine fibrils. 
belonging to the true corneal substance appear to pass into the posterior hyaline layer, although they cannot be traced further through its substance. . The structure of the membrane is, in consequence of its transparency, unknown, though the above observation seems to point to a fibrillar origin.

(5) The corneal endothelium is a single layer of polygonal cells of $0.02 \mathrm{~mm}$. diameter. The cells possess the power of altering

Fig. 255 .

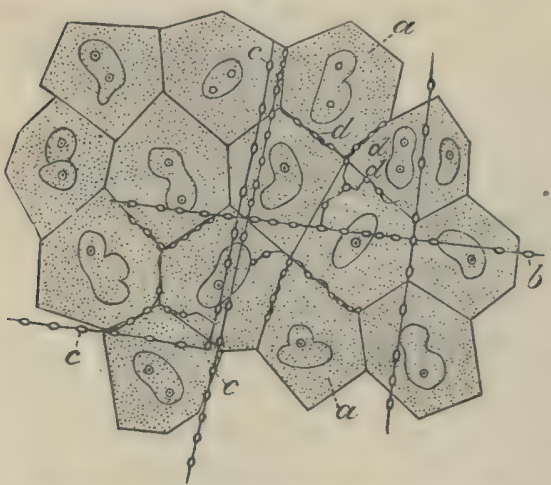

Preparation from cornea of Rana esculenta ; after

Klein. Hartnack's Syst., Obj. X immers, Oc. 3 .

a Endothelial cells.

$b$ Nuclei of endothelial cells.

c Nerves of third order in the tissue of the cornea propria.

d Nerves of the fourth order. their shape when stimulated (Klebs).

(6) The nerves of the cornea are derived from the ramus oplithalmica trigemini; they pierce the sclerotic coat in front of the sclerotic cartilage and then course towards the cornea, at the margin of which they form a coarse network of medullated fibres. From this about thirty nerves pass towards the cornea, which they enter, and then very quickly lose the main part of their medullary sheaths. According to Wolff, a portion of the nerves retain their medullary sheaths, or in some cases appear to regain it after having lost it.

The nerves passing from the plexus (nerves of the first order, Klein) give off smaller branches, which for a short distance have a serpentine or rectilinear course. By a few anastomoses they form a loose plexus (nerves of the second order, Klein). After a longer or shorter course they give off numerous lateral fibres, or terminate in several such fibres arising at one point (nerves of the third order, Klein). These are distinguished by their size, varying only within small limits, and by the possession of more or less regularly placed varicosities; the clearer portions are longitudinally striated as though made up of fibrillae; they have a nearly rectilinear course, and, after a longer or shorter course, turn into a direction which is at right angles to the former one; lastly, they remain for long distances unbranched. These nerves are connected one with another by cross fibres running at 
right angles to them, and in this way a rectangular trellis-work is formed.

The fibrils (nerves of the fourth order) given off by these nerves form networks around the connective-tissue corpuseles, but no direct connection between nerve and corpuscle has been traced; they always appear to lie on that surface of the corneal corpuscle which is directed towards the superficial surface of the cornea (Klein). In the endothelium covering the membrane of Descemet these fibrils can be traced coursing along the margins of the cells (Fig. 255 d), and sometimes undergoing dichotomous division (Klein).

Almost all observers have described these fibrils as possessing varicosities; Hulke, and more recently Wolf, however, deny their presence. Lavdowsky traces nerve-fibrils to the nuclei of the connective-tissue corpuscles.

(7) The anterior chamber is the space between the cornea and the iris, and is filled with a watery fluid, the aqueous humour. At the circumference of the chamber are a number of spaces (spaces of Fontana), formed by interruptions in the tissue between the posterior surface of the cornea and the iris; the result is that bands or trabeculae (ligamentum pectinutum iridis) pass from the one structure to the other, and between these are the spaces of Fontana.

According to Angelucei these trabeculae are of three kinds: trabeculae passing from the cornea to the iris, formed of connective-tissue; trabeculae from the cornea to the ciliary processes, which contain elastic tissue; trabeculae from the interstitial connective-tissue of the ciliary muscle to the cornea, and formed almost entirely of elastic tissue.

At the junction of the cornea and sclerotic, and just in front of the spaces of Fontana, is a larger and similar space, which may be traced round the whole circumference of the cornea; this, the canal of Schlemm (Sinus circularis iridis), is held to be a venous plexus by some observers (Angelueci, and others), according to others it is a lymphatic space in connection with the anterior chamber (Schwalbe, and others). It is certain that the vessels can be very easily injected from the anterior chamber, although a direct communication has not yet been seen.

c. The choroid coat and the iris (tunica choroidea et iris, tunicu rasculosa).

1. The choroid coat lines the deeper surface of the sclerotic coat, but is also prolonged under the cornea to form the iris. 
Fig. 256 .
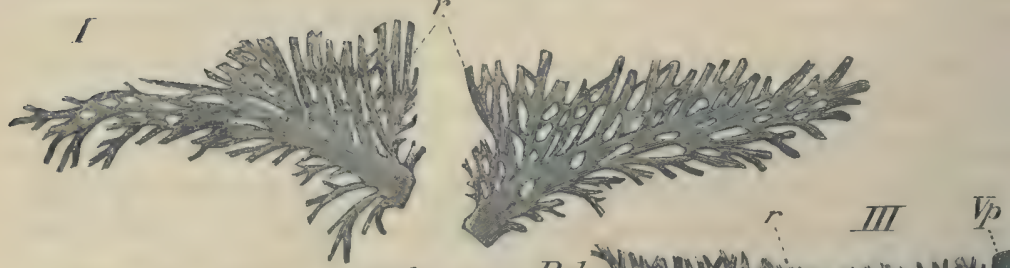

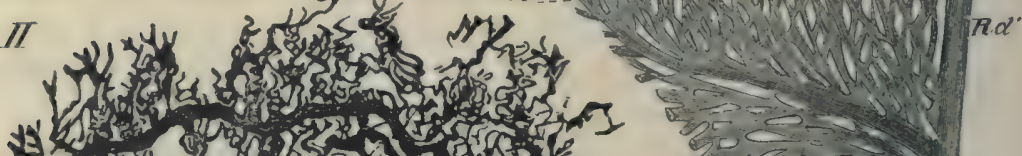

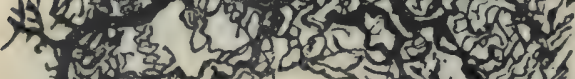

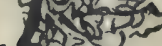
(4) $>$

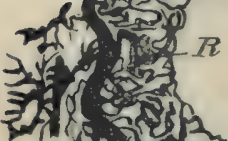
$R$
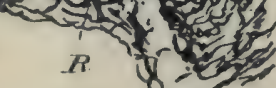

An

(N) $\pi / \pi$

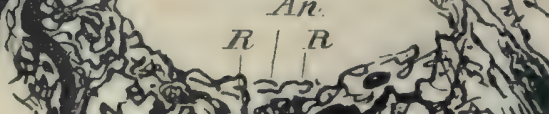

At
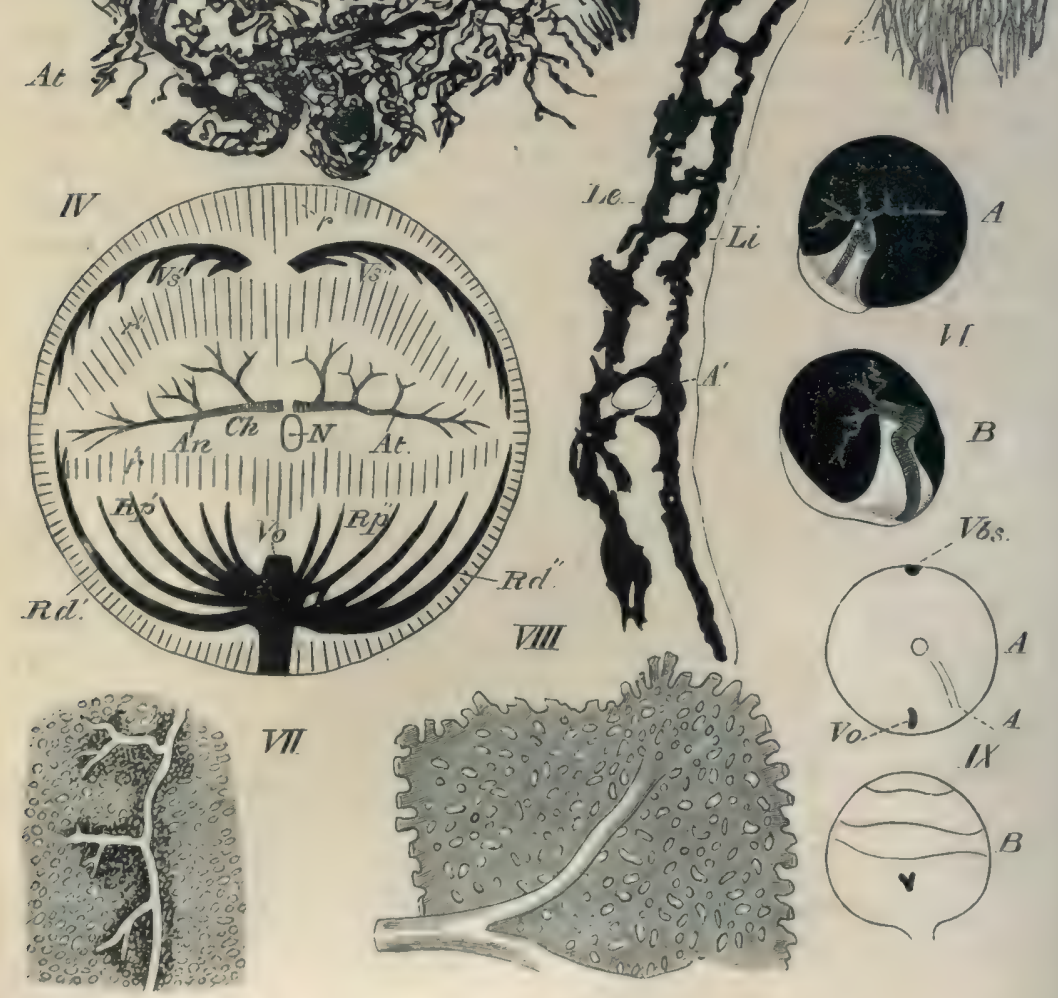
The choroid is firmly attached to the sclerotic in two positions, at the point of entrance of the optic nerve, and at the line of junction of the sclerotic and the cornea. Its external surface is closely applied to the deeper surface of the sclerotic, from which it is only separated by a very narrow serous cavity (supra-choroidal space), and to which it is attached by numerous vessels and nerves. The deep surface of the choroid is covered by the retina, to which it is closely attached, except at the ora serrata, the attachment being especially intimate at the processus ciliares.

The choroid coat consists of a fibrous layer containing corpuseles and traversed by a very rich vascular anastomosis. The corpuscles of this layer are deeply pigmented, in some cases to such an extent that the oval nucleus cannot be seen; the fibrous tissue is also pigmented, and has consequently a brownish tinge. That portion of the layer immediately below the sclerotic is termed the lamina fusca or suprachoroiclea, the vessels on the deeper surface forming the membrana choriocapillaris. This again is lined on its deeper surface by a hyaline membrane.

a. The arteries (Fig. $256 \mathrm{VI}, \mathrm{VII}, \mathrm{VIII})$ supplying this coat are two branches of the arteria ophthalmica; these form a capillary network (Fig. 256 VII) resembling the corresponding structure found in mammals. The meshes have approximately the same size, while the capillaries themselves vary considerably in size. This network is, however, only complete on the nasal, temporal,

Fig. 256 .

The vesols of the choroid and iris; after Hans Virchow.

1. The two roots of the V. bulbi superior. Magnified to times.

II. Vesels of the iris Magnified g times.

III. Origin of the ventral vein.

IV. Schems of the choroid veseals; seen from the proximal pole.

V. Transverse section through the ehoroid at the equator.

VI. The urigin of the chorvid arteries from the ophthalmic artery. The greater part of the sclervtic has been removed. Left eve twice natural size. A. From the proximal pole. B. From the temporal side.

VII. Part of a chorvilal artery attached to the chorincapillaris, Magnified ro times.

V11. A portion of the chorineapillaris, more highly magnified.

1X. The V. ophthalmica and $V$. bulbi superior on the selentic of the right eye. $\mathbf{A}$. Seen frum proximal pole. B. Soen from abova. Twioe nateral sise.

A Art ophthaimica.

d' Art. chorvidea.

in R. nasalis of the ophthalmic artery.

It R. temporalis of the ophthalmic artery.

ch Area of membraua chorimea pillaris.

Le Outer pigmented layer of chorvid.

Li Inner pigmented layer of choroid.

IN Optic nerve.

$r$ Vasa rocta.

Transitional part between ehoriocapillaris and ventral whorl.

$r^{\prime \prime}$ Transitional part hetween choriocapillaris and upper whorl.
$R$ Branches of the cirenlas iridis major.

Rd Distal not of vein of under surface of eye.

$R d^{\prime}$ Distal mout of nasal vein.

$R d^{\prime \prime}$ Pruximal ruot of naval vein.

$R p^{\prime}$ Sasal root of ventral vein.

$k y^{\prime \prime}$ Temporal root of ventral vein.

Vhs V. balbi superior.

Th T. Lyaloidea.

Vo V. ophthalmica.

Fp. Proximal root of vein of under surface of eve.

$F^{\prime}$ Nasal rnot of $\mathrm{V}$. bulbi superior.

V. $^{n}$ Temporal noot of $\mathrm{V}$. bulbi superior. 
and proximal part of the upper surfaces. Towards the corpus ciliare the meshes become wider and elongated; the capillaries then unite at acute angles parallel with the longitudinal axis of the eye. The network (choriocapillaris) exists in a simple layer within the two arteries which form it, and superficial to the veins (Virchow).

$\beta$. The veins of the choroid (Fig. 256 III, IV, IX) are (I) a vein which unites at the lowest point of the equator of the eye with the $V$. hyaloidea to form (2) the $V$. ophthalmica, two small branches of the $T$. bulbi superior, which unite outside the sclerotic, and (3) the vasa recta.

(I) The larger vein arises from the greater part of the under surface of the eye ; it gives off branches to each side, which radiate to form a 'whorl' or star-shaped capillary anastomosis (Fig. 256 III), the two halves of which have no connection. A proximal and a distal root can be distinguished in the anastomosis; the distal lies towards the corpus ciliare, and occupies exactly one-fourth of the circumference of the choroid at its junction with the corpus ciliare.

(2) The two branches of the $V$. bulbi superior lie alongside the corpus ciliare on the upper surface, and each occupies one-fourth of the circumference; they form a similar though simpler figure (Fig. $256 \mathrm{I}$ ) to the foregoing, each forming one half.

(3) The vasa recta are numerous parallel vessels which arise in the iris, and coursing centrally empty themselves into the branches of the $V$. bulbi superior on the superior surface, and into the branches of the venous capillaries on the inferior surface.

2. The iris is covered anteriorly by a layer of endothelium, continuous with that covering the posterior surface of the cornea, and of similar character. The border of the pupil (margo pupillaris) is of a golden colour, outside this bright ring to its outer margin (margo ciliaris) the iris is black; the golden colour is due to the presence of cells containing a pale yellow pigment; the nuclei of these cells are round and granular; the cells themselves have rounded outlines (Hoffmann). The black portion of the iris contains more irregular, spindle-shaped cells, with round nuclei, which are hidden by a dense mass of pigment-granules (Iwanoff and Hoffmann).

The true substance of the iris consists of muscle, nerves, bloodvessels, and a connective-tissue stroma, but on the posterior surface is another layer of black, pigmented cells, and this is again covered with a hyaline membrane, in which, however, a fibrous structure may be made out (Koganeï). 
The muscle-fibres are long, spindle-cells, which are abruptly swollen in the middle, where the nuclei are situated; the nucleus is oval, $0.009-0.0012 \mathrm{~mm}$. in length, $0.0025 \mathrm{~mm}$. broad, and oceupies nearly the whole of the swollen part of the cell (Hoffmann, Grünhagen).

According to Koganeï the iris possesses a M. constrictor iridlis (l.c. Berlin Sitzungsber.), but no $\mathbf{M}$. dilatator iridis ; in a former publication (l.c. Arch. mik. Anat.) he was unable to find any muscular fibre, and holds the muscle-fibres of Grünhagen to be connectivetissue elements.

The stroma consists of delicate connective-tissue fibrils, enclosing a very large number of pigmented, branched cells.

a. The arteries of the iris (Fig. $256 \mathrm{II}$ ) arise from an arch (see Vessels of Eye) formed by the A. oplthalmica in the corpus ciliare. It commences between the ventral and temporal surfaces by two branches: one courses along the temporal border, the other along the nasal, to meet each other on the nasal surface; the former courses through one-third, the latter embraces two-thirds of the cireumference at the iris.

The temporal artery courses along the ciliary border during the first third of its course, it then gradually approaches the border of the pupil; the nasal artery runs at once towards the pupil. On the nasal border of the pupil they anastomose by their branches, and so form a circulus iritis major.

Except near their termination, no small vessels arise from this arterial circle ; in Fig. $25^{6}$ II, for example, only five larger branches are given off, three from the temporal side and two from the nasal. The five large branches run towards the circumferential border of the iris and break up into numerous vessels, which form a very irregular and open network. From this network arise the va»a recta already described.

d. The lens is almost spherical, and is composed of cellular elements enclosed in a capsule (capsula lentis).

The capsule is a homogeneous, transparent, structureless, and highly elastic membrane. The deeper surface of the anterior eapsule is lined with a simple layer of regular nueleated six-sided epithelial cells.

The lens itself consists of long, flat fibres; seen from the surface these are broad, narrow edge-wise, and in section six-sided prisms. Those lying parallel to the anterior and posterior surfaces are 
broad and thicker, those towards the border are narrower. These cells are striated, both longitudinally and transversely (Arnold). The cells near the margin, however, have no transverse striation (Hoffmann). The cells of the central parts form a much closer and firmer structure than those at the periphery (Arnold). The peripheral cells are nucleated, and sometimes even possess two nuclei to one cell ; the central cells have no nuclei (Arnold).

The cells are held together by a cement-substance and by their serrated surfaces; the serrations are the cause of the transverse striations. The fibres of the lens have a simple arrangement : commencing at the middle point or pole of one surface they pass over the equator to the opposite pole; consequently the long borders of adjacent cells are in juxtaposition, and their pointed extremities meet at points in the axis of the lens (Hoffmann).

Ritter has described short, nucleated cells in the centre of the lens; these are held by Babuchin to be cells which have been arrested in their development.

Fig. 257 .
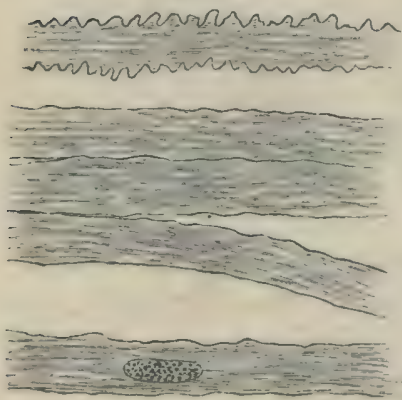

Fihres from the lens of the frog; after Hoffmann. Magnifled 700 tinues.

e. The retina is the innermost coat of the eye; in the recent state it is pale, soft, and smooth. The structures composing it are arranged in ten layers; from the deeper surface towards the choroid these are: the internal limiting membrane, the optic-fibre layer, the ganglion layer, the inner molecular layer, the inner nuclear layer, the outer molecular layer, the outer nuclear layer, the external limiting membrane, the layer of rods and cones, and the pigment layer.

These layers are held together by connective-tissue elements.

(I) The internal limiting membrane (Membrana limitans intema) will be described together with the connective-tissue elements (ro).

(2) The optic-fibre layer is formed by the fibres of the optic nerve. The nerve-fibres in their course towards the eye are possessed of medullary sheaths, but on piercing the sclerotic these sheaths are lost. The fibres are now pale, non-medullated, and of very varying thickness. In the mass of fibres nothing can be seen exrept an extremely fine fibrillation and very fine varicosities; the 
latter, however, appear to be artificial productions (Hoffmann). This layer of fibres extends over the inner surface of the retina, and gradually thins from the point of entrance of the optic nerve to the limits of the retina.

(3) The ganglion-layer lies immediately without the nerre-fibre laver (Fig. $258 \mathrm{l}$ ). The ganglion-cells are small and usually pear-shaped. The cells possess large nuclei, round which is a thin layer of very granular protoplasm. The cells have inner and outer processes; the inner pass into the nerve-fibre layer, the outer into the inner molecular layer in more or less radiating directions. Manz claims to have traced a direct connection between the inner processes and the fibres of the nerve-fibre layer.

Each ganglion-cell, whatever its shape or size, has only one inner process, which is easily distinguished from the outer process by its being more glistening, by the possession of varicosities, and becainse this process never branches.

The outer processes are single(Schwalbe) or rarely double (Hoffmann), and have as a rule a direction at right angles to the inner processes. Each outer process is finely granular, which suggests rather a prolongation of the cell-substance than a true process. Frequently they are branched, sometimes forming two equal sized processes, which give off finer twigs; at other times they appear to pass through the whole of the inner molecular layer without undergoing division (Schwalbe). The processes do not inosculate (Santi Sirena).

(4) The inner molecular layer (Fig. Fig. $25^{8}$.

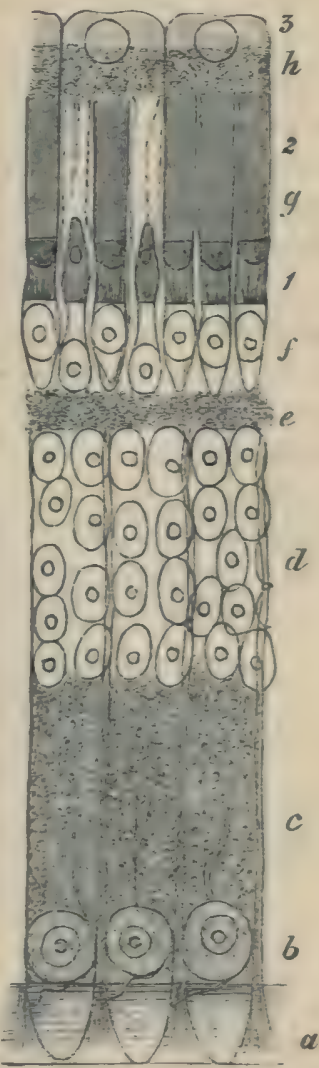

Tertical soction through retina of frog; after Hoffmann. Magnified 5 co times,

a Internal limiting membrane.

b Ganglion-cell layer.

c Internal molecular layer.

d Internal nuclear layer.

e External molecular layer.

$f$ External nuiclear layer.

g Layer of rodis and cones.

h Pigmeñted eppithelium layer.

1. Inner gegmentż of rods and ernes.

2. Guter agments of reds and cunes.

3. Outer transparent segmente of - pigmented epithelium.

$25^{8} \mathrm{c}$ ) is $0.07-0.08 \mathrm{~mm}$. thick (Hoffmann), and consists of a finely 
granular mass together with the outer processes of the ganglionlayer, and connective-tissue elements.

The granular matter consists of an extremely fine network or reticulum, through which numerous fine fibres course (Schultze, Kölliker, Manz, Heinemann, and others); according to Schultze the supposed molecules or granules of others (Henle, Merkel, and Retzius) are simply the fine meshes of this reticulum. The branched, outer processes of the ganglion-cells form a rich anastomosis in this layer.

(5) The inner nuclear layer (Fig. $258 d$ ) contains parts of two kinds of cellular elements ; these are radial nerve-fibres with large nuclei, and connective-tissue elements (see below, par. 10). The nerve-fibres are easily distinguished by their spindle-shaped varicosities; both cellular elements possess large oval nuclei. The bodies of the cells surrounding the nerve nuclei are almost filled by the nuclei, which have sharply-defined, rounded nucleoli. The fibres to which these cells are attached may be distinguished as inner and outer processes; the inner process is fine, irregularly varicose, and unbranched ; the outer process is thicker, finely granular, and is not varicose (Schwalbe). At the margin of the outer molecular layer the outer processes divide, usually into two branches, and at an acute angle to each other, though sometimes at a right angle. The further course of these branches in the outer molecular layer is unknown.

(6) The outer molecular layer (Fig. 258 e) corresponds in general with the inner molecular layer as regards its structure; it is, however, much thinner.

(7 and 9) The outer nuclear layer and the layer of rods and cones (Figs. 258 $f, g, 259$ ). The rods and cones are intimately connected with the elements of the outer nuclear layer, hence the two layers are best described together.

The rods (bacilli) have two parts or limbs, an outer and an inner, which differ in structure, and in chemical and physical eharacters. The outer part is highly refractive, the inner more homogeneous and less refractive, the two parts being sharply differentiated from one another.

The outer part is also weakly doubly refracting, the inner has no trace of this property. The rods are $0.05-0.06 \mathrm{~mm}$, in length, of which $0.035^{-0.04} \mathrm{~mm}$. belongs to the inner limb. The outer end of the outer limb is more or less rounded; the whole has a longitudinal striation (Schultze), due to its being composed of 
rounded fibrils, about twenty-four to each rod (Hensen). The fibrils are sharply differentiated from each other and have a slightly spiral course; when seen in transverse section these outer limbs do not appear to be round (Schultze), although others hold them to be perfectly rounded (Hoffmann and others), and that the loss of the cylindrical form is due to the methods of treatment. According to Merkel the longitudinal striation is caused by a canalisation of the outer limb, which aecording to him encloses the processes of the pigmented epithelial layer; he is also of opinion that the spiral appearance is an artificial product. In the latter opinion he is probably wrong, as perfectly fresh rods examined in aqueous humour show the same spiral appearance (Hoffmann) : against the canalisation view others observe that the longitudinal striation is most distinet near the inner limit of the outer limb, and that it is impossible to conceive that the processes of the pigment-cells should

Fig. 259 .

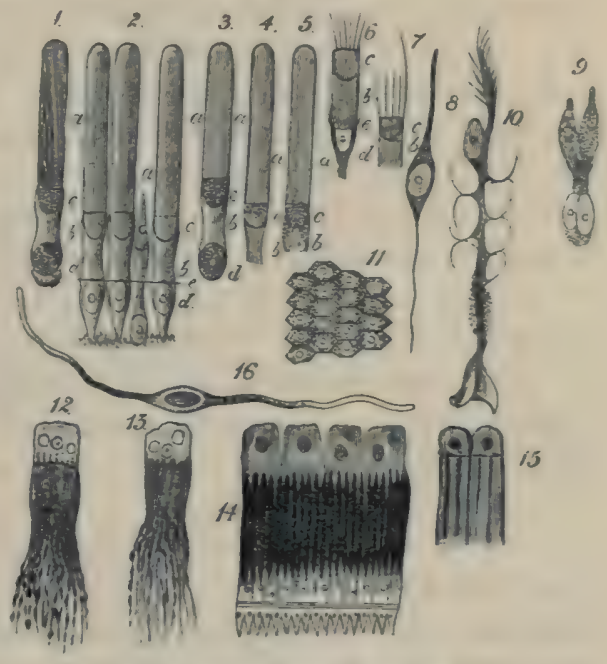

Various preparations from the eye of the frog: chiefly from the retina.

1. Rod from retins in aqueous humour, showing spiral striation.

2. Three rods and one cone after treatment with osmic acid.

3, 4, 5. Rods examined in rocent state.

6 , 7 . Inner segments of two rods after treatment with osmic acid.
a Outer limb.
b Inner limb.
c Lenticular body.
d Nuclens of onter nuclear layer.
e External limiting membrane

8. Nuclear body from inner nuclear layer.

9. Twin-cone.

10. Sustentacular fibre of retina.

11. Surface riew of pigmented epithelium of retina.

12, 13. Isolated pigmented cells of retina.

14. Four pigmented cells, rods and cones, external limiting membrane, and part of outer nuclear layer attached.

15. Two pigmented cells; each showing three attached rods.

16. Muscle-fibre from the iris.

Figr $x, 2,3,4,5,6,7,8,9$ are magnified soo timea. Fig. 20, 300 times. Fig. 16, 400 times. All are copied from Hoffmann's figures.

Figs. 12, 13, 14, 15 are copied from Morano's figures; Hartnack, Oc. II, Obj. 9 .

terminate with such extremely regular ends (Hoffmann).

In the central part of the inner end of the outer limb is seen a dark point when the structures are examined in transverse section (Ritter, Manz, Schiess, Schultze, and others). The 
cause of this is not elearly understood; some hold it to be a fibre (Ritter's fibres), others hold it to be an artificial product (Hensen).

After treatment with certain reagents the outer limbs show a transverse striation, which is probably produced by the action of these reagents on the sheath of the outer limbs; that a sheath is present is proved by its possession of a different refractive index (Zenker, Schultze) to the rest of the outer limb, and this transverse striation is not seen until the whole organ has undergone considerable post-mortem ehanges (Hoffmann). Should this change be allowed to proceed a stage further, the outer limbs of the rods split transversely and form small dises from $0.0005-0.00055 \mathrm{~mm}$. thick; this takes place in the outer limb only.

The inner segments of the rods (Figs. 258, 259) are short (0.020$0.022 \mathrm{~mm}$.) and of the same thickness as the outer limbs. When perfectly fresh they appear homogeneous; very quickly changes commence, which are probably due to coagulation. A plano-convex figure (Fig. 259) is then seen at the outer portion of the segment (lens-shaped figure of Schultze); with staining reagents it gives the same reactions as the outer segment of the rods. The rest of this segment forms a short cylinder, which probably has no distinct sheath (Hoffmann, Merkel) ; some observers are inclined to think that a sheath exists (Landolt, Schwalbe).

The outer segments of the rods are of two chief sizes (Schwalbe). Those of the one kind are large; the second variety occurs less frequently, and the segments are shorter, measuring only 0.002 to $0.0025 \mathrm{~mm}$. The inner segment is a long, thread-like process, except where it is swollen to enclose the lens-shaped body.

The rods are much more numerous than the cones, except at one small spot (macula lutea) on the posterior surface of the retina, where only cones are found (Krause).

The cones (coni) have each two segments like the rods (Figs. 258, 259). The outer segments are short $(4-5 \mu)$, they are slightly conical and terminate externally in a blunt point; they possess a longitudinal striation (Schultze), and very easily break up transversely into small discs, which, however, do not separate so completely as in the case of the rods, in consequence of the presence of a sheath continuous with a sheath on the inner segment.

The inner segments (Figs. 258, 259) have convex sides and measure $12-14 \mu$; like the corresponding parts of the rods they possess lens-shaped bodies at their junction with the outer segments, 
but the bodies differ in shape, being bi-convex or rather oval in form. The vinner segments are enclosed in a delicate sheath continuous with that of the outer segments.

In some cases two cones are united to form a twin-cone; in such cases the one is always larger than the other (Fig. 259 9), and has several peculiarities which distinguish it from the smaller.

The smaller or secondary member of a twin-cone is longer, and possesses a lens-shaped body which is plano-convex. The larger or principal member of a twin-eone is shorter, has a plano-convex body, but also an oval, homogeneous, glistening body, which is directly attached to the plano-convex body. The shape of the two members is also different.

The outer nuclear layer (Fig. $25^{8} f$ ) is $14-16 \mu$ thick; the nuclei lie in two layers. The nuclei belonging to rods and cones have the same characters, each nucleus being a large, oval, hyaline body, and enclosing a bright nucleolus. Each nucleus is surrounded by an extremely thin layer of finely granular matter. The inner processes of the nuclear bodies both of the rods and the cones extend to the outer molecular layer, are there dilated and serrated, where they become attached to the outer molecular layer (Schultze, Hoffmann). In some cases, however, the inner process of the nuclear bodies, belonging to the rods, forms only a short fine fibre.

In the ease of twin-cones the corresponding parts in the outer nuclear layer possess two nuclei (Schultze).

(8) The pigment layer (Figs. $25^{8} h$, and $259 \mathrm{II}, 12,13,14,15$ ) is not intimately attached to the rest of the retina. It consists of cylindrical cells in which two parts or segments are sharply differentiated ; the external part, directed towards the choroid coat, is of pale, or colourless granular protoplasm, and oceupies one-third of the length of the cell ; this part encloses a large, round, nucleolated nucleus. This colourless segment of the cell also includes one or two bright yellow, fat globules (Morano). Seen from the surface the cells are hexagonal (Fig. 259 11). The remaining two-thirds of the cells consists of a brush formed of numerous fine pigmented processes; the ultimate terminations of the processes, which lie parallel to each other, are frequently unpigmented; each cell possesses thirty to forty such processes (Morano).

The processes extend between the rods and cones as far as the external limiting membrane (Figs. 258, 259), or sometimes a little further (Merkel, Morano, Hoffmann). The processes from one pigment-cell surround a number of rods and cones; according to 
Morano twelve to fifteen rods and cones may be encased or surrounded by the processes of a single cell.

The thickness of this layer varies from $60-70 \mu$; the nuclei of the cells have a diameter of $10-12 \mu$, the width of a single cell is from $20-25 \mu$ (Hoffmann).

(Iо) The connective-tissue elements of the retina and the external and internal limiting membranes. The elements of the retina are supported by connective-tissue elements or sustentacular cells, which have a radial arrangement, and which form the two limiting membranes (Müller).

Each sustentacular cell (Fig. 259 10) has two segments, an inner and an outer, the boundary between these lying in the inner nuclear layer, and being marked by the presence of a large oval nucleus. The inner segment of each cell terminates internally in a wide 'foot' or base, or may form several such after having undergone division (Schultze): these bases together form a transparent, thin membrane, the internal limiting membrane (memurana limitans interna).

Within the ganglion-layer these cells possess peculiar appendages, which fit round the ganglion-cells and support them (Schwalbe).

The outer segments of the sustentacular cells extend into the outer molecular layer, and then break up into irregular processes which extend radially to the external limiting membrane, and which they probably form. The external limiting membrane (membrana limitans externa) is therefore a membrane corresponding to the internal limiting membrane, and formed by the flattened ends of the processes belonging to the sustentacular cells.

The sustentacular cells have a distinct, resistant cell-wall (Schwalbe); the cell-contents are a finely granular protoplasm, and a large oval, nucleated nucleus placed in the inner nuclear layer.

f. The ciliary processes have the same structure as the rest of the choroid coat : the vessels form more or less longitudinal meshes and are more irregular than in the rest of the choroid.

g. The posterior chamber and vitreous body (Fig. 260). The vitreous humour occupies the greater portion of the cavity of the eyeball, $i . e$. the posterior chamber. The humour consists of a mass of cells enclosed in a transparent hyaloid membrane (membrana liyaloidea), which is in contact with the internal limiting membrane of the retina.

The cells forming this structure are small, flattened, transparent, 
and nucleated (Iwanoff and Virchow); according to the former observer the cells have contractile powers.

The hyaloid membrane is described as structureless by Schwalbe, as fibrous by Pappenheim, Bowman, and Fuikbeiner.

The ressels of the vitreous body (Fig. 260) are as follows. The A. hyaloidea arises at the lowest point of the corpus ciliare; it almost immediately divides into two branches, which form a ring at a distance of about $0.5 \mathrm{~mm}$. from the lens and lying on the surface of the vitreous body (Fig. 260 I, II). One, $R$. nasalis, passes to the nasal side and courses through one-fourth of the circle; the

Fig. 260.
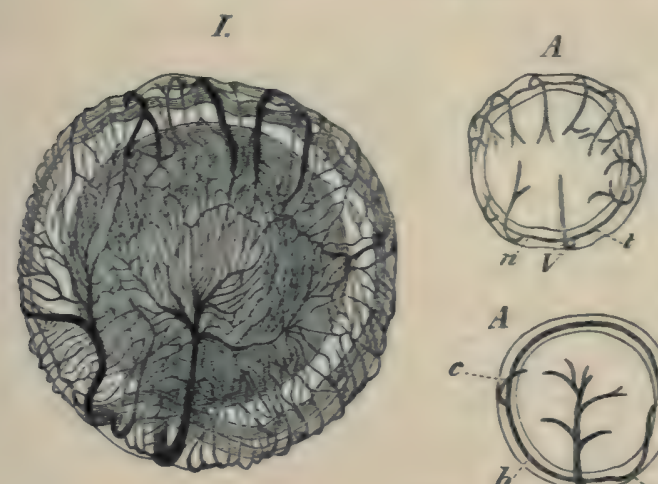

II.
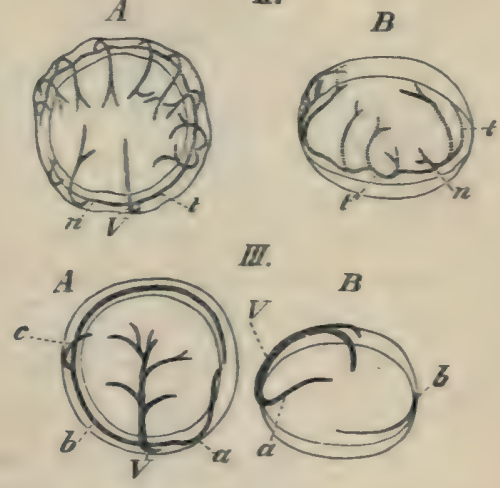

The vessels of the vitreous body; after Hans Virchow.

I. Vessels of the vitreous body; seen from the deeper pole and slightly frum above. Magnified 6 times

II. Arteries of the vitreous body of the right egre.

4 Seen from the proximal pole.

$B$ Seen from the nasal side.

111. Teins of the vitreous body of the left eye.

$A$ Seen from the proximal pole.

$B$ seen from the nasal side.
a Nasal rein.
$b$ Temporal rein.
c Branch (constant) of temporal vein.
$n$ R, nasalis of the ophthalmie artery.
I R. temporalis of the ophthalmic artery.
c Termination of the $\mathbf{R}$. temporalia.
$\checkmark$ Tentral rein.

other, $R$. temporalis, courses through three-fourths of the circle. The branches are all giren off proximally and at right angles to the circle (Fig. 260 I, II). From the $R$. nasalis only one branch arises, from the $R$. temporalis seven, the first of which corresponds in point of origin with the branch from the $R$. nasalis. The branches on the nasal and temporal surfaces of the vitreous body are the shortest. 
These branches form a capillary network (Fig. 260 I) with elongated meshes, formed by the capillaries anastomosing at acute angles. The capillary network is more dense towards the middle of the proximal surface than in other parts.

The veins arising from this network are three in number (Fig. 260 III) ; two of these accompany the arteries from their origin, and form a somewhat similar circle around the lens, while the third passes backwards along the ventral surface of the vitreous body to the papilla nervi optici. The nasal vein, however, takes a more proximal course than the corresponding artery, the branches of which it crosses; consequently the venous ring is not so perfect as the arterial. The nasal vein is larger and the temporal vein smaller than the corresponding arteries.

The ventral vein is formed near the papilla nervi optici by the union of two smaller branches. The capillary system of these vessels has the usual structure of capillaries, the cells being united by cement-substance (Zimmermann).

The blood-vessels of the vitreous body are accompanied by lymphaties; according to Iwanoff they completely enclose the capillaries: Zimmerman contradicts this view, as he has been unable to find lymphaties on that side of the eapillaries directed towards the vitreous body.

B. Appendages of the eye.

The appendages of the eye are the eye-muscles (see pp. 55-59), the eyelids, the Harderian gland, and the lachrymal duct.

a. The eyelids are two in number, an upper and a lower. The upper eyelid is intimately attached to the eyeball and follows the movements of that organ.

The lower eyelid (membrana nictitans) is much larger than the upper and has the same functions as the lower eyelid of higher vertebrates. It forms a transparent covering for the eyeball, and is raised by a special muscle (see p. $5^{8}$ ); functionally it takes the place of both eyelids of higher vertebrates.

The lower eyelid is a prolongation of the skin, but has only a few pigment-cells, except at its free margin, and no serous glands. Mucous glands are found in two or three rows, closely applied to one another, on the superficial surface of the lid ; on the deeper surface they are wanting. The stroma of the lid, like the cutis, is of connective-tissue.

Nerve-fibres can be traced in all directions through the substance 
of the lid, forming a wide-meshed plexus. Around each gland the plexus becomes finer and by numerous branchings much closer ; from the plexus twigs are given off, which divide to form a number of fibrils traceable into the epithelial cells of the glands (Openchowski).

The vessels of the lower eyelid have been investigated by Stricker, (l. c.); according to him they possess some interesting peculiarities. Many of these capillaries course within a lymphatic vessel, in some places the capillary being contracted by a projection from

Fig. 261.
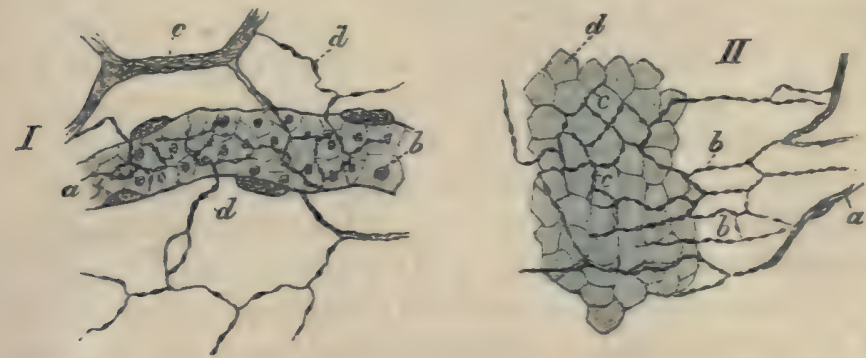

Preparations from the nictitating membrane of Rana esculenla to show distribution of nerves.

1. Preparation of the nietitating membrane to show nervous supply to a capillary reseel; after Klein. Hartnack, $\mathrm{Oa}$ III, Obj. 8.

a Capillary resel.

b Blood-oorpuscles.

$c$ and $d$ Non-nedullated nerve-fibres.

11. Tu shuw distribution of nerves in the epithelium; after Klein. Hartnack, Oc. 15, Obj. 8.

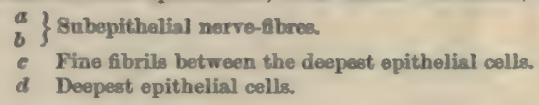

its inner wall; where this is found the accompanying lymphatic is correspondingly dilated. Such points are especially met with where the capillaries branch; in many cases the capillary was contracted to such an extent that the blood-corpuscles were unable to pass the obstruction. Stricker further observed in the living tissue that such constrictions could take place in a part which a short time previously had been comparatively wide and dilated; further, that many of the nerves were enclosed in similar lymphatics. Langer, however $(l . c$.$) , describes the vessels as being accompanied$ by an irregular network of small lymphatic vessels.

The distribution of the nerves in the lower eyelid has been described by Klein. In the epithelium they form a network resembling that found in the cornea (Fig. 26r II); along the bloodvessels the fine fibrils form a perivascular network, which supplies 
fine twigs to the walls of the vessels (Fig. 26I I). He distinguishes three kinds of pigmented cells.

b. The Harderian gland is situated at the inner angle of the eye, and is pear-shaped in form. It consists of a number of racemose glands held together by connective-tissue, the whole being enclosed in a relatively thick and strong capsule of connectivetissue.

The alveoli have a diameter of $0^{\circ} 040-0 \cdot 060 \mathrm{~mm}$. : they possess a lining of epithelium and a lumen which varies considerably in size. The epithelial layer is bounded externally by a membrana propria. The cells are placed eccentrically, they are cylindrical, and composed of finely granular protoplasm; each cell contains a pale, rounded nucleus. The ducts of the alveoli are lined with a single layer of cylindrical epithelium, the cells of which are usually shorter and narrower than those of the epithelium of the alveoli; the ducts open into a single main tube, lined with similar epithelium but strengthened externally by a layer of connective-tissue. The glands secrete a fluid which moistens the free surface of the eye.

The Harderian glands are surrounded by a rich capillary anastomosis which completely invests the alveoli.

c. The lachrymal duct opens behind and below into the nasal cavity (see p. $3^{89}$ ), anteriorly it can be traced forwards, as a small tube imbedded in connective-tissue and lying immediately beneath the skin, to the outer angle of the eye, where it opens by numerous tubules.

The lachrymal duct is lined with ciliated columnar epithelium. 
ADDENDA. 


\section{HISTOLOGY OF MUSCLE, CARTILAGE, BONE,}

\section{AND THE CONNECTIVE TISSUES.}

\section{IITERATURE.}

\section{MUSCLE AND NERVE-ENDINGS IN MUSCLE.}

Arnold, J., Gewebe der organischen Muskeln. Stricker's Gewebelehre, 1871. Vol. I, p. 142 .

Arnold, J., Ueber die Abscheidung des indigschwefelsauren Natrons im Muskelgewebe. Virchow's Arch. Vol, LXXI, p. I.

Babuchin, Ueber den feineren und Ursprung des Axencylinders. Centralbl. f. med. Wiss. I 868, p. 755 .

Barfurth, D., Die Riickbildung des Froschlarvenschwanzes und die sogenannten Sarkoplasten. Arch. f. mik. Anat. 1887. Vol. XXIX, p. 35.

Biedermann, W., Zur Lehre vom Bau der quergestreiften Muskelfaser. Wiener Sitzungsber. 1876. Vol, LXXIV, Pt. III, pp. 49-62.

v. Biesiadecki, A., and Herzig, A., Die verschiedenen Formen der quergestreiften Muskelfasern. Wiener Sitzungsber. 1859, Vol. XXXIII, p. I46: and in Moleschott's Untersuchungen, 1860, Vol. VI, p. I05.

du Bois-Reymond, $\mathbf{E} .$, Ueber facettenförmige Endigung der Muskelbündel. Berlin. Acad. Monatsber. 1872, pp. 791-814. Abstract in Centralbl. f. d. med. Wiss. 1873. No, 55, p. 868 .

Bowman. On the minute structure and movements of voluntary muscle. Phil. Trans. 1840, p. 457 .

Bremer, L., Ueber die Endigungen der markbaltigen und marklosen Nerven im quergestreiften Muskel. Arch. f. mik. Anat. 1882. Vol. XXI, p. 165.

Bremer, L., Ueber die Muskelspindeln nebst Bemerkungen über Structur, Neubildung, und Innervation der quergestreiften Muskelfaser. Arch. f. mik. Anat. 1883. Vol. XXII, p. 318.

Calberla, E., Studien über die Entwicklung der quergestreiften Muskeln und Nerven der Amphibien und Reptilien. Arch. f. mik. Anat. 1875. Vol. XI, p. 442 .

Calberla, E., Ueber die Endigungsweise der Nerven in den quergestreiften Muskeln der Amphibien. Dissert. Freiburg i. B. 1874; also in Zeitschr. f. d. wiss. Zool. I874, Vol. XXIV, pp. 164-178.

Chittenden, R. H., Histochemische Untersuchungen iiber das Sarkolemm und einige verwandte Membranen. Untersuch. d. physiol. Instituts d. Universität Heidelberg. Vol. III.

Cohnheim, J., Ueber die Endigung der Muskelnerven. Centralbl. f. d. med. Wiss. 1863, p. 865 .

Fberth, C. J., Untersuchungen uiber die normale und pathologische Leber. Virchow's Arch. 1864. Vol. XXXIX, p. 74.

Engelmann, T. W., Zur Lehre von der Nervenendigung im Muskel. Jenaische Zeitschr. 1868. Vol. IV, p. 30\%.

Ingelmann, T. W., Untersuchungen uber den Zusammenh. von Nerven u. Muskelfasern. Leipzig, 1863. 
Engelmann, T. W., Micmscopische Cntersuchungen über die quengestreifte Muskelsubstanz. Pfliiger's Arch. 1873. Vol. VII, pp. 33-71, and Pp. 155-IS;.

Ingelmann, T. W., Ceber die Endigung der motorischen Nerren in den quergestreiften Muskeln der Wirbelthiere. Centralbl. f. med. Wiss. $186_{3}$, p. 289 .

Ewald, A., Teber die Endigung der motorischen Nerven in den quergestreiften Muskeln. Pflüger's Areh. 1876. Vol. XII, p. 539.

Ewald, A., and Kūhne, W., Die Verdauung als histologische Methode. Heidelb. naturhistor.-med. Verhandl. 1877. Vol. I, p. 451.

Exner, s., Notiz zu der Frage ron der Faserverteilung mehrerer Nerven in einem Muskel. Pflüger's Arch. 1885. Vol. XXXVI, p. $57^{2}$.

Fischer, E., Ceber die Endigung der Nerven im quergestreiften Muskel der Wirbelthiere. Arch. f. mikrosk. Anat. 1877. Vol. XIII, p. $3^{6} 5$.

Froriep, A. Ceber das Sarcolemm und die Muskelkerne. Arch. f. Anat. u. Physiol. $18 ; 8$, p. 416.

Gerlach, J., Ceber das Verhalten der Nerven in den quergestreiften Muskelfaiden der Wirbelthiere. Sitzungsh. Erlangen. 1873. Vol. V, p. 97; Abstract in Centralbl. f. d. med. Wiss. 1874, p. 227.

Gerlach, J., Das Verhältniss der Nerven zu den willkürlichen Muskeln der Wirbelthiere. Leipzig, 1874 .

Gerlach, J., Ueber das Verhältniss der nerrösen und contractilen Substanz des quergestreiften Muskels. Arch. f. mik. Anst. 18:7. Vol. XIII, p. 399.

Golgi, C., Sui Nervi dei Tendini dell' Como e di altri Vertebrati e di un nuovo Organo Nervoso terminale Musculo-tendineo. Torino. Estr. dalle Memorie della Reale Acc. di Torino. Series II. 18So, Vol. XXXII.

Grützner, P., Zur Anatomie und Physiologie der quergestreiften Muskeln. Recueil Zoolog. Snisse, 1884. Vol. I, pp. 665-684.

Haycraft, J. B., Cpon the cause of the striation of roluntary muscular tiasae. Quart. Journ. Microe. Soc. r88r. Vol. XXI, p. 307.

Hensche, Ceber die Drüsen und glatten Muskeln in der änsseren Haut von Rana temporaria. Zeitechr, f. wiss. Zool, 1856. Vol. VII, p. 273.

Hensen, V., Ueber die Fntwicklnng des Gewebes und der Nerven im Schwanze der Froschlarve. Virchuw's Arch. 1864. Vol. XXX, p. 51.

Jakimovitsch, Ueber die Regeneration der glatten Muskelfasern. Centralbl. f. d. med. Wis: 1879, p. 897 .

Key, A., Bidrag till Nervernas ändningsätt i Musklerna. Förhandlingar vid Skandinariska Naturforskaemötet i Stockholm, 1863. Abstract in Centralbl. f. d. med. Wiss. I866, p. 212 . (Museles of frog's tongue.)

Klebs, E., Die Nerven der organischen Muskeln. Centralbl. f. d. med. Wiss. I863, p. $5^{6} \mathrm{r}$.

Klebs, E., Die Nerven der organischen Muskeln. Virchow's Arch. 1865. Vol. XXXII, pp. 169-198.

v. Kolliker, $\mathbf{\Lambda}$, Gewebelehre.

v. Kölliker, A., Einige Bemerkungen über die Endigung der Hautnerven u. den Bau der Muskeln. Zeitschr. f. wiss. Zonl. I8 $5 \%$. Tol. VIII, p. 3 II.

Krause, W., Ceber den Bau der quergestreiften Muskelfaser. Zeitschr. f. rat. Med. Vol. XXIII.

Krause, W., Die Nervenendigungen in den Froschmuskeln. Internat. Monatschr. 1884 Vol. I, pp. 194-203.

Krause, W., Die motorischen Endplatten, etc. Hannover, 1869.

Krause, W., Ceber die Endigungen der Muskelnerven. Göttinger Nachrichten. 1863 , p. 21 .

Krause, W., Ceber die Endigungen der Muskelnerven. Henle and Pfeufer's Zoitechr. 1863. Vol. XX, pp. I-19.

Kühne, W., Cntersuchungen über Bewegungen und Veränderungen der contractilen Substanzen. Arch. f. Anat. n. Phys. 1859, p. 816. 
Kühne, W., Die Muskelspindeln. Virchow's Arch. 1864. Vol. XXVIII, pp. 528-538.

Kühne, W., Untersuchungen über das Protoplasma und die Contractilität. Leipzig, 1864 .

Kühne, W., Ueber die peripherischen Endorgane der motorischen Nerven. Leipzig, I 862 .

Kühne, W., Zur Lehre von den Endplatten der Nervenhügel. Virchow's Arch. 1866. Vol. XXXIV, pp. 4I2-422.

Kühne, W., Ueber das Verhalten des Muskels zum Nerven. Verhandl, d. naturhist,-med. Vereins zu Heidelberg. I880. Vol. II, p. 227.

Kühne, W., Ueber Nervenendigungen in den Muskeln nach Beobachtungen von M. B. van Sykel. Abdruk. aus den Verhandl. d. Naturh. med. Verein zu Heidelberg. 1884. Vol. III, pp. 238-242.

Kühne, W., Wiederlegung der Bemerkung E. du Bois-Reymond's uiber mehrfache. Nervenendigungen einer Muskelfaser. Zeitschr. f. Biol. 1884. Vol. XX, pp. 53I-539.

Kühne, W., Ueber die Endigung der Nerven in den Muskeln. Virchow's Arch. 1866. Vol. XXVII, pp. 508-533.

Kühne, W., and Voit, C., Neue Untersuchungen über motorische Nervenendigung. Zeitschr. f. Biologie. Vol. XXXIII.

Lavdowsky, M., Die feinere Struktur und die Nervenendigungen der Froschharnblase. Arch. f. Anat. u. Physiol. 1872, p. 55.

Leboucq, H., Recherches sur le développement et la terminaison des nerves chez les larves des Batrachiens. Bull. de l'Acad. de roy. de Belgique. 1876. Vol. XLI, p. 56r.

Letzerich, L., Ueber die Endigungsweise der motorischen Nerven. Med. Centralz. $186_{3}$, No. 37 .

Leydig, F., Ueber Tastkörperchen und Muskelstructur. Arch. f. Anat. u. Physiol. 1856, p. 150 .

Löwit, Die Nerven der glatten Muskulatur. Sitzungsb. d. Wiener Acad. 1875. Vol. IXXI, Pt. III, p. 355 .

Marshall, C. F., The structure and distribution of striped and unstriped muscle. Quart. Journ. Micros. Sci, 1887. Vol. XXV.

Martin, H., Sur la structure de la fibre musculaire striée et sur les analogies de structure et fonction entre les tissus musculaires et les cellules à bâtonnets (protoplasma strié). Arch. de physiol. norm. et pathol. 1882, p. 465 .

Mayer, \$., Die sogenannten Sarkoplasten. Anat. Anzeiger, 1886. No. 9, p. 23r.

Mayer, s., Einige Bemerkungen zur Lehre von der Rückbildung der quergestreiften Muskelfasern. Prager Zeitschr. f. Heilkde. I887. Vol. VIII, p. I77.

Mays, K., Histo-physiol. Untersuchungen über die Verbreitung der Nerven in den Muskeln. Zeitschr. f. Biol. Vol. XX.

Mays, K., Ueber die Nervatur des Musculus rectus abdominis des Frosches. Heidelberg, 1886.

Meliand, B., A simplified view of the histology of the striped muscle-fibre. Quart. Journ. Micros. Sci. 1885. Vol. XXV, p. 37r.

Merkel, F., Der quergestreifte Muskel. Arch. f. mik. Anat. 1873. Vol. IX, pp. $293-36 \%$.

Minra, M., Untersuchungen über die motorischen Nervenendigungen der quergestreiften Muskelfasern. Virchow's Arch. 1886. Vol, CV, p. I29.

Nasse, O., Zur Anatomie und Physiologie der quergestreiften Muskelfasern. Leipzig, 1882. Abstract in Centralbl. f. d. med. Wiss. 1882, pp. 884 and 908.

Newman, D., New theory of contraction of striated muscle and demonstration of the composition of the broad dark bands. Journ. of Anat. and Physiol. 1879, p. 4.

Nicolaides, R., Ueber die caryokynetischen Erscheinungen der Muskelkörper während des Wachstums der quergestreiften Muskeln. Arch. f. Anat. u. Physiol. I883, p. 44I. 
Odenias, M. W., Undersükungen üfer de sensibla muskelnervena. Nord. Medie. Arch. Vol. IV, No. 18.

Paneth, J., Die Entwickelung von quergestreiften Muskelfasern aus Sarkoplasten. Wiener Sitzungsber. 1886. Vol. XCII, Pt. III, p. 56 I.

Petrowsky, Zur Frage über das Wachstum der Muskelfasern des Muskelgewebes beim Frosch. Med. Centralbl. No. 49, pp. 769-772.

Pohl-Pincus, Ueber die Muskelfasern des Froschherzens. Arch. f. mik. Anat. I884, Vol. XXIII, p. 500 ; and Terhandl. der Physiol. Gesell. zu Berlin. 1882-3. No. 9.

Ranvier, L., Appareils nerveux terminaux des museles de la vie organique; coeurs sanguins, coeurs lymphatiques; œsophagus; muscles lisses. Lecons recueillies par Weber et Lataste. Leçons d'Anatomie générale faites au Collège de France. Paris, 1880. Vol. VII, p. $35^{\circ}$.

Ranvier, L., Leçons sur l'histologie du Système nerveux. 18;8. Vol. II.

Reichert, K. E., Ueber das Verhalten der Nervenfasern bei dem Verlauf und Endigung in einem Hautmuskel des Frosches, Rana temporaria. Arch. f. Anat. u. Physiol. 1851, p. 29.

Retzius, Zur Kenntniss der quergestreiften Muskelfaser. Biolngische Untersuchungen. 1881, p. I.

Rouget, Note sur la terminaison des nerfs moteurs dans les unuscles chez les reptiles, les oiseaux et les mammiferes. Comptes rendus. I862. LV, p. $54^{8}$.

Sachs, C., Die quergestreifte Muskelfazer. Arch. f. Anat. u. Yhysiol. I\$-2, pp. $60 \%-648$.

Sachs, C., Die Nerven der Sehnen. Arch. f. Anat. u. Physiol. 1875 , p. 402.

Sandmann, D. G., Ueber die Verteilung der motorisehen Nervenendapparate in den quergestreiften Muskeln der Wirbelthiere. Arch. f. Anat. u. Physiol. $188_{5}$, p. $24^{\circ}$.

Schönn, Anatomische Untersuchungen im Bereich des Muskel- und Nervengewebes. Jenaische Zeitschr. 1865. Vol. II, pp. 26-60.

Schultze, M., Ceber Muskelkörperchen und das was man eine Zelle zu nennen habe. Arch. f. Anat. u. Physiol. 1816, p. 17.

Sokolow, A. A., Sur les transformations der terminaisons des nerfs dans les muscles de la grenouille après les section des nerfs. Arch. de Physiol. normale et pathologique, 1874, pp. 300-3r 5 .

Sokolow, A. A., Teber die Nervenendigungen in den Muskeln ausgehungerter Frösche. Medicin. Bote. 1876, St. Petersburg.

Tergast, P., Ceber das Verhältniss von Nerve und Muskel. Arch. f. mik, Anat. 1873. Vol. IX, p. 36.

v. Thanhoffer, L., Beiträge zur Histologie und Nervenendigung der quergestreiften Muskelfasern. Arch. f. mik. Anat. 1882. Vol. XXI, p. 26.

Thin, G., On the structure of muscular fibre. Quart. Journ. Microsc. Sci. 1877. Vol, XVI, pp. 251-259.

Tolotschinoff, Ceber das Verhalten der Nerven zu den glatten Muskelfasern der Froschharnblase. Arch, f. mik. Anat. 1869. Vol. V, p. 5 Io.

Trinchese, \$., Mémoire sur la terminaison périphérique des nerfs moteurs dans la série animale. Journ. de l'A nat. et de la Physiol. I867, pp. 485-504 (original in Italian, 1867).

Tschiriew, s., Sur les terminaisons nerveuses dans les muscles striés. Arch. de physiol. norm. et path. 1879. Vol. VI, p. 89.

Tschiriew, S., Sur les terminaisons nerveuses dans les muscles striéz. Compt. rend. 18;8. Vol. LXXXVII, p. 604 .

Unger, Untersuchungen über die quergestreiften Muskelfasern des lebenden Thieres. Wiener med. Jahrb. I879, p. 6I ; and in Centralbl. f. d. med. Wiss. 18\%9, No. 34, p. 622.

Wagener, G. R., Ueber die Verbindung von Muskel und Sehne unter einaader. Sitzungsber. naturw. Gesells. Marburg. 1874 , pp. $3^{8-46 .}$ 
Waldeyer, W., Ueber die Endigung der motorischen Nerven in den quergestreiften Muskeln. Centralbl. f. d. med. Wiss. 1863, p. 369 .

Waldeyer, W., Untersuchungen über den Ursprung und den Verlauf des Axencylinders bei Wirbellosen und Wirbelthieren, sowie über dessen Endverhalten in der quergestreiften Muskelfaser. Henle and Pfeuffer's Zeitschr. 1864. Vol. $\mathrm{XX}, \mathrm{pp} .193^{-257}$.

Weismann, A., Ueber die Musculatur des Herzens beim Menschen und in der Thierreihe. Arch, f. Anst. u. Physiol. 1861, p. 4 I.

Wolff, W., Ueber den Zusammenhang des Muskels mit der Sehne. Diss. Berlin, 1877 ; Abstract in Centralbl. f. d. med. Wiss. 187\%, p. 733 .

Consult also: Arnold, J., Kühne, W., and Schweigger-Seidel, F., in Stricker's Handbuch der Gew ebelehre.

\section{CARTILAGE AND BONE.}

Arnold, J., Ueber die Abscheidung des indigschwefelsauren Natrons im Knochengewebe. Virchow's Arch. 1877. Vol. LXXI, p. 17.

Arnold, J., Die Ausscheidung des indigschwefelsauren Narions im Knorpelgewebe. Virchow's Arch. 1878. Vol, LXXIII, p. I25.

Bigelow, W. S., Notiz über den Theilungsvorgang bei Knorpelzellen sowie über den Bau des Hyalinknorpels. Arch. f. mik. Anat. 1879. Vol. XVI, p. 457.

Boll, F., Untersuchungen über den Bau und die Entwicklung der Gewebe. Arch. f. mik. Anat. 1871. Vol. VII, p. 275.

Bruch, C., Ueber die Verknöcherung der Wirbelsäule bei den Batrachiern. Wiirzb. naturw. Zeitschr. 1862. Vol, III, pp. 225-238.

Bush, F., Das Knochengewebe der Batrachier nach den Untersuchungen von N. Kastschenko. Verhandl. d. physiol. Gesells. zu Berlin. 1881, pp. 358-361.

Flesch, Untersuchungen über die Grundsubstance des Hyalinknorpels. Würzburg, 1880.

Heidenhain, Zur Kenntniss des hyalinen Knorpels. Studien aus d. physiol. Inst. zu Breslau. 1863. Pt. II, p: I.

Hertwig, O., Anatomisch histologische Untersuchung des Skelets der Mundhöhle und der Zähne der Amphibien; supplement to Vol. XI. Arch. f. mikroskopische Anat. 1874, pp. 29-32.

Kastschenko, N., Ueber die Genese und Architectur der Batrachierknochen. Arch. f. mik. Anat. 1881. Vol. XIX, pp. I-52.

Kastschenko, N., Ueber die Krappfiribung der Froschgewebe. Arch. f. mik. Anat 1882. Vol. XXI, p. 357.

v. Kolliker, Gewebelehre Leipzig. 1867, p. 66.

Lehmann, J. C., Ueber den Knorpel in der Achillessehne des Frosches. Zeitschr. f. wiss. Zool. 1864 Vol. XIV, p. Iog.

Levschin, L., Ueber die Entwicklung des Knochengewebes des Frosches. Centralbl. f. med. Wiss. Nos. 18, 19.

Mays, C., Ueber den Bau der Sehnen, etc. Virchow's Arch. I879. Vol. LXXV, p. II 2.

Renaud, M. J., Système hyalin de soutènement des centres nerveux et de quelques organes des sens. Arch. de Physiol. 1881, p. 6.

Schleicher, W., Die Knorpelzelltheilung. Arch. f. mik. Anat. 1879. Vol. XVI, p. 248.

Spina, A., Ueber die Saftbahnen des hyalinen Knorpels. Wiener Sitzungsber. 1879. Vol. LXXX, Pt. III, p. $26 \%$.

Stadelmann, E., Die Histologie des 'Pseudoknorpels' in der Achillessehne des Frosehes, ete. Virchow's Arch. 1880, Vol. LXXX, p. 105; also as Dissert. inaug. Königsberg, 1878 . 
van Stricht, O., Recherches sur le cartilage hyalin. Annsles de la société de médi cine de Grand. 1885, pp. $221-232$.

Thin, G., On the structure of hyaline cartilage. Quart. Journ. Micros. Sci. 1876. Vol. XVI, pp. I-22.

v. Török, A., Der feinere Bau des Knorpels des Achillessehne des Frosches. Centralbl. f. d. med. Wiss. 18;2, No. 5, p. 66 ; and Verhandl. d. phys.-med. Gesells. zu Wïrzburg, 1872 , Vol. III, pp. 1-26.

\section{THE CONNECTIVE TISSUES.}

Billroth, T., Ueber die Epithelzellen der Froschzunge, den Bau des Cylinder- und Flimmerepithel und ihr Verhältniss zum Bindegewebe. Arch. f. Anat. u. Physiol. $185^{8}$, p. 159.

Bizzozero, G., Ueber den Bau des Sehnengewebes. Moleschott's Untersuchungen. I 876. Vol. XI, p. $3^{6}$.

Bobinsky. C., Zur Kenntniss des Baues, der Entwicklung and der regressiven Metamorphose der Fetzellen. Centralbl. f. d. med. Wiss. $188_{5}$. No. 43. pp. 753-755.

Boll, F., Untersuchungen über den Bau und die Entwicklung der Gewebe. Arch. f. mik. Anat. 187 I. Vol. VII, p. 276 .

Ciaccio, G. V., Nuove Ricerche sull' interna tessitura dei tendi. Memorie dell' Academie delle scienze dell Istituto di Bologna, 1872. Series III, Vol. II. Abstract in Centralbl. f. d. med. Wiss, 1873 .

Czumak, J., Notiz über elastizche Sehnen. Contralbl. f. med. Wiss. 1863. p. 785 .

Flemming, W., Ceber Bildung und Rtickbildung der Fettzelle im Bindegewebe; und Bemerkungen uber die Structur des letztern. Areh. f. mik. Anat. 18\%1. Vol. VII, p. 32 .

Gerlach, J., Ceber Bindegewebe. Sitzungsb. d. phys.-naed. Societait zu Erlangen. 1872, p. 78 .

Ginsburg, L., Ueber das Verhalten der Sehnenzellen bei der Entzündung. Virchow's Arch, 1882. Vol. IXXXVIII, p. 263.

Golgi, C., Sui Nervi dei Tendini dell' 'Tomo e di altri Vertebrati e di un nuovo Organo nervoso terminale Musculo-tendineo. Estr. dalle Memorie della Reale Acc. di Torino. 1880. Series II, Vol. XXXII, p. 29; No. 6, p. 86.

Hensen, $\nabla$., Ceber die Entwicklung des Gewebes und der Nerven im Schwanze der Froschlarve Tirchow's Arch. 1864. Vol. XXXI, p. \$1.

Hoyer, Ceber den Bau der Cylinder- und Flimnerepithelien und ibr Verhältniss zum Bindegewebe. Arch. f. Anat. u. Physiol. 1858, p. 163; also Dentsche Klinik. 1857, No. 2 I.

Iwanoff, A., Beiträge zur normalen und pathologischen Anstomie des Frosch-Glaskörpers. Centralbl. f. d. med. Wiss. 1868, p. I29.

Kollmann, Ceber den Bau der Sehne. Münchener Sitzungsber. 18-8. Abstract in Centralbl. f. d. med. Wiss. $18 \% 9$, p. 881 .

Maddox, On the apparent relation of nerve to connective-tissue corpuscles. Proc. Roy. Soc. Lond. 1868. Vol. XVI, p. 61.

Mays, C., Ceber den Bau der Sehnen mit besondere Berücksichtigung über Saftbahnen. Virchow's Arch. I879. Vol. LXXV, p. II2.

Sachs, C., Die Nerven der Sehnen. Arch. f. Anat. u. Physiol. 1875, p. 402.

Spina, A., Tntersuchungen des lebenden Bindegewebes. Oesterr. med. Jahrb. I884. Pt. II. 


\section{NOTE BY THE TRANSLATOR.}

Reference has already been made to the views of Messrs. Melland and Marshall on the structure of muscle-fibres. The opinion that the striation of voluntary muscle is wholly or in part due to the presence of a regularly arranged network was previously published by Retzius, Bremer, and others. The authors referred to have now for the first time shown the importance of this network in all vertebrate muscular tissues, whether voluntary or involuntary.

Mr. Marshall gives the following summary of the result of his researches, which the Translator has confirmed by his own observations :-

I. In all muscles which have to perform rapid and frequent movements, a certain portion of the muscle is differentiated to perform the function of contraction, and this portion takes on the form of a very regular and highly modified intracellular network.

2. This network, by its regular arrangement, gives rise to certain optical effects which cause the peculiar appearances of striped muscle.

3. The contraction of the striped muscle-fibre is probably caused by the active contraction of the longitudinal fibrils of the intracellular network; the transverse networks appear to be passively elastic, and by their elastic rebound cause the muscle to rapidly resume its relaxed condition when the longitudinal fibrils have ceased to contract; they are possibly also paths for the nervous impulse.

4. In some cases where muscle has been hitherto described as striped, but gives no appearance of the network on treatment with the gold and other methods, the apparent striation is due to optical effects caused by a corrugated outline in the fibre.

5. In muscles which do not perform rapid movements, but whose contraction is comparatively slow and peristaltic in nature, this peculiar network is not developed. In most if not all of the 
unstriped muscles of invertebrates there does not appear to be an intracellular network present in any form, but in the unstriped muscle of rertebrates there are longitudinal fibres only; these possibly represent a form of network intermediate between the typical irregular intracellular network of other cells and the highly modified network of striped muscle.

6. The cardiac muscle-cells contain a network similar to that of ordinary striped muscle. 


\title{
DESCRIPTION OF THE FIGURES ON PLATE II.
}

\author{
Fig. 180 (p. 278).
}

I. Preparation of the mucous membrane of the dorsal surface of the mouth and oesophagus to show the vascular supply. Arteries red, veins blue; after Schöbl.

II. Small portion of the above to show the dilatations on the capillaries; after Schöbl.

Fig. 187 (p. 285).

Fransverse section through the mucous membrane of the fundus of the stomach of Rana esculenta. Alcohol preparation, doubly stained with carmine and anilin blue. After Biedermann. (Oc. II, Byst. 7, Hartnack.)

Fig. 196 (p. 298).

I. Partial injection of the liver from the portal vein (blue): Rana esculenta.-G. $\mathbf{H}$.

II. Partial injection of the liver from the hepatic vein (red): Rana esculenta.-G. H.

III. Complete injection of the liver from the hepatic artery (red) and from the portal vein (blue) : Rana esculenta.-G. $\mathrm{H}$.

A Portal (interlobular) veing and their branches.

$B$ Hepatic (intralobular) reins and their branches.

C Hepatic arteries and their branches.

Fig. 208 (p. 318).

Two sections from the lung of Rana temporaria ; stained with borax-carmine,-G. $\mathbf{H}$.

I. The lung dilated (Hartnack, Oc, I, Syst. 3).

II. The lung contracted (Hartnack, Oc. I, Syst. 7).

$A$ Band of muscle cut transversely.

$B$ Band of muscle cut longitudinally.

C Muscular layer of surface.

Fig. $217(p .334)$.

Portions of two transverse vertical sections through the kidney, -G. $\mathbf{H}$.

I. Kidney of Rana esculenta, partial injection of the uriniferous tubes with silver nitrate (Hartnack, Oc. I, Syst. 7).

II. Kidney of Rana temporaria, stained with borax-carmine (Hartnack, Oc. I, Syst. 7).

Fig. 219 (p. 337).

Two portions from a gold preparation of the kidney of Rana csculenta.-G. H.

I. Showing the tendency to split into lobules.

II. Nerve-fibres accompanying the blood vessels.

a Blood-vessels,

$b$ Nerves, 


\section{A P PENDIX.}

\section{WORKS WHICH DESCRIBE ORGAXS OR SETS OF ORGANS IN THE FROG.}

Bettade, $\mathbf{D}$., Sulle diverse forme delle R. temp. in Europa e più partionlammente nell' Italia. Venexia, $188 \mathbf{5}$.

Brehm, A. C., Illustriertes Thierleben. Hildburghausen, I869. Vol. V.

Burdon-Sanderson, Handbook for the Phrsiolugical Laboratory. London, 18 ;3.

Camerana, $\mathbf{I}$., Recherches sur les variations de la $\mathbf{R}$. esculenta et du Bufo viridis dans le bassin de la Méditerranée. Paris, 1883.

Carus, C. G., Lehrbuch der vergleichenden Zootomie. 2nd Edit. Leipzig, 1834.

Cepède, Comte de la, Histoire naturelle des quadrupèdes ovipaires et des serpens. Paris, 1808.

Dugès, Recherches anatomiques et physiologiques sur les Reptiles. Ext. des Annales des Sciences naturelles. Paris, 1827.

Duméril and Bibron, Erpétologie générale ou histoire complete des Reptiles. 1836.

Ecker, A., Icones physiologicae. Leipzig, I85I-I859.

Fatio, V., Faune des rertébrés de la Suisse. Genève et Bâle, 18 72.

Gegenbaur, C., Grundzüge der vergl. Anatomie. Leipzig, 1870.

Gegenbaur, C., Grundriss der rergl. Anatomie. Leipzig, 18;8.

Gerlach, Handbuch der Hiatolngie. $1853-1854$.

Gesmer, C., Historia A nimslium. Iiber I. I55I.

Gesmer, C., Icones Animalium. 1560.

จ. Griesheim, A., Ceber die Zahlenverhältnisse der Geschlechter bei R. fusca. Pflüger's Arch. f. d. ges. Physiol. 1881. Vol. XXVI, p. 3.

Hoffmsnn, C. K., Bronn's Klassen und Ordnungen des Thierreichs. Tol. VI, Amphibien. Leiprig, $1873-1878$.

Howes, G. B., An Atlas of Practical Elementary Biology. London, I 88 5.

Huxley, T., Anatomy of the Vertebrated Animals. London, I8; I.

Huxley, T., Lectures on the Elements of Comparative Anatomy.

Huxley, T., Article Amphibia, Encyclopaedia Britannica. IXth Edit. 1875.

Klein, 刃., Beiträge zur Anatomie der ungeschwänzten Batrachier. Jahreshefte.

'Württemberg, 1850 , pp. I-84.

Klein, E., and Noble Smith, Atlas of Histology. London, 18;9-1880.

Kloezke, C. G., Dissertatio anatomica de Rana cornuta. Berolini, 1816.

v. Kolliker, A., Handbuch der Gewebelehre. 5th Edit. Leiprig, 1867.

Kuhl, H., Beiträge zur Zoologie der Rans esculenta : in Beitr. z. Zool. Frankfurt

a. M., 1820 .

Laurenti, J. N., Synopsis Reptilium. Viennae, I;63.

Leydig, F., Lehrbuch der Histologie. Frankfurt a. M., 1857.

Marshall, A. M., The Frog. 3rd Edit. London and Manchester, i 888.

Mayer, A. F., Beiträge zu einer anatomischen Monographie der Rana pipa. Acad.

Caes. Leop. Nov. Acta, 1825. Vol. XII, p. 527.

F $\mathbf{f}_{2}$ 
Meckel, J., Beiträge zur vergleichenden Anatomie. Leipzig, I8Ir.

Meckel, J., System der vergleichenden Anatomie. Halle, I833.

Mivart, St. Geo., On the Classification of the Anurous Batrachians. Proc. Zool. Soc. I869.

Mivart, St. Geo., The Common Frog. London, 1874.

Müller, J., Beiträge zur Anatomie und Naturgeschichte der Amphibien. Tiedemann's Zeitschr. 183I, p. I90.

Müller, J., The Physiology of the Senkes, etc. Translated by W. Baly. London, I 848 .

Owen, R., Anatomy of the Vertebrates. London, 1866.

Ranvier, I., Leçons d'anatomie générale. Paris, I880.

Rösel v. Rosenhof, Historia naturalis ranarum nostratium. Nümberg, 1758 .

Rudolphi and Breyer, Observationes anatomicae circa abricam Ranae pipae. Berolini, I81 1.

Rusconi, M., Développement de la grenouille commune. Milan, I826.

Schneider, J. G., Historia amphibiorum. Jenae, I799.

Schwalbe, G., Lehrbuch der Anatomie der Sinnesorgane. Erlangen, I885.

Stannius, H., Zootomie der Amphibien (Handb. der Zoot. der Wirbelthiere, 2 Buch). and Edit. Berlin, 1856 .

Stricker, s., Beiträge zur Biologie der Batrachier. Wien. Zool. Bot. Verhandl. 1866. Vol. XVI, pp. 45I-456.

Stricker, s., Handbuch der Gewebelehre.

Stricker, S., Manual of Human and Comparative Histology. Translated by H. Power. London, 187 o.

Swammerdam, J., Biblia Naturae Amstelodamensis. (Dutch and Latin by Gaubiuf. Leidae, $\mathrm{I}_{738 .)}$

Todd and Bowman, The Physiological Anatomy and Physiology of Man. London, I $845^{-1} 857$.

Vogt, C., Zoologische Briefe. Frankfurt \%. M., I85I.

Wagler, J., Natiurliches System der Amphibien. München, Stuttgart, and Tubingen, 1830 .

Wagner, R., Lehrbuch der vergleichenden Anatomie. Leipzig, 1834-1835.

Wagner, R., Icones Zootomicae. Leipzig, I84I.

Wagnex, R., Handwörterbuch der Physiologie. $\quad 184^{2}$.

Waters, W. H., Histological Notes. Manchester and London, 1884.

Wiedersheim, R., Lehrbuch der vergleichenden Anatomie der Wirbelthiere. and Edit. Jena, I886.

Wiedersheim, R., Elements of Comparative Anatomy of Vertebrates. Translated by N. Newton Parker. London, 1886.

\section{WORKS RELATING TO THE EMBRYOLOGY AND DEVELOPMENT OF THE FROG.}

Balfour, F. M., Treatise on Comparative Embryology. London, I88o.

Born, G., Beiträge zur Bastardirung zwischen den einheimischen Anurenarten. Pfliger's Arch. f. d. ges. Physiol. I883. Vol. XXXII, p. 453. 
Durham, H. Z., Note on the presence of a Neurenteric Canal in Rana. Quart. Journ. Micros. Sci. 1886. Vol. XXVI, p. 509.

Giles, A. E., The development of the fat-bodies in Rana temporaria. Quart. Journ. Micros. Sci. 1888. Vol. XXIX.

Goette, A., Kurze Mittheilungen aus der Entwicklungsgeschichte der Unke. Arch. f. mik. Anat. 1873. Vol. IX, p. 396.

Goette, A., Entwicklungsgeschichte der Unke. Leipzig, 1875 .

Hertwig, O., Die Entwicklung des mittleren Keimblattes der Wirbelthiere. Jena, I883.

Johnson, A., and Sheldon, L., Notes on the Development of the Newt (Triton cristatus). Quart. Journ. Micros. Sci. I886. Vol. XXVI, p. 573.

Marshall, A. M., The Frog : An Introduction to Anatomy, Histology, and Embryology. 3rd Edition. Manchester and London, I8S8.

Pflüger, E., Einige Beobachtungen zur Frage über die das Geschlecht bestimmenden Ursachen. P\&üger's Arch. f. d. ges. Physiol. 188r. Vol. XXVI.

Pflüger, E., Hat die Concentration des Samens einen Einfluss auf das Geschlecht ? Pflüger's Arch. f. d. ges. Physiol. 1883. Vol. XXIX, p. I.

Pflüger, ஐ., Zusammenstellung der Ergebnisse und Erörterung der Principien der Zeugung. Pflitger's Arch. f. d. ges. Physiol. I883. Vol. XXXII, p. 542.

Pfüger, $\mathbf{\text { B., }}$ and Smith, W. J., Experimente über Bastardirung der anuren Batrachier. Pflüger's Arch. f. d. ges. Physiol, 1883. Vol. XXXII, p. 5I9.

Remak, Untersuchungen über die Entwickelnng der Wirbelthiere. Berlin, I 855 .

8chultze, O., Zur ersten Entwickelung des braunen Grasfrosches. Leipzig, 1887.

Schultze, O., Die Entwicklung der Keimblätter und der Chorda dorsalis von Rana fusca. Zeitschr. f. wiss. Zool. I888. Vol. XLVII, p. 325.

Spencer, W. B., Some Notes on the Early Development of Rana temporaria. Quart. Journ. Micros. Sci. 1885. (Supplement.)

Stricker, s., Untersuchungen über die Entwicklung des Kopfes der Batrachier. Arch. f. Anat. u. Physiol. 1864, p. 52.

Törok, A., Beiträge zur Kenntaiss der ersten Anlagen der Sinnesorgane und der primären Schädelformation bei den Batrachiern. Moleschott's Cntersuchungen, 1870. Vol. $\mathrm{X}$, p. 338.

\section{ADDITIONS TO THE LISTS GIVEN AT THE HEADS OF THE SECTIONS.}

\section{The Bones.}

Albrecht, P., Note sur le basi-occipital des batraciens anoures. Extr. d. Bullet. d. Musée royal d'hist. nat. de Belgique. I883. Vol. II.

Born, G., Die sechste Zehe der Anuren. Morphol. Jahrb. 1876. Vol. I.

Born, G., Ueber das Skelet des Fersenhöckers von Rana fusca, etc. Sitzungsb. d. Schles. Gesell. f, vaterländ. Cultur. 1879.

Born, G., Nachträge zu Carpus und Tarsus. Morph. Jahrb, I880. Vol. VI.

Eckex, A., Icnnes physiologicae. Leipzig, I88I-1889. 
Ecker, A., Die Anatomie des Frosches. 2nd Edition. Braunschweig, I888, pp. I $7-62$.

Gegenbaur, Untersuchungen zur vergl. Anatomie der Wirbelsäule bei Reptilien und Amphibien. Leipzig, I862.

Gegenbaur, Grundzüge der vergl. Anatomie. Leipzig, I 870.

Goette, A., Brustbein und Schultergürtel auf entwickelungsgeschichtlicher Grundlage verglichen bei Amphibien und Anurioten. Arch. f. mik. Anat. 1877 . Vol. XIV, p. 502 .

Howes, G. B., On some abnormalities of the Frog's vertebral column. Anat. Anz. 1886. Vol. I, Pt. II.

Leydig, F., Ueber den Bau der Zehen bei Batrachiern und die Bedeutung des Fersenhöckers. Morphol. Jahrb, I876. Vol. II.

Parker, W. K., A monograph on the structure and development of the shouldergirdle and sternum. Ray. Soc. $186 \%$.

Schneider, J. G., Historia amphibiorum. Jenae, I799.

Stöhr, P., Zur Entwickelungsgeschichte des Anurenschädels. Zeitschr. f. wiss. Zool. I88I. Vol. XXXVI.

Törok, A., Beiträge zur Kenntniss der ersten Anlagen der Sinnesorgane und der primären Schädelformation bei den Batrachiern. Moleschott's Untersuchungen. 1870. Vol. X, p. 338 .

\section{The Muscles.}

Albrecht, P., Beitrag zur Morphologie des M. omohyoides und der ventralen inneren Interbranchial-Musculatur. Inaug. Dissert. Kiel, 1876 .

Ecker, A., Die Anatomie des Frosches. 2nd Edition. Braunschweig, I888, pp. $65-139$.

Hoffmann, C. K., Bronn's Klassen und Ordnungen des Thierreichs. Vol. VI. Amphibien. Leiprig, 1873-1878.

Howes, G. B., An Atlas of Practical Elementary Biolngy. London, r885.

\section{Nervous System.}

Engelmann, T. W., Ueber die Discontinuität des Axencylinders und den fibrillïren Bau der Nervenfasern. Pflitger's Arch. f. d. ges. Physiol. 1880. Vol. XXII, p. I.

Grandry, Recherches sur la structure interne du cylindre de l'axe et des cellules nerveuses. Bull. de l'Acad. Roy. du Belgique. I 868.

Hodge, C. F., Some effects of stimulating ganglion-cells. (Some anatomical details regarding the relations of nerve-fibres with nerve-cells are given.) American Journ. of Phys. I888.

Owsjannikow, P., Ueber die Rinde des Grosshirns. Mémoires de l'acad. inpériale des sciences de St. Pétersbourg. 1879. Series VII, Vol. XXVI, No. II.

Spiro, Physiologisch-topographische Untersuchungen am Rïickenmark des Frosehes. Mémoires de l'acad. impériale des sciences de St. Pétersbourg. 18\%o. Series VII, Vol. XVI, No. 7 .

Waldeyer, W., Untersuchungen iber den Ursprung und Verlauf des Axencylinders. Henle u. Pfeuffer's Zeitschr. 1864. Vol. XX, pp. 193-257.

Consult also: Gerlach, J., Mayer, s., and Schultze, M., in Stricker's Handbuch der Gewebelehre. 


\section{The Vascular System.}

Barthol, P., Sopra il sistema linfatico dei Rettili. Pavia, 1833 .

Blaschek, A., Untersuchungen uiber Herz, Pericard, Endocard, und Pericardhöhle.

Sehenk's Mitt. 1885. New Series, p. 32.

Fberth, C. J., in Stricker's Handbuch der Gewebelehre.

Klein, $\mathbf{H}$, On the peripheral distribution of non-medullated nerve-fibres (nerves of the blood-vessels in the frog's tongue). Quart. Journ. Micros. Sci. $1 \& ; 2$. Vol. XII, p. 123 .

Mayer, s., Studien zur Histologie und Physiologie des Blutgefässsystems. Wiener Sitzungsb. 1886. Vol, XCII, Pt. III, p. 45.

v. Recklinghausen, F., (The lymphatics) in Stricker's Handbuch der Gewebelehre. Rollett, A., (The Blood) in Stricker's Handbuch der Gewebelehre.

Teichmann, L., Cntersuchungen über das Saugadersystem. Leipzig, I861.

\section{The Amimentary Canal.}

Heidenhain, R., Beiträge zur Kenntnisz des Pancreas. Pflüger's Arch. f. d. ges. Phyviol. 1875. Vol. X, p. 557.

Krause, W., Anatomische Untersuchungen (Tongue). Hannover, I 86I.

Consult also: Klein, E., The Oral Cavity and the Oesophagus; Mñller, W., The Spleen; Eberth, C. J., The Liver, in Stricker's Handbuch der Gewebelehre.

\section{The Lungs and Larynx.}

Holmgren, F., Methode zur Beobachtung des Kreislaufs in der Froschlunge. Beitr. z. Anat. u. Physiol. Festgabe f. C. Ludwig. Leipzig, 18 74 .

Meckel, J. F., Beitrïge zur Geschichte des Respirations-Systemes der Amphibien. Meckel's Arch. 1849. Vol. V.

Schmidt, C., De l'épithelium pulmonaire. 1866.

Williams, Article Respiration, in Todd's Cyclopaedia of Anat. and Physiol. 1859 . Vol. V.

\section{The Urino-Genital System, the Adrexals, and the Fat-Bodies.}

Aeby, C., Teher glatte Muskelfagern in Ovarium und Mesovarium von Wirbelthieren. Arch. f. Anat. ๒. Physiol. 1859, p. 675.

Giles, A. E., The derelopment of the fat-bodies in Rana temporaria. Quart. Journ. Micros. Sci. 1888. Vol. XXIX.

Grohe, F., Ueber die Bewegung der Samenkörper. Virchow's Arch. 186ฐ̃. Vol. XXXII, p. 416.

Virchow, R., Ceber die Dotterplättchen bei den Fischen und Amphibien. Zeitschr. f. wiss. Zool. 1849. Vol. IV.

Consult also: Eberth, C. J.; v. La Valette St. George; Ludwig, C.; Grünwald ; Obersteiner, H.; and Stricker, S., in Stricker's Handbuch der Gewebelehre. 


\section{The Skin and Sense-Organs.}

\section{a. The Skin.}

Busch, A., Phänomene aus dem Leben der Pigmentzellen. Arch. f. Anat. u. Physiol. I856, p. 415.

\section{b. Special Organs of Tactile Sensation.}

Mitrophanow, P., Zur Entwicklungsgeschichte und Innervation der Nervenhügel der Urodelenlarven. Biologisches Centralb. I887, p. I74.

\section{c. The. Organs of Taste.}

Beale, I. S., New Observations upon the Minute Anatomy of the Papillae of the Frog's Tongue. Phil. Trans, 1865. Vol, CLV, p. 443.

Fngelmann, T. W., in Stricker's Handbuch der Gewebelehre.

Maddox, R. I., A Contribution to the Minute Anatomy of the Fungiform Papillae and terminal arrangement of Nerve to striped Muscular Tissue in the Tongue of the common Frog. Monthly Micros. Journ. I869, p. I.

\section{d. The Ear.}

Albrecht, P., Sur la valeur morphologique de la trompe d'Eustache, Communication faite à la Société d'Anatomie Pathologique de Bruxelles. $\quad 1884$.

v. Kölliker, Handbuch der Gewebelehre. 5th Edit. Leipzig, 1867.

Leydig, F., Handbuch der Histologie. Frankfurt a. M., 1857.

Rüdinger, in Stricker's Handbuch der Gewebelehre.

\section{e. The Nose.}

Marshell, A. M., Morphology of the Vertebrate Olfactory Organ. Quart. Journ. Micros. Sci. 1879. Vol. XIX, p. 330.

\section{f. The Eye.}

Ciaccio, G. V., Beobachtungen über den inneren Bau des Glaskörpers im Auge des Menschen und der Wirbelthiere im Allgemeinen. Moleschott's Untersuchungen, 187o. Vol. X, p. 383 .

Hannover and Finkbeiner, Vergleichende Untersuchungen der Stärke des Glaskörpers bei den Wirbelthieren. Zeitschr. f, wiss. Zool. 1855. Vol. VI, p. 335. Hirschberg, J., Zur Dioptric und Ophthalmologie der Fish- und Amphibienangen. Arch. f. Anat. u. Physiol. I887, p. 493.

Ranvier, $\mathrm{L}$., Le mécanisme de la Sécrétion. Leçons faites au Collége de France en 1886-188\%. (Nictitating membrane.)

Consult also: Rollett and Stieda, in Stricker's Handbuch der Gewebelehre. 


\section{N D E X.}

Abducens nerve, p. I 7 .

Acetabulum, 48. nuclens, 146 .

Acromial, 39 .

Adrenals, 348.

Ala magna, 25 .

ntemporalis, 25 .

Alar cartilages, 28.

Alimentary canal, $25^{8}$.

Ampulla anterior, 396 .

" external, 398.

posterior, 398 .

Angulo-splenial, 34.

Ankle, 50.

Anterior ampulla, 396 .

" brachial lymph-sac, 259.

n brachio-rsidial septum, 258 .

" brachio-ulnar septum, 258.

" chamber, 409 .

Aorta dorsal, 233.

Aponeurosis plantaris, 105.

Arachnoid, 162.

Arteria basillaris, 163 .

" bulbi, 222.

" circumflexa genu. lat. sup., 238.

$"$ " $"$ inf., 238.

$n \quad " \quad$ "med. sup., 238.

". comm. ant., 163. ", inf., 238 .

coraco-clavicularie, 231.

costo-cervicalis, 231.

cruris inf., 239.

cut. calcanei, 239.

cut. fem. med., 237.

" $"$ post., 237.

"pectoris, $23 \mathrm{I}$.

haemorrhoid. inf., 236.

lobi hemisph. inf. ext., 163.

" , sup. int., 163.

" optici, 163.

malleol. lat., 240.

malleol. med., 240.

pharyngo-maxill., 230.

ramus auricularis, 228, 230.

" maxillaris comm., 228.

$$
\Rightarrow \text { inf., } 230 .
$$$$
\text { 3) sup., } 228 .
$$

" orbito-nasalis, 228.

scapularis post., 232.

, sup., 232.

spinalis ant., 163 .
A rteris subscapularis, 232.

" suralis, 239.

Arteries, 222.

" of brain, 162.

$\Rightarrow$ of choroid, 4 II.

" of foot, 240 .

" of byaloid, 421.

, of iris, 413 .

" of skin, 376 .

"y of vitreous body, 421

Artery, ant. palatine, 224.

" "tibial, 239.

", brachial, $23^{2}$.

"s carotid, 224 .

.. ciliary, 226.

,. coeliaco-mesenteric, 233.

" femoral, 236.

") gastric, 233.

" haemorrhoidal, 235.

" hepatic, 298.

, hraloid, 226 .

" iliac, 235 .

.. internal carotid, 225.

" laryngeal, 226.

" lingual, 224.

, lumbar, 235 .

" mesenteric, 234.

, occipital, 228.

". occipito-vertebral, 226.

," cesophageal, 226.

, ophthalmie, 225, 411, 41?

," peroneal, 23 I.

.. pharyngeal. 224.

, post. palatine, 234

.. radial, 232 .

.. renal, 333 .

.. $\quad$ sciatic, 236 .

, spermatic, 236 .

., subelavian, 231 .

$\therefore \quad$ tibial, 238 .

., ulnar, 233.

, urimo-genital, 235

", vertebral, 226 .

") vesico-epigastric, 235 .

Articular processe8, I7.

Articulations of vertebrae, 19.

$$
\text { , of atlas, } 24 \text {. }
$$

Arytenoid cartilages, 313.

Astragalus, 50.

Atlas, 18.

Auditory nerve, I 72. 
A uditory nucleus, 144.

Auerbach's plexus, 292.

Auricles, 214.

Auriculo-ventricular valves, 216.

Axillary septum, 258.

Axis-cylinder, 202.

Bidder's ganglion, 220.

Bile-ducts, 298.

Bladder, gall-, 295, 299.

Blood, 262. urinary, 338 .

Bones and joints, 13.

Bowman's glands, 387 .

Brachial nerve, I83.

Brachio-ulnar lymph-sac, 259.

Braìu, I4I. radial, 259.

Calcaneum, 50.

Calcified cartilage, 15.

Canales coccygei, 2 I.

Canalis vertebralis, 20. rami ant. acustici, 393.

Capitulum radii, 43 .

Capsule of labyrinth, 391 . , of lens, 413.

Carotid arch, 222.

, gland, 223.

Cartilage, calcified, 15 .

" of shoulder-girdle, 40.

, of skull, 29.

Cartilages of larynx, 312. , of nose, 27,385 .

Cauda equina, 135,189 .

Cava recto-vesicalis, 304 .

Cavitas sigmoidea maj., 43 .

Central canal of cord, 137 . , group of cells, r39.

Cerebellum, 148.

Cerebral hemispheres, I56.

Chamber, anterior, 409.

$$
\text { ," posterior, } 420 \text {. }
$$

Chiasma, optic, $1_{53}, I_{55}, 167$.

Chorda dorsalis, 20.

Chordae tendinear, 216.

Choroid coat, 409 .

, plexus of fourth vent., 142,164 .

Ciliary nerves", 169 . third " 153,164 .

" processes, 420.

Cireulns iridis major, $4^{\mathrm{I}} 3$.

Claricle, 39.

Cloaca, 347 .

Columella auris, 25, 390 .

Commissura anterior, I59. inferior, 140. posterior, I59.

" superior, I40.

" transversa, I54.
Common bile-duct, 296.

Cones, $4^{18}$.

Conus medullaris, 135 .

Coracoid, 39.

Coracoid foramen, 39 .

Cornea, 406.

Corpora quadrigemina, $\mathbf{I}_{52}$.

Corpus callosum, I 58, I 59 .

" striatum, $158,159$.

Corpuscles of blood, 263 . ,. of Hassall, $32 \mathrm{I}$.

Coverings of brain and cord, 162 .

Cranial nerves, I41, 167 .

Cranium, 23.

Cricoid cartilage, 312 .

Crista acustica, 397.

" deltoider, $4 \mathrm{I}$.

", medialis, 42 .

Crusta petrosa, 279 .

Cupula terminalis, 398 .

Cutaneous glands, 372 .

Cuticula dentis, 279 .

Cutis, 369.

Cystic duct, 295.

Dentale, 35.

Dentary, 34 .

Dentine, 279.

Descemet's membrane, 407 .

Dorsal lymph-sac, 255.

$\because$ roots, 140 .

, septum, 252.

Duct, common bile-, 296.

" cystic, 295 .

Ductus choledoous, 296.

" endolymphaticus, $39^{8}$.

" fenestra ovalis, 394 .

, perilymphaticus, 395 .

" Wirsungianus, zor.

Dura mater, $\mathbf{1 6 2 .}$

Ear, 389 .

Enamel, 279 .

Enlargements of cord, 133,137 .

Epicoracoids, 37 .

Epidermis, 367 .

Epiglottis, 317.

Episternum, 36.

Epithelium of ventricles, etc., 160.

Exoccipitals, 23.

External limiting membrane, 420 .

Extrastapedial, 26, 390 .

Eye, 405 .

Eyelids, 422.

Facial nerve, 17 I.

Fat-bodies, $34^{8}$.

Femoral lymph-sac, 260.

Fibra arcuatae cerebelli, 149 . 
Fibres of brain, $16 \mathrm{r}$.

Filiform papillae, $3^{80}$.

Filum terminale, 135 .

Foramen condyloideum, 24 .

s magnum, 23.

3) Monroi, I57.

, orale, 24 .

"parietale, I56. $_{5} 6$.

, rotundum, $39^{2}$.

Furmatio reticularis, I 40 .

Fosea condyloidea, 24. tympanica, 24.

Fourth ventricle, $I_{42}$.

Fronto-parietsl bones, 26.

Fungiform papillae, 380 .

Gall-bladder, 295, 299.

Ganglia of bladder, $34^{\circ}$.

," of heart, 220.

" of epinal, $17 \%$.

Ganglion ciliare, 168.

, condyloideum, 173 .

, Gasserii, 168.

,. interpeduneulare, I52.

,$\quad$ layer, $4 \mathrm{I}$.

,, nervi vagi, 173 .

Gasserian ganglion, 168.

Glands, Bowman's, $3^{87}$.

" cutaneous, $3 i^{2}$.

", gastric, 285 .

,$\quad$ Harder's, 424.

,. intermaxillary, 280 .

,. Lieberkiuhn's, 288.

, nasal, 3 S6.

, oesophageal, 283.

,. of nictitating membrane, 423 .

.. periganglionic, 180 .

$\because \quad$ thymus, $3^{20}$.

") thyroid, $3^{22}$.

Glossopharyngeal nerve, 172 .

Goblet-cells, 289.

Goll's colvunns, I 4 .

Grey matter, I39.

Hair-cells of ear, 404. of nose, 388 .

Harder's glands, 424.

Hassall's corpuseles, 321 .

Heart, 213, 214.

n endothelium, 320 .

" mnscle, 216.

"nerves, 219.

". structure of, a 16.

Hepatic arteries, 42I.

$$
\text { ", portal system, } 248 .
$$

Hip-joint, 49.

Humerns, 4I.

Hyaloid artery, 42 I.

, membrane, $42 \mathrm{I}$.
Hyoid, 35.

Hypogloessl nerve, 182.

Ilia, 47 .

Iliac lymph-sac, 257 .

., septum, 253.

Inferior femoral septum, 259 . sinus, $3^{83}$.

Infundibulum, 153 .

Inguinal septum, 254.

Inner molecular layer, $4 \mathrm{I} 5$.

"nuclear " 416.

Interfemoral lymph-8ac, 260.

Intermaxillary glands, 280 .

Intermediate fem. septum, 259.

Internal enr, 39r.

" limiting membrane, 414, 420 .

" muscles of eye, $4^{13}$.

Interstapedial, $25,39 \mathrm{I}$.

Intestine, 286.

Intumescentia ant. and post., I35.

Iris, 412.

Ischia, 48.

Kidney, 332.

Knee-joint, 50.

Labyrinth membranous, 395.

" $\quad$ osseous, 391.

Lachrymal duct, $3^{87}$.

Layena cochlea, too.

Lamins fusca, $4^{11}$.

, suprachoroidea, 4 II.

$"$ terminalis, I53, I57.

Large intestine, 292.

Larsngeal nerve, I 75.

Larynx, 3 II.

Lateral group of cells, 139 .

, lymph-8ac, 255.

", sense-organs, 379 .

Lens, 413 . sinus, $3^{80}$.

Lieberkưhn's glands, 288, 293.

Ligament. calcanei, 19.

,. coronarium, 303 ,

", gastro-duodenale, 305 .

". hepato-duodenale, 287 . 305.

. intercruralia, I9.

$" \quad$ interspinalia, 19.

" pectinatom iridis, 409.

,, suspensor. hepatis, 304 .

,$\quad$ verteb. comm. ant., I9.

, ", " post., I9.

Limiiking membrane," external, 420 .

Lip", 275 . internal, 4I $4,420$.

Literature on adrenals, 330. 
Literature on alimentary cknal, 268.

\begin{tabular}{|c|c|c|}
\hline " & ", & blood, $2 \mathrm{II}$. \\
\hline " & $"$ & blood-vessels, 205. \\
\hline$"$ & $"$ & bones and joints, $I_{3}$. \\
\hline$=9$ & " & cartilage, 43I. \\
\hline$"$ & " & connective tissues, 432 . \\
\hline$"$ & $"$ & ear, $35^{\circ}$. \\
\hline$"$ & $"$ & emoryology, 430-437. \\
\hline , & ", & fat-bodies, 330 . \\
\hline$"$ & 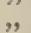 & gall-bladder, 272. \\
\hline ", & , & general, 435-436. \\
\hline$"$ & " & heart, 205 . \\
\hline " & " & intestine, 270 . \\
\hline " & ", & Iarynx, 309. \\
\hline$"$ & " & Miver, 272 \\
\hline$"$ & " & lungs, 309. \\
\hline$\because "$ & $"$ & lymphatic system; 209. \\
\hline ", & , & mouth, 268 . \\
\hline ", & " & muscle structure, $4^{2} 7$. \\
\hline$"$ & $"$ & muscles, 54 \\
\hline ", & " & nervous system, 122. \\
\hline ", & " & nose, 357. \\
\hline$"$ & $"$ & pancreas, 272 \\
\hline$"$ " & $"$ & respiratory 8ystem, 300 \\
\hline 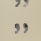 & " & skin, 353 . \\
\hline ", & " & spleen, 273. \\
\hline " & ", & taste-organs, 356 . \\
\hline 'g & "' & thymus, 310. \\
\hline "’ & $"$ & thyroid, 3 IO. \\
\hline$"$ & $"$ & urino-genital systen \\
\hline "' & $"$ & \\
\hline
\end{tabular}

Liver, 394.

cells, 298.

", pigment of, 299.

, vessels of, 297.

Lower eyelid, 422.

". nasal glands, 386.

Lungs, 317.

Lymph, 264.

Lymph-hearts, 261, 264.

Lymph-sacs of ant. extremity, 258 .

$" \quad, \quad$ of hinder extremity, 259.

Lymphatic system, $25 \mathrm{I}$.

Macula lutea, 4I9.

Malpighian bodies of kidney, 334.

Mandible, 34." of epleen, 303 .

Maxillary bones, 32 . septum, 253

Meckel's cartilage, 35 .

Mediostapedial, 25, 390.

Medulla oblongats, I42.

Medullary segments, 202. sheath, $20 \mathrm{r}$.

Medullated nerves, 20I.

Meissner's plexus, 291.
Membrana choriocapillaris, $4^{11 .}$

"limitans ext., 420 .

" .,$\quad$ int., 414,420 .

" nictitans, 58,422 .

, suprachoroidea, 4II.

Membrane of Descemet, 407 .

Membranous labyrinth, 395 .

Mentomeckelian cartilage, 35 .

Mesocephalic ganglion, I68.

Metacarpus, 46.

Metatarsus, $5^{2}$.

Meynert's fibres, I 55 .

Molecular layer, inner, 415 .

" " outer, 4rg.

Motor-oculi, 167 .

Mouth, 275.

Movements of hand, 46 .

Mucons glands of skin, 375 .

Müller's fibres, $4^{20}$.

Muscle, histology, 433.

Muscles, 53.

Muscles of abdomen, 67 .

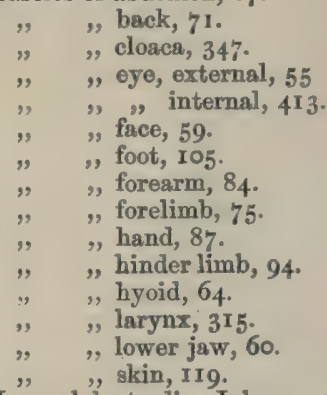

Muso. abduct. dig. I brev., II4.

\begin{tabular}{|c|c|c|}
\hline " & " & $n$ II, \\
\hline "? & 9 & $"$ g, long., $9 \mathrm{I}$. \\
\hline " & " & " V, II 3. \\
\hline " & . & "V brev., I16. \\
\hline " & $"$ & ") I long., IIo. \\
\hline$"$ & " & " $\frac{\boldsymbol{L}}{\boldsymbol{V}}$ " 80 . \\
\hline " & "9 & $\begin{array}{l}V \text { prim., } 91 . \\
V \text { secund. }\end{array}$ \\
\hline " & " & hallucis, Iog. \\
\hline , & " & pollicis, 87 . \\
\hline " & "3 & brev, II 4 . \\
\hline " & adduet. & brev., roo. \\
\hline ", & $"$ & dig. I long., I09. \\
\hline , & " & " 11,89 \\
\hline$"$ & " & "Y, $\mathrm{N}_{3}$. \\
\hline " & , & mangus, 99. \\
\hline ", & ", & $\begin{array}{l}\text { magnus, } 99 . \\
\text { pollicis, } 87 \text {. }\end{array}$ \\
\hline 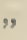 & anconaei & i, 87 . \\
\hline " & antibrac & hii la \\
\hline " & 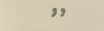 & 85. \\
\hline$"$ & biceps fe & $\begin{array}{l}\text { pror. } \\
\text { m., } 96 .\end{array}$ \\
\hline " & cocuygeo & $18,120$. \\
\hline ", & " & -iliscus, 74. \\
\hline
\end{tabular}


Mrse. coccygeo-sacralis, 73 .

compressor cloacae, 348 .

constrictor aditus laryngis, 315 .

constrictor iridis, $4^{1} 3$.

coraco-humeralis, 82.

encullaris, 7 r.

cutaneus dorri, 1 I9.

$$
" \text { pectoris, II9. }
$$

dilator aditus laryngis, 315 .

deltoidens, 82 .

depressor maxill. inf., 60.

dilator iridis, $4{ }^{\mathrm{I}} 3$. palpebrae inf., 58 .

.. , narium, 59.

.. extensor brevis, 106.

.. $\quad$ " carpi ulnaris, 86.

,. $\quad$.. cruris brevis, $\mathrm{IO}_{4}$

, $\quad$ " digit. I brev., 1 I 4 .

, $\quad " \quad$, "long., II4.

.. $\quad$, II brev., II 4 .

,. $\quad$ ",$\quad$ long., II 4 .

.. $\quad$ " $\quad$ " prop. brev., 92.

.. $\quad, \quad, \quad, \quad$ long., 92.

$. . \quad, \quad$ III brev., I15.

, long., 115 .

, prop., 93 .

IV, 116.

", brev., 116.

"prop., 93.

V brev., 1 I5.

, long., II 5 .

", comm. brev., $9 \mathrm{I}$.

dorsi comm., 73 .

"'. antibrach. lat. superf., 85

".

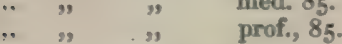

.. " brev, digit. I, roo.

$. . \quad " \quad, \quad$ IV, II2.

.. " " , ", 113.

..,$\quad$ earpi radialis, 84 .

,. ", " ulnaris, 84 .

.. $\quad$ digit. comm., 85,87 .

,I, II, I08.

"II brev., 89 .

, II long., 88.

, II prop., IIO.

II tert., 89.

, III brev., 89.

, III long., 89.

, III prop., III.

, III, IV, V, 107.

IV brev., 90.

," long., 90.

," prop., 112.

"V brev., 90.

, , long., 90.

", "prop., 113.

metacarp. digit. III, 90.

$$
\text { , } \quad \text { IV, } 90 .
$$

metatars. digit. II, I IO.

III, III.
Muse. flex, metatars. digit. IV, I I a.

" " phal. prop. dig. III, II 2.

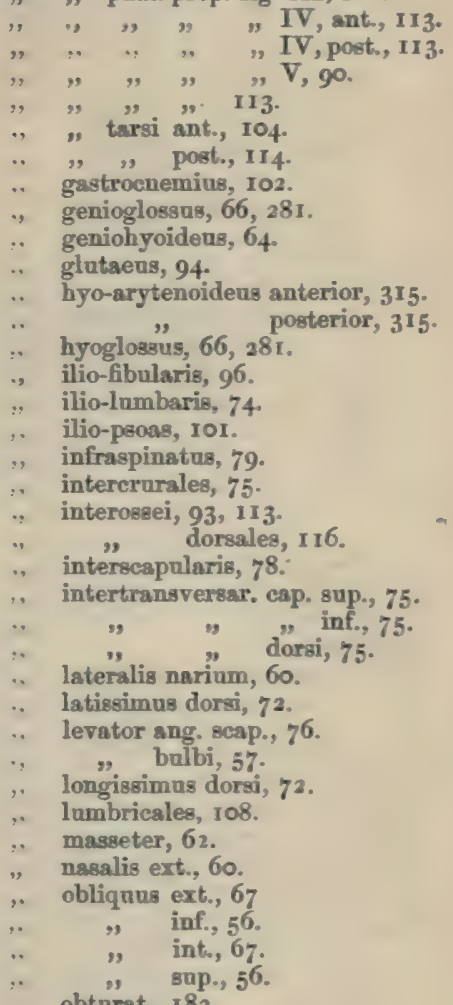

obturat., 182 .

omohyoideas, 65 .

opponens dig. I, I 10.

, , II, 89 .

" $\quad$ V, 90.

palmaris brev., 87 .

pectineus, Ioo.

pectoralis, 8o.

petrohyoideus ant., 65 .

petrohyoidei post., 66, 315 .

plantaris, 107 .

protrahens scap., 76 .

pterygoidens, $6 \mathrm{r}$.

pyriformis, 95 .

quadratus fem., II2.

rectus abdom., 67 .

$"$ extern. bulbi, 55 .

, fem. ant., 95 .

infer. ,; 55 .

inter., 55 .

intern, maior, 97.

super. ant, 56 .

" intern. minor, 98.

retractor bulbi, 56 . 
Musc. Eartorius, 97.

semimembranosus, 97 .

semitendinosus, Ioo.

sphincter ani, 347 .

sternohyoideus, 64 .

sternomastoideus, 76 .

sternoradialis, 82 .

submaxillaris, 62 .

submentalis, 63 .

subscapularis, 78 .

temporalis, $6 \mathbf{r}$.

tibialis ant., 104.

" post., 103.

transverso-scapularis maior, 77 .

$$
" \quad \text { " }
$$

transversus metacarp., 93 . minor, 77 .

" plant., 108

triceps femoris, 95 .

vastus ext., 96 .

, int., 96.

Nasal bones, 33.

" cartilages, 385 .

", glands, 403 .

Nephrostomes, 336.

Nerve, abducens, I 7 .

,, auditory, 172.

, brachial, 183 .

, facial, 17 .

", fifth spinal, $x 87$.

,. fourth spinal, 188.

, glossopharyngeal, I 72.

,2 hypoglossal, 182.

.. laryngeal, 175 .

" oculo-motor, 167 .

"olfactory, $16 \%$.

,. optic, 167, 405 .

"pathetic, $1_{42}, 168$.

" palatine, 169 .

" peroneal, 195.

" pneumogastric, I73.

radial, 186.

,. sixth spinal, 188.

spinal, 175 .

structure of, $20 \mathrm{r}$.

sympathetic, 197.

third spinal, $\mathbf{3} 88$.

tibial trigeminal, 168 .

" vagus, 173 .

Nerves, I67.

$$
\begin{aligned}
& \text { of Cornea, } 408 . \\
& " \quad \text {, ear, 403. } \\
& \text { ", heart, 2I9. } \\
& \text { " lungs, 3I9. } \\
& \text { " oesophagus, } 286 . \\
& \text { " skin, 378. } \\
& \text { " stomach, } 286 .
\end{aligned}
$$

Nervi ciliares, 169.

Nervus, coccygeus, 189 .

, coraco-clavicularis, 183 .

.. eruralis, 189.
Nerrus cut. antibrach. inf., 185. cut. antibrach. sup., I 85 . eut. dorsi pedis lat., 196. ileo-hypogastricus, 189 . peroneus, I95.

$$
\begin{array}{ll}
" & \text { comm. inf, } 196 . \\
" & \text { lateralis, I96. } \\
\text { " medialis, I96. }
\end{array}
$$

ramus accessorius, 174 .

anterior, 173 .

auricularis, $\mathrm{I} / 2$.

cardiacus, 175 .

cut. sxillarik, 183 .

eutaneus dors., I74.

, cruris lat., 196.

" $\quad$ med., I94.

", ", post., 194.

fem., 189 .

" lat., 187 .

".. med., 186.

" sup., 186.

dorsalis, 185 .

gastricus, $\mathbf{r}_{75}$.

hyoideus, I 72 .

hyomandibularis, 172.

laryngeus, 175.

lateralis, 185 .

mandibularis, I 70 .

maxillaris, $I$ yo.

maxillo-mandibularis, 1 7o.

muscularis, 187 .

ophthalmicus, 169.

palatinus, $\mathbf{I}$ I.

pectoralis, 185 .

posterior, I73.

pulmonalis, 175 .

scapularis, $I 74$.

subscapularis, 185 .

ulnaris lat., $I 86$.

" " med., 185.

") tibialis, 194, 195.

Neurilemma, 201.

Nictitating membrane, 423 .

Non-medullated fibres, 202.

Nose, $3^{8} 3$.

" skeleton, $27,383,3^{8} 5$.

Nuclear layer, inner, 416 .

Nucleus abducens, 416

$$
\begin{aligned}
& \text { outer, } 41 \\
& \text { I }
\end{aligned}
$$

auditory, 144.

eentralis, I44.

magnus, $\mathrm{I}_{47}, \mathrm{I}_{5} 2$.

medullae oblongatae, I44.

pneumogastric, $\mathbf{I}_{4} \mathbf{6}$.

trigeminal, I 45 .

Oculo-motor nerve, 167 .

nuclens, I5I.

Oesophrageal glands, 283 .

Oesophagus, 282.

Olfactory nerve, 167 . 
Omosternum, 36.

Opereulo-angulare, 35.

Operculum, 25.

Optic chiasms, $153,155,167$.

" commissure, I54.

, fibre larer, $4^{14}$.

, lobes, $x_{49}$.

", nerve, $167,405$.

,2 tracts, I 2.

$\mathrm{O}_{8}$ articulare, 35 .

" capitato-hamatum, 45 .

", cuboideum, $5 x$.

", cuneiformia, 52 .

", en ceinture, 27 .

, lunatum, 44

, multangulum maius, 45 .

" minus, 45 . minus, 4 .

" occipitale basilare, 23 .

",$\quad$ superiuis, 23.

pyramidale, 44 .

Ostium abdominale, 304,345 .

Outer nuclear layer, 416.

Ovaries, 344.

Oviducte, 304, 345 .

Palatine artery, 224.

", bones, 33.

"nerves, 169.

Pancreas, 300.

Papilla acustic lagenae, 400 .

Papillae of skin, 370.

" of tongree, 380 .

Parasphenoid, 26.

Pars basilaris cochleae, 400 .

, commissuralis, $147,152$.

" media, 135.

n neglects, 400 .

"peduncularis, 143, 152.

Partes condyloideae, 23.

Pathetic nerve, 142, 168.

Pectoral lymph-sac, 255.

Pelvis, 4:. septum, 253.

Pericardium, 213.

Periganglionie glands, 180.

Perilymphatic space, 393.

Perineal septum, 253.

Peritonem, 303 .

Phalanges of foot, 52 .

Pia mater, 162 .

Pigment of cerebellum, I 49.

\begin{tabular}{|c|c|}
\hline "9 & , cord, I4I. \\
\hline 23 & , hemispheres, 160. \\
\hline & , liver, 299. \\
\hline$a$ & "medulla, $x_{48}$ \\
\hline 27 & " optic lobes, I52. \\
\hline |' & " thalamencephalon, I55. \\
\hline
\end{tabular}

Pigment-layer, 419.

Pineal body, 155.

Pituitary body, 154, 156 .

Plexus, Auerbach's, 292.

$$
\text { 2. lateralis, } 165 \text {. }
$$

") Meissner' 8,29 I.

Pneumogastric nerve, 146, 173.

Pons Varolii, I 49.

nucleus, 146.

Fortal systems, $24 \%$.

, vein, 297.

Posterior chamber, 420 .

Pre-arytenoid cartilagea, 314.

Precuracoid, 40.

Premaxillary bones, 33.

Processez, articular, 17 .

$$
\text { "spinous, } 17 \text {. }
$$

" transverse, 17 .

Processus coracoidens, 40.

" coronoidens, mandible, 34 .

" " " radio-ulnsar, 43.

" mastoideus, 24

", sygomaticus, 30.

Prootic bones, 24.

Pterygoid bones, 3r.

Pubes, 49.

Pulmo-cutaneous arch, 2 zo.

Pulp-cavity, 279.

Purkinge's cells, 148 .

Radio-nlnar, 43.

Rami communicantes, I8I, 199.

Rana aquatica, 3 .

", escplenta, 4 .

, flaviventris, 7 .

" gibboen, 3 .

" innoxia, 3 .

, oryrhinus, 7,9 .

" rubeta, 3 .

" temporaria, 7 .

Receptaculum seminis, 337 .

Recessus utriculi, 396.

Remak's ganglion, 220.

Renal arteries, 333 .

" portal vein, 332 .

", veins, 333 .

Reproductive organs, 34I.

Retins, $4 \mathrm{I}_{4}$.

Retinal pigment, 419.

Ritter's fibres, 418.

Rods and cones, 416.

Roots of spinal nerves, 175 .

Round bundle, 154, 159.

Saccus endolymphaticus, $395,398$.

"fenestra ovalis, 395 .

" perilymphaticus, 395 .

Sacrum, I9.

Scapula, 37.

Sciatic artery, 236.

" nerve, 192 .

" plexts, I91. 
Selerotic coat, 405 .

Semicircular canal, ant., 396. 9 g $\quad$ g ext., 398.

Septa, of Iymph-sacs, $25_{2}$.

Septum medium, I 39 .

Serous glands of skin, 372 .

Shoulder-girdle, 37.

, -joint, 42.

Sinus, superior, 383 .

Sinus venosus, $2 I_{4}$.

Skeleton, I5.

Skin, 367 .

$$
\text { of nose, } 27,3^{8} 3,3^{85} \text {. }
$$

Skull, 2 I.

Small intestine, 286.

Sphenethmoid, 27.

Spinal cord, I35.

, ganglia, I77.

9, nerves, I35, I75, I8 I.

9 roots of, $I 75$.

Spinous processes, $\mathrm{I}_{7}$.

Spleen, 302.

Squamosal bones, 30 .

Sternum, 36.

Styloid cartilage, 25.

Submaxillary lymph-sac, 255 .

Substantia reticulosa, $\mathbf{I} 38$.

Sulcus longitud. inf., 135 .

Superior sinus, 383 sup., 135 .

Supplemental toe, $5,47,374$.

Supra-femoral lymph-8ac, 260.

, $\because$ septum, 259

Suprascapula, 37.

Suprastapedial, 26, 390.

Suspensorium, 30.

Sylvian aqueduct, I5o.

Sympathetic system, 197 .

Symphysis pubis, 48 .

Systemic arch, 226.

Tactile sensation, organs, 377 .

Taste-organs, 380 .

Teeth, 278.

Tegmentum vasculosum, 395, 402 .

Temporary papillae, 370 .

Testis, 34I.

Thalamencephalon, $\mathrm{I}_{53}$.

Thalamus-tubercinereum strand, I54, I 55,159 .

Third ventricle, I53.

Thymus gland, 320 .

Thyroid gland, 322 .

Tibio-femoral septum, 260.

Tibio-fibula, 49.

Toes, 5, 47, 374.

Tongue, 280 .

Tonsils, 323 .

Touch-corpuscles, 379 .

" -8pots, 378 .
Transverse processes, 17.

Trigeminal nerve, I68.

Tron nucleus, I45.

cus arteriosus, 216 .

Tuberculus maius, 42 .

Tympanic membrane, 389 . , ring, 26.

Tympanum, 389, 390.

Upper nasal gland, 386 .

Ureters, 337.

Urinary bladder, 338 . organs, 332.

Uriniferous tubes, 334 .

Urino-genital system, 330 .

Urostyle, 2 I.

Utricle, 396.

Vagus, 173 .

Valvula cerebelli, 148 .

Vasa efferentia, 34I.

, recta, $4^{12}, 4^{1} 3$.

Vein, anterior abdominal, 248.

" ", caval, $24 \pi$.

,$\quad$ orbital, 245.

" $"$ tibial, 250.

brachial, 246.

cardiac, 249.

caval anterior, 24I.

, posterior, 246 .

cutanenus, 244.

dorso-lumbar, 248.

external jugular, 24 I.

facial, 245.

femoral, 249.

gastric, 249.

haemorrhoidal, 249.

hepatic, $247,297$.

hepatic portal, 249.

iliac, 247.

innominate, 242.

internal jugular, 243 .

intestinal, 249.

jugular, extęrnal, $24 \mathrm{I}$.

lingual, $24 \mathrm{I}$.

internal, 243.

mandibular, 242.

median orbital, 243.

nasal, 245.

ophthelmic, 412.

orbital anterior, 245 .

, median, 243 .

, posterior, 245 .

ovarian, 247.

oviducal, 248.

portal, 297.

posterior caval, 246.

posterior orbital, 245 . 
Vein, pulmonary, 241.

, radial, 246 .

"renal, 247,333 .

2. renal portal, 332 .

9 sciatic, $247,250$.

" spermatic, 247 .

"splenic, 249.

", subelavian, 244.

") subecapular, 244. ulnar, $2+6$.

vertebral, 244 .

Veins, $24 \mathrm{I}$.

Vens bulbi anterior, 222.

. , y aperior, 412.

" " posterior, 222.

, spinalis anterior, 164 .

" $"$ posterior, 165.

" superior, 164 .

Ventral lyunph-8ac, 255.
Ventral nucleus, I55. septum, 252 .

Ventricle of heart, 215.

Ventricles of brain, $\mathbf{1 5 3}$.

Vertebrae, 16. of larynx, 316 .

" structure of, 20.

Vertebral column, 16.

Vessels of brain, 162 .

;) of liver, 297 .

Vitreons body, 420.

Vocal cords, 315 .

"sacs, 320.

Vomerine teeth, 276 .

Vomers, 34.

Webs, 5, 275.

Wrist-joint, 45 .

THE END. 




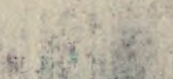

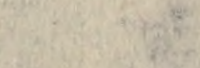

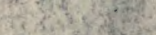

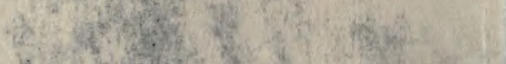

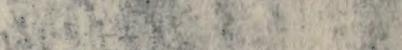

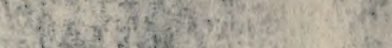

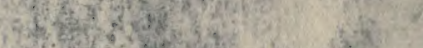

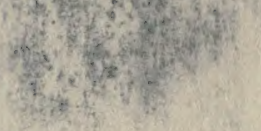

(F)

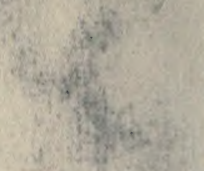

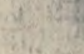
(6)

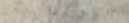
Q.

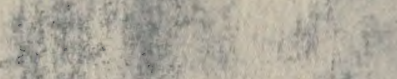

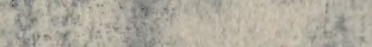
15.t.

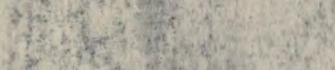

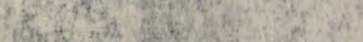

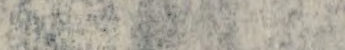
(6)

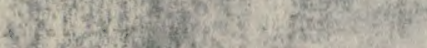

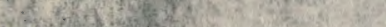
Nowenthos Hein 4 Wh
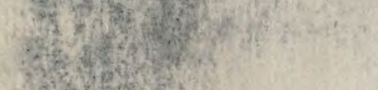

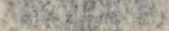

1.5.

$x+3=15$ 


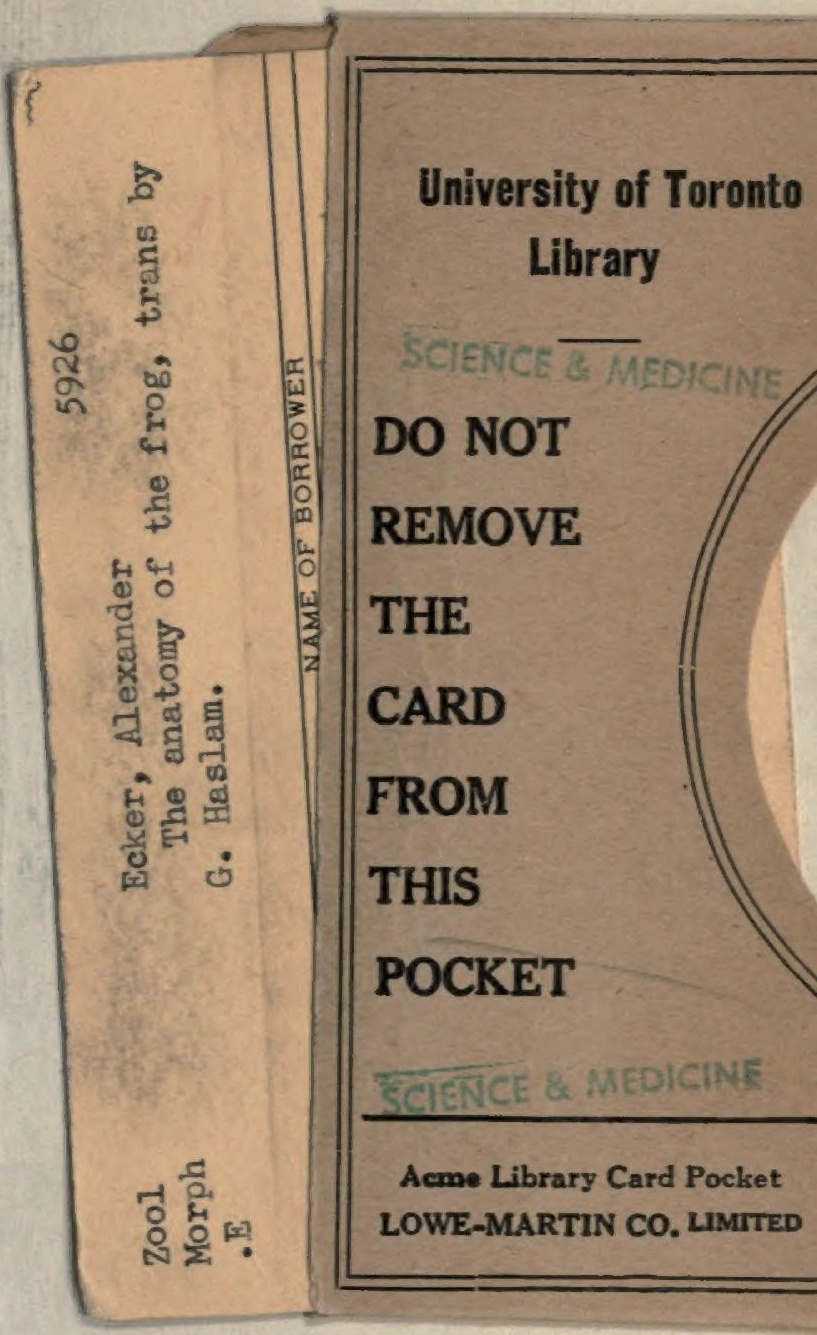


